UNIVERSIDADE DE SÃO PAULO

INSTITUTO DE GEOCIÊNCIAS

\title{
MORFOMETRIA E SIMULAÇÃO NUMÉRICA DE CAMPOS DE DUNAS COSTEIROS: ESTUDO BASEADO EM EXEMPLOS BRASILEIROS
}

\author{
André Oliveira Sawakuchi
}

Orientador: Prof. Dr. Paulo César Fonseca Giannini

\section{TESE DE DOUTORAMENTO}

Programa de Pós-Graduação em Geologia Sedimentar

SÃO PAULO

2006 


\section{ERRATA}

Página $36,3^{\circ}$ parágrafo, $1^{\mathrm{a}}$ linha - Onde se lê "Figura 3 " leia-se "Figura 1.3".

Página $36,3^{\circ}$ parágrafo, $2^{\mathrm{a}}$ linha - Onde se lê “...por Ivanov (1996) foi $-0,85$. . leia-se “...por Ivanov (1996) foi $\underline{0,85}$ ”.

Página 36, Figura 1.4 - A curva do gráfico refere-se à função $S(t)=t^{-0,85}$

Página 37, Equação 1.4 - Onde se lê “ $R=\frac{S}{S^{*}}=\left(\frac{t^{*}}{t}\right)^{-m}$ ” leia-se “ $R=\frac{S}{S^{*}}=\left(\frac{t^{*}}{t}\right)^{m}$ ”.

Página $38,1^{\circ}$ parágrafo, $3^{\mathrm{a}}$ linha - Onde se lê “...este tipo de depósito é $-0,35$ (Sadler, 1981)." leia-se "...este tipo de depósito é $\underline{0,35}$ (Sadler, 1981)".

Página 38, Equação 1.5 - Onde se lê “ $R=\left(\frac{10}{30}\right)^{-(-0,35)}=0,68$ " leia-se " $R=\left(\frac{10}{30}\right)^{(0,35)}=0,68$ ".

Página $41,3^{\circ}$ parágrafo, $3^{\mathrm{a}}$ linha - Onde se lê "A Equação 6 pode ser expressa de maneira simplificada (Equação 7):" leia-se "A Equação 1.6 pode ser expressa de maneira simplificada (Equação 1.7):"”.

Página $68,3^{\circ}$ parágrafo, $4^{\mathrm{a}}$ linha - Onde se lê ".... menores ou iguais a $5 \ldots$.. . leia-se “.... maiores ou iguais a $5 . . . . "$

Página $69,2^{\circ}$ parágrafo, $3^{\mathrm{a}}$ linha - Onde se lê “...relação entre as duas categorias avaliadas.” leiase "...relação entre os grupos e as categorias avaliadas".

Página $75,1^{\circ}$ parágrafo, $8^{\mathrm{a}}$ linha - Onde se lê “...atingir valores próximos a $\underline{0,5} \ldots$.” leia-se “...atingir valores próximos a $\underline{0,2} \ldots .$.

Página $117,1^{\circ}$ parágrafo, $14^{\mathrm{a}}$ linha - Onde se lê “...mesomaré.” leia-se “...macromaré.”.

Página $166,1^{\circ}$ parágrafo, $9^{\mathrm{a}}$ linha - Em relação à passagem: “.... cada experimento foi repetido 30 vezes, sendo que o resultado final corresponde à média das 30 simulações.”. Apenas os experimentos com período de 1.000 anos foram repetidos 30 vezes. Os experimentos de intervalo de tempo maior (50.000 e 100.000 anos) foram repetidos 15 ou 5 vezes.

Página 197, título do ítem 4.7.4 - Onde se lê "Conclusões derivadas dos experimentos de simulação sob condições climáticas estacionárias" leia-se "Conclusões derivadas dos experimentos de simulação com intervalo de tempo de 1.000 anos".

Página 244, legenda da Figura 4.58, $3^{\mathrm{a}}$ linha - Onde se lê “...fácies de frente (․ㅡ)...” leia-se “...fácies de frente $(\underline{\mathrm{Ft}}) . . . "$. 
Página 244, legenda da Figura 4.58, 6 a linha - Onde se lê “As fácies de centro e..." leia-se "As fácies de frente e...”.

Página $247,2^{\circ}$ parágrafo, $9^{\mathrm{a}}$ linha - Onde se lê “...linha de costa sob NRM estável provoque estabilização da linha de costa..." leia-se "linha de costa sob NRM estável provoque estabilização do campo de dunas...".

Página 279, legenda da Figura 6.3, $4^{\mathrm{a}}$ e $5^{\mathrm{a}}$ linha - Onde se lê "A migração vertical ocorrerá somente se $\underline{P_{c}}$ superar $\underline{P e}$." leia-se "A migração vertical ocorrerá somente se $\underline{P e}$ superar $\underline{P_{c}}$.".

Página 291, legenda da Tabela A1, $5^{\text {a }}$ linha - Onde se lê "Valor de p inferior a 5,0..." leia-se "Valor de freqüência esperada inferior a 5,0...".

Página 294, legenda das tabela A7 e A8, $3^{\mathrm{a}}$ e $4^{\mathrm{a}}$ linha - Onde se lê “...entre a o número de meses secos..." leia-se "...entre a amplitude de maré...".

Página 294, legenda da Tabela A8, 6 linha - Onde se lê "Valor de p inferior a 5,0..." leia-se "Valor de freqüência esperada inferior a 5,0...".

Página 295, legendas das tabelas A9 e A10, $3^{\mathrm{a}}$ e $4^{\mathrm{a}}$ linha - Onde se lê "...entre a o número de meses secos e a freqüência de atuação dos ventos." leia-se '...entre a amplitude de maré e a velocidade média dos ventos.".

Página 295, legenda da Tabela A10, 6 a linha - Onde se lê "Valor de p inferior a 5,0 deve ser..." leia-se "Valor de freqüência esperada inferior a 5,0 deve ser...".

Página 296, legenda da Tabela A12, $3^{\text {a }}$ e $4^{\mathrm{a}}$ linha - Onde se lê “...entre a o número de meses

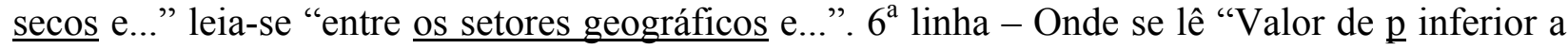
5,0 deve..." leia-se "Valor de freqüência esperada inferior a 5,0 deve...".

Páginas 297 e 298, legendas das tabelas A13, A14 e A15, 3 $3^{\mathrm{a}}$ e $4^{\mathrm{a}}$ linha - Onde se lê “...entre a o número de meses secos e..." leia-se "...entre os setores geográficos e...". $6^{\text {a }}$ linha - Onde se lê "Valor de p inferior a 5,0 deve..." leia-se "Valor de freqüência esperada inferior a 5,0 deve...". 


\section{AGRADECIMENTOS}

Alguns orientadores atiram o aluno na piscina para que ele aprenda a nadar. Porém, são raros os orientadores que conseguem ensinar o aluno a nadar antes de se atirarem na piscina. Estes raros orientadores fazem nascer no aluno a vontade de se atirar na piscina por livre e espontânea vontade. Expresso profunda gratidão e admiração pelo meu orientador Prof. Dr. Paulo César Fonseca Giannini.

Agradeço ao Prof. Dr. Pedro A. Tonelli (Instituto de Matemática e Estatística-USP) e ao MSc. Hilton Garcia Fernandes (Laboratório de Sistemas Integráveis-POLI-USP) por se interessarem pelo problema que lhes apresentei. Sem nossas animadas reuniões não haveria capítulo 4.

A assessoria do amigo de turma MSc. Carlos Henrique Grohmann de Carvalho (Guano) foi fundamental para obtenção de dados a partir de imagens de satélite, no uso do programa ArcView GIS 3.2 e na formatação do texto para impressão.

As análises estatísticas dos dados morfométricos (capítulo 3) foram realizadas graças aos ensinamentos do primo-irmão e estatístico Leonardo Girardi Sawakuchi.

Os inteligentíssimos "palpites" e comentários do Prof. Dr. Renato Paes de Almeida foram essenciais na alimentação de diversas idéias apresentadas nesta tese. Também o agradeço pela ajuda nas atividades didáticas e por disponibilizar seu micro novo para a realização de experimentos de simulação.

Agradeço ao amigo Daniel Rodrigues do Nascimento Junior (Pegmatito) pelas informações detalhadas e discussões sobre as dunas da Ilha Comprida.

A correção do Abstract ficou a cargo do meu irmão e físico-viajante Gabriel Oliveira Sawakuchi.

Aos colegas de turma remanescentes no IG-USP MSc. Paula Garcia Carvalho do Amaral (Pi), MSc. Frederico Meira Faleiros (Bambi) e MSc. Sérgio Williams de Oliveira Rodrigues (Arazila) agradeço a amizade e o auxílio na resolução de problemas do dia-a-dia.

Muitas idéias desta tese também foram alimentadas por conversas de corredor ou de bandeijão mantidas com os colegas do Programa de Pós-Graduação em Geologia Sedimentar (Rodrigo Marques (Portuga), Emilio Soares, Liliane Janikian, Ana Lúcia Gesicki, Chahrazéd Morenghi, Lucas Warren, Gabriel Pérez-Vieira, Cleber Calça, Fernanda Quaglio, Cristiano Chiessi, Rafael Casati, Milene Fornari e Marcos Eduardo Hartwig).

Também registro meus sinceros agradecimentos a todos os funcionários do IG-USP e em especial aos funcionários da gráfica, biblioteca e secretaria de pós-graduação pela presteza no atendimento.

Sou grato à FAPESP pelo apoio financeiro prestado durante o primeiro ano de execução deste estudo. 


\section{RESUMO}

Este trabalho trata da dinâmica de sistemas deposicionais eólicos costeiros, com ênfase na influência de variáveis climáticas, oceanográficas e fisiográficas sobre a evolução de campos de dunas. As variáveis controladoras da dinâmica dos sistemas eólicos costeiros incluem o regime de chuvas e ventos, a amplitude de maré, o aporte sedimentar costeiro e a fisiografia da costa. O entendimento da relação entre variáveis atuantes no sistema deposicional e os produtos sedimentares gerados é de extrema importância para a interpretação e descrição de depósitos sedimentares antigos. Além disto, o entendimento desta relação permitiria a elaboração de modelos de sistemas deposicionais com capacidade de inferência da dinâmica do sistema em termos dos seus produtos e vice-versa.

Este estudo é organizado em seis capítulos. O capítulo um trata da exposição de conceitos, tais como complexidade, não-uniformidade e descontinuidade, que devem ser considerados ao se estudar sistemas deposicionais. Neste capítulo, destaca-se o controle dos processos sedimentares por variávies aleatórias. Isto sustenta o uso de abordagem probabílistica na descrição de sistemas deposicionais. O capítulo dois envolve uma breve síntese bibliográfica sobre sistemas deposicionais eólicos costeiros. O capítulo três contempla análises estatísticas de características morfométricas dos campos de dunas da costa brasileira medidas em imagens de satélite. Estas análises tiveram como objetivo a avaliação da relação entre características morfométricas dos campos de dunas e fatores climáticos, oceanográficos e fisiográficos. Tais análises revelaram que a ocorrência, o tamanho e a forma dos campos de dunas são controlados mais por fatores ligados à fisiografia da costa e ao aporte sedimentar costeiro do que por fatores climáticos (regime de ventos e chuva). O capítulo quatro envolve a simulação númerica de um modelo conceitual de sistema eólico costeiro. Experimentos de simulação permitiram avaliar a influência do aporte sedimentar costeiro, da amplitude de maré e do regime de ventos e chuvas sobre o desenvolvimento de campos de dunas e a migração da linha de costa. Os experimentos realizados evidenciaram que a sedimentação eólica e a migração da linha de costa são mais sensíveis ao aporte sedimentar costeiro do que às demais variáveis envolvidas no modelo. Isto encontra correspondência com os resultados das análises morfométricas do capítulo três. A evolução de campos de dunas costeiros pode ser influenciada pela dinâmica de migração da linha de costa. Linha de costa estável ou transgressiva favoreceria o desenvolvimento de campos de dunas enquanto que linha de costa regressiva provocaria diluição do aporte sedimentar eólico, o que seria desfavorável à manutenção e crescimento de campos de dunas. Sob certas condições, a intensificação da freqüência de ocorrência de chuvas pode estabilizar a linha de costa e facilitar o desenvolvimento de campos de dunas. Este resultado, de certo modo paradoxal, demonstra que o clima pode afetar de modo indireto a sedimentação eólica costeira. Assim, a relação entre clima e formação de dunas pode ser complexa. A influência da migração da linha de costa sobre a sedimentação eólica permite ainda analisar o desenvolvimento dos campos de dunas em termos de variações do nível relativo do mar. Nos capítulos cinco e seis são apresentados exemplos de análises de depósitos eólicos sob a óptica dos conceitos derivados dos capítulos anteriores. O capítulo 5 apresenta a análise do significado genético das sucessões de fácies eólicas das unidades Pirambóia, Botucatu, Serra Geral e Cauiá. O capítulo 6 apresenta o modo como modelos de sistemas deposicionais eólicos podem ser utilizados na caracterização das heterogeneidades de reservatórios eólicos de hidrocarbonetos.

Independente dos resultados alcançados, esta tese procurou demonstrar que para uma melhor compreensão do registro sedimentar é necessário o estudo do funcionamento dos sistemas deposicionais. O entendimento da dinâmica de sistemas deposicionais permite modos mais 
precisos e dedutivos de descrição e interpretação dos depósitos sedimentares. Algumas conclusões, tais como a influência indireta do clima sobre a sedimentação eólica (através da migração da linha de costa), destoam do senso comum, cujo conhecimento advém de observações de curto intervalo de tempo em sistemas deposicionais ativos. Neste contexto, a simulação coloca-se como ótima ferramenta para o estudo de sistemas deposicionais, pois permite análises que contemplam o longo intervalo de tempo envolvido na evolução dos sistemas deposicionais. 


\begin{abstract}
This study deals with the relation between coastal eolian system dynamics and variables acting on the coastal zone. These variables include rain and wind regime, tidal range, coastal physiography and sedimentary supply. The knowledge of the relation between variables responsible for eolian system dynamics and their products is of large importance for the interpretation and description of ancient eolian sediments. Furthermore, the understanding of coastal eolian system dynamics would allow the construction of depositional system models with general and deductive character.

This work is divided in six chapters. Chapter one shows the concepts of complexity, nonuniformity and discontinuity which may be considered in the study of depositional systems. The main point of this chapter is the random behavior of sedimentary processes which supports a probabilistic model for depositional systems. Chapter two presents a brief revision of eolian depositional systems. Chapter three comprises statistical analyzes of geographic distribution and morphometric properties of Quaternary dunefields of the Brazilian coast. These analyzes were based on satellite images data and the main objective was to verify the influence of tidal range, coastal phisiography, wind and rain regime and coastal sedimentary supply on the development and morphology of dunefields. An important conclusion is that the development, size and morphology of dunefields are more associated with coastal phisiography and sedimentary supply than with climatic factors. Chapter four presents the simulation of a conceptual coastal eolian system model. Simulations allow to analyze the eolian system dynamics with a more analytical approach. The simulations showed that dunefield growth and coastline migration are more sensitive to coastal sedimentary supply than to other variables, like wind velocity and frequency of rain occurrence. This is in agreement with conclusions derived from analyzes of morphometric properties and geographic distribution of dunefields (chapter three). The coastline behavior may be very important to dunefield evolution. Stable or transgressive coastline favor the sand supply to the dunefield while regressive coastline dilutes the eolian sand supply. Therefore, dunefield maintenance and growth are favored by transgressive or stable coastline. The increasing of rain frequency can induce coastline stability under some conditions. Thus, there is a complex relation between climate and coastal eolian sedimentation. Chapters five and six present examples of how the concepts about dunefields dynamics, derived from chapters three and four, can be used to interpret ancient eolian deposits and to understanding the heterogeneities of eolian hydrocarbon reservoirs.

This work attempts to demonstrate that for better comprehension of the sedimentary record it is necessary to study how depositional systems behave. The understanding of depositional system dynamics permits a more deductive description and interpretation of the sedimentary record. The relation between climate and coastal dunefield growth disagree with conclusions from common sense whose knowledge is provided by short time observations of active depositional systems. In this context, simulation is a powerful tool to study depositional systems since it allows to analyze depositional systems behavior in their real and long time span.
\end{abstract}




\section{LISTA DE FIGURAS}

\section{CAPÍTULO 1}

Figura 1.1 - Modelo conceitual de sistema deposicional fluvial. $\mathrm{F}=$ área fonte, $\mathrm{T}=$ canal tributário, $\mathrm{C}=$ canal principal, $\mathrm{P}$ = planície de inundação, $\mathrm{D}=$ canal distributário e $\mathrm{B}=$ zona de deposição (planície aluvial, lago ou mar). As setas indicam o sentido do fluxo de sedimentos entre as partes do sistema. 29

Figura 1.2 - Exemplo de sistema fluvial atual. Área fonte (F), canais tributários (T), planície de inundação (P) e canal principal (C) da bacia de drenagem do rio Jáchal (San Jose de Jáchal, Argentina). Foto de Sérgio Willians de Oliveira Rodrigues (2004).

Figura 1.3- Variação das taxas de acumulação de sedimentos em função do intervalo de tempo. As isolinhas definem a densidade de dados (número de dados $=25.000$ ). A separação entre zonas de máxima densidade resulta das quatro técnicas de estimação utilizadas: medidas contínuas, observações históricas, datações radiocarbono e datações por bioestratigrafia. Adaptado de Sadler (1981 apud Ivanov, 1996).

Figura 1.4 - Variação da taxa de sedimentação $S$ (m/1000 anos) em função do intervalo de tempo $t$ (anos)........... 36

Figura 1.5 - Gráfico da representatividade $R$ em função do intervalo de tempo $t^{*}$ para o exemplo citado acima. O intervalo de tempo envolvido na formação do depósito é $30 \mathrm{Ma}$. Se a seção for dividida em intervalos de $10 \mathrm{Ma}$, têmse representatividade de $68 \%$. Isto indica que apenas cerca de 2 dos 3 intervalos de 10 Ma são representados por sedimentos. Nota-se que a representatividade diminui para intervalos de tempo menores. 38

Figura 1.6 - Idade do horizonte situado $100 \mathrm{~m}$ abaixo do topo da seção. A representatividade permite avaliar a imprecisão da estimativa. Para intervalos de tempo de $10 \mathrm{Ma}$, esta seção apresenta representatividade 0,68. Assim, $20,4 \mathrm{Ma}(68 \%)$ seriam representados por sedimentos e 9,6 Ma (32\%) por descontinuidades. A) Caso extremo em que o intervalo não registrado situa-se no topo da seção. B) Caso extremo em que o intervalo não registrado situa-se na base da seção. O intervalo de tempo representado por sedimentos é expresso por $\mathrm{dt}(\mathrm{dt}=20,4 \mathrm{Ma}$, que corresponde a $68 \%$ do intervalo de tempo abrangido pela seção).

Figura 1.7- Eficiência dos eventos deposicionais de um sistema (Wolman \& Miller, 1960). a) Fluxo de material transportado em função da magnitude da força $(q(x))$. b) Distribuição de freqüências (lognormal) da magnitude da força $(f(x))$. c) Eficiência da força $(E(x)=q(x) f(x))$. A eficiência $(E(x))$ apresenta um valor máximo. 43

Figura 1.8 - Distribuição de freqüências de $q(x)\left(q(x)=x^{n}\right)$ para $n$ igual a 2 e $x$ com distribuição normal de média 5 e desvio padrão $1(\mathrm{~N}=1000)$. Notar a assimetria positiva da distribuição de freqüências.. 44

Figura 1.9 - Distribuição de freqüências dos fluxos $q(x)$ registrados pelos sistemas $1(\mathrm{~N}=292)$ e $2(\mathrm{~N}=913)$. Estas distribuições diferem da distribuição de $q(x)$ dos eventos ocorridos (Figura 1.8), pois $q(x)_{\max }=20$ e $q(x)_{\max 2}=40$.

Figura 1.10 - Freqüência e espessura (magnitude) dos depósitos de escorregamento gerados durante tempestade nas encostas do lago Tutira, Nova Zelândia (Gomez et al., 2002).

Figura 1.10 - Freqüência e espessura (magnitude) dos depósitos de escorregamento gerados durante tempestade nas encostas do lago Tutira, Nova Zelândia (Gomez et al., 2002). 46

Figura 1.11 - (a) Representação de seção estratigráfica através de curva em escada. Os trechos inclinados correspondem a incrementos de sedimentos preservados e os trechos horizontais a hiatos deposicionais. (Sadler \& Strauss, 1990). O padrão em escada resulta da inconstância da deposição e preservação dos sedimentos. Tal padrão repete-se em diferentes escalas de espaço e tempo (círculo). (b) Curva de subsidência construída a partir dos estratos preservados da Bacia do Paraná (Milani \& Ramos, 1998). Dado que o padrão em escada se repete em diversas escalas, a maior parte do intervalo de tempo da história da bacia seria representada por hiatos deposicionais. RI= superseqüência Rio Ivaí; $\mathrm{P}=$ superseqüência Paraná; $\mathrm{GI}=$ superseqüência Gondwana I; GIII= superseqüência Gondwana III e B= superseqüência Bauru. 48 


\section{CAPÍTULO 2}

Figura 2.1 - Distribuição mundial das principais áreas costeiras com sedimentação eólica arenosa. Adaptado de Carter et al. (1990). 51

Figura 2.2 - Campos de dunas em Marte (Malin et al., 1998). Estes campos de dunas ocupam depressões topográficas, que parecem condicionar a direção de migração das dunas. Predominam dunas transversais, as quais apresentam bifurcação e orientação variável. Resolução de $5 \mathrm{~m} /$ pixel e área aproximada de 2,3 x 3,6 km. 52

Figura 2.3 -Principais elementos morfológicos de um sistema eólico (Laguna, SC). Dunas (Dn), depressões interdunas (Id) e zonas de deflação (Zd). Foto de Paulo César Fonseca Giannini (2002). 53

Figura 2.4 - Modelo conceitual de sistema eólico (Kocurek \& Havholm, 1993 apud Giannini et al.). Qi = influxo e $\mathrm{Qe}=$ efluxo. 54

Figura 2.5 - Diferenciação das dunas livres segundo a variabilidade do regime de ventos (RDP/DP) e disponibilidade de areia (EST). Quanto menor o valor da razão (RDP/DP), maior a variabilidade do regime de ventos. DP é a deriva pontencial (drift potential) e RDP é a magnitude do vetor resultante da deriva potencial (resultant drift potential). EST é a espessura equivalente de areia (equivalent sand thickeness). Adaptado de Wasson \& Hyde (1983) apud Giannini et al. (2006). 55

Figura 2.6 - Elementos de uma duna vegetada do tipo parabólica. Localidade de Ibiraqüera, Laguna (SC). Foto de Paulo César Fonseca Giannini (2002). 56

Figura 2.7 - Distribuição dos campos de dunas transgressivos na costa brasileira (destacados em coloração cinza). As setas pretas indicam rumos de migração de dunas, obtidos através de medidas de estratificações cruzadas realizadas por Bigarella (1970/1971). As áreas K, L e M correspondem a campos de dunas interiores estabilizados. Adaptado de Giannini et al. (2005). 59

\section{CAPÍTULO 3}

Figura 3.1 - Variáveis morfométricas dos campos de dunas (Lençóis Maranhenses, costa do Estado do Maranhão). O valor de $\mathrm{C}$ é de aproximadamente $62 \mathrm{~km}$. $\mathrm{A}$ = área total; $\mathrm{P}=$ perímetro; $\mathrm{ADV}$ = áreas de deflação ou recobertas por vegetação; $\mathrm{D}=$ distância máxima de avanço; $\theta=$ azimute de avanço; $\mathrm{C}=$ comprimento da linha de costa adjacente; $\alpha$ = ângulo entre a direção de avanço e a direção da linha de costa.

Figura 3.2 - Valores da razão $P / \sqrt{A}$ para algumas formas geométricas regulares. A circunferência apresenta a menor razão $P / \sqrt{A}$. O aumento desta razão ocorre com o "alongamento" da forma. Formas equidimensionais apresentam valores menores de $P / \sqrt{A}$

Figura 3.3 - Gráficos de variação dos valores médios para variável arbitrária (X): o ponto central é o valor médio e as barras correspondem ao erro padrão da média (erro padrão $=$ desvio padrão $/ \sqrt{N}$ ). Neste caso, a variabilidade entre os grupos 1 e 2 é maior que a variabilidade interna de cada grupo. Assim, pode-se dizer que os grupos 1 e 2 apresentam valores distintos da variável $\mathrm{X}$. 66

Figura 3.4 - Histogramas das variáveis A, P, ADV, D e C. Notar a elevada assimetria positiva e concentração dos dados em pequeno intervalo, apesar da distribuição de freqüências envolver longa amplitude. .71 
Figura 3.5 - Histogramas das variáveis $\mathrm{A} / \mathrm{C}, P / \sqrt{A}\left(\mathrm{P} / \mathrm{A}^{\wedge} 0,5\right)$ e ADV/A. A distribuição de freqüências da variável $\mathrm{A} / \mathrm{C}$ é semelhante às distribuições das variáveis $\mathrm{A}, \mathrm{P}, \mathrm{C}$ e ADV. Já as variáveis $P / \sqrt{A}$ e ADV/A apresentam distribuições de menor assimetria e diferenças entre os diversos percentis também são menores. 72

Figura 3.6 - Histograma da variável $\alpha$. Distribuição unimodal simétrica semelhante à distribuição de Von Mises

Figura 3.7 - Dendrograma da análise de agrupamento realizada a partir das variáveis $\mathrm{A} / \mathrm{C}, \mathrm{ADV} / \mathrm{A}, \mathrm{D} / \mathrm{C}$ e $P / \sqrt{A}$. Utilizaram-se o método de Ward e a distância euclidiana ao quadrado. A similaridade máxima entre observações equivale a 100. Quatro grupos principais são reconhecidos, sendo que estes grupos podem ser divididos em subgrupos. 74

Figura 3.8 - Comparação entre os grupos 1, 2, 3 e 4 . O ponto central é o valor médio e as barras correspondem ao erro padrão da média (erro padrão $=$ desvio padrão/ $\sqrt{N}$ ). .75

Figura 3.9 - Exemplos de campos de dunas pertencentes aos grupos 1, 2, 3 e 4. 1) Campo de dunas adjacente às praias da Pedra Branca, do Rosado e Porto de Mangues (Porto de Mangues, RN). As principais características são a elevada razão $\mathrm{A} / \mathrm{C}$ e a alta proporção de áreas de deflação ou vegetadas $(\mathrm{A} / \mathrm{C}=5,51, \mathrm{ADV} / \mathrm{A}=0,28, P / \sqrt{A}=8,00 \mathrm{e}$ $\mathrm{D} / \mathrm{C}=0,68)$. 2) Campo de dunas da praia de Ibiraqüera (Imbituba, $\mathrm{SC}$ ). Notar a elevada distância relativa de avanço (A/C=1,04, $\mathrm{ADV} / \mathrm{A}=0,37, P / \sqrt{A}=8,32$ e $\mathrm{D} / \mathrm{C}=1,17$ ). 3) Campo de dunas da Ilha das Canárias (MA), que se situa a oeste da foz do rio Parnaíba. A característica marcante dos campos de dunas deste grupo são os altos valores de $P / \sqrt{A}$, indicativos de campos de dunas mais alongados (A/C=0,36, $\mathrm{ADV} / \mathrm{A}=0,01, P / \sqrt{A}=16,00 \mathrm{e} \mathrm{D} / \mathrm{C}=0,34$ ). 4) Campo de dunas dos Lençóis Maranhenses (MA). Trata-se do maior campo de dunas da costa brasileira, o qual apresenta como traços peculiares a elvadíssima razão $\mathrm{A} / \mathrm{C}$ e a baixa proporção de áreas de deflação ou vegetadas $(\mathrm{A} / \mathrm{C}=14,50, \mathrm{ADV} / \mathrm{A}=0,07, P / \sqrt{A}=9,60$ e $\mathrm{D} / \mathrm{C}=0,53)$. 78

Figura 3.10 - A oeste dos Lençóis Maranhenses, a costa é caracterizada por baías estuarinas. Os campos de dunas deste trecho são menores e ocorrem em praias de ilhas ou zonas interbaías (A). A leste, a costa é mais retilínea, com campos de dunas maiores e separados por canais de maré (B).

Figura 3.11 - Campos de dunas truncados por canais de maré na costa norte (Estado do Maranhão). A) Campos de dunas livres segmentados por canais de maré. B). Canal de maré barrado por campo de dunas. C) Área de retrocordões eólicos com campo de dunas em processo de estabilização a sotavento. Esta área é separada da linha de costa atual por zona com canais de maré desprovida de feições eólicas. D) Campo de dunas com zona de retrocordões (feições eólicas reliquiares), que separa áreas de dunas ativas a barlavento e sotavento. .83

Figura 3.12 - Campo de dunas livres (barcanas e cadeias barcanóides) com zonas de deflação (Nova Tatajuba, CE). Notar os canais de maré transversais à linha de costa bloqueados pelo avanço do campo de dunas. 84

Figura 3.13 - Azimute de migração dos campos de dunas do primeiro setor. Os rumos mais freqüentes são SW-W, W e NW. Azimute médio $=273,09^{\circ}$, desvio padrão circular $=29,11^{\circ}, \mathrm{N}=91$.

Figura 3.14 - Correlação entre a direção da linha de costa e o rumo de avanço dos campos de dunas. Notar que os campos de dunas com rumo de migração $\mathrm{NW}$ ou NW/N são predominantes em trechos de linha de costa com orientação mais próxima a N-S $(0-30$ e >120). Os campos de dunas com rumo de migração SW são mais freqüentes em regiões com linha de costa de orientação mais próxima a E-W (60-90 e 90-120). 86

Figura 3.15 - Ângulo entre o rumo de migração dos campos de dunas e a direção da linha de costa $(\alpha)$. Notar o predomínio de valores próximos à $45^{\circ}$. Ângulo médio $=41,33^{\circ}$; Desvio padrão circular $=17,51^{\circ} ; \mathrm{N}=85$. . . . 87

Figura 3.16 - Campo de dunas de Potengi (AL) adjacente à foz do rio São Franscisco (divisa SE/AL). Notar o avanço sobre planície de cordões litorâneos. $\mathrm{A} / \mathrm{C}=2,05 ; \mathrm{ADV} / \mathrm{A}=0,28 ; P / \sqrt{A}=7,78$. 89 
Figura 3.17 - Azimute de migração dos campos de dunas do segundo setor. Os azimutes W e W-NW são os mais freqüentes. Azimute médio $=284,06^{\circ}$, desvio padrão circular $=45,45^{\circ}, \mathrm{N}=22$.

Figura 3.18 - Correlação entre o azimute de migração dos campos de dunas e a direção da linha de costa. Notar a associação entre campo de dunas com rumo de migração $\mathrm{W}$ ou W/NE e linha de costa com direção aproximadamente N-S (0 a 40). 90

Figura 3.19 - Ângulo entre o rumo de avanço dos campos de dunas e a direção da linha de costa $(\alpha)$. Notar o predomínio de campos de dunas com migração perpendicular à costa. Ângulo médio $=68,93^{\circ}$, Desvio padrão circular $=20,25^{\circ}, \mathrm{N}=21$. 91

Figura 3.20 - Campos de dunas da região de Cabo Frio e Arraial do Cabo (RJ). Os campos de dunas apresentam rumos de migração opostos e elevada proporção de zonas de deflação ou vegetadas. 92

Figura 3.21 - Trecho da costa de Santa Catarina entre Imbituba e Jaguaruna. A norte de Laguna, os campos de dunas apresentam rumo de migração oblíquo à costa enquanto que a sul, o rumo de migração é subparalelo à costa. A) Campo de dunas de Itapirubá (Imbituba, SC). Este campo de dunas apresenta ampla zona de deflação ou recoberta por vegetação situada a barlavento e forma menos alongada (A/C=0,91; $\mathrm{ADV} / \mathrm{A}=0,50 ; P / \sqrt{A}=9,59)$. B) Campo de dunas de Campo Bom (Jaguaruna, SC). Trata-se de campo de dunas alongado com menor proporção de áreas de deflação ou vegetadas $(\mathrm{A} / \mathrm{C}=1,16 ; \mathrm{ADV} / \mathrm{A}=0,23 ; P / \sqrt{A}=12,13)$. 96

Figura 3.22 - Campo de dunas na Ilha dos Marinheiros (Rio Grande, RS) isolado da área fonte praial pelo sistema lagunar. 97

Figura 3.23 - Azimute de migração dos campos de dunas. Azimute médio $=235,99^{\circ}$; Desvio padrão circular $=41,41^{\circ}$; $\mathrm{N}=32$.

Figura 3.24 - Campos de dunas com rumo de avanço próximo a N (Florianópolis, SC). 99

Figura 3.25 - Relação entre o rumo de migração dos campos de dunas e a direção da linha de costa. Notar que não há grande variação da direção da linha de costa e que esta não influencia o rumo de migração dos campos de dunas.

Figura 3.26 - Ângulo entre o rumo de migração dos campos de dunas e a direção da linha de costa. Ângulo médio $=22,74^{\circ}$, desvio padrão circular $=20,92^{\circ}, \mathrm{N}=32$. 100

Figura 3.27 - Gráficos de intervalo de variação das variáveis A/C, ADV/A, $P / \sqrt{A}$ e D/C em termos do número de meses secos (Mesomaré). 108

Figura 3.28 - Gráficos de intervalo de variação das variáveis A/C, ADV/A, $P / \sqrt{A}$ e D/C em termos do regime de ventos. Distinguem-se os campos de dunas de região com quatro a oito meses secos e regime de mesomaré (Meso_A e Meso_B) dos campos de dunas de região com zero a três meses secos e regime de micromaré (Micro_A e Micro_B $)$. Meso_A=ventos com freqüência de $64 \%$ em janeiro e Meso_B=ventos com freqüência entre 43 e $54 \%$ em janeiro; Micro_A=ventos com freqüência entre 43 e 54\% em janeiro e Micro_B=ventos com freqüência entre 26 e $32 \%$ em janeiro. 115

Figura 3.29 - Gráficos de intervalo de variação das variáveis A/C, ADV/A, $P / \sqrt{A}$ e D/C em termos da amplitude de maré (quatro a seis meses secos). 119

Figura 3.30 - Gráficos de intervalo de variação das variáveis A/C, ADV/A, $P / \sqrt{A}$ e D/C em termos da amplitude de maré (zero a três meses secos). 120 
Figura 3.31 - Influência do ângulo de migração em relação à linha de costa $(\alpha)$ sobre a distância de avanço dos campos de dunas. Campos de dunas mais transversais à costa requerem maior volume de areia para alcançar uma mesma distância de avanço (D) que campos de dunas mais paralelos à costa. A área a ser acrescentada para cobrir a mesma distância de avanço é menor para campos de dunas de ângulo de avanço menor. 126

Figura 3.32 - Gráficos de intervalo de variação das variáveis A/C, ADV/A, $P / \sqrt{A}$ e D/C medidas nos setores 1,2 e 3. O ponto central é o valor médio e as barras correspondem ao erro padrão da média (erro padrão $=$ desvio padrão/ $\sqrt{N}$ ), que é uma medida de variabilidade. Apenas as variáveis $P / \sqrt{A}$ e $\mathrm{D} / \mathrm{C}$ discriminam os três setores. As variáveis $\mathrm{A} / \mathrm{C}$ e $\mathrm{ADV} / \mathrm{A}$ discriminam apenas o setor 2 dos setores 1 e 3 .

Figura 3.33 - Área da zona intermarés (Área $=\mathrm{Amp} \times(\mathrm{C} / \mathrm{sen} \theta))$. Amp $=$ amplitude de maré, Com $=$ comprimento da costa, $\mathrm{L}=$ largura da costa e $\theta=$ inclinação da zona intermarés.

Figura 3.34 - Campos de dunas dos Lençóis Maranhenses. Notar a mudança da fisiografia da linha de costa a oeste dos Lençóis Maranhenses.

Figura 3.35 - Lobos de diferentes hieraquias (1, 2 e 3$)$ que formam a frente de avanço do campo de dunas dos Lençóis Maranhenses. Esta geometria seria indicativa de crescimento ou avanço por pulsos... 133

Figura 3.36 - Taxas de sedimentação das gerações eólicas 1 e 2 calculadas a partir de idades TL e LOE (Sawakuchi, 2003). 134

Figura 3.37 - Freqüência acumulada (P(E,L)L) do tamanho de avalanches em pilhas de arroz de diferentes tamanhos (L). As diversas curvas correspondem a pilhas de tamanho distinto e foram deslocadas para demonstrar a equivalência da forma (Frette et al., 1996)...... 135

Figura 3.38 - Distribuição de freqüências da variável A/C. 135

Figura 3.39 - Gráfico log-log entre tamanho (A/C > que) e freqüência acumulada (N(A/C >que). Nota: A/C $\mathrm{em} \mathrm{m}^{2} / \mathrm{m}$. 136

Figura 3.40 - A variação linear entre a freqüência acumulada (N(A/C)) e tamanho (A/C) torna-se mais nítida quando se utiliza o ponto médio das classes de tamanho. 136

\section{CAPÍTULO 4}

Figura 4.1 - Representação esquemática do modelo conceitual de sistema eólico costeiro. Vc=volume do campo de dunas; $\mathrm{Vf}=$ =volume da área fonte; $\mathrm{Vfa}=$ volume acumulado de sedimentos costeiros; qce=fluxo de entrada de sedimentos no campo de dunas; qcs=fluxo de saída de sedimentos do campo de dunas; $d x=$ regressão da linha de costa pela progradação do reservatório de sedimentos costeiros acumulados; amp=amplitude de maré; nrm=nível relativo do mar.

Figura 4.2 - Representação formal do modelo conceitual de sistema eólico costeiro. qce=fluxo de entrada de sedimentos no campo de dunas; qcs=fluxo de saída de sedimentos do campo de dunas; qfe=fluxo de entrada de sedimentos na área fonte por correntes costeiras ou desembocaduras de rios; qfs=fluxo de saída de sedimentos da área fonte por correntes costeiras; qfae=fluxo de entrada de sedimentos no reservatório de sedimentos costeiros; qfas=fluxo de saída de sedimentos no reservatório de sedimentos costeiros. 144

Figura 4.3 - Sistema de campos de dunas desenvolvidos em cadeia formada por $\mathrm{n}$ segmentos praiais. O desenvolvimento de campo de dunas $(\mathrm{Vc} 1, \mathrm{Vc} 2, \ldots, \mathrm{Vcn})$ em cada segmento de costa é influenciado pelas trocas de sedimentos entre áreas fontes vizinhas (Vf1, Vf2,...,Vfn) e destas com as zonas de inframaré (Vi1, Vi2,..., Vin) e reservatórios de sedimentos costeiros acumulados (Vfa1, Vfa2,...,Vfan). Fluxos de sedimentos: qce=fluxo de entrada no campo de dunas; qcs=fluxo de saída do campo de dunas; qfle=fluxo de entrada na área fonte por corrente costeira longitudinal; qfls=fluxo de saída da área fonte por corrente costeira longitudinal; qfte=fluxo de entrada na área fonte por corrente costeira transversal; qfts=fluxo de saída da área fonte por corrente costeira transversal; qfas=fluxo de 
saída do reservatório de sedimentos costeiros acumulados; qfae=fluxo de entrada no reservatório de sedimentos costeiros acumulados.

Figura 4.4 - Interação entre os fatores que podem restringir o transporte de sedimentos eólicos.

A interação gera oito situações possíveis, sendo que o transporte eólico ocorre em apenas uma situação (s/chuva, maré baixa e $\mathrm{v}>=\mathrm{vt}$ ).

Figura 4.5 - Distribuição de freqüências das velocidades dos ventos registrados em Torres (RS) entre 1970 e 1982. Adaptado de Tomazelli (1990).

Figura 4.6 - Variação da velocidade do vento $(V)$ em função do logaritmo da altura $(z)$, com diferentes gradientes de velocidade $\left(V_{*_{I}}\right.$ e $\left.V_{*_{2}}\right)$.

Figura 4.7 - Velocidade de arrasto limiar $\left(V_{*}\right)$ para grãos com diferentes diâmetros. Adaptado de Bagnold (1941).

Figura 4.8 - Variável aleatória simulada a partir de modelo lognormal com média qm igual a 10 e parâmetro de dispersão dq de valor variável. A elevação de dq provoca aumento da assimetria da distribuição de freqüência.... 157

Figura 4.9 - Geometria da zona intermaré. A redução do volume de sedimentos implica redução do ângulo de inclinação da zona intermaré. Amp=amplitude de maré; Com=comprimento da costa; $\theta=$ inclinação da zona intermaré; L=largura da zona intermaré. Os índices max e min indicam respectivamente máximo e mínimo........ 159

Figura 4.10 - Progradação (Vf > Vfmax) e retrogradação (Vf < Vfmin) da área fonte induzida pelo balanço sedimentar costeiro. $\mathrm{Vc}=$ volume do campo de dunas; $\mathrm{Vfa}=$ volume do reservatório de sedimentos costeiros acumulados; Vfmax= volume máximo d área fonte; Vfmin=volume mínimo da área fonte; Vf=volume da área fonte em dado instante; $\mathrm{dx}=$ distância de regressão ou transgressão; $\mathrm{h}=$ altura que define o volume erodido do campo de dunas; $a m p=$ amplitude de maré; $\mathrm{nrm}=$ nível relativo do mar em dado instante.

Figura 4.11 - Variação da duração do período seco em termos dos parâmetros A (amplitude), K (freqüência) e B (valor mínimo). 163

Figura 4.12 - Fluxograma para simulação de sistema eólico costeiro de campo de dunas único. 165

Figura 4.13 - Estimativa do volume do campo de dunas de Itapirubá (Imbituba, SC). Volume estimado=3,29 x 10 $\mathbf{m}^{3}$.

Figura 4.14 - Estimativa do volume de dunas frontais. As dunas frontais foram consideradas volumes prismáticos. Esta aproximação fornece volumes máximos de sedimentos. 169

Figura 4.15 - Resultado da simulação de 1000 anos do modelo de sistema eólico costeiro sob condições de sazonalidade acentuada e $\mathbf{q f e}=\mathbf{q f s}$. Foram utilizados os seguintes valores para simulação de qfe e qfs: qfemtemp $=$ qfsmtemp $=\mathbf{0 , 1}, \quad$ dqfetemp $=$ dqfstemp $=\mathbf{1}, \quad$ qfemseca $=q$ fsmsseca $=\mathbf{0 , 0 0 3}, \quad$ dqfeseca $=$ dqfsseca $=\mathbf{0 , 3}$, qfemumida $=$ qfsmumida $=\mathbf{0 , 0 0 6}$, dqfeumida $=$ dqfsumida $=\mathbf{0 , 3}$. 174

Figura 4.16 - Resultado da simulação de 1000 anos do modelo de sistema eólico costeiro sob condições de sazonalidade acentuada e $\mathbf{q f e}=\mathbf{q f s}$. Foram utilizados os seguintes valores para simulação de qfe e qfs: qfemtemp $=$ qfsmtemp $=\mathbf{0 , 1}, \quad$ dqfetemp $=$ dqfstemp $=\mathbf{1}, \quad$ qfemseca $=q$ fsmsseca $=\mathbf{0 , 0 3}, \quad$ dqfeseca $=$ dqfsseca $=\mathbf{0 , 3}$, qfemumida $=$ qfsmumida $=\mathbf{0 , 0 6}$, dqfeumida $=$ dqfsumida $=\mathbf{0 , 3}$. . 175

Figura 4.17 - Resultados da simulação de 1000 anos do modelo de sistema eólico costeiro sob condições de sazonalidade acentuada e qfe=qfs. Foram utilizados os seguintes valores para simulação de qfe e qfs: qfemtemp $=$ qfsmtemp $=\mathbf{1}, \quad$ dqfetemp $=$ dqfstemp $=\mathbf{1}, \quad$ qfemseca $=q$ fsmseca $=\mathbf{0 , 3}, \quad$ dqfeseca $=$ dqfsseca $=\mathbf{0 , 3}$, qfemumida $=$ qfsmumida $=\mathbf{0 , 6}$, dqfeumida $=$ dqfsumida $=\mathbf{0 , 3}$. 176 
Figura 4.18 - Resultado da simulação de 1000 anos do modelo de sistema eólico costeiro sob condições de sazonalidade acentuada, $\mathbf{q f e}=\mathbf{q f s}$ e amplitude de maré igual a $\mathbf{4} \mathbf{~ m}$. Foram utilizados os seguintes valores para simulação de qfe e qfs: qfemtemp=qfsmtemp=0,1, dqfetemp=dqfstemp=1, qfemseca=qfsmsseca=0,003, dqfeseca $=$ dqfsseca $=\mathbf{0 , 3}$, qfemumida $=$ qfsmumida $=\mathbf{0 , 0 0 6}$, dqfeumida $=$ dqfsumida $=\mathbf{0 , 3}$.

Figura 4.19 - Resultado da simulação de 1000 anos do modelo de sistema eólico costeiro sob condições de sazonalidade acentuada, $\mathbf{q} \mathbf{f e}=\mathbf{q f} \mathbf{f}$ e variação periódica da duração da estação seca. Foram utilizados os seguintes valores para simulação de qfe e qfs: qfemtemp=qfsmtemp=0,1, dqfetemp=dqfstemp=1, qfemseca=qfsmsseca=0,003, dqfeseca $=$ dqfsseca $=\mathbf{0 , 3}$, qfemumida $=$ qfsmumida $=\mathbf{0 , 0 0 6}$, dqfeumida $=$ dqfsumida $=\mathbf{0 , 3}$.

Figura 4.20 - Resultado da simulação de 1000 anos do modelo de sistema eólico costeiro sob condições de sazonalidade acentuada e qfe $>\mathbf{q f s}$. Foram utilizados os seguintes valores para simulação de qfe e qfs: qfemtemp=0,11, qfsmtemp $=\mathbf{0 , 1 0}$; dqfetemp $=$ dqfstemp $=\mathbf{1}, \quad$ qfemseca $=\mathbf{0 , 0 0 3 1}, \quad$ qfsmsseca $=\mathbf{0 , 0 0 3 0}$, dqfeseca $=$ dqfsseca $=\mathbf{0 , 3}$, qfemumida $=\mathbf{0 , 0 0 6 1}$, qfsmumida $=\mathbf{0 , 0 0 6 0}$, dqfeumida $=$ dqfsumida $=\mathbf{0 , 3} \ldots \ldots \ldots \ldots \ldots \ldots \ldots \ldots . . .182$

Figura 4.21 - Resultado da simulação de 1000 anos do modelo de sistema eólico costeiro sob condições de sazonalidade acentuada e qfe>qfs. Foram utilizados os seguintes valores para simulação de qfe e qfs: qfemtemp $=\mathbf{0 , 1 5}, \quad$ qfsmtemp $=\mathbf{0 , 1 0}$; dqfetemp $=$ dqfstemp $=\mathbf{1}, \quad$ qfemseca $=\mathbf{0 , 0 0 3 5}, \quad$ qfsmsseca $=\mathbf{0 , 0 0 3 0}$, dqfeseca $=$ dqfsseca $=\mathbf{0 , 3}$, qfemumida $=\mathbf{0 , 0 0 6 5}$, qfsmumida $=\mathbf{0 , 0 0 6 0}$, dqfeumida $=\mathrm{dqfsumida}=\mathbf{0 , 3} \ldots$ 183

Figura 4.22 - Resultado da simulação de 1000 anos do modelo de sistema eólico costeiro sob condições de sazonalidade acentuada e qfe $>\mathbf{q f s}$. Foram utilizados os seguintes valores para simulação de qfe e qfs: qfemtemp $=\mathbf{0 , 1 5}, \quad$ qfsmtemp $=\mathbf{0 , 1 0}$; dqfetemp $=$ dqfstemp $=\mathbf{3}, \quad$ qfemseca $=\mathbf{0 , 0 0 3 5}, \quad$ qfsmsseca $=\mathbf{0 , 0 0 3 0}$, dqfeseca $=$ dqfsseca $=\mathbf{3}$, qfemumida $=\mathbf{0 , 0 0 6 5}$, qfsmumida $=\mathbf{0 , 0 0 6 0}$, dqfeumida $=$ dqfsumida $=\mathbf{3}$. 184

Figura 4.23 - Resultado da simulação de 1000 anos do modelo de sistema eólico costeiro sob condições de sazonalidade acentuada e qfe> $>\mathbf{q f s}$. Foram utilizados os seguintes valores para simulação de qfe e qfs: qfemtemp=0,1, qfsmtemp $=\mathbf{0 , 0 1}$; dqfetemp $=$ dqfstemp $=\mathbf{1}, \quad$ qfemseca $=\mathbf{0 , 0 3}, \quad$ qfsmsseca $=\mathbf{0 , 0 0 3}, \quad$ dqfeseca $=$ dqfsseca $=\mathbf{0 , 3}$, qfemumida $=\mathbf{0 , 0 6}$, qfsmumida $=\mathbf{0 , 0 0 6}$, dqfeumida $=$ dqfsumida $=\mathbf{0 , 3}$. 186

Figura 4.24 - Resultado da simulação de 1000 anos do modelo de sistema eólico costeiro sob condições de sazonalidade acentuada e qfe $>\mathbf{q f s}$. Foram utilizados os seguintes valores para simulação de qfe e qfs: qfemtemp=0,2, qfsmtemp $=\mathbf{0 , 1}$; dqfetemp $=$ dqfstemp $=\mathbf{1}, \quad$ qfemseca $=\mathbf{0 , 0 0 6}, \quad$ qfsmsseca $=\mathbf{0 , 0 0 3}, \quad$ dqfeseca $=$ dqfsseca $=\mathbf{0 , 3}$, qfemumida $=\mathbf{0 , 0 1 2}$, qfsmumida $=\mathbf{0 , 0 0 6}$, dqfeumida $=\mathrm{dqfsumida}=\mathbf{0 , 3}$. 187

Figura 4.25 - Resultado da simulação de 1000 anos do modelo de sistema eólico costeiro sob condições de sazonalidade acentuada e $\mathbf{q f e}>\mathbf{q f s}$. Foram utilizados os seguintes valores para simulação de qfe e qfs: qfemtemp $=\mathbf{0 , 1 5}, \quad$ qfsmtemp $=\mathbf{0 , 1 0}$; dqfetemp $=$ dqfstemp $=\mathbf{1}, \quad$ qfemseca $=\mathbf{0 , 0 0 3 5}, \quad$ qfsmsseca $=\mathbf{0 , 0 0 3 0}$, dqfeseca $=$ dqfsseca $=\mathbf{0 , 3}$, qfemumida $=\mathbf{0 , 0 0 6 5}$, qfsmumida $=\mathbf{0 , 0 0 6 0}$, dqfeumida $=$ dqfsumida $=\mathbf{0 , 3} \ldots$ 188

Figura 4.26 - Resultado da simulação de 1000 anos do modelo de sistema eólico costeiro sob condições de sazonalidade acentuada e qfe $>\mathbf{q f s}$. Foram utilizados os seguintes valores para simulação de qfe e qfs: qfemtemp=0,1, qfsmtemp $=\mathbf{0 , 0 1}$; dqfetemp $=$ dqfstemp $=\mathbf{1}, \quad$ qfemseca $=\mathbf{0 , 0 3}, \quad$ qfsmsseca $=\mathbf{0 , 0 0 3}, \quad$ dqfeseca $=$ dqfsseca $=\mathbf{0 , 3}$, qfemumida $=\mathbf{0 , 0 6}$, qfsmumida $=\mathbf{0 , 0 0 6}$, dqfeumida $=\mathrm{dqfsumida}=\mathbf{0 , 3}$. 190

Figura 4.27 - Resultado da simulação de 1000 anos do modelo de sistema eólico costeiro sob condições de sazonalidade acentuada e $\mathbf{q f e}<\mathbf{q f s}$. Foram utilizados os seguintes valores para simulação de qfe e qfs: qfemtemp $=\mathbf{0 , 1 0}, \quad$ qfsmtemp $=\mathbf{0 , 1 1}$; dqfetemp $=$ dqfstemp $=\mathbf{1}, \quad$ qfemseca $=\mathbf{0 , 0 0 3 0}, \quad$ qfsmsseca $=\mathbf{0 , 0 0 3 1}$, dqfeseca $=$ dqfsseca $=\mathbf{0 , 3}$, qfemumida $=\mathbf{0 , 0 0 6 0}$, qfsmumida $=\mathbf{0 , 0 0 6 1}$, dqfeumida $=\mathrm{dqfsumida}=\mathbf{0 , 3}$.

Figura 4.28 - Resultado da simulação de 1000 anos do modelo de sistema eólico costeiro sob condições de sazonalidade acentuada e $\mathbf{q f e}<\mathbf{q f s}$. Foram utilizados os seguintes valores para simulação de qfe e qfs: qfemtemp=0,10, qfsmtemp $=\mathbf{0 , 1 2} ; \quad$ dqfetemp $=$ dqfstemp $=\mathbf{1}, \quad$ qfemseca $=\mathbf{0 , 0 0 3 0}, \quad$ qfsmsseca $=\mathbf{0 , 0 0 3 2}$, dqfeseca $=$ dqfsseca $=\mathbf{0}, \mathbf{3}$, qfemumida $=\mathbf{0 , 0 0 6 0}$, qfsmumida $=\mathbf{0 , 0 0 6 2}$, dqfeumida $=$ dqfsumida $=\mathbf{0 , 3} \ldots$ 
Figura 4.29 - Resultado da simulação de 1000 anos do modelo de sistema eólico costeiro sob condições de sazonalidade acentuada e $\mathbf{q f e}<\mathbf{q f s}$. Foram utilizados os seguintes valores para simulação de qfe e qfs: qfemtemp=0,10, qfsmtemp $=\mathbf{0 , 1 5}$; dqfetemp $=$ dqfstemp $=\mathbf{1}, \quad$ qfemseca $=\mathbf{0 , 0 0 3 0}, \quad$ qfsmsseca $=\mathbf{0 , 0 0 3 5}$, dqfeseca $=$ dqfsseca $=\mathbf{0}, 3$, qfemumida $=\mathbf{0 , 0 0 6 0}$, qfsmumida $=\mathbf{0 , 0 0 6 5}$, dqfeumida $=\mathrm{dqfsumida}=\mathbf{0}, \mathbf{3} \ldots$ 194

Figura 4.30 - Resultado da simulação de 1000 anos do modelo de sistema eólico costeiro sob condições de sazonalidade acentuada e $\mathbf{q f e}<\mathbf{q f s}$. Foram utilizados os seguintes valores para simulação de qfe e qfs: qfemtemp=0,10, qfsmtemp $=\mathbf{0 , 1 5}$; dqfetemp $=$ dqfstemp $=\mathbf{1}, \quad$ qfemseca $=\mathbf{0 , 0 0 3 0}, \quad$ qfsmsseca $=\mathbf{0 , 0 0 3 5}$, dqfeseca $=$ dqfsseca $=\mathbf{0}, \mathbf{3}$, qfemumida $=\mathbf{0 , 0 0 6 0}$, qfsmumida $=\mathbf{0 , 0 0 6 5}$, dqfeumida $=$ dqfsumida $=\mathbf{0}, 3$. 195

Figura 4.31 - Resultado da simulação de 1000 anos do modelo de sistema eólico costeiro sob condições de sazonalidade acentuada e $\mathbf{q f e}<\mathbf{q} \mathbf{f s}$. Foram utilizados os seguintes valores para simulação de qfe e qfs: qfemtemp $=\mathbf{0 , 1 0}, \quad$ qfsmtemp $=\mathbf{0 , 1 5}$; dqfetemp $=$ dqfstemp $=\mathbf{1}, \quad$ qfemseca $=\mathbf{0 , 0 0 3 0}, \quad$ qfsmsseca $=\mathbf{0 , 0 0 3 5}$, dqfeseca $=$ dqfsseca $=\mathbf{0 , 3}$, qfemumida $=\mathbf{0 , 0 0 6 0}$, qfsmumida $=\mathbf{0 , 0 0 6 5}$, dqfeumida $=$ dqfsumida $=\mathbf{0 , 3} \ldots \ldots \ldots \ldots \ldots \ldots \ldots \ldots \ldots . . . \ldots \ldots$

Figura 4.32 - Resultado da simulação de 100000 anos (1000 séculos) do modelo de sistema eólico costeiro sob condições de sazonalidade acentuada, variabilidade climática interanual estacionária, $\mathbf{q f e}=\mathbf{q f s}$ e regime de micromaré $(\mathrm{amp}=0,6 \mathrm{~m})$. Foram utilizados os seguintes valores para simulação de qfe e qfs: qfemtemp=qfsmtemp=0,10; dqfetemp=dqfstemp=1, qfemseca $=\mathbf{0 , 0 0 3}=$ qfsmsseca $=\mathbf{0 , 0 0 3}$, dqfeseca $=$ dqfsseca $=\mathbf{0 , 3}$, qfemumida $=$ qfsmumida $=\mathbf{0 , 0 0 6}$, dqfeumida $=$ dqfsumida $=\mathbf{0 , 3}$. Estes resultados correspondem à média de 15 experimentos. $\mathrm{S}=$ séculos.

Figura 4.33 - Resultado da simulação de 100000 anos (1000 séculos) do modelo de sistema eólico costeiro sob condições de sazonalidade acentuada, variabilidade climática interanual estacionária, $\mathbf{q f e}=\mathbf{q f s}$ e regime de macromaré $(\mathrm{amp}=10 \mathrm{~m})$. Foram utilizados os seguintes valores para simulação de qfe e qfs: qfemtemp=qfsmtemp=0,10; dqfetemp=dqfstemp=1, qfemseca $=\mathbf{0 , 0 0 3}=$ qfsmsseca $=\mathbf{0 , 0 0 3}$, dqfeseca $=$ dqfsseca $=\mathbf{0 , 3}$, qfemumida $=$ qfsmumida $=\mathbf{0 , 0 0 6}$, dqfeumida $=$ dqfsumida $=\mathbf{0 , 3}$. Estes resultados correspondem à média de 15 experimentos. $\mathrm{S}=$ séculos. 202

Figura 4.34 - Resultado da simulação de 100000 anos (1000 séculos) do modelo de sistema eólico costeiro sob condições de sazonalidade acentuada, variabilidade climática interanual estacionária, $\mathbf{q f e}>\mathbf{q f s}$ e regime de micromaré $(\mathrm{amp}=0,6 \mathrm{~m})$. Foram utilizados os seguintes valores para simulação de qfe e qfs: qfemtemp=0,15, qfsmtemp $=\mathbf{0 , 1 0}$; dqfetemp $=$ dqfstemp $=\mathbf{3}, \quad$ qfemseca $=\mathbf{0 , 0 0 3 5}, \quad$ qfsmsseca $=\mathbf{0 , 0 0 3 0}$, dqfeseca $=$ dqfsseca $=\mathbf{3}$, qfemumida $=\mathbf{0 , 0 0 6 5}$, qfsmumida $=\mathbf{0 , 0 0 6 0}$, dqfeumida $=\mathrm{dqfsumida}=\mathbf{3}$. Estes resultados correspondem à média de 5 experimentos. $\mathrm{S}=$ séculos. 204

Figura 4.35 - Resultado da simulação de 100000 anos (1000 séculos) do modelo de sistema eólico costeiro sob condições de sazonalidade acentuada, variabilidade climática interanual estacionária, qfe $>\mathbf{q f s}$ e regime de macromaré $(a m p=10 \mathrm{~m})$. Foram utilizados os seguintes valores para simulação de qfe e qfs: qfemtemp=0,15, qfsmtemp $=\mathbf{0 , 1 0}$; dqfetemp $=$ dqfstemp $=\mathbf{3}$, qfemseca $=\mathbf{0 , 0 0 3 5}, \quad$ qfsmsseca $=\mathbf{0 , 0 0 3 0}, \quad$ dqfeseca $=$ dqfsseca $=\mathbf{3}$, qfemumida $=\mathbf{0 , 0 0 6 5}$, qfsmumida $=\mathbf{0 , 0 0 6 0}$, dqfeumida $=\mathrm{dqfsumida}=\mathbf{3}$. Estes resultados correspondem à média de 5 experimentos. $\mathrm{S}=$ séculos.

Figura 4.36 - Resultado da simulação de 50000 anos (500 séculos) do modelo de sistema eólico costeiro sob regime de micromaré $(a m p=0,6 \mathrm{~m})$ e $\mathbf{q f e}>\mathbf{q f s}$. Foram utilizados os seguintes valores para simulação de qfe e qfs: qfemtemp $=\mathbf{0 , 1 5}, \quad$ qfsmtemp $=\mathbf{0 , 1 0}$; dqfetemp $=$ dqfstemp $=\mathbf{3}, \quad$ qfemseca $=\mathbf{0 , 0 0 3 5}, \quad$ qfsmsseca $=\mathbf{0 , 0 0 3 0}$, dqfeseca $=$ dqfsseca $=\mathbf{3}$, qfemumida $=\mathbf{0 , 0 0 6 5}, \quad$ qfsmumida $=\mathbf{0 , 0 0 6 0}$, dqfeumida $=$ dqfsumida $=\mathbf{3}$. Estes resultados correspondem à média de 5 experimentos. $\mathrm{S}=$ séculos. 210

Figura 4.37 - Resultado da simulação de 50000 anos (500 séculos) do modelo de sistema eólico costeiro sob regime de macromaré $(\mathrm{amp}=10 \mathrm{~m})$ e $\mathbf{q f e}>\mathbf{q f s}$. Foram utilizados os seguintes valores para simulação de qfe e qfs: qfemtemp $=\mathbf{0 , 1 5}, \quad$ qfsmtemp $=\mathbf{0 , 1 0}$; dqfetemp $=$ dqfstemp $=\mathbf{3}, \quad$ ffemseca $=\mathbf{0 , 0 0 3 5}, \quad$ qfsmsseca $=\mathbf{0 , 0 0 3 0}$, dqfeseca $=$ dqfsseca $=\mathbf{3}$, qfemumida $=\mathbf{0 , 0 0 6 5}$, qfsmumida $=\mathbf{0 , 0 0 6 0}$, dqfeumida $=$ dqfsumida $=\mathbf{3}$. Estes resultados correspondem à média de 5 experimentos. $\mathrm{S}=$ séculos. 
Figura 4.38 - Resultado da simulação de 50000 anos (500 séculos) do modelo de sistema eólico costeiro sob regime de micromaré $(\mathrm{amp}=0,6 \mathrm{~m}), \mathbf{q f e}>\mathbf{q f s}$ e aumento da diferença entre as freqüências de chuva das estações seca e úmida. Foram utilizados os seguintes valores para simulação de qfe e qfs: qfemtemp=0,15, qfsmtemp=0,10; dqfetemp $=$ dqfstemp=3, qfemseca $=\mathbf{0 , 0 0 3 5}, \quad$ qfsmsseca $=\mathbf{0 , 0 0 3 0}, \quad$ dqfeseca $=$ dqfsseca $=\mathbf{3}, \quad$ qfemumida $=\mathbf{0 , 0 0 6 5}$, qfsmumida $=\mathbf{0 , 0 0 6 0}$, dqfeumida $=$ dqfsumida $=\mathbf{3}$. Estes resultados correspondem à média de 5 experimentos. Probabilidades de chuva: $\operatorname{ctemp1}=0.8$ e ctemp2 $=0.9$; cseca1 $=0.01$ e cseca2 $=0.02 ;$ cumida1 $=0.7$ e cumida2 $=0.9$. $\mathrm{S}=$ séculos......

Figura 4.39 - Resultado da simulação de 50000 anos (500 séculos) do modelo de sistema eólico costeiro sob regime de macromaré $(\mathrm{amp}=10 \mathrm{~m})$, qfe $>\mathbf{q f s}$ e aumento da diferença entre as freqüências de chuva das estações seca e úmida. Foram utilizados os seguintes valores para simulação de qfe e qfs: qfemtemp=0,15, qfsmtemp=0,10; dqfetemp $=$ dqfstemp $=\mathbf{3}, \quad$ qfemseca $=\mathbf{0 , 0 0 3 5}, \quad$ qfsmsseca $=\mathbf{0 , 0 0 3 0}, \quad$ dqfeseca $=$ dqfsseca $=\mathbf{3}, \quad$ qfemumida $=\mathbf{0 , 0 0 6 5}$, qfsmumida $=\mathbf{0 , 0 0 6 0}$, dqfeumida $=$ dqfsumida $=\mathbf{3}$. Estes resultados correspondem à média de 5 experimentos. Probabilidades de chuva: $\operatorname{ctemp1}=0.8$ e ctemp2 $=0.9$; cseca1 $=0.01$ e cseca2 $=0.02 ;$ cumida1 $=0.7$ e cumida2 $=0.9$. $\mathrm{S}=$ séculos....... 216

Figura 4.40 - Resultado da simulação de 50000 anos (500 séculos) do modelo de sistema eólico costeiro sob regime de micromaré $(\mathrm{amp}=0,6 \mathrm{~m})$, amplificação da diferença da velocidade do vento entre os períodos seco e úmido e $\mathbf{q f e}>\mathbf{q f s}$. Foram utilizados os seguintes valores para simulação de qfe e qfs: qfemtemp=0,15, qfsmtemp=0,10; dqfetemp=dqfstemp=3, qfemseca $=\mathbf{0 , 0 0 3 5}, \quad$ qfsmsseca $=\mathbf{0 , 0 0 3 0}, \quad$ dqfeseca $=$ dqfsseca $=\mathbf{3}, \quad$ qfemumida $=\mathbf{0 , 0 0 6 5}$, qfsmumida $=\mathbf{0 , 0 0 6 0}$, dqfeumida $=$ dqfsumida $=\mathbf{3}$. Estes resultados correspondem à média de 5 experimentos . $\mathrm{S}=$ séculos. Velocidades médias e dispersão da velocidade do vento: vmtemp=20 e dvtemp=0.5; vmseca=15 e dvseca $=0.3$; vmumida $=5$ e dvumida $=0.3$. 219

Figura 4.41 - Resultado da simulação de 50000 anos (500 séculos) do modelo de sistema eólico costeiro sob regime de macromaré $(\mathrm{amp}=10 \mathrm{~m})$, amplificação da diferença da velocidade do vento entre os períodos seco e úmido e qfe $>$ qfs. Foram utilizados os seguintes valores para simulação de qfe e qfs: qfemtemp=0,15, qfsmtemp=0,10; dqfetemp $=$ dqfstemp=3, qfemseca $=\mathbf{0 , 0 0 3 5}, \quad$ qfsmsseca $=\mathbf{0 , 0 0 3 0}, \quad$ dqfeseca $=$ dqfsseca $=\mathbf{3}, \quad$ qfemumida $=\mathbf{0 , 0 0 6 5}$, qfsmumida $=\mathbf{0 , 0 0 6 0}$, dqfeumida $=$ dqfsumida $=\mathbf{3}$. Estes resultados correspondem à média de 5 experimentos . $\mathrm{S}=$ séculos. Velocidades médias e dispersão da velocidade do vento: vmtemp=20 e dvtemp=0.5; vmseca $=\mathbf{1 5}$ e dvseca $=0.3 ;$ vmumida $=5$ e dvumida $=0.3$. 221

Figura 4.42 - Resultado da simulação de 50000 anos (500 séculos) do modelo de sistema eólico costeiro sob regime de micromaré $(\mathrm{amp}=0,6 \mathrm{~m})$, amplificação da diferença da probabilidade de ocorrência de tempestade entre os períodos seco e úmido e qfe>qfs. Foram utilizados os seguintes valores para simulação de qfe e qfs: qfemtemp=0,15, qfsmtemp $=\mathbf{0 , 1 0}$; dqfetemp $=$ dqfstemp $=\mathbf{3}$, qfemseca $=\mathbf{0 , 0 0 3 5}, \quad$ qfsmsseca $=\mathbf{0 , 0 0 3 0}, \quad$ dqfeseca $=$ dqfsseca $=\mathbf{3}$, qfemumida $=\mathbf{0 , 0 0 6 5}$, qfsmumida $=\mathbf{0 , 0 0 6 0}$, dqfeumida $=\mathrm{dqfsumida}=\mathbf{3}$. Estes resultados correspondem à média de 5 experimentos. $\mathrm{S}=$ séculos. Probabilidades de ocorrência de tempestade: tempsecal $=0.02$ e tempseca2 $=0.05$; tempumida $1=0.2$ e tempumida $2=0.3$.

Figura 4.43 - Resultado da simulação de 50000 anos (500 séculos) do modelo de sistema eólico costeiro sob regime de macromaré $(a m p=10 \mathrm{~m})$, amplificação da diferença da probabilidade de ocorrência de tempestade entre os períodos seco e úmido e qfe>qfs. Foram utilizados os seguintes valores para simulação de qfe e qfs: qfemtemp=0,15, qfsmtemp $=\mathbf{0 , 1 0}$; dqfetemp $=$ dqfstemp $=\mathbf{3}, \quad$ qfemseca $=\mathbf{0 , 0 0 3 5}, \quad$ qfsmsseca $=\mathbf{0 , 0 0 3 0}, \quad$ dqfeseca $=$ dqfsseca $=\mathbf{3}$, qfemumida $=\mathbf{0 , 0 0 6 5}$, qfsmumida $=\mathbf{0 , 0 0 6 0}$, dqfeumida $=\mathrm{dqfsumida}=\mathbf{3}$. Estes resultados correspondem à média de 5 experimentos. $\mathrm{S}=$ séculos. Probabilidades de ocorrência de tempestade: tempseca $1=0.02$ e tempseca $2=0.05$; tempumida $1=0.2$ e tempumida $2=0.3$.

Figura 4.44 - Volume de sedimentos transportados da área fonte para a área de deposição $(\Delta \mathrm{V})$ e variação da área de deposição $(\Delta \mathrm{A})$ pela regressão da linha de costa $(\Delta \mathrm{x})$ durante certo intervalo de tempo $(\Delta \mathrm{t})$. A variação da área de deposição corresponde a $\Delta \mathrm{A}=\Delta \mathrm{x} * \mathrm{com}$, sendo que "com" é comprimento da costa... 227

Figura 4.45 - Linha de costa estável (dx) e volume de sedimentos eólicos com crescimento linear (Vc) ao longo do tempo. Vc1, Vc2 e Vc3 representam taxas de crescimento distintas. A origem do gráfico $(\mathrm{dx}=0)$ indica a posição inicial da linha e costa. Os algarismos 1, 2, 3 e 4 representam o tamanho do campo de dunas (para determinada taxa 
de crescimento de $\mathrm{Vc}$ ) em períodos de tempo sucessivos. Há diminuição da taxa de crescimento em área e de avanço com o tempo. Vc e dx são representados pelo eixo y (vertical). O eixo x (horizontal) representa o tempo (t)......... 229

Figura 4.46 - Linha de costa estável (dx) e volume de sedimentos eólicos $(\mathrm{Vc})$ com crescimento exponencial (taxa de crescimento crescente). $\mathrm{O}$ aumento da taxa de crescimento de Vc pode manter a velocidade de avanço e a expansão em área do campo de dunas. 229

Figura 4.47 - Linha de costa (dx) com regressão em "escada" e crescimento linear do volume de sedimentos eólicos $(\mathrm{Vc})$. As fases de regressão são separadas por períodos de estabilidade. O crescimento em área e avanço do campo de dunas seguiria padrão em pulsos, caracterizado por crescimento e avanço acelerado durante períodos de linha de costa estável e crescimento e avanço reduzido ou nulo em períodos de linha de costa regressiva. 231

Figura 4.48 - Linha de costa $(\mathrm{dx})$ transgressiva e crescimento linear do volume de sedimentos eólicos. A trangressão também é linear e é indicada pela tendência decrescente de $\mathrm{dx}$. A transgressão erode a retaguarda do campo de dunas e atua contra seu crescimento em área.. 233

Figura 4.49 - Transgressão da linha de costa sob NRM estável ou em ascensão. Sob NRM estável há erosão completa dos depósitos da retaguarda do campo de dunas enquanto que sob NRM ascendente há erosão apenas parcial e submersão de parte dos depósitos eólicos situados a retaguarda. 233

Figura 4.50 - Transgressão da linha de costa seguida por estabilização e crescimento linear do volume de sedimentos eólicos. A transgressão da linha de costa seguida por estabilização provoca variações da taxa de crescimento do campo de dunas. Assim, haveria fase inicial de avanço com crescimento em área pouco acelerado, devido à erosão costeira, seguida por fase de crescimento acelerado (linha de costa estável) sucedida por redução da taxa de crescimento provocada pela elevação da área. 234

Figura 4.51 - Crescimento de Vc, com taxa constante, sob linha de costa com tendência de migração variável. A migração da linha de costa $(\mathrm{dx})$ compreende fase inicial de transgressão seguida por ciclos regressivos-transgressivos de amplitude variável, separados por fase de estabilização. 235

Figura 4.52 - Divisão morfodinâmica do sistema eólico costeiro. qir=fluxo de sedimentos da zona intermaré para a retaguarda; qrc=fluxo de sedimentos da retaguarda para o centro; qcf= fluxo de sedimentos do centro para a frente. A regularidade de qir é menor que a dos demais fluxos, pois o primeiro apresenta dois agentes bloqueadores (maré e chuva). A redução de qcf ocorre com o crescimento das dunas na porção central do sistema. 237

Figura 4.53 - Crescimento do sistema eólico sob linha de costa estável. O crescimento no sentido onshore produzirá sucessão ascendente formada por fácies de frente, centro e retaguarda. Os números 1, 2 e 3 representam linhas de tempo em instantes sucessivos. 238

Figura 4.54 - Crescimento do sistema eólico com expansão da porção central sobre as porções periféricas. Neste caso, associação de fácies de centro recobriria associações de fácies periféricas (de retaguarda e de frente). Isto ocorreria mediante elevação do aporte primário ao longo do tempo. Os números 1, 2, 3, 4 e 5 representam linhas de tempo sucessivas. A partir da linha de tempo 3, há expansão da associação de fácies de centro sobre as associações de fácies periféricas (retaguarda e frente). 238

Figura 4.55 - Gerações de campos de dunas formadas pela regressão seguida de estabilização da linha de costa. A regressão acelerada da linha de costa (de L1 para L2) provoca isolamento do campo de dunas da sua área fonte primária. Novo campo de dunas irá se formar após a estabilização da linha de costa. Os números 1 e 2 representam as linhas de tempo nos instantes anterior e posterior à fase de regressão acelerada. As fácies de frente do campo de dunas mais jovem recobrirão as fácies de retaguarda do campo de dunas mais antigo. 239

Figura 4.56 - A estabilidade prolongada da linha de costa (L2) pode propiciar o crescimento do campo de dunas situado a barlavento. A amalgamação dos campos de dunas pode provocar sobreposição das fácies de centro do campo de dunas mais velho pelas fácies de centro do mais novo. Os números $1,2,3$, e 5 indicam linhas de tempo em momentos sucessivos. A regressão ocorreu durante fase após a linha de tempo 1. Em 3, 4 e 5 há crescimento das duas gerações de campos de dunas. A geração de campo de dunas situada a barlavento passa a ser fonte da situada a 
sotavento. O aporte sedimentar para o campo de dunas a sotavento diminui com o crescimento do campo de dunas situado a barlavento.

Figura 4.57 - Imersão da frente e retaguarda do campo de dunas por transgressão da linha de costa sob NRM ascendente. A formação de corpo lagunar restringe o crescimento do campo de dunas. O confinamento do campo de dunas e a imersão de suas periferias favorece a concentração do aporte eólico e o desaparecimento das fácies de baixo aporte. NRM1/L1 e NRM2/L2 indicam respectivamente a posição do nível relativo do mar e da linha de costa em períodos sucessivos.

Figura 4.58 - Modelo de sucessão de fácies para um ciclo de expansão e retração do sistema eólico costeiro. A fase de expansão é representada pelo avanço da associação de fácies de centro (Ct) sobre as associações de fácies de frente $(\mathrm{Rt})$ e retaguarda $(\mathrm{Rd})$. $\mathrm{Na}$ associação de fácies de centro, este avanço produz espessamento ascendente das fácies de dunas e adelgaçamento das fácies de interdunas. A fase de retração é caracterizada por padrão inverso de sobreposição de associação de fácies e variação da espessura das fácies. As associações de fácies de centro e retaguarda contém fácies eólicas de suprimento sedimentar mais reduzido, as quais podem se interdigitar a fácies de sistemas deposicionais vizinhos (lagunar, estuarino, costa dominada por ondas etc). 244

Figura 4.59 - Modelo de sucessão de fácies para ciclo de expansão e retração do sistema eólico com duas gerações de campos de dunas. Os números 1 e 2 referem-se respectivamente às gerações mais antiga e mais nova. Na região central haverá sobreposição da associação de fácies de retaguarda da geração mais velha (Rd1) por associação de fácies de frente $(\mathrm{Ft} 2)$ da geração mais nova. 245

Figura 4.60 - Estabilização e erosão do campo de dunas provocada pela queda do NRM. Há formação de superfície de erosão fluvial. 248

Figura 4.61 - Variação do nível relativo do mar na costa brasileira durante os últimos 120 ka (dados compilados de Martin et al. (1988), Corrêa (1996), Angulo \& Lessa (1997) e Angulo et al. (1999)).

Figura 4.62 - Gerações de dunas dunas frontais, blowouts (D1, D2 e D3) e campo de dunas (CD) separadas por zona de cordões litorâneos (C1, C2 e C3). A geração mais nova (D3) é mais ampla e caracterizada por diversos cordões de dunas frontais ou de blowouts. A geração D2 desaparece rumo nordeste, onde há amalgamação entre as zonas de cristas praiais C2 e C3 (C2/C3). Notar ainda que a nordeste, onde a ilha é mais estreita, há a formação de pequeno campo de dunas. Foto aérea da Ilha Comprida (SP).

Figura 4.63 - A geração eólica 2 é separada da geração eólica 4 por zona de cordões litorâneos (Sistema planície costeira holocênico). A geração eólica 3 é formada por fácies eólicas de baixo suprimento sedimentar, que se desenvolvem sobre o sistema planície costeira holocênico. A geração eólica 2 teria se desenvolvido em contexto de linha de costa transgressiva/estável. A geração 3 representaria fase de linha de costa com regressão acelerada e a geração 4 representaria fase mais recente de linha de costa mais estável. Por este motivo, as gerações 2 e 4 seriam mais desenvolvidas que a geração 3. Idades TL/OSL confirma a contemporaneidade entre a geração eólica 3 e os cordões litorâneos do sistema planície costeira (amostras BA(A)1 e BA(B)1). As idades TL/OSL também indicam que a atividade da geração eólica 2 persistiu por alguns milhares de anos após o início da regressão da linha de costa e formação da planície costeira (amostras B(B)1 e B(B)2))...... 258

Figura 4.64 - Dunas estabilizadas ou em processo de estabilização truncadas pelo sistema lagunar e separadas dos campos de dunas livres (dunas ativas) em atividade. Os campos de dunas livres avançam sobre planície de cordões litorâneos, o que evidencia fase regressiva (progradacional) após a instalação do sistema lagunar que isolou as dunas em processo de estabilização. Região costeira de Mostardas (RS). 260

Figura 4.65 - Área de dunas vegetadas (estabilizadas ou em processo de estabilização) a sotavento do campo de dunas dos Lençóis Maranhenses (dunas ativas). Notar o truncamento das dunas vegetadas pelo sistema de baía estuarina. As dunas ativas avançam sobre a área de dunas vegetadas. 261 


\section{CAPÍTULO 5}

Figura 5.1 - Principais fácies que compõem a Formação Pirambóia: fácies de lençol de areia (La), fácies de dunas (Dn), fácies de interdunas (Id) e fácies de barras de rios entrelaçados (Re).

Figura 5.2 - A seção A representa as formações Botucatu e Serra Geral aflorantes na serra de Botucatu (Botucatu, SP). A seção B foi elaborada por Fernandes (1998) e representa unidades do Grupo Caiuá (formações Rio Paraná e Santo Anastácio) e do Grupo Bauru (Formação Vale do Rio do Peixe), que afloram em Pereira Barreto (SP). A associação de fácies basal do Grupo Caiuá é indicativa de campos de dunas de suprimento elevado. Esta associação equivale às associações de fácies eólicas das formações Botucatu e Serra Geral. As formações Santo Anastácio e Vale do Rio do Peixe contêm associações de fácies eólicas de suprimento reduzido (periferia de campos de dunas).

\section{CAPÍTULO 6}

Figura 6.1 - Preenchimento diferencial de hidrocarbonetos em fácies de dunas e interdunas da Formação Pirambóia. As fácies de dunas são preenchidas preferecialmente por hidrocarbonetos (arenito fino de cor preta) enquanto que fácies de interdunas (arenito fino pelítico esbranquiçado) podem servir de barreira interna à migração dos hidrocarbonetos. Foto: Paulo César Fonseca Giannini. 277

Figura 6.2 - Transporte de glóbulo de óleo através da garganta de um poro (Berg, 1975). Em A, a pressão capilar $(P c)$ na superfície do glóbulo é uniforme, de modo que não há gradiente de pressão capilar. Ao adentrar na garganta do poro, a pressão capilar no topo do glóbulo torna-se superior à da base (B). Isto cria um gradiente de pressão capilar com força dirigida para baixo, contrária à força de flutuação $(P e)$. Ao atravessar a garganta do poro, a pressão capilar no topo do glóbulo é igualada pela pressão da base (C). Nesta condição, o gradiente de pressão capilar é nulo e o glóbulo é transportado para cima pela força de flutuação. A migração secundária ocorre quando a força de flutuação $(P e)$ supera o gradiente de pressão capilar dirigido para baixo $(P c)$. A retenção de hidrocarbonetos ocorre quando a força de flutuação não for suficiente para que o glóbulo de óleo adentre a garganta do poro. $R t$ representa o raio da garganta do poro, $R p$ o raio do poro conectado à garganta e $\gamma$ representa a tensão interfacial óleo-água..... 277

Figura 6.3 - Fácies de dunas (Dn) entre fácies de interdunas (Id). A pressão capilar $(P c)$ das fácies de interdunas relaciona-se ao conteúdo de sedimentos pelíticos e a altura máxima da coluna de hidrocarbonetos (HC) das fácies de dunas relaciona-se à espessura das séries de estratificações cruzadas e ao número de séries sobrepostas. A migração vertical ocorrerá somente se $P c$ superar $P e$.

Figura 6.4 - Modelo de reservatório para sistema eólico desenvolvido sob suprimento sedimentar crescente. A maior freqüência de fácies de interdunas dificulta a migração vertical na porção inferior do depósito eólico. A migração através das fácies de interdunas dependerá da altura da coluna de óleo nas fácies subjacentes. A espessura e conectividade vertical das fácies de dunas (E) determina a altura máxima da coluna de hidrocarbonetos subjacente a fácies de interdunas. $\mathrm{O}$ aprisionamento de hidrocarbonetos pode ocorrer com o recobrimento de fácies de dunas por fácies de interdunas. 281

Figura 6.5 - Dinâmica de migração secundária controlada pela sucessão de fácies de dunas e interdunas. A fácies de dunas (Dn) recebe hidrocarbonetos a partir da fácies de interdunas subjacente (fluxo HC(Id1-Dn)). A presença de fácies de interdunas sobre a fácies de dunas provoca contenção da migração secundária até que a altura da coluna de hidrocarbonetos (h) alcance certo valor (hcr) suficiente para que $P e$ (força de flutuação) supere $P c$ (pressão capilar da fácies de interduna). O fluxo para a fácies sobrejacente ( $\mathrm{HC}(\mathrm{Dn}-\mathrm{Id} 2))$ ocorrerá quando h superar hcr. Isto tornará a migração secundária descontínua e dependente da superação de um valor crítico (hcr) de altura da coluna de hidrocarbonetos. 282 


\section{LISTA DE TABELAS}

\section{CAPÍTULO 3}

Tabela 3.1 - Estatísticas descritivas das variáveis A, P, ADV e C.

70

Tabela 3.2 - Estatísticas descritivas das variáveis $\mathrm{A} / \mathrm{C}, P / \sqrt{A}, \mathrm{ADV} / \mathrm{A}$ e $\mathrm{D} / \mathrm{C}$. 71

Tabela 3.3 - Estatísticas descritivas do ângulo entre o rumo de avanço do campos de dunas e direção da linha de $\operatorname{costa}(\alpha)$. 73

Tabela 3.4 - Estatísticas descritivas da variável A/C para os grupos 1, 2, 3 e 4 76

Tabela 3.5 - Estatísticas descritivas da variável ADV/A para os grupos 1, 2, 3 e 4 .76

Tabela 3.6 - Estatísticas descritivas da variável $P / \sqrt{A}$ para os grupos $1,2,3$ e 4 . 76

Tabela 3.7 - Estatísticas descritivas da variável D/C para os grupos 1, 2, 3 e 4. 76

Tabela 3.8 - Freqüência de atuação e velocidade média dos ventos de cada octante. Apenas os ventos com freqüência superior a 10\% estão representados. Dados coletados entre 1951 e 1972 na região entre São Luís (MA) e Luís Correia (PI) (DHN, 1974). 80

Tabela 3.9 - Freqüência de atuação e velocidade média dos ventos de cada octante. Apenas os ventos com freqüência superior a 10\% estão representados. Dados coletados entre 1951 e 1972 na região de Fortaleza (DHN, 1974)......80

Tabela 3.10 - Freqüência de atuação e velocidade média dos ventos de cada octante. Apenas os ventos com freqüência superior a 10\% estão representados. Dados coletados entre 1951 e 1972 na região entre Salvador (BA) e Aracaju (SE) (DHN, 1974) 88

Tabela 3.11 - Freqüência de atuação e velocidade média dos ventos de cada octante. Apenas os ventos com freqüência superior a 10\% estão representados. Dados coletados entre 1951 e 1972 nas proximidades de Cabo Frio (RJ) (DHN, 1974). 88

Tabela 3.12 - Freqüência de atuação e velocidade média dos ventos de cada octante. Apenas os ventos com freqüência superior a 10\% estão representados. Dados coletados entre 1951 e 1972 na Ilha de Santa Catarina (SC) (DHN, 1974). 94

Tabela 3.13 - Freqüência de atuação e velocidade média dos ventos de cada octante. Apenas os ventos com freqüência superior a 10\% estão representados. Dados coletados entre 1951 e 1972 na região do cabo de Santa Marta (Laguna, SC) (DHN, 1974). 94

Tabela 3.14 - Freqüência de atuação e velocidade média dos ventos de cada octante. Apenas os ventos com freqüência superior a 10\% estão representados. Dados coletados entre 1951 e 1972 na região de Rio Grande (RS) (DHN, 1974). 95

Tabela 3.15 - Freqüência de atuação e velocidade média dos ventos de cada octante. Apenas os ventos com freqüência superior a 10\% estão representados. Dados coletados entre 1951 e 1972 na região de Chuí (RS) (DHN, 1974). 95

Tabela 3.16 - Resultados do teste qui-quadrado para verificação de associação entre categorias de campos de dunas classificadas pelo número de meses secos, velocidade e freqüência de atuação dos ventos geradores de dunas, amplitude de maré e setores geográficos. Valores de p inferiores a 0,05 indicam existência de associação entre as categorias comparadas (rejeição da hipótese de distribuição uniforme). 105 
Tabela 3.17 - Estatísticas descritivas da variável A/C para campos de dunas desenvolvidos em regiões com zero a três, quatro a seis e sete a oito meses secos (mesomaré).

Tabela 3.18 - Estatísticas descritivas da variável ADV/A para campos de dunas desenvolvidos em regiões com zero a três, quatro a seis e sete a oito meses secos.

Tabela 3.19 - Estatísticas descritivas da variável $P / \sqrt{A}$ para campos de dunas desenvolvidos em regiões com zero a três, quatro a seis e sete a oito meses secos.

Tabela 3.20 - Estatísticas descritivas da variável D/C para campos de dunas desenvolvidos em regiões com zero a três, quatro a seis e sete a oito meses secos.

Tabela 3.21 - Tabela de correspondência e teste qui-quadrado para avaliar a dependência entre os grupos morfológicos 1, 2 e 3 e o número de meses secos (total). $\mathrm{O}$ valor de $\mathrm{p}$ indica que não há relação entre grupos morfológicos e categorias definidas em termos de número de meses secos. Neste caso, aceita-se a hipótese de que as freqüências de contagem observadas e esperadas são equivalentes.

Tabela 3.22 - Tabela de correspondência e teste qui-quadrado para avaliar a dependência entre grupos morfológicos (grupos 1 e 2) e o número de meses secos (mesomaré). O valor de p indica que não há relação entre grupos morfológicos e categorias definidas em termos de número de meses secos. Neste caso, aceita-se a hipótese de que as freqüências de contagem observadas e esperadas são equivalentes.

Tabela 3.23 - Estatísticas descritivas da variável A/C para campos de dunas agrupados pela freqüência de atuação dos ventos dos meses de janeiro e julho (zonas sob regime de mesomaré e quatro a oito meses secos e sob regime de micromaré e zero a três meses secos). Q1: primeiro quartil, Q3: terceiro quartil. 113

Tabela 3.24 - Estatísticas descritivas da variável ADV/A para campos de dunas agrupados pela freqüência de atuação dos ventos dos meses de janeiro e julho (zonas sob regime de mesomaré e quatro a oito meses secos e sob regime de micromaré e zero a três meses secos). Q1: primeiro quartil, Q3: terceiro quartil. 113

Tabela 3.25 - Estatísticas descritivas da variável $P / \sqrt{A}$ para campos de dunas agrupados pela freqüência de atuação dos ventos dos meses de janeiro e julho (zonas sob regime de mesomaré e quatro a oito meses secos e sob regime de micromaré e zero a três meses secos). Q1: primeiro quartil, Q3: terceiro quartil.

Tabela 3.26 - Estatísticas descritivas da variável D/C para campos de dunas agrupados pela freqüência de atuação dos ventos dos meses de janeiro e julho (zonas sob regime de mesomaré e quatro a oito meses secos e sob regime de micromaré e zero a três meses secos). Q1: primeiro quartil, Q3: terceiro quartil. 114

Tabela 3.27 - Estatísticas descritivas da variável A/C para campos de dunas agrupados pela amplitude de maré (quatro a seis meses secos). 116

Tabela 3.28 - Estatísticas descritivas da variável A/C para campos de dunas agrupados pela amplitude de maré (zero a três meses secos). 116

Tabela 3.29 - Estatísticas descritivas da variável ADV/A para campos de dunas agrupados pela amplitude de maré (quatro a seis meses secos).......

Tabela 3.30 - Estatísticas descritivas da variável ADV/A para campos de dunas agrupados pela amplitude de maré (zero a três meses secos).

Tabela 3.31 - Estatísticas descritivas da variável $P / \sqrt{A}$ para campos de dunas agrupados pela amplitude de maré (quatro a seis meses secos). 
Tabela 3.32 - Estatísticas descritivas da variável $P / \sqrt{A}$ para campos de dunas agrupados pela amplitude de maré (zero a três meses secos). 118

Tabela 3.33 - Estatísticas descritivas da variável D/C para campos de dunas agrupados pela amplitude de maré (quatro a seis meses secos).

Tabela 3.34 - Estatísticas descritivas da variável D/C para campos de dunas agrupados pela amplitude de maré (zero a três meses secos).

Tabela 3.35 - Tabela de contingência e teste qui-quadrado para avaliar a dependência entre os grupos morfológicos 1,2 e 3 e a amplitude de maré (total). $\mathrm{O}$ valor de $\mathrm{p}$ indica que não há dependência entre grupos morfológicos $\mathrm{e}$ amplitude de maré. Assim, aceita-se a hipótese de que as freqüências de contagem observadas e esperadas são equivalentes. Notar que há valores de freqüência esperada inferiores a 5,0. Neste caso, mesmos valores significativos de $\mathrm{p}$ devem ser interpretados com cautela.

Tabela 3.36 - Tabela de contingência (freqüências de contagem) e teste qui-quadrado para avaliar a dependência entre grupos morfológicos (grupos 1 e 2) e a amplitude de maré (zero a três meses secos). $\mathrm{O}$ valor de p superior a 0,05 indica que não há relação entre grupos morfológicos e amplitude de maré. Notar que há valores de freqüência esperada inferiores a 5,0. Neste caso, mesmos valores significativos de $\mathrm{p}$ devem ser interpretados com cautela.... 121

Tabela 3.37 - Tabela de contingência (freqüências de contagem) e teste qui-quadrado para avaliar a dependência entre grupos morfológicos (grupos 1 e 2) e a amplitude de maré (quatro a seis meses secos). $\mathrm{O}$ valor de p inferior a 0,05 indica que existe dependência entre grupos morfológicos e amplitude de maré. Notar que há valor de freqüência esperada inferior a 5,0. Neste caso, mesmos valores significativos de $\mathrm{p}$ devem ser interpretados com cautela. ....... 122

Tabela 3.38 - Estatísticas descritivas da variável A/C para os setores 1, 2 e 3. Os setores 1 e 3 apresentam valores médios mais elevados. Notar os elevados valores do desvio padrão, terceiro quartil e valor máximo no setor 1 .... 123

Tabela 3.39 - Estatísticas descritivas da variável ADV/A para os setores 1, 2 e 3. Salienta-se a semelhança entre os setores 1 e 3 e elevada variabilidade nos três setores. O setor 2 distingue-se dos demais por apresentar maior freqüência de valores menores de ADV/A.

Tabela 3.40 - Estatísticas descritivas da variável $P / \sqrt{A}$ para os setores 1,2 e 3. Esta variável apresenta variabilidade menor que as variáveis A/C e ADV/A. Destaca-se a menor diferença relativa entre os quartis e o menor valor do desvio padrão em relação à média. 125

Tabela 3.41 - Estatísticas descritivas da variável D/C para os setores 1, 2 e 3 125

Tabela 3.42 - Tabela de contingência e teste qui-quadrado para avaliar a dependência entre os grupos morfológicos 1,2 e 3 e os setores geográficos 1,2 e 3 . O valor de p indica rejeição da equivalência entre freqüências observadas e esperadas. Neste caso, deve haver relação entre setores geográficos e grupos morfológicos. 128

\section{CAPÍTULO 4}

Tabela 4.1 - Volumes estimados para dunas frontais de alturas e inclinação das faces distintas. $\mathrm{h}=\mathrm{altura} ; \boldsymbol{\gamma}=$ ângulo de inclinação das faces; com=comprimento.

Tabela 4.2 - Intervalos de confiança da freqüência de ocorrência de tempestades, porcentagem de dias secos e velocidade do média anual do vento.

Tabela 4.3 - Média e desvio padrão dos intervalos de confiança das variáveis de interesse (simulação de 1000 anos), cujos resultados encontram-se na Figura 4.15.

Tabela 4.4 - Média e desvio padrão dos intervalos de confiança das variáveis de interesse (simulação de 1000 anos), cujos resultados encontram-se na Figura 4.16. 
Tabela 4.5 - Média e desvio padrão dos intervalos de confiança das variáveis de interesse (simulação de 1000 anos), cujos resultados encontram-se na Figura 4.17.

Tabela 4.6 - Média e desvio padrão dos intervalos de confiança das variáveis de interesse (simulação de 1000 anos), cujos resultados encontram-se na Figura 4.18 . 178

Tabela 4.7 - Média e desvio padrão dos intervalos de confiança das variáveis de interesse (simulação de 1000 anos), cujos resultados encontram-se na Figura 4.19. 180

Tabela 4.8 - Média e desvio padrão dos intervalos de confiança das variáveis de interesse (simulação de 1000 anos), cujos resultados encontram-se na Figura 4.20. 182

Tabela 4.9 - Média e desvio padrão dos intervalos de confiança das variáveis de interesse (simulação de 1000 anos), cujos resultados encontram-se na Figura 4.21 184

Tabela 4.10 - Média e desvio padrão dos intervalos de confiança das variáveis de interesse (simulação de 1000 anos), cujos resultados encontram-se na Figura 4.22. 185

Tabela 4.11 - Média e desvio padrão dos intervalos de confiança das variáveis de interesse (simulação de 1000 anos), cujos resultados encontram-se na Figura 4.23. 186

Tabela 4.12 - Média e desvio padrão dos intervalos de confiança das variáveis de interesse (simulação de 1000 anos), cujos resultados encontram-se na Figura 4.24. 187

Tabela 4.13 - Média e desvio padrão dos intervalos de confiança das variáveis de interesse (simulação de 1000 anos), cujos resultados encontram-se na Figura 4.25.

Tabela 4.14 - Média e desvio padrão dos intervalos de confiança das variáveis de interesse (simulação de 1000 anos), cujos resultados encontram-se na Figura 4.26.

Tabela 4.15 - Média e desvio padrão dos intervalos de confiança das variáveis de interesse (simulação de 1000 anos), cujos resultados encontram-se na Figura 4.27.

Tabela 4.16 - Média e desvio padrão dos intervalos de confiança das variáveis de interesse (simulação de 1000 anos), cujos resultados encontram-se na Figura 4.28.

Tabela 4.17 - Média e desvio padrão dos intervalos de confiança das variáveis de interesse (simulação de 1000 anos), cujos resultados encontram-se na Figura 4.29. 194

Tabela 4.18 - Média e desvio padrão dos intervalos de confiança das variáveis de interesse (simulação de 1000 anos), cujos resultados encontram-se na Figura 4.30. 195

Tabela 4.19 - Média e desvio padrão dos intervalos de confiança das variáveis de interesse (simulação de 1000 anos), cujos resultados encontram-se na Figura 4.31....

Tabela 4.20 - Média e desvio padrão dos intervalos de confiança das variáveis de interesse (simulação de 100000 anos, $\mathrm{N}=15$ ), cujos resultados encontram-se na Figura 4.32.

Tabela 4.21 - Média e desvio padrão dos intervalos de confiança das variáveis de interesse (simulação de 100000 anos, $\mathrm{N}=15$ ), cujos resultados encontram-se na Figura 4.33.

Tabela 4.22 - Média e desvio padrão dos intervalos de confiança das variáveis de interesse (simulação de 100000 anos, $\mathrm{N}=5$ ), cujos resultados encontram-se na Figura 4.34 . 
Tabela 4.23 - Média e desvio padrão dos intervalos de confiança das variáveis de interesse (simulação de 100000 anos, $\mathrm{N}=5$ ), cujos resultados encontram-se na Figura 4.35.

Tabela 4.24 - Média e desvio padrão dos intervalos de confiança das variáveis de interesse (simulação de 50000 anos, $\mathrm{N}=5$ ), cujos resultados encontram-se na Figura 4.36.

Tabela 4.25 - Média e desvio padrão dos intervalos de confiança das variáveis de interesse (simulação de 50000 anos, $\mathrm{N}=5$ ), cujos resultados encontram-se na Figura 4.37.

Tabela 4.26 - Média e desvio padrão dos intervalos de confiança das variáveis de interesse (simulação de 50000 anos, $\mathrm{N}=5$ ), cujos resultados encontram-se na Figura 4.38.

Tabela 4.27 - Média e desvio padrão dos intervalos de confiança das variáveis de interesse (simulação de 50000 anos, $\mathrm{N}=5$ ), cujos resultados encontram-se na Figura 4.39.

Tabela 4.28 - Média e desvio padrão dos intervalos de confiança das variáveis de interesse (simulação de 50000 anos, $\mathrm{N}=5$ ), cujos resultados encontram-se na Figura 4.40.

Tabela 4.29 - Média e desvio padrão dos intervalos de confiança das variáveis de interesse (simulação de 50000 anos, $\mathrm{N}=5$ ), cujos resultados encontram-se na Figura 4.41

Tabela 4.30 - Média e desvio padrão dos intervalos de confiança das variáveis de interesse (simulação de 50000 anos, $\mathrm{N}=5$ ), cujos resultados encontram-se na Figura 4.42 .

Tabela 4.31 - Média e desvio padrão dos intervalos de confiança das variáveis de interesse (simulação de 50000 anos, $\mathrm{N}=5$ ), cujos resultados encontram-se na Figura 4.43.

Tabela 4.32 - Estatísticas descritivas das idades TL/OSL das gerações eólicas (1, 2 e 3) do litoral centro-sul catarinense (Sawakuchi, 2003). A idade mínima da geração eólica 1 foi obtida em fácies de deflação (areia com cascalho). Idades em $10^{3}$ anos.

\section{CAPÍTLO 6}

Tabela 6.1 - Valores de porosidade (média) e permeabilidade (horizontal e vertical) em fácies de dunas e interdunas do arenito Nugget (campo petrolífero Anschutz Ranch East, Utah-Wyoming, EUA). Fonte: Lindquist (1988)...... 274 


\section{LISTA DE QUADROS}

\section{CAPÍTULO 3}

Quadro 3.1 - Cores falsas das principais feições superficiais visíveis nos mosaicos do programa GeoCover.

Quadro 3.2 - Tabela de freqüências esperadas e observadas. As freqüências esperadas podem ser por exemplo classes de campos de dunas de $k$ setores geográficos. Utiliza-se a análise de agrupamento para dividir os mesmos campos de dunas a partir de variáveis morfométricas em $k$ grupos. 68

Quadro 3.3 - Nas colunas estão representadas as categorias (a, b e c) e nas linhas os grupos definidos por análise de agrupamento (1, 2 e 3$)$. As freqüências observadas são representadas por $o_{i j}$, sendo $i$ grupos e $j$ categorias. Por exemplo, $o_{l a}$ é a freqüência de observações do grupo 1 que pertencem à categoria a. No caso de não haver relação entre grupos e categorias, as freqüências observadas de um mesmo grupo seriam iguais. Se houver preferência de certo grupo por certa categoria, pode-se supor relação entre grupos e categorias. A preferência é medida pela quantidade $Q^{2}$, sendo que o modelo proposto é a distribuição não homogênea das amostras de um mesmo grupo entre as categorias.

\section{CAPÍTULO 4}

Quadro 4.1 - Descrição dos parâmetros que compõem o modelo e seus respectivos valores utilizados nos experimentos de simulação.

Quadro 4.2 - Descrição das variáveis cujos influência sobre a sedimentação eólica foi avaliada através dos experimentos de simulação. 168

Quadro 4.3 - Variáveis mantidas constantes nas simulações para avaliação da influência dos fluxos de entrada e saída de sedimentos costeiros no sistema eólico. Notar o contraste das probabilidades de tempestade e chuva, velocidade média do vento e fluxo de entrada e saída de sedimentos da área fonte entre as estações seca e úmida. A designação de cada variável pode ser vista no Quadro 4.2. 171

Quadro 4.4 - Probabilidades de chuva, velocidade média e dispersão do vento e valores médios e dispersões dos fluxos de saída de sedimentos do campo de dunas para as estações seca, úmida e condição de tempestade. 209

Quadro 4.5 - Relações entre NRM, migração da linha de costa, elementos da estratigrafia de seqüências e dinâmica do sistema eólico costeiro 251

\section{CAPÍTULO 5}

Quadro 5.1 - Comparação entre a área fonte de sistemas eólicos costeiro e com fonte aluvial de clima seco 265

\section{CAPÍTULO 6}

Quadro 6.1 - Caracterização qualitativa de propriedades sedimentológicas, morfométricas e petrofísicas das fácies de dunas, interdunas e lençol de areia. As propriedades das fácies listadas na tabela são classificadas de modo relativo entre si. 


\section{ÍNDICE}

\section{CAPÍTULO 1 - COMPLEXIDADE EM SISTEMAS DEPOSICIONAIS}

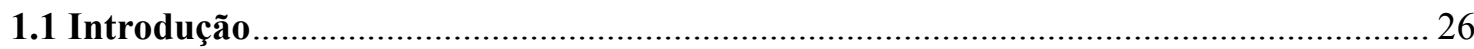

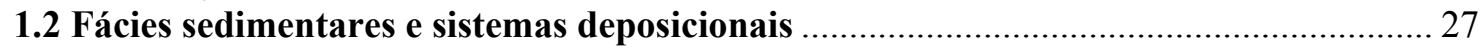

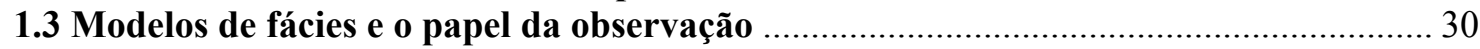

1.4 Convergência, divergência e classificação de sistemas deposicionais ........................... 32

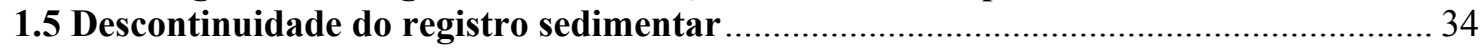

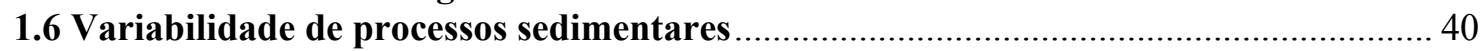

1.7 Criticalidade auto-organizada em sistemas geológicos ............................................... 45

1.8 Dinâmica de sistemas deposicionais e a leitura do registro sedimentar ........................ 49

CAPÍTULO 2 - SISTEMAS DEPOSICIONAIS EÓLICOS

2.1 Sistemas deposicionais eólicos: área de ocorrência e tipos ......................................... 51

2.2 Sistemas deposicionais eólicos quaternários da costa brasileira ................................. 56

2.3 Importância econômica dos depósitos sedimentares eólicos ........................................ 60

\section{CAPÍTULO 3 - MORFOMETRIA DOS CAMPOS DE DUNAS QUATERNÁRIOS DA} COSTA BRASILEIRA

3.1 Introdução

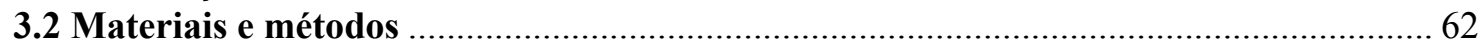

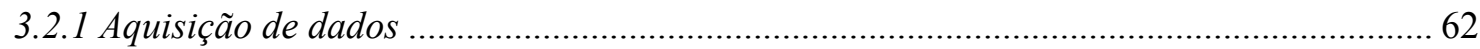

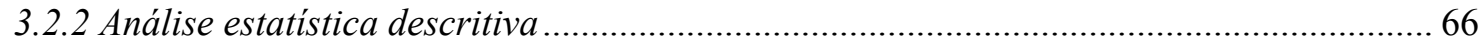

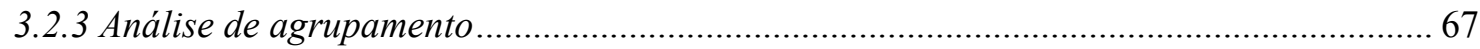

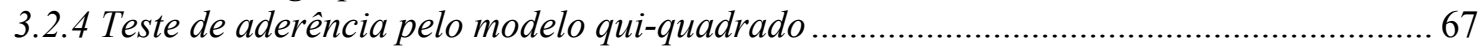

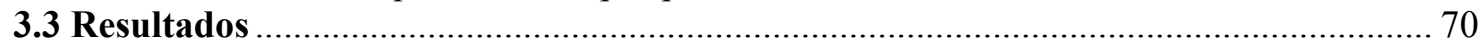

3.3.1 Estatística descritiva das variáveis morfométricas ............................................................. 70

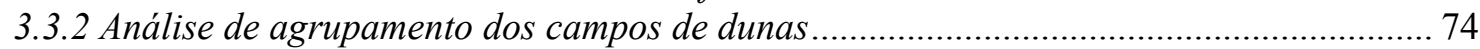

3.3.3 Distribuição geográfica dos campos de dunas da costa brasileira ..................................... 79

3.3.3.1 Setor 1 (Maranhão, Piauí, Ceará e Rio Grande do Norte) ............................................. 79

3.3.3.2 Setor 2 (Alagoas, Sergipe, Bahia, Espirito Santo, Rio de Janeiro e São Paulo) ............ 87

3.3.3.3 Setor 3 (Paraná, Santa Catarina e Rio Grande do Sul)................................................. 93

3.3.4 Variação das características morfométricas dos campos de dunas em termos

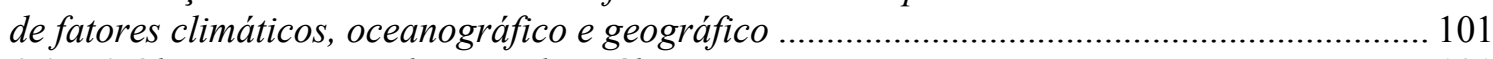

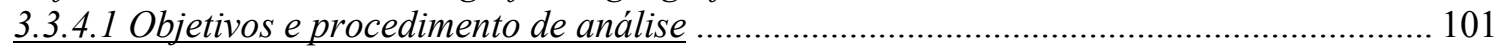

3.3.4.2 Classificação dos campos de dunas em termos do número de meses secos,

freqüência de atuação e velocidade do vento e amplitude de maré.............................................. 102

3.3.4.2.1 Classificação dos campos de dunas em termos do número de meses secos................. 102

3.3.4.2.2 Classificação dos campos de dunas em termos da velocidade e freqüência

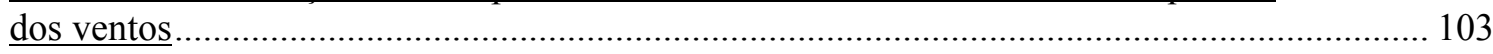

3.3.4.2.3 Classificação dos campos de dunas em termos da amplitude de maré......................... 103

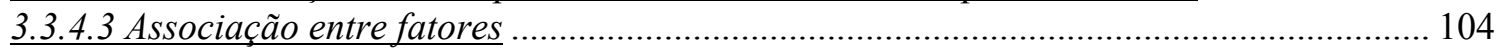

3.3.4.4 Comparação entre campos de dunas em termos do número de meses secos .................. 106

3.3.4.5 Comparação entre campos de dunas em termos da velocidade e freqüência

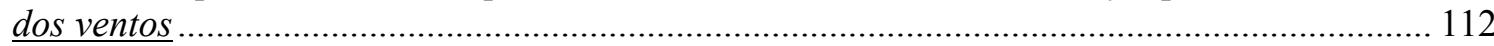

3.3.4.6 Comparação entre campos de dunas em termos da amplitude de maré ......................... 116

3.3.4.7 Morfologia e tamanho dos campos de dunas vs. setores geográficos 1, 2 e 3................ 122

3.3.5 O campo de dunas dos Lençóis Maranhenses ................................................................ 128

3.3.6 Fatores controladores do aporte eólico nos sistemas eólicos costeiros ............................ 131

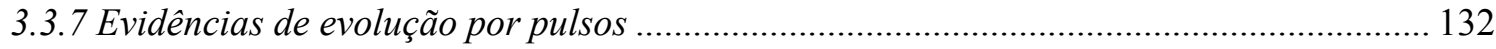


CAPÍTULO 4 - SIMULAÇÃO DE SISTEMAS DEPOSICIONAIS EÓLICOS COSTEIROS

4.1 Introdução.

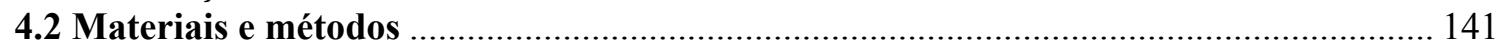

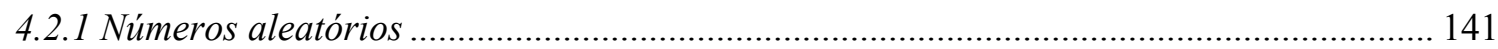

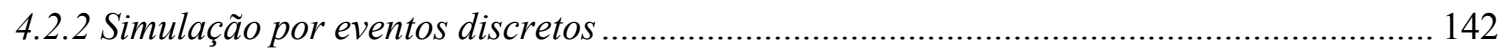

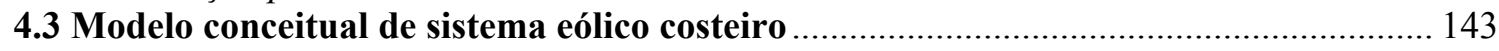

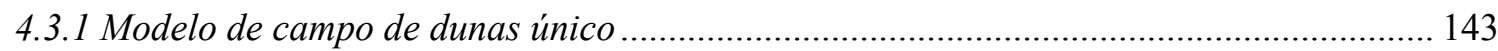

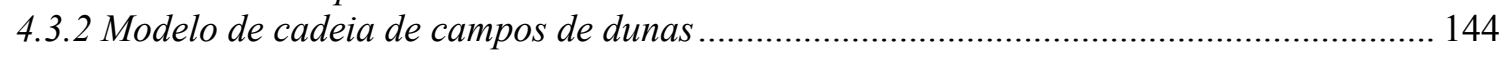

4.4 Simulação dos fluxos de entrada e saída de sedimentos .................................................. 146

4.4.1 Fluxo de entrada de sedimentos no campo de dunas (qce) .............................................. 146

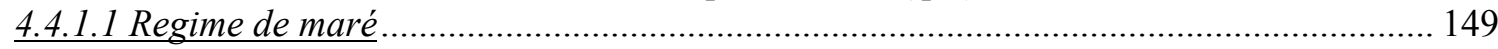

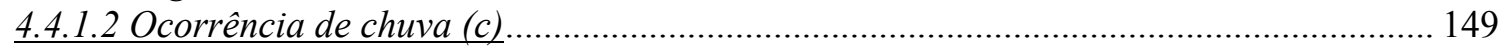

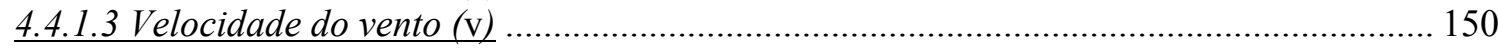

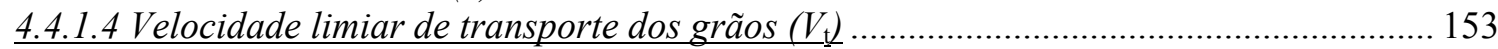

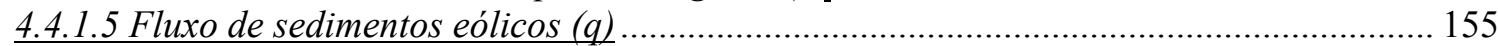

4.5.2 Fluxo de saída de sedimentos do campo de dunas (qcs) e fluxos de entrada e saída de sedimentos na área fonte ( $q f s, q f e, q f l e, q f l s, q f t e$ e qfts) e no reservatório de sedimentos costeiros acumulados

4.5.3 Variação de volume da área fonte e sua influência sobre os fluxos de entrada e saída de sedimentos no campo de dunas e no reservatório de sedimentos costeiros acumulados ...... 159 4.5.4 Variabilidade climática e sua influência sobre os fluxos de entrada e saída de

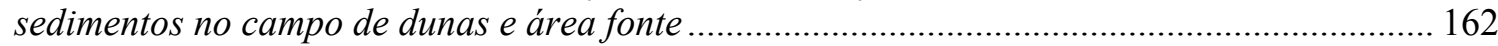

4.6 Fluxograma para simulação de sistema eólico de campo de dunas único...................... 164

4.7 Simulação de sistema eólico de campo de dunas único …............................................ 165

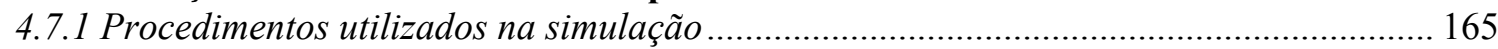

4.7.2 Variáveis e valores dos parâmetros utilizados nos experimentos de simulação................ 166

4.7.3 Experimentos com variação do aporte sedimentar costeiro para periodo de

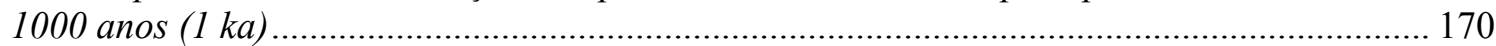

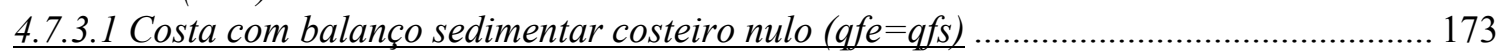

4.7.3.2 Costa com balanço sedimentar costeiro positivo (qfe $>$ qfs) ......................................... 181

4.7.3.3 Costa com balanço sedimentar costeiro negativo $(q f e<q f s)$........................................ 191

4.7.4 Conclusões derivadas dos experimentos de simulação sob condições climáticas estacionárias .................................................................................................................. 197

4.8 Experimentos com variabilidade climática interanual para período de dezenas de

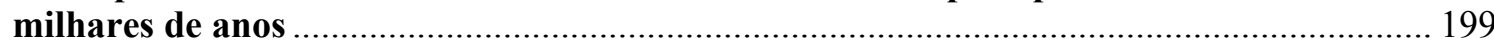

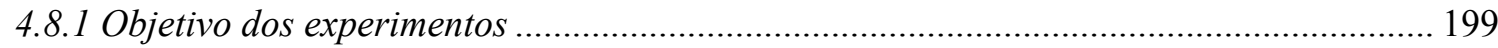

4.8.2 Experimentos de referência: variabilidade climática interanual estacionária ................. 199

4.8.3 Experimentos com variabilidade climática interanual modelada pelos ciclos de

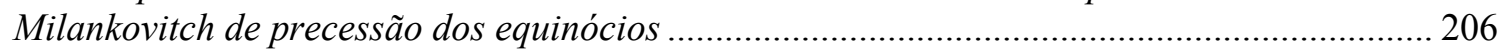

4.8.3.1 Efeito climático do ciclo de precessão dos equinócios ................................................... 206

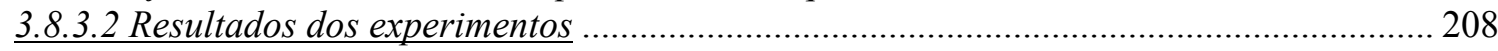

4.9 Considerações sobre o desenvolvimento de campos de dunas costeiros....................... 225

4.10 Modelos de fácies baseados na dinâmica de crescimento do campo de dunas............ 235

4.11 Dinâmica de sistemas eólicos costeiros e estratigrafia de seqüências ........................ 245

4.12 Considerações sobre a sedimentação eólica na costa brasileira .................................. 251

CAPÍTULO 5 - SISTEMAS EÓLICOS INTERIORES

5.1 Influência do tamanho e dinâmica da área fonte sobre a evolução de 
campos de dunas.

5.2 Considerações sobre as sucessões de fácies eólicas de depósitos antigos

5.2.1 Análise de fácies em depósitos eólicos

5.2.2 As sucessões de fácies eólicas das formações Pirambóia, Botucatu, Serra Geral e do Grupo Caiuá

CAPÍTULO 6 - CONSIDERAÇÕES SOBRE OS DEPÓSITOS EÓLICOS COMO RESERVATÓRIOS DE HIDROCARBONETOS

6.1 Reservatórios eólicos ............................................................................................... 274

6.2 Modelos de reservatórios eólicos baseados em modelos de fácies sedimentares........... 276

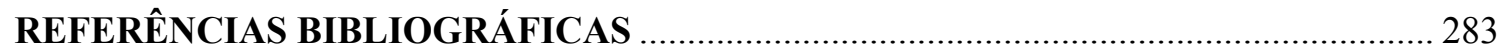

ANEXO 1 - Tabelas de correspondência e teste qui-quadrado para avaliação da associação entre número de meses secos, velocidade e freqüência dos ventos, amplitude de maré e setores geográficos

ANEXO 2 - ALGORITMO DO PROGRAMA PARA SIMULAÇÃO DO SISTEMA EÓLICO COSTEIRO (SISTEOLCO)

A2.1 Algoritmo para representação dos resultados através de valores anuais

A2.2 Algoritmo para representação dos resultados através de valores seculares 


\section{COMPLEXIDADE EM SISTEMAS DEPOSICIONAIS}

\subsection{Introdução}

O preenchimento de bacias sedimentares envolve a interação entre processos atuantes em diversas escalas. Estes processos podem ser variáveis e descontínuos no espaço e no tempo. Os depósitos sedimentares apresentam heterogeneidades desde microscópicas até megascópicas, as quais resultam da variabilidade temporal e espacial dos processos que controlam desde a geração, transporte e deposição de sedimentos, nas escalas de grão e de fácies, até o preenchimento de bacias sedimentares, na escala da arquitetura deposicional.

A maneira como as propriedades sedimentológicas (mineralogia, textura ${ }^{1}$, petrotrama ${ }^{2}$, estruturas $^{3}$ e geometria externa) de um depósito sedimentar relacionam-se entre si constitui um dos problemas fundamentais da geologia sedimentar. Em escala mesoscópica (decimétrica a métrica), os produtos formados por processos sedimentares podem ser classificados em termos de fácies. Desta forma, os depósitos sedimentares constituem agrupamentos de fácies geneticamente relacionadas, os sistemas deposicionais. Assim, a dinâmica de um sistema deposicional, e conseqüentemente sua heterogeneidade faciológica, é expressa pela variação temporal e espacial dos processos sedimentares responsáveis pelo seu funcionamento. Considerando-se esta relação processo-produto, o estudo da dinâmica (processos) de sistemas deposicionais auxiliaria compreender a maneira como as propriedades sedimentológicas de um depósito sedimentar (produtos) se relacionam.

A compreensão da relação entre a variabilidade temporal e espacial dos processos sedimentares e as propriedades sedimentológicas dos depósitos gerados por estes processos é de grande importância para o entendimento da história da Terra. Tal relação também apresenta importância econômica, por exemplo, para a modelagem de reservatórios de hidrocarbonetos, cujo problema fundamental é a caracterização das heterogeneidades petrofísicas, as quais dependem da variabilidade das propriedades sedimentológicas. Segundo Tyler \& Finley (1991), a tecnologia atual permite extrair, em média, apenas 34\% do total de óleo contido nos reservatórios

\footnotetext{
${ }^{1}$ propriedades físicas individuais dos grãos (tamanho e forma).

2 refere-se à distribuição espacial dos grãos uns em relação aos outros (empacotamento, imbricação, paralelismo).

${ }^{3}$ propriedade geométrica meso a macroscópica resultante do arranjo espacial organizado (segregação) dos grãos ou do cimento; esta segregação pode ser quanto à mineralogia, textura ou petrotrama.
} 
descobertos nos EUA. Esta parcela varia de acordo com a complexidade do reservatório, que é definida pelo sistema deposicional que o constitui. Parcela significativa do óleo descoberto apresenta-se economicamente ou tecnologicamente não recuperável. Isto deve-se, em grande parte, à dificuldade em caracterizar adequadamente o efeito das variações das propriedades petrofísicas dos reservatórios sobre o fluxo de óleo. Esta dificuldade é expressa pela incapacidade em prever satisfatoriamente as heterogeneidades do reservatório nas diversas escalas, que pode ser atribuída, pelo menos em parte, à abordagem comumente adotada no estudo de depósitos sedimentares, que enfatiza aspectos descritivos do depósito e desfavorece a elaboração de modelos processo-produto com capacidade de predição.

\subsection{Fácies sedimentares e sistemas deposicionais}

A introdução do termo "fácies" na geologia é atribuída a Gressly (1838 apud Anderton, 1985). A partir de meados do século XX, este termo passou a ser utilizado de forma mais freqüente e adquiriu sentidos diversos na geologia. Na geologia sedimentar, ele é utilizado para descrever volume de rocha ou sedimentos caracterizado por conjunto de propriedades, tais como granulação, geometria e estruturas, que o torna distintivo. Até a década de 1950, o termo fácies era utilizado em sentido quase puramente descritivo, para referir-se a variações laterais em unidades litoestratigráficas. A partir do final da década de 1950, o avanço e a popularização dos estudos sobre ambientes de sedimentação modernos permitiram associar processos sedimentares a seus respectivos produtos. Assim, o termo fácies adquiriu um significado interpretativo em termos de processos deposicionais (Anderton, 1985). As fácies sedimentares podem ser consideradas unidades básicas de descrição macroscópica de depósitos sedimentares. Cada fácies possui um conjunto de características sedimentológicas específicas que as distingue entre si.

O conceito de sistemas deposicionais ganhou popularidade na geologia sedimentar a partir do trabalho de Fisher \& McGowen (1969). Para analisar o contexto deposicional de ocorrências de petróleo, estes autores dividiram os depósitos sedimentares do Grupo Wilcox (Terciário do Texas, EUA) em sistemas deposicionais, os quais foram denominados de acordo com ambientes fisiográficos de sedimentação modernos (sistemas planície costeira, lagunar, plataformal etc). Sistemas deposicionais contemporâneos de uma mesma bacia sedimentar interagem entre si através das entradas e saídas de sedimentos de cada sistema. Além disto, cada 
sistema deposicional compreende um conjunto de partes que interagem entre si. Estas interações ocorrem por meio de processos sedimentares (produção, transporte, deposição e erosão de sedimentos), os quais regem a dinâmica destes sistemas. As fácies sedimentares são produtos desta dinâmica. Na abordagem por sistemas deposicionais, destaca-se a relação genética entre as partes do sistema e entre sistemas vizinhos. Isto a tornaria vantajosa, em relação a uma abordagem puramente descritiva, tal como a litoestratigrafia.

Os sistemas deposicionais passaram a ser representados por modelos de fácies, os quais serviriam de norma para a análise de depósitos sedimentares antigos (Walker \& James, 1992). No entanto, a concepção excessivamente descritiva destes modelos, com ênfase na escala de arquitetura deposicional e seu suposto caráter de norma fizeram com que servissem mais como esquemas classificatórios do que como base para a compreensão do funcionamento destes sistemas. Este tipo de enfoque não prioriza o funcionamento dos sistemas e o entendimento da geração de seus produtos. Isto dificulta a compreensão da variabilidade dos produtos nas diversas escalas e a formulação de modelos gerais com capacidade de predição.

Relações processo-produto podem ser bem estabelecidas na escala de processos básicos de transporte e deposição, tais como queda e fluxo de grãos ou migração de formas de leito. Diversos trabalhos demonstram esta relação na escala de formas de leito (laminação e estratificação) para diferentes modos de transporte e deposição (Bagnold, 1941; Sundborg, 1956; Rubin \& McCulloch, 1980; Wasson \& Hyde, 1983; Anderson \& Bunas, 1993; Makse et al., 1997). A dinâmica de sistemas deposicionais envolve essencialmente a sucessão no tempo e espaço destes processos básicos, os quais apesar de serem individualmente bem compreendidos, não permitem a descrição precisa do depósito como um todo. A elaboração de modelos de sistemas deposicionais em termos de processos básicos (ou dos seus respectivos produtos) requer o conhecimento da variabilidade no tempo e no espaço destes processos, assim como também dos processos de erosão que provocam a destruição de depósitos previamente formados. Portanto, o problema em questão também pode ser visto pela perspectiva da escala. Neste caso, o desafio para elaboração de modelos processo-produto consistiria na compreensão da variabilidade dos processos básicos nas escalas de tempo e espaço de desenvolvimento de sistemas deposicionais.

Todo sistema deposicional pode ser descrito em termos dos fluxos de entrada e saída de sedimentos do sistema e das partes que constituem o sistema (fácies). O sistema fluvial por exemplo pode ser representado pelo fluxo de sedimentos da área fonte para os canais tributários, 
destes para o canal principal, dos canais para as áreas de planície de inundação e vice-versa e do canal principal ou de canais distributários para uma planície aluvial, lago ou mar (Figura 1.1).

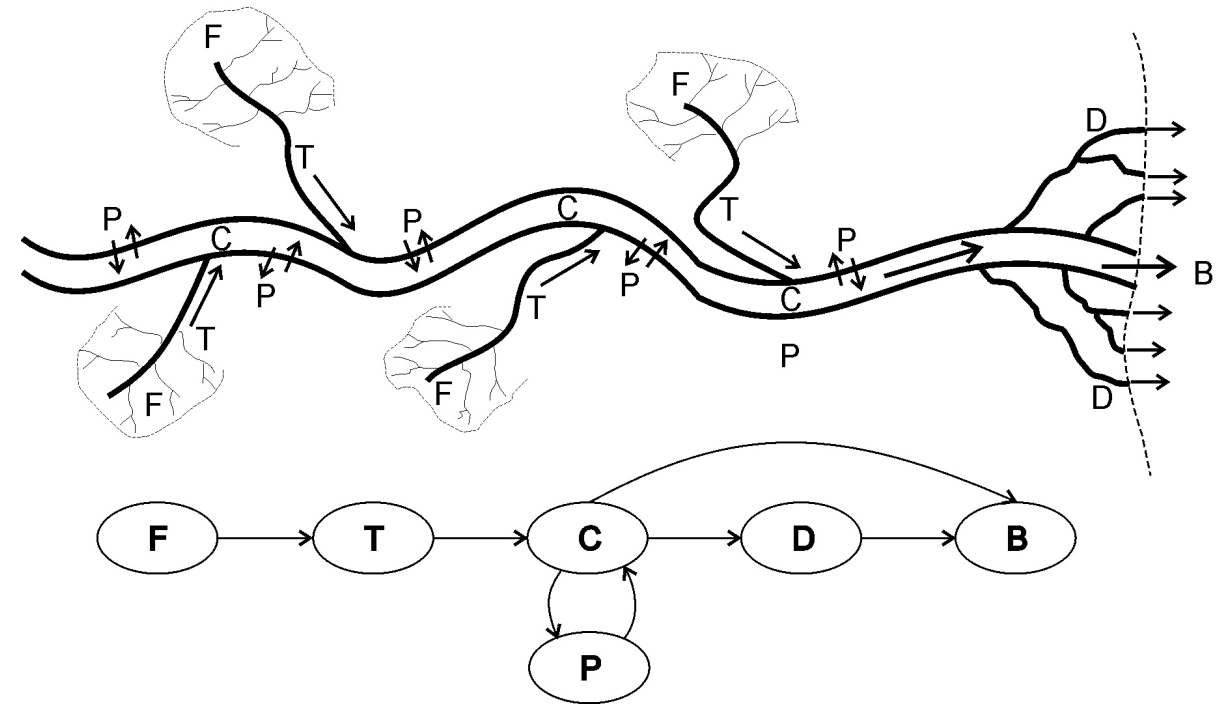

Figura 1.1 - Modelo conceitual de sistema deposicional fluvial. $\mathrm{F}=$ área fonte, $\mathrm{T}=$ canal tributário, $\mathrm{C}=$ canal principal, $\mathrm{P}=$ planície de inundação, $\mathrm{D}=$ canal distributário e $\mathrm{B}=$ zona de deposição (planície aluvial, lago ou mar). As setas indicam o sentido do fluxo de sedimentos entre as partes do sistema.

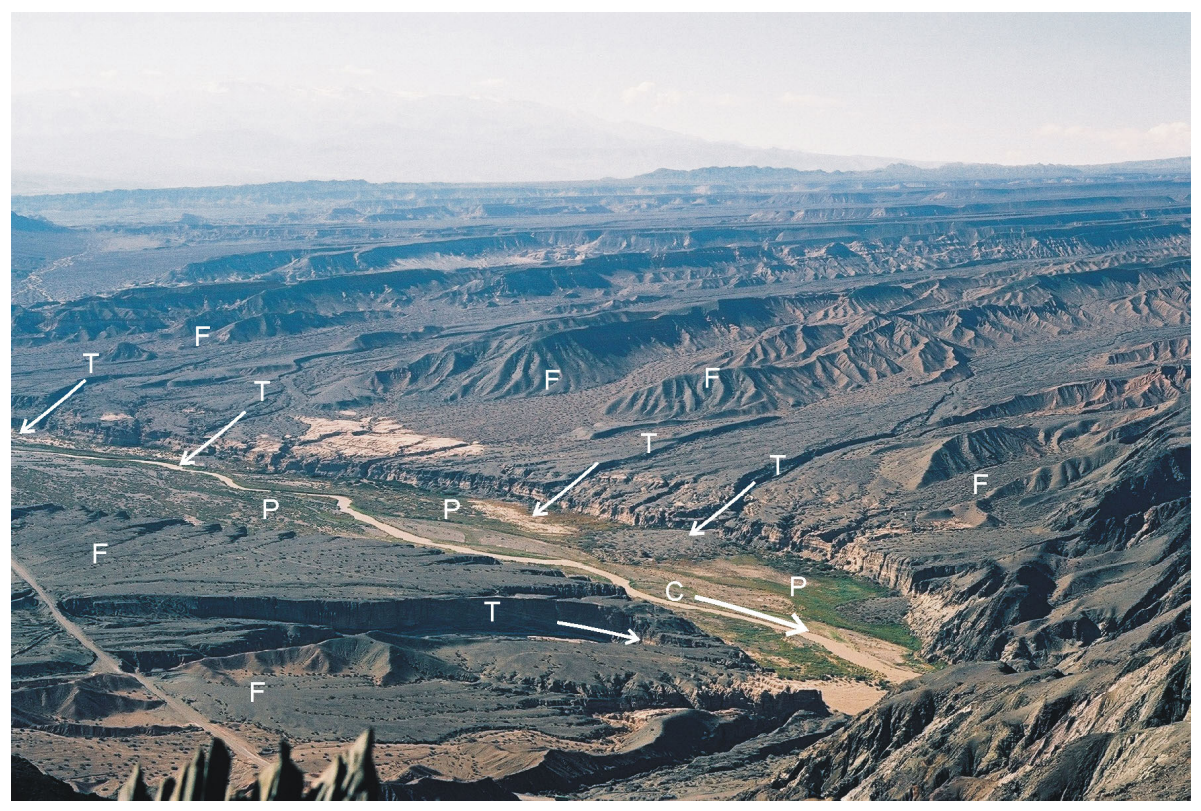

Figura 1.2 - Exemplo de sistema fluvial atual. Área fonte $(\mathrm{F})$, canais tributários $(\mathrm{T})$, planície de inundação (P) e canal principal (C) da bacia de drenagem do rio Jáchal (San Jose de Jáchal, Argentina). Foto de Sérgio Willians de Oliveira Rodrigues (2004). 
A dinâmica do sistema fluvial é controlada pelos processos responsáveis pelo fluxo de sedimentos entre as partes do sistema. A probabilidade de certo volume de sedimentos permanecer em determinada parte do sistema e ser incorporado ao registro sedimentar é variável. A preservabilidade dos sedimentos da planície de inundação, por exemplo, depende da freqüência de cheias, as quais possibilitam o transporte de sedimentos a partir do canal, e da migração lateral do canal, que pode erodir os sedimentos da planície de inundação. Este exemplo ilustra que apesar dos sistemas fluviais apresentarem sempre os mesmos elementos, a distribuição espacial e a proporção entre os produtos (fácies) gerados pela sua dinâmica podem ser extremamente variados.

\subsection{Modelos de fácies e o papel da observação}

Segundo Rosemblueth \& Weiner (1945), "Nenhuma parte substancial do Universo é tão simples que possa ser compreendida e controlada sem abstração. A abstração consiste em substituir a parte do Universo em estudo por um modelo semelhante, porém de estrutura mais simples. Os modelos constituem portanto uma necessidade primordial de qualquer procedimento cientifico.". Assim, modelos são representações da realidade elaboradas pela mente humana. Os modelos permitem a manipulação experimental de sistemas reais, de modo que possibilitam avaliar a maneira como a alteração de certos aspectos influencia o comportamento do sistema. Um modelo deve reunir duas qualidades conflitantes: realismo e simplicidade. O realismo confere precisão à abstração do sistema real enquanto que a simplicidade permite sua manipulação experimental.

Modelos de fácies propostos para descrever sistemas deposicionais, tais como os apresentados por Walker \& James (1992), são baseados em observações de sistemas deposicionais modernos. Muitas vezes estes modelos são vistos como norma. Segundo Anderton (1985), modelos de fácies serviriam como norma apenas sob o ponto de vista de um universo determinista, onde a variabilidade não afetaria as características de sistemas do mesmo tipo, os quais também não poderiam sofrer mudanças ao longo do tempo. Porém, se for considerado que os processos atuantes em sistemas deposicionais são governados por fenômenos probabilísticos, sistemas do mesmo tipo admitem múltiplas possibilidades e distinguiriam-se entre si no que diz respeito à distribuição de suas fácies. Assim, tais modelos apóiam-se em princípio contestável e 
não são capazes de explicar de modo satisfatório a variabilidade faciológica dos depósitos sedimentares (Anderton, 1985).

Problemas associados a sistemas geológicos em geral (incluindo os sistemas deposicionais) freqüentemente admitem múltiplas explicações, as quais são muito mais históricas e descritivas (sucessão de fatos) do que dedutivas. O modo como estes modelos são elaborados leva a rever o papel da observação na ciência. Na abordagem histórico-descritiva, as explicações (modelos) são formuladas com base em lógica comparativa e em geral são expressas em termos de sistema de referência, cujo funcionamento não precisa ser necessariamente compreendido para fornecer tais explicações. Para tanto, deve ser assumida a priori a existência de sistemas equivalentes. A equivalência passa a ser um problema fundamental sobre o qual se apóiam tais modelos de fácies. A lógica comparativa tem alcance limitado, pois é restrita ao que se observa. Assim, esta equivalência fica restrita aos elementos observados, que nem sempre compreendem todos os elementos existentes. Além disto, tais explicações são pouco preditivas, ou seja, não favorecem a inferência de possibilidades não observadas (a serem testadas). Soma-se a isto o fato deste método utilizar-se de lógica indutiva, pois proposições gerais são formuladas a partir de enunciados singulares, baseados nas observações realizadas. As observações devem alimentar problemas, cujas explicações devem ser baseadas em proposições universais, que por sua vez devem apresentar caráter preditivo para orientar novas observações, que servirão de teste de consistência do modelo elaborado. Esta lógica implica caráter infinito para a ciência, pois um modelo negado por nova observação deve ser substituído por outro mais geral. Esta lógica dedutiva foi proposta por Popper (1934) para explicar o modo de operação da ciência empírica, ou seja, aquela que lida com observações e experimentos. Para expressar melhor a limitação do uso da lógica indutiva considere-se o exemplo a seguir (derivado do exemplo clássico apresentado por Popper (1934)). Suponha-se que exista na natureza 95\% de cisnes brancos e 5\% de cisnes pretos e que em certa região, onde foi realizado estudo sobre cisnes, existam apenas cisnes brancos. Todas as observações realizadas serão de cisnes brancos. Isto pode levar à proposição de que todos os cisnes são brancos. Assim, a cor branca passaria a ser traço característico dos cisnes e poderia conduzir à situação de apenas cisnes brancos serem reconhecidos como cisnes. Porém, tal afirmação não se justifica uma vez que não se observaram todos os cisnes da natureza. Neste exemplo, a proposição (hipótese) foi formulada para descrever as observações e não para explicar problemas derivados das observações. De acordo com Popper 
(1934), "uma hipótese só admite prova empírica após haver sido formulada". Assim, o fato de todos os cisnes observados serem brancos não serve de prova para a proposição "todos os cisnes são brancos". Assim, tal proposição coloca-se mais como problema do que como explicação. Exemplos análogos podem ser reconhecidos na geologia. A proposição "todos os cisnes são brancos" também é errônea, pois a variabilidade da cor dos cisnes não é contemplada pelas observações realizadas. Este é mais uma questão que limita a proposição de enunciados diretamente baseados em observações e que deve ser considerada para os modelos de fácies elaborados a partir da observação de sistemas deposicionais modernos.

\subsection{Convergência, divergência e classificação de sistemas deposicionais}

Problemas cuja explicação permite hipóteses múltiplas excludentes ou não entre si são comuns na geologia. É comum ouvir que não há consenso sobre a idade de uma unidade estratigráfica, sobre a paleogeografia ou sobre os sistemas deposicionais de uma dada bacia, sobre a origem de certa forma circular de relevo, sobre os fatores que provocaram a extinção de um conjunto de espécies etc. A geologia está repleta de exemplos deste tipo, ou seja, situações que admitem diversas explicações. Esta multiplicidade de explicações pode ser atribuída à atuação de processos convergentes. Ou seja, processos distintos que produzem resultados semelhantes. Por outro lado, também é comum deparar-se com situação inversa. Isto quer dizer, encontrar coisas com aspecto distinto produzidas por processos semelhantes. Por exemplo, a queda do nível de base pode aumentar a erosão nas partes mais próximas à borda de uma bacia e a deposição nas partes mais profundas. O degelo após um período glacial faz com que haja elevação do nível relativo do mar em algumas zonas e rebaixamento em outras devido à glacioisostasia. Neste caso, um mesmo processo apresenta efeitos diversos.

Convergência e divergência constituem apenas parte das controvérsias que devem ser levadas em consideração ao estudar-se sistemas geológicos. Schumm (1991) apresenta os problemas de abordagem fundamentais que afetam diretamente a lógica comparativa freqüentemente adotada como base das explicações a questões relacionadas a sistemas geológicos. Dentre estes problemas, destacam-se os seguintes:

a) Problemas de escala: envolvem variações que ocorrem em função da escala e da 
posição de observação. Comportamentos distintos podem estar associados a observações tomadas em escalas distintas de tempo e espaço ou a particularidades do local onde foram realizadas. $\mathrm{O}$ tamanho e o intervalo de tempo determinam a sensibilidade do sistema a mudanças. A velocidade de resposta de um sistema a uma perturbação dependerá do tamanho do primeiro e da intensidade da última. Desta forma, o tamanho do sistema em relação à intensidade e duração da perturbação controla sua sensibilidade à mudança (inércia). Assim, sistemas de tamanho elevado serão pouco sensíveis a mudanças de intensidade pequena e de curta duração. Isto afeta diretamente o uso de modelos baseados em observações de sistemas naturais modernos para interpretar sistemas antigos que formam o registro geológico. $\mathrm{O}$ estado atual de dado sistema pode ser em grande parte resultado de uma série de perturbações passadas, as quais não ocorrem atualmente. Portanto, o estado atual de um sistema seria em parte devido a acontecimentos passados (herança) e em parte devido aos processos atuais. A parcela de explicação que cabe à herança e a parcela que cabe aos processos atuais dependem do tamanho do sistema, pois sistemas menores seriam mais susceptíveis à mudanças e portanto mais influenciados por processos de menor intensidade $\mathrm{e}$ maior freqüência de ocorrência. A idade do sistema também influenciaria estas parcelas, pois sistemas mais antigos foram expostos a maior variedade de processos, principalmente processos de baixa frequiência de ocorrência e alta intensidade. Assim, "quanto maior o intervalo de tempo e a área, menos exatas serão as predições e interpretações baseadas nas condições presentes" (Schumm, 1991). Assim, menor será a validade do atualismo.

b) Problemas de causa e efeito: dizem respeito a variações que ocorrem devido à relação entre perturbações a um sistema e seus efeitos. Esta relação pode apresentar: b1. divergência: perturbações podem gerar processos semelhantes que produzem efeitos distintos. Assim, a variabilidade dos processos é menor que a dos efeitos. b2. convergência: processos distintos podem ter efeitos semelhantes. Neste caso, a variabilidade dos processos é maior que a dos seus efeitos. b3. Eficiência: refere-se à relação entre a intensidade da perturbação e a intensidade da resposta a esta perturbação.

Todos os problemas formulados por Schumm (1991) estão relacionados à variabilidade dos processos ou produtos gerados por um sistema. Sob este ponto de vista, sistemas deposicionais do mesmo tipo poderiam gerar depósitos sedimentares com características diversas. 
Paradoxalmente, poderia se pensa por exemplo que, sob alguns aspectos, certos depósitos sedimentares eólicos poderiam ser mais parecidos com certos depósitos fluviais do que com outros depósitos eólicos. Neste caso, a classificação dos sistemas deposicionais baseada em critério fisiográfico não seria muito funcional para se atingir certos objetivos. Esta classificação pouco auxilia por exemplo na resolução de problemas relacionados à cronologia de depósitos sedimentares ou à distribuição espacial de fácies sedimentares. Assim, coloca-se a seguinte questão: haveria critério de classificação que permitisse explicar com maior precisão a constituição temporal e espacial de depósitos sedimentares?

Classificações são baseadas em semelhanças. Atualmente, os sistemas deposicionais são classificados a partir de semelhanças descritivas de suas partes (fácies). Ou seja, um sistema é do tipo A se for composto pelas fácies X, Y e Z, do tipo B se for composto pelas fácies $\mathrm{M}, \mathrm{N}$, e $\mathrm{X}$, etc. Uma mesma fácies pode ocorrer em mais de um sistema deposicional de modo que um sistema se distingue do outro através do conjunto de fácies. Assim, levanta-se a questão: um mesmo conjunto de fácies poderia representar dinâmicas distintas? Para expressar de forma mais clara esta questão, considere a seguinte metáfora. Duas cidades ( 1 e 2) são compostas pelos mesmos elementos: veículos, edifícios, casas e pessoas. Se utilizarmos como critério de classificação o conjunto de elementos, ambas cidades seriam equivalentes e corresponderiam ao mesmo tipo de sistema. Porém, se for considerada a distribuição espacial, proporção e o número de elementos (tamanho), as duas cidades são distintas entre si, principalmente no que diz respeito à sua dinâmica.

Se a variabilidade faciológica de um depósito sedimentar depende da dinâmica do respectivo sistema deposicional, porque não classificar os sistemas deposicionais com base na dinâmica de funcionamento? Talvez assim a variabilidade faciológica poderia ser melhor descrita e prevista. Porém, tal classificação só seria possível através do conhecimento da relação entre a dinâmica dos sistemas e seus respectivos depósitos.

\subsection{Descontinuidade do registro sedimentar}

Segundo Ager (1993), o registro estratigráfico é incompleto, com estratos e fósseis de ampla distribuição, porém separados por hiatos deposicionais cuja duração supera o intervalo de tempo representado nos estratos preservados. Esta proposição baseia-se em observações, 
realizadas em escala global, de fósseis e unidades estratigráficas e levou o autor citado a propor à famosa analogia entre a história da Terra e a vida de um soldado: “...the history of any part of the earth, like the life of a soldier, consists of long periods of boredom and short periods of terror" (Ager, 1993, pg.141). Portanto, o registro sedimentar seria descontínuo.

Sadler (1981) observou que taxas de sedimentação aumentam com a diminuição do intervalo de tempo utilizado para calculá-las (Figura 1.3). Esta constatação deriva da análise de dados compilados de trabalhos realizados em diversos depósitos sedimentares com idades distintas. Segundo este autor, a relação inversamente proporcional entre taxas de acumulação e intervalo de tempo resulta da irregularidade dos processos sedimentares. Assim, quanto maior o intervalo de tempo envolvido na evolução de um depósito sedimentar, maior a freqüência de ocorrência de descontinuidades (intervalos de não deposição ou erosão), que implica menor quantidade de processos representados por depósitos.

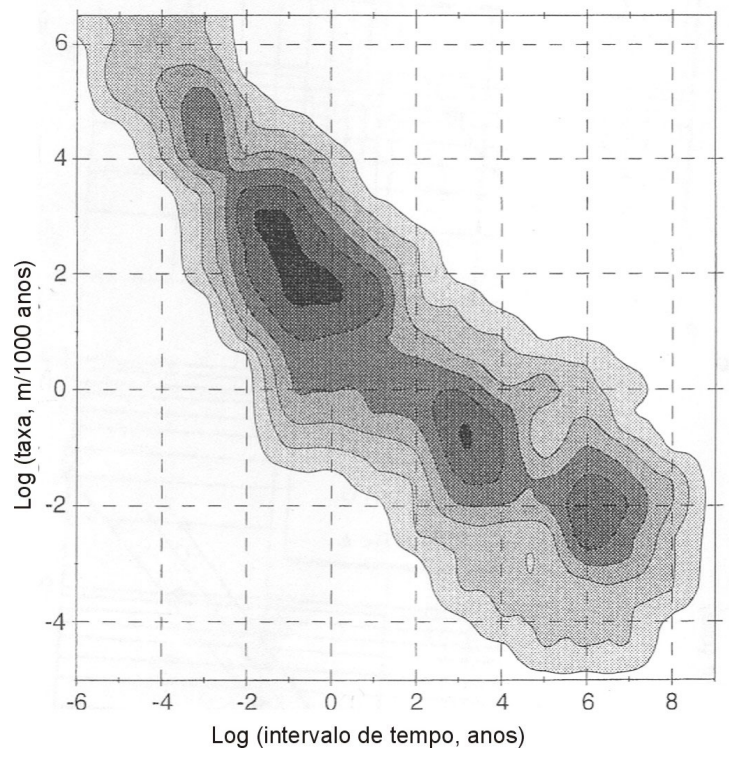

Figura 1.3- Variação das taxas de acumulação de sedimentos em função do intervalo de tempo. As isolinhas definem a densidade de dados (número de dados $=25.000$ ). A separação entre zonas de máxima densidade resulta das quatro técnicas de estimação utilizadas: medidas contínuas, observações históricas, datações radiocarbono e datações por bioestratigrafia. Adaptado de Sadler (1981 apud Ivanov, 1996).

Os dados compilados por Sadler (1981) e apresentados na Figura 1.3 indicam que taxa de sedimentação e intervalo de tempo apresentam correlação linear negativa em escala logarítmica. 
Sendo $S$ a taxa de sedimentação e $t$ o intervalo de tempo, temos que (Equação 1.1):

$$
\log S(t)=-m \log t
$$

O parâmetro $m$ corresponde ao gradiente da reta ajustada ao gráfico de $S(t)$ em escala bilogarítmica. A correlação linear em escala logarítmica indica que o intervalo de tempo é uma função de potência da taxa de sedimentação. Assim, temos que (Equação 1.2):

$$
S(t)=t^{-m}
$$

Ivanov (1996) estimou o coeficiente angular $(m)$ da reta ajustada ao gráfico da Figura 3. O valor de $m$ obtido por Ivanov (1996) foi $-0,85$. Assim, a taxa de sedimentação $S(\mathrm{~m} / 1000$ anos) em função do intervalo de tempo $t$ (anos) pode ser expressa pela seguinte equação (Equação 1.3):

$$
S(t)=t^{-0,85} \quad 10^{-5}<t<10^{5}
$$

A maior variação da taxa de sedimentação $(S)$ ocorre para intervalos de tempo menores que 10.000 anos (Figura 1.4).

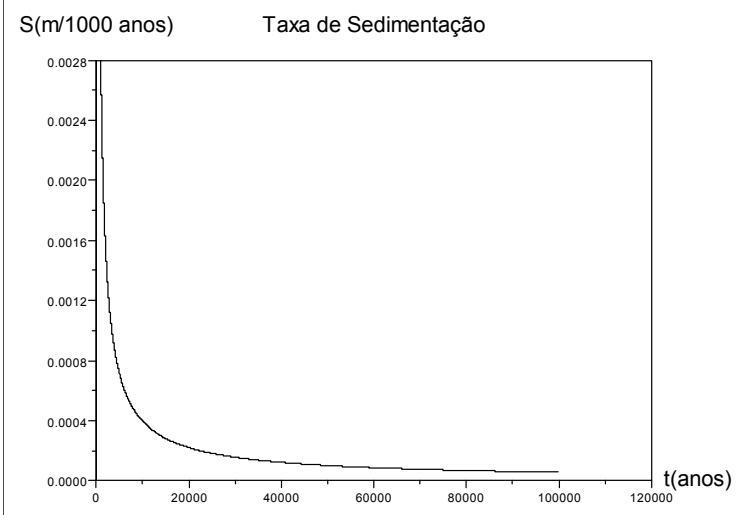

Figura 1.4 - Variação da taxa de sedimentação $S(\mathrm{~m} / 1000$ anos) em função do intervalo de tempo $t$ (anos).

Segundo Sadler (1981) e Sadler \& Strauss (1990), a "representatividade" (stratigraphic 
completeness) de uma seção estratigráfica, em escala de tempo $t$, corresponde à fração dos intervalos de tamanho $t$ que deixam registro sedimentar. Em uma seção completa, todos os intervalos de tempo de tamanho $t$ deixaram registro sedimentar. Assim, uma seção completa não é necessariamente uma seção desprovida de hiatos. É apenas uma seção cujos hiatos não apresentam duração maior que $t$. A representatividade equivale a uma proporção e pode assumir valores entre 0 e 1 . Isto permite interpretá-la em termos probabilísticos como sendo a probabilidade de preservação de certo volume de sedimentos depositados durante um intervalo de tempo $t$. De acordo com Sadler \& Strauss (1990), a representatividade de uma seção estratigráfica é controlada por três fatores principais: i) taxa de sedimentação, ii) variabiliadade da taxa de sedimentação e iii) idade. Quanto maior a taxa de sedimentação, maior a probabilidade dos sedimentos depositados resistirem à eventos erosivos. A idade também influencia a probabilidade de preservação de sedimentos previamente depositados, porém em escala de tempo maior. Sedimentos mais distantes do topo da seção (maior idade) seriam menos suceptíveis à erosão e portanto apresentariam maior probabilidade de preservação. A variabilidade da taxa de sedimentação influenciará a variação da taxa de sedimentação e da idade dos sedimentos de uma seção.

A representatividade $(R)$ pode ser expressa (Equação 1.4) pela razão entre a taxa de sedimentação mínima $(S)$, calculada a partir do intervalo de tempo envolvido na formação de todo pacote sedimentar em questão, e a taxa de sedimentação média para uma determinado intervalo de tempo $\left(S^{*}\right)$.

$$
R=\frac{S}{S^{*}}=\left(\frac{t^{*}}{t}\right)^{-m}
$$

$\mathrm{Na}$ Equação 1.4, $t$ é o intervalo de tempo envolvido na formação de todo o depósito sedimentar, $t_{*}$ é o intervalo de tempo envolvido na formação de determinada parcela do depósito e $m$ é o expoente da função $S(t)$. O valor de $m$ varia conforme o sistema deposicional. A "representatividade esperada" de determinada unidade sedimentar pode ser calculada conhecendo-se o intervalo de tempo envolvido na sua geração $(t)$ e utilizando-se a Equação 1.4. O valor de $m$ de alguns tipos de depósitos sedimentares (fluviais, plataformais terrígenos, plataformais carbonáticos, lacustres e abissais carbonáticos) pode ser obtido em Sadler (1981). 
Por exemplo, considere uma unidade de calcários plataformais com $300 \mathrm{~m}$ de espessura, cujas idades do topo e da base são respectivamente 250 e $280 \mathrm{Ma}$. Assim, o valor de $t$ é $30 \mathrm{Ma}$. O valor de $m$ para este tipo de depósito é $-0,35$ (Sadler, 1981). A "representatividade esperada" para intervalos de tempo de $10 \mathrm{Ma}(t *)$ é (Equação 1.5):

$$
R=\left(\frac{10}{30}\right)^{-(-0,35)}=0,68
$$

Este resultado indica que apenas $68 \%$ dos intervalos de tempo de 10 Ma são representados por sedimentos e que $32 \%$ são representados por descontinuidades erosivas ou não deposicionais. Se considerarmos intervalos de $1 \mathrm{Ma}$, a representatividade será aproximadamente 0.30 , ou seja, apenas $30 \%$ destes intervalos de tempo serão representados por sedimentos. O gráfico de $R\left(t^{*}\right)$ para o exemplo apresentado pode ser visto na Figura 1.5.

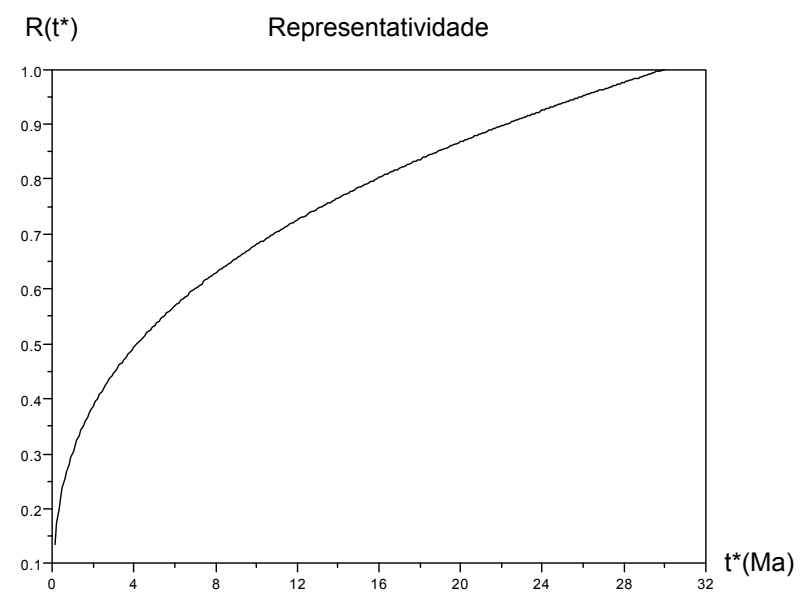

Figura 1.5 - Gráfico da representatividade $R$ em função do intervalo de tempo $t^{*}$ para o exemplo citado acima. O intervalo de tempo envolvido na formação do depósito é $30 \mathrm{Ma}$. Se a seção for dividida em intervalos de $10 \mathrm{Ma}$, têm-se representatividade de $68 \%$. Isto indica que apenas cerca de 2 dos 3 intervalos de $10 \mathrm{Ma}$ são representados por sedimentos. Nota-se que a representatividade diminui para intervalos de tempo menores.

Ainda em relação ao exemplo apresentado, considere a seguinte questão: "Qual seria a idade do horizonte situado $100 \mathrm{~m}$ abaixo do topo da seção?". Se for considerada taxa de sedimentação uniforme e contínua, a idade deste horizonte seria 260 Ma. Porém, se levarmos em 
consideração que cerca de 1/3 do intervalo de tempo de 10 Ma não apresenta registro sedimentar, teríamos estimativas bastante diversas. Este intervalo de tempo não registrado pode estar distribuído por toda seção ou, nos casos extremos, concentrar-se na base ou no topo da seção. Se o intervalo não registrado situar-se no topo, o horizonte de $100 \mathrm{~m}$ teria idade de $266,4 \mathrm{Ma}$, e caso se situasse na base, idade de 256,8 Ma (Figura 1.6). Este exemplo ilustra a incerteza em se definir a cronologia de eventos interpretados a partir do registro sedimentar. Tal fato é de suma importância para a geologia histórica, a interpolação de idades e para a correlação estratigráfica baseada em descontinuidades físicas.

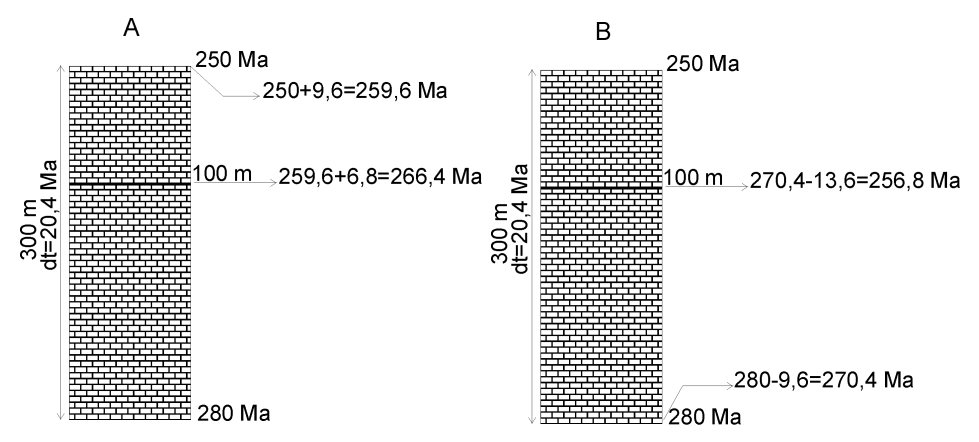

Figura 1.6 - Idade do horizonte situado $100 \mathrm{~m}$ abaixo do topo da seção. A representatividade permite avaliar a imprecisão da estimativa. Para intervalos de tempo de $10 \mathrm{Ma}$, esta seção apresenta representatividade 0,68. Assim, 20,4 Ma (68\%) seriam representados por sedimentos e 9,6 $\mathrm{Ma}(32 \%)$ por descontinuidades. A) Caso extremo em que o intervalo não registrado situa-se no topo da seção. B) Caso extremo em que o intervalo não registrado situa-se na base da seção. $\mathrm{O}$ intervalo de tempo representado por sedimentos é expresso por $\mathrm{dt}(\mathrm{dt}=20,4 \mathrm{Ma}$, que corresponde a $68 \%$ do intervalo de tempo abrangido pela seção).

Korvin (1992) denominou de "paradoxo da taxa de sedimentação" a discrepância observada entre taxas de sedimentação calculadas para intervalos de tempo diferentes de um mesmo depósito. Isto demonstra a irregularidade da construção do registro sedimentar e contraria o conceito de sedimentação contínua (Ivanov, 1996). O "paradoxo da taxa de sedimentação" leva à reconsideração do uso potencial dos modelos de fácies, confeccionados com base em analogias com sistemas deposicionais modernos, para prever a distribuição de fácies em depósitos sedimentares antigos. Os modelos de fácies são elaborados a partir de depósitos acumulados durante o Quaternário (período que envolve aproximadamente $2 \mathrm{Ma}$ ), sendo frequente o uso destes modelos para descrever e interpretar depósitos cujo intervalo de tempo de formação alcança dezenas de milhões de anos. Portanto, os estudos baseados em analogias com ambientes 
de sedimentação modernos são sustentados por uma suposta equivalência entre depósitos gerados em intervalos de tempo substancialmente distintos. As conclusões de Sadler (1981) contrapõemse a esta suposta equivalência, pois quanto maior o intervalo de tempo envolvido na geração do depósito, maior o número de descontinuidades, menor o número de partes geneticamente relacionadas e maior a disparidade com cenários de sedimentação modernos, os quais compreendem intervalo de tempo relativamente curto. Portanto, estudos baseados em modelos análogos, tais como os modelos de fácies usuais (Walker \& James, 1992), devem ser vistos com cautela.

$\mathrm{O}$ "paradoxo da taxa de sedimentação" também apresenta implicações importantes em relação à sensibilidade da sedimentação em registrar eventos de duração variável. Taxas de sedimentação elevadas permitiriam o registro de processos de curta duração. Porém, taxas elevadas associam-se a intervalos de tempo curtos, que apresentariam baixa probabilidade de coincidirem com eventos pouco freqüentes. Isto conduz à idéia de que a sedimentação favorece o registro de processos freqüentes e de curta duração.

Sadler (1981) também observou correspondência entre taxas de movimentação tectônica vertical (soerguimento e subsidência) e intervalo de tempo. Assim como as taxas de sedimentação, as taxas de movimentação tectônica vertical também aumentam com a diminuição do intervalo de tempo. Há uma relação de proporcionalidade entre taxas de acumulação de sedimentos e de movimentação tectônica vertical para intervalos de tempo superiores a 1000 anos (Sadler, 1981). Este relação deve ser levada em consideração por exemplo na correlação de depósitos gerados em regimes tectônicos diferentes baseada em descontinuidades físicas, tal como na estratigrafia de seqüências. Quanto maior forem as taxas de movimentação vertical em uma bacia, maior serão as taxas de acumulação de sedimentos e menor será a freqüência de ocorrência de descontinuidades. Logo, depósitos gerados em regimes tectônicos diferentes apresentarão freqüências distintas de descontinuidades. Isto tem impacto direto na proposta de correlação da estratigrafia de seqüências, cuja gênese das descontinuidades físicas é atribuída principalmente ao nível relativo do mar.

\subsection{Variabilidade de processos sedimentares}

Eventos de grande magnitude e baixa frequência de ocorrência são denominados 
"catastróficos". Clifton (1988) utiliza a designação "convulsivo" para se referir a eventos de energia extraordinariamente elevada e abrangência regional. A observação de tais eventos ganha destaque quando há impacto sobre sociedades humanas. Isto pode sobrevalorizar a importância destes eventos para a construção do registro geológico. Eventos catastróficos do ponto de vista humano podem não ser catastróficos sob ponto de vista geológico. Wolman \& Miller (1960) e Hsü $(1983$; 1989) estudaram a importância dos eventos de alta intensidade na dinâmica de sistemas geológicos.

Os processos que atuam na superfície terrestre dependem da interação entre uma força constante (gravidade) e forças altamente variáveis, tais como as derivadas da dinâmica atmosférica. Para que estes processos operem, é necessário que um esforço crítico $\left(\tau_{c}\right)$ seja ultrapassado (Wolman \& Miller, 1960). No caso do transporte de sedimentos, o valor deste esforço crítico depende do diâmetro dos grãos e da força que os mantêm coesos e o esforço responsável pelo movimento dos grãos ( $\tau$ ) pode ser representado por correntes geradas por ondas, ventos, rios, etc. O transporte só será efetivado se a força $\tau$ superar a força crítica $\tau_{c}$. Neste caso, a quantidade de material transportado $(q)$ relaciona-se com a diferença entre $\tau$ e $\tau_{c}$, conforme a Equação 1.6 (Wolman \& Miller, 1960).

$q=k\left(\tau-\tau_{c}\right)^{n}$

onde $k$ é uma constante relacionada às características do material transportado e $n$ é um número positivo. O fluxo de material transportado $q$ é uma função de potência da diferença entre $\tau$ e $\tau_{c}$. A Equação 6 pode ser expressa de maneira simplificada (Equação 7):

$$
q(x)=x^{n}
$$

A variável $x$ representa a força excedente a uma força crítica. O intervalo de variação da força $\tau$ pode ser muito maior que o da força crítica $\left(\tau_{c}\right)$. Assim, podem haver eventos cuja magnitude seja muito maior que a magnitude da força crítica. Desta forma, a taxa de sedimentos transportados também será altamente variável. 
Se $q$ for o fluxo de sedimentos transportados, o valor da força associada ao transporte $(x)$ pode ser suficiente para transportar uma quantidade de sedimentos maior do que a disponível no sistema. Neste caso, o valor de $q$ será limitado pelo tamanho do sistema e não pela variabilidade de $x$.

Neste estudo, define-se evento deposicional como sendo "os processos atuantes durante o intervalo de tempo delimitado pelo instante em que $\tau$ supera $\tau_{c}$ e pelo instante em que $\tau$ volta a ser inferior a $\tau_{c}$ ". Segundo Wolman \& Miller (1960), a eficiência $\left(E_{i}\right)$ de um evento qualquer depende da sua magnitude $\left(\tau_{\dot{i}}\right)$ em relação à magnitude da força crítica $\left(\tau_{c}\right)$ e da sua frequência de ocorrência $\left(F_{i}\right)$ (Equação 1.8).

$E_{i}=F_{i}\left(\tau_{i}-\tau_{c}\right)^{n}$

De acordo com Wolman \& Miller (1960), a magnitude de diversos eventos naturais, tais como inundações, ventos e chuvas, apresenta distribuição lognormal. Desta forma, eventos de grande magnitude apresentam baixa frequência de ocorrência. Considerando que o fluxo de material transportado é uma função de potência da magnitude destes eventos, o produto entre o fluxo de material transportado e a distribuição de frequência (lognormal) da magnitude dos eventos apresentará um valor máximo (máxima eficiência). A frequência de ocorrência deste valor máximo e a magnitude do evento correspondente a este valor caracterizam os processos mais eficientes do sistema e servem de parâmetro comparativo para determinar a importância relativa dos processos de intensidade elevada e baixa frequência de ocorrência na dinâmica do referido sistema (Figura 1.7). 


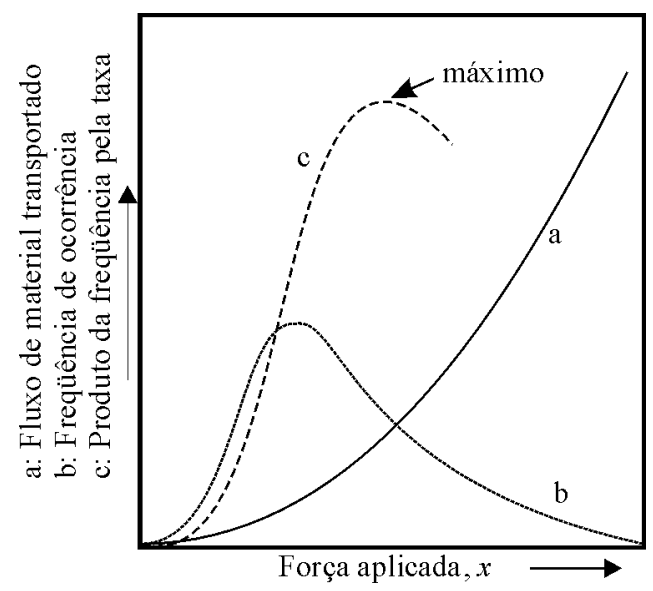

Figura 1.7- Eficiência dos eventos deposicionais de um sistema (Wolman \& Miller, 1960). a) Fluxo de material transportado em função da magnitude da força $(q(x))$. b) Distribuição de freqüências (lognormal) da magnitude da força $(f(x))$. c) Eficiência da força $(E(x)=q(x) f(x))$. A eficiência $(E(x))$ apresenta um valor máximo.

Wolman \& Miller (1960) concluíram que em sistemas fluviais, a maior parcela de sedimentos é transportada por eventos que ocorrem uma ou duas vezes por ano, o que indica que os eventos mais eficientes são os de magnitude moderada. Para estes autores, o transporte de sedimentos pelo vento também segue esta mesma tendência. Ventos com velocidades moderadas transportam a maior parcela de sedimentos. No entanto, a importância dos eventos menos freqüentes e de maior intensidade aumenta com a diminuição do tamanho do sistema. Em rios com bacia de drenagem pequena, cerca de $90 \%$ dos sedimentos são transportados por eventos que ocorrem uma vez a cada cinco anos (Wolman \& Miller, 1960). Isto sugere que a eficiência dos eventos de maior magnitude e menor freqüência também depende do tamanho do sistema. Porém, deve ser considerado o fato de que Wolman \& Miller (1960) utilizaram dados derivados de observações diretas, os quais apresentam abrangência temporal limitada. Isto faz com que eventos de baixa freqüência e com magnitude suficiente para afetar significativamente os sistemas maiores não sejam contemplados. Ou seja, tal fato induziria à supervalorização dos eventos de freqüência e magnitude moderada. No entanto, isto não invalida o modo de abordagem proposto, que destaca-se por enfatizar aspectos da dinâmica do sistema.

Se considerarmos que a magnitude de um evento é registrada através do volume de material remobilizado e depositado, o volume de sedimentos disponível para transporte sedimentar pode ser fator limitante para o registro da variabilidade dos processos atuantes no sistema. Neste caso, a magnitude máxima registrada equivaleria ao máximo volume de 
sedimentos disponíveis ao transporte, que por sua vez pode estar relacionado ao tamanho do sistema. Assim, sistemas de tamanho distintos apesar de sujeitos aos mesmos processos, poderiam gerar depósitos distintos. Para expressar melhor esta idéia, considere o seguinte exemplo: dois sistemas com tamanhos D1 e D2 $(D 1<D 2)$, cujos volumes de sedimentos disponíveis ao transporte são proporcionais aos seus tamanhos. Suponha que estes dois sistemas estão sujeitos a eventos deposicionais cujas magnitudes $(x)$ apresentam a mesma distribuição de probabilidades (ex. distribuição normal). A partir da simulação da variável $x$, pode-se calcular os valores de $q(x)$, através da Equação 1.7. A distribuição de freqüências de $q(x)$ para $n$ igual a 2 e $x$ com distribuição normal com média 5 e desvio padrão 1 pode ser observada na Figura 1.8.

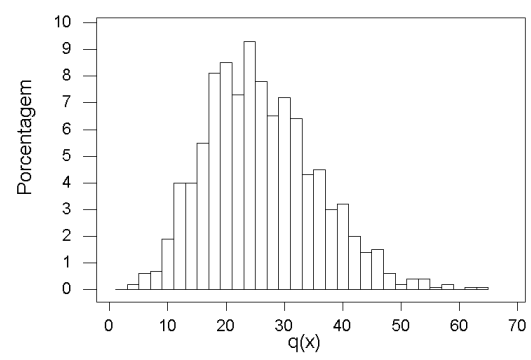

Figura 1.8 - Distribuição de freqüências de $q(x)\left(q(x)=x^{n}\right)$ para $n$ igual a 2 e $x$ com distribuição normal de média 5 e desvio padrão $1(\mathrm{~N}=1000)$. Notar a assimetria positiva da distribuição de freqüências.

O valor máximo de $q(x)$ é limitado pelo volume de sedimentos disponíveis ao transporte durante certo intervalo de tempo. Se for considerado que os dois sistemas em questão apresentam volumes disponíveis distintos, seus respectivos valores máximos de $q(x)$ também serão distintos, sendo $q(x)_{\max 1}<q(x)_{\max 2}$. Eventos cuja magnitude é suficiente para gerar fluxos maiores que $q(x)_{\max }$ serão registrados como eventos de magnitude " $q(x)_{\max }$ ", ou seja, não serão registrados com magnitude real. Suponha-se que $q(x)_{\max }=20$ e $q(x)_{\max 2}=40$ (para a distribuição de freqüências de $q(x)$ da Figura 1.8). A distribuição de freqüências dos eventos registrados pelos dois sistemas será distinta da distribuição de freqüências dos eventos ocorridos (Figura 1.9). A distribuição dos eventos registrados seria equivalente à dos eventos ocorridos somente se $q(x)$ dos eventos ocorridos não sofresse restrição pelo volume de sedimentos disponíveis. Somente neste caso é que o registro seria completo. Além disto, não só o tamanho mas a variabilidade (em termos de $q(x)$ ) do registro nos sistemas 1 e 2 seriam diferentes. De maneira análoga, a variação 
da força crítico $\left(\tau_{c}\right)$ exerceria a mesma influência sobre o sistema que a variação do tamanho.
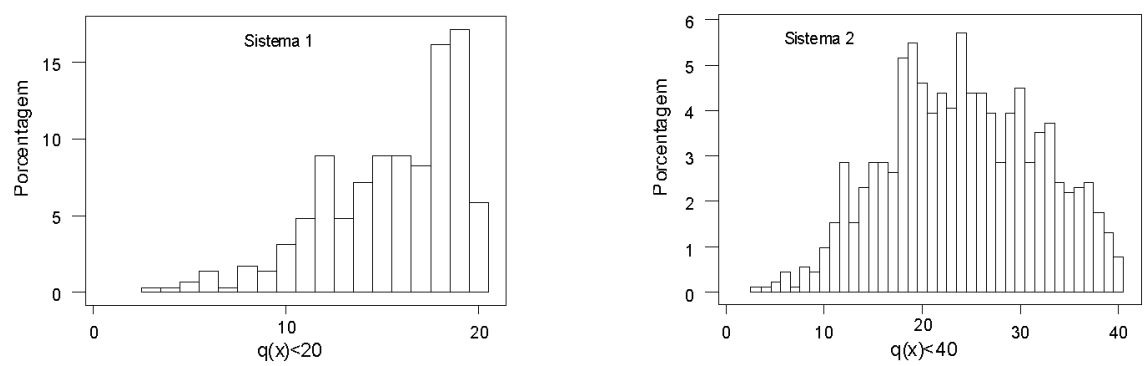

Figura 1.9 - Distribuição de freqüências dos fluxos $q(x)$ registrados pelos sistemas $1(\mathrm{~N}=292)$ e 2 $(\mathrm{N}=913)$. Estas distribuições diferem da distribuição de $q(x)$ dos eventos ocorridos (Figura 1.8), pois $q(x)_{\max }=20$ e $q(x)_{\max 2}=40$.

As fácies de um sistema deposicional podem ser condicionadas pelo fluxo de sedimentos de modo que a variabilidade faciológica estaria diretamente ligada à variabilidade do fluxo de sedimentos. Neste caso, sistemas do mesmo tipo, porém de tamanhos e/ou forças críticas diferentes, podem ter constituição faciológica distinta. Esta relação tem implicação importante por exemplo para reconstituição de cenários passados a partir da análise de fácies sedimentares e para a caracterização de reservatórios de hidrocarbonetos. No primeiro caso, a variação de tamanho de um sistema deposicional no decorrer de sua existência pode causar a falsa impressão de mudança ambiental, pois a variação faciológica poderia estar relacionada apenas à características do sistema (variação de tamanho e/ou força crítica). Reservatórios de hidrocarbonentos são comumente classificados a partir de sistemas deposicionais. Tal classificação é útil, pois supõe-se forte associação entre tipos de sistemas e heterogeneidades petrofísicas. Porém, sabe-se que um mesmo tipo de sistema pode ser altamente variável no que diz respeito às suas heterogeneidades.

\subsection{Criticalidade auto-organizada em sistemas geológicos}

A magnitude e freqüência de ocorrência de diversas variáveis associadas a processos geológicos, tais como terremotos, extinções e sedimentação relacionam-se entre si através de leis de potência (power laws) (Rothman et al., 1994; Bak, 1997; Gomez et al., 2002). Estas variáveis apresentam distribuição de freqüências com cauda positiva, tal como a distribuição exponencial 
por exemplo. Variáveis que seguem leis de potência apresentam relação linear em escala bilogarítmica (Figura 1.10).

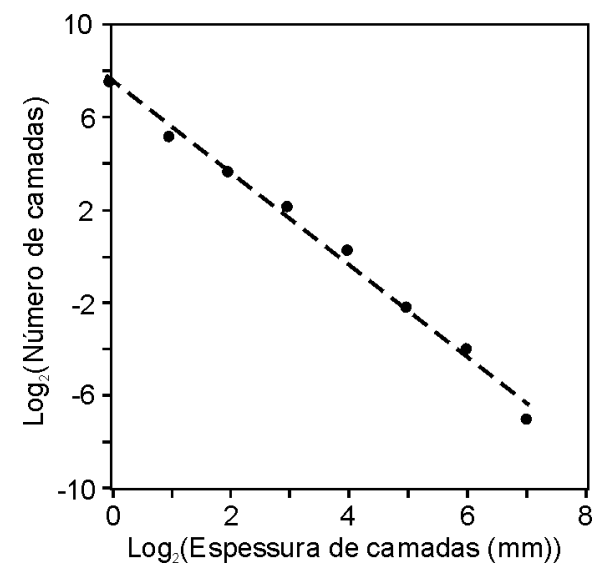

Figura 1.10 - Freqüência e espessura (magnitude) dos depósitos de escorregamento gerados durante tempestade nas encostas do lago Tutira, Nova Zelândia (Gomez et al., 2002).

Freqüência $(\mathrm{N})$ e magnitude (s) das variáveis da Figura 1.10 relacionam-se entre si através da seguinte expressão (Equação 1.9):

$$
N(s)=s^{-\eta}
$$

Ao extrairmos o logaritmo da Equação 1.9, nota-se que o expoente $\eta$ corresponde à inclinação da reta do gráfico de $N(s)$ em escala logarítmica. Este expoente pode apresentar valores diversos, de modo que pode ser considerado parâmetro característico da função $N(s)$. Leis de potência, além de indicar que a magnitude varia de forma inversa com a freqüência de ocorrência, indicam também que apesar de haver grande variação de tamanho, não há variação das feições de um produto gerado por um mesmo processo. Ou seja, indicam que os processos responsáveis pela formação de feições muito pequenas são os mesmos que os responsáveis pela formação das feições muito grandes. Desta forma, haveria invariância escalar e a variabilidade de tamanho (ou magnitude) seria uma característica intrínseca da dinâmica do sistema em questão (geometria fractal). Assim, extinções em massa por exemplo seriam regidas pelos mesmos mecanismos que pequenas extinções.

Segundo Bak (1997), sistemas cujas variáveis seguem leis de potência evoluem de modo irregular, caracterizado pela alternância entre períodos longos com pequenas transformações e 
períodos curtos de grandes transformações. Tal comportamento seria característico de sistemas complexos alimentados por energia externa e com processos cuja ocorrência depende da superação de uma força crítica ("atrito interno"). Este comportamento foi denominado de "criticalidade auto-organizada" (CAO) (self-organized criticality) por Bak et al. (1987). Sistemas com CAO são sistemas que convergem naturalmente para um estado crítico. No estado crítico, alterações locais no sistema podem provocar grandes revoluções que se desenvolvem através de processos em cadeia. Tais sistemas são alimentados por fonte externa de energia e evoluem através de períodos de acumulação seguidos de períodos de dissipação concentrada de energia. A CAO deve ser robusta ao ponto de não ser afetada pela variabilidade das variáveis que compõem o sistema. Certos sistemas podem apresentar comportamento crítico sob condições de funcionamento específicas. Nestas circunstâncias, a criticidade não seria genuinamente CAO.

Avalanches em pilhas de areia foi o modelo clássico utilizado por Bak et al. (1987) para descrever e estudar o comportamento crítico auto-organizado. Ao se despejar areia sobre uma superfície plana, as avalanches se iniciarão somente a partir do momento em que a pilha atingir uma certa altura. As avalanches ocorrerão sempre que o ângulo de inclinação de algum flanco da pilha superar o ângulo máximo de estabilidade da areia. Mesmo através da manutenção da alimentação regular da pilha, uma nova avalanche só ocorrerá quando a inclinação crítica for superada. A alimentação regular torna as avalanches inevitáveis e estas apresentam grande variedade de tamanho, mas não de forma.

Apesar do mecanismo de funcionamento das avalanches da pilha de areia ser conhecido, não é possível prever de forma determinística o momento e o tamanho de uma avalanche. Porém, é possível realizar previsões probabilísticas.

Avalanches de todos os tamanhos podem ser iniciadas pela entrada de apenas um grão de areia. A dimensão da avalanche dependerá do deslocamento sucessivo de grãos sobre áreas da pilha com inclinação próxima ao ângulo crítico. Assim, o tamanho da avalanche dependeria apenas da organização dos grãos na pilha no instante da superação da inclinação crítica em determinado local. Assim, avalanches seriam processos em cadeia e a dimensão destas não dependeria de fatores externos. Apesar de haver invariância escalar, o tamanho dos eventos é limitado pelo tamanho do sistema. No caso da pilha de areia, não pode haver avalanches menores que um grão e nem maiores que a pilha. A pilha de areia apresenta comportamento estável até que o estado crítico seja alcançado em determinada parte. O tempo necessário para alcançar o 
estado crítico é em geral maior que período de desenvolvimento das avalanches. Isto faz com que sistemas com comportamento crítico auto-organizado evoluam por espasmos. Este padrão corresponde ao proposto por Gould \& Eldredge (1993) para explicar o modo como a evolução das espécies se processa. Estes autores denominaram tal padrão evolutivo de "equilíbrio pontuado". A evolução de sistemas com equilíbrio pontuado pode ser descrita por curva do tipo escada ("devil's staircaise").

Seções estratigráficas sempre envolvem intervalos de erosão ou não deposição de modo que a história completa da acumulação de sedimentos nunca pode ser completamente recuperada. Isto faz com que os incrementos de sedimentos preservados em função do tempo apresentem padrão em escada (Figura 1.11a) (Sadler \& Strauss, 1990). Logo, os sistemas responsáveis pela deposição e preservação de sedimentos operariam de modo inconstante. Se forem tomadas como exemplo as superseqüências estratigráficas que compõem a Bacia do Paraná (Milani \& Ramos, 1998), nota-se que a representatividade na escala de tempo de dezenas de milhões de anos é inferior a 0,5 (Figura 1.11b). Ou seja, a maior parte dos intervalos de tempo não seria contemplada pelo registro sedimentar.
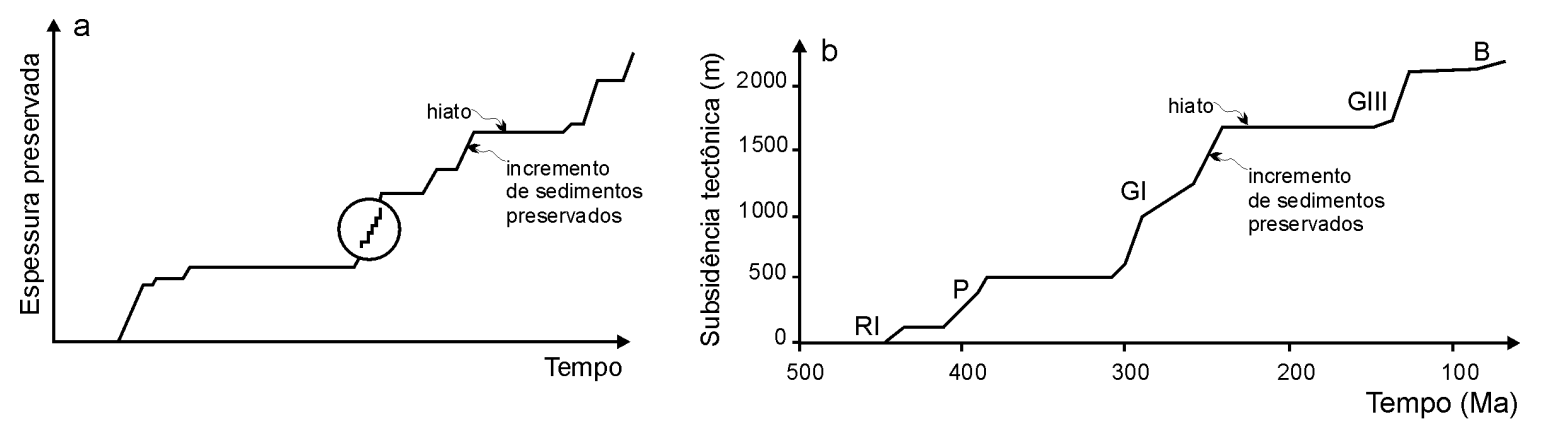

Figura 1.11 - (a) Representação de seção estratigráfica através de curva em escada. Os trechos inclinados correspondem a incrementos de sedimentos preservados e os trechos horizontais a hiatos deposicionais. (Sadler \& Strauss, 1990). O padrão em escada resulta da inconstância da deposição e preservação dos sedimentos. Tal padrão repete-se em diferentes escalas de espaço e tempo (círculo). (b) Curva de subsidência construída a partir dos estratos preservados da Bacia do Paraná (Milani \& Ramos, 1998). Dado que o padrão em escada se repete em diversas escalas, a maior parte do intervalo de tempo da história da bacia seria representada por hiatos deposicionais. $\mathrm{RI}=$ superseqüência Rio Ivaí; $\mathrm{P}=$ superseqüência Paraná; $\mathrm{GI}=$ superseqüência Gondwana I; GIII= superseqüência Gondwana III e B= superseqüência Bauru.

Rothman et al. (1994), Ivanov (1996) e Gomez et al. (2002) demonstraram através de observações ou dados de simulação que sistemas deposicionais podem apresentar CAO. Do ponto 
de vista conceitual, sistemas deposicionais apresentam características comuns a sistemas com $\mathrm{CAO}$, pois recebem fluxo de energia ou materiais externos e os processos de transporte e deposição operam através da superação de valores críticos das forças de coesão entre grãos detríticos. Assim, o modelo de criticalidade auto-organizada poderia ser utilizado para descrição da dinâmica de sistemas deposicionais.

\subsection{Dinâmica de sistemas deposicionais e a leitura do registro sedimentar}

Os conceitos expostos nos itens anteriores permitem que se façam algumas proposições acerca do modo de ver o registro sedimentar. Estas proposições colocam-se como questões que merecem ser levadas em consideração ao se estudar sistemas deposicionais. As proposições são as seguintes:

1. A interpretação do registro sedimentar em termos de relações de causa e efeito é ambígua, uma vez que certos processos podem gerar o mesmo produto e um mesmo produto pode ser resultado de diferentes processos.

2. O registro sedimentar é descontínuo. Parte significativa do tempo de vida de um sistema deposicional pode não ser contemplada pela formação ou preservação de depósitos sedimentares. Estas descontinuidades tornam-se mais freqüentes quanto maior for o tempo de vida do sistema. Assim, a elaboração de modelos de fácies baseada em sistemas deposicionais recentes deve considerar as diferenças de escala entre estes sistemas, que podem ser de curta duração, e sistemas antigos, os quais podem ser de longa duração.

3. A importância relativa de eventos de baixa freqüência de ocorrência e alta intensidade (catastróficos) pode depender do tipo, tamanho e sensibilidade do sistema. Assim, posições categóricas em termos da dicotomia catastrofismo vs. gradualismo não seriam aconselháveis.

4. Sistemas deposicionais do mesmo tipo (classificação fisiográfica) poderiam apresentar faciologia distinta, mesmo quando sujeitos a mesmas condições de operação. Isto derivaria do 
fato da sensibilidade do sistema em registrar eventos deposicionais depender de fatores que não estão ligados à fisiografia, tais como tamanho e distribuição dos esforços críticos (inércia).

5. A evolução por espasmos de sistemas com comportamento crítico auto-organizado sugere que observações de curto intervalo de tempo não refletem a variabilidade da dinâmica do sistema. As características dos produtos de sistemas recentes poderiam ser mais resultado de herança que dos processos atuantes hoje em dia. Isto pensando no sistema como um todo.

6. A invariância escalar de sistemas com CAO pode ser usada como justificativa para o uso de modelos escala no estudo da dinâmica de sistemas deposicionais.

7. A variabilidade dos produtos nem sempre equivale à variabilidade dos processos. Assim, tal como proposto por Ager (1993), o registro geológico não seria representativo do passado. 


\section{SISTEMAS DEPOSICIONAIS EÓLICOS}

\subsection{Sistemas deposicionais eólicos: área de ocorrência e tipos}

Sistemas deposicionais eólicos são formados pela deposição de sedimentos arenosos transportados pelo vento em áreas costeiras ou continentais de clima úmido a árido. Estes sedimentos arenosos podem ser de origem praial (lacustre ou marinha), aluvial ou derivados da deflação do substrato em áreas áridas, onde não haja cobertura vegetal suficiente para impedir a erosão eólica. Os depósitos de areia eólica ocorrem quando há desaceleração do vento devido à presença de depressões, que propiciam o desconfinamento do fluxo é́lico, ou de obstáculos topográficos que servem de barreira ao vento (Glennie, 1970). A deposição destes sedimentos arenosos proporciona a formação de diversas formas deposicionais com dimensões, texturas e estruturas sedimentares distintas (fácies). Sistemas eólicos comumente interagem com outros sistemas deposicionais, podendo originar depósitos sedimentares mistos (fluviais-eólicos, marinhos costeiros - eólicos e lacustres costeiros - eólicos).

Os maiores depósitos modernos de sedimentos arenosos eólicos encontram-se em áreas desérticas (Brookfield, 1992). Estas acumulações podem receber designações distintas, tais como ergs, mares de areia (sand seas) ou campos de dunas (dunefields). Os sistemas eólicos costeiros, apesar de serem formados por campos de dunas menores, podem constituir feições ubíquas ao longo de centenas de quilômetros da orla costeira (Figura 2.1).

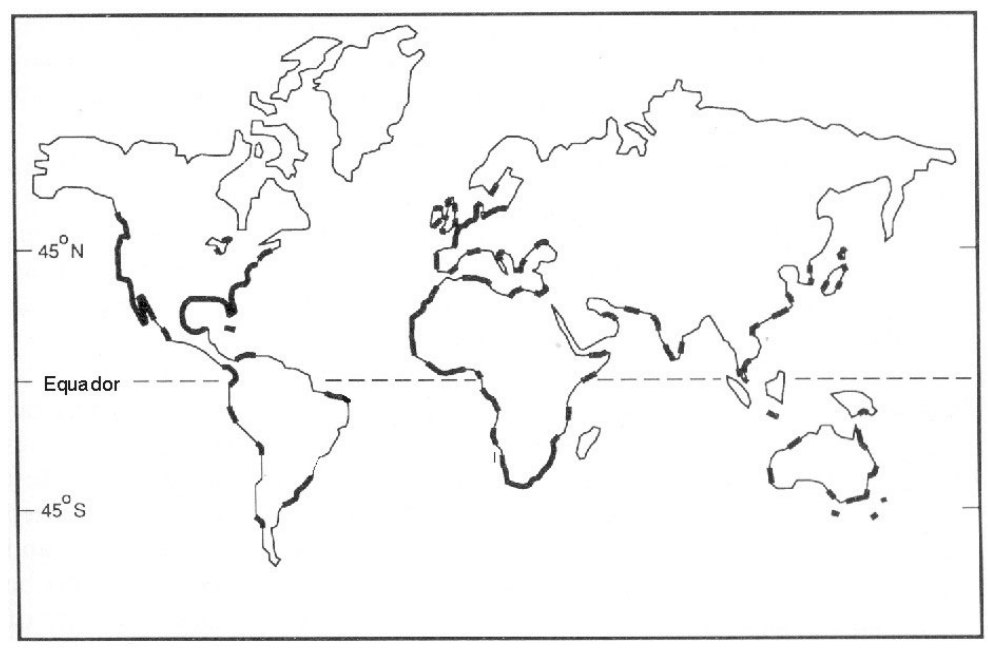

Figura 2.1 - Distribuição mundial das principais áreas costeiras com sedimentação eólica arenosa. Adaptado de Carter et al. (1990). 
Campos de dunas não constituem exclusividade do planeta Terra. As missões espaciais para observação do planeta Marte (Mars 2, 3, 4, 5, 6 e 7, Mariners 4, 6, 7 e 9 e Vikings 1 e 2) revelaram que campos de dunas são feições morfológicas comuns na paisagem marciana (Figura 2.2). Isto torna os sistemas eólicos peculiares em relação aos sistemas deposicionais que dependem de água líquida, uma vez que a existência de tais sistemas ativos em outros planetas ainda não foi comprovada. A análise dos campos de dunas de Marte permite obter informações acerca da dinâmica atmosférica e constituição de Marte (Malin et al., 1998; Thomas et al., 1999). Deste modo, a compreensão da dinâmica de sistemas eólicos também é importante para a exploração planetária.

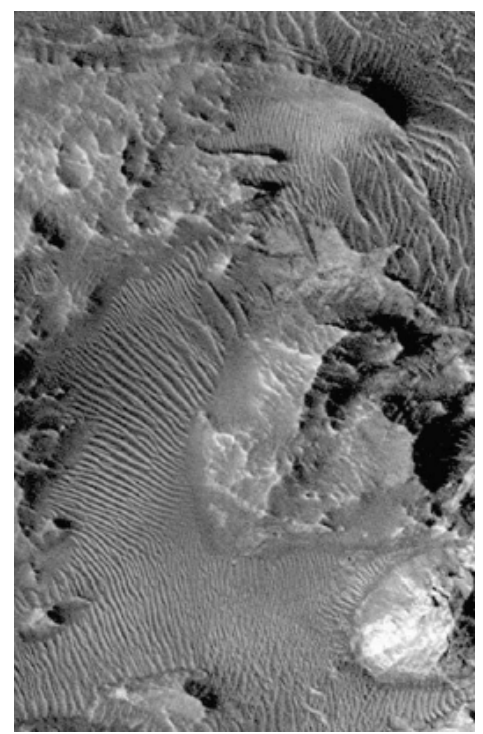

Figura 2.2 - Campos de dunas em Marte (Malin et al., 1998). Estes campos de dunas ocupam depressões topográficas, que parecem condicionar a direção de migração das dunas. Predominam dunas transversais, as quais apresentam bifurcação e orientação variável. Resolução de $5 \mathrm{~m} /$ pixel e área aproximada de $2,3 \times 3,6 \mathrm{~km}$.

Os campos de dunas apresentam formas e dimensões variáveis e compreendem três hierarquias principais de formas de leito conforme os comprimentos de onda: marcas onduladas $\left(10^{-2} \mathrm{~m}\right)$, dunas $(\mathrm{m})$ e draas $\left(10^{2}-10^{3} \mathrm{~m}\right)$. Estas formas de leito apresentam geometrias variáveis, as quais são condicionadas pelo regime de ventos (direção, intensidade e regularidade), disponibilidade de sedimentos e pela presença ou ausência de vegetação (Wasson \& Hyde, 1983). As depressões e planícies interdunares constituem outros elementos morfológicos importantes e seus sedimentos podem diferir texturalmente dos sedimentos dunares. As zonas de deflação 
desenvolvem-se em regiões de alta energia eólica e baixa disponibilidade de sedimentos. Nestas zonas, os processos erosivos predominam sobre os deposicionais e há formação de depósitos sedimentares residuais. Estes elementos morfológicos podem ser observados na Figura 2.3.
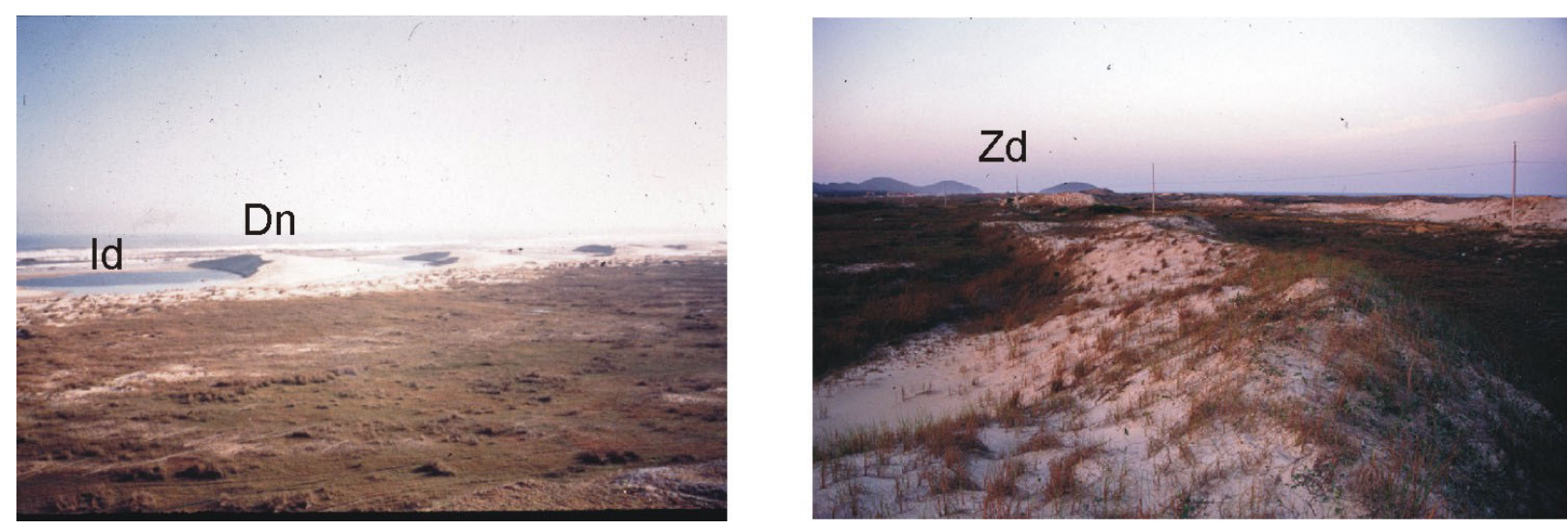

Figura 2.3 -Principais elementos morfológicos de um sistema eólico (Laguna, SC). Dunas (Dn), depressões interdunas (Id) e zonas de deflação (Zd). Foto de Paulo César Fonseca Giannini (2002).

A dimensão e as características morfológicas e texturais dos campos de dunas dependem do saldo de entrada e saída de sedimentos arenosos (Mainguet \& Chemin, 1983). O crescimento de um campo de dunas ocorre quando a entrada de sedimentos supera a saída enquanto que o contrário provoca diminuição. Quando a saída de sedimentos supera a entrada, há deflação do campo de dunas, com alteração textural dos sedimentos remanescentes por concentração residual.

Kocurek \& Havholm (1993) descrevem os sistemas eólicos em termos dos fluxos de entrada (influxo - Qi) e saída (efluxo - Qe) de sedimentos do sistema e em termos dos espaços disponíveis para acumulação e preservação de sedimentos. O espaço de preservação situa-se abaixo do nível freático, que é considerado como sendo o nível de base da erosão eólica. $\mathrm{O}$ espaço de acumulação situa-se entre o nível freático e a altura a partir da qual a velocidade do vento é alta o suficiente para impedir a deposição de sedimentos (altura de equilíbrio). O modelo conceitual de sistema eólico proposto por Kocurek \& Havholm (1993) pode ser visto na Figura 2.4 . 


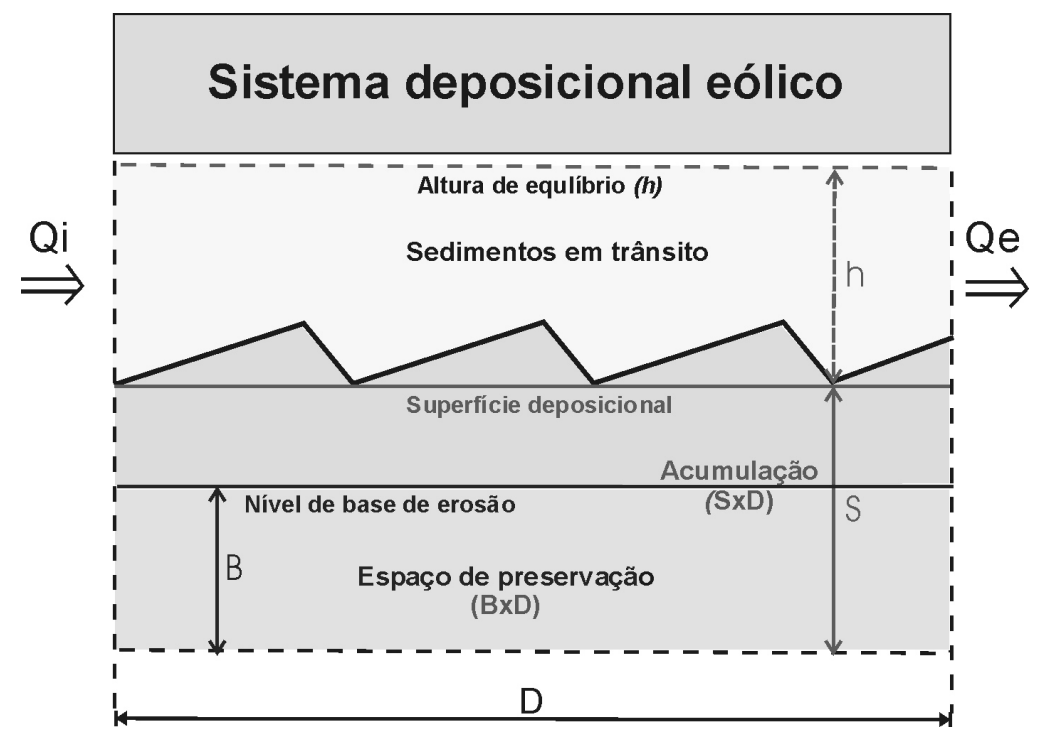

Figura 2.4 - Modelo conceitual de sistema eólico (Kocurek \& Havholm, 1993 apud Giannini et al.). $\mathrm{Qi}=$ influxo e $\mathrm{Qe}=$ efluxo.

De acordo com o modelo conceitual de Kocurek \& Havholm (1993), os sistemas deposicionais eólicos podem ser classificados segundo a proximidade entre o nível freático e a superfície deposicional em secos e úmidos. Os sistemas eólicos secos são caracterizados por nível freático muito abaixo da superfície deposicional, que proporciona elevada disponibilidade de sedimentos incoesos. A estabilização deste tipo de sistema seria controlada por fatores relacionados ao aporte (disponibilidade de sedimentos de entrada no sistema) ou por fatores aerodinâmicos . Nos sistemas eólicos úmidos, o nível freático situa-se próximo à superfície deposicional, o que favorece o aumento da coesão dos sedimentos e conseqüente redução da disponibilidade de sedimentos para o transporte eólico. Este tipo de sistema pode ser estabilizado pelo desenvolvimento de horizontes de cimentação ou por recobrimento pela vegetação (clima úmido). Sistemas eólicos úmidos podem desenvolver-se tanto em áreas de clima úmido quanto árido. Em zonas de clima árido, sistemas eólicos úmidos podem desenvolver-se nas adjacências de corpos de água (lago ou mar). Neste caso, a proximidade do nível freático à superfície deposicional ocorre devido à proximidade do corpo de àgua.

No entanto, o modelo de sistema deposicional eólico de Kocurek \& Havholm (1993) foi elaborado com o objetivo de servir de base para a interpretação de depósitos eólicos segundo o arcabouço conceitual da estratigrafia de seqüências (Vail et al., 1977; Posamentier \& Vail, 1988). Assim, não descreve de maneira satisfatória aspectos ligados à dinâmica interna do sistema, 
principalmente no que diz respeito aos processos responsáveis pela variabilidade faciológica dos depósitos eólicos.

Por serem relativamente homogêneos em termos granulométricos, as heterogeneidades ligadas a tipos de estratificação e geometria (forma e dimensão) de séries de estratificações ganham destaque na definição das fácies formadas neste tipo de sistema deposicional. Estes dois aspectos estão intimamente relacionados aos tipos de formas de leito desenvolvidos em campos de dunas. Morfologia e dimensão de formas de leito eólica são controladas pelo regime de ventos, aporte de sedimentos e presença de vegetação. As formas dunares desprovidas de vegetação (dunas livres) podem ser classificadas em quatro tipos: barcanas, transversais, longitudinais e estrela. Cada tipo de duna livre corresponde a uma situação específica de regime de ventos e disponibilidade de areia (Wasson \& Hyde, 1983). Dunas barcanas e longitudinais ocorreriam em regiões com baixa disponibilidade de areia, sendo que as primeiras seriam formadas em regime de ventos menos variado que as últimas. Já dunas transversais e estrela seriam típicas de regiões com alta disponibilidade de areia, sendo as primeiras formadas em regime de ventos com variabilidade intermediária entre os responsáveis pela geração de dunas barcanas e longitudinais. A origem das dunas do tipo estrela é atribuída a regime de ventos altamente variado (Figura 2.5).

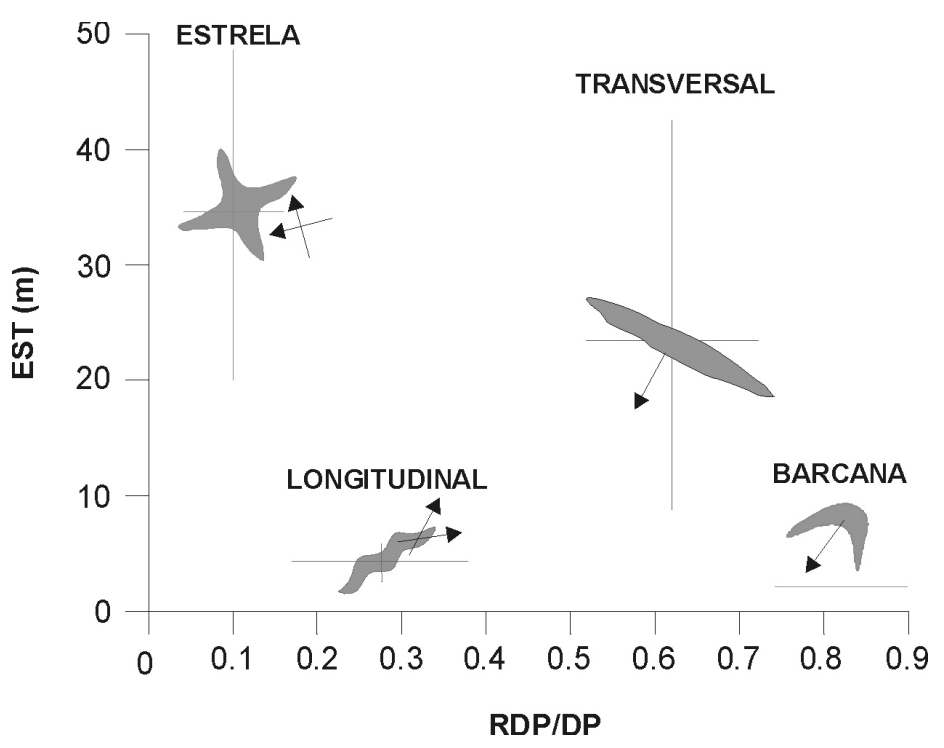

Figura 2.5 - Diferenciação das dunas livres segundo a variabilidade do regime de ventos (RDP/DP) e disponibilidade de areia (EST). Quanto menor o valor da razão (RDP/DP), maior a variabilidade do regime de ventos. DP é a deriva pontencial (drift potential) e RDP é a magnitude do vetor resultante da deriva potencial (resultant drift potential). EST é a espessura equivalente de areia (equivalent sand thickeness). Adaptado de Wasson \& Hyde (1983) apud Giannini et al. (2006). 
Dunas formadas em associação com o crescimento de vegetação (dunas vegetadas) também podem apresentar uma variedade de formas (Martinho, 2004; Martinho et al., 2006; Giannini et al., 2005). A vegetação atua como agente redutor da disponibilidade de areia para o retrabalhamento eólico. Desta forma, processos de deflação podem desempenhar papel importante no desenvolvimento de dunas vegetadas (Figura 2.6). Assim, dunas vegetadas desenvolvem-se em zonas onde o clima e a baixa disponibilidade de areia propiciam o desenvolvimento de vegetação sobre a superfície deposicional.

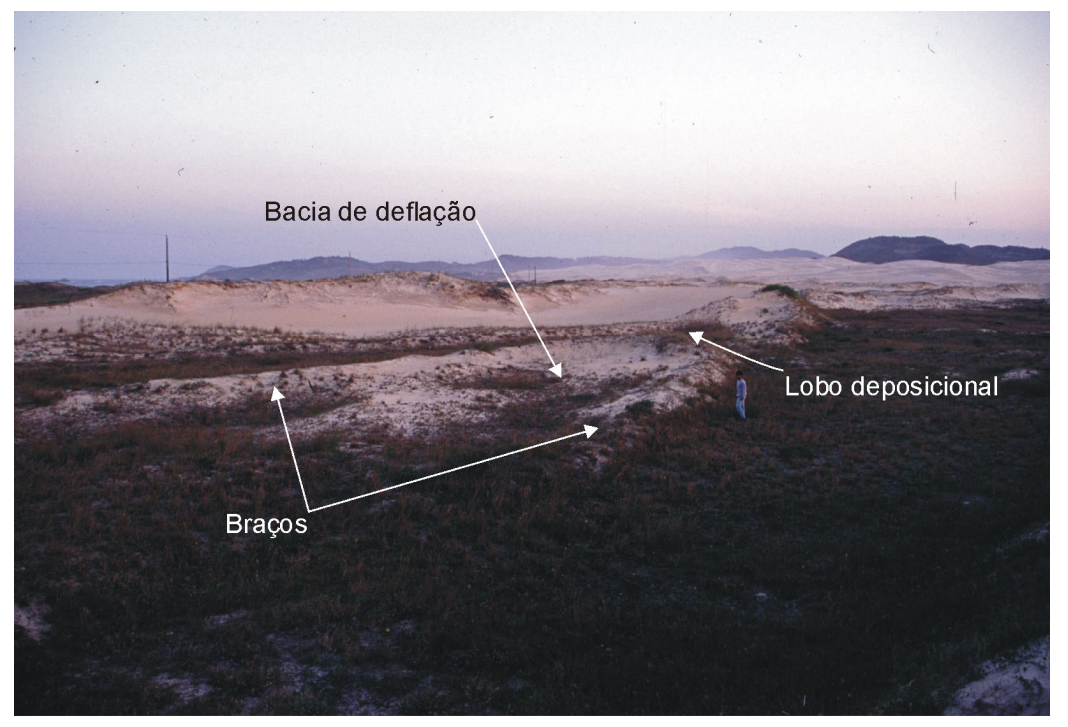

Figura 2.6 - Elementos de uma duna vegetada do tipo parabólica. Localidade de Ibiraqüera, Laguna (SC). Foto de Paulo César Fonseca Giannini (2002).

\subsection{Sistemas deposicionais eólicos quaternários da costa brasileira}

Os sistemas deposicionais eólicos quaternários da orla costeira brasileira fazem parte do sistema de sedimentação da margem continental passiva da América do Sul. Os depósitos eólicos formados nestes sistemas são constituídos por formas ativas vegetadas e formas livres, desprovidas de vegetação.

As formas ativas vegetadas podem formar séries de cordões de dunas frontais, campos de nebkhas e de dunas parabólicas (Martinho, 2004; Martinho et al. 2006; Giannini et al. 2005).

As formas livres correspondem a lençóis de areia ou dunas transversais, barcanas ou a cadeias barcanóides. Estas formas podem constituir acumulações de areia transgressivas, ou seja, 
que avançam sobre o continente. Quando estas acumulações são constituídas por campos de dunas, estes são denominados "campos de dunas transgressivos" (Gardner, 1955).

A ocorrência de fácies eólicas vegetadas ou livres é condicionada pela relação entre aporte eólico e taxa de crescimento da vegetação. Esta relação pode variar localmente, de modo que as duas fácies podem ocorrer lado a lado. Isto pode ser observado em diversos setores da costa brasileira como, por exemplo, nos depósitos eólicos do litoral centro-sul catarinense (Giannini \& Santos, 1994; Martinho, 2001).

Os campos de dunas transgressivos ocorrem em trechos da costa norte, nordeste, sudeste e sul do Brasil (Figura 2.7). São constituídos principalmente por cadeias barcanóides, dunas barcanas e dunas transversais. O rumo de migração das dunas não é constante ao longo da costa, podendo apresentar grandes variações locais ou regionais (Bigarella, 1972).

$\mathrm{Na}$ costa norte (trecho da costa das regiões Norte e Nordeste com orientação oeste-leste), os campos de dunas transgressivos ocorrem, de forma descontínua, desde a ponta dos Mangues (a leste de São Luís, MA) até o rio Ceará (extremo oeste de Fortaleza, CE). Este trecho da costa contém campos de dunas transgressivos com maior extensão em área do Brasil. São formados por ventos com rumo SW no setor oeste e W no setor leste. O maior representante é o campo de dunas dos Lençóis Maranhenses, formado por cadeias barcanóides que migram para SW. No setor a oeste da ponta dos Mangues, a costa deixa de ser retilínea, pois passa a ser dominada por estuários. Os campos de dunas deste setor apresentam tamanho relativamente menor e se desenvolvem principalmente na porção de costa-afora de ilhas presentes nas baías estuarinas.

$\mathrm{Na}$ costa nordeste, os campos de dunas transgressivos ocorrem desde a ponta do Mucuripe (CE) até Tibau do Sul (RN). Os campos mais extensos deste setor encontram-se na costa cearense, entre a ponta do Mucuripe e Canoa Quebrada, e são formados por dunas barcanas e cadeias barcanóides (Claudino Sales \& Peulvast, 2001). A sul do rio Potengi (RN), tornam-se reduzidos e de ocorrência restrita. Os campos de dunas transgressivos da costa nordeste apresentam dois rumos de migração. Os que se situam entre a ponta do Mucuripe (CE) e São Miguel do Gostoso (RN) migram aproximadamente para W. Já os que se situam a sul deste trecho, migram para NW. Neste setor, destacam-se ainda os campos de dunas desenvolvidos nas zonas de progradação associadas à foz do rio São Francisco (SE/AL) e à foz do rio Piauí (SE/BA). Os campos de dunas que ocorrem de maneira isolada na foz do rio São Francisco são caracterizados por três domínios (Barbosa, 1997): o externo ou de lençol de areia, o intermediário 
ou de dunas isoladas e interdunas e o interno, constituído por dunas compostas e de precipitação. O rumo dominante de migração das dunas é W (Barbosa, 1997).

Os campos de dunas transgressivos da costa sudeste são pequenos e pouco abundantes. Destes, podem ser citados o campo de dunas desenvolvido na foz do rio Itaúnas (norte do Espírito Santo) e os campos de dunas de Cabo Frio (RJ). Os campos de dunas transgressivos de Cabo Frio são constituídos por dunas barcanas e cadeias barcanóides com rumo de migração aproximadamente SW.

O setor sul da costa brasileira conta com ampla área de ocorrência de campos de dunas transgressivos nos estados de Santa Catarina e Rio Grande do Sul. Ocorrem a partir da ilha de Santa Catarina, onde apresentam rumo de migração para NW. A sul desta localidade, passam a migrar para SE ou S. Em Santa Catarina, podem ser destacados os campos de dunas situados entre Imbituba e Laguna. Estes são formados por cadeias barcanóides, dunas trasnversais e dunas barcanas e apresentam frentes de avanço com geometria parabólica (Giannini, 1993). Em alguns setores, como a sul do cabo de Santa Marta, apresentam rumo de migração subparalelo à linha de costa (Giannini, 1993; Martinho, 2004). No estado do Rio Grande do Sul, os campos de dunas livres apresentam maior continuidade e área de recobrimento. Segundo Tomazelli (1994), também são constituídos por dunas barcanas, cadeias barcanóides e dunas transversais, podendo apresentar campos de nebkhas na porção externa adjacente. 


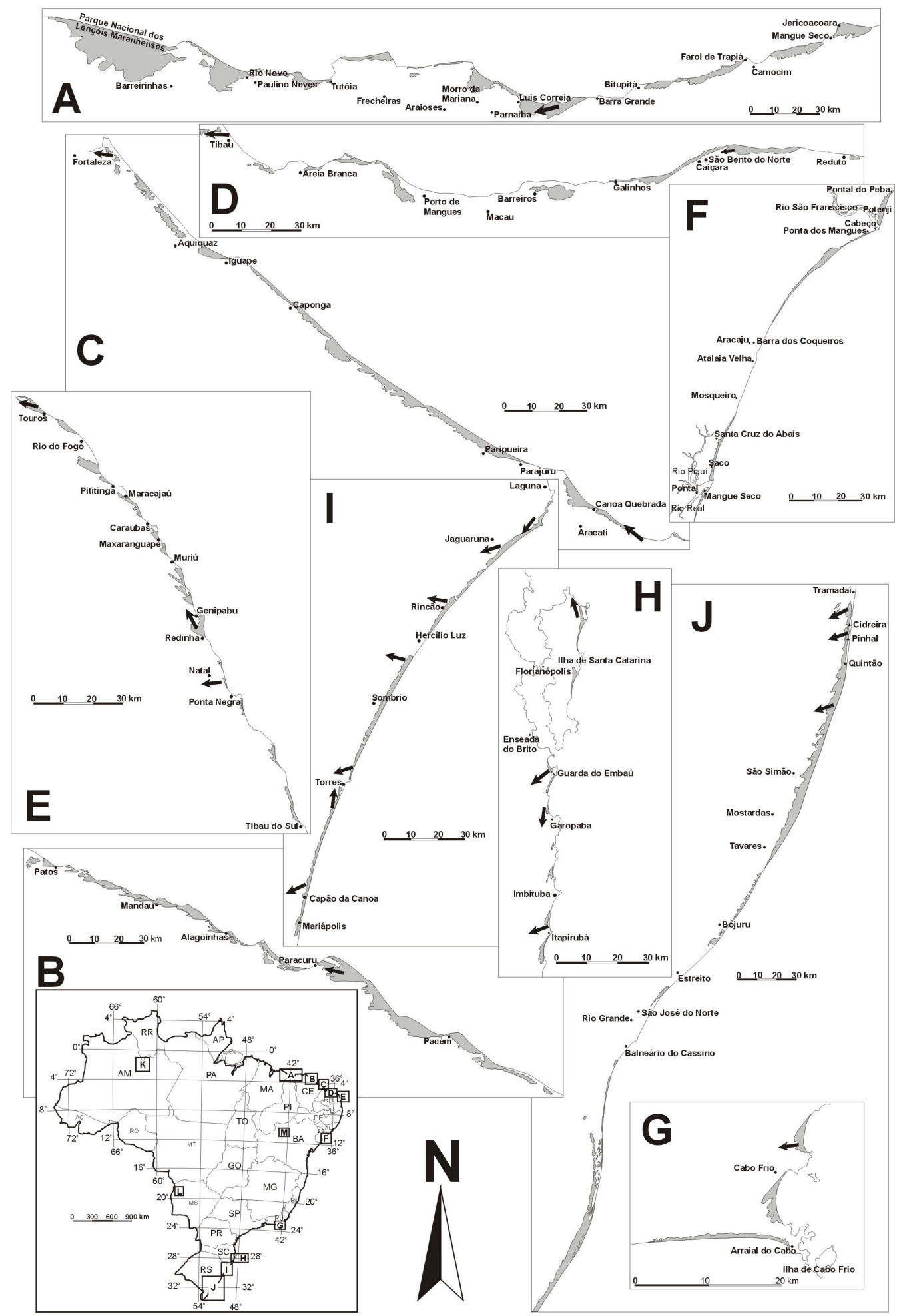

Figura 2.7 - Distribuição dos campos de dunas transgressivos na costa brasileira (destacados em coloração cinza). As setas pretas indicam rumos de migração de dunas, obtidos através de medidas de estratificações cruzadas realizadas por Bigarella (1970/1971). As áreas K, L e M correspondem a campos de dunas interiores estabilizados. Adaptado de Giannini et al. (2005). 


\subsection{Importância econômica dos depósitos sedimentares eólicos}

Depósitos eólicos arenosos constituem importantes reservatórios de petróleo em diversas bacias (ex. Mar do Norte, Solimões e Recôncavo). O maior aqüífero do mundo (Aqüìfero Guarani) é formado por arenitos eólicos da Bacia do Paraná (formações Pirambóia e Botucatu). Os sedimentos eólicos são importantes fontes de areia para construção civil e de sílica para a indústria de vidros. A sedimentação eólica pode promover a concentração de minerais pesados e a formação de jazidas de bens minerais, tais como diamante, zircão e rutilo. Estes fatos ilustram a importância econômica dos sedimentos de origem eólica.

As propriedades petrofísicas (porosidade e permeabilidade) dos depósitos eólicos, que permitem sua caracterização como reservatórios de água ou hidrocarbonetos, e as suas propriedades texturais e mineralógicas, úteis para a prospecção e caracterização de minérios, são controladas, em primeira instância, pela dinâmica dos processos deposicionais atuantes no sistema eólico. Estas propriedades também influenciarão a história diagenética dos depósitos eólicos, que pode alterar as características petrofísicas, texturais e mineralógicas dos sedimentos através da compactação, cimentação e dissolução pós-deposicional. Portanto, a compreensão da variabilidade dos processos deposicionais do sistema eólico é de fundamental importância para o aproveitamento econômico dos depósitos eólicos. 


\section{MORFOMETRIA DOS CAMPOS DE DUNAS QUATERNÁRIOS DA COSTA BRASILEIRA}

\subsection{Introdução}

A costa brasileira possui cerca de $8000 \mathrm{~km}$ de comprimento e compreende ambientes fisiográficos diversos. Os ambientes fisiográficos atuais que compõem a costa brasileira resultam de diversos fatores, porém constituem produto de um fator comum, que agiu de forma mais ou menos semelhante nos últimos 18 ka: o Nível Relativo do Mar (NRM). O NRM na costa brasileira sofreu elevação de cerca de $130 \mathrm{~m}$ após o último máximo glacial, há cerca de $18 \mathrm{ka}$ (Kowsmann \& Costa, 1979; Corrêa, 1996). A partir de 5 ka AP, o NRM sofreu queda de poucos metros até atingir seu nível atual. No litoral centro-sul de Santa Catarina, por exemplo, esta queda foi de pelo menos 2,1 $\pm 0,5 \mathrm{~m}$ (Angulo et al., 1999). Com base na análise de diversos indicadores, Suguio et al. (1985) admitem a existência de dois períodos com queda do NRM abaixo do nível presente durante os últimos 5 ka (4,1-3,8 ka AP e 3,0-2,7 ka AP). No entanto, estas oscilações negativas não são evidentes nos dados obtidos a partir da datação de carapaças de vermetídeos, que são considerados indicadores mais seguros de NRM (Angulo et al., 1999). Independente de haver ou não estas oscilações negativas holocênicas do NRM, em maior escala, a plataforma brasileira encontra-se afogada, pois a queda de NRM holocênica é pequena se comparada à elevação ocorrida após o último máximo glacial. Assim, a queda de NRM holocênica pode ser encarada como fase de estabilização do NRM em posição elevada. O afogamento da plataforma brasileira após o último máximo glacial e a sucessiva queda (ou estabilização) do NRM produziram efeitos diversos em diferentes trechos da costa. A diversidade de efeitos resulta da interação do NRM com variáveis de ação local ou regional, tais como aporte sedimentar costeiro, relevo e amplitude de maré. Em zonas de aporte sedimentar mais elevado houve a formação de planícies costeiras ou barreiras arenosas, sendo que estas últimas geraram lagunas. $\mathrm{O}$ aporte sedimentar costeiro é maior próximo à desembocadura de grandes rios e/ou em zonas onde o relevo da plataforma interna é menos acidentado. Outros trechos são caracterizados por numerosas baías e ilhas formadas principalmente por rochas ígneas e metamórficas. Esta morfologia é característica de zona de relevo mais acidentado, afogado e com baixo aporte sedimentar. Este é o caso, por exemplo, do litoral norte de São Paulo e sul do Rio de Janeiro, 
onde a serra do Mar é mais proeminente. Em parte da costa norte (Pará e Maranhão) sobressai o efeito da maré como agente modelador da fisiografia costeiro. Esta região apresenta com característica marcante a grande quantidade de canais de maré e baías alongadas transversais à linha de costa, as quais diferem das baías da costa sudeste, pois constituem feições formadas pela ação da maré e não pelo afogamento de relevo preexistente. Parte da costa das regiões Sudeste (Espirito Santo) e Nordeste (Bahia, Sergipe, Alagoas, Paraíba e Rio Grande do Norte) distinguese dos demais trechos pela presença de falésias (escarpas quase verticais adjacentes à costa). Estas falésias são formadas pela erosão de rocha sedimentares pouco consolidadas da Formação Barreiras, que devem constituir importante fonte de sedimentos arenosos para este setor da costa. Os campos de dunas costeiros desenvolvem-se no contexto desta multiplicidade de ambientes fisiográficos, que pode exercer grande influência sobre sua geração, desenvolvimento e morfologia.

Campos de dunas costeiros podem ser encontrados em diversos trechos das costas norte, leste e sul do Brasil (Giannini et al., 2005), sendo que a distribuição espacial, tamanho e forma destes campos de dunas é variável ao longo da costa. Campos de dunas podem ser feições comuns de alguns trechos e ocorrerem de modo localizado em outros. A dinâmica, assim como os fatores que proporcionam o desenvolvimento destes campos de dunas, dependem da interação entre as diversas variáveis climáticas, fisiográficas e oceanográficas atuantes na zona costeira. A interação entre estas variávies pode gerar dinâmica complexa, uma vez que estas exibem variabilidade em diversas escalas de tempo e espaço e algumas são variáveis aleatórias.

Devido à grande extensão e diversidade de ambientes fisiográficos da costa brasileira, estes campos de dunas constituem objeto adequado para o estudo da dinâmica de sistemas eólicos costeiros e de sua relação com as variáveis mencionadas. Nesta pesquisa, aspectos relacionados à distribuição espacial, dimensão e morfologia destes campos de dunas foram estudados através de imagens do satélite Landsat 7.

\subsection{Materiais e métodos}

\subsubsection{Aquisição de dados}

Observações acerca da morfologia e medidas relacionadas à forma e tamanho dos campos de dunas da costa brasileira foram realizadas em mosaicos elaborados a partir de imagens do 
satélite Landsat-7 obtidas entre os anos de 1997 e 2003. Estes mosaicos são disponibilizados para uso público pelo programa GeoCover (NASA) e podem ser obtidos no endereço eletrônico zulu.ssc.nasa.gov/mrsid.

De acordo com a NASA, os mosaicos do programa GeoCover foram confeccionados a partir das bandas Landsat ETM+ 7 (short wave infrared - SWIR), 4 (near-infrared - NIR) e 2 (verde), cujas resoluções foram melhoradas através de composição com a banda 8 (pancromática). A banda 7 foi apresentada como vermelho, a banda 4 como verde e a banda 2 como azul. Segundo informações da NASA, afim de maximizar as informações de cada mosaico, foi aplicada técnica de ajuste de contraste conhecida como LOCAL (Locally Optimized Continuousty Adjusted Look-up-tables). Esta técnica realiza ajustes em áreas com amplitude de contraste excessiva (GeoCover, NASA). Os mosaicos são apresentados em cores falsas e projeção UTM, sendo o tamanho do pixel de 14,25 m. O Quadro 3.1 contém as cores falsas das principais feições superficiais que aparecem nos mosaicos GeoCover. Os arquivos dos mosaicos utilizados são do tipo MrSID.

\begin{tabular}{|l|l|}
\hline Feição superficial & Cor falsa \\
& $\begin{array}{l}\text { Vermelho: Banda 7 } \\
\text { Verde: Banda 4 } \\
\text { Azul: Banda 2 }\end{array}$ \\
\hline Árvores e arbustos & Tons de verde \\
\hline Plantações & Tons de verde \\
\hline Vegetação de áreas inundadas & Tons de verde \\
\hline Água “limpa" & Preto a azul escuro \\
\hline Água com sedimentos em suspensão & Tons de azul \\
\hline Áreas urbanas & Lavanda \\
\hline Áreas com solo ou rochas expostas & Magenta, Lavanda ou rosa claro \\
\hline Acumulações de areia & Branco, amarelo claro ou azulado \\
\hline
\end{tabular}

Quadro 3.1 - Cores falsas das principais feições superficiais visíveis nos mosaicos do programa GeoCover.

Para a digitalização dos campos de dunas e obtenção dos dados morfométricos utilizou-se o software ArcView GIS 3.2. As variáveis relativas aos campos de dunas, medidas diretamente nas imagens, foram: área total (A), perímetro (P), soma das áreas de deflação ou recobertas por vegetação (ADV), distância máxima de avanço (D), comprimento e direção da linha de costa 
adjacente ao campo de dunas $(\mathrm{C}$ e $\alpha)$, azimute de avanço $(\theta)$ e ângulo entre a direção de avanço e a direção da linha de costa adjacente $(\alpha)$. Estas variáveis morfométricas podem ser observadas na Figura 3.1.

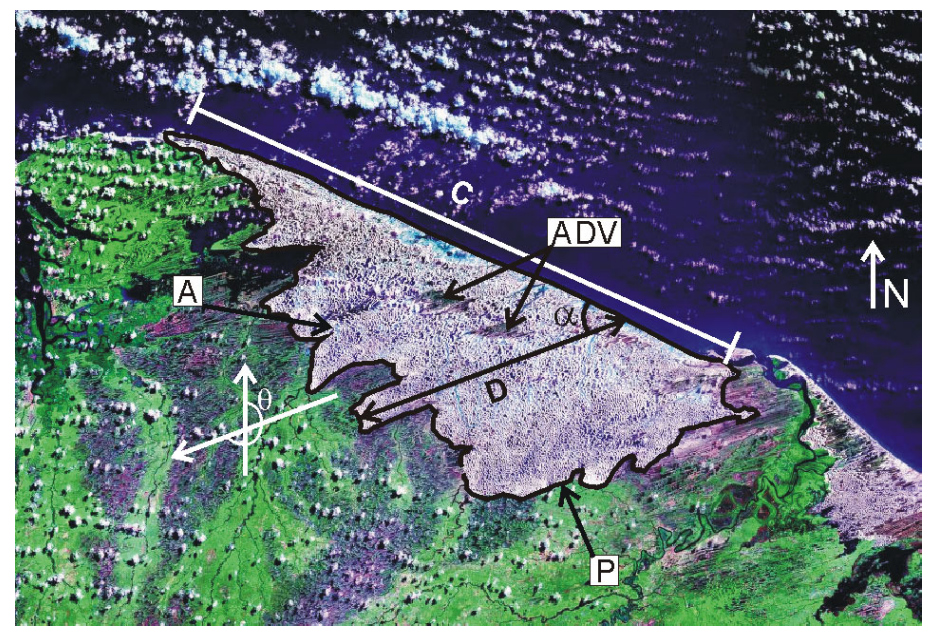

Figura 3.1 - Variáveis morfométricas dos campos de dunas (Lençóis Maranhenses, costa do Estado do Maranhão). $\mathrm{O}$ valor de $\mathrm{C}$ é de aproximadamente $62 \mathrm{~km}$. $\mathrm{A}=$ área total; $\mathrm{P}=$ perímetro; $\mathrm{ADV}=$ áreas de deflação ou recobertas por vegetação; $\mathrm{D}=$ distância máxima de avanço; $\theta=$ azimute de avanço; $\mathrm{C}=$ comprimento da linha de costa adjacente; $\alpha$ = ângulo entre a direção de avanço e a direção da linha de costa.

Utilizaram-se as variáveis medidas para o cálculo das razões $\mathrm{A} / \mathrm{C}, \mathrm{ADV} / \mathrm{A}, P / \sqrt{A}$ e $\mathrm{D} / \mathrm{C}$. A razão $\mathrm{A} / \mathrm{C}$ proporcionaliza a área total do campo de dunas em relação ao comprimento da linha de costa adjacente, ou seja, seria uma medida do tamanho do campo de dunas relativo ao comprimento de sua área fonte (praia). Esta razão pode ser interpretada como medida da capacidade de crescimento dos campos de dunas e de distribuição de areia pelo vento (maior esta razão, maior o suprimento e/ou capacidade de distribuição dos sedimentos em área). No entanto, deve ser levado em consideração que o crescimento de alguns campos de dunas pode ser restringido por barreiras topográficas ou pela presença de canais de maré, lagos ou lagunas. Estes campos de dunas podem ocupar área menor, porém conter elevado volume de areia. A razão $\mathrm{ADV} / \mathrm{A}$ equivale à proporção de áreas de deflação ou recobertas por vegetação. Se for considerado que tanto a deflação quanto a colonização por vegetação estão associados à baixas taxas de acumulação de areia, esta razão seria indicador inverso da disponibilidade de areia para transporte e deposição dentro do campo de dunas. Porém, o crescimento de vegetação é influenciado pela quantidade de umidade e a deflação pela velocidade do vento. Assim, tal razão seria indicador relativo da disponibilidade de areia. A variável D/C pode ser considerada uma 
medida azimutal da forma dos campos de dunas, pois mede o grau de alongamento dos campos de dunas no sentido do avanço. Também pode ser considerada indicador da capacidade de distribuição de sedimentos no sentido do avanço dos campos de dunas. A razão $P / \sqrt{A}$ não varia com o tamanho da forma e depende apenas da geometria e da sinuosidade do contorno do campo de dunas. Os campos de dunas costeiros apresentam contorno sinuoso principalmente na sua face de sotavento, onde é comum a presença de lobos de avanço. A sinuosidade do contorno provoca aumento da razão $P / \sqrt{A}$. No entanto, os campos de dunas analisados possuem contorno de morfologia semelhante de modo que a relação entre comprimento e largura passa a ser o principal fator de controle da variação da razão $P / \sqrt{A}$. Excluído o efeito da sinuosidade, formas equidimensionais (menor diferença entre comprimento e largura) apresentam valores menores de $P / \sqrt{A}$ em relação a formas alongadas (Figura 3.2). Assim, esta razão foi usada para caracterizar a forma externa dos campos de dunas e pode ser interpretada como medida da relação entre comprimento e largura.

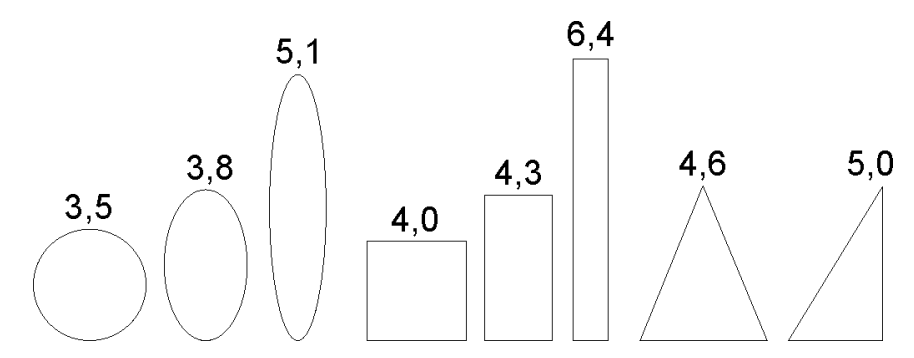

Figura 3.2 - Valores da razão $P / \sqrt{A}$ para algumas formas geométricas regulares. A circunferência apresenta a menor razão $P / \sqrt{A}$. O aumento desta razão ocorre com o "alongamento" da forma. Formas equidimensionais apresentam valores menores de $P / \sqrt{A}$.

Apesar de haver certa ambiguidade no significado dos valores das razões A/C, ADV/A e $P / \sqrt{A}$, estas três variáveis, mais a variável $\mathrm{D} / \mathrm{C}$, caracterizam respectivamente o tamanho relativo, a morfologia interna e a morfologia externa dos campos de dunas. Estes foram os principais critérios usados na classificação morfométrica dos campos de dunas da costa brasileira.

Os campos de dunas medidos foram categorizados segundo fatores geográficos (setor da costa), climáticos (número de meses secos e velocidade média e freqüência de atuação do vento) e oceanográficos (amplitude de maré) da região onde foram obtidos. Desta forma, foi possível 
avaliar a relação entre estas variáveis categóricas e as variáveis ligadas à morfologia dos campos de dunas.

\subsubsection{Análise estatística descritiva}

Os dados obtidos foram organizados em planilhas do software EXCEL 2000 e analisados no software MINITAB Release 13.0. Os dados foram resumidos por estatísticas descritivas (média, desvio padrão, quartis, mediana, máximo, mínimo e assimetria) e representados por histogramas e gráficos de variação da média (Figura 3.3). Gráficos de variação da média foram utilizados para avaliação preliminar da variabilidade das propriedades morfométricas de grupos de campos de dunas estabelecidos a priori com base em critérios climáticos, oceanográficos e geográficos. Os gráficos de variação da média permitem comparar a variabilidade interna de um grupo com a variabilidade entre os grupos.

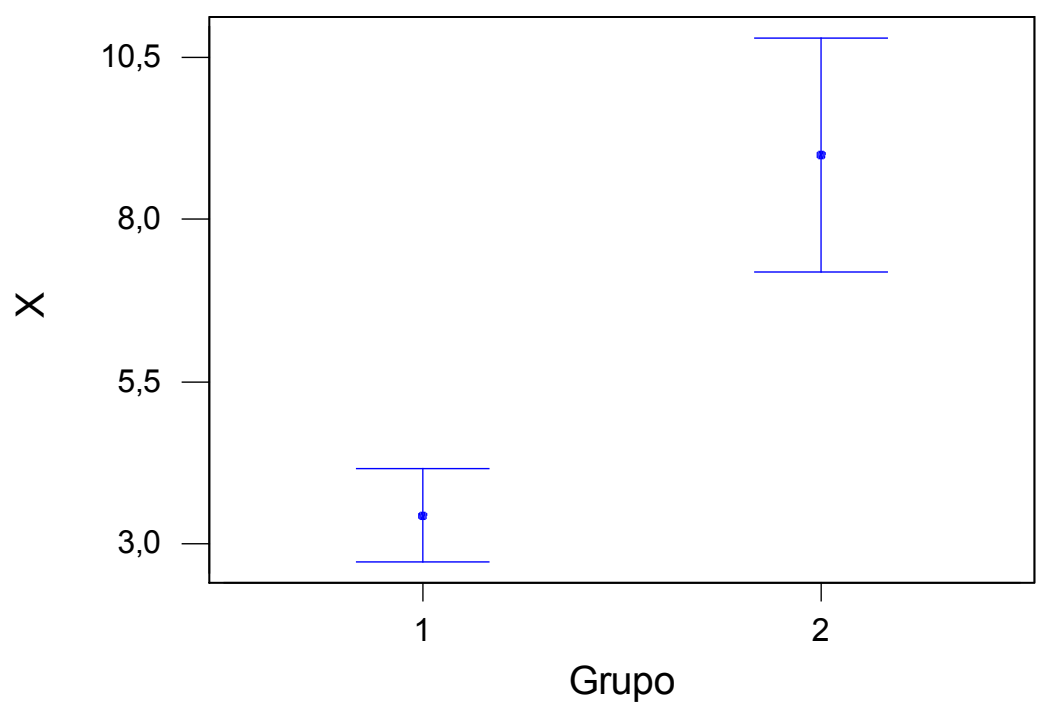

Figura 3.3 - Gráficos de variação dos valores médios para variável arbitrária $(\mathrm{X})$ : o ponto central é o valor médio e as barras correspondem ao erro padrão da média (erro padrão $=$ desvio padrão/ $\sqrt{N}$ ). Neste caso, a variabilidade entre os grupos 1 e 2 é maior que a variabilidade interna de cada grupo. Assim, pode-se dizer que os grupos 1 e 2 apresentam valores distintos da variável $\mathrm{X}$. 


\subsubsection{Análise de agrupamento}

A análise de agrupamento mede a semelhança entre observações e as separa em grupos (Manly, 1994). A semelhança equivale à distância entre pontos calculada a partir dos valores das variáveis utilizadas na análise. Há vários métodos de medida desta distância, sendo que neste estudo utilizou-se a distância euclidiana ao quadrado. A distância euclidiana é uma medida de dissimilaridade, ou seja, quanto menor seu valor, mais parecidas são as observações comparadas. Támbém há diversos métodos de agrupamento, os quais utilizam critérios distintos. Neste trabalho, optou-se pelo método de Ward, que é apropriado para variáveis de natureza quantitativa (passíveis do cálculo de média). O agrupamento realizado por este método segue critério de variância mínima. Assim, as observações são aglomeradas de modo que os grupos criados tenham variância mínima (grupos homogêneos) e sejam diferentes entre si. Variáveis com intervalo de variação distintos devem ser normalizadas para evitar sobrevalorização das variáveis de maiores valores absolutos.

A análise de agrupamento foi utilizada para classificação dos campos de dunas com base nas variáveis medidas nas imagens de satélite. Portanto, trata-se de classificação baseada no tamanho e forma dos campos de dunas. O agrupamento também serviu para avaliação da influência de fatores climáticos, oceanográficos e geográficos sobre a morfologia e tamanho dos campos de dunas. Para isto, utilizou-se o teste qui-quadrado para avaliar a correspondência entre grupos definidos pela análise de agrupamento (grupos morfológicos) e grupos definidos a priori a partir das variáveis climáticas, oceanográficas e geográficas.

\subsubsection{Teste de aderência pelo modelo qui-quadrado}

Testes de aderência são utilizados para avaliar a adequação de modelos probabilísticos, previamente estabelecidos, a determinado conjunto de dados (Magalhães \& Lima, 2001). Para isto, compara-se a tabela de freqüência dos dados amostrais divididos em categorias (freqüência observada) com a tabela de freqüência do modelo proposto (freqüência esperada) (Quadro 3.2). 


\begin{tabular}{|l|l|l|l|l|l|}
\hline Categoria & 1 & 2 & 3 & $\ldots$ & $k$ \\
\hline Freqüência esperada & $\mathrm{e}_{1}$ & $\mathrm{e}_{2}$ & $\mathrm{e}_{3}$ & $\ldots$ & $\mathrm{e}_{k}$ \\
\hline Freqüência observada & $\mathrm{o}_{1}$ & $\mathrm{o}_{2}$ & $\mathrm{o}_{3}$ & $\ldots$ & $\mathrm{o}_{k}$ \\
\hline
\end{tabular}

Quadro 3.2 - Tabela de freqüências esperadas e observadas. As freqüências esperadas podem ser por exemplo classes de campos de dunas de $k$ setores geográficos. Utiliza-se a análise de agrupamento para dividir os mesmos campos de dunas a partir de variáveis morfométricas em $k$ grupos.

A aderência dos dados amostrais ao modelo proposto é avaliado mediante o seguinte teste de hipóteses:

$\mathrm{H}_{0}$ : os dados seguem o modelo proposto

$\mathrm{H}_{\mathrm{a}}$ : os dados não seguem o modelo proposto

A discrepância entre os dados amostrais e o modelo proposto é medida pela quantidade $Q^{2}$ (Equação 3.1), que é utilizada para decidir sobre as hipóteses $\mathrm{H}_{0}$ e $\mathrm{H}_{\mathrm{a}}$.

$$
Q^{2}=\sum_{i=1}^{k} \frac{\left(o_{i}-e_{i}\right)^{2}}{e_{i}},
$$

onde, $k$ é o número de categorias, $o_{i}$ é a freqüência observada e $e_{i}$ a freqüência esperada para a categoria $i$. A distribuição de $\mathrm{Q}^{2}$ pode ser aproximada por um modelo Qui-Quadrado com parâmetro $\mathrm{k}-1$. Esta aproximação será mais eficaz se todas as freqüências esperadas forem menores ou iguais a 5 (Magalhães \& Lima, 2001).

Utilizou-se o teste de aderência para avaliar a correspondência entre grupos de campos de dunas definidos a partir de variáveis climáticas, oceanográficas e geográficas e grupos definidos por características morfométricas. Ou seja, tal teste foi usado para analisar a influência de fatores climáticos, oceanográficos e geográficos sobre a morfologia e tamanho dos campos de dunas. Os procedimentos envolvidos neste teste foram:

1. Divisão dos campos de dunas em categorias (definidas a partir de variáveis climáticas, oceanográficas ou geográficas) e cálculo da freqüência de cada categoria. 
2. Agrupamento dos campos de dunas através da utilização de variáveis morfométricas. O número de grupos deve ser igual ao número de categorias definidas no item anterior.

3. Comparação através de tabela de correspondência (Quadro 3.3) entre as categorias climáticas, oceanográficas ou geográficas e os grupos morfométricos.

4. Avaliação das correspondência por meio de teste qui-quadrado.

\begin{tabular}{|l|l|l|l|}
\hline & a & b & c \\
\hline $\mathbf{1}$ & $o_{1 a}$ & $o_{1 b}$ & $o_{1 c}$ \\
\hline $\mathbf{2}$ & $o_{2 a}$ & $o_{2 b}$ & $o_{2 c}$ \\
\hline $\mathbf{3}$ & $o_{3 a}$ & $o_{3 b}$ & $o_{3 c}$ \\
\hline
\end{tabular}

Quadro 3.3 - Nas colunas estão representadas as categorias (a, b e c) e nas linhas os grupos definidos por análise de agrupamento (1,2 e 3). As freqüências observadas são representadas por $o_{i j}$, sendo $i$ grupos e $j$ categorias. Por exemplo, $o_{1 a}$ é a freqüência de observações do grupo 1 que pertencem à categoria a. No caso de não haver relação entre grupos e categorias, as freqüências observadas de um mesmo grupo seriam iguais. Se houver preferência de certo grupo por certa categoria, pode-se supor relação entre grupos e categorias. A preferência é medida pela quantidade $Q^{2}$, sendo que o modelo proposto é a distribuição não homogênea das amostras de um mesmo grupo entre as categorias.

As freqüências observadas são comparadas com freqüências esperadas, as quais são calculadas com base na hipótese de que a distribuição dos dados entre as categorias avaliadas é homogênea, ou seja, sob a hipótese de que não há relação entre as duas categorias avaliadas. A hipótese nula considera que a freqüência observada equivale à freqüência esperada. A partir das freqüências observadas e esperadas calcula-se a estatística qui-quadrado e a partir desta, a probabilidade (p) de cometer erro tipo I, ou seja, rejeitar a hipótese nula quando esta é verdadeira. Quanto menor o valor de $\mathrm{p}$, menor a probabilidade de cometer este tipo de erro. O valor limite comumente utilizado é 0,05 . Assim, a hipótese nula é rejeitada quando p for menor que 0,05 . Valores de p acima de 0,05 sugerem que não há diferença entre freqüências observadas e esperadas e, portanto, que inexiste dependência entre as categorias analisadas. Para estas análises, foi usado o software Minitab Release 13.0. 


\subsection{Resultados}

\subsubsection{Estatistica descritiva das variáveis morfométricas}

Medidas das variávies descritas no ítem 3.2.1 (área (A), perímetro (P), áreas de deflação ou recobertas por vegetação (ADV), distância máxima de avanço (D), comprimento da linha de costa adjacente $(C)$, rumo de migração $(\theta)$ e ângulo entre a direção de avanço e a direção da linha de costa $(\alpha)$ ) foram realizadas em 214 campos de dunas distribuídos ao longo da costa das regiões Norte, Nordeste, Sudeste e Sul do Brasil. No entanto, apenas as variáveis A, P e C foram quantificadas em todos os 214 campos de dunas observados. Em alguns campos de dunas não foi possível medir com segurança o sentido de avanço, que impossibilitou a quantificação das variáveis $\mathrm{D}$ e $\alpha$. Além disto, a atividade antrópica impediu a obtenção de medidas seguras de ADV em alguns campos de dunas.

As variáveis $\mathrm{A}, \mathrm{P}, \mathrm{ADV}, \mathrm{D}$ e $\mathrm{C}$ apresentam em comum o fato do desvio padrão ser significativamente maior que a média (Tabela 3.1). Estas variáveis apresentam amplo intervalo de variação (mais de uma ordem de magnitude) e suas distribuições de freqüências são unimodais com elevada assimetria postiva (assimetria $>3,28$ ), semelhantes à distribuição exponencial (Figura 3.4).

\begin{tabular}{|c|l|l|l|l|l|l|l|l|l|}
\hline Variável & \multicolumn{1}{|c|}{ Média } & $\begin{array}{c}\text { Desvio } \\
\text { padrão }\end{array}$ & $\begin{array}{c}\text { Primeiro } \\
\text { quartil }\end{array}$ & Mediana & $\begin{array}{c}\text { Terceiro } \\
\text { quartil }\end{array}$ & Mínimo & Máximo & Assimetria & N \\
\hline $\mathrm{A}\left(\mathrm{km}^{2}\right)$ & 21,17 & 88,05 & 0,83 & 2,49 & 10,21 & 0,06 & 1000,62 & 8,56 & 214 \\
\hline $\mathrm{P}\left(\mathrm{km}^{2}\right)$ & 34,53 & 54,81 & 9,61 & 16,54 & 35,75 & 1,44 & 440,50 & 4,67 & 214 \\
\hline $\mathrm{ADV}\left(\mathrm{km}^{2}\right)$ & 5,72 & 17,29 & 0,06 & 0,39 & 2,85 & 0,00 & 132,36 & 5,20 & 207 \\
\hline $\mathrm{D}(\mathrm{km})$ & 3,78 & 4,58 & 0,99 & 2,13 & 4,71 & 0,16 & 36,27 & 3,28 & 159 \\
\hline $\mathrm{C}(\mathrm{km})$ & 12,09 & 19,63 & 3,15 & 5,93 & 12,62 & 0,49 & 166,28 & 5,07 & 211 \\
\hline
\end{tabular}

Tabela 3.1 - Estatísticas descritivas das variáveis A, P, ADV e C. 

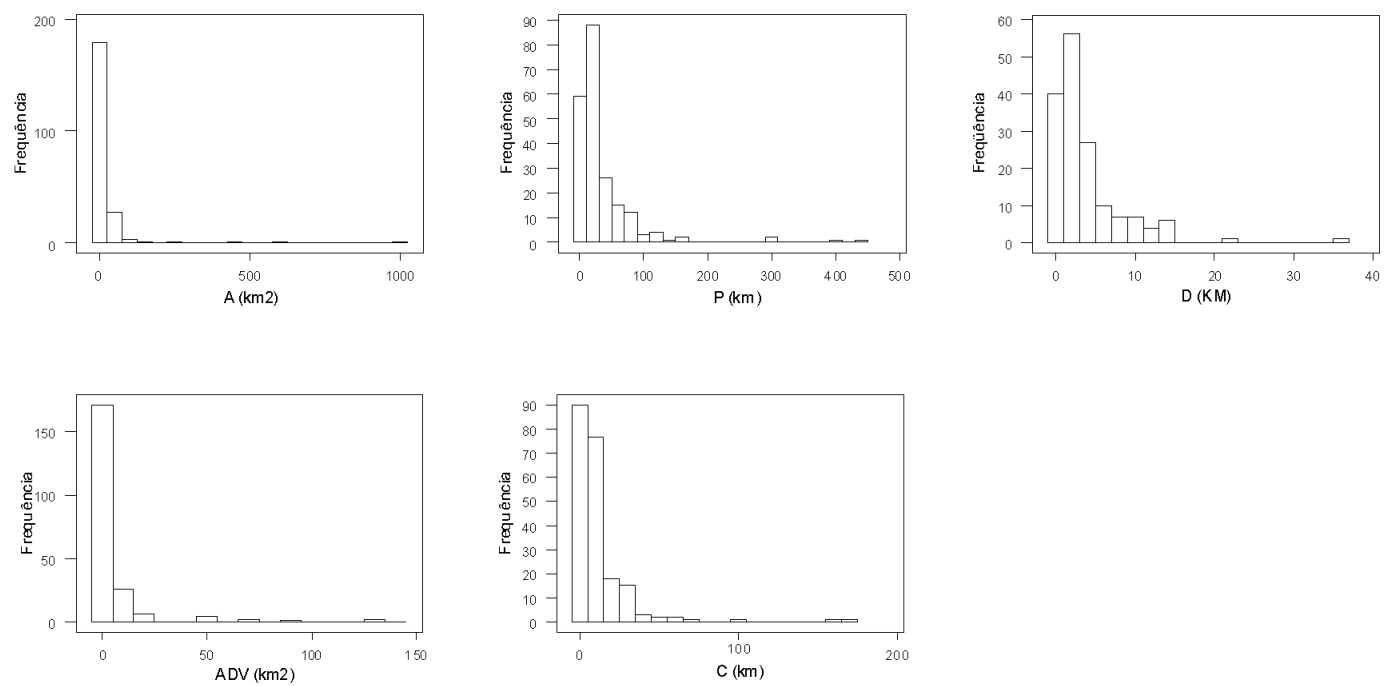

Figura 3.4 - Histogramas das variáveis A, P, ADV, D e C. Notar a elevada assimetria positiva e concentração dos dados em pequeno intervalo, apesar da distribuição de freqüências envolver longa amplitude.

A partir das variáveis $\mathrm{A}, \mathrm{P}, \mathrm{ADV}, \mathrm{D}$ e $\mathrm{C}$ obtiveram-se as variáveis $P / \sqrt{A}, \mathrm{ADV} / \mathrm{A}, \mathrm{D} / \mathrm{C}$ e A/C. Estas variáveis também apresentam assimetria positiva, sendo que a assimetria da variável $\mathrm{A} / \mathrm{C}$ é maior que a assimetria das demais variáveis (Tabela 3.2). A variável $\mathrm{A} / \mathrm{C}$ também distingue-se pelo desvio padrão ser maior que a média. A proporção de áreas de deflação ou recobertas por vegetação apresenta distribuição mais uniforme para valores inferiores a 0,4. Destaca-se ainda a grande semelhança entre as distribuições de freqüências das variáveis $P / \sqrt{A}$ e D/C (Figura 3.5).

\begin{tabular}{|c|l|l|l|l|l|l|l|l|l|}
\hline Variável & \multicolumn{1}{|c|}{ Média } & $\begin{array}{c}\text { Desvio } \\
\text { padrão }\end{array}$ & $\begin{array}{c}\text { Primeiro } \\
\text { quartil }\end{array}$ & Mediana & $\begin{array}{c}\text { Terceiro } \\
\text { quartil }\end{array}$ & Mínimo & Máximo & Assimetria & N \\
\hline $\begin{array}{c}\mathrm{A} / \mathrm{C} \\
(\mathrm{km} 2 / \mathrm{km})\end{array}$ & 0,84 & 1,30 & 0,19 & 0,40 & 1,10 & 0,06 & 14,50 & 6,24 & 211 \\
\hline $\begin{array}{c}P / \sqrt{A} \\
(\mathrm{~km} / \mathrm{km} 2)\end{array}$ & 11,74 & 4,94 & 8,35 & 10,36 & 13,95 & 5,10 & 33,93 & 1,61 & 214 \\
\hline $\begin{array}{c}\mathrm{ADV} / \mathrm{A} \\
\mathrm{km} 2 / \mathrm{km} 2)\end{array}$ & 0,24 & 0,19 & 0,09 & 0,21 & 0,34 & 0,00 & 0,95 & 1,00 & 207 \\
\hline $\begin{array}{c}\mathrm{D} / \mathrm{C} \\
\mathrm{km} / \mathrm{km})\end{array}$ & 0,43 & 0,40 & 0,15 & 0,33 & 0,57 & 0,01 & 2,76 & 2,35 & 157 \\
\hline
\end{tabular}

Tabela 3.2 - Estatísticas descritivas das variáveis $\mathrm{A} / \mathrm{C}, P / \sqrt{A}, \mathrm{ADV} / \mathrm{A}$ e $\mathrm{D} / \mathrm{C}$. 

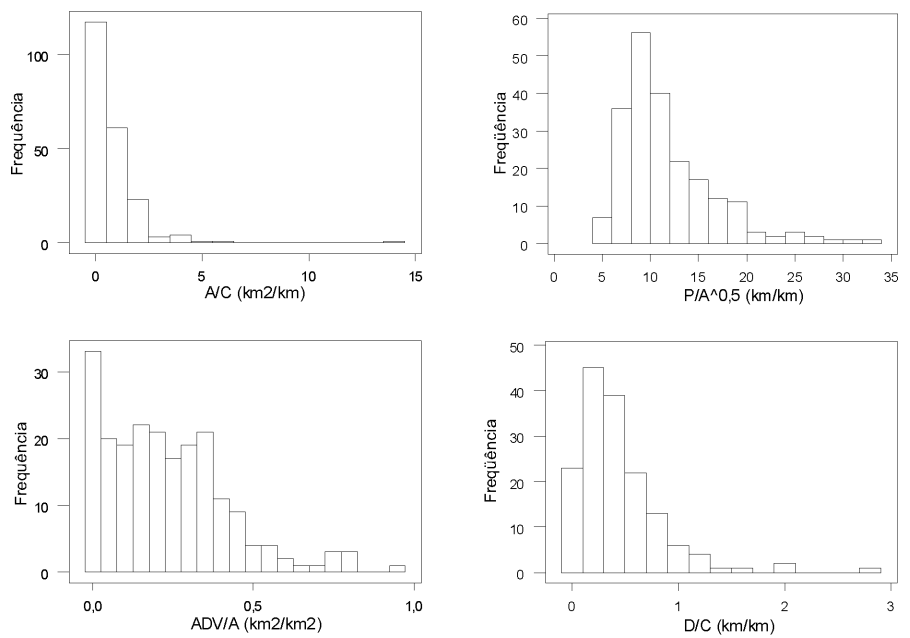

Figura 3.5 - Histogramas das variáveis $\mathrm{A} / \mathrm{C}, P / \sqrt{A}\left(\mathrm{P} / \mathrm{A}^{\wedge} 0,5\right)$ e $\mathrm{ADV} / \mathrm{A}$. A distribuição de freqüências da variável $\mathrm{A} / \mathrm{C}$ é semelhante às distribuições das variáveis $\mathrm{A}, \mathrm{P}, \mathrm{C}$ e $\mathrm{ADV}$. Já as variáveis $P / \sqrt{A}$ e ADV/A apresentam distribuições de menor assimetria e diferenças entre os diversos percentis também são menores.

Todas estas variáveis têm como característica comum a elevada variabilidade, de modo que os campos de dunas da costa brasileira constituem população heterogênea no que diz respeito à forma externa, tamanho relativo e morfologia interna (caracterizada pela proporção de áreas de deflação ou vegetadas). As distribuições de freqüências, caso exponenciais, indicariam que as variáveis A, P, C, ADV e A/C seguem leis de potência. Segundo Bak (1997), isto pode ser interpretado como produto da dinâmica de sistemas complexos com criticalidade auto-organizada (cap.1).

O ângulo entre o rumo de avanço dos campos de dunas e a linha de costa $(\alpha)$ apresenta valor médio de $41,15^{\circ}$, moda próxima a $45^{\circ}$ e variância circular relativamente baixa $(0,08)$ (Tabela 3.3). Esta variável apresenta distribuição de freqüências unimodal quase simétrica, semelhante à distribuição de Von Mises (Figura 3.6). A distribuição de Von Mises equivale à distribuição normal, porém descreve variáveis angulares (Mardia, 1972). 


\begin{tabular}{|l|l|l|l|l|l|}
\hline Variável & Ângulo médio & $\begin{array}{l}\text { Magnitude do } \\
\text { vetor ângulo } \\
\text { médio }\end{array}$ & $\begin{array}{l}\text { Variância } \\
\text { circular }\end{array}$ & $\begin{array}{l}\text { Desvio padrão } \\
\text { circular }\end{array}$ & $\mathbf{N}$ \\
\hline$\alpha$ & $41,15^{\circ}$ & 0,92 & 0,08 & $23,37^{\circ}$ & 138 \\
\hline
\end{tabular}

Tabela 3.3 - Estatísticas descritivas do ângulo entre o rumo de avanço do campos de dunas e direção da linha de costa $(\alpha)$.

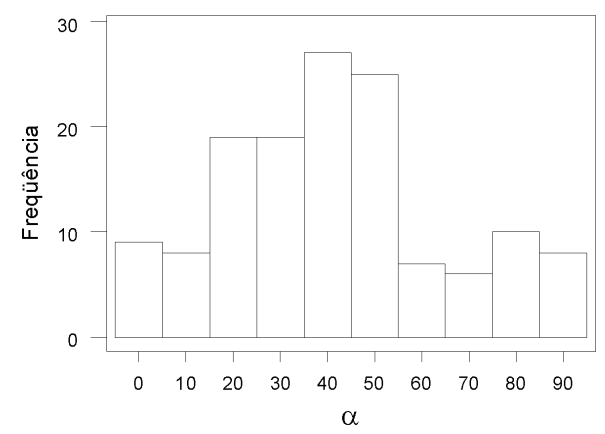

Figura 3.6 - Histograma da variável $\alpha$. Distribuição unimodal simétrica semelhante à distribuição de Von Mises.

O ângulo entre o rumo de avanço dos campos de dunas e a linha de costa apresenta moda próxima a $45^{\circ}$. Campos de dunas com rumo de avanço subparalelo ou perpendicular à costa são menos freqüentes. $\mathrm{O}$ transporte eólico subparalelo à costa pode desfavorecer a permanência dos sedimentos no campo de dunas, pois a proximidade à costa por mais tempo favoreceria o retorno dos sedimentos para face litorânea pela ação das ondas. Ângulos próximos a $90^{\circ}$ também não seriam os mais favoráveis para alimentação dos campos de dunas, já que a distância de área fonte percorrida pelo vento seria menor. Caso a zona intermaré seja estreita, a distância percorrida pelo vento pode não ser suficiente para saturá-lo em sedimentos, de modo que sua capacidade de transporte não seria completamente preenchida. Assim, haveria dois extremos desfavoráveis, de modo que ângulos próximos a $45^{\circ}$ configurariam a situação mais favorável à alimentação e manutenção de sedimentos nos campos de dunas por situar-se equidistante aos dois extremos desfavoráveis. Logo, a orientação do vento em relação à direção da linha de costa pode constituir fator que afeta a dinâmica de formação e manutenção de campos de dunas costeiros. Mudanças na orientação do vento ou da linha de costa poderiam implicar tanto formação quanto destruição e estabilização de campos de dunas. A relação entre o rumo de avanço dos campos de dunas e a direção da linha de costa pode ser útil por exemplo para estudos de paleogeografia, já que 
permitiria inferir direção preferencial da linha de costa a partir do rumo de migração de dunas costeiras, que pode ser estimado através da análise de rumos de mergulho de estratificações cruzadas.

\subsubsection{Análise de agrupamento dos campos de dunas}

Os campos de dunas medidos foram agrupados segundo as variávies $\mathrm{A} / \mathrm{C}, \mathrm{ADV} / \mathrm{A}, \mathrm{D} / \mathrm{C}$ e $P / \sqrt{A}$. A análise de agrupamento revelou a existência de quatro grupos principais de campos de dunas (Figura 3.7). A similaridade entre os elementos de cada grupo é variável de modo que estes grupos, exceto o grupo 4 que é composto apenas por um elemento (campo de dunas dos Lençóis Maranhenses), podem ser subdividos em subgrupos. Desta forma, têm-se três grupos heterogêneos de campos de dunas bem distintos entre si e um campo de dunas de características bem particulares.

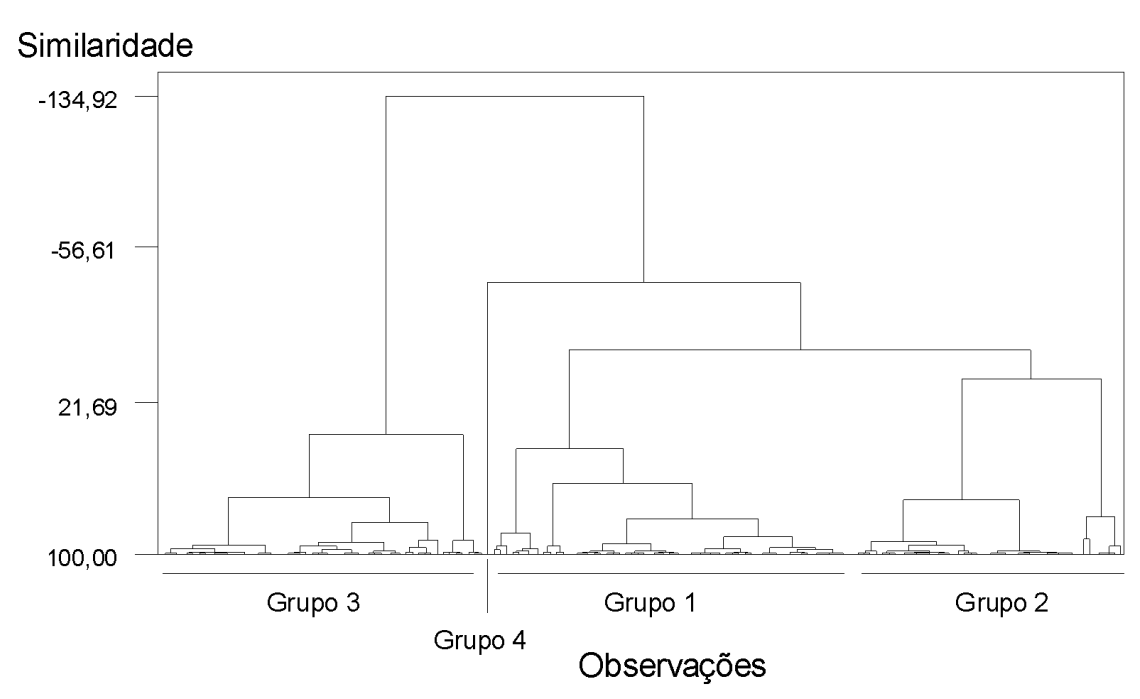

Figura 3.7 - Dendrograma da análise de agrupamento realizada a partir das variáveis $\mathrm{A} / \mathrm{C}$, ADV/A, D/C e $P / \sqrt{A}$. Utilizaram-se o método de Ward e a distância euclidiana ao quadrado. A similaridade máxima entre observações equivale a 100. Quatro grupos principais são reconhecidos, sendo que estes grupos podem ser divididos em subgrupos.

O campo de dunas dos Lençóis Maranhenses (grupo 4) distingue-se dos 214 campos de dunas analisados por apresentar elevado tamanho relativo e pequena proporção de zonas de deflação ou vegetadas. Este campo de dunas será analisado de forma mais detalhada nas seções 
seguintes. O tamanho relativo $(\mathrm{A} / \mathrm{C})$ dos campos de dunas que compõem os grupos 1,2 e 3 é semelhante, sendo que o tamanho médio diminui do grupo 1 para o grupo 3. A característica distintiva do grupo 1 são os campos de dunas com elevada proporção de zonas de deflação ou vegetadas e formas menos alongadas. Os campos de dunas do grupo 2 também correspondem a formas menos alongadas, porém distinguem-se dos campos de dunas do grupo 1 pela elevada distância relativa de migração (D/C). A característica marcante do grupo 3 são os campo de dunas alongados com pequena distância relativa de avanço. Apesar da proporção de zonas de deflação ou vegetadas dos grupos 2 e 3 atingir valores próximos a 0,5 , esta apresenta valores menores que os observados no grupo 1. As estatísticas descritivas das variáveis $\mathrm{A} / \mathrm{C}, \mathrm{ADV} / \mathrm{A}$, $P / \sqrt{A}$ e D/C para cada grupo encontram-se nas tabelas 3.4 a 3.7 .

Fato que chama a atenção é que apenas a variável D/C é capaz de discriminar os quatro grupos entre si. Isto pode ser observado nos gráficos da Figura 3.8, onde somente os valores médios da variável D/C não se sobrepõem pelo intervalo de variação (variabilidade).
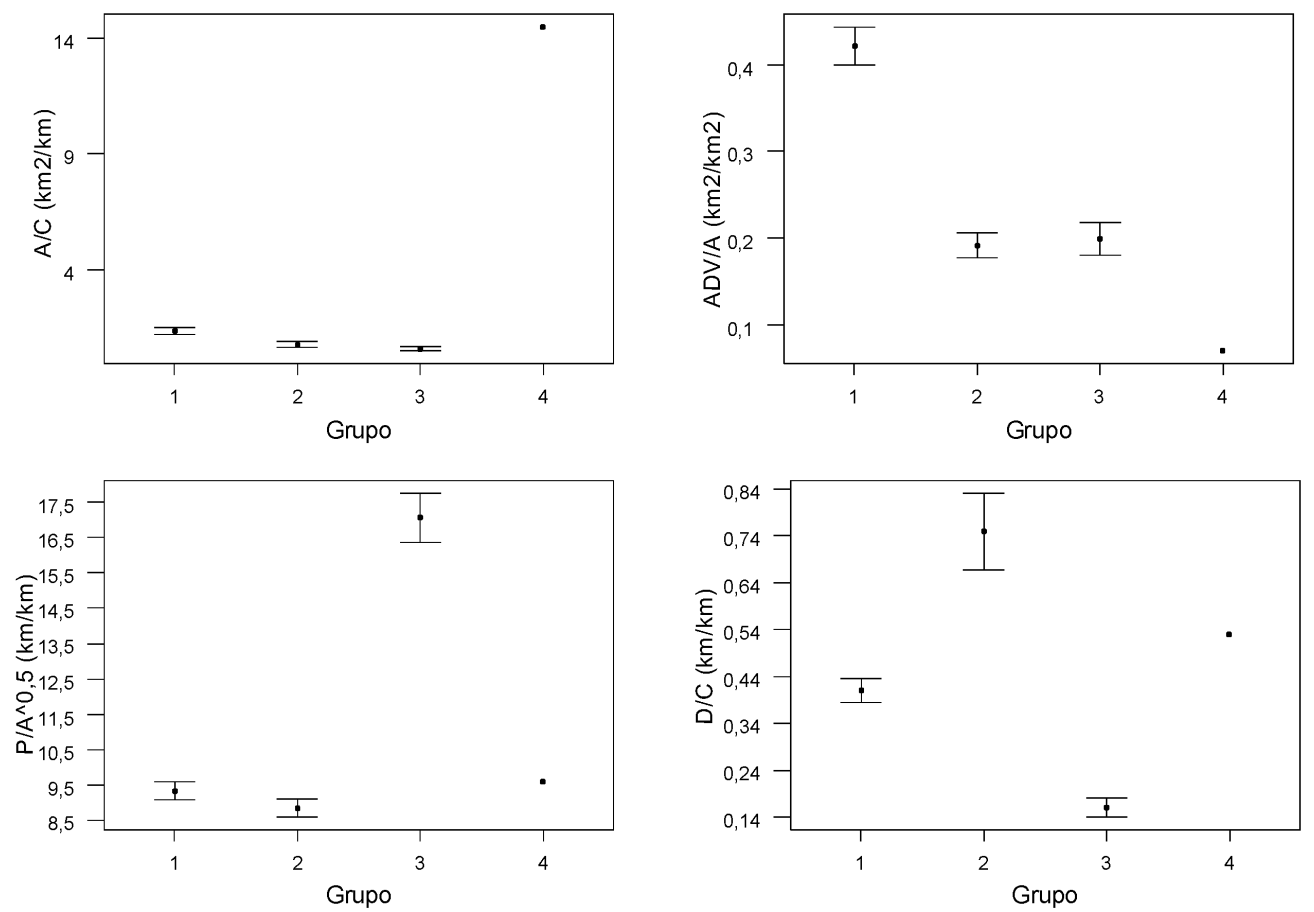

Figura 3.8 - Comparação entre os grupos 1, 2, 3 e 4 . O ponto central é o valor médio e as barras correspondem ao erro padrão da média (erro padrão $=$ desvio padrão $\sqrt{N}$ ). 


\begin{tabular}{|l|l|l|l|l|l|l|l|l|l|}
\hline \multicolumn{2}{|c|}{ A/C } \\
\hline Grupo & Média & $\begin{array}{l}\text { Desvio } \\
\text { padrão }\end{array}$ & $\begin{array}{l}\text { Primeiro } \\
\text { quartil }\end{array}$ & Mediana & $\begin{array}{l}\text { Terceiro } \\
\text { quartil }\end{array}$ & Mínimo & Máximo & Assimetria & $\mathbf{N}$ \\
\hline 1 & 1,35 & 1,13 & 0,56 & 1,10 & 1,76 & 0,11 & 5,51 & 1,75 & 58 \\
\hline 2 & 0,77 & 0,81 & 0,26 & 0,47 & 1,10 & 0,17 & 4,37 & 2,80 & 43 \\
\hline 3 & 0,58 & 0,68 & 0,17 & 0,34 & 0,72 & 0,08 & 3,85 & 2,92 & 52 \\
\hline 4 & 14,50 & $*$ & $*$ & 14,50 & $*$ & 14,50 & 14,50 & $*$ & 1 \\
\hline
\end{tabular}

Tabela 3.4 - Estatísticas descritivas da variável A/C para os grupos 1, 2, 3 e 4.

\begin{tabular}{|l|l|l|l|l|l|l|l|l|l|}
\hline \multicolumn{2}{|c|}{ ADV/A } \\
\hline Grupo & Média & $\begin{array}{l}\text { Desvio } \\
\text { padrão }\end{array}$ & $\begin{array}{l}\text { Primeiro } \\
\text { quartil }\end{array}$ & Mediana & $\begin{array}{l}\text { Terceiro } \\
\text { quartil }\end{array}$ & Mínimo & Máximo & Assimetria & $\mathbf{N}$ \\
\hline 1 & 0,42 & 0,17 & 0,31 & 0,38 & 0,48 & 0,19 & 0,95 & 1,28 & 58 \\
\hline 2 & 0,19 & 0,10 & 0,12 & 0,17 & 0,25 & 0,00 & 0,41 & 0,50 & 43 \\
\hline 3 & 0,20 & 0,13 & 0,07 & 0,21 & 0,32 & 0,00 & 0,51 & 0,26 & 52 \\
\hline 4 & 0,07 & $*$ & $*$ & 0,07 & $*$ & 0,07 & 0,07 & $*$ & 1 \\
\hline
\end{tabular}

Tabela 3.5 - Estatísticas descritivas da variável ADV/A para os grupos 1, 2, 3 e 4.

\begin{tabular}{|l|l|l|l|l|l|l|l|l|l|}
\hline \multicolumn{2}{|c|}{$P / \sqrt{A}$} \\
\hline Grupo & Média & $\begin{array}{l}\text { Desvio } \\
\text { padrão }\end{array}$ & $\begin{array}{l}\text { Primeiro } \\
\text { quartil }\end{array}$ & Mediana & $\begin{array}{l}\text { Terceiro } \\
\text { quartil }\end{array}$ & Mínimo & Máximo & Assimetria & $\mathbf{N}$ \\
\hline 1 & 9,34 & 1,92 & 7,85 & 9,27 & 10,77 & 5,20 & 15,53 & 0,31 & 58 \\
\hline 2 & 8,86 & 1,73 & 7,57 & 8,74 & 10,43 & 5,11 & 12,23 & $-0,02$ & 43 \\
\hline 3 & 17,06 & 5,05 & 13,47 & 15,54 & 18,67 & 11,06 & 33,93 & 1,51 & 52 \\
\hline 4 & 9,60 & $*$ & $*$ & 9,60 & $*$ & 9,60 & 9,60 & $*$ & 1 \\
\hline
\end{tabular}

Tabela 3.6 - Estatísticas descritivas da variável $P / \sqrt{A}$ para os grupos 1, 2, 3 e 4 .

\begin{tabular}{|l|l|l|l|l|l|l|l|l|l|}
\hline \multicolumn{2}{|c|}{$\mathrm{D} / \mathrm{C}$} \\
\hline Grupo & Média & $\begin{array}{l}\text { Desvio } \\
\text { padrão }\end{array}$ & $\begin{array}{l}\text { Primeiro } \\
\text { quartil }\end{array}$ & Mediana & $\begin{array}{l}\text { Terceiro } \\
\text { quartil }\end{array}$ & Mínimo & Máximo & Assimetria & N \\
\hline 1 & 0,41 & 0,20 & 0,27 & 0,39 & 0,52 & 0,03 & 1,22 & 1,22 & 58 \\
\hline 2 & 0,75 & 0,54 & 0,32 & 0,69 & 0,94 & 0,15 & 2,76 & 1,73 & 43 \\
\hline 3 & 0,16 & 0,15 & 0,06 & 0,11 & 0,20 & 0,01 & 0,63 & 1,69 & 52 \\
\hline 4 & 0,53 & $*$ & $*$ & 0,53 & $*$ & 0,53 & 0,53 & $*$ & 1 \\
\hline
\end{tabular}

Tabela 3.7 - Estatísticas descritivas da variável D/C para os grupos 1, 2, 3 e 4.

Na Figura 3.9 são exibidas imagens de campos de dunas dos grupos 1, 2 e 3 e dos Lençóis Maranhenses (grupo 4). Deve ser chamada atenção para o fato de que os grupos 1, 2 e 3 
correspondem a conjuntos de campos de dunas. Assim, os exemplos apresentados na Figura 3.9 ilustram apenas campos de dunas mais típicos de cada grupo.

Os grupos de campos de dunas 1, 2 e 3, definidos pela análise de agrupamento, possuem representantes em todos os setores da costa brasileira. Isto sugere que apesar das diferenças fisiográficas e climáticas existentes entre os diversos setores da costa, a interação entre as variáveis responsáveis pelo desenvolvimento de campos de dunas gera produtos de tamanho e morfologia semelhantes. Ou seja, tamanho e morfolgia dependeriam muito mais da interação entre fatores do que de fatores isolados. Assim, por exemplo, campos de dunas de tamanho elevado se desenvolveriam tanto em áreas de clima úmido quanto em áreas secas.

Se for considerado o grande número de campos de dunas envolvidos na análise de agrupamento e a elevada variabilidade das variáveis morfométricas utilizadas para descrevê-los, o fato de existir apenas quatro grupos maiores de campos de dunas pode ter significado importante para a compreensão da dinâmica de sistemas eólicos costeiros. Assim, a variabilidade de tamanho e morfologia dos campos de dunas pode ser menor que a variablidade das variáveis responsáveis pelo desenvolvimento destes campos de dunas. Deste modo, mesmo que a dinâmica resulte da interação entre variáveis de elevada variabilidade, como por exemplo o regime de ventos e de chuvas, a variabilidade destas variáveis não é impressa nos produtos gerados pelo sistema eólico. Este comportamento pode indicar a existência de limites a serem superados para que a atuação de determinadas variáveis seja efetiva para o sistema. Neste caso, a variabilidade da dinâmica do sistema seria menor que a das variáveis responsáveis pelo funcionamento do sistema. Por exemplo, o transporte de areia pelo vento só ocorre se certo valor de velocidade for superado. Esta velocidade limite depende do tamanho dos grãos e do grau de coesão da areia, que pode ser função de diversos fatores. Tanto a velocidade do vento quanto a velocidade limite para haver transporte podem ser altamente variáveis. No entanto, apenas a variabilidade do período em que a velocidade do vento superar a velocidade limite interferirá nos produtos gerados pela dinâmica do sistema eólico.

A análise de agrupamento tornou evidente o caráter particular do campo de dunas dos Lençóis Maranhenses. Esta particularidade indica que fatores locais podem ser bastante importantes para o desenvolvimento de sistemas eólicos. 

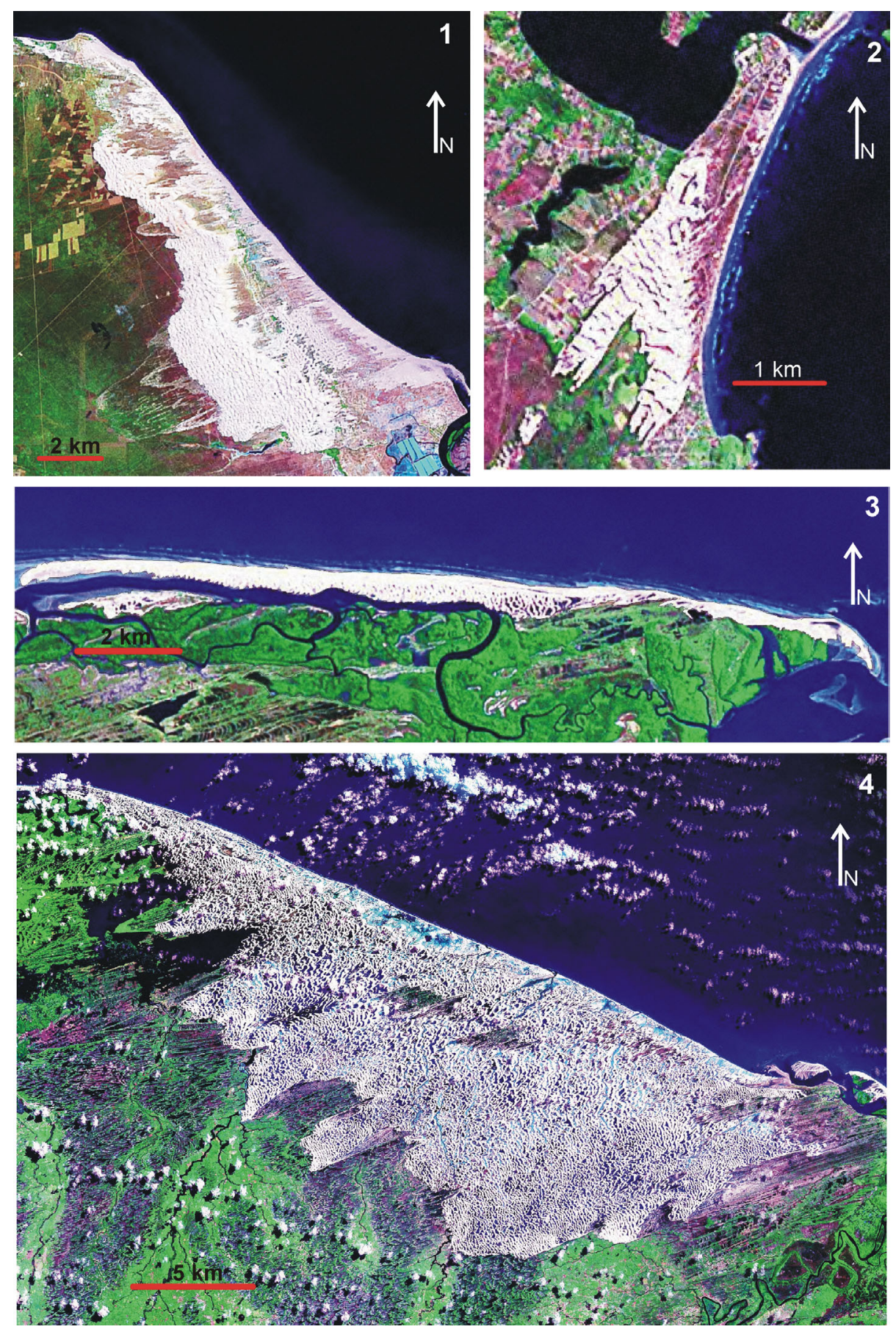

Figura 3.9 - Exemplos de campos de dunas pertencentes aos grupos 1, 2, 3 e 4. 1) Campo de dunas adjacente às praias da Pedra Branca, do Rosado e Porto de Mangues (Porto de Mangues, $\mathrm{RN})$. As principais características são a elevada razão $\mathrm{A} / \mathrm{C}$ e a alta proporção de áreas de deflação ou vegetadas $(\mathrm{A} / \mathrm{C}=5,51, \mathrm{ADV} / \mathrm{A}=0,28, P / \sqrt{A}=8,00$ e $\mathrm{D} / \mathrm{C}=0,68)$. 2) Campo de dunas da praia de Ibiraqüera (Imbituba, SC). Notar a elevada distância relativa de avanço $(\mathrm{A} / \mathrm{C}=1,04$, $\mathrm{ADV} / \mathrm{A}=0,37, P / \sqrt{A}=8,32$ e $\mathrm{D} / \mathrm{C}=1,17)$. 3) Campo de dunas da Ilha das Canárias (MA), que se situa a oeste da foz do rio Parnaíba. A característica marcante dos campos de dunas deste grupo são os altos valores de $P / \sqrt{A}$, indicativos de campos de dunas mais alongados $(\mathrm{A} / \mathrm{C}=0,36$, 
$\mathrm{ADV} / \mathrm{A}=0,01, P / \sqrt{A}=16,00$ e $\mathrm{D} / \mathrm{C}=0,34)$. 4) Campo de dunas dos Lençóis Maranhenses (MA). Trata-se do maior campo de dunas da costa brasileira, o qual apresenta como traços peculiares a elvadíssima razão $\mathrm{A} / \mathrm{C}$ e a baixa proporção de áreas de deflação ou vegetadas $(\mathrm{A} / \mathrm{C}=14,50$, $\mathrm{ADV} / \mathrm{A}=0,07, P / \sqrt{A}=9,60$ e $\mathrm{D} / \mathrm{C}=0,53)$.

\subsubsection{Distribuição geográfica dos campos de dunas da costa brasileira}

Em relação à distribuição dos campos de dunas, a costa brasileira pode ser dividida em três setores (1, 2 e 3), os quais abrangem campos de dunas de tamanho e morfologia variada. Estes setores são separados entre si por amplas zonas desprovidas de campos de dunas. Os setores 1 e 3 destacam-se em relação ao setor 2 por contemplarem campos de dunas maiores e em quantidade mais elevada. Estes três setores apresentam características climáticas, fisiográficas e oceanográficas distintas. $\mathrm{O}$ setor 1 corresponde à parcela da costa setentrional e da costa leste (estados do Maranhão, Piauí, Ceará e Rio Grande do Norte). O setor 2 está contido na costa leste e abrange parte da costa da região nordeste (estados da Paraíba, Pernambuco, Alagoas, Sergipe e Bahia) e parte da costa da região sudeste (Espírito Santo, Rio de Janeiro e São Paulo). O setor 3 insere-se na costa sul, sendo formado pela região costeira dos estados do Paraná, Santa Catarina e Rio Grande do Sul.

\subsubsection{Setor 1 (Maranhão, Piauí, Ceará e Rio Grande do Norte)}

Neste setor, a costa apresenta as seguintes orientações maiores (de oeste para leste): E-W, NW-SE, E-W e N-S. A amplitude de maré é variável (aproximadamente 2 a até mais de $6 \mathrm{~m}$ ), sendo que há predomínio de regime de mesomaré (amplitude de 2 a $4 \mathrm{~m}$ ). Zona de macromaré ocorre apenas na sua porção oeste (a oeste da Ponta dos Mangues, MA). Na maior parte, o clima é tropical, com quatro a seis meses secos e chuvas concentradas no verão. Zona de clima semiárido (sete a oito meses secos) ocorre na costa dos estados do Ceará e Rio Grande do Norte. Neste clima, as chuvas também se concentram no verão, porém pode apresentar longos períodos de estiagem (três a quatro anos) (IBGE, 1992). Na costa maranhense, os ventos mais freqüentes são os de leste, cuja velocidade média varia entre 5,7 e $8,2 \mathrm{~m} / \mathrm{s}$ (Tabela 3.8). No mês de janeiro (representativo do verão), a freqüência média dos ventos de leste é de $64 \%$, sendo também importantes os ventos de nordeste (33\%), que atuam com velocidades mais moderadas $(3,6$ a 5,1 
$\mathrm{m} / \mathrm{s}$ ). No mês de julho (representativo do inverno), há diminuição da freqüência dos ventos de leste $(44 \%)$ e de nordeste e aumento da freqüência dos ventos de sudeste (25\%). Na região leste deste setor (costa do Ceará e Rio Grande do Norte), os ventos de leste são dominantes somente no verão, período em que atuam com velocidade média mais baixa $(3,6$ a $5,1 \mathrm{~m} / \mathrm{s})$. No inverno, ventos de sudeste são mais freqüentes (58\%) e velozes $(5,7$ a 8,2 m/s) (Tabela 3.9).

\begin{tabular}{|c|c|c|c|c|c|c|c|c|}
\hline \multicolumn{9}{|c|}{ Mês de Janeiro } \\
\hline Octante & $\mathrm{N}$ & $\mathrm{S}$ & $\mathrm{E}$ & $\mathrm{W}$ & $\mathrm{NE}$ & $\mathrm{SE}$ & SW & NW \\
\hline Freqüência (\%) & $*$ & $*$ & 64 & $*$ & 33 & $*$ & $*$ & $*$ \\
\hline Velocidade $(\mathrm{m} / \mathrm{s})$ & $*$ & $*$ & 5,7 a 8,2 & $*$ & 3,6 a 5,1 & $*$ & $*$ & $*$ \\
\hline \multicolumn{9}{|c|}{ Mês de julho } \\
\hline Octante & $\mathrm{N}$ & $\mathrm{S}$ & $E$ & $\mathrm{~W}$ & $\mathrm{NE}$ & SE & SW & NW \\
\hline Freqüência (\%) & $*$ & $*$ & 44 & 11 & 7 & 25 & $*$ & $*$ \\
\hline Velocidade $(\mathrm{m} / \mathrm{s})$ & $*$ & $*$ & 5,7 a 8,2 & 5,7 a 8,2 & 5,7 a 8,2 & 5,7 a 8,2 & $*$ & $*$ \\
\hline
\end{tabular}

Tabela 3.8 - Freqüência de atuação e velocidade média dos ventos de cada octante. Apenas os ventos com freqüência superior a 10\% estão representados. Dados coletados entre 1951 e 1972 na região entre São Luís (MA) e Luís Correia (PI) (DHN, 1974).

\begin{tabular}{|l|l|l|l|l|l|l|l|l|}
\hline \multicolumn{8}{|c|}{ Mês de Janeiro } \\
\hline Octante & N & S & E & W & NE & SE & SW & NW \\
\hline Freqüência (\%) & $*$ & $*$ & 54 & $*$ & $*$ & 29 & $*$ & $*$ \\
\hline Velocidade (m/s) & $*$ & $*$ & 3,6 a 5,1 & $*$ & $*$ & 3,6 a 5,1 & $*$ & $*$ \\
\hline \multicolumn{7}{|c|}{ Mês de julho } \\
\hline Octante & N & S & E & W & NE & SE & SW & NW \\
\hline Freqüência (\%) & $*$ & 11 & 26 & $*$ & $*$ & 58 & $*$ & $*$ \\
\hline Velocidade (m/s) & $*$ & 5,7 a 8,2 & 5,7 a 8,2 & $*$ & $*$ & 5,7 a 8,2 & $*$ & $*$ \\
\hline
\end{tabular}

Tabela 3.9 - Freqüência de atuação e velocidade média dos ventos de cada octante. Apenas os ventos com freqüência superior a 10\% estão representados. Dados coletados entre 1951 e 1972 na região de Fortaleza (DHN, 1974).

Os campos de dunas desta região ocorrem ao longo de toda costa, são formados principalmente por dunas barcanas ou cadeias barcanóides e apresentam grande variedade de tamanho. No entanto, é alta a proporção de campos de dunas de tamanho elevado, com destaque para o maior campo de dunas da costa brasileira (Lençóis Maranhenses). A proporção de áreas de deflação ou vegetadas é variável e predominam rumos de migração transversais oblíquos $\left(>30^{\circ}\right)$ em relação aos subparalelos à costa $\left(<30^{\circ}\right)$. Também pode haver zona com dunas parabólicas 
estabilizadas a sotavento, que pode ocupar área maior que a do próprio campo de dunas ativo adjacente.

A extremidade oeste deste setor é dominada por grandes baías estuarinas e seus campos de dunas são menores e restritos a praias situadas na face offshore de ilhas ou zonas interbaías. A leste da zona das grandes baías, a costa torna-se mais retilínea, com praias longas separadas por canais de maré e campos de dunas de tamanho maior (Figura 3.10).
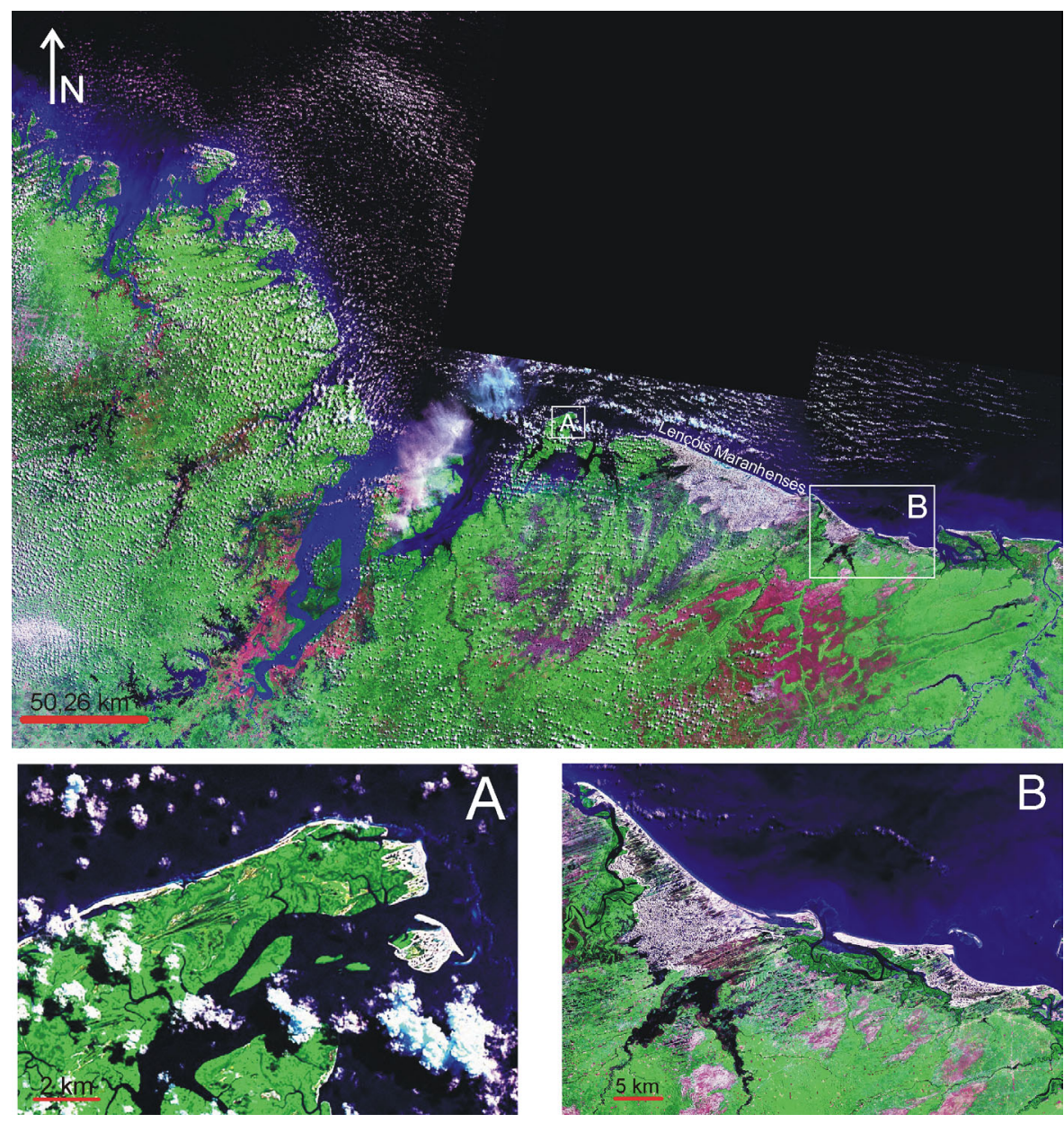

Figura 3.10 - A oeste dos Lençóis Maranhenses, a costa é caracterizada por baías estuarinas. Os campos de dunas deste trecho são menores e ocorrem em praias de ilhas ou zonas interbaías (A). A leste, a costa é mais retilínea, com campos de dunas maiores e separados por canais de maré (B).

$\mathrm{Na}$ costa norte, há campos de dunas que se encontram segmentados por canais de maré ou separados da linha de costa atual por zona com canais de maré, desprovida de feições eólicas 
(Figura 3.11). Eles podem ser considerados campos de dunas em processo de estabilização, pois estão desconectados da área fonte praial e ocupam pequena porção a sotavento de ampla área com feições eólicas reliquiares (retrocordões). Alguns campos de dunas apresentam áreas de dunas ativas a sotavento e barlavento separadas por zona com retrocordões. A zona de retrocordões, nesta região, tem maior eixo transversal ao sentido de avanço das dunas e constitui área mais plana, de modo que pode ser caminho preferencial para estabelecimento de canais de maré. O contato da zona de retrocordões com as áreas de dunas ativas poderia exercer papel de barragem e orientar os canais de maré. Assim, a formação de áreas de retrocordões favoreceria a fragmentação dos campos de dunas por canais de maré. Isto provocaria o isolamento de parte do campo de dunas da sua área fonte e restrição da área de avanço. A formação de retrocordões estaria ligada à variação do aporte e velocidade de migração das dunas. Períodos chuvosos diminuem a velocidade de migração das dunas por aumento da coesão da areia e a umidade das áreas interdunas diminui o aporte para a face de barlavento das dunas. A diminuição do aporte para a face de sotavento é menor, pois esta é alimentada por sedimentos da face de barlavento. Assim, o déficit de sedimentos, associado à umidade das zonas interdunas, propicia o desenvolvimento de vegetação no sopé da face de barlavento. O aporte éolico recupera-se em períodos secos subseqüentes e o aumento da velocidade de migração das dunas provoca o destacamento destas do sopé da face de barlavento vegetada. Esta vegetação atua como barreira para alimentação da face de barlavento, que produz pequeno acúmulo de areia e favorece ainda mais o destacamento da duna do seu sopé vegetado (Hesp, com verb.). Para que haja a formação de retrocordões, os perídos chuvosos e secos devem ter duração suficiente para o desenvolvimento de vegetação no sopé da face de barlavento. Assim, nem sempre a alternância entre períodos secos e chuvosos produziria retrocordões. A segmentação de campos de dunas por canais de maré também é favorecida pela intensidade da ação da maré. A costa norte reúne estas duas característica favoráveis à segmentação de campos de dunas por canais de maré, ou seja, existência de estações seca e chuvosas bem definidas e amplitude de maré elevada em relação aos demais trechos da costa brasileira. De modo menos freqüente há o fechamento de canais de maré transversais à costa pelo avanço de campos de dunas. Estas observações levam à suposição de que a ação das maré pode interferir na dinâmica de sistemas eólicos costeiros, seja na limitação do espaço para crescimento ou avanço de campos de dunas ou na separação entre estes e suas áreas fontes. 


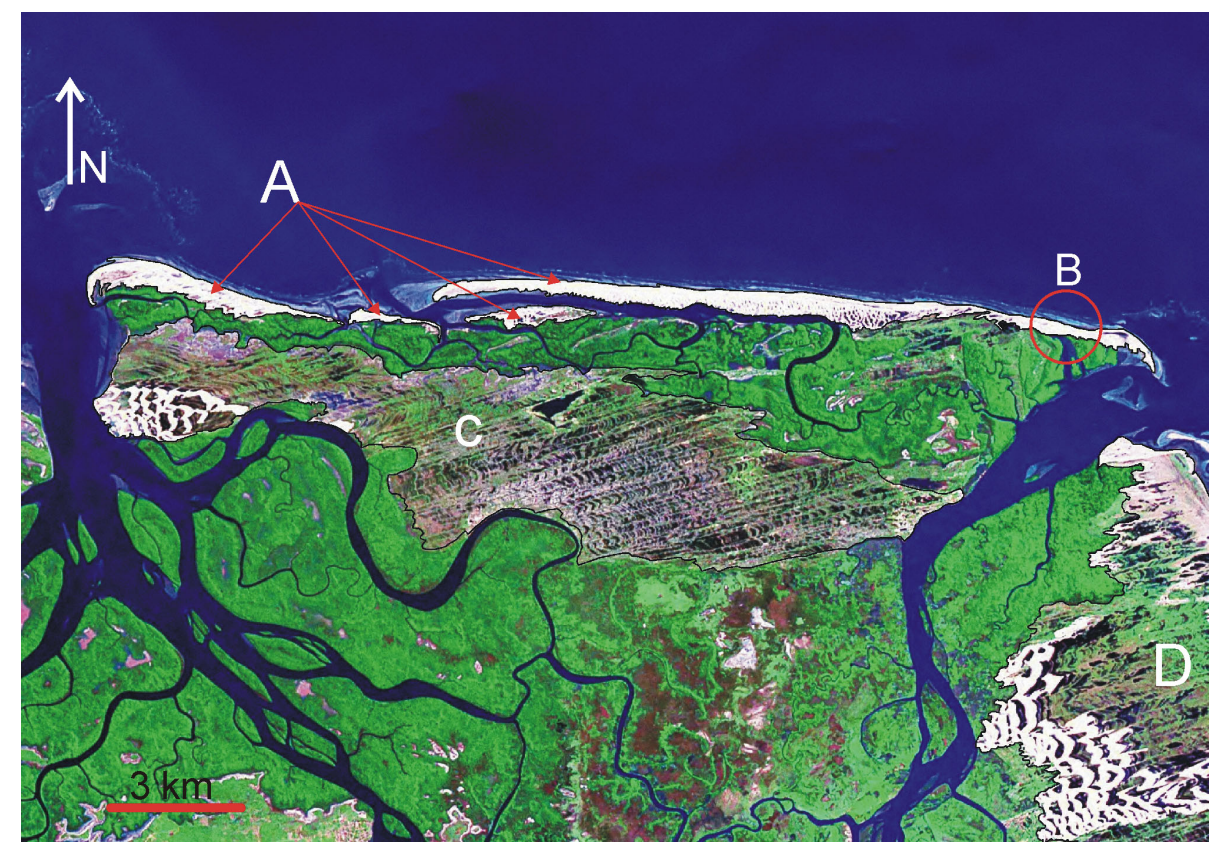

Figura 3.11 - Campos de dunas truncados por canais de maré na costa norte (Estado do Maranhão). A) Campos de dunas livres segmentados por canais de maré. B). Canal de maré barrado por campo de dunas. C) Área de retrocordões eólicos com campo de dunas em processo de estabilização a sotavento. Esta área é separada da linha de costa atual por zona com canais de maré desprovida de feições eólicas. D) Campo de dunas com zona de retrocordões (feições eólicas reliquiares), que separa áreas de dunas ativas a barlavento e sotavento.

Para leste, as zonas de retrocordões são reduzidas, sendo mais comum a presença de zonas de deflação desprovidas de formas eólicas reliquiares. Também torna-se incomum o isolamento de campos de dunas por canais de maré subparalelos à linha de costa. Há predomínio de canais de maré transversais à linha de costa, os quais são freqüentemente bloqueados pelo avanço dos campos de dunas (Figura 3.12). Isto pode ser atribuído à redução de intensidade da ação das marés e clima com estações seca e chuvosa menos definidas. 


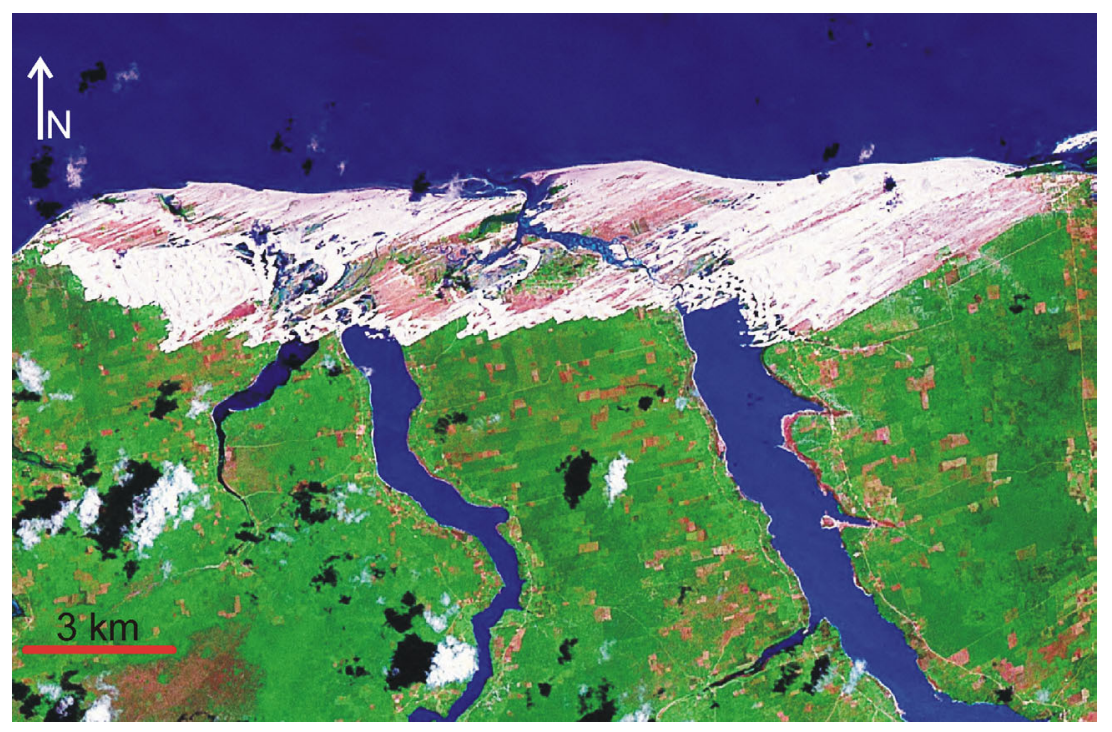

Figura 3.12 - Campo de dunas livres (barcanas e cadeias barcanóides) com zonas de deflação (Nova Tatajuba, CE). Notar os canais de maré transversais à linha de costa bloqueados pelo avanço do campo de dunas.

O rumo de migração dos campos de dunas varia entre SW e NW (Figura 3.13). Na porção oeste (até Jericoaquara, CE), o rumo predominante é o SW. A leste desta localidade, passam a ocorrer campos de dunas com rumo de avanço E, o qual predomina até a região de Areia Branca (RN). De Areia Branca até São Bento do Norte (RN), os campos de dunas voltam a migrar principalmente para SW. A oeste de São Bento do Norte, o rumo de avanço muda para NW, que persiste até o final deste setor. Estes rumos de migração são compatíveis com o sentido dos ventos de superfície atuantes neste setor: os ventos alísios de nordeste ou leste e de sudeste. A Zona de Convergência Intertropical separa os dominíos destes dois ventos e sua posição varia ao longo do ano (desloca-se para norte durante o inverno) de modo que a área de atuação destes dois ventos também é variável. Dados meteorológicos (DHN, 1974) indicam que no litoral maranhense os ventos mais freqüentes são os ventos de leste, seguidos pelos ventos de nordeste, que são os responsáveis pela formação da maior parte dos campos de dunas deste trecho. Os campos de dunas passam a migrar de acordo com os ventos mais freqüentes de leste apenas quando há mudança da orientação da linha de costa. A costa do Maranhão, Piauí e parte da costa do Ceará (até as proximidades de Aranaú) são de orientação aproximadamente E-W e apresentam apenas campos de dunas com rumo de migração para SW ou SW-W. A oeste de Aranaú (CE), a costa adquire direção NW-SE e seus campos de dunas passam a migrar para W até as proximidades de Areia Branca $(\mathrm{RN})$. A oeste de Areia Branca até São Miguel do Gostoso (RN), 
reaparecem os campos de dunas com rumo de migração SW. Neste trecho, a linha de costa volta a adquirir orientação próxima a E-W. A direção da linha de costa muda para orientações próximas a N-S a oeste de São Miguel do Gostoso (RN), a partir de onde os campos de dunas com rumo de migração NW passam a ser ubíquos. Porém, nesta zona, os ventos de sudeste passam a ser os mais freqüentes. Portanto, parece haver íntima relação entre a direção da linha de costa e o rumo de migração dos campos de dunas deste setor (Figura 3.14). Nos trechos com linha de costa de orientação E-W, os ventos de nordeste, mesmo não sendo os mais freqüentes, são os responsáveis pela formação dos campos de dunas. Nos trechos com linha de costa de orientação NW-SE, os ventos de leste (mais freqüentes) podem atuar no transporte eólico costeiro de modo que se tornam responsáveis pela formação dos campos de dunas. Quando a costa adquire orientação NW/N-SE/S, os predominantes passam a ser os ventos de sudeste, que são os responsáveis pelo avanço dos campos de dunas.

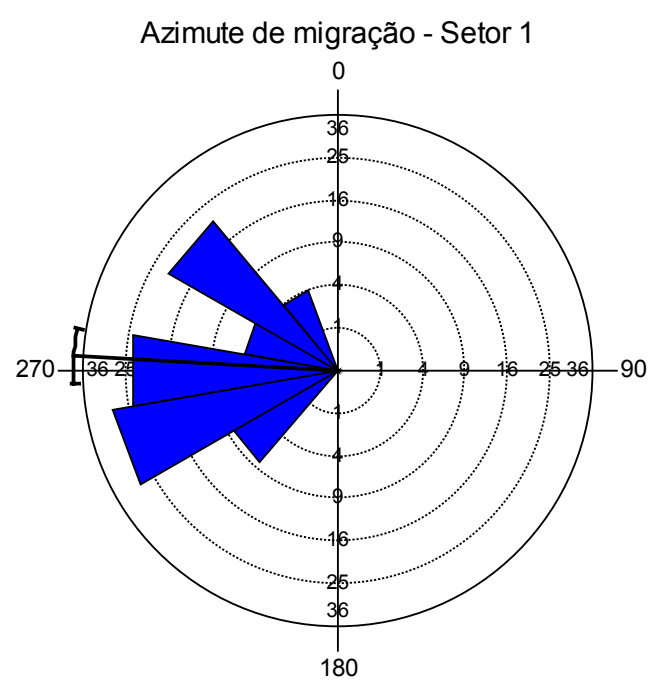

Figura 3.13 - Azimute de migração dos campos de dunas do primeiro setor. Os rumos mais freqüentes são SW-W, W e NW. Azimute médio $=273,09^{\circ}$, desvio padrão circular=29,1 ${ }^{\circ}, \mathrm{N}=91$. 


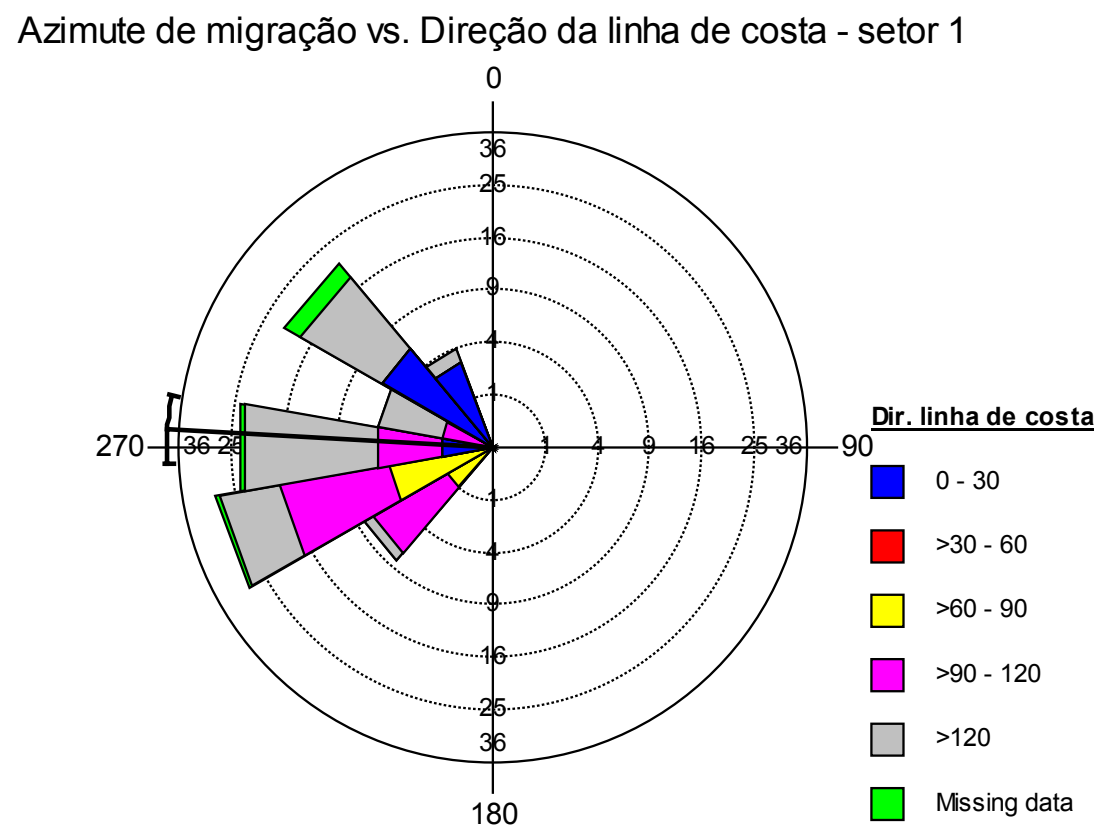

Figura 3.14 - Correlação entre a direção da linha de costa e o rumo de avanço dos campos de dunas. Notar que os campos de dunas com rumo de migração NW ou NW/N são predominantes em trechos de linha de costa com orientação mais próxima a N-S (0-30 e >120). Os campos de dunas com rumo de migração $\mathrm{SW}$ são mais freqüentes em regiões com linha de costa de orientação mais próxima a E-W (60-90 e 90-120).

Conclui-se que, neste setor, tanto os ventos de nordeste quanto os de leste e sudeste atuam sob condições propícias ao desenvolvimento de campos de dunas. A orientação da linha de costa em relação ao rumo dos ventos predominantes na superfície pode determinar o rumo de migração dos campos de dunas. No caso deste setor, por exemplo, os ventos de leste e sudeste são incapazes de atuarem como ventos de onshore em trechos com linha de costa de direção E-W. Já os ventos de nordeste podem atuar como ventos de onshore ao longo de toda costa do primeiro setor (orientação E-W, N-S e NW-SE). Estas relações têm impacto sobre o uso de rumos de mergulho de estraficações cruzadas, medidas em arenitos eólicos, na reconstrução da paleocirculação atmosférica, pois o vento predominante na superfície pode não ser o registrado pela sedimentação eólica.

Em relação ao ângulo entre o rumo de migração dos campos de dunas e a direção da linha de costa $(\alpha)$, predominam ângulos próximos à $45^{\circ}$ (Figura 3.15). Isto pode ser fator favorável ao tamanho relativo elevado dos campos de dunas deste setor, pois segundo a relação proposta anteriormente, $45^{\circ}$ seria o ângulo de máxima eficiência de transporte de sedimentos para o campo de dunas. 


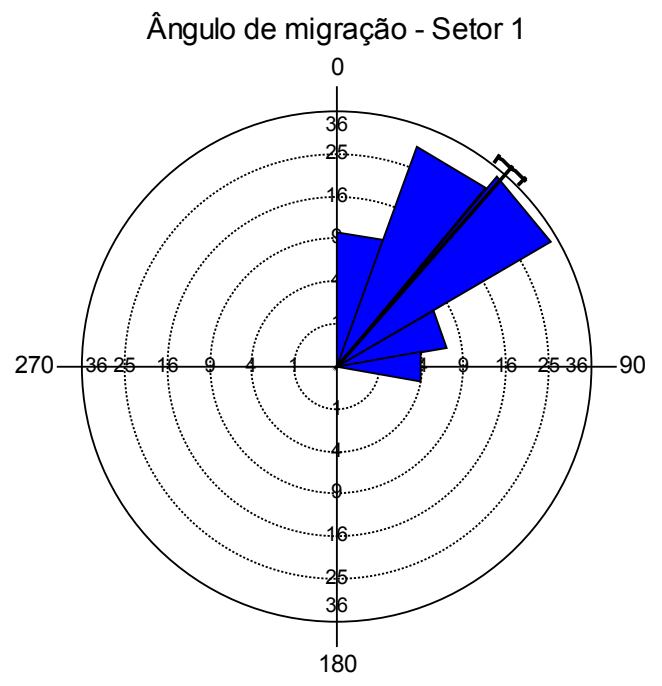

Figura 3.15 - Ângulo entre o rumo de migração dos campos de dunas e a direção da linha de costa $(\alpha)$. Notar o predomínio de valores próximos à $45^{\circ}$. Ângulo médio $=41,33^{\circ}$; Desvio padrão circular $=17,51^{\circ} ; \mathrm{N}=85$.

\subsubsection{Setor 2 (Alagoas, Sergipe, Bahia, Espírito Santo, Rio de Janeiro e São Paulo)}

Este setor situa-se em região de clima tropical úmido litorâneo. As chuvas são bem distribuídas ao longo do ano, sendo que o número de meses secos varia de zero a três. A costa deste setor encontra-se sob regime de mesomaré a norte e micromaré a sul. A norte, a costa é mais retilínea e marcada pela presença de falésias da Formação Barreiras, que são interrompidas pela desembocadura de grandes rios (São Franscisco, Jequitinhonha, Doce e Paraíba do Sul). A sul, a costa é mais recortada e tem como característica peculiar a proximidade à serra do Mar no litoral do Estado de São Paulo. Na região costeira entre Salvador (BA) e Aracaju (SE) o vento leste é dominante (49\%) no verão (mês de janeiro), seguido pelo vento nordeste (26\%). No inverno (julho), o ventos de sudeste passam a ser dominantes (43\%) e os ventos de leste passam a ter freqüência de atuação secundária (36\%) (Tabela 3.10). Na região de Cabo Frio (RJ), o vento nordeste é dominante no inverno (29\%) e verão (32\%). Os ventos de norte e de leste apesar de menos freqüentes, também são importantes em ambos os períodos (Tabela 3.11). 


\begin{tabular}{|c|c|c|c|c|c|c|c|c|}
\hline \multicolumn{9}{|c|}{ Mês de Janeiro } \\
\hline Octante & $\mathrm{N}$ & $\mathrm{S}$ & $\mathrm{E}$ & $\mathrm{W}$ & $\mathrm{NE}$ & SE & SW & NW \\
\hline Freqüência (\%) & * & * & 49 & * & 26 & 14 & * & * \\
\hline Velocidade $(\mathrm{m} / \mathrm{s})$ & * & * & 3,6 a 5,1 & * & 3,6 a 5,1 & 3,6 a 5,1 & * & * \\
\hline \multicolumn{9}{|c|}{ Mês de julho } \\
\hline Octante & $\mathrm{N}$ & $\mathrm{S}$ & $\mathrm{E}$ & $\mathrm{W}$ & $\mathrm{NE}$ & SE & SW & NW \\
\hline Freqüência (\%) & * & 13 & 36 & $*$ & $*$ & 43 & $*$ & * \\
\hline Velocidade $(\mathrm{m} / \mathrm{s})$ & * & 5,7 a 8,2 & 3,6 a 5,1 & * & * & 5,7 a 8,2 & * & * \\
\hline
\end{tabular}

Tabela 3.10 - Freqüência de atuação e velocidade média dos ventos de cada octante. Apenas os ventos com freqüência superior a 10\% estão representados. Dados coletados entre 1951 e 1972 na região entre Salvador (BA) e Aracaju (SE) (DHN, 1974).

\begin{tabular}{|l|l|l|l|l|l|l|l|l|l|}
\hline \multicolumn{7}{|c|}{ Mês de Janeiro } \\
\hline Octante & N & S & E & W & NE & SE & SW & NW \\
\hline Freqüência $(\%)$ & 16 & $*$ & 14 & $*$ & 32 & $*$ & $*$ & $*$ \\
\hline Velocidade (m/s) & 5,7 a 8,2 & $*$ & 3,6 a 5,1 & $*$ & 5,7 a 8,2 & $*$ & $*$ & $*$ \\
\hline \multicolumn{8}{|c|}{ Mês de julho } \\
\hline Octante & N & S & E & W & NE & SE & SW & NW \\
\hline Freqüência $(\%)$ & 11 & $*$ & 21 & $*$ & 29 & 11 & $*$ & $*$ \\
\hline Velocidade (m/s) & 3,6 a 5,1 & $*$ & 3,6 a 5,1 & $*$ & 5,7 a 8,2 & 3,6 a 5,1 & $*$ & $*$ \\
\hline
\end{tabular}

Tabela 3.11 - Freqüência de atuação e velocidade média dos ventos de cada octante. Apenas os ventos com freqüência superior a 10\% estão representados. Dados coletados entre 1951 e 1972 nas proximidades de Cabo Frio (RJ) (DHN, 1974).

Os campos de dunas desta zona não são feições ubíquas da costa como no primeiro setor. Estão distribuídos de modo irregular, sendo comuns em regiões próximas à desembocadura de grandes rios (Figura 3.16). Nesta situação, avançam sobre planície de cordões litorâneos. Apenas parte do litoral do Rio de Janeiro (região de Cabo Frio e Arraial do Cabo) constitui exceção a este padrão, aí se encontrando barreiras arenosas, lagunas e maior freqüência de campos de dunas. Os campos de dunas deste setor apresentam tamanho relativo reduzido, pois são longos e estreitos, sendo mais freqüente a presença de cavas de deflação (blowouts) e dunas parabólicas. 


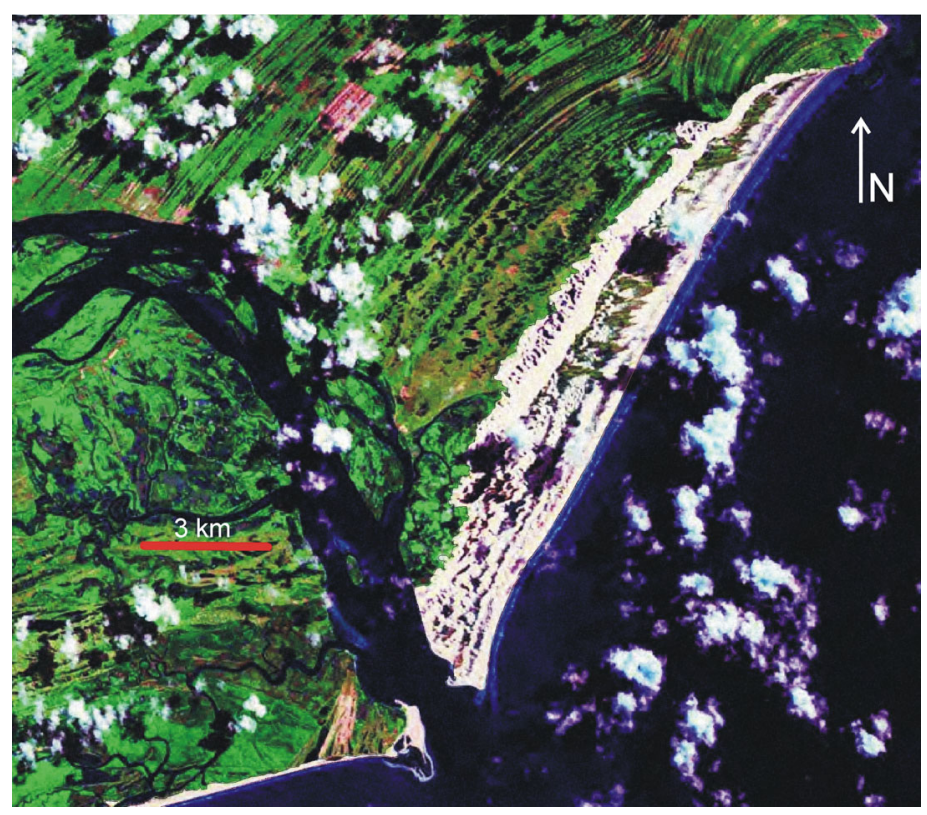

Figura 3.16 - Campo de dunas de Potengi (AL) adjacente à foz do rio São Franscisco (divisa $\mathrm{SE} / \mathrm{AL})$. Notar o avanço sobre planície de cordões litorâneos. $\mathrm{A} / \mathrm{C}=2,05 ; \mathrm{ADV} / \mathrm{A}=0,28$; $P / \sqrt{A}=7,78$.

Os principais azimutes de migração dos campos de dunas do setor 2 são $\mathrm{W}$ e W/NW (Figura 3.17). Destaca-se também a presença de campos de dunas com rumos de migração opostos aos rumos principais. A maioria dos campos de dunas que ocorrem na costa dos estados de Alagoas, Sergipe, Bahia e Espirito Santo apresenta rumo de migração W. Neste trecho da costa, os ventos de leste são os mais freqüentes. Já na região de Cabo Frio (RJ), o azimute SW torna-se o principal rumo de migração, que é coincidente com os ventos mais freqüentes (NE). Portanto, neste setor há correspondência entre o rumo de migração dos campos de dunas e os ventos mais freqüentes. Exceção ocorre apenas na costa do Rio de Janeiro entre a ilha da Marambaia e Arraial do Cabo, onde a linha de costa apresenta direção próxima a E-W. Esta região contém campos de dunas migrando para NE, o que indica condições favoráveis à formação de campos de dunas por ventos de sudoeste. Ventos de sul ou sudoeste associam-se à massa de ar Polar Atlântica (fria e seca), cuja atuação é mais freqüente apenas durante o inverno. Ventos associados à massa de ar Polar Atlântica seriam menos favoráveis ao transporte eólico costeiro, pois frequentemente esta massa de ar frio, em seu avanço rumo norte, provoca chuvas ao encontrar-se com a massa de ar Tropical Atlântica (quente e úmida). 


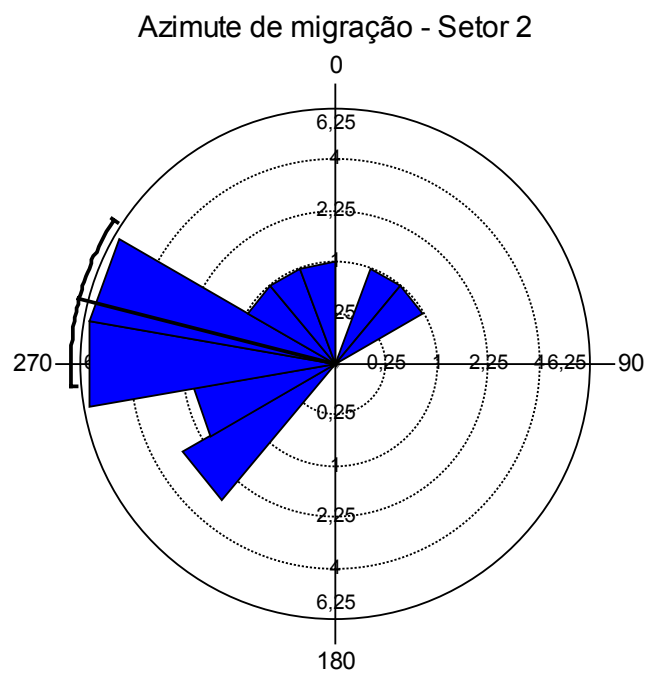

Figura 3.17 - Azimute de migração dos campos de dunas do segundo setor. Os azimutes W e WNW são os mais freqüentes. Azimute médio $=284,06^{\circ}$, desvio padrão circular $=45,45^{\circ}, \mathrm{N}=22$.

Verifica-se ainda a preferência de campos de dunas com rumo de migração $W$ e W/NW por linha de costa de orientação N-S a NE-SW. Rumos de migração NE ocorrem apenas em zonas com linha de costa de direção próxima a E-W (Figura 3.18).

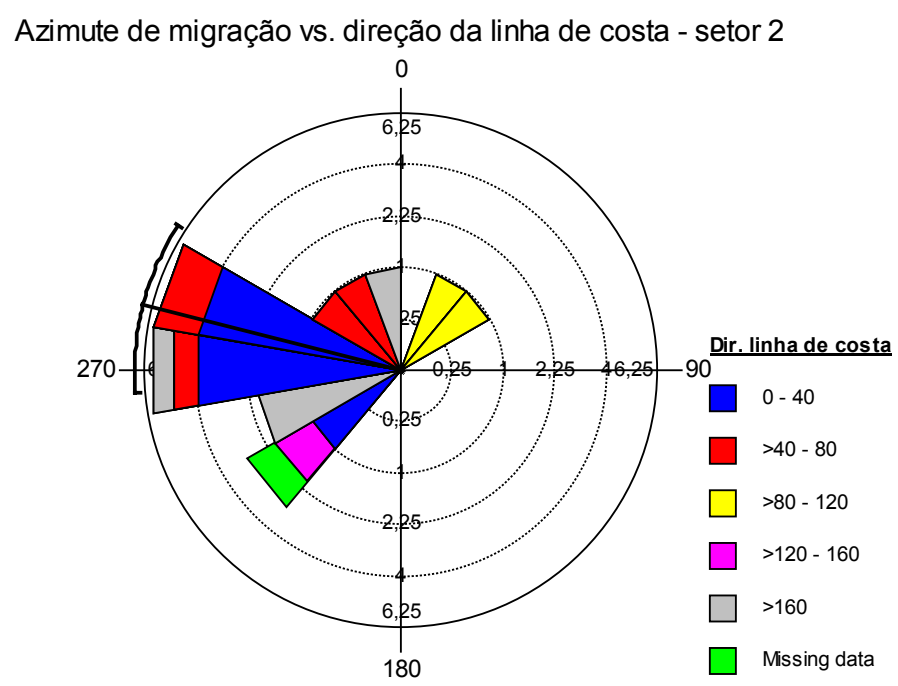

Figura 3.18 - Correlação entre o azimute de migração dos campos de dunas e a direção da linha de costa. Notar a associação entre campo de dunas com rumo de migração $\mathrm{W}$ ou W/NE e linha de costa com direção aproximadamente N-S (0 a 40). 
Os campos de dunas deste setor apresentam rumo de migração mais transversal à costa, com predomínio de campos de dunas com migração perpendicular à direção da linha de costa (Figura 3.19).

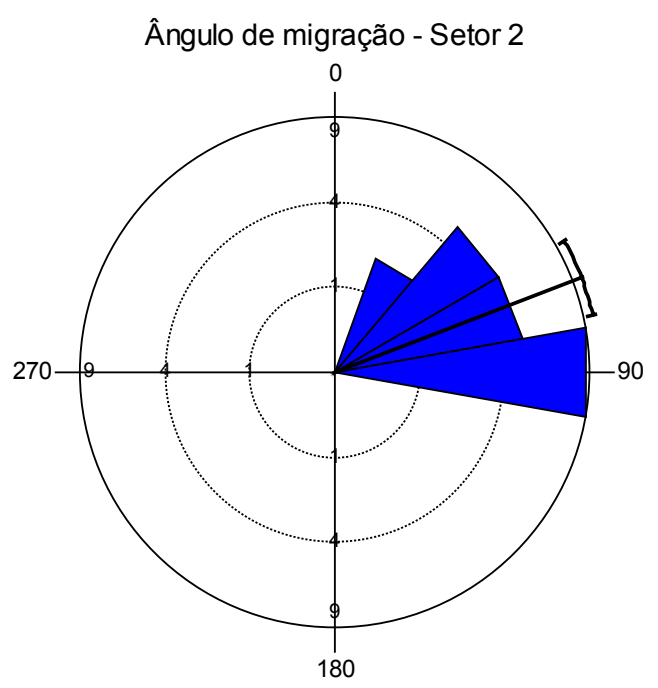

Figura 3.19 - Ângulo entre o rumo de avanço dos campos de dunas e a direção da linha de costa $(\alpha)$. Notar o predomínio de campos de dunas com migração perpendicular à costa. Ângulo médio $=68,93^{\circ}$, Desvio padrão circular $=20,25^{\circ}, \mathrm{N}=21$.

$\mathrm{Na}$ região de Cabo Frio e Arraial do Cabo (RJ), o litoral é caracterizado por lagunas e barreiras arenosas estreitas. As ilhas de rochas cristalinas de Arraial do Cabo servem de ancoradouro para barreiras arenosas perpendiculares entre si sobre as quais avançam campos de dunas com rumos de migração opostos (Figura 3.20). O campo de dunas da restinga de Massambaba apresenta área fonte longa e distância de avanço reduzida, com rumo de migração NE enquanto que o campo de dunas da praia das Dunas possui maior distância de avanço e rumo de migração SW. Ambos campos de dunas apresentam elevada proporção de zonas de deflação ou vegetadas $(0,36$ a 0,40$)$ e suas áreas de migração são restritas pela laguna de Araruama. 


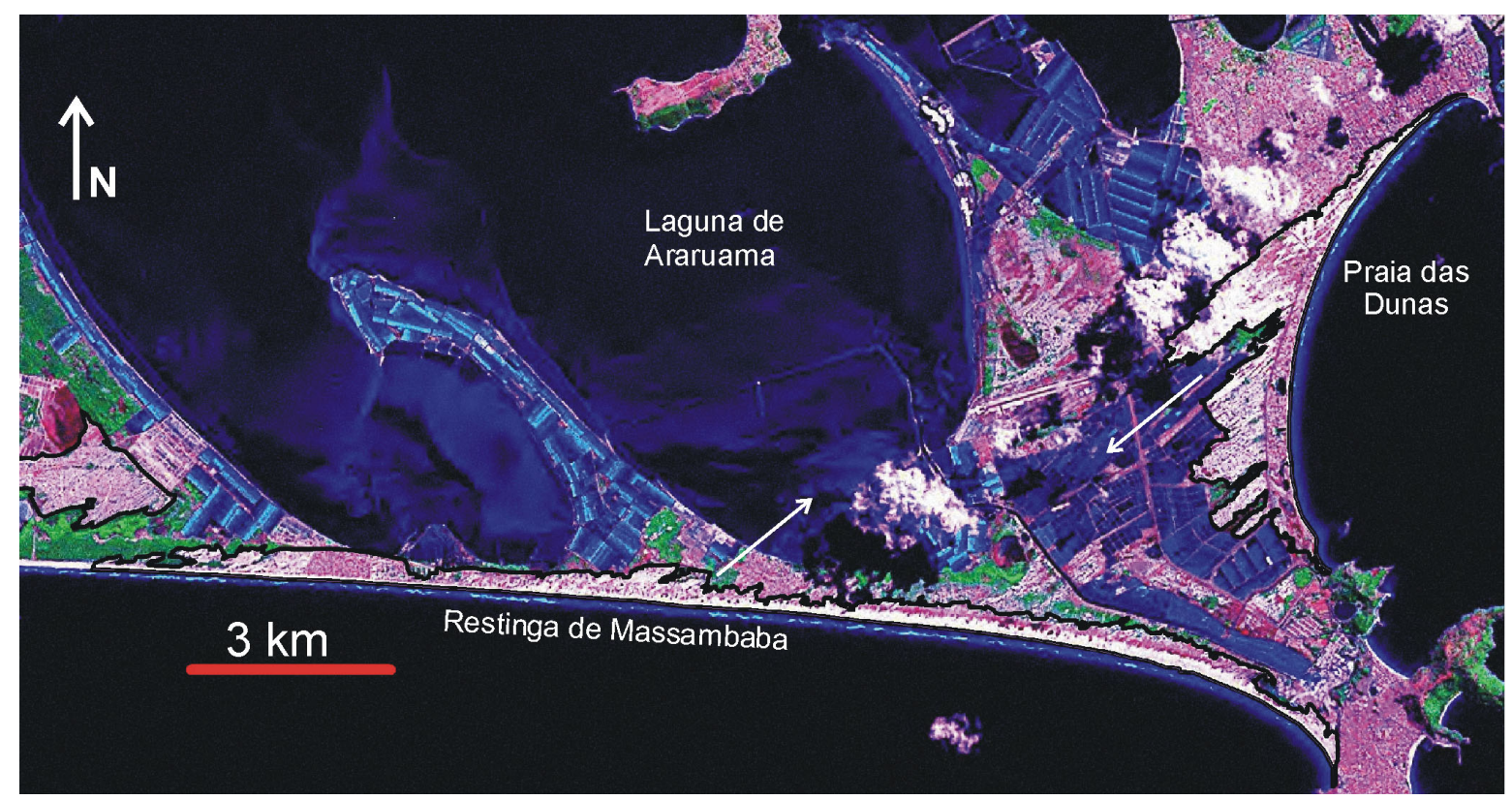

Figura 3.20 - Campos de dunas da região de Cabo Frio e Arraial do Cabo (RJ). Os campos de dunas apresentam rumos de migração opostos e elevada proporção de zonas de deflação ou vegetadas.

Assim como no setor 1, a situação observada na região de Cabo Frio e Arraial do Cabo indica que o vento mais freqüente pode ser impedido de atuar na formação de dunas devido à disposição da linha de costa.

No setor 2, a maior parte da costa é desprovida de campos de dunas e seu traço característico é a distribuição irregular dos campos de dunas, com concentração preferêncial nas adjacências de desembocaduras fluviais ou sobre ilhas barreiras. Nas proximidades de desembocaduras fluviais, os campos de dunas desenvolvem-se principalmente sobre planícies de cordões litorâneos. Tanto desembocaduras fluviais quanto zonas de formação de ilhas barreiras constituem regiões preferenciais para deposição de sedimentos arenosos. Esta associação sugere que o aporte arenoso é variável importante para a formação de campos de dunas costeiros. A fisiografia da costa deste setor também pode ser fator que restringe a formação de campos de dunas. Grande parte deste trecho (ES, BA, SE, AL, PE e PB) apresenta falésias da Formação Barreiras (composta predominantemente por sedimentos terrígenos imaturos), que além de diminuírem o espaço para o desenvolvimento de campos de dunas também podem provocar o engrossamento dos sedimentos praiais e proporcionar praias mais reflexivas, cuja dinâmica favorece o transporte de sedimentos para costa-afora. Outras segmentos de costa desprovidos de 
campo de dunas, tais como o litoral sul do Rio de Janeiro, São Paulo, Paraná e norte de Santa Catarina apresentam em comum a proximidade da serra do Mar ao litoral e/ou da densa floresta da Mata Altântica. Soma-se a isto a elevada pluviosidade destes setores e a pequena quantidade de desembocaduras de grandes rios. O único grande rio que desemboca nesta região é o rio Ribeira do Iguape. Nas adjacências deste rio a planície costeira é mais larga e possui praias, que apesar de não conterem grandes campos de dunas, apresentam dunas frontais altas ou campos de cavas de deflação ou pequenas dunas parabólicas. Assim, fatores ligados à fisiografia da costa e à granulação, disponibilidade e reposição de sedimentos arenosos na zona intermarés podem ser mais importantes que a freqüência de ocorrência de chuvas ou ao regime de ventos no controle da geração e desenvolvimento de campos de dunas.

\subsubsection{Setor 3 (Paraná, Santa Catarina e Rio Grande do Sul)}

Este setor pertence a região de clima subtropical, com pluviosidade elevada (desprovida de mês seco) caracterizada por chuvas bem distribuídas ao longo do ano. Todo o setor encontrase sob regime de micromaré. A fisiografia de costa dominada por ilhas-barreiras e lagunas é característica marcante da maior parte deste setor. O regime de ventos é ditado pelos anticiclones Tropical do Atlântico Sul e Migratório Subpolar, aos quais se associam ventos de E e NE, e pela migração de frentes frias formadas nas zonas entre anticiclones e que vêm acompanhadas de ventos ciclônicos de sul. Na Ilha de Santa Catarina (SC), apesar de predominar a atuação de ventos de nordeste tanto no inverno (21\%) quanto no verão (27\%), ventos de norte, sul, leste e sudoeste também são importantes (Tabela 3.12). Na região do cabo de Santa Marta (Laguna, SC), há aumento significativo da freqüência de atuação de ventos de nordeste (43\% no verão e 39\% no inverno). Após os ventos de nordeste, os ventos de sul são os mais atuantes (Tabela 3.13). 


\begin{tabular}{|l|l|l|l|l|l|l|l|l|}
\hline \multicolumn{1}{|c|}{ Mês de Janeiro } \\
\hline Octante & N & S & E & W & NE & SE & SW & NW \\
\hline Freqüência (\%) & 13 & 19 & 18 & $*$ & 27 & $*$ & $*$ & $*$ \\
\hline Velocidade (m/s) & 5,7 a 8,2 & 5,7 a 8,2 & 3,6 a 5,1 & $*$ & 3,6 a 5,1 & $*$ & $*$ & $*$ \\
\hline \multicolumn{7}{|c|}{ Mês de julho } \\
\hline Octante & N & S & E & W & NE & SE & SW & NW \\
\hline Freqüência (\%) & 19 & 16 & $*$ & $*$ & 21 & $*$ & 14 & $*$ \\
\hline Velocidade (m/s) & 5,7 a 8,2 & 3,6 a 5,1 & $*$ & $*$ & 5,7 a 8,2 & $*$ & 5,7 a 8,2 & $*$ \\
\hline
\end{tabular}

Tabela 3.12 - Freqüência de atuação e velocidade média dos ventos de cada octante. Apenas os ventos com freqüência superior a 10\% estão representados. Dados coletados entre 1951 e 1972 na Ilha de Santa Catarina (SC) (DHN, 1974).

\begin{tabular}{|l|l|l|l|l|l|l|l|l|l|}
\hline \multicolumn{8}{|c|}{ Mês de Janeiro } \\
\hline Octante & N & S & E & W & NE & SE & SW & NW \\
\hline Freqüência (\%) & $*$ & 18 & 12 & $*$ & 43 & $*$ & $*$ & $*$ \\
\hline Velocidade (m/s) & $*$ & 3,6 a 5,1 & 2,0 a 3,1 & $*$ & 5,7 a 8,2 & $*$ & $*$ & $*$ \\
\hline \multicolumn{8}{|c|}{ Mês de julho } \\
\hline Octante & N & S & E & W & NE & SE & SW & NW \\
\hline Freqüência (\%) & $*$ & 16 & $*$ & 11 & 39 & $*$ & 15 & $*$ \\
\hline Velocidade (m/s) & $*$ & 3,6 a 5,1 & $*$ & 3,6 a 5,1 & 5,7 a 8,2 & $*$ & 5,7 a 8,2 & $*$ \\
\hline
\end{tabular}

Tabela 3.13 - Freqüência de atuação e velocidade média dos ventos de cada octante. Apenas os ventos com freqüência superior a 10\% estão representados. Dados coletados entre 1951 e 1972 na região do cabo de Santa Marta (Laguna, SC) (DHN, 1974).

Na região de Rio Grande (RS), os ventos de nordeste ainda são os mais freqüentes (27\% no verão e $21 \%$ no inverno). Porém, há redução da freqüência e da velocidade destes ventos (Tabela 3.14). A sul, na região de Chuí (RS), os ventos de nordeste deixam de ser dominantes e cedem lugar para ventos de leste no verão $(26 \%)$ e ventos de norte no inverno (23\%) (Tabela 3.15). Assim como nas demais regiões, a velocidade média dos ventos varia entre 3,6 e $8,2 \mathrm{~m} / \mathrm{s}$. 


\begin{tabular}{|l|l|l|l|l|l|l|l|l|l|}
\hline \multicolumn{10}{|c|}{ Mês de Janeiro } \\
\hline Octante & N & S & E & W & NE & SE & SW & NW \\
\hline Freqüência $(\%)$ & 16 & 14 & 19 & $*$ & 27 & 11 & $*$ & $*$ \\
\hline Velocidade (m/s) & 3,6 a 5,1 & 3,6 a 5,1 & 3,6 a 5,1 & $*$ & 3,6 a 5,1 & 3,6 a 5,1 & $*$ & $*$ \\
\hline \multicolumn{8}{|c|}{ Mês de julho } \\
\hline Octante & N & S & E & W & NE & SE & SW & NW \\
\hline Freqüência $(\%)$ & 15 & 11 & $*$ & $*$ & 21 & $*$ & 19 & $*$ \\
\hline Velocidade (m/s) & 3,6 a 5,1 & 3,6 a 5,1 & $*$ & $*$ & 3,6 a 5,1 & $*$ & 5,7 a 8,2 & $*$ \\
\hline
\end{tabular}

Tabela 3.14 - Freqüência de atuação e velocidade média dos ventos de cada octante. Apenas os ventos com freqüência superior a 10\% estão representados. Dados coletados entre 1951 e 1972 na região de Rio Grande (RS) (DHN, 1974).

\begin{tabular}{|l|l|l|l|l|l|l|l|l|}
\hline \multicolumn{10}{|c|}{ Mês de Janeiro } \\
\hline Octante & N & S & E & W & NE & SE & SW & NW \\
\hline Freqüência (\%) & 16 & 17 & 26 & $*$ & 18 & $*$ & $*$ & $*$ \\
\hline Velocidade (m/s) & 3,6 a 5,1 & 5,7 a 8,2 & 3,6 a 5,1 & $*$ & 3,6 a 5,1 & $*$ & $*$ & $*$ \\
\hline \multicolumn{8}{|c|}{ Mês de julho } \\
\hline Octante & N & S & E & W & NE & SE & SW & NW \\
\hline Freqüência (\%) & 23 & 17 & $*$ & 15 & $*$ & $*$ & $*$ & $*$ \\
\hline Velocidade (m/s) & 3,6 a 5,1 & 3,6 a 5,1 & $*$ & 2,0 a 3,1 & $*$ & $*$ & $*$ & $*$ \\
\hline
\end{tabular}

Tabela 3.15 - Freqüência de atuação e velocidade média dos ventos de cada octante. Apenas os ventos com freqüência superior a 10\% estão representados. Dados coletados entre 1951 e 1972 na região de Chuí (RS) (DHN, 1974).

Assim como no setor 1, este setor apresenta grande quantidade de campos de dunas, os quais passam a ser feições comuns da costa a partir da ilha de Santa Catarina. Os campos de dunas livres também são constituídos principalmente por dunas barcanas e cadeias barcanóides, sendo que alguns campos de dunas apresentam dunas transversais. Formas eólicas com vegetação, tais como dunas parabólicas, nebkhas, rastros lineares residuais (trailing ridges), rupturas de deflação (blowouts) e cordões de precipitação (precipitation ridges) são freqüentes, principalmente em campos de dunas com elevada proporção de zonas de deflação ou com vegetação. Ilhas barreiras e lagunas são feições características deste setor. A morfologia e a distribuição dos campos de dunas ao longo da costa permitem dividir este setor em duas partes (Figura 3.21). A parte norte estende-se da ilha de Santa Catarina até Laguna (SC). Nesta região, a sedimentação eólica é mais descontínua, caracterizada por campos de dunas separados por pontões rochosos, com áreas de deflação ou vegetadas situadas a barlavento (adjacente à area fonte) e rumo de migração mais oblíquo à linha de costa. Já na porção a sul de Laguna, há maior 
continuidade da sedimentação eólica, com campos de dunas longos, rumo de migração subparalelo ou oblíquo à costa e áreas de deflação ou vegetadas de distribuição irregular. Nesta parte, as praias são extremamente longas e retilíneas, pois quase não há pontões rochosos de modo que os campos de dunas são separados principalmente por desembocaduras lagunares.

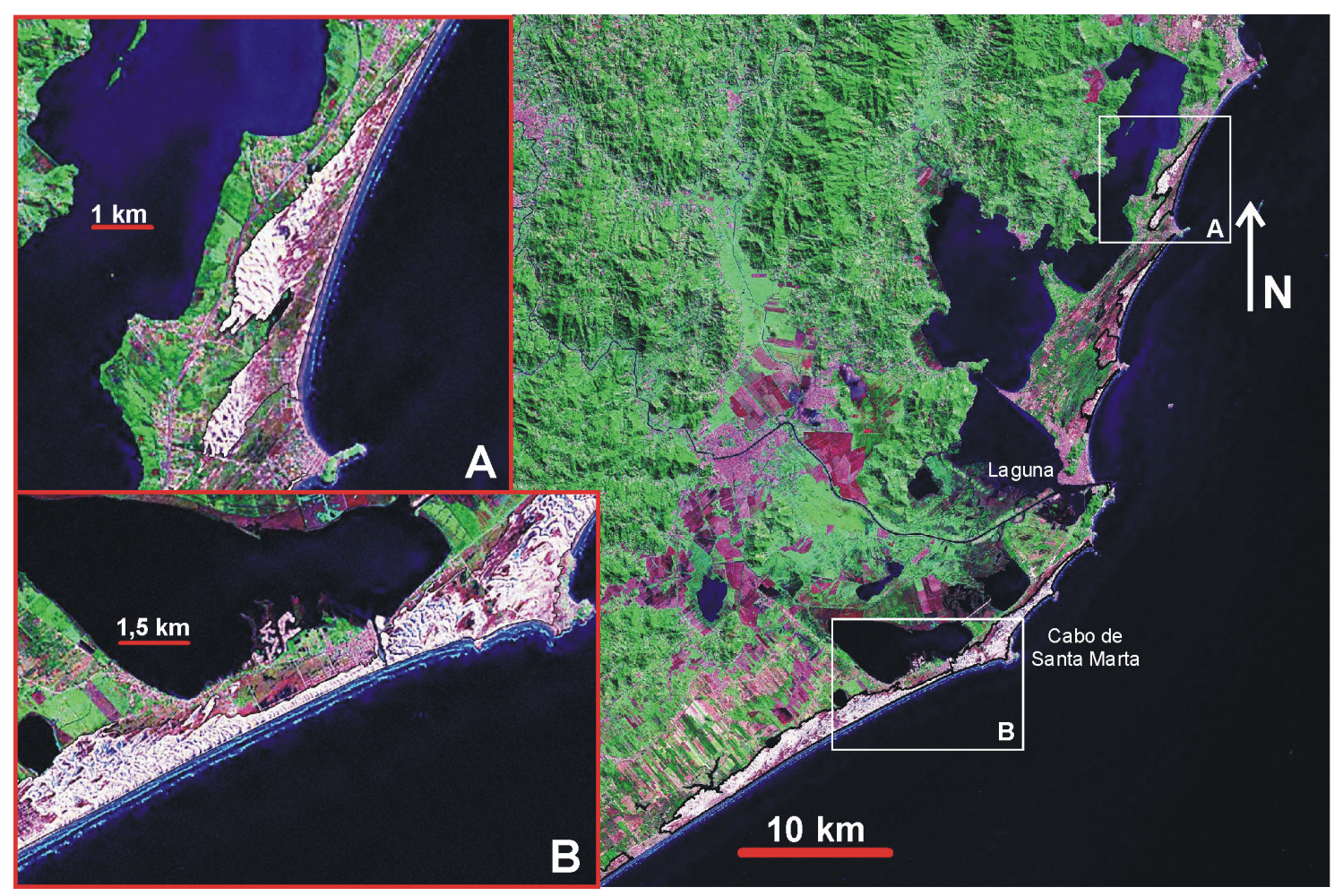

Figura 3.21 - Trecho da costa de Santa Catarina entre Imbituba e Jaguaruna. A norte de Laguna, os campos de dunas apresentam rumo de migração oblíquo à costa enquanto que a sul, o rumo de migração é subparalelo à costa. A) Campo de dunas de Itapirubá (Imbituba, SC). Este campo de dunas apresenta ampla zona de deflação ou recoberta por vegetação situada a barlavento e forma menos alongada $(\mathrm{A} / \mathrm{C}=0,91 ; \mathrm{ADV} / \mathrm{A}=0,50 ; P / \sqrt{A}=9,59)$. B) Campo de dunas de Campo Bom (Jaguaruna, SC). Trata-se de campo de dunas alongado com menor proporção de áreas de deflação ou vegetadas $(\mathrm{A} / \mathrm{C}=1,16 ; \mathrm{ADV} / \mathrm{A}=0,23 ; P / \sqrt{A}=12,13)$.

Apesar das lagunas e dos corpos lagunares residuais constituírem obstáculo ao avnaço dos campos de dunas, na maior parte deste setor o espaço disponível para avanço dos campos de dunas sobre as barreiras não é totalmente ocupado. Isto pode indicar que a velocidade de progradação das barreiras holocênicas é maior que a velocidade de avanço dos campos de dunas no sentido transversal à costa. Alguns campos de dunas encontram-se segmentados por 
desembocaduras do sistema lagunar. Isto ocorre por exemplo nos arredores de Rio Grande (RS), onde chama atenção a presença de campo de dunas isolado pelo sistema lagunar (Figura 3.22).

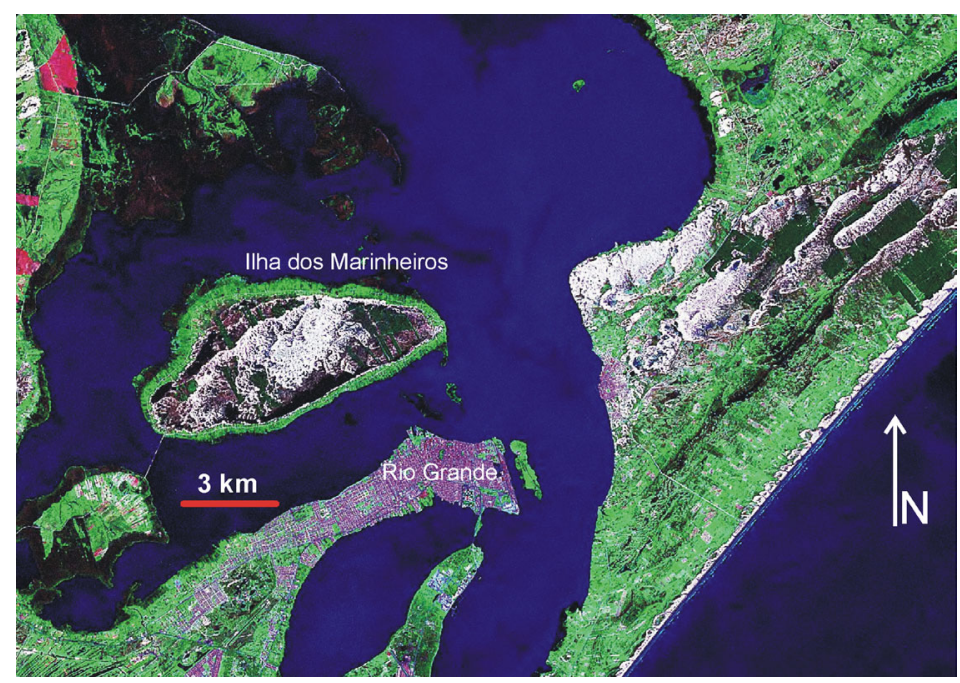

Figura 3.22 - Campo de dunas na Ilha dos Marinheiros (Rio Grande, RS) isolado da área fonte praial pelo sistema lagunar.

Por restringir-se às proximidades de desembocaduras, a segmentação dos campos de dunas pelo sistema lagunar pode estar associada a dinâmica autocíclica dos sistemas eólico e lagunar. Assim, descarta-se a hipótese desta segmentação estar relacionada à eventual subida do nível relativo do mar.

O rumo de avanço dos campos deste setor abrange predominantemente azimutes do quadrante SW (Figura 3.23). Este setor também conta com zona onde a migração dos campos de dunas ocorre segundo o rumo de ventos de freqüência secudária. Este é o caso dos campos de dunas da Ilha de Santa Catarina (SC) e de Torres (RS). Nas demais áreas há correspondência entre os ventos mais freqüentes e o rumo de avanço dos campos de dunas. Destaca-se ainda o fato de haver diminuição da freqüência do vento nordeste (dominante na maior parte deste setor) no sentido sul. A diminuição da freqüência de atuação dos ventos de nordeste para sul é acompanhada do aumento da variabilidade do rumo dos ventos. Na região de Chuí (RS), apesar dos ventos de leste tornarem-se mais freqüentes, ventos de norte, nordeste, sul e oeste apresentam freqüência de atuação significativa. 


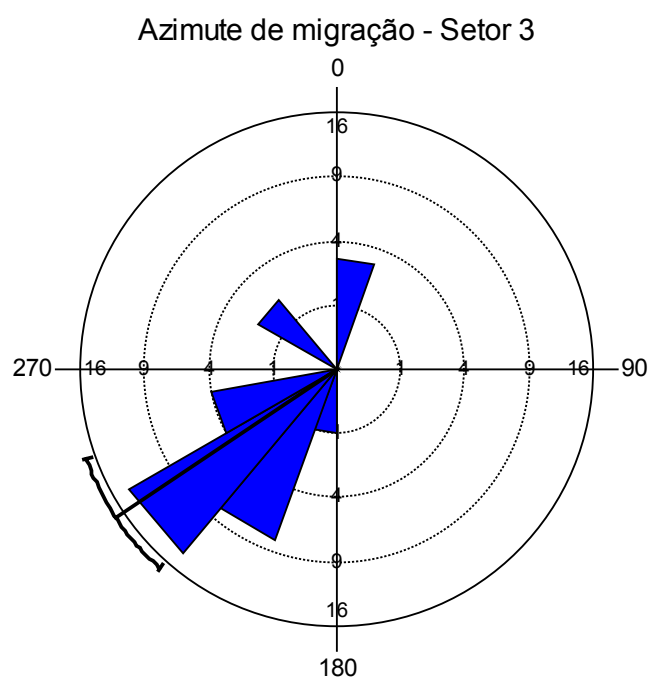

Figura 3.23 - Azimute de migração dos campos de dunas. Azimute médio=235,99 ${ }^{\circ}$; Desvio padrão circular $=41,41^{\circ} ; \mathrm{N}=32$.

Segundo Bigarella (1972, 1975), a migração dos campos de dunas da Ilha de Santa Catarina (SC) para $\mathrm{N}$ resulta da presença de obstáculos topográficos à ação dos ventos de $\mathrm{NE}$, que são os ventos geradores da maior parte dos campos de dunas desta região. No entanto, em outras áreas deste setor há campos de dunas em situação semelhante à que ocorre na Ilha de Santa Catarina, ou seja, praias de orientação NNE/SSW delimitadas por morros. Giannini (1993) atribui o rumo de migração para $\mathrm{N}$ ao caráter particular do regime de ventos da ilha. De acordo com este autor, os ventos de S e SE atuam de modo mais efetivo que nas demais áreas deste setor, sendo que representam cerca de $86 \%$ da DEP (Deriva Eólica Potencial; trata-se de medida proporcional à freqüência de atuação e ao quadrado da velocidade do vento) enquanto que na região de Laguna, por exemplo, estes ventos representam 53\% da DEP. Giannini et al. (2005), chamam atenção ainda para o fato de que os campos de dunas da ilha de Santa Catarina desenvolvem-se na parte norte das praias (Figura 3.24). Estes autores atribuem tal fato à disponibilidade de sedimentos praiais ser maior na parte norte das praias devido ao sentido NNE da corrente de deriva litorânea. Esta relação também é observada nos demais campos de dunas deste setor e torna evidente a importância da manutenção da disponibilidade de sedimentos costeiros para o desenvolvimento de campos de dunas. 


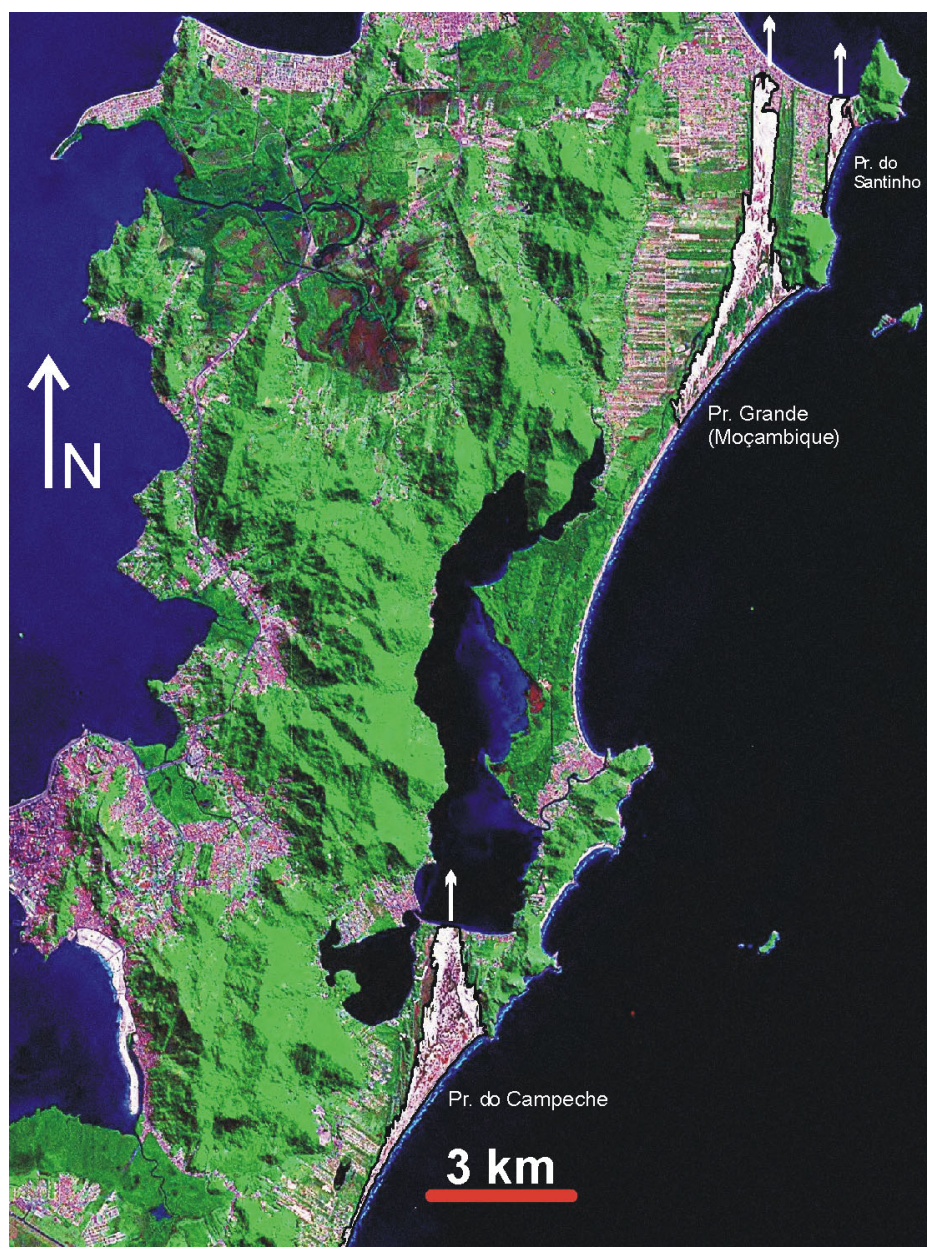

Figura 3.24 - Campos de dunas com rumo de avanço próximo a N (Florianópolis, SC).

Não se observa grande variação da direção da linha de costa deste setor. A norte do cabo de Santa Marta a orientação média da linha de costa é NNE/SSW. Ao sul do cabo, há mudança abrupta para orientação próxima a SW/NE. Apesar de abrupta, esta mudança não influencia a formação de campos de dunas dos ventos atuantes neste setor (Figura 3.25). A variação da direção da linha de costa afeta apenas o ângulo entre o rumo de avanço dos campos de dunas e a direção da linha de costa. A norte do cabo de Santa Marta, os campos de dunas migram de forma mais oblíqua à costa enquanto que a sul, a migração é subparalela. 
Azimute de migração vs. direção da linha de costa - setor 3

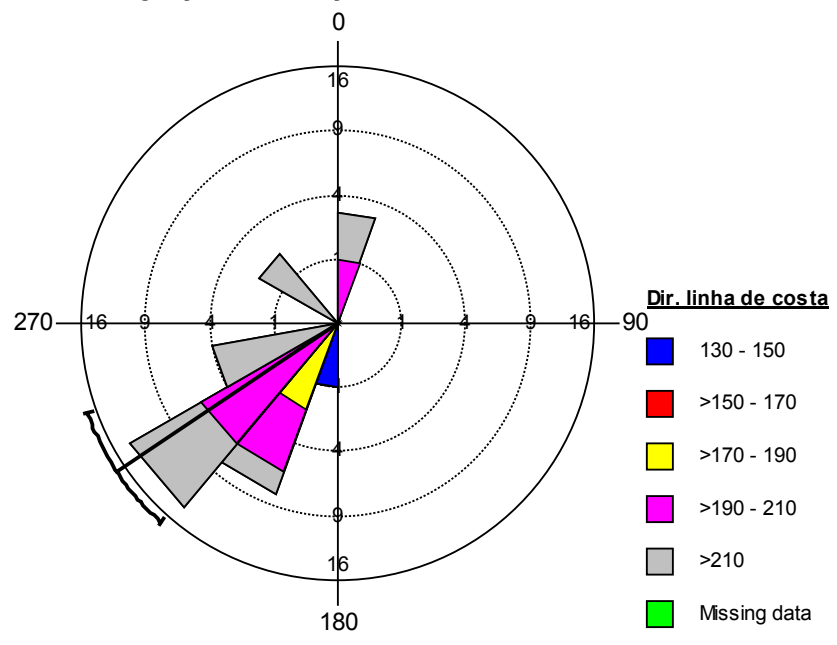

Figura 3.25 - Relação entre o rumo de migração dos campos de dunas e a direção da linha de costa. Notar que não há grande variação da direção da linha de costa e que esta não influencia o rumo de migração dos campos de dunas.

Este setor difere dos demais por apresentar campos de dunas com rumo de avanço subparalelo à costa (Figura 3.26). Como já mencionado, esta característica pode ser relacionada à direção da linha de costa pouco variável e ao fato dos ventos de NE atuarem sob condições mais propícias ao transporte eólico (exceção apenas para a ilha de Santa Catarina).

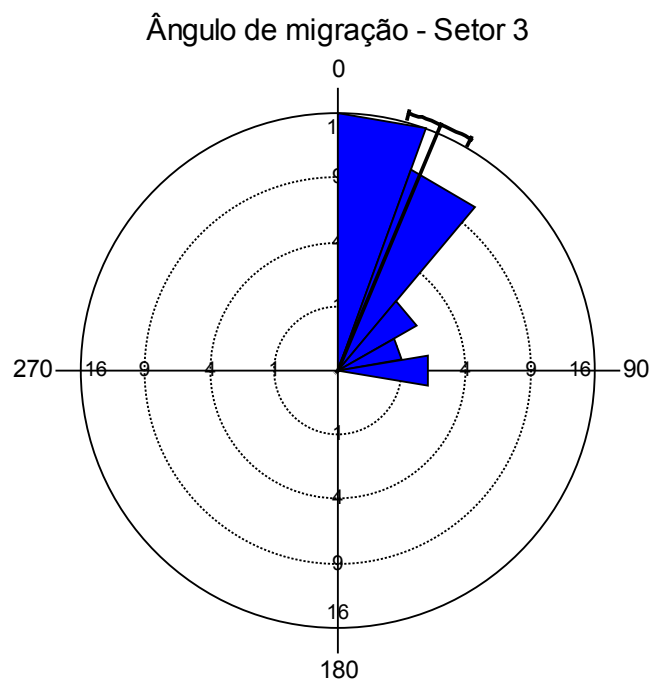

Figura 3.26 - Ângulo entre o rumo de migração dos campos de dunas e a direção da linha de costa. Ângulo médio $=22,74^{\circ}$, desvio padrão circular $=20,92^{\circ}, \mathrm{N}=32$. 
3.3.4 Variação das características morfométricas dos campos de dunas em termos de fatores climáticos, oceanográfico e geográfico

\subsubsection{Objetivos e procedimento de análise}

Os campos de dunas classificados segundo fatores climáticos (número de meses secos e velocidade e freqüência dos ventos), amplitude de maré e localização geográfica foram comparados entre si através de suas características morfométricas. Para esta comparação, foram utilizadas estatísticas descritivas, gráficos de intervalo de variação, análise de agrupamento e tabelas de correspondência acompanhadas de teste qui-quadrado. Assim, procurou-se avaliar o efeito de cada um daqueles fatores mencionados sobre o tamanho e a morfologia dos campos de dunas. A comparação entre os três setores geográficos previamente definidos (setores 1, 2 e 3) visou avaliar a variabilidade das características dos campos de dunas de cada setor e verificar se, a despeito desta variabilidade, é possível discriminar os referidos setores através de seus campos de dunas. Também serviu para avaliar de modo quantitativo as observações apresentadas no item anterior.

A análise comparativa compreendeu as seguintes etapas:

1. Cálculo de estatíticas descritivas das categorias de campos de dunas em comparação. As estatísticas descritivas serviram para avaliação da variabilidade das características morfométricas dos campos de dunas e comparação qualitativa.

2. Elaboração de gráficos de intervalo de variação para comparação de classes de campos de dunas através de seus valores médios.

3. Análise de agrupamento, confecção de tabelas de correspondência e teste qui-quadrado. A análise de agrupamento serviu para definir grupos morfométricos de campos de dunas, os quais foram comparados, mediante tabelas de correspondência e teste qui-quadrado, com categorias de campos de dunas definidas a priori em termos de fatores climáticos, amplitude de maré ou localização geográfica. 
3.3.4.2 Classificação dos campos de dunas em termos do número de meses secos, freqüencia de atuação e velocidade do vento e amplitude de maré

\subsection{Classificação dos campos de dunas em termos do número de meses secos}

As regiões onde há desenvolvimento de campos de dunas foram classificadas em termos do número de meses secos ao longo do ano. Esta classificação foi baseada no zoneamento climático do Brasil elaborado com base em estatísticas de pluviosidade do Instituto Brasileiro de Geografia e Estatística (IBGE, 1992). Assim, as regiões com campos de dunas costeiros foram divididas em três classes: zero a três, quatro a seis e sete a oito meses secos. A primeira classe diferencia-se das demais não somente pelo número absoluto de meses secos, mas também pela distribuição das chuvas ao longo do ano: as regiões incluídas nesta classe situam-se em zona de clima tropical úmido litorâneo e subtropical, que apresentam chuvas bem distribuídas no decorrer do ano, sendo raros os períodos longos de estiagem. As regiões com quatro a seis meses secos apresentam clima tropical, sendo que as chuvas se concentram no verão (entre os meses de janeiro a abril). As regiões com sete a oito meses secos são de clima semi-árido, que além de apresentarem chuvas concentradas em três ou quatro meses do ano, podem ser submetidas a períodos de estiagem com três a quatro anos de duração (Sant'Anna Neto \& Nery, 2005).

A classificação dos campos de dunas em termos do número de meses secos teve como objetivo avaliar a influência da precipitação pluviométrica sobre o tamanho e a morfologia dos campos de dunas. Isto serviu para comparar campos de dunas desenvolvidos em regiões com número variável de meses secos. Porém, não se deve esquecer a associação entre o número de meses secos e a amplitude de maré na costa brasileira, onde as regiões mais secas encontram-se se sob regime de mesomaré e macromaré enquanto que as regiões mais úmidas estão sob regime de micromaré. Logo, devido à associação entre número de meses secos e amplitude de maré, a avaliação da influência da pluviosidade sobre o tamanho e forma dos campos de dunas foi feita apenas para campos de dunas sob um mesmo regime de maré. Para isto, foram utilizados os campos de dunas de costa sob regime de mesomaré, escolhidos por constituírem maior número e por se desenvolverem em regiões com número de meses secos mais variável (zero a três, quatro a seis e sete a oito meses secos). 


\subsection{Classificação dos campos de dunas em termos da velocidade e freqüência dos ventos}

Dados de freqüência de atuação e velocidade média de ventos coincidentes com o rumo de avanço dos campos de dunas foram compilados a partir de atlas de estações meteorológicas distribuídas ao longo da costa brasileira. Estes dados dizem respeito a período de 21 anos (coletados entre os anos de 1951 e 1972, DHN (1974)) e foram utilizados para caracterizar o regime de ventos atuante nas áreas dos campos de dunas. Utilizaram-se freqüências de atuação e velocidades médias relativas aos meses de janeiro (representativo do verão) e julho (representativo do inverno), de estações meteorológicas situadas nas seguintes localidades: porto de Chuí (RS), sul de Rio Grande (RS), Santa Marta (Laguna, SC), Florianópolis (SC), proximidades de Cabo Frio (RJ), proximidades de Fortaleza (CE) e entre São Luis (MA) e Luís Correia (PI). Os dados compilados permitiram avaliar o regime de ventos de apenas uma parcela dos campos de dunas envolvidos nas análises morfométricas. Apesar disto, foi possível caracterizar o regime de ventos de 116 campos de dunas, sendo 68 do setor geográfico 1,9 do setor geográfico 2 e 28 do setor geográfico 3. Três categorias de campos de dunas foram definidas com base na freqüência de atuação dos ventos do mês de janeiro ( 26 a 32\%, 43 a $54 \%$ e $64 \%$ ) e outras três, para os ventos do mês de julho (21 a 29\%, 39 a 44\% e 58\%). Em relação à velocidade média destes ventos, foram definidas duas categorias: 3,6 a $5,1 \mathrm{~m} / \mathrm{s}$ e 5,7 a $8,2 \mathrm{~m} / \mathrm{s}$ (para os meses de janeiro e julho).

\subsection{Classificação dos campos de dunas em termos da amplitude de maré}

A fim de avaliar a influência da maré sobre a morfologia e tamanho dos campos de dunas, estes foram classificados, segundo a amplitude de maré da zona costeira onde se desenvolvem, em três classes: macromaré, mesomaré e micromaré. A amplitude de maré pode afetar o desenvolvimento de campos de dunas, pois determina a área da zona intermarés exposta à ação dos ventos de onshore e o volume de sedimentos armazenados na zona intermarés. Neste caso, amplitude de maré e aporte eólico estariam relacionados, pois quanto maior a amplitude de maré, maior o reservatório de sedimentos na zona intermarés, maior a área de sedimentos praiais expostos à ação dos ventos e, portanto, mais favoráveis seriam as condições para manutenção de aporte eólico regular e elevado. No entanto, a maré também pode atuar de forma diversa, à 
medida que consiga alterar a fisiografia da costa. Costas com amplitude de maré elevada apresentam canais de maré como característica fisiográfica marcante. Estes canais podem interferir de forma negativa no crescimento dos campos de dunas, pois podem atuar como barreira ao crescimento de campos de dunas, isolar campos de dunas da área fonte praial bem como retirar areia dos campos de dunas e transportar sedimentos da zona intermarés para costaafora. Deste modo, a maré pode exercer efeitos opostos sobre o desenvolvimento de campos de dunas costeiros. Nesse sentido, configuraria variável de cárater divergente.

A pluviosidade também pode influenciar o aporte eólico, pois a ocorrência de chuvas pode aumentar a coesão dos sedimentos e inibir seu transporte pelo vento. Assim, para avaliar a suposta relação entre amplitude de maré e aporte eólico é necessário eliminar o efeito da pluviosidade. Por este motivo, apenas campos de dunas de mesmo regime pluviométrico foram comparados entre si no que diz respeito à amplitude de maré. Confrontaram-se campos de dunas de regiões com quatro a seis meses secos, que envolvem costas de mesomaré e macromaré, e campos de dunas de regiões com zero a três meses secos, que abrangem costas de micromaré e mesomaré.

\subsubsection{Associação entre fatores}

A avaliação do efeito de fatores individuais (meses secos, velocidade e freqüência de ventos, amplitude de maré e setores geográficos) sobre tamanho e morfologia dos campos de dunas pode tornar-se complicada caso haja associação entre estes fatores. Neste caso, torna-se difícil distinguir o efeito de cada fator ou a influência de um fator sobre outro. Em vista disso, a associação entre fatores climáticos, amplitude de maré e setores geográficos foi previamente avaliada mediante tabelas de correspondência e teste qui-quadrado (tabelas A1 a A15, Anexo 1).

Exceto a comparação entre o número de meses secos e a velocidade média dos ventos geradores de dunas atuantes no verão (janeiro), todas as demais comparações resultaram em associação entre categorias. Isto pode ser observado na Tabela 3.16, onde são sumariadas as estatísticas qui-quadrado e os valores de p (probabilidade de rejeitar a hipótese nula de que não há associação entre as categorias analisadas) para cada teste de associação. A hipótese nula (ausência de associação) foi rejeitada para valores de p inferiores a 0,05. 


\begin{tabular}{|l|l|l|l|}
\hline Categorias comparadas & $\begin{array}{l}\text { Graus de } \\
\text { liberdade }\end{array}$ & $\begin{array}{l}\text { Qui- } \\
\text { quadrado }\end{array}$ & p \\
\hline Meses secos vs. setores geográficos & 4 & 214,00 & 0,000 \\
\hline Meses secos vs. amplitude de maré & 4 & 205,83 & 0,000 \\
\hline Meses secos vs. freq. ventos geradores de dunas (jan.) & 2 & 83,442 & 0,000 \\
\hline Meses secos vs. freq. ventos geradores de dunas (jul.) & 2 & 83,433 & 0,000 \\
\hline Meses secos vs. veloc. ventos geradores de dunas (jan.) & 1 & 3,317 & 0,069 \\
\hline Meses secos vs. veloc. ventos geradores de dunas (jul.) & 1 & 42,870 & 0,000 \\
\hline Amplitude de maré vs. freq. ventos geradroes de dunas (jan.) & 4 & 109,704 & 0,000 \\
\hline Amplitude de maré vs. freq. ventos geradores de dunas (jul.) & 4 & 109,122 & 0,000 \\
\hline Amplitude de maré vs. veloc. ventos geradores de dunas (jan.) & 2 & 21,21 & 0,000 \\
\hline Amplitude de maré vs. veloc. ventos geradores de dunas (jul.) & 2 & 42,870 & 0,000 \\
\hline Amplitude de maré vs. setores geográficos & 4 & 185,81 & 0,000 \\
\hline Setores geográficos vs. freq. ventos geradores de dunas (jan.) & 4 & 86,997 & 0,000 \\
\hline Setores geográficos. vs. freq. ventos geradores de dunas (jul.) & 4 & 83,580 & 0,000 \\
\hline Setores geográficos vs. veloc. ventos geradores de dunas (jan.) & 2 & 18,412 & 0,000 \\
\hline Setores geográficos vs. veloc. ventos geradores de dunas (jul.) & 2 & 59,746 & 0,000 \\
\hline
\end{tabular}

Tabela 3.16 - Resultados do teste qui-quadrado para verificação de associação entre categorias de campos de dunas classificadas pelo número de meses secos, velocidade e freqüência de atuação dos ventos geradores de dunas, amplitude de maré e setores geográficos. Valores de p inferiores a 0,05 indicam existência de associação entre as categorias comparadas (rejeição da hipótese de distribuição uniforme).

Os campos de dunas de regiões com zero a três meses secos ocorrem nos setores geográficos 2 e 3 e preferencialmente em costa sob regime de micromaré, ventos geradores de dunas com freqüência de atuação entre 21 a 32\% e velocidade média variável (entre 3,6 a 5,1 m/s e entre 5,7 e $8,2 \mathrm{~m} / \mathrm{s}$ ). Já os campos de dunas de regiões mais secas (quatro a oito meses secos) pertencem todos ao setor geográfico 1. Esses campos de dunas encontram-se preferencialmente em costa sob regime de mesomaré e são gerados por ventos com freqüência de atuação entre 43 e $64 \%$ (janeiro) e entre 39 e 58\% (julho). Durante o mês de janeiro, cerca de 58\% dos campos de dunas estão sob ação de ventos com velocidade média entre 5,7 e $8,2 \mathrm{~m} / \mathrm{s}$. O restante encontra-se sob ação de ventos com velocidade média entre 3,6 e 5,1 m/s. Durante o mês de julho, $100 \%$ dos campos de dunas estão sob ação de ventos com velocidade média entre 5,7 e 8,2 m/s. Portanto, nota-se que as regiões mais úmidas possuem menor amplitude de maré e ventos, coincidentes com o rumo de migração dos campos de dunas, menos freqüentes e menos velozes. A regiões mais secas apresentam amplitude de maré mais elevada e encontram-se sob ação de ventos onshore mais freqüentes e velozes. 


\subsubsection{Comparação entre campos de dunas em termos do número de meses secos}

A média do tamanho relativo dos campos de dunas $(\mathrm{A} / \mathrm{C})$ de regiões com zero a três meses secos aparenta ser semelhante à de regiões com sete a oito meses secos (Tabela $3.17 \mathrm{e}$ Figura 3.27). O valor médio mais elevado de $\mathrm{A} / \mathrm{C}$ ocorre em regiões com quatro a seis meses secos. Apesar disto, o tamanho relativo dos campos de dunas da classe com zero a três meses secos apresenta menor intervalo interquartil e menor desvio padrão. Nota-se também que os campos de dunas desta classe possuem valor máximo menos elevado e menor valor do terceiro quartil. Isto indica que apesar da semelhança entre os valores médios, as regiões com maior número de meses secos apresentam maior proporção de campos de dunas de tamanho elevado.

Deve ser destacado o fato de haver um controle geográfico sobre a distribuição do número de meses secos. As regiões com quatro a seis e sete a oito meses secos estão situadas na costa nos estados do Rio Grande do Norte, Ceará, Piauí e Maranhão, enquanto que as regiões com zero a três meses secos estão localizadas na costa de Sergipe, Bahia e Espirito Santo. Desta forma, há relação entre a classificação baseada em número de meses secos e os setores geográficos 1 e 2 , sendo que as regiões com quatro a seis e sete a oito meses secos pertencem ao setor geográfico 1 e as regiões com zero a três meses secos encontram-se no setor 2. Para eliminar o efeito da setorização geográfica, deve-se limitar a comparação apenas aos campos de dunas de regiões com quatro a seis e sete a oito meses secos pertencentes ao setor geográfico 1. Neste caso, observa-se que apesar do tamanho médio dos campos de dunas das regiões com quatro a seis meses secos ser mais elevado, os valores dos percentis (quartis e mediana) são semelhantes. $O$ tamanho médio mais elevado dos campos de dunas das regiões com quatro a seis meses secos ocorre devido à existência de campo de dunas de tamanho anomalamente grande (Lençóis Maranhenses) nesta região. Este campo de dunas afeta significativamente o valor médio. Por constituir exceção, o tamanho anômalo deste campo de dunas deve depender de condições locais, de modo que não reflete características regionais da zona costeira tais como a pluviosidade e o regime de ventos. 


\begin{tabular}{|l|l|l|l|l|l|l|l|l|l|}
\hline \multicolumn{10}{|c|}{ A/C (Mesomaré) } \\
\hline $\begin{array}{l}\text { Meses } \\
\text { secos }\end{array}$ & Média & $\begin{array}{l}\text { Desvio } \\
\text { padrão }\end{array}$ & $\begin{array}{l}\text { Primeiro } \\
\text { quartil }\end{array}$ & Mediana & $\begin{array}{l}\text { Terceiro } \\
\text { quartil }\end{array}$ & Mínimo & Máximo & Assimetria & N \\
\hline a 3 & 0,85 & 0,59 & 0,36 & 0,82 & 1,17 & 0,21 & 2,05 & 1,09 & 9 \\
\hline 4 a 6 & 1,27 & 2,11 & 0,23 & 0,56 & 1,69 & 0,06 & 14,50 & 4,90 & 55 \\
\hline 7 a 8 & 0,90 & 1,04 & 0,22 & 0,55 & 1,36 & 0,08 & 5,51 & 2,69 & 50 \\
\hline
\end{tabular}

Tabela 3.17 - Estatísticas descritivas da variável A/C para campos de dunas desenvolvidos em regiões com zero a três, quatro a seis e sete a oito meses secos (mesomaré).

A proporção média de zonas de deflação ou recobertas por vegetação (ADV/A) dos campos de dunas desenvolvidos em regiões com zero a três, quatro a seis e sete a oito meses secos é semelhante (Tabela 3.18 e Figura 3.27). Destaca-se apenas a maior variabilidade da proporção destas zonas em campos de dunas de regiões úmidas (zero a três meses secos). Isto é evidenciado pelo maior intervalo interquartil e pelo maior erro padrão (expresso nos gráficos de intervalo de variação).

\begin{tabular}{|c|c|c|c|c|c|c|c|c|c|}
\hline \multicolumn{10}{|c|}{ ADV/A (Mesomaré) } \\
\hline $\begin{array}{l}\text { Meses } \\
\text { secos }\end{array}$ & Média & $\begin{array}{l}\text { Desvio } \\
\text { padrão }\end{array}$ & $\begin{array}{l}\text { Primeiro } \\
\text { quartil }\end{array}$ & Mediana & $\begin{array}{l}\text { Terceiro } \\
\text { quartil }\end{array}$ & Mínimo & Máximo & Assimetria & $\mathbf{N}$ \\
\hline 0 a 3 & 0,27 & 0,22 & 0,08 & 0,28 & 0,45 & 0,00 & 0,62 & 0,50 & 9 \\
\hline 4 a 6 & 0,25 & 0,20 & 0,10 & 0,21 & 0,36 & 0,00 & 0,95 & 1,15 & 55 \\
\hline 7 a 8 & 0,29 & 0,18 & 0,17 & 0,29 & 0,37 & 0,00 & 0,76 & 0,75 & 50 \\
\hline
\end{tabular}

Tabela 3.18 - Estatísticas descritivas da variável ADV/A para campos de dunas desenvolvidos em regiões com zero a três, quatro a seis e sete a oito meses secos.

Em relação à forma $(P / \sqrt{A})$, os campos de dunas de regiões mais úmidas (zero a três meses secos) são mais alongados (valores mais elevados de $P / \sqrt{A}$ ) que os campos de dunas das regiões com quatro a seis e sete a oito meses secos, os quais apresentam forma semelhante (Tabela 3.19 e Figura 3.27). 


\begin{tabular}{|l|l|l|l|l|l|l|l|l|l|}
\hline \multicolumn{10}{|c|}{$P / \sqrt{A}$ (Mesomaré) } \\
\hline $\begin{array}{l}\text { Meses } \\
\text { secos }\end{array}$ & Média & $\begin{array}{l}\text { Desvio } \\
\text { padrão }\end{array}$ & $\begin{array}{l}\text { Primeiro } \\
\text { quartil }\end{array}$ & Mediana & $\begin{array}{l}\text { Terceiro } \\
\text { quartil }\end{array}$ & Mínimo & Máximo & Assimetria & N \\
\hline 0 a 3 & 11,93 & 3,30 & 9,27 & 12,27 & 14,04 & 7,78 & 18,26 & 0,69 & 9 \\
\hline 4 a 6 & 10,92 & 3,18 & 8,74 & 10,41 & 12,22 & 5,20 & 19,16 & 0,81 & 55 \\
\hline 7 a 8 & 10,46 & 3,37 & 7,61 & 9,37 & 13,16 & 5,81 & 19,38 & 0,75 & 50 \\
\hline
\end{tabular}

Tabela 3.19 - Estatísticas descritivas da variável $P / \sqrt{A}$ para campos de dunas desenvolvidos em regiões com zero a três, quatro a seis e sete a oito meses secos.

A distância de migração relativa dos campos de dunas de regiões mais úmidas (expressa pela relação $\mathrm{D} / \mathrm{C}$ ) é menor que a dos campos de dunas de regiões mais secas (Tabela $3.20 \mathrm{e}$ Figura 3.27).

\begin{tabular}{|l|l|l|l|l|l|l|l|l|l|}
\hline \multicolumn{10}{|c|}{$\mathrm{D} / \mathrm{C}$ (Mesomaré) } \\
\hline $\begin{array}{l}\text { Meses } \\
\text { secos }\end{array}$ & Média & $\begin{array}{l}\text { Desvio } \\
\text { padrão }\end{array}$ & $\begin{array}{l}\text { Primeiro } \\
\text { quartil }\end{array}$ & Mediana & $\begin{array}{l}\text { Terceiro } \\
\text { quartil }\end{array}$ & Mínimo & Máximo & Assimetria & N \\
\hline 0 a 3 & 0,11 & 0,06 & 0,09 & 0,10 & 0,14 & 0,03 & 0,25 & 1,37 & 8 \\
\hline 4 a 6 & 0,45 & 0,40 & 0,25 & 0,37 & 0,53 & 0,11 & 2,76 & 4,44 & 48 \\
\hline 7 a 8 & 0,45 & 0,35 & 0,22 & 0,33 & 0,61 & 0,07 & 2,02 & 2,49 & 43 \\
\hline
\end{tabular}

Tabela 3.20 - Estatísticas descritivas da variável D/C para campos de dunas desenvolvidos em regiões com zero a três, quatro a seis e sete a oito meses secos.
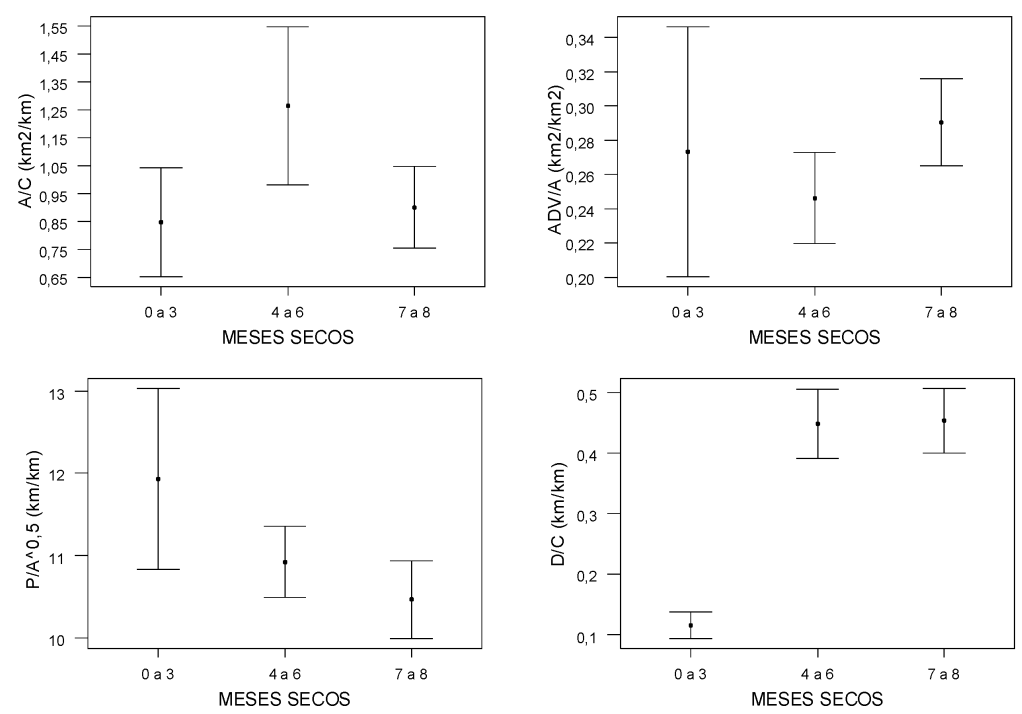

Figura 3.27 - Gráficos de intervalo de variação das variáveis $\mathrm{A} / \mathrm{C}, \mathrm{ADV} / \mathrm{A}, P / \sqrt{A}$ e $\mathrm{D} / \mathrm{C}$ em termos do número de meses secos (Mesomaré). 
As regiões mais secas distinguem-se principalmente pela maior variação de tamanho de seus campos de dunas e pela maior proporção de campos de dunas de tamanho muito elevado. A ocorrência de campos de dunas maiores nas regiões mais secas é indício de que a pluviosidade influencia o crescimento dos campos de dunas. Apesar da redução da pluviosidade proporcionar a formação de campos de dunas maiores, parece haver outras variáveis, que apresentam capacidade de superar o efeito da pluviosidade no desenvolvimento de campos de dunas.

A presença de campos de dunas de tamanho relativamente elevado em regiões desprovidas de mês seco sugere que a variação de pluviosidade em escala mensal não restringe a formação de campos de dunas costeiros. O mesmo pode ser dito acerca da sazonalidade da pluviosidade. Outra característica que diferencia as regiões com zero a três meses secos das regiões com quatro a seis e sete a oito meses secos é a distribuição das chuvas ao longo do ano. As regiões mais úmidas apresentam chuvas mais bem distribuídas enquanto que nas regiões mais secas as chuvas concentram-se em determinado período. Desta forma, a sazonalidade é mais acentuada nas regiões mais secas. A diminuição da sazonalidade poder atuar como redutor do tamanho dos campos de dunas, mas não impede o seu desenvolvimento.

Há semelhança na proporção média de zonas de deflação ou vegetadas nos campos de dunas de regiões úmidas a secas. Tanto a deflação quanto o desenvolvimento de vegetação podem ser favorecidos pela redução do aporte eólico primário (fornecimento de sedimentos da área fonte para o campo de dunas). O desenvolvimento de vegetação seria mais favorecido em campos de dunas de áreas úmidas enquanto que a deflação predominaria nos de áreas mais secas. Neste caso, campos de dunas de áreas úmidas e secas poderiam possuir proporções semelhantes de zonas de deflação ou vegetadas (ADV/A). Condições climáticas muito favoráveis ao transporte eólico, como por exemplo longo período seco e ventos freqüentes de velocidade elevada, podem ser nocivas ao desenvolvimento de campos de dunas com elevada proporção de dunas livres caso haja baixa disponibilidade de sedimentos na área fonte.

Os campos de dunas de regiões mais úmidas apresentaram valores mais elevados de $P / \sqrt{A}$, indicativos de formas mais alongadas. Deve ser destacado que pode haver campos de dunas alongados com distância de avanço (D/C) pequena ou grande. Campos de dunas desenvolvidos em linha de costa longa e com pequena distância de avanço produzem formas alongadas de modo transversal ao rumo de migração. Estas formas seriam características de campos de dunas em estágio inicial de desenvolvimento ou de campos de dunas de baixo aporte 
eólico. Neste caso, a frente de avanço será mais extensa e a migração e crescimento do campo de dunas precisará de elevado volume de sedimentos em curto intervalo de tempo. Já campos de dunas de linha de costa curta e com distância de avanço elevada geram formas alongadas no sentido do rumo de migração. Este tipo de alongamento estaria associado a campos de dunas em estágio mais avançado de desenvolvimento ou a costa de aporte eólico elevado. Nas regiões úmidas sob regime de mesomaré, há predomínio de campos de dunas com rumo de avanço mais perpendicular à costa. Logo, o alongamento elevado destes campos de dunas pode indicar condições de baixo aporte sedimentar ou que tais campos de dunas encontram-se em estágio inicial de desenvolvimento. A maior umidade desta região pode constituir fator redutor do aporte sedimentar eólico.

Utilizou-se o conjunto da variáveis medidas para a definição de grupos morfométricos de campos de dunas, os quais foram comparados com as classes de campos de dunas definidas em termos do número de meses secos. Foram realizadas duas comparações. Na primeira utilizaramse campos de dunas de regiões com amplitude de maré variável (micromaré a macromaré). A segunda comparação visou à eliminação de eventual influência da amplitude de maré de modo que envolveu apenas campos de dunas de zona sob regime de mesomaré.

No primeiro caso, os campos de dunas foram separados em três grupos morfométricos (grupos 1, 2 e 3), que abrangem regiões com zero a três, quatro a seis e sete a oito meses secos. No segundo caso, foram definidos apenas dois grupos morfométricos (grupos 1 e 2), pois para melhorar a confiabilidade da análise foi necessário unir os campos de dunas de regiões com quatro a seis e sete a oito meses secos em uma mesma categoria (quatro a oito meses secos). Em ambos os casos, o teste qui-quadrado revelou não haver associação entre as categorias de campos de dunas definidas em termos do número de meses secos e os grupos morfométricos (tabelas 3.21 e 3.22). 


\begin{tabular}{|l|l|l|l|l|l|}
\hline Número de meses secos (Total) & Grupo 1 & Grupo 2 & Grupo 3 & Total \\
\hline 0 a 3 & Freq. observada & 13 & 15 & 25 & 53 \\
\cline { 2 - 7 } & Freq. esperada & 20,09 & 14,90 & 18,01 & 53,00 \\
\hline \multirow{4}{4}{ a 6 } & Freq. observada & 27 & 17 & 15 & 57 \\
\cline { 2 - 6 } & Freq. esperada & 21,61 & 16,02 & 19,37 & 57,00 \\
\hline \multirow{7}{7}{ a 8 } & Freq. observada & 20 & 11 & 12 & 43 \\
\cline { 2 - 6 } & Freq. esperada & 16,30 & 12,08 & 14,61 & 43,00 \\
\hline \multirow{7}{*}{ Total } & Freq. observada & 58 & 43 & 52 & 153 \\
\cline { 2 - 6 } & Freq. esperada & 58,00 & 43,00 & 52,00 & 153,00 \\
\hline \multicolumn{7}{|c|}{ Teste qui-quadrado } \\
\hline Qui-quadrado $=8,198$ Graus de liberdade $=4$ & $\mathrm{p}=0,085$ \\
\hline
\end{tabular}

Tabela 3.21 - Tabela de correspondência e teste qui-quadrado para avaliar a dependência entre os grupos morfológicos 1,2 e 3 e o número de meses secos (total). $\mathrm{O}$ valor de $\mathrm{p}$ indica que não há relação entre grupos morfológicos e categorias definidas em termos de número de meses secos. Neste caso, aceita-se a hipótese de que as freqüências de contagem observadas e esperadas são equivalentes.

\begin{tabular}{|l|l|l|l|l|}
\hline Número de meses secos (Mesomaré) & Grupo 1 & Grupo 2 & Total \\
\hline 0 a 3 & Freq. observada & 5 & 3 & 8 \\
\cline { 2 - 5 } & Freq. esperada & 6,04 & 1,96 & 8,00 \\
\hline \multirow{2}{*}{ a a 8 } & Freq. observada & 69 & 21 & 90 \\
\cline { 2 - 5 } & Freq. esperada & 67,96 & 22,64 & 90,00 \\
\hline \multirow{2}{*}{ Total } & Freq. observada & 74 & 24 & 98 \\
\cline { 2 - 5 } & Freq. esperada & 74,00 & 24,00 & 98,00 \\
\hline \multicolumn{5}{|c|}{ Teste qui-quadrado } \\
\hline Qui-quadrado $=0,797$ & Graus de liberdade $=1$ & $\mathrm{p}=0,372$ \\
\hline
\end{tabular}

Tabela 3.22 - Tabela de correspondência e teste qui-quadrado para avaliar a dependência entre grupos morfológicos (grupos 1 e 2) e o número de meses secos (mesomaré). $\mathrm{O}$ valor de $\mathrm{p}$ indica que não há relação entre grupos morfológicos e categorias definidas em termos de número de meses secos. Neste caso, aceita-se a hipótese de que as freqüências de contagem observadas e esperadas são equivalentes.

A análise de agrupamento acompanhada de teste qui-quadrado indica que variações de pluviosidade não imprimem um conjunto de características morfométricas particulares nos campos de dunas da costa brasileira. Assim, a influência da pluviosidade é mais nítida em aspectos particulares, como por exemplo na proporção de zonas de deflação ou vegetadas (ADV/A), do que no conjunto de aspectos dos campos de dunas. 


\subsubsection{Comparação entre campos de dunas em termos da velocidade e freqüência dos ventos}

A relação entre regime de ventos (velocidade e freqüência de atuação) e tamanho e forma de campos de dunas foi avaliada por meio da comparação entre classes de campos de dunas formadas sob regime de ventos distintos, porém sob mesmo regime de maré, e número de meses secos. Para cada regime de maré e número de meses secos, foram estabelecidas duas classes de campos de dunas, as quais foram definidas pela freqüência de atuação dos ventos dos meses de janeiro e julho. Estas classes de campos de dunas foram comparadas entre si.

Os ventos mais freqüentes atuantes durante os meses de janeiro e julho também apresentam velocidade média maior que a dos ventos menos freqüentes. Portanto, a eficácia dos ventos mais freqüentes no transporte de sedimentos é favorecida também pela sua velocidade mais elevada.

Valores mais elevados de $\mathrm{A} / \mathrm{C}$ correlacionam-se à maiores freqüências de atuação dos ventos de janeiro (Tabela 3.23 e Figura 3.28). Isto sugere que os ventos de janeiro são mais importantes para o crescimento dos campos de dunas, de modo que devem ser mais efetivos no transporte eólico que os ventos do mês de julho. O transporte de sedimentos eólicos pelos ventos atuantes durante o mês de julho é prejudicado pela maior freqüência de chuvas neste período. Isto é mais acentuado nos campos de dunas das regiões com quatro a oito meses secos, as quais são caracterizadas por inverno mais chuvoso e portanto, por maior sazonalidade de precipitação pluviométrica. Também nota-se que os campos de dunas de regiões mais secas e de costa de mesomaré apresentam valores mais elevados de A/C. Isto indica que estes dois fatores também contribuem para a elevação do tamanho dos campos de dunas. 


\begin{tabular}{|c|c|c|c|c|c|c|c|c|c|c|c|}
\hline \multicolumn{12}{|c|}{$\mathbf{A} / \mathbf{C}$} \\
\hline & $\begin{array}{l}\text { Freq. ventos } \\
\text { (janeiro) }\end{array}$ & $\begin{array}{l}\text { Freq. ventos } \\
\text { (julho) }\end{array}$ & Média & $\begin{array}{l}\text { Desv. } \\
\text { pad. }\end{array}$ & Q1 & Mediana & Q3 & Mín. & Máx. & Assim. & $\mathbf{N}$ \\
\hline \multirow{2}{*}{$\begin{array}{l}\text { Mesomaré } \\
\text { e } 4 \text { a } 8 \\
\text { meses } \\
\text { secos }\end{array}$} & $\begin{array}{l}43 \text { a } 54 \% \\
(3,6 \text { a } 5,1 \mathrm{~m} / \mathrm{s})\end{array}$ & $\begin{array}{l}58 \% \\
(5,7 \text { a } 8,2 \mathrm{~m} / \mathrm{s})\end{array}$ & 0,96 & 0,67 & 0,26 & 0,90 & 1,49 & 0,08 & 2,3 & 0,28 & 28 \\
\hline & $\begin{array}{l}64 \% \\
(5,7 \text { a } 8,2 \mathrm{~m} / \mathrm{s})\end{array}$ & \begin{tabular}{|l|}
39 a $44 \%$ \\
$(5,7$ a $8,2 \mathrm{~m} / \mathrm{s})$
\end{tabular} & 2,01 & 3,12 & 0,33 & 0,92 & 2,22 & 0,12 & 14,5 & 3,32 & 22 \\
\hline \multirow{2}{*}{$\begin{array}{l}\text { Micromaré } \\
\text { e } 0 \text { a } 3 \\
\text { meses } \\
\text { secos }\end{array}$} & $\begin{array}{l}26 \text { a } 32 \% \\
(3,6 \text { a } 8,2 \mathrm{~m} / \mathrm{s})\end{array}$ & $\begin{array}{l}21 \text { a } 29 \% \\
(3,6 \text { a } 8,2 \mathrm{~m} / \mathrm{s})\end{array}$ & 0,68 & 0,94 & 0,15 & 0,3 & 0,62 & 0,10 & 3,85 & 2,23 & 35 \\
\hline & $\begin{array}{l}43 \text { a } 54 \% \\
(5,7 \text { a } 8,2 \mathrm{~m} / \mathrm{s})\end{array}$ & $\begin{array}{l}39 \text { a } 44 \% \\
(5,7 \text { a } 8,2 \mathrm{~m} / \mathrm{s})\end{array}$ & 0,83 & 0,45 & 0,39 & 0,9 & 1,16 & 0,34 & 1,76 & 0,66 & 11 \\
\hline
\end{tabular}

Tabela 3.23 - Estatísticas descritivas da variável A/C para campos de dunas agrupados pela freqüência de atuação dos ventos dos meses de janeiro e julho (zonas sob regime de mesomaré e quatro a oito meses secos e sob regime de micromaré e zero a três meses secos). Q1: primeiro quartil, Q3: terceiro quartil.

Não é notada relação entre a freqüência e velocidade dos ventos e a proporção de áreas de deflação ou vegetadas (ADV/A) (Tabela 3.24 e Figura 3.28). Isto sugere que o regime de ventos influencia de modo parcial a formação de zonas de deflação ou vegetadas.

\begin{tabular}{|c|c|c|c|c|c|c|c|c|c|c|c|}
\hline \multicolumn{12}{|c|}{ ADV/A } \\
\hline & $\begin{array}{l}\text { Freq. ventos } \\
\text { (janeiro) }\end{array}$ & $\begin{array}{l}\text { Freq. ventos } \\
\text { (julho) }\end{array}$ & Média & $\begin{array}{l}\text { Desv. } \\
\text { pad. }\end{array}$ & Q1 & Mediana & Q3 & Mín. & Máx. & Assim. & $\mathbf{N}$ \\
\hline \multirow{2}{*}{$\begin{array}{l}\text { Mesomaré } \\
\text { e } 4 \text { a } 8 \\
\text { meses } \\
\text { secos }\end{array}$} & $\begin{array}{l}43 \text { a } 54 \% \\
(3,6 \text { a } 5,1 \mathrm{~m} / \mathrm{s})\end{array}$ & $\begin{array}{l}58 \% \\
(5,7 \text { a } 8,2 \mathrm{~m} / \mathrm{s})\end{array}$ & 0,27 & 0,20 & 0,11 & 0,24 & 0,39 & 0 & 0,76 & 0,62 & 28 \\
\hline & $\begin{array}{l}64 \% \\
(5,7 \text { a } 8,2 \mathrm{~m} / \mathrm{s})\end{array}$ & \begin{tabular}{|l|}
39 a $44 \%$ \\
$(5,7$ a $8,2 \mathrm{~m} / \mathrm{s})$
\end{tabular} & 0,25 & 0,24 & 0,06 & 0,17 & 0,42 & 0 & 0,95 & 1,38 & 22 \\
\hline \multirow{2}{*}{$\begin{array}{l}\text { Micromaré } \\
\text { e } 0 \text { a } 3 \\
\text { meses } \\
\text { secos }\end{array}$} & $\begin{array}{l}26 \text { a } 32 \% \\
(3,6 \text { a } 8,2 \mathrm{~m} / \mathrm{s})\end{array}$ & $\begin{array}{l}21 \text { a } 29 \% \\
(3,6 \text { a } 8,2 \mathrm{~m} / \mathrm{s})\end{array}$ & 0,19 & 0,14 & 0,06 & 0,18 & 0,31 & 0,0 & 0,51 & 0,50 & 36 \\
\hline & $\begin{array}{l}43 \text { a } 54 \% \\
(5,7 \text { a } 8,2 \mathrm{~m} / \mathrm{s})\end{array}$ & $\begin{array}{l}39 \text { a } 44 \% \\
(5,7 \text { a } 8,2 \mathrm{~m} / \mathrm{s})\end{array}$ & 0,37 & 0,18 & 0,24 & 0,36 & 0,42 & 0,2 & 0,82 & 1,83 & 10 \\
\hline
\end{tabular}

Tabela 3.24 - Estatísticas descritivas da variável ADV/A para campos de dunas agrupados pela freqüência de atuação dos ventos dos meses de janeiro e julho (zonas sob regime de mesomaré e quatro a oito meses secos e sob regime de micromaré e zero a três meses secos). Q1: primeiro quartil, Q3: terceiro quartil.

Para campos de dunas desenvolvidos sob mesmo regime de chuvas e de maré, nota-se correlação entre a geometria externa dos campos de dunas e a freqüência de atuação dos ventos de janeiro. Campos de dunas mais alongados relacionam-se a ventos de janeiro com menor freqüência de atuação (Tabela 3.25 e Figura 3.28). Ventos menos freqüentes proporcionariam 
menor avanço. Isto acarretaria em formas mais alongadas para campos de dunas com migração transversal à costa (linha de costa muito mais longa que a distância de avanço).

\begin{tabular}{|c|c|c|c|c|c|c|c|c|c|c|c|}
\hline \multicolumn{12}{|c|}{$P / \sqrt{A}$} \\
\hline & $\begin{array}{l}\text { Freq. ventos } \\
\text { (janeiro) }\end{array}$ & $\begin{array}{l}\text { Freq. ventos } \\
\text { (julho) }\end{array}$ & Média & $\begin{array}{l}\text { Desv. } \\
\text { pad. }\end{array}$ & Q1 & Mediana & Q3 & Mín. & Máx. & Assim. & $\mathbf{N}$ \\
\hline \multirow{2}{*}{$\begin{array}{l}\text { Mesomaré } \\
\text { e } 4 \text { a } 8 \\
\text { meses } \\
\text { secos }\end{array}$} & $\begin{array}{l}43 \text { a } 54 \% \\
(3,6 \text { a } 5,1 \mathrm{~m} / \mathrm{s})\end{array}$ & $\begin{array}{l}58 \% \\
(5,7 \text { a } 8,2 \mathrm{~m} / \mathrm{s})\end{array}$ & 11,44 & 3,37 & 8,45 & 11,12 & 14,14 & 5,80 & 18,20 & 0,19 & 28 \\
\hline & $\begin{array}{l}64 \% \\
(5,7 \text { a } 8,2 \mathrm{~m} / \mathrm{s})\end{array}$ & $\begin{array}{l}39 \text { a } 44 \% \\
(5,7 \text { a } 8,2 \mathrm{~m} / \mathrm{s})\end{array}$ & 10,28 & 2,26 & 8,38 & 10,19 & 11,56 & 7,08 & 16,00 & 0,78 & 22 \\
\hline \multirow{2}{*}{$\begin{array}{l}\text { Micromaré } \\
\text { e } 0 \text { a } 3 \\
\text { meses } \\
\text { secos }\end{array}$} & $\begin{array}{l}26 \text { a } 32 \% \\
(3,6 \text { a } 8,2 \mathrm{~m} / \mathrm{s})\end{array}$ & $\begin{array}{l}21 \text { a } 29 \% \\
(3,6 \text { a } 8,2 \mathrm{~m} / \mathrm{s})\end{array}$ & 14,57 & 6,06 & 10,10 & 13,06 & 18,65 & 5,53 & 30,22 & 0,63 & 37 \\
\hline & $\begin{array}{l}43 \text { a } 54 \% \\
(5,7 \text { a } 8,2 \mathrm{~m} / \mathrm{s})\end{array}$ & $\begin{array}{l}39 \text { a } 44 \% \\
(5,7 \text { a } 8,2 \mathrm{~m} / \mathrm{s})\end{array}$ & 9,24 & 1,80 & 8,32 & 9,59 & 10,09 & 5,67 & 12,13 & $-0,44$ & 11 \\
\hline
\end{tabular}

Tabela 3.25 - Estatísticas descritivas da variável $P / \sqrt{A}$ para campos de dunas agrupados pela freqüência de atuação dos ventos dos meses de janeiro e julho (zonas sob regime de mesomaré e quatro a oito meses secos e sob regime de micromaré e zero a três meses secos). Q1: primeiro quartil, Q3: terceiro quartil.

Assim como foi observado para a variável $P / \sqrt{A}$, a distância de avanço em relação ao comprimento da costa (D/C) de campos de dunas desenvolvidos sob mesmo regime de chuvas e de maré correlaciona-se com a freqüência de atuação dos ventos do mês de janeiro. Desta forma, ventos mais freqüentes se associam a campos de dunas com maior distância de avanço (Tabela 3.26 e Figura 3.28). Isto confirma o que foi suposto através da variável $P / \sqrt{A}$. Portanto, a distância de avanço deve ser significativamente influenciada pela freqüência de atuação dos ventos do período mais seco.

\begin{tabular}{|c|c|c|c|c|c|c|c|c|c|c|c|}
\hline \multicolumn{12}{|c|}{$\mathrm{D} / \mathrm{C}$} \\
\hline & $\begin{array}{l}\text { Freq. ventos } \\
\text { (janeiro) }\end{array}$ & $\begin{array}{l}\text { Freq. ventos } \\
\text { (julho) }\end{array}$ & Média & $\begin{array}{l}\text { Desv. } \\
\text { pad. }\end{array}$ & Q1 & Mediana & Q3 & Mín. & Máx. & Assim. & $\mathbf{N}$ \\
\hline \multirow{2}{*}{$\begin{array}{l}\text { Mesomaré } \\
\text { e } 4 \text { a } 8 \\
\text { meses } \\
\text { secos }\end{array}$} & $\begin{array}{l}43 \text { a } 54 \% \\
(3,6 \text { a } 5,1 \mathrm{~m} / \mathrm{s})\end{array}$ & $\begin{array}{l}58 \% \\
(5,7 \text { a } 8,2 \mathrm{~m} / \mathrm{s})\end{array}$ & 0,35 & 0,25 & 0,18 & 0,28 & 0,47 & 0,07 & 1,08 & 1,51 & 23 \\
\hline & $\begin{array}{l}64 \% \\
(5,7 \text { a } 8,2 \mathrm{~m} / \mathrm{s})\end{array}$ & $\begin{array}{l}39 \text { a } 44 \% \\
(5,7 \text { a } 8,2 \mathrm{~m} / \mathrm{s})\end{array}$ & 0,39 & 0,14 & 0,30 & 0,38 & 0,48 & 0,11 & 0,71 & 0,23 & 18 \\
\hline \multirow{2}{*}{$\begin{array}{l}\text { Micromaré } \\
\text { e } 0 \text { a } 3 \\
\text { meses } \\
\text { secos }\end{array}$} & $\begin{array}{l}26 \text { a } 32 \% \\
(3,6 \text { a } 8,2 \mathrm{~m} / \mathrm{s})\end{array}$ & $\begin{array}{l}21 \text { a } 29 \% \\
(3,6 \text { a } 8,2 \mathrm{~m} / \mathrm{s})\end{array}$ & 0,34 & 0,37 & 0,06 & 0,19 & 0,51 & 0,02 & 1,34 & 1,42 & 20 \\
\hline & $\begin{array}{l}43 \text { a } 54 \% \\
(5,7 \text { a } 8,2 \mathrm{~m} / \mathrm{s})\end{array}$ & $\begin{array}{l}39 \text { a } 44 \% \\
(5,7 \text { a } 8,2 \mathrm{~m} / \mathrm{s})\end{array}$ & 0,93 & 0,41 & 0,61 & 0,86 & 1,17 & 0,54 & 1,93 & 1,55 & 11 \\
\hline
\end{tabular}

Tabela 3.26 - Estatísticas descritivas da variável D/C para campos de dunas agrupados pela freqüência de atuação dos ventos dos meses de janeiro e julho (zonas sob regime de mesomaré e quatro a oito meses secos e sob regime de micromaré e zero a três meses secos). Q1: primeiro quartil, Q3: terceiro quartil. 

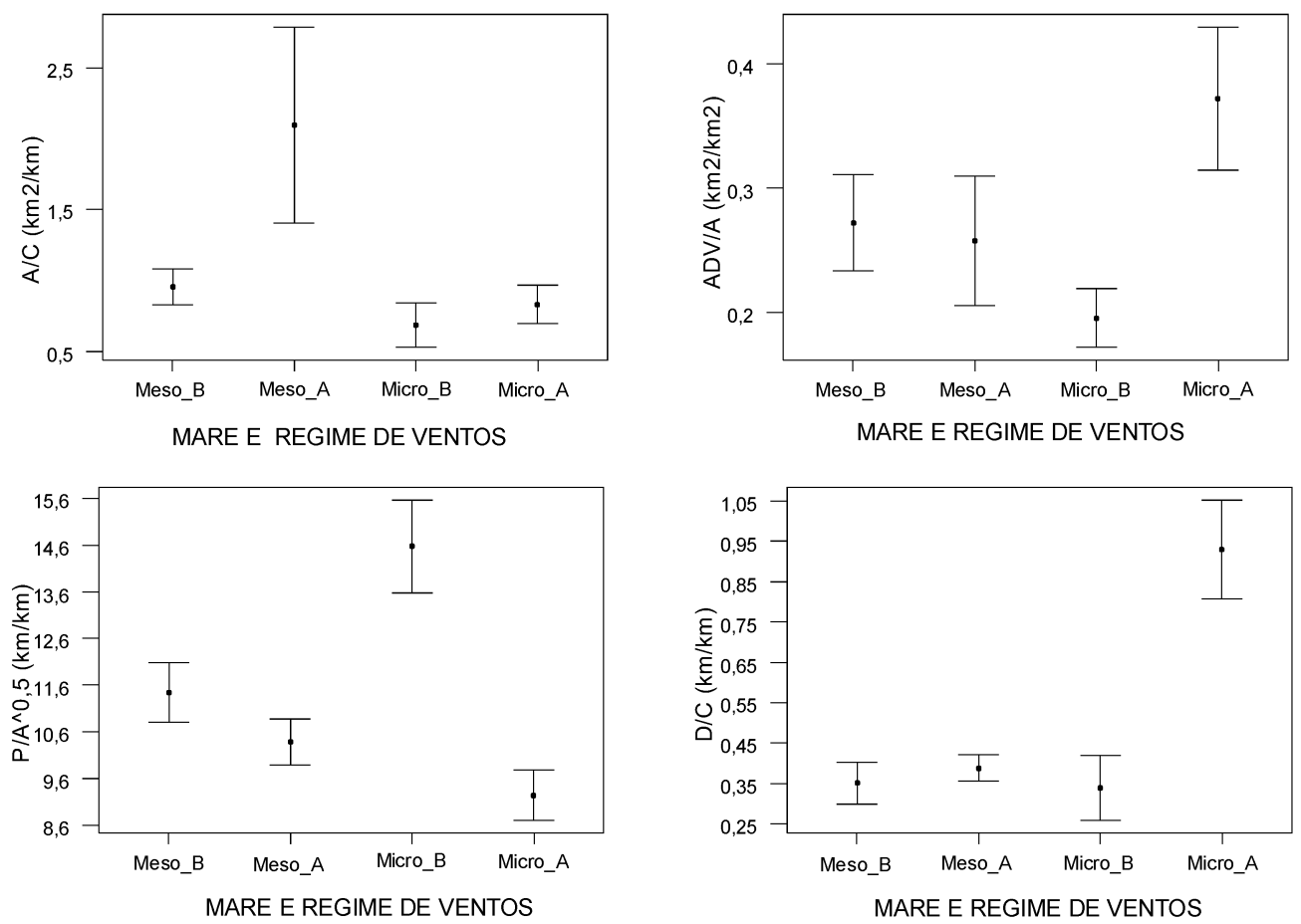

Figura 3.28 - Gráficos de intervalo de variação das variáveis $\mathrm{A} / \mathrm{C}, \mathrm{ADV} / \mathrm{A}, P / \sqrt{A}$ e $\mathrm{D} / \mathrm{C}$ em termos do regime de ventos. Distinguem-se os campos de dunas de região com quatro a oito meses secos e regime de mesomaré (Meso_A e Meso_B) dos campos de dunas de região com zero a três meses secos e regime de micromaré (Micro_A e Micro_B). Meso_A=ventos com freqüência de $64 \%$ em janeiro e Meso_B=ventos com freqüência entre 43 e $54 \%$ em janeiro; Micro_A=ventos com freqüência entre $\overline{4} 3$ e $54 \%$ em janeiro e Micro_B=ventos com freqüência entre 26 e $32 \%$ em janeiro.

As comparações realizadas sugerem que o regime de ventos (freqüência e velocidade) constitui variável importante para a definição do tamanho, geometria externa e distância de avanço dos campos de dunas da costa brasileira. Exceto o tamanho relativo $(\mathrm{A} / \mathrm{C})$, a correlação entre regime de ventos e as demais variáveis só é notada quando se comparam campos de dunas de mesmo regime pluviométrico e de maré. Isto indica que a influência da pluviosidade e da amplitude de maré pode sobrepujar a influência do regime de ventos. 


\subsubsection{Comparação entre campos de dunas em termos da amplitude de maré}

Campos de dunas que se desenvolvem em zonas com regime de mesomarés apresentam área relativa $(\mathrm{A} / \mathrm{C})$ mais elevada que campos de dunas de zonas sob regime de macromarés ou micromarés (tabelas 3.27 e 3.28 e figuras 3.29 e 3.30). Isto sugere que a maré exerce efeito diverso sobre o tamanho dos campos de dunas. O tamanho menor dos campos de dunas de zonas sob regime de macromarés pode ser atribuído à limitação da área de crescimento. Correntes de maré muito intensas provocariam segmentação da costa, através da formação de baías e canais transversais à linha de costa. Estes canais e baías tornariam os segmentos praiais mais curtos. Outro fator que pode reduzir o tamanho dos campos de dunas das zonas sob regime de macromaré é a tendência da maré em transportar os sedimentos arenosos da zona intermaré para a zona de submaré. Esta tendência seria mais efetiva sob regime de macromaré e diminuiria a disponibilidade de areia para alimentação de campos de dunas. $\mathrm{O}$ fator redutor de tamanho dos campos de dunas sob regime de micromaré pode estar associado à menor área praial exposta à ação de ventos de onshore e ao menor volume do reservatório de sedimentos na zona intermarés. Ambas limitações não devem ser tão efetivas em zonas com regime de mesomarés, de modo que estas zonas apresentariam condições mais propícias a aporte eólico costeiro regular e elevado.

\begin{tabular}{|l|l|l|l|l|l|l|l|l|l|}
\hline \multicolumn{2}{|c|}{ A/C (4 a 6 meses secos) } \\
\hline $\begin{array}{l}\text { Amplitude } \\
\text { de maré }\end{array}$ & Média & $\begin{array}{l}\text { Desvio } \\
\text { padrão }\end{array}$ & $\begin{array}{l}\text { Primeiro } \\
\text { quartil }\end{array}$ & Mediana & $\begin{array}{l}\text { Terceiro } \\
\text { quartil }\end{array}$ & Mínimo & Máximo & Assimetria & N \\
\hline Macromaré & 0,34 & 0,27 & 0,14 & 0,28 & 0,38 & 0,09 & 1,12 & 1,82 & 19 \\
\hline Mesomaré & 1,27 & 2,11 & 0,23 & 0,56 & 1,69 & 0,06 & 14,50 & 4,90 & 55 \\
\hline
\end{tabular}

Tabela 3.27 - Estatísticas descritivas da variável A/C para campos de dunas agrupados pela amplitude de maré (quatro a seis meses secos).

\begin{tabular}{|l|l|l|l|l|l|l|l|l|l|}
\hline \multicolumn{10}{|c|}{ A/C (0 a 3 meses secos) } \\
\hline $\begin{array}{l}\text { Amplitude } \\
\text { de maré }\end{array}$ & Média & $\begin{array}{l}\text { Desvio } \\
\text { padrão }\end{array}$ & $\begin{array}{l}\text { Primeiro } \\
\text { quartil }\end{array}$ & Mediana & $\begin{array}{l}\text { Terceiro } \\
\text { quartil }\end{array}$ & Mínimo & Máximo & Assimetria & N \\
\hline Mesomaré & 0,85 & 0,59 & 0,36 & 0,82 & 1,17 & 0,21 & 2,05 & 1,09 & 9 \\
\hline Micromaré & 0,62 & 0,74 & 0,15 & 0,34 & 0,90 & 0,07 & 3,85 & 2,30 & 78 \\
\hline
\end{tabular}

Tabela 3.28 - Estatísticas descritivas da variável A/C para campos de dunas agrupados pela amplitude de maré (zero a três meses secos). 
A proporção de zonas de deflação ou recobertas por vegetação é maior nos campos de dunas de costas sob regime de mesomaré do que nos de costas sob regime de macromaré (Tabela 3.29 e Figura 3.29). Quando se comparam valores de ADV de campos de dunas de mesomaré com valores obtidos em campos de dunas de micromaré, não se notam grandes diferenças (Tabela 3.30 e Figura 3.30). A menor proporção de zonas de deflação ou cobertas por vegetação observada em campos de dunas de zona de macromaré pode significar aporte mais elevado e/ou mais regular, devido ao maior reservatório de sedimentos na área fonte e à maior área de exposição de sedimentos ao transporte pelo vento. No entanto, a proporção de zonas de deflação ou recobertas por vegetação pode estar relacionada ao tamanho dos campos de dunas. A manutenção de dunas livres em campos de dunas maiores necessita de maior volume de sedimentos. Neste caso, o desenvolvimento de deflação ou vegetação é facilitado caso não existam sedimentos suficientes para o abastecimento contínuo da área fonte praial. A análise da variável $\mathrm{A} / \mathrm{C}$ tornou evidente o tamanho mais reduzido dos campos de dunas sob regime de mesomaré. Assim, a menor proporção de zonas de deflação ou cobertas por vegetação observada nestes campos de dunas pode estar relacionada ao tamanho e não à influência da amplitude de maré sobre o aporte sedimentar.

\begin{tabular}{|l|l|l|l|l|l|l|l|l|l|}
\hline \multicolumn{2}{|c|}{ ADV/A (4 a 6 meses secos) } \\
\hline $\begin{array}{l}\text { Amplitude } \\
\text { de maré }\end{array}$ & Média & $\begin{array}{l}\text { Desvio } \\
\text { padrão }\end{array}$ & $\begin{array}{l}\text { Primeiro } \\
\text { quartil }\end{array}$ & Mediana & $\begin{array}{l}\text { Terceiro } \\
\text { quartil }\end{array}$ & Mínimo & Máximo & Assimetria & N \\
\hline Macromaré & 0,15 & 0,14 & 0,02 & 0,12 & 0,25 & 0,00 & 0,49 & 0,86 & 19 \\
\hline Mesomaré & 0,25 & 0,20 & 0,10 & 0,21 & 0,36 & 0,00 & 0,95 & 1,15 & 55 \\
\hline
\end{tabular}

Tabela 3.29 - Estatísticas descritivas da variável ADV/A para campos de dunas agrupados pela amplitude de maré (quatro a seis meses secos).

\begin{tabular}{|l|l|l|l|l|l|l|l|l|l|}
\hline \multicolumn{2}{|c|}{ ADV/A (0 a 3 meses secos) } \\
\hline $\begin{array}{l}\text { Amplitude } \\
\text { de maré }\end{array}$ & Média & $\begin{array}{l}\text { Desvio } \\
\text { padrão }\end{array}$ & $\begin{array}{l}\text { Primeiro } \\
\text { quartil }\end{array}$ & Mediana & $\begin{array}{l}\text { Terceiro } \\
\text { quartil }\end{array}$ & Mínimo & Máximo & Assimetria & N \\
\hline Mesomaré & 0,27 & 0,22 & 0,08 & 0,28 & 0,45 & 0,00 & 0,62 & 0,50 & 9 \\
\hline Micromaré & 0,21 & 0,19 & 0,06 & 0,19 & 0,33 & 0,00 & 0,82 & 1,22 & 74 \\
\hline
\end{tabular}

Tabela 3.30 - Estatísticas descritivas da variável ADV/A para campos de dunas agrupados pela amplitude de maré (zero a três meses secos). 
O valor médio da variável $P / \sqrt{A}$ aumenta com a diminuição da amplitude de maré (tabelas 3.31 e 3.32 e figuras 3.29 e 3.30 ), sendo que valores mais elevados de $P / \sqrt{A}$ indicam campos de dunas mais alongados. O alongamento dos campos de dunas ocorre principalmente paralelo à direção da linha de costa. Canais de maré transversais à costa são mais freqüentes em zonas sob regime de mesomarés e macromarés. Estes canais consituem barreira ao crescimento de campos de dunas em direção paralela à costa. Isto pode explicar porque os campos de dunas mais alongados estão situados em zona costeira sob regime de micromarés. Além disto, lagunas são feições características do trecho da costa brasileira sob regime de micromaré que possui campos de dunas. As lagunas conferem forma alongada, na direção da linha de costa, à área sobre a qual os campos de dunas podem avançar. Assim, induzem a formação de campos de dunas mais alongados. Também deve ser mencionado o fato de que a zona costeira sob regime de micromaré contém proporção significativa de campos de dunas com rumo de migração subparalelo à costa e praias mais extensas. Isto também favorece a gênese de formas mais alongadas.

\begin{tabular}{|l|l|l|l|l|l|l|l|l|l|}
\hline \multicolumn{10}{|c|}{$P / \sqrt{A}$ (4 a 6 meses secos) } \\
\hline $\begin{array}{l}\text { Amplitude } \\
\text { de maré }\end{array}$ & Média & $\begin{array}{l}\text { Desvio } \\
\text { padrão }\end{array}$ & $\begin{array}{l}\text { Primeiro } \\
\text { quartil }\end{array}$ & Mediana & $\begin{array}{l}\text { Terceiro } \\
\text { quartil }\end{array}$ & Mínimo & Máximo & Assimetria & $\mathbf{N}$ \\
\hline Macromaré & 9,31 & 1,85 & 8,18 & 9,14 & 10,34 & 6,49 & 13,04 & 0,42 & 19 \\
\hline Mesomaré & 10,92 & 3,18 & 8,74 & 10,41 & 12,22 & 5,20 & 19,16 & 0,81 & 55 \\
\hline
\end{tabular}

Tabela 3.31 - Estatísticas descritivas da variável $P / \sqrt{A}$ para campos de dunas agrupados pela amplitude de maré (quatro a seis meses secos).

\begin{tabular}{|l|l|l|l|l|l|l|l|l|l|}
\hline \multicolumn{10}{|c|}{$P / \sqrt{A}$ (0 a 3 meses secos) } \\
\hline $\begin{array}{l}\text { Amplitude } \\
\text { de maré }\end{array}$ & Média & $\begin{array}{l}\text { Desvio } \\
\text { padrão }\end{array}$ & $\begin{array}{l}\text { Primeiro } \\
\text { quartil }\end{array}$ & Mediana & $\begin{array}{l}\text { Terceiro } \\
\text { quartil }\end{array}$ & Mínimo & Máximo & Assimetria & $\mathbf{N}$ \\
\hline Mesomaré & 11,93 & 3,30 & 9,27 & 12,27 & 14,04 & 7,78 & 18,26 & 0,69 & 9 \\
\hline Micromaré & 13,62 & 6,55 & 8,68 & 11,44 & 17,20 & 5,11 & 33,93 & 1,02 & 81 \\
\hline
\end{tabular}

Tabela 3.32 - Estatísticas descritivas da variável $P / \sqrt{A}$ para campos de dunas agrupados pela amplitude de maré (zero a três meses secos).

A variável $\mathrm{D} / \mathrm{C}$ (distância relativa de avanço) apresenta comportamento similar ao da variável $P / \sqrt{A}$, ou seja, a distância relativa de avanço é menor para amplitudes de maré mais elevadas (tabelas 3.33 e 3.34 e figuras 3.29 e 3.30). O maior comprimento da maioria dos campos 
de dunas ocorre na direção do avanço. Logo, campos de dunas mais alongados, que são mais comuns em zonas de menor amplitude de maré, também apresentam maior distância de avanço.

\begin{tabular}{|l|l|l|l|l|l|l|l|l|l|}
\hline \multicolumn{2}{|c|}{ D/C (4 a 6 meses secos) } \\
\hline $\begin{array}{l}\text { Amplitude } \\
\text { de maré }\end{array}$ & Média & $\begin{array}{l}\text { Desvio } \\
\text { padrão }\end{array}$ & $\begin{array}{l}\text { Primeiro } \\
\text { quartil }\end{array}$ & Mediana & $\begin{array}{l}\text { Terceiro } \\
\text { quartil }\end{array}$ & Mínimo & Máximo & Assimetria & N \\
\hline Macromaré & 0,35 & 0,30 & 0,14 & 0,21 & 0,54 & 0,09 & 0,94 & 1,36 & 10 \\
\hline Mesomaré & 0,45 & 0,40 & 0,25 & 0,37 & 0,53 & 0,11 & 2,76 & 4,44 & 48 \\
\hline
\end{tabular}

Tabela 3.33 - Estatísticas descritivas da variável D/C para campos de dunas agrupados pela amplitude de maré (quatro a seis meses secos).

\begin{tabular}{|l|l|l|l|l|l|l|l|l|l|}
\hline \multicolumn{10}{|c|}{ D/C (0 a 3 meses secos) } \\
\hline $\begin{array}{l}\text { Amplitude } \\
\text { de maré }\end{array}$ & Média & $\begin{array}{l}\text { Desvio } \\
\text { padrão }\end{array}$ & $\begin{array}{l}\text { Primeiro } \\
\text { quartil }\end{array}$ & Mediana & $\begin{array}{l}\text { Terceiro } \\
\text { quartil }\end{array}$ & Mínimo & Máximo & Assimetria & N \\
\hline Mesomaré & 0,11 & 0,06 & 0,09 & 0,10 & 0,14 & 0,03 & 0,25 & 1,37 & 8 \\
\hline Micromaré & 0,47 & 0,48 & 0,06 & 0,30 & 0,85 & 0,01 & 1,93 & 1,04 & 48 \\
\hline
\end{tabular}

Tabela 3.34 - Estatísticas descritivas da variável D/C para campos de dunas agrupados pela amplitude de maré (zero a três meses secos).
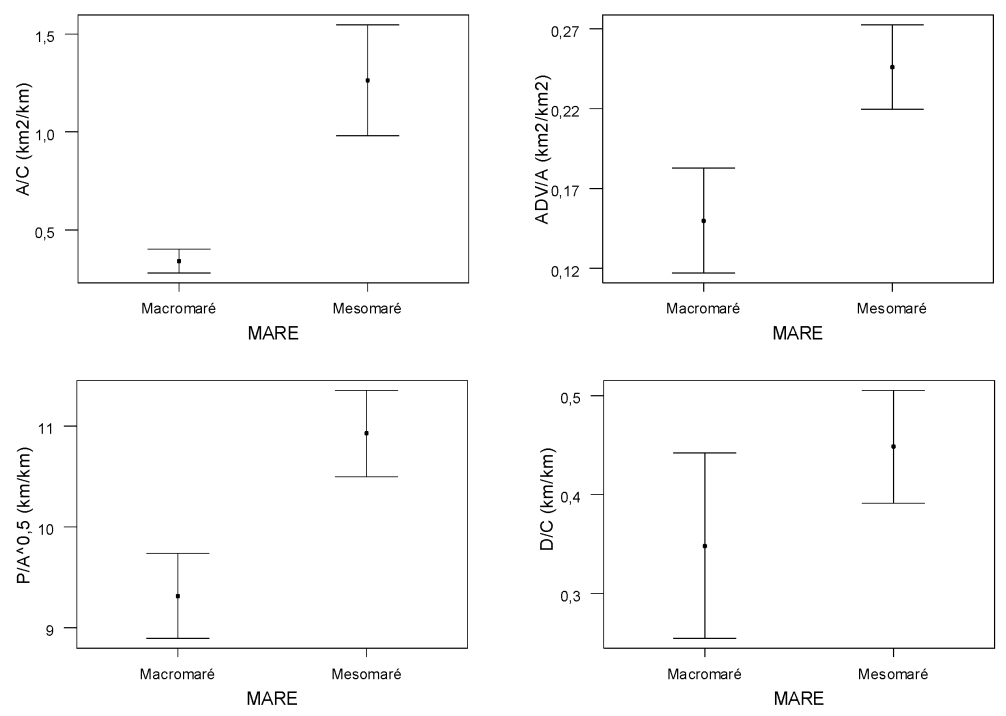

Figura 3.29 - Gráficos de intervalo de variação das variáveis $\mathrm{A} / \mathrm{C}, \mathrm{ADV} / \mathrm{A}, P / \sqrt{A}$ e $\mathrm{D} / \mathrm{C}$ em termos da amplitude de maré (quatro a seis meses secos). 

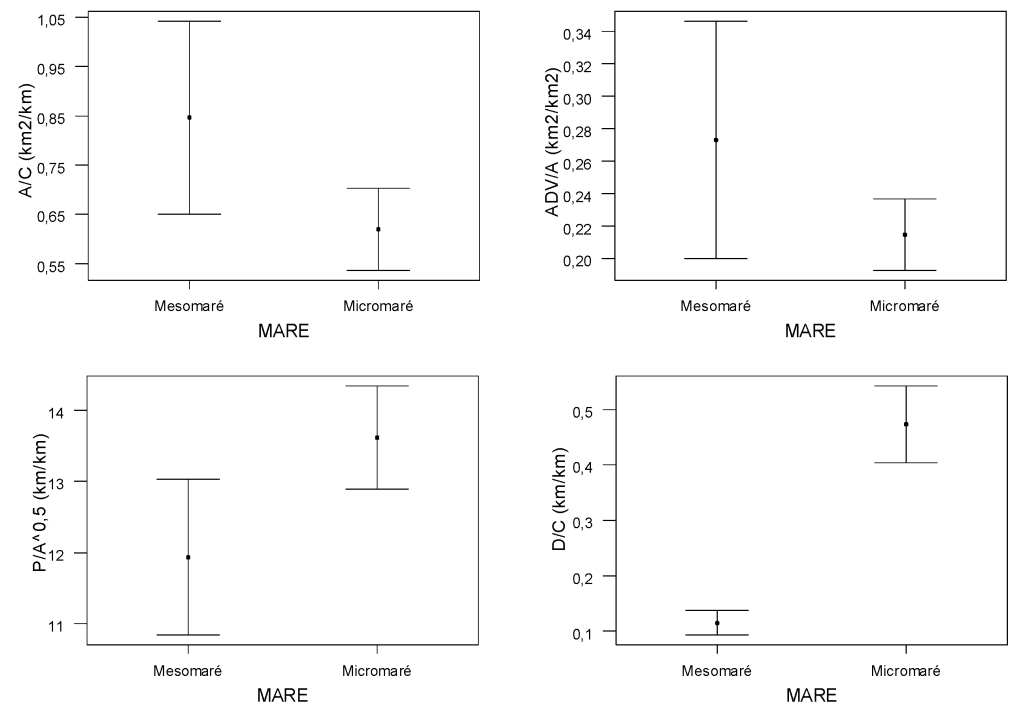

Figura 3.30 - Gráficos de intervalo de variação das variáveis $\mathrm{A} / \mathrm{C}, \mathrm{ADV} / \mathrm{A}, P / \sqrt{A}$ e $\mathrm{D} / \mathrm{C}$ em termos da amplitude de maré (zero a três meses secos).

Grupos morfométricos definidos com base em características morfológicas e tamanho dos campos de dunas foram comparados com categorias de campos de dunas definidas pela amplitude de maré. Assim como nas demais análises deste tipo, foram feitas comparações que envolveram a totalidade dos campos de dunas e comparações entre campos de dunas separados pelo número de meses secos (4 a 6 e 0 a 3). Os campos de dunas de regiões com 0 a 3 meses secos ocorrem em costas sob regime de mesomaré ou micromaré enquanto que os de regiões com 4 a 6 meses secos são de costas com regime de mesomaré ou macromaré. Nas comparações que envolveram a totalidade dos campos de dunas e os campos de dunas de regiões com 0 a 3 meses secos não se observou associação entre a amplitude de maré e grupos morfométricos (tabelas 3.35 e 3.36). No entanto, constatou-se associação entre grupos morfométricos e amplitude de maré para os campos de dunas de regiões com 4 a 6 meses secos (Tabela 3.37). Os campos de dunas de setor com macromaré apresentaram diferenciação extrema de tamanho e morfologia. Já os campos de dunas de costa de mesomaré possuem maior variedade de tamanho e tipos morfológicos de modo que ocorrem em proporção equilibrada entre os dois grupos morfométricos. Ou seja, a intensidade do efeito da macromaré parece ser alta o suficiente para imprimir características morfométricas particulares aos campos de dunas. Isto indica que a capacidade de certa variável em modificar as 
características dos campos de dunas depende dos valores absolutos das variáveis que atuam mutuamente na dinâmica do sistema eólico. Equivale a dizer que a sensibilidade do sistema eólico a determinada variável não é uniforme.

\begin{tabular}{|l|l|l|l|l|l|}
\hline Amplitude de maré (total) & Grupo 1 & Grupo 2 & Grupo 3 & Total \\
\hline \multirow{3}{*}{ Macromaré } & Freq. observada & 3 & 4 & 3 & 10 \\
\cline { 2 - 7 } & Freq. esperada & 3,79 & 2,81 & 3,40 & 10,00 \\
\hline \multirow{2}{*}{ Mesomaré } & Freq. observada & 45 & 24 & 29 & 98 \\
\cline { 2 - 7 } & Freq. esperada & 37,15 & 27,54 & 33,31 & 98,00 \\
\hline \multirow{7}{*}{ Total } & Freq. observada & 10 & 15 & 20 & 45 \\
\cline { 2 - 7 } & Freq. esperada & 17,06 & 12,65 & 15,29 & 45,00 \\
\hline & Freq. observada & 58 & 43 & 52 & 153 \\
\cline { 2 - 6 } & Freq. esperada & 58,00 & 43,00 & 52,00 & 153,00 \\
\hline \multicolumn{7}{|c|}{ Teste qui-quadrado } \\
\hline Qui-quadrado=8 $=8,193$ & Graus de liberdade $=4$ & $\mathrm{p}=0,085$ \\
\hline
\end{tabular}

Tabela 3.35 - Tabela de contingência e teste qui-quadrado para avaliar a dependência entre os grupos morfológicos 1,2 e 3 e a amplitude de maré (total). $\mathrm{O}$ valor de $\mathrm{p}$ indica que não há dependência entre grupos morfológicos e amplitude de maré. Assim, aceita-se a hipótese de que as freqüências de contagem observadas e esperadas são equivalentes. Notar que há valores de freqüência esperada inferiores a 5,0. Neste caso, mesmos valores significativos de $\mathrm{p}$ devem ser interpretados com cautela.

\begin{tabular}{|l|l|l|l|l|}
\hline \multicolumn{2}{|c|}{ Amplitude de maré (0 a 3 meses secos) } & $\begin{array}{l}\text { Grupo } \\
\text { 1 }\end{array}$ & $\begin{array}{l}\text { Grupo } \\
\mathbf{2}\end{array}$ & Total \\
\hline \multirow{2}{*}{ Mesomaré } & Freq. observada & 5 & 3 & 8 \\
\cline { 2 - 5 } & Freq. esperada & 4,53 & 3,47 & 8,00 \\
\hline \multirow{2}{*}{ Ticromaré } & Freq. observada & 25 & 20 & 45 \\
\cline { 2 - 5 } & Freq. esperada & 25,47 & 19,53 & 45,00 \\
\hline \multirow{5}{*}{ Total } & Freq. observada & 30 & 23 & 53 \\
\cline { 2 - 5 } & Freq. esperada & 30,00 & 23,00 & 53,00 \\
\hline \multicolumn{5}{|c|}{ Teste qui-quadrado } \\
\hline Qui-quadrado $=0,133$ & Graus de liberdade $=1$ & $\mathrm{p}=0,715$ \\
\hline
\end{tabular}

Tabela 3.36 - Tabela de contingência (freqüências de contagem) e teste qui-quadrado para avaliar a dependência entre grupos morfológicos (grupos 1 e 2) e a amplitude de maré (zero a três meses secos). $\mathrm{O}$ valor de $\mathrm{p}$ superior a 0,05 indica que não há relação entre grupos morfológicos $\mathrm{e}$ amplitude de maré. Notar que há valores de freqüência esperada inferiores a 5,0. Neste caso, mesmos valores significativos de $\mathrm{p}$ devem ser interpretados com cautela. 


\begin{tabular}{|l|l|l|l|l|}
\hline \multicolumn{2}{|l|}{ Amplitude de maré (4 a 6 meses secos) } & $\begin{array}{l}\text { Grupo } \\
1\end{array}$ & $\begin{array}{l}\text { Grupo } \\
\mathbf{2}\end{array}$ & Total \\
\hline \multirow{2}{*}{ Macromaré } & Freq. observada & 10 & 0 & 10 \\
\cline { 2 - 5 } & Freq. esperada & 5,79 & 4,21 & 10,00 \\
\hline \multirow{2}{*}{ Mesomaré } & Freq. observada & 23 & 24 & 47 \\
\cline { 2 - 5 } & Freq. esperada & 27,21 & 19,79 & 47,00 \\
\hline \multirow{2}{*}{ Total } & Freq. observada & 33 & 24 & 57 \\
\cline { 2 - 5 } & Freq. esperada & 33,00 & 24,00 & 57,00 \\
\hline \multicolumn{5}{|c|}{ Teste qui-quadrado } \\
\hline Qui-quadrado=8,82 & Graus de liberdade=1 $=0,003$ \\
\hline
\end{tabular}

Tabela 3.37 - Tabela de contingência (freqüências de contagem) e teste qui-quadrado para avaliar a dependência entre grupos morfológicos (grupos 1 e 2) e a amplitude de maré (quatro a seis meses secos). $\mathrm{O}$ valor de $\mathrm{p}$ inferior a 0,05 indica que existe dependência entre grupos morfológicos e amplitude de maré. Notar que há valor de freqüência esperada inferior a 5,0. Neste caso, mesmos valores significativos de $\mathrm{p}$ devem ser interpretados com cautela.

\subsubsection{Morfologia e tamanho dos campos de dunas vs. setores geográficos 1, 2 e 3}

Os setores geográficos 1 (Maranhão, Piauí, Ceará e Rio Grande do Norte), 2 (Alagoas, Sergipe, Bahia, Espirito Santo, Rio de Janeiro e São Paulo) e 3 (Paraná, Santa Catarina e Rio Grande do Sul) reúnem conjunto de características particulares no que diz respeito aos fatores que influenciam o desenvolvimento de campos de dunas (número de meses secos, velocidade e freqüência do vento e amplitude de maré). Assim, foi possível avaliar o efeito da influência de fatores associados sobre o tamanho e morfologia dos campos de dunas.

Os setores 1 e 3 apresentam valores médios mais elevados de $\mathrm{A} / \mathrm{C}$, sendo que o primeiro diferencia-se do segundo por apresentar maior variabilidade (indicada pelo maior desvio padrão, assimetria e distância entre quartis) (Tabela 3.38 e Figura 3.32). Apesar dos setores 1 e 3 possuírem regimes de chuvas anuais bem distintos (o setor 1 apresenta estação seca mais bem definida e ventos de janeiro mais freqüentes que o setor 3), ambos contêm campos de dunas com altos valores de A/C. Tanto o setor 1 quanto o 3 apresentam condições relativamente favoráveis ao desenvolvimento de campos de dunas. A elevada variabilidade de $\mathrm{A} / \mathrm{C}$ e a existência de campos de dunas com valores de $\mathrm{A} / \mathrm{C}$ anomalamente elevados sugerem que variáveis locais são de grande importância para o crescimento dos campos de dunas. Ou seja, variáveis locais podem propiciar condições excepcionais para crescimento de campos de dunas. Isto parece ser mais freqüente no setor 1. Observa-se exemplo disto na área de ocorrência dos Lençóis Maranhenses, 
que constitui campo de dunas de tamanho anômalo e ocorre adjacente a campos de dunas bem menores.

\begin{tabular}{|l|l|l|l|l|l|l|l|l|l|}
\hline \multicolumn{2}{|c|}{ A/C } \\
\hline Setor & Média & $\begin{array}{l}\text { Desvio } \\
\text { padrão }\end{array}$ & $\begin{array}{l}\text { Primeiro } \\
\text { quartil }\end{array}$ & Mediana & $\begin{array}{l}\text { Terceiro } \\
\text { quartil }\end{array}$ & Mínimo & Máximo & Assimetria & N \\
\hline 1 & 0,98 & 1,58 & 0,22 & 0,44 & 1,37 & 0,06 & 14,50 & 5,70 & 124 \\
\hline 2 & 0,37 & 0,42 & 0,13 & 0,20 & 0,44 & 0,07 & 2,05 & 2,58 & 36 \\
\hline 3 & 0,84 & 0,83 & 0,22 & 0,58 & 1,16 & 0,10 & 3,85 & 1,78 & 51 \\
\hline
\end{tabular}

Tabela 3.38 - Estatísticas descritivas da variável A/C para os setores 1,2 e 3 . Os setores 1 e 3 apresentam valores médios mais elevados. Notar os elevados valores do desvio padrão, terceiro quartil e valor máximo no setor 1 .

Os setores 1 e 3 possuem proporção de áreas de deflação ou vegetadas (ADV/A) muito semelhantes, de modo que não há diferenças significativas entre eles quanto a esse parâmetro. Já o setor 2 distingue-se dos demais pelas proporções menores de áreas de deflação ou vegetadas (Tabela 3.39 e Figura 3.32) e por possuir campos de dunas relativamente menores. Assim, a maior proporção de áreas de deflação ou vegetadas pode ser explicada em termos do tamanho relativo dos campos de dunas. A manutenção de dunas livres em campos de dunas menores requer menor aporte de areia de modo que os campos de dunas maiores seriam mais facilmente vegetados ou expostos à deflação caso houvesse período prolongado de redução do aporte eólico costeiro. A elevada variabilidade da variável ADV/A também sugere atuação importante de fatores locais. Tal como observado para a variável A/C, é comum observar situação caracterizada por campos de dunas adjacentes com valores bem distintos de ADV/A. Exemplo desta situação ocorre no litoral centro-sul de Santa Catarina na região entre Laguna e Jaguaruna. A norte de Laguna, há campos de dunas com elevada proporção de área de deflação ou vegetada se comparados à campos de dunas situados a sul. Giannini (1993) atribui a diferença ao balanço entre aporte e energia eólica (aporte/energia), a qual determinará a razão influxo/efluxo eólico. Baixo aporte ou energia eólica elevada favoreceriam a redução da razão influxo/efluxo e, portanto, a formação de zonas de deflação ou recobertas por vegetação. Martinho (2004), Giannini et al. (2005) e Martinho et al. (2006) incluem o ângulo de incidência do vento entre os fatores controladores da razão influxo/efluxo. Altos ângulos de incidência diminuiriam estão razão, sendo então mais favoráveis à formação de zonas de deflação ou vegetadas do que ângulos 
baixos. No entanto, os valores de ADV/A podem variar significativamente entre campos de dunas adjacentes e com rumo de migração em relação à linha de costa semelhante. Isto pode ser observado em alguns trechos da costa do Maranhão e do Ceará. Desta forma, pode haver outros fatores locais mais importantes para a formação de zonas de deflação ou vegetadas. O fluxo de sedimentos para o campo de dunas é ditado pela velocidade e distância percorrida pelo vento na área fonte $(f e t c h)$. O preenchimento da capacidade máxima de transporte de areia por vento com dada velocidade requer que este percorra certa distância (distância para haver saturação do fluxo). A saturação do fluxo de saída de sedimentos do campo de dunas (efluxo) é facilitada pela ampla área do campo de dunas enquanto que a saturação do fluxo de entrada (influxo) é dificultada pela pela menor largura da zona intermaré. Desta forma, para um mesmo ângulo de incidência, a largura da área fonte pode constituir fator local importante para o controle do fluxo de entrada de sedimentos no campo de dunas (efluxo). Ventos de alta velocidade atuando sobre área fonte estreita (pequena amplitude de maré) favoreceriam mais a saída do que a entrada de sedimentos no campo de dunas.

\begin{tabular}{|l|l|l|l|l|l|l|l|l|l|}
\hline \multicolumn{2}{|c|}{ ADV/A } \\
\hline Setor & Média & $\begin{array}{l}\text { Desvio } \\
\text { padrão }\end{array}$ & $\begin{array}{l}\text { Primeiro } \\
\text { quartil }\end{array}$ & Mediana & $\begin{array}{l}\text { Terceiro } \\
\text { quartil }\end{array}$ & Mínimo & Máximo & Assimetria & N \\
\hline 1 & 0,25 & 0,19 & 0,10 & 0,22 & 0,36 & 0,00 & 0,95 & 0,94 & 124 \\
\hline 2 & 0,17 & 0,17 & 0,00 & 0,13 & 0,28 & 0,00 & 0,62 & 1,00 & 36 \\
\hline 3 & 0,26 & 0,20 & 0,11 & 0,22 & 0,36 & 0,00 & 0,82 & 1,20 & 47 \\
\hline
\end{tabular}

Tabela 3.39 - Estatísticas descritivas da variável ADV/A para os setores 1, 2 e 3. Salienta-se a semelhança entre os setores 1 e 3 e elevada variabilidade nos três setores. O setor 2 distingue-se dos demais por apresentar maior freqüência de valores menores de ADV/A.

Em relação à geometria dos campos de dunas, observa-se variabilidade relativamente menor em comparação com as demais variáveis. Os campos de dunas mais alongados ocorrem no setor 2 enquanto que os dos setores 1 e 3 apresentam alongamentos menores e semelhantes (Tabela 3.40 e Figura 3.32). Os valores mais elevados de $P / \sqrt{A}$ dos campos de dunas do setor 2 resultam do rumo de avanço transversal à costa, pequena distância de avanço e linha de costa longa. Por apresentar menor variabilidade, esta parece ser uma variável menos sensitiva a fatores locais que as demais variáveis analisadas. Esta variável discrimina melhor os setores 1, 2 e 3 que 
as variáveis $\mathrm{A} / \mathrm{C}$ e $\mathrm{ADV} / \mathrm{A}$ (Figura 3.32). Desta forma, constituiria variável mais indicativa de fatores de atuação mais regional.

\begin{tabular}{|l|l|l|l|l|l|l|l|l|l|}
\hline \multicolumn{2}{|c|}{$P / \sqrt{A}$} \\
\hline Setor & Média & $\begin{array}{l}\text { Desvio } \\
\text { padrão }\end{array}$ & $\begin{array}{l}\text { Primeiro } \\
\text { quartil }\end{array}$ & Mediana & $\begin{array}{l}\text { Terceiro } \\
\text { quartil }\end{array}$ & Mínimo & Máximo & Assimetria & N \\
\hline 1 & 10,49 & 3,12 & 8,16 & 9,97 & 12,17 & 5,20 & 19,38 & 0,86 & 124 \\
\hline 2 & 15,74 & 6,98 & 9,45 & 14,51 & 19,40 & 7,05 & 33,93 & 0,92 & 37 \\
\hline 3 & 11,86 & 5,30 & 8,19 & 10,37 & 15,81 & 5,11 & 25,92 & 1,06 & 53 \\
\hline
\end{tabular}

Tabela 3.40 - Estatísticas descritivas da variável $P / \sqrt{A}$ para os setores 1,2 e 3 . Esta variável apresenta variabilidade menor que as variáveis $\mathrm{A} / \mathrm{C}$ e $\mathrm{ADV} / \mathrm{A}$. Destaca-se a menor diferença relativa entre os quartis e o menor valor do desvio padrão em relação à média.

Assim como a variável $P / \sqrt{A}$, a distância de avanço em relação ao comprimento da linha de costa $(\mathrm{D} / \mathrm{C})$ também discrimina os três setores estudados (Figura 3.32). O maior valor de D/C ocorre no setor 3, seguido, em ordem decrescente, pelos setores 1 e 2 (Tabela 3.41). Esta medida pode estar associada ao ângulo entre o rumo de avanço do campo de dunas e a direção da linha de costa. Poderia pensar-se que campos de dunas com rumo de avanço mais transversal apresentariam maior distância de avanço. Porém, ocorre justamente o contrário. As menores distâncias de avanço, tanto em termos absolutos quanto em relação ao comprimento da linha de costa, ocorrem no setor 2 , onde os campos de dunas apresentam rumo de migração mais transversal à costa. $\mathrm{O}$ setor 3 , onde há grande número de campos de dunas com rumo de migração subparalelo à costa, possui valores maiores de $\mathrm{D} / \mathrm{C}$ enquanto que o setor 1 , onde são freqüentes os campos de dunas com rumo de migração oblíquo, apresenta valores intermediários. O avanço em sentido perpendicular à direção da linha de costa requer maior volume de sedimentos, pois é o caso de máxima expansão da área do campo de dunas (Figura 3.31).

\begin{tabular}{|l|l|l|l|l|l|l|l|l|l|}
\hline \multicolumn{2}{|c|}{ D/C } \\
\hline Setor & Média & $\begin{array}{l}\text { Desvio } \\
\text { padrão }\end{array}$ & $\begin{array}{l}\text { Primeiro } \\
\text { quartil }\end{array}$ & Mediana & $\begin{array}{l}\text { Terceiro } \\
\text { quartil }\end{array}$ & Mínimo & Máximo & Assimetria & N \\
\hline 1 & 0,44 & 0,37 & 0,22 & 0,35 & 0,55 & 0,07 & 2,76 & 3,55 & 101 \\
\hline 2 & 0,14 & 0,17 & 0,02 & 0,09 & 0,16 & 0,01 & 0,81 & 2,70 & 25 \\
\hline 3 & 0,65 & 0,50 & 0,18 & 0,61 & 0,92 & 0,03 & 1,93 & 0,60 & 31 \\
\hline
\end{tabular}

Tabela 3.41 - Estatísticas descritivas da variável D/C para os setores 1, 2 e 3. 
A redução do ângulo de migração em relação à linha de costa $(\alpha)$ aumenta o comprimento da área fonte $(\mathrm{C})$ em relação à largura da frente de avanço, que pode refletir-se em elevação do aporte de sedimentos para o campo de dunas (Figura 3.31). Isto também pode favorecer o avanço, em distância absoluta, de campos de dunas subparalelos à costa. $\mathrm{O}$ aumento do comprimento da linha de costa atua no sentido de diminuir a razão D/C. Assim, este aumento poderia favorecer a elevação da distância de migração em termos absolutos, mas não a elevação da razão D/C. No entanto, nota-se que mesmo a razão $\mathrm{D} / \mathrm{C}$ apresenta valores maiores nos campos de dunas com migração subparalela à costa. Logo, o efeito do aumento de $\mathrm{D}$ é maior que o do aumento de $\mathrm{C}$ sobre a razão $\mathrm{D} / \mathrm{C}$. Isto sugere que o aumento de $\mathrm{D}$ em função do aumento de $\mathrm{C}$, devido à redução de $\alpha$, não é linear. A relação entre a distância de avanço e o ângulo de migração em relação à linha de costa deve influenciar a velocidade de avanço dos campos de dunas. Neste caso, a velocidade de avanço seria maior em campos de dunas com ângulo de avanço menor. No entanto, não deve ser esquecido o efeito de outros fatores sobre a distância e a velocidade de migração, tais como a presença de barreiras e a variação do regime de ventos ou de chuvas.

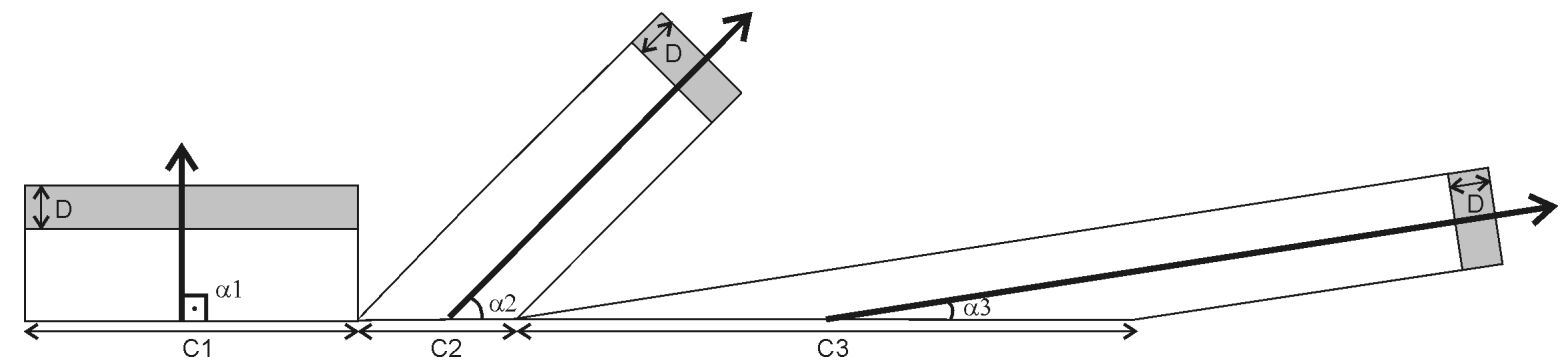

Figura 3.31 - Influência do ângulo de migração em relação à linha de costa $(\alpha)$ sobre a distância de avanço dos campos de dunas. Campos de dunas mais transversais à costa requerem maior volume de areia para alcançar uma mesma distância de avanço (D) que campos de dunas mais paralelos à costa. A área a ser acrescentada para cobrir a mesma distância de avanço é menor para campos de dunas de ângulo de avanço menor. 

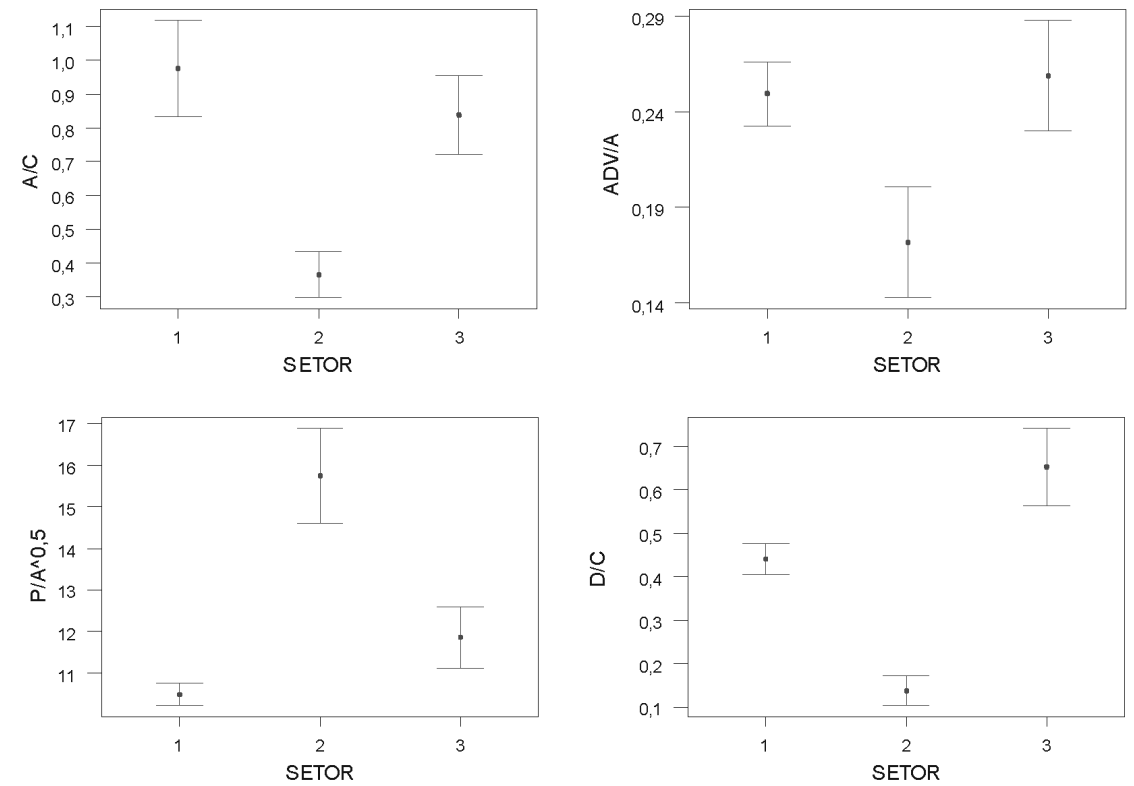

Figura 3.32 - Gráficos de intervalo de variação das variáveis $\mathrm{A} / \mathrm{C}, \mathrm{ADV} / \mathrm{A}, P / \sqrt{A}$ e $\mathrm{D} / \mathrm{C}$ medidas nos setores 1,2 e 3 . O ponto central é o valor médio e as barras correspondem ao erro padrão da média (erro padrão = desvio padrão $/ \sqrt{N}$ ), que é uma medida de variabilidade. Apenas as variáveis $P / \sqrt{A}$ e $\mathrm{D} / \mathrm{C}$ discriminam os três setores. As variáveis $\mathrm{A} / \mathrm{C}$ e $\mathrm{ADV} / \mathrm{A}$ discriminam apenas o setor 2 dos setores 1 e 3 .

O tamanho e as características morfológicas dos campos de dunas dos três setores analisados dependem tanto de fatores de atuação local quanto regional. Tamanho (A/C) e proporção de zonas de deflação ou recobertas por vegetação (ADV/A) parecem ser mais dependentes de fatores locais enquanto que a distância relativa de avanço (D/C) e a forma externa $(P / \sqrt{A})$ variam mais em função de fatores regionais. Todas estas características resultam da dinâmica do sistema eólico costeiro, que parece ser regida tanto por fatores de atuação regional quanto local. Destaca-se o papel dos fatores locais, os quais podem produzir grandes variações das características dos campos de dunas, assim como também definir áreas favoráveis e desfavoráveis à sedimentação eólica.

Os campos de dunas foram separados em três grupos morfológicos, os quais foram definidos em termos da associação entre as variáveis $\mathrm{A} / \mathrm{C}, \mathrm{ADV} / \mathrm{A}, \mathrm{D} / \mathrm{C}$ e $P / \sqrt{A}$. A distribuição dos campos de dunas que constituem os grupos morfológicos 1, 2 e 3 em termos dos setores geográficos 1, 2 e 3 pode ser observada na Tabela 3.42. O valor elevado da estatística qui- 
quadrado e o valor de p inferior a 0,05 indicam que há discrepância significativa entre as freqüências esperadas e observadas, ou seja, rejeita-se a hipótese de distribuição uniforme entre grupos e setores. Logo, a distribuição dos campos de dunas pertencentes aos grupos 1, 2 e 3 pelos setores geográficos 1, 2 e 3 não é homogênea, de modo que deve haver dependência entre setores geográficos e grupos morfológicos. Esta dependência é expressa pela relação entre o grupo morfológico 1 e o setor geográfico 1, entre o setor 2 e o grupo 3 e entre o setor 3 e o grupo 2 .

\begin{tabular}{|l|l|l|l|l|l|}
\hline \multicolumn{2}{|c}{} & Grupo 1 & Grupo 2 & Grupo 3 & Total \\
\hline \multirow{2}{*}{ Setor 1 } & Freq. observada & 45 & 28 & 27 & 100 \\
\cline { 2 - 7 } & Freq. esperada & 39,91 & 28,10 & 33,99 & 100,00 \\
\hline \multirow{2}{*}{ Setor 2 } & Freq. observada & 4 & 3 & 18 & 25 \\
\cline { 2 - 7 } & Freq. esperada & 9,48 & 7,03 & 8,50 & 25,00 \\
\hline \multirow{7}{*}{ Totor 3 } & Freq. observada & 9 & 12 & 7 & 28 \\
\cline { 2 - 7 } & Freq. esperada & 10,61 & 7,87 & 8,50 & 25,00 \\
\hline & Freq. observada & 58 & 43 & 52 & 153 \\
\cline { 2 - 6 } & Freq. esperada & 58,00 & 43,00 & 52,00 & 153,00 \\
\hline \multicolumn{7}{|c|}{ Teste qui-quadrado } \\
\hline Qui-quadrado=21,944 Graus de liberdade $=4$ & $\mathrm{p}=0,000$ \\
\hline
\end{tabular}

Tabela 3.42 - Tabela de contingência e teste qui-quadrado para avaliar a dependência entre os grupos morfológicos 1, 2 e 3 e os setores geográficos 1,2 e 3 . O valor de p indica rejeição da equivalência entre freqüências observadas e esperadas. Neste caso, deve haver relação entre setores geográficos e grupos morfológicos.

\subsubsection{O campo de dunas dos Lençóis Maranhenses}

O campo de dunas dos Lençóis Maranhenses situa-se entre a desembocadura do rio Preguiças (a leste) e uma grande baía estuarina (baía do Tubarão). A direção da linha de costa é aproximadamente N113, o sentido regional da corrente de deriva litorânea é WNW e o rumo de migração das dunas é pouco variável, com azimute próximo a N245. Este é um campo de dunas assimétrico, com área maior a leste, e sentido de avanço transversal à costa $\left(\alpha=48^{\circ}\right)$. Em relação à morfologia das dunas, há franco predomínio de dunas barcanas e cadeias barcanóides separadas entre si por depressões interdunares com centenas de metros de largura, as quais são inundadas durante períodos de chuva ou por elevação da maré (nas zonas mais próximas à costa). À frente do campo de dunas dos Lençóis Maranhenses há extensa área com dunas parabólicas inativas, que avança 90 a $100 \mathrm{~km}$ continente adentro. 
Este campo de dunas apresenta tamanho anomalamente elevado em relação aos demais campos de dunas da costa brasileira, sendo que sua área (A) é duas ordens de magnitude maior que a área da maioria dos campos de dunas e seu valor de $\mathrm{A} / \mathrm{C}$ é uma ordem de magnitude maior que a de 75\% dos campos de dunas. Além disto, apresenta baixíssima proporção de áreas de deflação ou recobertas por vegetação $(\mathrm{ADV} / \mathrm{A}=0,07)$. Portanto, pode ser considerado caso ideal para investigar os fatores que favorecem o aporte eólico em zonas costeiras.

A zona costeira que abrange os Lençóis Maranhenses apresenta clima quente semi-úmido (quatro a seis meses secos), regime de macromarés (amplitude $>4 \mathrm{~m}$ ) e possui como característica fisiográfica marcante a grande quantidade e porte de canais de maré situados a oeste do campo de dunas. A velocidade média dos ventos de nordeste (a $10 \mathrm{~m}$ de altura), responsáveis pelo avanço do campo de dunas, varia entre 3,6 e $5,1 \mathrm{~m} / \mathrm{s}$ no mês de janeiro e entre 5,7 a $8,2 \mathrm{~m} / \mathrm{s}$ no mês de julho. Os ventos de leste são predominantes na região durante os meses de janeiro (64\%) e julho (44\%). Os ventos de nordeste, apesar de direcionarem a migração das dunas e o sentido de avanço do campo de dunas, possuem freqüência de atuação secundária (7\% em julho e 33\% em janeiro). O regime de ventos foi caracterizado por dados coletados entre 1951 e 1972 (DHN, 1974).

O tamanho anômalo dos Lençóis Maranhenses está associado a uma série de condições que favorecem a regularidade e magnitude do aporte sedimentar eólico. Contudo, estas condições podem ter importância distinta, de modo que se coloca como problema a proporção com que cada fator contribui para esta anomalia de aporte.

O volume de sedimentos transportados da área fonte para o campo de dunas depende do tamanho da área exposta à ação do vento. Se a zona intermarés for considerada equivalente a um plano inclinado, sua área será produto da largura (L) pelo comprimento (Com). A largura da zona intermarés depende da amplitude de maré e da sua inclinação, que por sua vez é função da granulação dos sedimentos e da energia das ondas. Assim, para uma mesma inclinação e um mesmo comprimento de linha de costa, a área da zona intermarés será proporcional à amplitude de maré (Figura 3.33). 


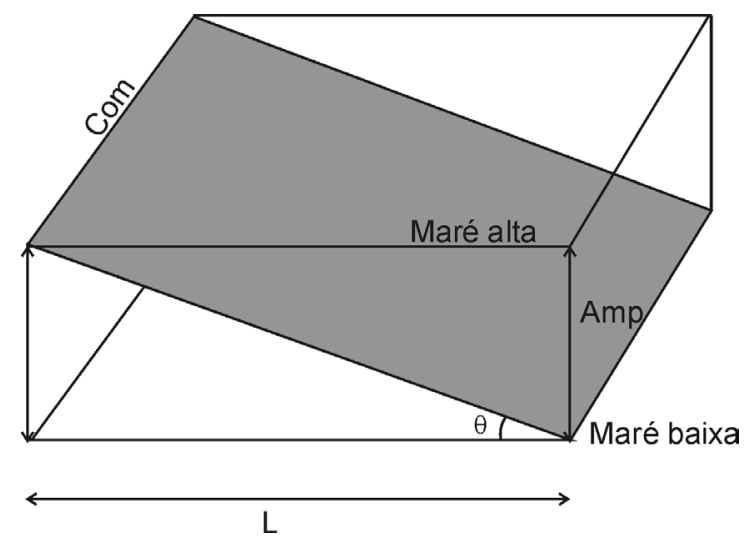

Figura 3.33 - Área da zona intermarés (Área $=A m p \times(C / \operatorname{sen} \theta))$. Amp $=$ amplitude de maré, Com $=$ comprimento da costa, $\mathrm{L}=$ largura da costa e $\theta=$ inclinação da zona intermarés.

A costa maranhense encontra-se sob regime de macromarés (amplitude $>4 \mathrm{~m}$ ). Assim, o aporte eólico neste setor da costa brasileira é favorecido pela ampla zona de intermarés. Porém, além da área de zona intermaré, parece haver outros fatores responsáveis pelo tamanho elevado do campo de dunas dos Lençóis Maranhenses, uma vez que há grande variedade de tamanho de campos de dunas neste setor da costa brasileira. $\mathrm{O}$ mesmo ocorre em relação à velocidade média e freqüência dos ventos e à pluviosidade, pois estas duas variáveis favorecem o aporte eólico regionalmente (no setor 1) e não apenas na região dos Lençóis Maranhenses.

A oeste dos Lençóis Maranhenses, há mudança marcante da fisiografia costeira, a qual passa a ser caracterizada pela ocorrência de grandes baías estuarinas transversais à costa. As correntes de maré enchente e vazante destas baías atuam como obstáculo à corrente de deriva litorânea longitudinal (efeito molhe hidráulico). O bloqueio da corrente de deriva litorânea proporciona o acúmulo dos sedimentos transportados por esta corrente nas adjacências a barlamar destas baías (Figura 3.34). O excesso de sedimentos, devido ao bloqueio da corrente de deriva litorânea pelo efeito molhe hidráulico a oeste dos Lençóis Maranhenses, associado à grande amplitude de maré podem ser os principais fatores responsáveis pelo elevado tamanho em área deste campo de dunas. 


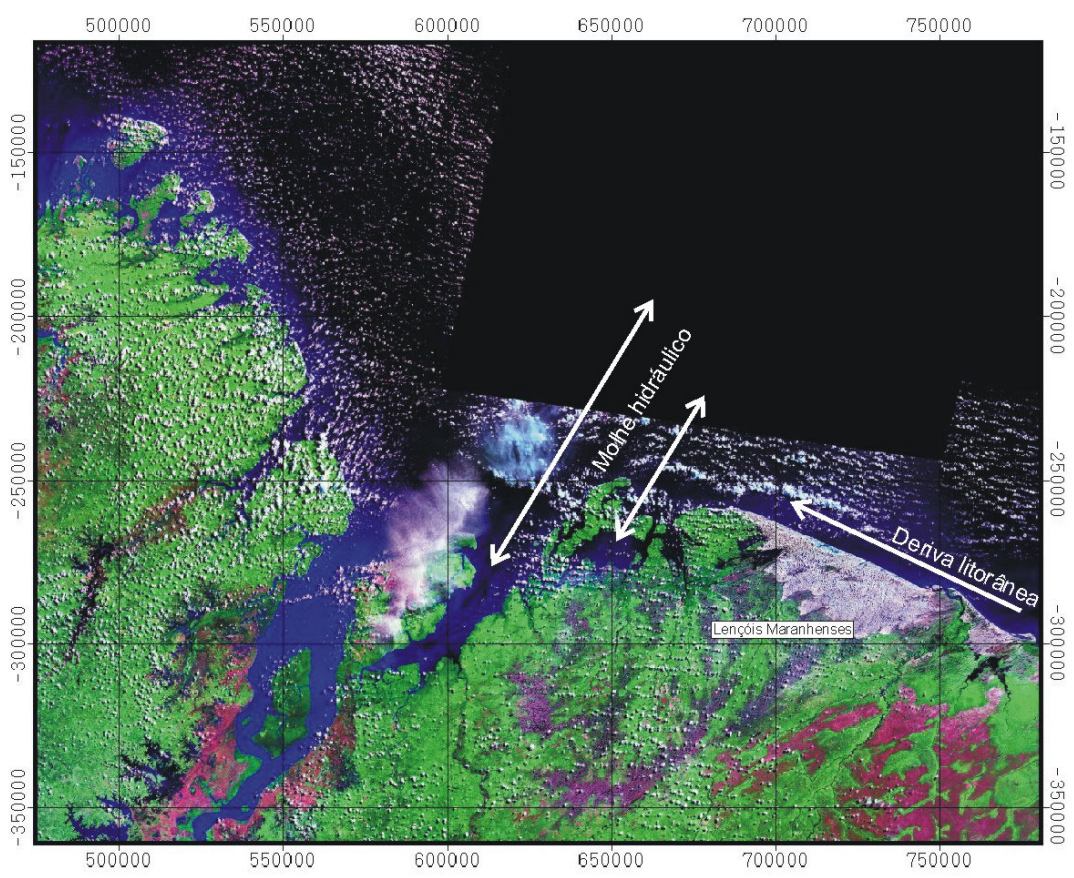

Figura 3.34 - Campos de dunas dos Lençóis Maranhenses. Notar a mudança da fisiografia da linha de costa a oeste dos Lençóis Maranhenses.

Assim, o elevado tamanho do campo de dunas dos Lençóis Maranhenses é atribuído principalmente à manutenção de grande volume de sedimentos na zona intermarés adjacente aos Lençóis Maranhenses. Desta forma, a regularidade do aporte eólico é condicionada pela elevada disponibilidade de sedimentos na área fonte, que resulta do barramento da corrente de deriva litorânea por correntes de maré situadas a oeste dos Lençóis Maranhenses. Portanto, a elevada variabilidade espacial do tamanho e morfologia dos campos de dunas costeiros estaria ligada à dinâmica do transporte sedimentar costeiro, que condiciona localmente a disponibilidade de sedimentos na área fonte.

\subsubsection{Fatores controladores do aporte eólico nos sistemas eólicos costeiros}

A análise do tamanho e forma dos campos de dunas da costa brasileira revelou características importantes acerca da dinâmica de sistemas eólicos costeiros. Estes campos de dunas ocorrem em regiões desde semi-áridas até úmidas, com amplitude de maré variável (micromaré a macromaré), e podem ser gerados por ventos de velocidade e freqüência de atuação também variáveis. Apesar da pluviosidade, regime de ventos e amplitude de maré influenciarem 
o aporte de sedimentos eólicos, a regularidade do transporte de sedimentos eólicos parece estar ser mais afetada por fatores que controlam o volume de sedimentos arenosos na zona intermarés.

A manutenção do aporte eólico depende da capacidade de reposição de sedimentos arenosos na zona intermarés. Estes sedimentos, que alimentam os sistemas eólicos costeiros, são transportados do continente para a costa por sistemas fluviais ou derivam da erosão por ondas. Ao chegarem na bacia marinha, estes sedimentos são distribuídos por correntes litorâneas longitudinais ou transversais. Desta forma, o volume de sedimentos em determinado setor da costa depende do aporte primário, condicionado pela dinâmica do aporte fluvial e da erosão costeira, e da entrada e saída de sedimentos devido à dinâmica das correntes atuantes na costa (deriva litorânea longitudinal e correntes transversais, que atuam no transporte onshore-offshore). O transporte costeiro depende do regime de ondas e marés, da existência de obstáculos (hidráulicos ou topográficos) e da declividade da plataforma interna. Substrato íngreme favorece o transporte offshore enquanto que o contrário favorece o aprisionamento de sedimentos próximos à costa (Roy et al., 1994).

O NRM também afeta o volume de sedimentos diponível para alimentar os sistemas eólicos costeiros, pois determina o espaço para acomodação de sedimentos na plataforma (espaço entre o nível do mar e a superfície deposicional). A subida do NRM aumenta o espaço para acomodação de sedimentos na plataforma, favorecendo o acúmulo de sedimentos nos sistemas deposicionais da borda da bacia, dentre os quais se incluem os sistemas eólicos costeiros. Além disto, a elevação do NRM induz erosão costeira por migração do nível de base das ondas continente adentro. Portanto, a elevação do NRM aumenta o volume de sedimentos nos sistemas deposicionais costeiros. Já a queda do NRM diminui o espaço de acomodação na plataforma, favorecendo o transporte de sedimentos para as zonas mais profundas da bacia.

\subsubsection{Evidências de evolução por pulsos}

Algumas características observadas nos depósitos eólicos quaternários da costa brasileira sugerem que a sedimentação eólica se processa por pulsos e pode ser descontínua no tempo. As principais evidências que embasam esta hipótese são a geometria em lobos da frente de avanço de alguns campos de dunas e hiatos deposicionais eólicos ou intervalos de baixo aporte eólico que separam fases de crescimento de dunas frontais ou campos de dunas. 
A geometria multiescalar e em lobos da frente de avanço dos campos de dunas pode ser observada no campo de dunas dos Lençóis Maranheneses (Figura 3.35). Neste campo de dunas, é possível observar pelo menos três hierarquias de lobos de avanço, as quais indicariam avanços de magnitude variável.

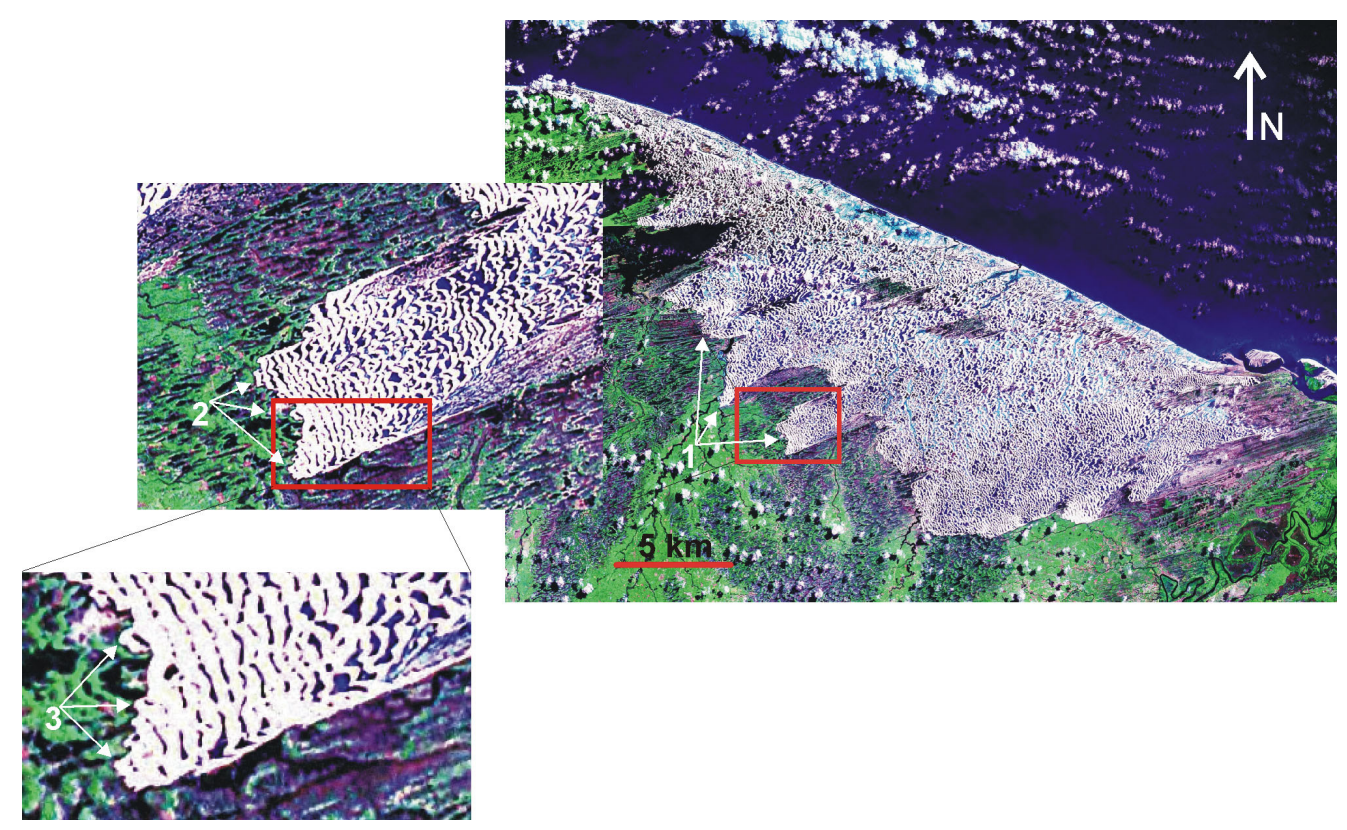

Figura 3.35 - Lobos de diferentes hieraquias (1, 2 e 3) que formam a frente de avanço do campo de dunas dos Lençóis Maranhenses. Esta geometria seria indicativa de crescimento ou avanço por pulsos.

O caráter pulsátil da sedimentação eólica também é notado na distribuição temporal de dunas frontais. Exemplo disto ocorre na Ilha Comprida (SP) onde se reconhecem duas fases principais de formação de dunas frontais (Guedes, 2003 e Giannini et al., 2003, 2006). A fase mais antiga é representada por cordão de dunas frontais de altura elevada, com blowouts, que se encontra isolado em meio a cordões litorâneos. A segunda fase corresponde a paleodunas frontais mais recentes, adjacentes à costa atual.

As gerações eólicas 1, 2, 3 e 4 do litoral centro-sul catarinense (Giannini, 1993 e Giannini et al., 2006) também seriam indicativas de que a sedimentação eólica costeira opera por pulsos. Segundo Giannini (1993), a geração eólica 1 é contemporânea ao máximo NRM correspondente ao interglacial Riss-Würm e separa-se das gerações eólicas 2, 3, e 4 (pós-Würm) por longo hiato deposicional. Idades TL (termoluminescência) e LOE (luminescência opticamente estimulada) 
obtidas por Sawakuchi (2003) indicaram que, apesar de não haver hiato deposicional entre as gerações eólicas 2, 3 e 4, estas três gerações representam momentos mais favoráveis ao desenvolvimento de campos de dunas, ou seja, intensificação do aporte eólico. Estas idades permitiram também detectar grandes variações de taxas de sedimentação entre as gerações eólicas 1 e 2 (Figura 3.36).

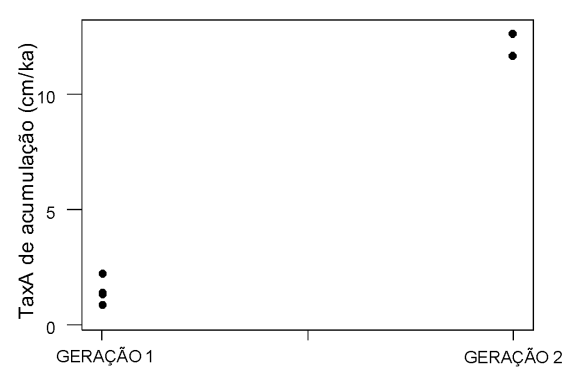

Figura 3.36 - Taxas de sedimentação das gerações eólicas 1 e 2 calculadas a partir de idades TL e LOE (Sawakuchi, 2003).

O aporte sedimentar eólico costeiro depende de diversas variáveis ligadas ao transporte e disponibilidade de sedimentos arenosos praiais. Portanto, é de natureza multivariada. Períodos de intensificação do aporte eólico podem estar ligados à convergência de condições favoráveis ao aporte eólico. As diversas variáveis que determinam o aporte eólico atuam de forma independente de modo que a convergência destas variáveis para condições favoráveis ao aporte apresente probabilidade reduzida. Isto faz com que períodos de aporte eólico muito elevado sejam restritos no tempo e pouco freqüentes.

\subsubsection{Tamanho dos campos de dunas $(A / C)$ e criticalidade auto organizada (CAO)}

A relação entre tamanho e freqüência de ocorrência de campos de dunas é similar à que ocorre em avalanches de pilhas de areia ou leques aluviais. O tamanho das avalanches e dos leques aluviais apresentam distribuição de freqüências exponencial. A freqüência de ocorrência de variáveis ligadas ao tamanho da avalanche ou leque pode ser descrita por leis de potência. 
Freqüência de ocorrência e classes de tamanho relacionam-se de forma linear em gráficos log-log (Figura 3.37).

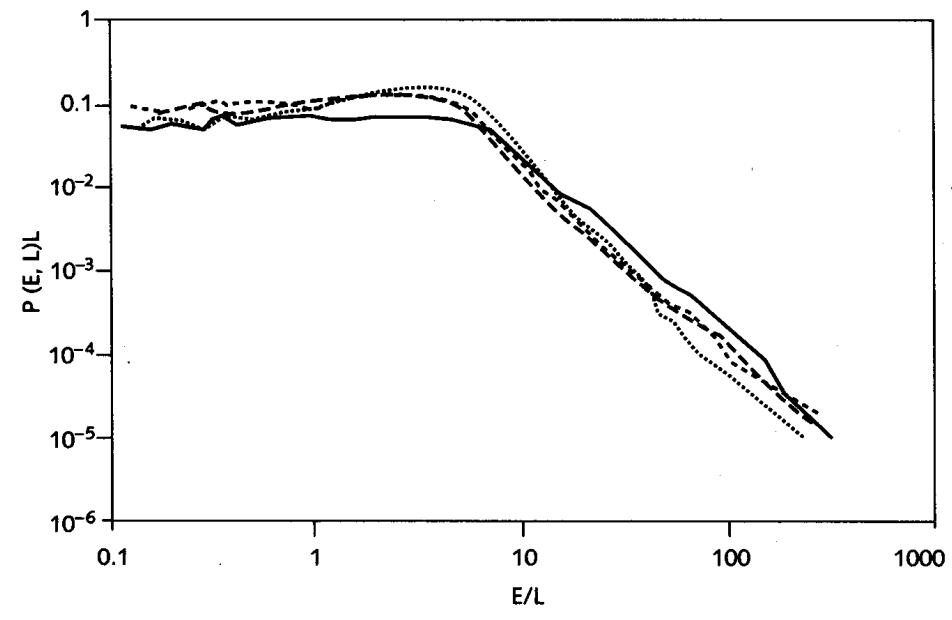

Figura 3.37 - Freqüência acumulada $(\mathrm{P}(\mathrm{E}, \mathrm{L}) \mathrm{L})$ do tamanho de avalanches em pilhas de arroz de diferentes tamanhos (L). As diversas curvas correspondem a pilhas de tamanho distinto e foram deslocadas para demonstrar a equivalência da forma (Frette et al., 1996).

A área dos campos de dunas da costa brasileira (A/C) aparenta possuir distribuição de freqüências exponencial (Figura 3.38).

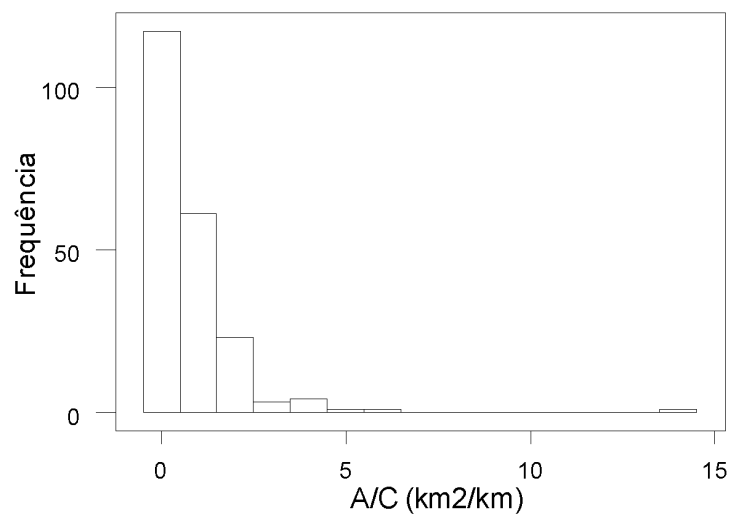

Figura 3.38 - Distribuição de freqüências da variável A/C. 
Ao classificarem-se os valores de $\mathrm{A} / \mathrm{C}$ em termos de suas freqüências acumuladas, nota-se padrão bastante semelhante ao ocorrido em avalanches geradas por pilhas de areia (Figura 3.39). Valores de A/C superiores a 1000 parecem variar de forma linear com a freqüência acumulada.

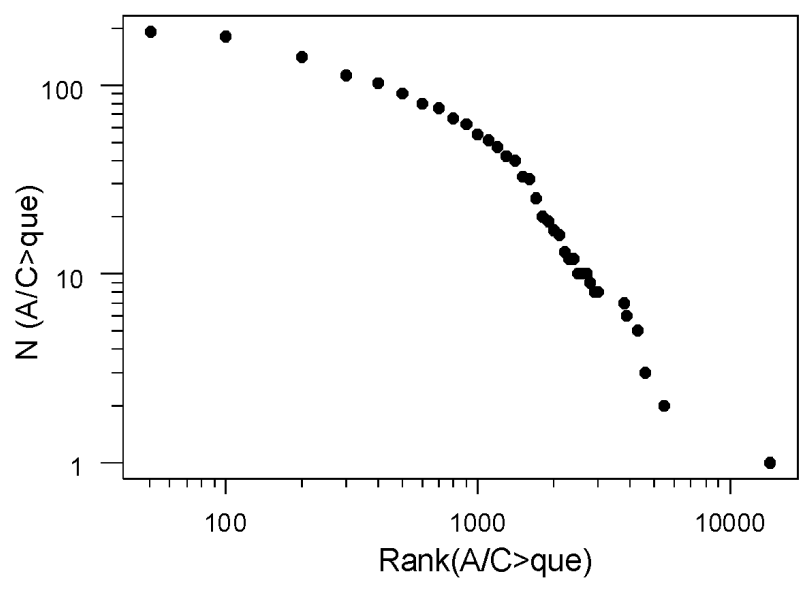

Figura 3.39 - Gráfico log-log entre tamanho (A/C $>$ que) e freqüência acumulada (N(A/C $>$ que). Nota: $\mathrm{A} / \mathrm{C} \mathrm{em} \mathrm{m}^{2} / \mathrm{m}$.

A variação linear torna-se mais nítida quando se relaciona a freqüência de ocorrência com o ponto médio de classes de tamanho (Figura 3.40).

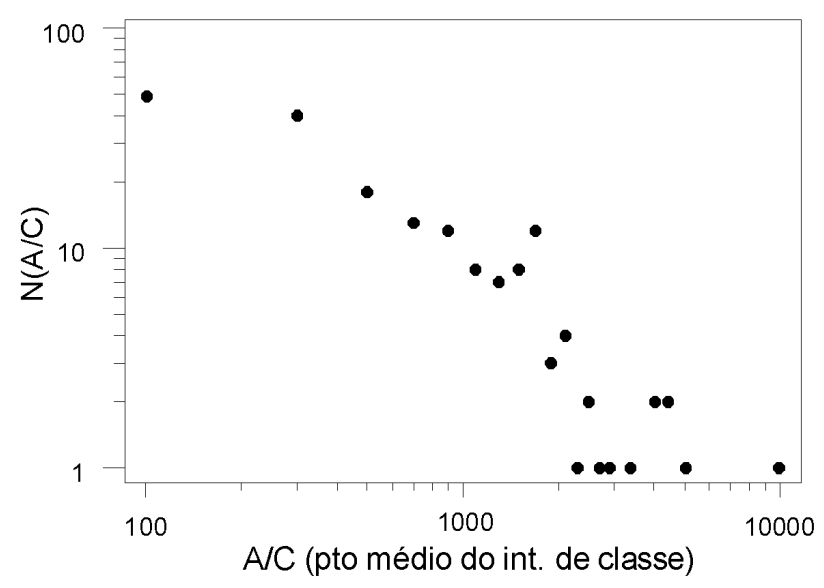

Figura 3.40 - A variação linear entre a freqüência acumulada $(\mathrm{N}(\mathrm{A} / \mathrm{C}))$ e tamanho $(\mathrm{A} / \mathrm{C})$ torna-se mais nítida quando se utiliza o ponto médio das classes de tamanho. 
A semelhança da variação de tamanho entre avalanches, leque aluviais e campos de dunas sugere a existência de semelhança da dinâmica responsável pela geração destas formas. Formas cujo tamanho se relaciona com a freqüência de ocorrência por leis de pontência podem ser produto da dinâmica de sistema complexo com criticalidade auto-organizada (CAO). A dinâmica de sistemas com CAO caracteriza-se por ser não-linear, operar pela superação de valores críticos e por produzir eventos de porte extremamente variado, que depende do estado em que se encontra o sistema e não apenas da intensidade de perturbações externas. No caso das pilhas de areia, a alimentação constante e lenta produz avalanches, cujo tamanho depende do estado da pilha no momento em que ocorre a avalanche. Estes sistemas também evoluem de forma pulsátil no sentido de que as avalanches configuram períodos curtos de elevado fluxo de material. Ao se fazer analogia entre sistemas eólicos costeiros e pilhas de areia, as avalanches do sistema eólico corresponderiam ao fluxo de sedimentos da área fonte para o campo de dunas. Logo, a variabilidade de tamanho dos campos de dunas estaria ligada à dinâmica do fluxo de sedimentos eólicos, cujo porte dependeria do estado do sistema em determinado momento. O "estado do sistema" poderia corresponder ao estado em que se encontra a área fonte em termos do volume de sedimentos arenosos e disponibilidade destes sedimentos ao transporte eólico. Perturbações momentâneas de alta intensidade, como por exemplo período com ventos de velocidade muitíssimo elevada, não implicariam necessariamente em mudança drástica do campo de dunas, pois a efetividade de tal perturbação estaria condicionada ao estado do sistema. Sob certos estados, perturbações de intensidades diversas poderiam ter o mesmo efeito sobre o sistema eólico.

\subsection{Conclusões}

A elevada variação da intensidade do efeito das variáveis responsáveis pela dinâmica dos campos de dunas costeiros dificulta a correlação entre variáveis particulares e características dos campos de dunas. No entanto, a análise da influência da posição geográfica, fatores climáticos e amplitude de maré sobre a morfologia e tamanho dos campos de dunas da costa brasileira revelou aspectos interessantes acerca do desenvolvimento destes campos de dunas, os quais são sumariados a seguir. 
1. O pequeno intervalo de tempo (cerca de 20 a 50 anos) dos dados climáticos utilizados na análise associado à idade milenar dos campos de dunas da costa brasileira remete a duas hipóteses. A) Campos de dunas fazem parte de sistema sensível aos fatores climáticos estudados. Neste caso, refletiriam as condições recentes e apresentariam pequena memória. B) Campos de dunas são feições pouco sensíveis aos fatores climáticos estudados e portanto, o fato de apresentarem tamanho e características morfológicas associadas a fatores climáticos atuais indicaria que as condições climáticas atuais (representadas por dados dos últimos 50 anos) persistem por longo período de tempo.

2. Tamanho e morfologia dos campos de dunas resultam da interação entre diversos fatores. Esta interação apresenta como característica marcante a produção de campos de dunas com tamanho e morfologia altamente variada.

3. Estas análises não permitem avaliar a sensibilidade da resposta dos campos de dunas a variáveis independentes ligada ao clima ou fisiografia da costa. No entanto, revela diversas possibilidades de atuação destas variáveis. A compreensão da sensibilidade de resposta dos campos de dunas aos diversos fatores que influenciam suas característcas morfológicas e de tamanho é fundamental para a compreensão da dinâmica de sistemas eólicos costeiros.

4. As análises realizadas revelaram que o tamanho e a morfologia dos campos de dunas são influenciados por variáveis climáticas e oceanográficas de atuação regional e que variáveis de atuação local podem ser extremamente importantes.

5. Qual seria a variável (ou variáveis) local de grande importância? O aporte sedimentar costeiro (sedimentos trazidos para a zona intermaré por correntes costeiras) pode apresentar grandes variações em pequeno espaço. $\mathrm{O}$ efeito do clima sobre a dinâmica de sistemas eólicos costeiros pode ser mais efetivo através da influência exercida sobre o aporte sedimentar costeiro do que através da influência direta sobre o transporte de sedimentos pelo vento. O clima pode influenciar o aporte sedimentar costeiro através das alterações que provoca na vazão dos rios que desembocam na costa ou através da energia das ondas, geram correntes costeiras.

6. A pluviosidade, descrita em termos do número de meses secos, não parece ser fator restritivo à formação de campos de dunas na costa brasileira.

7. O regime de ventos (freqüência de atuação e velocidade) influencia o tamanho relativo (A/C), a forma externa $(P / \sqrt{A})$ e a distância relativa de avanço (D/C) dos campos de dunas. A 
influência sobre A/C é mais significativa do que sobre $P / \sqrt{A}$ e D/C. A influência sobre estas duas últimas variáveis só é notada quando se comparam campos de dunas de mesmo regime de chuvas e de maré.

8. A amplitude de maré e seu efeito sobre a fisiografia da costa parecem influenciar a geometria externa dos campos de dunas. Canais de maré podem restringir o crescimento lateral ou o avanço dos campos de dunas. Assim, a disposição dos canais de maré podem ser determinantes para a forma dos campos de dunas.

9. A distinção do efeito de determinada variável sobre as características morfológicas e de tamanho dos campos de dunas é dificultada pela possibilidade de efeito comum a mais de uma variável e pela influência mútua entre variáveis.

10. A amplitude de maré pode exercer efeitos distintos sobre tamanho e morfologia de campos de dunas. Esta variável pode atuar tanto a favor quanto contra o crescimento de campos de dunas. Por este motivo, a avaliação de seu efeito sobre as características morfológicas e tamanho dos campos de dunas é ambígua. Amplitude de maré elevada propicia ampla área de zona intermaré, o que favorece o aporte eólico. No entanto, também pode favorecer correntes de maré mais intensas, que podem transportar sedimentos arenosos da zona intermaré para a zona de submaré. O efeito benéfico para crescimento de campo de dunas ocorreria mediante aporte sedimentar costeiro elevado. Sob aporte sedimentar costeiro reduzido, a amplitude de maré elevada contribuiria para o esgotamento de sedimentos da área fonte eólica. Este é um exemplo de efeitos distintos associados à mesma variável.

11. Grupos de campos de dunas definidos por variáveis morfométricas estão associados a grupos de campos de dunas definidos por setorização geográfica. Não é possível associar o conjunto de características morfométricas a variáveis inidividuais, tais como pluviosidade e amplitude de maré. Isto indica que as características morfométricas dos campos de dunas resultam da interação mútua entre diversas variáveis climáticas, oceanográficas e fisiográficas.

12. A ocorrência e as características morfométricas dos campos de dunas da costa brasileira não podem ser associadas à variável exclusiva, como por exemplo pluviosidade. Este fato é importante para a interpretação do significado paleoclimático de campos de dunas estabilizados ou depósitos eólicos. 


\section{SIMULAÇÃO DE SISTEMAS DEPOSICIONAIS EÓLICOS COSTEIROS}

\subsection{Introdução}

A análise do tamanho e morfologia dos campos de dunas da costa brasileira serviu apenas como subsídio para a elaboração de suposições acerca da dinâmica dos sistemas eólicos costeiros. O estudo da dinâmica dos campos de dunas através da correlação entre propriedades morfométricas e características físiográficas ou climáticas da costa é limitado pelo reduzido alcance temporal dos dados. Os campos de dunas são produto da dinâmica atuante durante milhares de anos, de modo que o estado atual destes campos de dunas e dos fatores que os influenciam pode não ser representativo desta dinâmica. Não é permitido avaliar, por exemplo, se as características atuais são resultados de herança (dinâmica pretérita) ou se são representativas das condições atuais. No entanto, independente deste problema, o estudo dos campos de dunas recentes subsidiou a elaboração de modelo conceitual, onde se destaca a importância do aporte sedimentar costeiro na dinâmica dos sistemas eólicos. Assim, pode-se estudar a dinâmica destes sistemas a partir da simulação deste modelo conceitual. O estudo da dinâmica de sistemas de grande dimensão, elevada duração e sujeitos a variabilidades de escala é impraticável mediante o uso de modelos físicos ou observação de sistemas reais, seja por fatores tecnológicos ou limitação temporal. A simulação numérica de modelos conceituais coloca-se como método mais adequado (ou o único possível) para o estudo da dinâmica destes sistemas.

Em termos gerais, simulação é uma experiência ou ensaio realizado com o auxílio de modelos, que constituem representações simbólicas de sistemas reais. A simulação de um sistema é a operação de um modelo formulado para descrever este sistema. Este modelo permite manipulações impraticáveis com a entidade real, devido à barreiras econômicas, tecnológicas, temporais, espaciais etc. As propriedades relativas ao comportamento e ao estado de um sistema podem ser analisadas através do estudo da operação do modelo formulado para descrever o respectivo sistema. Em termos lógicos, a definição formal de "simulação" pode ser assim expressa (Churchman, (1963)):

" $x$ simula $y "$ é verdade se e somente se:

i) $\quad x$ e $y$ forem sistemas formais;

ii) $\quad y$ for considerado o sistema real; 
iii) $\quad x$ for considerado uma aproximação do sistema real;

iv) as regras válidas em $x$ não estiverem isentas de erro.

O surgimento dos computadores potencializou a simulação de sistemas através de modelos matemáticos (modelos formais). Neste caso, a simulação torna-se uma técnica utilizada para realizar experiências em computadores (Naylor et al., 1971). Portanto, a simulação equivale a um experimento virtual, utilizado para gerar dados e testar modelos teóricos.

A simulação foi utilizada nesta tese para analisar modelos conceituais que relacionam a sedimentação eólica costeira a fatores climáticos (velocidade dos ventos e ocorrência de chuvas), oceanográficos (aporte sedimentar costeiro, amplitude de maré e nível do mar) e sedimentológicos (granulação dos sedimentos da área fonte). Algumas destas variáveis são consideradas aleatórias de modo que a sedimentação pode ser considerada como dependente de uma sucessão de eventos aleatórios. Neste caso, a sedimentação passa a ser um processo de natureza estocástica. Variáveis aleatórias podem ser simuladas a partir de geradores de números aleatórios. Desta forma, pode-se simular o sistema em questão e investigar o efeito de perturbações e a interação entre os processos deste sistema.

\subsection{Materiais e métodos}

\subsubsection{Números aleatórios}

A geração de números aleatórios permite a simulação de processos governados por variáveis aleatórias (Sobol, 1976). Pode-se simular variáveis aleatórias com qualquer distribuição de probabilidades utilizando-se uma variável padrão com distribuição uniforme entre 0 e 1 . Seqüências de números aleatórios com distribuição uniforme podem ser geradas a partir de dispositivos mecânicos ou eletrônicos de sorteio ou a partir de algoritmos matemáticos. Neste último caso, utiliza-se a denominação "números pseudoaleatórios". O uso de números aleatórios para a resolução de problemas matemáticos é antiga, podendo-se citar o cálculo do valor de $\pi$ executado por Comte de Buffon em 1777 (Kalos \& Whitlock, 1986). Porém, antes do surgimento dos computadores, a geração de números aleatórios era muito trabalhosa, de modo que restringia o uso deste método para a resolução de problemas matemáticos. Assim, o desenvolvimento dos computadores digitais, iniciado durante a Segunda Guerra Mundial, aumentou drasticamente o 
potencial de utilização deste método. Neste período, destaca-se o seu uso na resolução de problemas de física nuclear. Metropolis \& Ulam (1949) empregaram números aleatórios no estudo de sistemas compostos por múltiplas partes e dependentes de processos determinísticos (condições iniciais que conduzem a situações únicas) e estocásticos (sucessão de eventos aleatórios, ou seja, eventos cujo único resultado final não pode ser previsto através das condições iniciais). A abordagem adotada por estes autores no estudo de sistemas determinísticos-estocásticos foi denominada "Método de Monte Carlo". A partir daí o método popularizou-se, passando a ser utilizado no estudo de problemas pertencentes a diversas ciências. Atualmente, a simulação através de geradores de números aleatórios é vista como uma ferramenta que pode ser utilizada no estudo de qualquer fenômeno natural descrito por variáveis aleatórias.

\subsubsection{Simulação por eventos discretos}

A abordagem adotada no estudo de sistemas deposicionais eólicos foi a simulação por eventos discretos. Nesta abordagem, a evolução do sistema em função do tempo é avaliada através da análise de certas quantidades de interesse (Ross, 1990). Os elementos principais da simulação por eventos discretos são variáveis e eventos. Utilizam-se três tipos básicos de variáveis: variável de tempo, variáveis de contagem e variáveis de estado do sistema. A variável de tempo computa o tempo decorrido desde o início da simulação enquanto que as variáveis de contagem registram o número de ocorrências de um certo evento. As variáveis de estado armazenam informações que descrevem o estado do sistema no instante $t$. A cada evento ocorrido, atualizam-se os valores destas variáveis e coletam-se os dados de interesse. Os algoritmos da simulação foram desenvolvidos no software Scilab 3.1.1. Os dados gerados foram analisados no mesmo software e no software MINITAB Release 13.0. 


\subsection{Modelo conceitual de sistema eólico costeiro}

\subsubsection{Modelo de campo de dunas único}

Sistemas deposicionais eólicos costeiros são formados pelo transporte de sedimentos arenosos da zona intermarés por ventos que sopram do mar para o continente (onshore winds). Desta forma, apresentam como particularidade o fato de a área fonte ser representada pela zona intermarés. Estes sistemas são constituídos por três partes fundamentais: campo de dunas $(\mathrm{Vc})$, prisma de sedimentos da zona intermaré ou área fonte (Vf) e reservatório de sedimentos costeiros acumulados (Vfa). O volume do campo de dunas depende dos fluxos de entrada e saída de sedimentos a partir da área fonte (qce e qcs). A entrada de sedimentos no campo de dunas equivale ao fluxo eólico enquanto que a saída ocorreria principalmente através da erosão por ondas ou canais de maré. Já o volume de sedimentos da área fonte, além de depender das trocas com a área adjacente emersa, que inclui o campo de dunas, depende também do fluxo de sedimentos devido à correntes litorâneas longitudinais e transversais e do fluxo de entrada de sedimentos a partir de rios que desembocam na costa. O volume do reservatório de sedimentos costeiros acumulados aumenta sempre que o volume da área fonte superar certo valor máximo (Vfmax) e diminui quando ele for inferior a certo valor mínimo (Vfmin). Desta forma, o aumento de Vfa implica regressão da linha de costa e a diminuição, transgressão. A representação esquemática deste sistema pode ser observada na Figura 4.1.

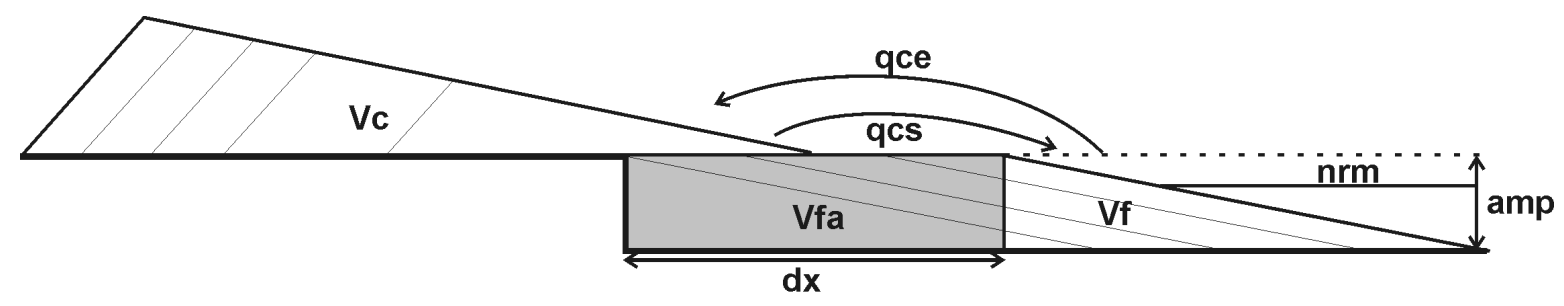

Figura 4.1 - Representação esquemática do modelo conceitual de sistema eólico costeiro. $\mathrm{Vc}=$ volume do campo de dunas; $\mathrm{Vf}=$ volume da área fonte; $\mathrm{Vfa}=$ volume acumulado de sedimentos costeiros; qce=fluxo de entrada de sedimentos no campo de dunas; qcs=fluxo de saída de sedimentos do campo de dunas; $\mathrm{dx}=$ regressão da linha de costa pela progradação do reservatório de sedimentos costeiros acumulados; amp=amplitude de maré; $n$ rm=nível relativo do mar. 
A dinâmica do sistema eólico costeiro depende dos fluxos de entrada e saída de sedimentos nos três reservatórios representados na Figura 4.1: campo de dunas, área fonte e reservatório de sedimentos costeiros acumulados. A representação formal deste sistema pode ser observada na Figura 4.2.

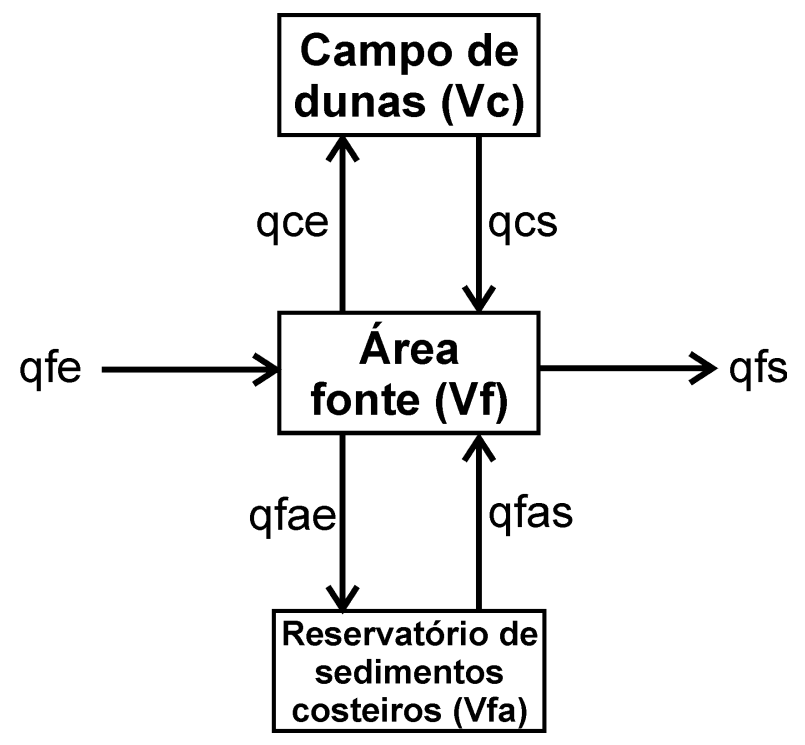

Figura 4.2 - Representação formal do modelo conceitual de sistema eólico costeiro. qce=fluxo de entrada de sedimentos no campo de dunas; qcs=fluxo de saída de sedimentos do campo de dunas; qfe=fluxo de entrada de sedimentos na área fonte por correntes costeiras ou desembocaduras de rios; qfs=fluxo de saída de sedimentos da área fonte por correntes costeiras; qfae=fluxo de entrada de sedimentos no reservatório de sedimentos costeiros; qfas=fluxo de saída de sedimentos no reservatório de sedimentos costeiros.

\subsubsection{Modelo de cadeia de campos de dunas}

O modelo conceitual apresentado no item anterior descreve a dinâmica de um único campo de dunas. No entanto, os setores da costa onde há sedimentação eólica são caracterizados pela sucessão de campos de dunas, que ocupam segmentos de costa individualizados por desembocaduras lagunares, canais de maré ou pontões rochosos. Desta forma, os campos de dunas fazem parte de um sistema maior que compreende diversos segmentos de costa, os quais interagem entre si através de trocas de sedimentos governadas pela corrente de deriva litorânea. Estes segmentos também interagem com a zona de inframaré através de correntes costeiras transversais. Assim, há um sistema maior que compreende uma cadeia de segmentos praiais, 
sendo que o desenvolvimento de campos de dunas depende não só da dinâmica de cada segmento praial, mas também da dinâmica que controla a interação entre os segmentos.

A dinâmica de cada segmento praial equivale à dinâmica de um único campo de dunas descrita no item 4.3.1. Os fluxos de entrada e saída de sedimentos da área fonte pela ação de correntes costeiras são divididos em fluxos longitudinais e fluxos transversais. Os fluxos longitudinais (qfle e qfls) são responsáveis pela troca de sedimentos com segmentos praiais adjacentes enquanto que os fluxos transversais (qfte e qfts) respondem pela troca de sedimentos entre as zonas de intermaré e inframaré. A representação formal deste sistema pode ser observada na Figura 4.3.

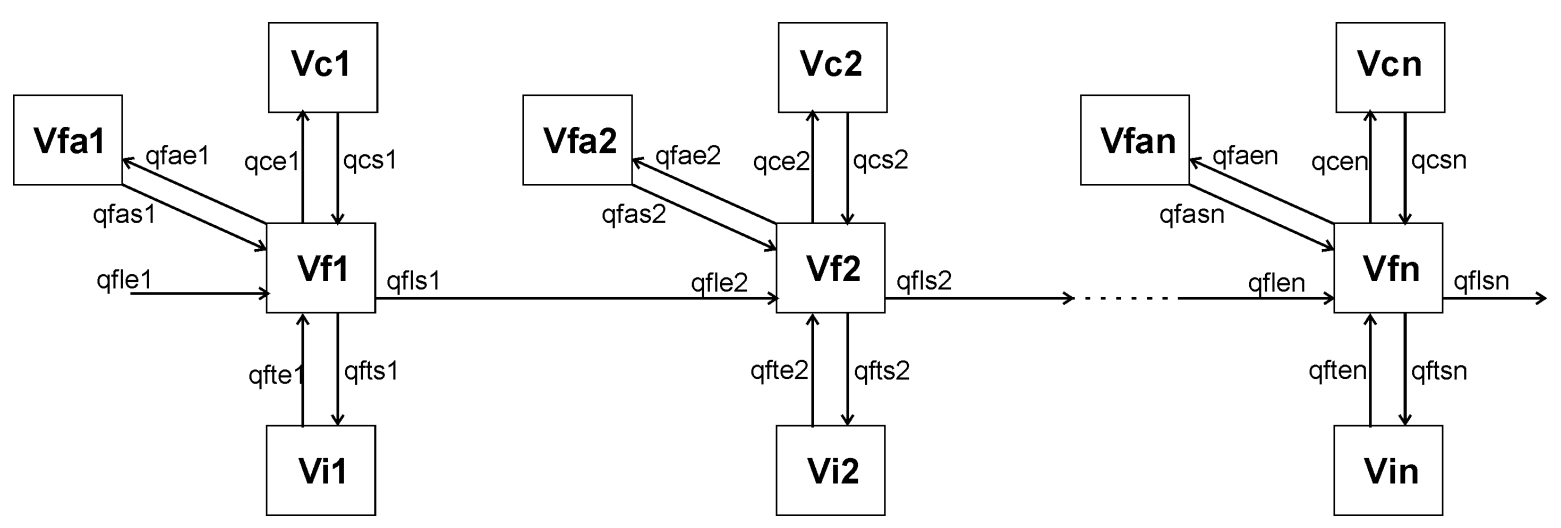

Figura 4.3 - Sistema de campos de dunas desenvolvidos em cadeia formada por $\mathrm{n}$ segmentos praiais. O desenvolvimento de campo de dunas $(\mathrm{Vc} 1, \mathrm{Vc} 2, \ldots, \mathrm{Vcn})$ em cada segmento de costa é influenciado pelas trocas de sedimentos entre áreas fontes vizinhas (Vf1, Vf2,..,Vfn) e destas com as zonas de inframaré (Vi1, Vi2,..., Vin) e reservatórios de sedimentos costeiros acumulados (Vfa1, Vfa2,...,Vfan). Fluxos de sedimentos: qce=fluxo de entrada no campo de dunas; qcs=fluxo de saída do campo de dunas; qfle=fluxo de entrada na área fonte por corrente costeira longitudinal; qfls=fluxo de saída da área fonte por corrente costeira longitudinal; qfte=fluxo de entrada na área fonte por corrente costeira transversal; qfts=fluxo de saída da área fonte por corrente costeira transversal; qfas=fluxo de saída do reservatório de sedimentos costeiros acumulados; qfae=fluxo de entrada no reservatório de sedimentos costeiros acumulados.

O fluxo de entrada de sedimentos no primeiro segmento praial corresponde à entrada de sedimentos a partir de fonte continental (desembocadura fluvial, por exemplo). Estes sedimentos são distribuídos ao longo da cadeia pela corrente de deriva litorânea longitudinal. Os fluxos de sedimentos governados por agentes costeiros subaquosos (qcs, qfle, qfls, qfte, qfts, qfae e qfas) são tratados como variáveis aleatórias e descritos por distribuições de probabilidades. No entanto, estes fluxos são condicionados ao volume de sedimentos presente nos reservatórios fornecedores 
e à variável independente (variável de restrição), que expressa a dificuldade em haver troca de sedimentos entre os diversos reservatórios. Tal variável exprime o conjunto de fatores que facilitam ou dificultam a troca de sedimentos por correntes costeiras entre reservatórios adjacentes. Deste modo, esta variável de restrição descreve as particularidades fisiográficas ou dinâmicas de cada segmento praial que interferem no transporte de sedimentos costeiros.

\subsection{Simulação dos fluxos de entrada e saída de sedimentos}

\subsubsection{Fluxo de entrada de sedimentos no campo de dunas (qce)}

O transporte eólico (qce) depende do grau de coesão dos sedimentos e da velocidade do vento em relação à velocidade limiar de transporte dos grãos disponíveis na área fonte. A coesão dos sedimentos da zona intermaré é condicionada pela umidade devido a chuvas ou a imersão pela maré. $\mathrm{O}$ volume de sedimentos na área fonte também condiciona o transporte eólico, que sofrerá redução com a diminuição do volume de sedimentos na área fonte. A justificativa para esta restrição é a redução da área da zona intermaré devido ao balanço negativo de sedimentos. Assim, o fluxo de sedimentos eólicos depende de uma sucessão de condições que possibilitam o transporte eólico, ou seja, que definem a ocorrência do evento "há transporte eólico". No caso do sistema eólico costeiro, este evento ocorrerá se, parte da zona intermaré estiver emersa (nível de maré < nível de maré máximo), não houver chuva e a velocidade do vento (v) for maior ou igual à velocidade limiar de transporte dos grãos (vt) disponíveis na área fonte. Assim, há três fatores independentes que podem restringir o evento "há transporte eólico": ocorrência de chuva, maré

alta e ventos com velocidade abaixo da velocidade limiar de transporte dos grãos. Desta forma, a interação entre as variáveis em questão resulta nos seguintes casos (Figura 4.4): 


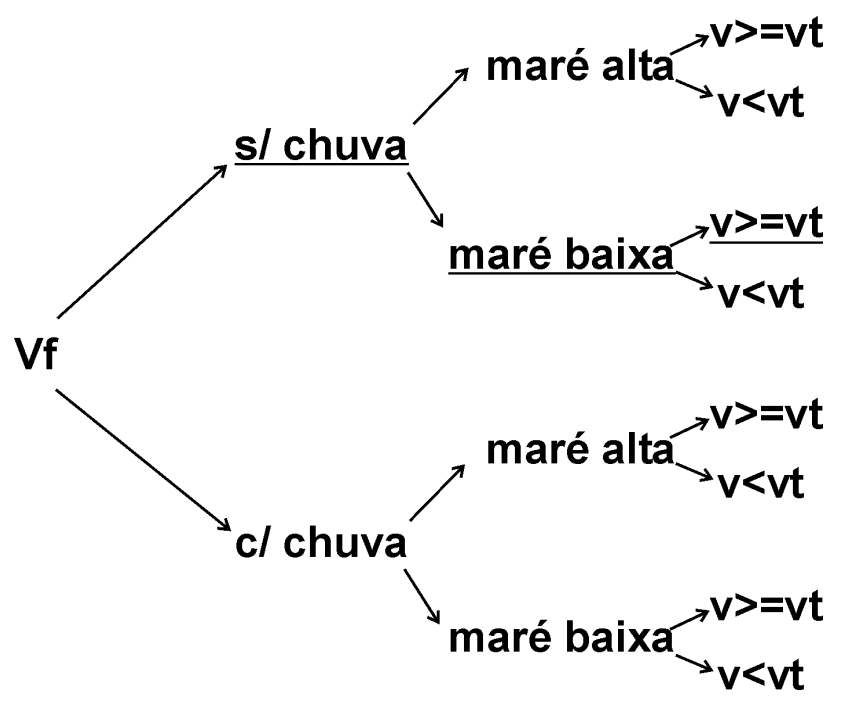

Figura 4.4 - Interação entre os fatores que podem restringir o transporte de sedimentos eólicos. A interação gera oito situações possíveis, sendo que o transporte eólico ocorre em apenas uma situação ( $\mathrm{s}$ /chuva, maré baixa e v $>=\mathrm{vt}$ ).

Os três fatores que determinam a ocorrência do transporte eólico apresentam variabilidade temporal e espacial distinta. O regime de maré possui pouca variação por longos trechos de costa. Variações locais importantes podem ocorrer apenas de modo restrito, como por exemplo, em estuários. Tais variações podem afetar o transporte costeiro, mas não interferem na dinâmica de imersão e emersão da zona intermaré praial. A principal variabilidade temporal da amplitude de maré é de caráter determinístico (ditada pela interação Terra-Lua) e de escala subanual. O regime de ventos e de chuva também pode ser pouco variável por longos trechos de costa, porém, pode apresentar variações locais significativas devido à influência da topografia. Estes dois fatores destacam-se por apresentarem variabilidade em diversas escalas de tempo e por serem regidos por processos probabilísticos. $\mathrm{O}$ volume de sedimentos na área fonte, apesar de não impedir o transporte eólico, atua como agente redutor (menor o volume, menor o fluxo de sedimentos eólicos). Este volume é controlado pela dinâmica das correntes costeiras e pelo aporte continental de sedimentos, os quais são dependentes de diversos fatores climáticos. $\mathrm{O}$ transporte e deposição de sedimentos costeiros também são influenciados pela fisiografia da costa. Portanto, é controlado por fluxos de sedimentos cuja variação é probabilística e imprevisível por modelos determinísticos. Esta conjunção de fatores faz com que o volume de sedimentos disponíveis na área fonte apresente elevada variabilidade no tempo e no espaço. Desta forma, o aporte eólico costeiro, que determina o desenvolvimento dos campos de dunas, resulta da sucessão de eventos, 
cuja maioria é de natureza probabilística. Portanto, configura processo de natureza estocástica. A interação entre os fatores que controlam o aporte eólico costeiro resulta em oito combinações sendo que o aporte eólico costeiro ocorre em apenas uma dessas combinações (Figura 4.4). Ou seja, a manutenção de aporte eólico costeiro regular requer que diversos fatores independentes operem em condições propícias ao transporte eólico. Isto conduz à idéia de que a probabilidade de formação de campos de dunas costeiras, que depende de aporte eólico costeiro regular, é menor que a probabilidade de não formação. No entanto, o fato de longos trechos da costa brasileira apresentarem campos de dunas como feições ubíquas indica que os fatores que controlam o aporte eólico operam na natureza sob condições pouco restritivas à manutenção do aporte eólico costeiro. A análise da variação de tamanho e distribuição espacial dos campos de dunas da costa brasileira sugere que o aporte sedimentar costeiro, que determina o volume de sedimentos na área fonte, seja o fator de maior variabilidade e mais restritivo à formação e crescimento dos campos de dunas.

O aporte eólico costeiro não controla apenas a formação e crescimento do campo de dunas. O fluxo de sedimentos arenosos para o campo de dunas determina também a morfologia das dunas e a ação de processos erosivos ou estabilizadores de dunas, tais como a pedogênese. Fluxo elevado de sedimentos favorece o desenvolvimento de dunas livres e a diminuição do espaçamento entre dunas (depressões interdunares) e inibe a ação de processos estabilizadores, tais como cimentação e recobrimento por vegetação, ou erosivos. Logo, a variação do fluxo de sedimentos para o campo de dunas ao longo do tempo controla as características dos sedimentos acumulados e, portanto, define a distribuição de fácies e superfícies de truncamento nos depósitos eólico. Assim, o significado das variações faciológicas e a compreensão da distribuição das fácies sedimentares estão associados ao entendimento da variação temporal do aporte eólico costeiro.

O fluxo de entrada de sedimentos no campo de dunas ocorre quando o volume de sedimentos na área fonte for superior a um volume crítico, não houver chuva, a zona intermaré estiver emersa e a velocidade do vento for superior à velocidade limiar de transporte dos grãos de sedimentos disponíveis na área fonte. Assim, o fluxo de sedimentos eólicos só é calculado caso haja esta sucessão de eventos. Desta forma, o cálculo do fluxo de sedimentos eólicos depende da simulação das variáveis que determinam a sucessão de eventos que possibilita a ocorrência do transporte eólico. Estas variáveis são consideradas independentes, sendo que o diâmetro dos grãos é considerado constante durante cada iteração. 


\subsubsection{Regime de maré}

O nível de maré apresenta variação cíclica diária, podendo apresentar um (diurna) ou dois (semi-diurna) ciclos durante um dia. As alturas máxima e mínima do nível de maré nestes ciclos diários são denominadas respectivamente preamar e baixamar. Os níveis de preamar e baixamar também sofrem variações cíclicas, porém estas são de periodicidade aproximadamente quinzenal. Os ciclos de variação do nível de maré podem ser assimétricos de modo que o intervalo de tempo entre baixamar e preamar pode ser diferente do intervalo de tempo entre preamar e baixamar. Desta forma, o tempo de exposição da área fonte durante um dia pode diferir do tempo de imersão. As marés são ondas rasas de grande velocidade $(20-200 \mathrm{~m} / \mathrm{s})$ e grande comprimento de onda de modo que podem ser descritas pela teoria de ondas (Equação 4.1). Neste caso, a variação do nível de maré em função do tempo $(t)$ é gradual. Conseqüentemente, a área emersa da zona intermarés também variará de forma gradual. Esta variação pode ser expressa pela equação:

$$
y=H \operatorname{sen}\left(\frac{2 \pi}{T} t\right)
$$

onde $y$ é o deslocamento vertical, $H$ é a altura da onda, $T$ é o período e $t$ é o tempo.

Uma alternativa mais simples é considerar apenas a existência de dois níveis de maré (nível de maré alta e nível de maré baixa). Assim, em relação ao nível de maré, a área fonte apresentaria dois estados: imerso e emerso. A duração em horas ao longo do dia do estado emerso (dt) define o tempo máximo diário de atuação do transporte eólico enquanto que a duração do estado imerso (24-dt) define a duração dos demais fluxos, os quais são controlados por agentes subaquosos.

\subsubsection{Ocorrência de chuva (c)}

A variável chuva (c) possui dois eventos possíveis, os quais determinam a ocorrência (c = 0) ou não de chuva $(c=1)$. A ocorrência de chuva pode ser simulada através de uma cadeia de Markov com dois estados. A probalidade de chover no instante $t+1$ é influenciada pela ocorrência ou não de chuva no instante t. Desta forma, caso ocorra chuva no instante $t$, a probabilidade de 
chover no instante $\mathrm{t}+1$ será $\alpha\left(p_{00}\right)$ e se não ocorrer chuva no instante $\mathrm{t}$, a probabilidade de chover em $\mathrm{t}+1$ será $\beta\left(p_{10}\right)$. A matriz probabilidades de transição será:

$$
A=\left|\begin{array}{ll}
\alpha & 1-\alpha \\
\beta & 1-\beta
\end{array}\right| \text { e } \begin{aligned}
& p_{00}=\alpha=1-p_{01} \\
& p_{10}=\beta=1-p_{11}
\end{aligned}
$$

Logo, a simulação da variável chuva no instante $t$ depende apenas da atribuição de probabilidades de ocorrência de chuva no dado instante e de sorteio realizado a partir de variável aleatória padrão (u) com distribuição uniforme no intervalo entre 0 e 1 . Por exempo, para $\alpha$ $\left(p_{00}\right)=0,6$ e $\beta\left(p_{10}\right)=0,3$, ocorrerá chuva em $(\mathrm{t}+1)$ sempre que:

$$
\begin{aligned}
& 0 \leq \mathrm{u} \leq 0,3 \text { caso } \mathrm{c}(\mathrm{t})=1 \\
& 0 \leq \mathrm{u} \leq 0,6 \operatorname{caso} \mathrm{c}(\mathrm{t})=0
\end{aligned}
$$

\subsubsection{Velocidade do vento (v)}

A velocidade do vento pode ser descrita por modelos de distribuição de probabilidades discretos ou contínuos. A Figura 4.5 apresenta a distribuição de freqüências das velocidades dos ventos atuantes na zona costeira de Torres (RS), entre os anos de 1970 e 1982. Trata-se de medidas tomadas a $10 \mathrm{~m}$ de altura, as quais foram compiladas por Tomazelli (1990) a partir de banco de dados do INMET (Instituto Nacional de Meteorologia). Neste caso, a distribuição das velocidades do vento foi determinada de forma empírica.

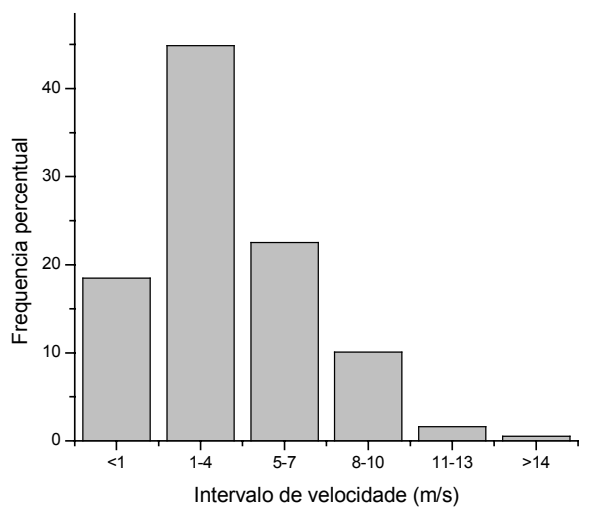

Figura 4.5 - Distribuição de freqüências das velocidades dos ventos registrados em Torres (RS) entre 1970 e 1982. Adaptado de Tomazelli (1990). 
Segundo Bagnold (1941), a velocidade do vento $(V)$ apresenta distribuição lognormal e aumenta de forma linear com o logaritmo da altura $(z)$. A velocidade de arrasto $\left(V_{*}\right)$, que determina a capacidade de transporte do vento, é proporcional à tangente da reta definida pela variação de $V$ em função do logaritmo de $z$. Logo, a relação entre $V$ e $V *$ é expressa por (Equação 4.3):

$V(z)=5.75 V_{*}(\log z-\log k)$

A velocidade de arrasto $\left(V_{*}\right)$ define a taxa de aumento da velocidade do vento $(V)$ pela altura (z). Portanto, corresponde ao gradiente de $V$. A constante $k$ indica a altura onde $V$ tem valor igual a zero e está associada à rugosidade da superfície. De acordo com Bagnold (1941), o valor de $k$ está associado ao diâmetro dos grãos (d) que recobrem a superfície (Equação 4.4):

$k=\frac{d}{30}$

Os valores de $V_{*}$ e $k$ constituem as características fundamentas do perfil de velocidade do vento (Figura 4.6).

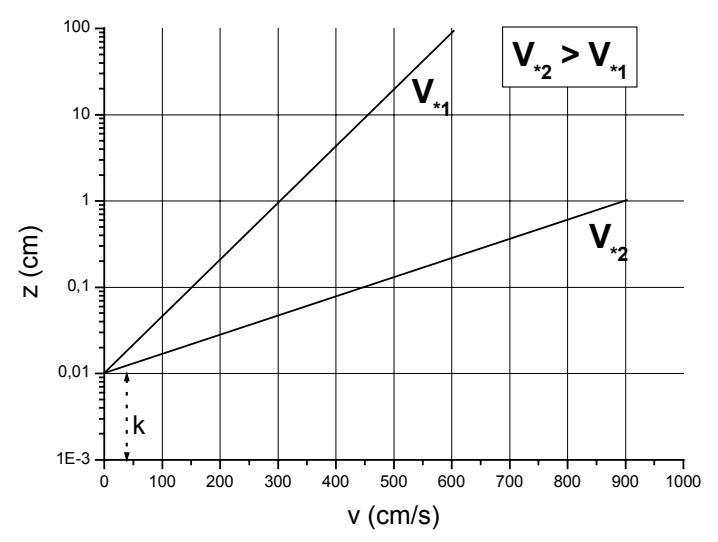

Figura 4.6 - Variação da velocidade do vento $(V)$ em função do logaritmo da altura $(z)$, com diferentes gradientes de velocidade $\left(V_{*_{1}} \mathrm{e} V_{*_{2}}\right)$. 
A entrada dos grãos em movimento modifica o perfil vertical de velocidade do vento. Durante o transporte de sedimentos, a velocidade do vento em função da altura $(V(z))$ passa a ser descrita por (Equação 4.5):

$V(z)=5.75 V_{*} \log \frac{z}{k^{\prime}}+V_{t}$

onde $k$ ' é uma constante que está relacionada com a altura da zona de transporte dos grãos. O valor de $k^{\prime}$ pode ser considerado igual a $0.3 \mathrm{~cm}$ para areia fina uniforme ou $1 \mathrm{~cm}$ para areias comumente encontradas em dunas (Bagnold, 1941). $V_{\mathrm{t}}$ é a velocidade de arrasto limiar (por impacto) da areia em questão medida na altura $k^{\prime}$.

Howard et al. (1978) propõem a seguinte equação para descrever o perfil vertical de velocidade do vento (Equação 4.6):

$V(z)=2.5 V_{*} \ln \left(z / z_{0 a}\right)$

onde $V(z)$ é a velocidade do vento na altura $\mathrm{z}$ e $z_{0 \mathrm{a}}$ é a altura da rugosidade devido aos grãos em saltação. O parâmetro $z_{0 a}$ é a altura da rugosidade devido aos grãos em saltação, sendo determinado pelo ponto de intersecção da curva da velocidade de arrasto com o eixo y (Equação 4.7):

$z_{0 a}=k^{\prime} \exp \left(-K V_{t} / V_{*}\right)$

onde $K$ é a constante de Von Karman $(K=0.4)$ e $V_{t}$ é a velocidade limiar para movimento dos grãos na altura $k^{\prime}$.

White \& Shulz (1977 apud Namikas, 2003) também apresentam uma função logarítmica para descrever o perfil vertical de velocidade do vento (Equação 4.8):

$V(z)=V_{*} / K \ln \left(z / z_{0}\right)$ 
onde $V(z)$ é a velocidade do vento na altura $z, V *$ é a velocidade de arrasto, $K$ é a constante de Von Karman e $z_{0}$ é a rugosidade da superfície.

Para cada iteração, simulou-se um valor de velocidade do vento através da distribuição lognormal, que é caracterizada por um valor médio (vm) e por um parâmetro de dispersão dos valores em torno da média $(\mathrm{dv})$. O parâmetro dv tem significado análogo ao desvio padrão, ou seja, quanto maior dv, maior a dispersão dos valores de velocidade do vento. A partir do valor de v simulado, calculou-se a velocidade de arrasto vs (velocidade cisalhante). A velocidade do vento também foi condicionada à variabilidade climática subanual e interanual. Assim, os valores de vm e dv da estação seca diferem dos valores da estação úmida.

\subsubsection{Velocidade limiar de transporte dos grãos $\left(V_{t}\right)$}

A granulação dos sedimentos transportados é controlada pela velocidade de arrasto do vento $\left(V_{*}\right)$. A velocidade de arrasto limiar ( $V_{*_{t}}$ - velocidade acima da qual o grão é transportado) para grãos com diferentes diâmetros foi determinada por Bagnold (1941) de maneira empírica e encontra-se representada na Figura 4.7.

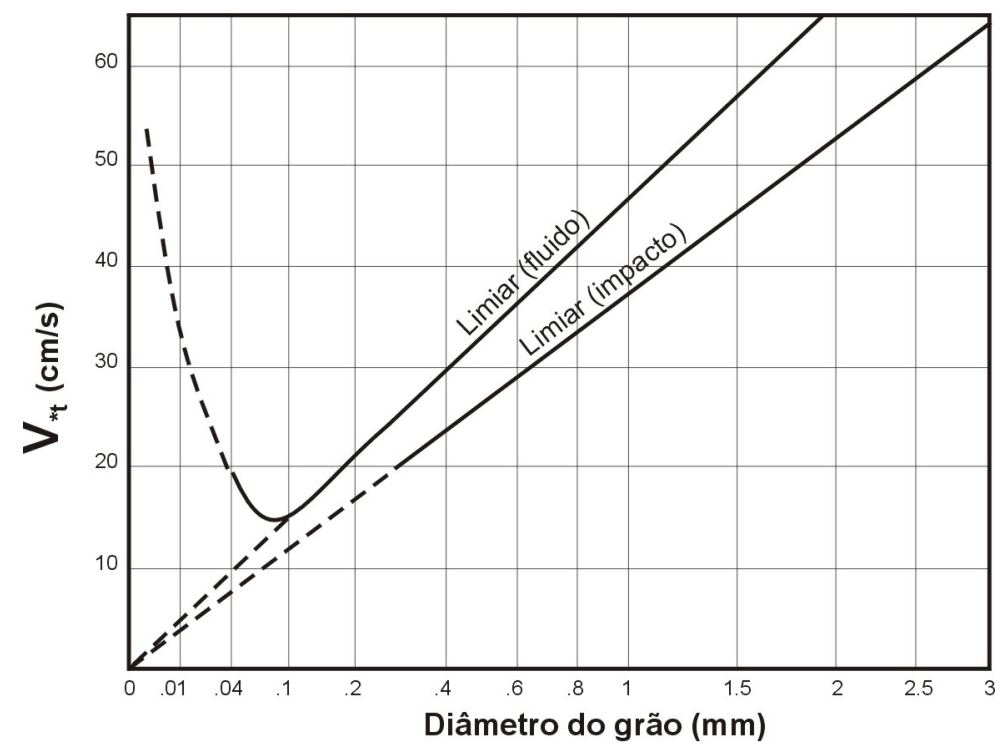

Figura 4.7 - Velocidade de arrasto limiar $\left(V_{*}\right)$ para grãos com diferentes diâmetros. Adaptado de Bagnold (1941). 
A velocidade de arrasto limiar $\left(V_{*}\right)$ é decrescente para o intervalo granulométrico inferior a 0,088 mm (grãos menores que o tamanho mediano da classe areia muito fina: acima de 3.5 phi). A diminuição da rugosidade da superfície impede que os grãos respondam de maneira individual à atuação das forças derivadas do movimento do ar. Os grãos passam a não se comportar mais como obstáculos individuais à passagem da corrente de ar, pois há formação de superfície lisa. Isto eleva consideravelmente a velocidade de arrasto mínima para movimentar os grãos. $\mathrm{O}$ número de Reynolds $(R)$ define uma superfície como lisa ou rugosa (Equação 4.9).

$$
R=\frac{V_{*} \cdot d}{\delta}
$$

onde $d$ é diâmetro dos grãos, $V_{*}$ é a velocidade de arrasto do fluxo e $\delta$ é a viscosidade do fluido $\left(\delta_{\mathrm{ar}}=0.14\right)$.

Para o ar, o valor crítico do número de Reynolds, que define uma superfície como lisa ou rugosa, é igual a 3.5. Valores superiores a 3.5 indicam superfície rugosa, ou seja, os grãos podem ser considerados como obstáculos individuais à passagem do fluido (Bagnold, 1941).

A velocidade de arrasto limiar $\left(V_{*}\right)$ em função do diâmetro dos grâos $(d)$ pode ser expressa da seguinte forma (Equação 4.10):

$$
V_{*_{t}}=A_{v} \sqrt{\frac{\sigma-\rho}{\rho} g d}
$$

onde $\rho$ é a densidade do ar, $\sigma$ é a densidade do grão e $g$ é a aceleração da gravidade. O coeficiente $A_{v}$ pode ser considerado constante se o número de Reynolds $(R)$ apresentar a mesma ordem de grandeza. Para sedimentos formados por grãos com diâmetro maior ou igual a 0,25 mm, o valor de $A$ para o ar é 0,1 (Bagnold, 1941). O coeficiente $A$ aumenta para grãos com diâmetro menor que $0,25 \mathrm{~mm}$. Esta variação do comportamento de $A$ é função da mudança do caráter da superfície de rugosa para lisa. $\mathrm{O}$ valor do número de Reynolds que marca esta mudança é 3,5, que é muito próximo ao valor calculado para grãos com diâmetro igual a $0,25 \mathrm{~mm}$ cuja velocidade de arrasto limiar $\left(V_{*}\right)$ é aproximadamente $20 \mathrm{~cm} / \mathrm{s}$. 
Segundo Bagnold (1941), a relação entre a velocidade do vento na altura $z(V(z))$ e a velocidade de arrasto $\left(V_{*}\right)$ pode ser descrita por (Equação 4.11 ):

$$
V(z)=5.75 V_{*} \log \frac{z}{k}
$$

onde $k$ é a constante que representa a rugosidade da superfície. Assim, através das equações 4.10 e 4.11, chega-se à seguinte expressão:

$$
V_{t}(z)=5.75 A_{v} \sqrt{\frac{\sigma-\rho}{\rho} g d} \log \frac{z}{k}
$$

Através da Equação 4.12, é possível calcular as velocidades necessárias para transportar grãos com diferentes diâmetros.

\subsubsection{Fluxo de sedimentos eólicos (q)}

Existem diversas equações para descrever o fluxo de sedimentos transportados pelo vento. A taxa de transporte de sedimentos $(q)$ depende essencialmente da velocidade do vento e do diâmetro dos grãos. Bagnold (1941) propôs a seguinte equação (Equação 4.13) para descrever a taxa de transporte de areia pelo vento:

$$
q=C\left(\sqrt{\frac{d}{D}}\right) V_{*} \frac{\rho}{g}
$$

onde $V *$ é a velocidade de arrasto $\left(\mathrm{ms}^{-1}\right), d$ é o diâmetro do grão $(\mathrm{mm}), D$ é o diâmetro padrão $(D=0,25 \mathrm{~mm}), C$ é um coeficiente cujo valor é 1,8 segundo Bagnold (1941). As constantes $\rho$ e $g$ são respectivamete a densidade do $\operatorname{ar}\left(1,22 \mathrm{kgm}^{-3}\right)$ e a aceleração da gravidade $\left(9,81 \mathrm{~ms}^{-2}\right)$.

Sarre (1988) testou diversas equações para descrever o transporte eólico na zona de intermarés da costa de Sauton (sudoeste da Inglaterra). De acordo com este autor, todas as equações que relacionam o fluxo de sedimentos $(q)$ com o cubo da velocidade de arrasto $\left(\mathrm{V}_{*}\right) \mathrm{e}$ 
com a velocidade de arrasto crítica $\left(V_{*_{t}}\right)$ descrevem o transporte eólico de forma satisfatória. Dentre estas equações, destaca-se a de White (1979) (Equação 4.14), que foi a que melhor se ajustou aos dados obtidos através de medidas de campo.

$$
q=2.61 V_{*}^{3}\left(1-V_{* t} / V_{*}\right)\left(1+V_{* t}^{2} / V_{*}^{2}\right) \rho / g
$$

onde $q$ é a taxa de transporte de sedimentos $\left(\mathrm{kgm}^{-1} \mathrm{~s}^{-1}\right), V_{*}$ é a velocidade de arrasto, $\rho$ é a densidade do ar, $g$ é a aceleração da gravidade e $V_{*_{t}}$ é a velocidade de arrasto crítica para um determinado diâmetro de grão (acima da qual os grãos entram em movimento). Neste estudo, o fluxo de sedimentos eólicos para o campo de dunas (qce) foi calculado a partir da equação de White (1979).

4.5.2 Fluxo de saída de sedimentos do campo de dunas (qcs) e fluxos de entrada e saída de sedimentos na área fonte ( $q f s, q f e, q f l e, q f l s$, qfte e qfts) e no reservatório de sedimentos costeiros acumulados

Os fluxos de entrada e saída de sedimentos dependem de diversos fatores de natureza complexa, tais como taxa de intemperismo no continente, regime de ondas ou marés e fisiografia da plataforma, que podem dificultar ou facilitar a entrada ou saída de sedimentos da zona intermarés. Supõe-se que estes fluxos são isotrópicos ao longo da interface entre os reservatórios envolvidos na troca sedimentar e independentes do fluxo de entrada de sedimentos no campo de dunas. Assim, foram considerados variáveis aleatórias e seus tempos de atuação dependentes da duração do período de imersão (24-dt) e do volume de sedimentos disponíveis no reservatório fonte. Estas variáveis foram simuladas pela distribuição lognormal. Esta distribuição compreende apenas valores positivos, sendo caracterizada por valor médio e parâmetro de dispersão, que determina a assimetria da distribuição de freqüência (Figura 4.8). 

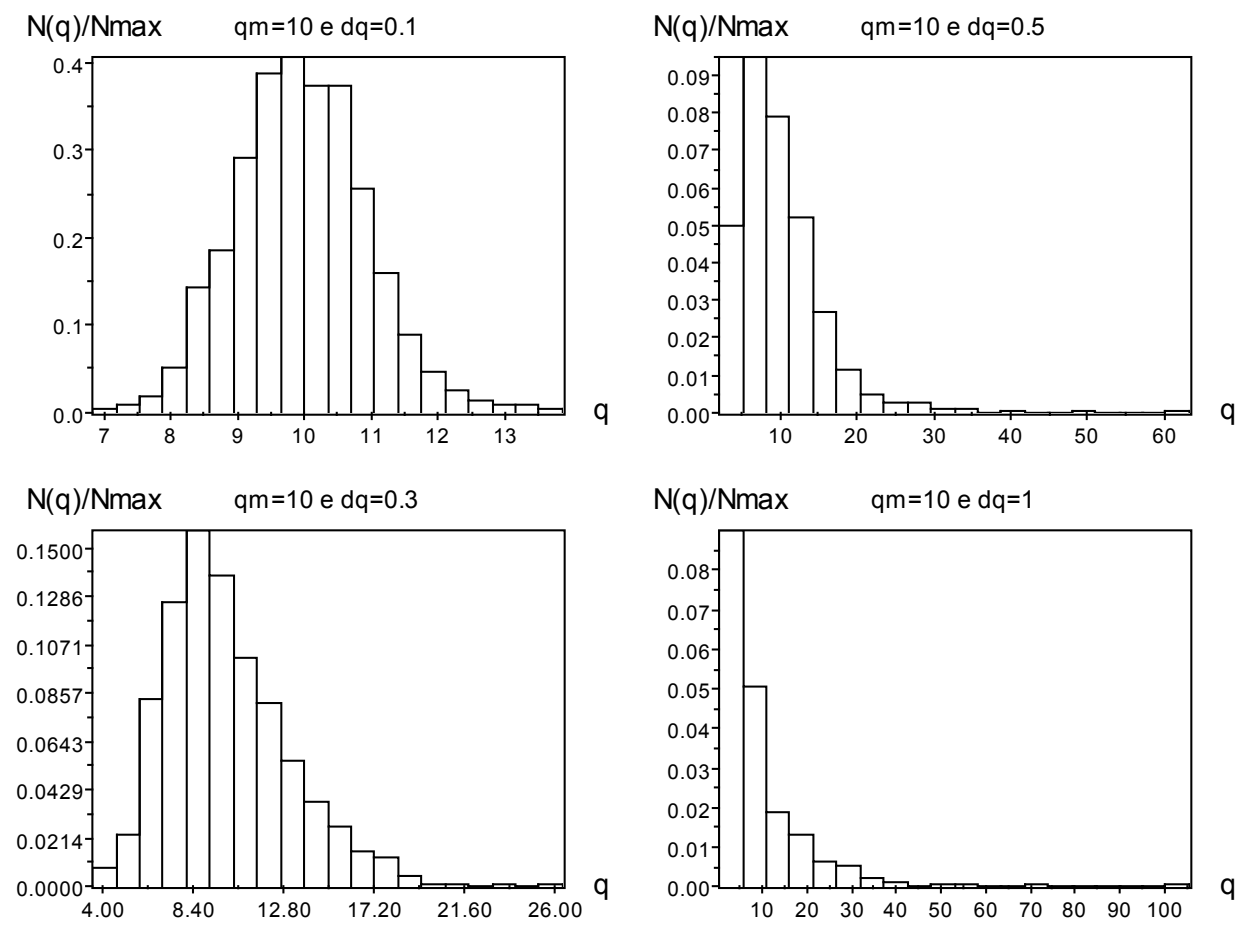

Figura 4.8 - Variável aleatória simulada a partir de modelo lognormal com média qm igual a 10 e parâmetro de dispersão dq de valor variável. A elevação de dq provoca aumento da assimetria da distribuição de freqüência.

O fluxo de saída de sedimentos do campo de dunas (qcs) é condicionado pelo volume de sedimentos na área fonte. A redução do volume da área fonte amplifica o valor de qcs. O condicionamento do fluxo de saída de sedimentos do campo de dunas à redução do volume de sedimentos na área fonte baseia-se no pressuposto de que o déficit de sedimentos costeiros implica erosão da zona costeira emersa. Esta erosão ocorreria mediante ação das ondas ou correntes de maré.

No sistema de campo de dunas único, os fluxos qfe e qfs envolvem o transporte litorâneo longitudinal e transversal. Estes fluxos são independentes e não são condicionados ao volume da área fonte. Já no sistema de cadeia de campos de dunas, a troca de sedimentos entre áreas fontes adjacentes (qfle e qfls) e entre área fonte e zona de intermaré (qfte e qfts) não é uniforme, pois deve ser levada em consideração a heterogeidade dos fatores que dificultam esta troca. A facilidade de troca de sedimentos entre áreas fontes adjacentes separadas por desembocaduras de canais de maré ou por pontões rochosos dependerá, por exemplo, do porte do canal de maré ou da topografia do porção submersa do pontão rochoso. O mesmo ocorre com as trocas transversais 
com a zona de costa-afora. A inclinação do substrato favorece a saída de sedimentos da área fonte em detrimento da entrada. Desta forma, cada segmento praial é caracterizado por coeficientes, que expressam a proporção de sedimentos que entram (rle e rte) ou saem (rts) da área fonte por correntes costeiras. Estes coeficientes assumem valores entre 0 e 1 e determinam a proporção do volume de sedimentos, transportados por um fluxo de troca (qfls, qfts ou qfte) simulado a partir de modelo probabilístico, que efetivamente são transferidos ao reservatório destino. Assim, considere-se por exemplo um sistema com dois segmentos praiais com suas respectivas áreas fontes (Vf1 e Vf2) e reservatórios de inframaré (Vi1 e Vi2). O fluxo de entrada de sedimentos em Vf2 a partir de Vf1 será uma proporção do fluxo de saída longitudinal da área fonte Vf1. Esta proporção é definida pelo coeficiente rle2. Assim, tem-se que (Eq. 4.15):

$q f l e 2=r l e 2 * q f l s 1$

De modo análogo, os fluxos responsáveis pela troca de sedimentos entre as áreas fontes e as áreas de inframaré serão definidos pelos coeficientes (rte1, rte2, rts1 e rts2). Logo, tem-se que (Equação 4.16):

$$
\begin{aligned}
& \text { qfte } 1=q f t e 1^{\prime} * r t e 1 \\
& \text { qfts } 1=q f t s 1^{\prime} * r t s 1 \\
& \text { qfte } 2=q f t e 2^{\prime} * r t e 2 \\
& \text { qfts } 2=\text { qfts } 2{ }^{\prime} * r t s 2
\end{aligned}
$$

O fluxo efetivo corresponde a uma proporção do fluxo simulado por sorteio aleatório (qfte' e qfts'), sendo esta proporção correspondente aos coeficientes rte e rts.

A variação do volume no reservatório de sedimentos costeiros acumulados depende do balanço sedimentar da área fonte. Este reservatório receberá sedimentos sempre que o volume de sedimentos da área fonte superar certo valor máximo (Vfmax) e perderá sedimentos quando o volume da área fonte for inferior a certo valor mínimo. O aumento de volume implica apenas o recebimento do volume excedente na área fonte (Vf-Vfmax, para Vf $>$ Vfmax) enquanto que a redução requer a preenchimento da área fonte até seu valor mínimo com sedimentos derivados do 
reservatório de sedimentos costeiros acumulados e do campo de dunas (Vfmin-Vf, para Vfmin > Vf).

4.5.3 Variação de volume da área fonte e sua influência sobre os fluxos de entrada e saída de sedimentos no campo de dunas e no reservatório de sedimentos costeiros acumulados

O volume da área fonte equivale a um prisma definido pela amplitude de máre e inclinação da zona intermaré (Figura 4.9). A redução de volume devido a balanço negativo de sedimentos na área fonte implica aumento da inclinação da zona intermaré.

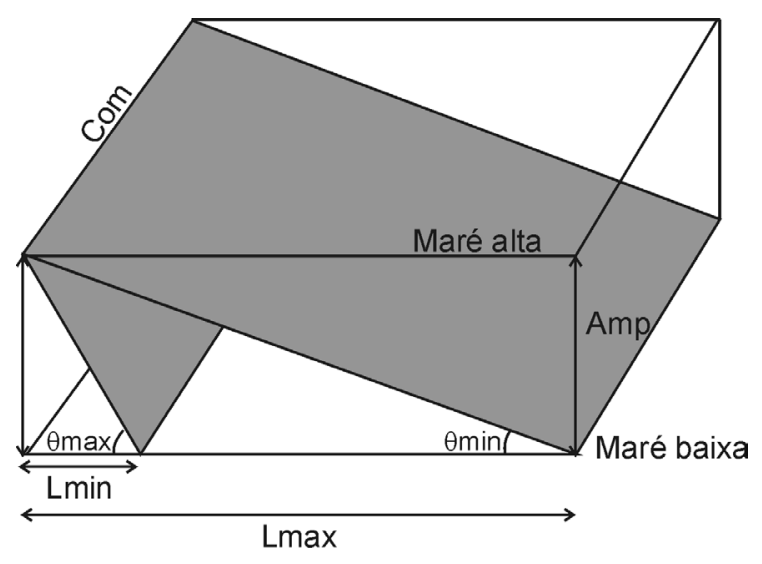

Figura 4.9 - Geometria da zona intermaré. A redução do volume de sedimentos implica redução do ângulo de inclinação da zona intermaré. Amp=amplitude de maré; $\mathrm{Com}=$ comprimento da costa; $\theta=$ inclinação da zona intermaré; $L=$ largura da zona intermaré. Os índices max e min indicam respectivamente máximo e mínimo.

$\mathrm{O}$ volume (Vf) do prisma de sedimentos que define a área fonte pode ser calculado pela seguinte expressão (Equação 4.17):

$V f=\frac{c o m * a m p * l a r}{2}$, sendo que lar $=\frac{A m p}{\tan \theta}$

A dinâmica da área fonte é ditada pelos volumes máximo (Vfmax) e mínimo (Vfmin). Quando o volume da área fonte supera o valor máximo (Vf $>$ Vfamx) há progradação do prisma de intermaré e regressão da linha de costa. O excesso de sedimentos (Vf-Vfmax) é incorporado 
ao reservatório de sedimentos costeiros acumulados. A redução de Vf abaixo de Vfmin implica erosão do campo de dunas e do reservatório de sedimentos costeiros acumulados. Neste caso, a diferença (Vfmin-Vf) é transferida do campo de dunas e do reservatório de sedimentos costeiros acumulados para a área fonte. Assim, há retrogradação do área fonte e transgressão da linha de costa. O mecanismo de progradação e retrogradação da área fonte pode ser observado na Figura 4.10 .
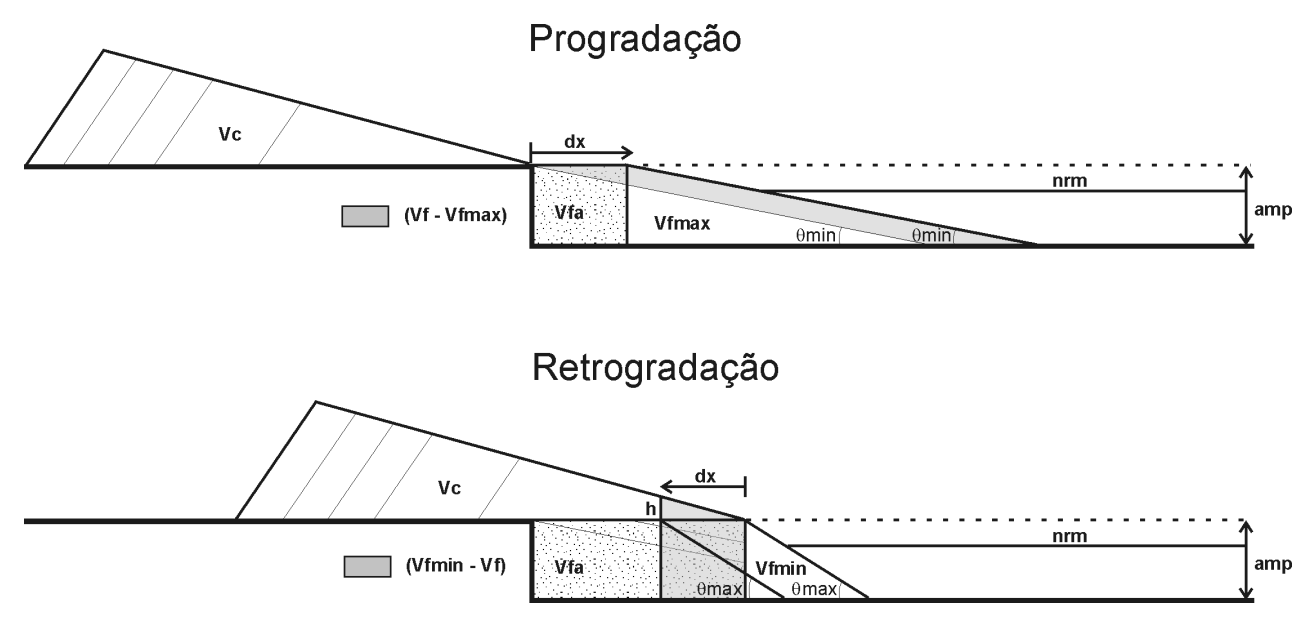

Figura 4.10 - Progradação (Vf $>$ Vfmax) e retrogradação (Vf $<$ Vfmin) da área fonte induzida pelo balanço sedimentar costeiro. $\mathrm{Vc}=$ volume do campo de dunas; $\mathrm{Vfa}=$ volume do reservatório de sedimentos costeiros acumulados; Vfmax= volume máximo d área fonte; Vfmin=volume mínimo da área fonte; $\mathrm{Vf}=$ volume da área fonte em dado instante; $\mathrm{dx}=$ distância de regressão ou transgressão; $h=a l t u r a$ que define o volume erodido do campo de dunas; amp=amplitude de maré; nrm=nível relativo do mar em dado instante.

A regressão da linha de costa por progradação da área fonte depende do excesso de sedimentos na área fonte (Vf-Vfmax) e pode ser calculada da seguinte forma (Equação 4.18):

$d x=\frac{(V f-V f \text { max })}{c o m * a m p}$, sendo $\mathrm{Vf}>\mathrm{Vfmax} \mathrm{e}$,

onde $d x$ é a distância de regressão, com o comprimento da costa e amp a amplitude de maré.

A distância de transgressão (dx) devido à retrogradação resulta da difereça (Vfmin-Vf), quando Vfmin > Vf, e pode ser expressa por (Equação 4.19): 
$d x=\frac{2(V f \min -V f)}{\operatorname{com}(h+2 a m p)}$, sendo Vfmin $>$ Vf e,

onde h é altura que define a parcela erodida do campo de dunas. A diferença (Vfmin-Vf) deve ser retirada do campo de dunas e do reservatório de sedimentos costeiros acumulados para recompor o volume mínimo da área fonte. Logo (Equação 4.20),

$(V f \min -V f)=D V c+D V f a$,

onde DVc corresponde à parcela de sedimentos derivados do campo de dunas e DVfa à parcela derivada do reservatório de sedimentos costeiros acumulados. Considerando que ambos os volumes possuem geometria prismática, os mesmos podem ser calculados pelas seguintes expressões (equações 4.21 e 4.22):

$D V c=\frac{h * d x * c o m}{2}$

$D V f a=a m p * d x * c o m$

Caso os volumes DVc e DVfa sejam respectivamente superiores a Vc e Vfa, o volume da área fonte não será recomposto até seu volume mínimo. Ou seja, a reposição dos sedimentos da área fonte é limitada pelos volumes disponíveis no reservatório de sedimentos costeiros acumulados e no campo de dunas em dado instante. Assim, a condição de retrogradação (Vfmin $>$ Vf) se extenderá ao instante seguinte.

$\mathrm{O}$ volume de sedimentos na área fonte em determinado instante t também influencia o fluxo eólico (qce) e o fluxo de saída de sedimentos do campo de dunas pela ação de ondas ou maré (qcs). A diminuição do volume da fonte atua como redutor do aporte eólico e amplificador da erosão do campo de dunas por agentes costeiros. Os fluxos qce e qcs em dado instante sofrerão redução ou amplificação por um coeficiente definido a partir da razão Vf/Vfmax. Assim, temos que (equações 4.23 e 4.24): 


$$
\begin{aligned}
& q c e=q c e^{\prime}\left(\frac{V f}{V f \max }\right), \\
& q c s=q c s^{\prime}\left(1-\frac{V f}{V f \max }\right),
\end{aligned}
$$

onde qce' e qcs'são fluxos simulados a partir de variáveis aleatórias independentes do volume da fonte. O fluxo qce'é calculado a partir da velocidade do vento simulada e diâmetro dos grãos de sedimentos.

4.5.4 Variabilidade climática e sua influência sobre os fluxos de entrada e saída de sedimentos no campo de dunas e área fonte

O modelo climático adotado para a simulação do sistema eólico costeiro é totalmente probabílistico e compreende dois estados fundamentais: tempo bom e tempestade. A ocorrência de tempestades foi simulada a partir de uma cadeia de Markov de dois estados da mesma forma que a ocorrência de chuva. A variabilidade climática em diversas escalas de tempo pode ser representada através da variação das probabilidades de tempestade e chuva em função do tempo. A variabilidade subanual é representada pela partição do ano em dois períodos: estação seca e estação úmida. Para cada período são estabelecidos valores distintos de probabilidades de ocorrência de tempestade. Além disto, as condições de tempo bom do período seco diferem das condições do período úmido. Desta forma, o sistema opera em três condições climáticas: tempestade, tempo bom da estação seca e tempo bom da estação úmida. Logo, a variabilidade subanual (sazonalidade) é caracterizada pela duração da estação seca em número de dias ao longo do ano (tseca). A variabilidade interanual foi modelada pela variação da duração da estação seca ao longo dos anos. Neste modelo, a duração da estação seca foi descrita por função senoidal (Equação 4.25).

$$
t_{\text {sec } a}=\operatorname{int}\left(A \operatorname{sen}\left(K * t_{\max }\right)+A\right)+B
$$


sendo, $\mathrm{t}_{\text {seca }}$ a duração da estação seca em dias, $t_{\max }$ a duração do ano em dias $\left(t_{\max }=365\right), A$ a amplitude de variação da duração da estação seca, $K$ a freqüência de variação da duração da estação seca e B o valor mínimo da estação seca. A variabilidade climática representada em termos dos parâmetros A, K e B pode ser observada na Figura 4.11.

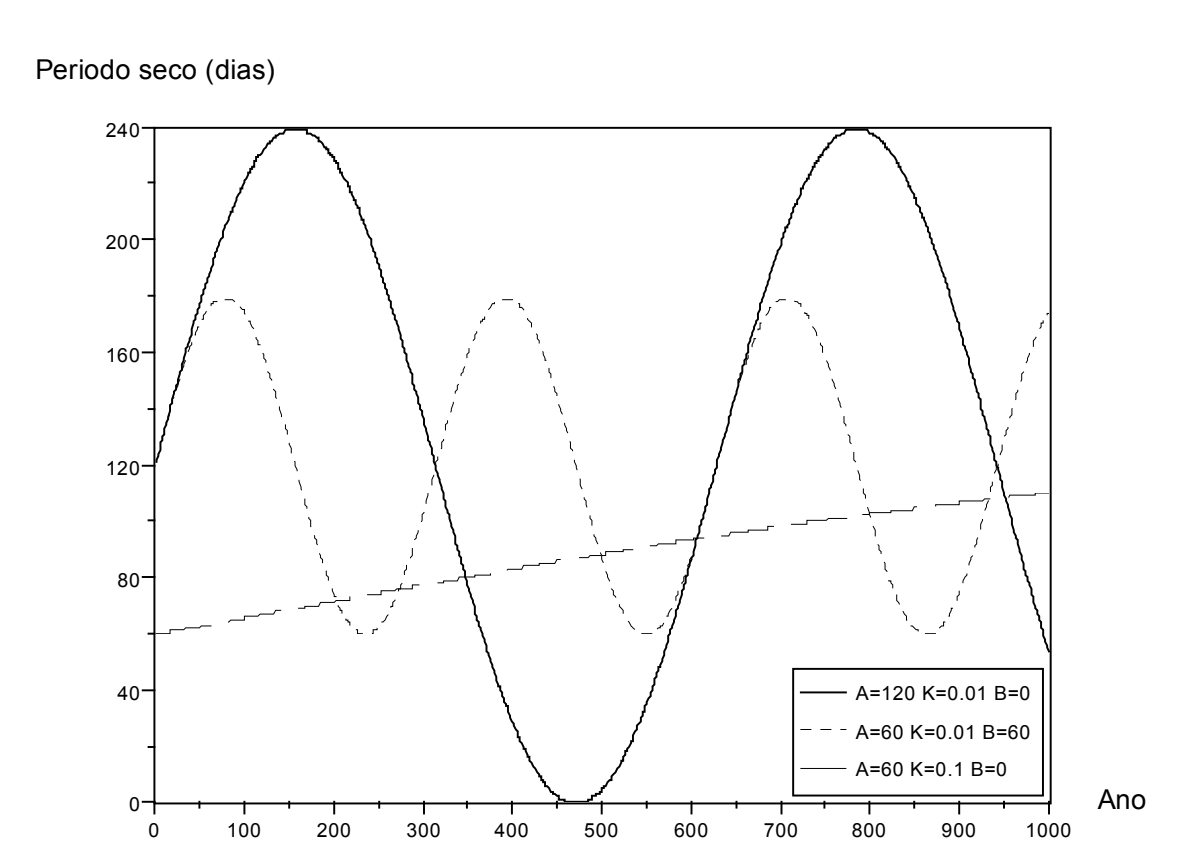

Figura 4.11 - Variação da duração do período seco em termos dos parâmetros A (amplitude), K (freqüência) e B (valor mínimo).

A variabilidade interanual é controlada pela variação dos parâmetros $\mathrm{A}, \mathrm{K}$ e $\mathrm{B}$, que definem o modo de variação da duração da estação seca e, portanto, da probabilidade de ocorrência das três condições de operação (tempestade, tempo bom úmido e tempo bom seco). Estas três condições apresentam valores distintos de probabilidade de chuva, velocidade média e variabilidade do vento e valores médios e variabilidades de fluxos de entrada e saída dependentes de agentes subaquosos (qcs, qfle, qfls, qfte e qfts). A influência direta do clima sobre o transporte eólico ocorre mediante a dependência com a velocidade do vento e ocorrência de chuva. A variabilidade climática espacial é significativa apenas no modelo de cadeia de campos de dunas, o qual pode abranger longos trechos de costa. Tal variabilidade pode ser modelada através da atribuição de valores particulares de probabilidades de chuva e tempestade, assim como das variáveis que dependem da condição climática, para cada segmento ou conjunto de segmentos da cadeia. A vinculação entre sedimentação e eventos climáticos permitiu o estudo da influência do 
clima (freqüência de tempestades e regime de chuvas e ventos) sobre a dinâmica da sedimentação eólica costeira.

\subsection{Fluxograma para simulação de sistema eólico de campo de dunas único}

O sistema eólico costeiro de campo de dunas único compreende apenas um segmento praial. Este sistema envolve a troca de sedimentos entre o campo de dunas e a zona intermaré adjacente e desta com o reservatório de sedimentos costeiros acumulados (qcs), além da entrada e saída de sedimentos da zona intermaré pela atividade de correntes litorâneas transversais e longitudinais. Os processos que compõem a dinâmica deste sistema e as condições determinantes da ocorrência destes processos podem ser visualizados no fluxograma da Figura 4.12. O algoritmo expresso no fluxograma envolve um loop diário e um loop anual. No loop diário, são simulados a condição climática (tempo bom ou tempestade), os fluxos de troca de sedimentos entre área fonte e campo de dunas, os fluxos de entrada e saída de sedimentos da área fonte por correntes costeiras e a entrada e saída de sedimentos do reservatório de sedimentos costeiros acumulados. No loop anual, as condições climáticas sofrem modificação pela alteração de duração da estação seca. Cada iteração do algoritmo corresponde a um dia. Os volumes de areia transferidos entre os elementos do sistema são calculados a partir dos respectivos fluxos de troca, da dimensão da interface entre os elementos envolvidos na troca e do intervalo de tempo de atuação do fluxo. O algoritmo do programa de simulação encontra-se no Anexo 2. 


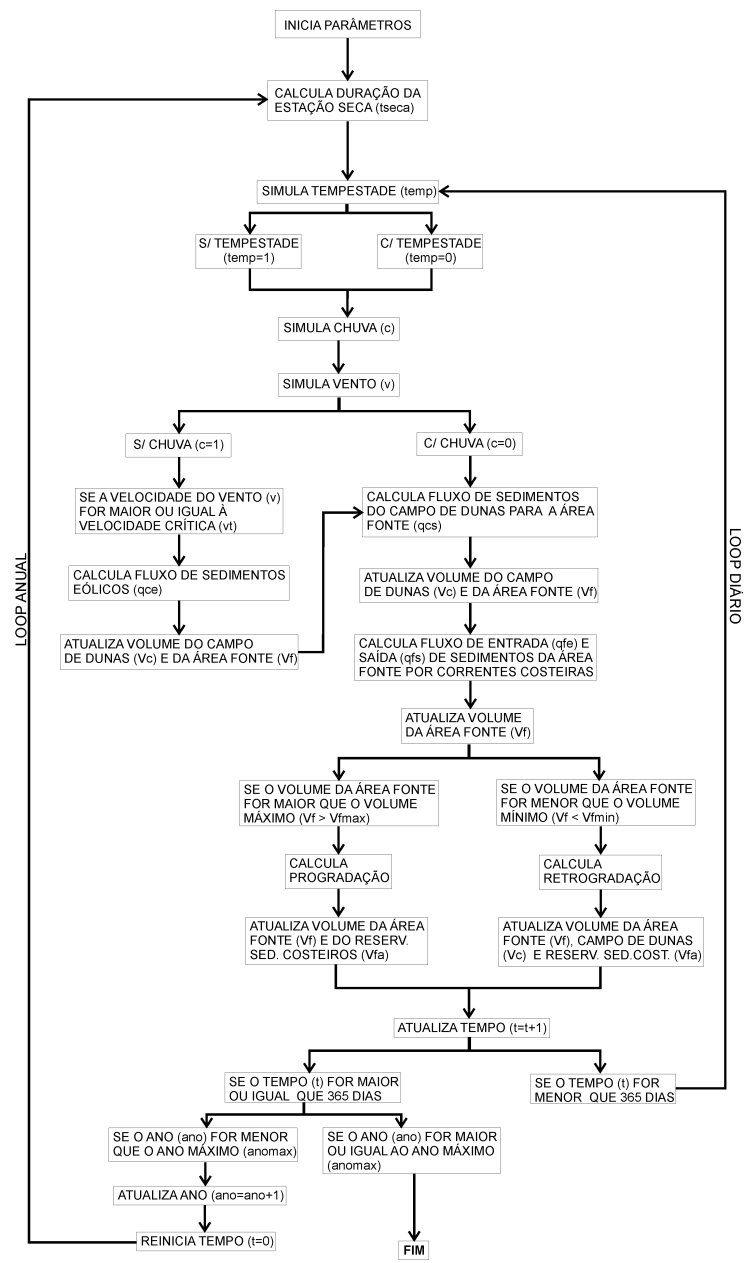

Figura 4.12 - Fluxograma para simulação de sistema eólico costeiro de campo de dunas único.

\subsection{Simulação de sistema eólico de campo de dunas único}

\subsubsection{Procedimentos utilizados na simulação}

O principal objetivo desta simulação foi avaliar a sensibilidade do modelo em relação a variáveis ligadas a aporte, clima e amplitude de maré. A evolução do volume do campo de dunas foi analisada em termos de fatores climáticos (freqüência de ocorrência de tempestades e chuvas e velocidade média do vento), amplitude de maré e aporte sedimentar costeiro. Para a avaliação da influência de cada fator sobre a dinâmica de variação do volume do campo de dunas, realizouse um conjunto de experimentos, nos quais os demais parâmetros do modelo foram mantidos constantes. Os experimentos envolveram simulações de intervalos de tempo de 1000 anos, 50.000 
anos e 100.000 anos. Assim, foi possível estudar as tendências de variação de escala sub-milenar e milenar. Nas simulações de intervalo de tempo de 1000 anos, as quantidades de interesse foram representadas por valores anuais, enquanto que, nas simulações de 50.000 anos e 100.000 anos, apenas valores seculares foram armazenados. Para as quantidades que dizem respeito a volumes (Vf, Vc e Vfa) e para a distância de regressão ou transgressão (dx) foram armazenados apenas os valores do final de cada ano ou cada século. Já os valores relacionados às demais variáveis (fluxos de sedimentos, velocidade do vento e porcentagem de dias secos ou tempestades) correspondem a médias anuais ou seculares. Por tratar-se de modelo altamente dependente de variáveis aleatórias, cada experimento foi repetido 30 vezes, sendo que o resultado final corresponde à média das 30 simulações. Também foram calculados intervalos de confiança $(95 \%$, distribuição normal) para cada valor anual ou secular das quantidades de interesse (Equação 4.26). Estes procedimentos equivalem aos recomendados por Ross (1990). Os intervalos de confiança foram representados pelas estatísticas média e desvio padrão. Os resultados dos experimentos de simulação foram expressos por meio de gráficos de dispersão.

$I C=\frac{1.96 S}{\sqrt{N}}, \quad$ sendo $\mathrm{S}$ o desvio padrão e $\mathrm{N}$ o número de simulações.

\subsubsection{Variáveis e valores dos parâmetros utilizados nos experimentos de simulação}

No Quadro 4.1, estão representados os valores dos parâmetros do modelo que foram mantidos constantes em todos os experimentos de simulação e no Quadro 4.2, as variáveis cuja influência sobre a sedimentação eólica costeira foi avaliada. Os ângulos mínimo e máximo de inclinação da zona intermaré foram escolhidos de modo a serem compatíveis respectivamente com os ângulos de inclinação de praias dissipativas e reflexivas. O comprimento da costa (com) corresponde ao comprimento da praia de Itapirubá (Imbituba, SC), a qual conta com campo de dunas cujo volume foi estimado. 


\begin{tabular}{|l|l|l|}
\hline Parâmetro & Descrição & $\begin{array}{l}\text { Valor utilizado na } \\
\text { simulação }\end{array}$ \\
\hline $\mathrm{dt}$ & $\begin{array}{l}\text { Intervalo de tempo ao longo do dia durante o qual pode } \\
\text { haver transporte eólico da área fonte para o campo de } \\
\text { dunas. Define o período de zona intermaré emersa e com } \\
\text { sedimentos incoesos. }\end{array}$ & \\
\hline angmin & $\begin{array}{l}\text { Ângulo de inclinação mínima da zona intermaré. } \\
\text { Determina o volume máximo de sedimentos na área fonte. }\end{array}$ & angmin=1 \\
\hline angmax & $\begin{array}{l}\text { Ângulo de inclinação máxima da zona intermaré. Define o o } \\
\text { volume de sedimentos na zona intermaré abaixo do qual } \\
\text { pode haver transporte de sedimentos do campo de dunas e } \\
\text { do reservatório de sedimentos costeiros acumulados para a } \\
\text { zona intermaré. }\end{array}$ & \\
\hline com & Comprimento da linha de costa & \\
\hline $\mathrm{d}$ & $\begin{array}{l}\text { Diâmetro dos grãos de sedimentos. Para todas } \\
\text { simulações foi utilizado diâmetro constante. }\end{array}$ & $\mathrm{Com}=0,00025 \mathrm{~m}$ \\
\hline Vfmax & Volume máximo de sedimentos na área fonte & $39186,334 \mathrm{~m}$ \\
\hline Vfmin & Volume mínimo de sedimentos na área fonte & $3879,1568 \mathrm{~m}$ \\
\hline ar & Densidade do ar & $\mathrm{ar}=1,225 \mathrm{~kg} / \mathrm{m}^{3}$ \\
\hline $\mathrm{qz}$ & Densidade dos grãos de sedimentos (quartzo) & $\mathrm{qz}=2650 \mathrm{~kg} / \mathrm{m}^{3}$ \\
\hline areia & Densidade da areia & $\mathrm{areia}=1650 \mathrm{~kg} / \mathrm{m}^{3}$ \\
\hline $\mathrm{g}$ & Aceleração da gravidade & $\mathrm{g}=9,8 \mathrm{~m} / \mathrm{s}^{2}$ \\
\hline ds & Diâmetro dos grãos que recobrem a superfície & $\mathrm{Ds}=0,00025 \mathrm{~m}$ \\
\hline
\end{tabular}

Quadro 4.1 - Descrição dos parâmetros que compõem o modelo e seus respectivos valores utilizados nos experimentos de simulação. 


\begin{tabular}{|c|c|}
\hline Variável & Descrição \\
\hline $\begin{array}{l}\text { tempseca1/tempseca2; } \\
\text { tempumida1/tempumida2 }\end{array}$ & $\begin{array}{l}\text { Probabilidade de ocorrência de tempestade nas estações seca e } \\
\text { úmida (temp2>temp1) }\end{array}$ \\
\hline $\begin{array}{l}\text { cseca1/cseca2, } \\
\text { cumida1/cumida2; } \\
\text { ctemp } 1 / \text { ctemp } 2\end{array}$ & $\begin{array}{l}\text { Probabilidade de chuva nas condições de tempestade e tempo } \\
\text { bom dos períodos úmido e seco }(\mathrm{c} 2>\mathrm{c} 1)\end{array}$ \\
\hline $\begin{array}{l}\text { vmumida; } \quad \text { vmseca; } \\
\text { vmtemp }\end{array}$ & $\begin{array}{l}\text { Velocidade média do vento nas condições de tempestade e } \\
\text { tempo bom dos períodos úmido e seco }\end{array}$ \\
\hline dvumida; dvseca; dvtemp & $\begin{array}{l}\text { Variabilidade da velocidade do vento nas condições de } \\
\text { tempestade e tempo bom dos períodos úmido e seco }\end{array}$ \\
\hline A & Amplitude de variação da duração da estação seca (dias) \\
\hline $\mathrm{K}$ & $\begin{array}{l}\text { Freqüência de variação da duração da estação seca. Se K } \\
\text { aumenta, a frequêencia aumenta. }\end{array}$ \\
\hline B & Duração mínima da estação seca (dias) \\
\hline amp & Amplitude de maré (m) \\
\hline $\begin{array}{l}\text { qfemtemp; qfemseca; } \\
\text { qfemumida }\end{array}$ & $\begin{array}{l}\text { Fluxo médio de entrada de sedimentos na área fonte por } \\
\text { correntes costeiras nas condiçóes de tempestade e tempo bom } \\
\text { dos períodos seco e úmido }\left(\mathrm{m}^{3} / \mathrm{m}^{*} \text { hora }\right) \text {. }\end{array}$ \\
\hline $\begin{array}{l}\text { dqfetemp; } \\
\text { dqfeumida }\end{array}$ & $\begin{array}{l}\text { o de entrada de sedimentos na área fonte } \\
\text { ss nas condições de tempestade e tempo } \\
\text { o e úmido }\left(\mathrm{m}^{3} / \mathrm{m}^{*} \text { hora }\right) \text {. }\end{array}$ \\
\hline $\begin{array}{l}\text { qfsmtemp; } \\
\text { qfsmumida }\end{array}$ & $\begin{array}{l}\text { Fluxo médio de saída de sedimentos da área fonte por correntes } \\
\text { costeiras nas condições de tempestade e tempo bom dos } \\
\text { períodos seco e úmido }\left(\mathrm{m}^{3} / \mathrm{m}^{*} \text { hora). }\right.\end{array}$ \\
\hline $\begin{array}{l}\text { dqfstemp; } \\
\text { dqfsumida }\end{array}$ & $\begin{array}{l}\text { Variabilidade do fluxo de saída de sedimentos da área fonte por } \\
\text { correntes costeiras nas condições de tempestade e tempo bom } \\
\text { de período sedo e úmido }\left(\mathrm{m}^{3} / \mathrm{m}^{*} \text { hora }\right) \text {. }\end{array}$ \\
\hline $\begin{array}{l}\text { qcsmtemp; } \\
\text { qcsmumida }\end{array}$ & $\begin{array}{l}\text { Fluxo médio de saída de sedimentos do campo de dunas pela } \\
\text { ação de ondas ou maré nas condições de tempestade e tempo } \\
\text { bom de período seco e úmido }\left(\mathrm{m}^{3} / \mathrm{m}^{*} \text { hora }\right) \text {. }\end{array}$ \\
\hline $\begin{array}{l}\text { dqcstemp; } \\
\text { dqcsumida }\end{array}$ & $\begin{array}{l}\text { Variabilidade do fluxo de saída de sedimentos do campo de } \\
\text { dunas pela ação de ondas ou maré nas condições de tempestade } \\
\text { e tempo bom de período seco e úmido }\left(\mathrm{m}^{3} / \mathrm{m}^{*} \text { hora }\right) \text {. }\end{array}$ \\
\hline
\end{tabular}

Quadro 4.2 - Descrição das variáveis cujos influência sobre a sedimentação eólica foi avaliada através dos experimentos de simulação.

O volume do campo de dunas de Itapirubá foi estimado a partir de levantamento topográfico executado com altímetro e GPS (Figura 4.13). A topografia do substrato do campo de dunas foi considerada plana, pois foram obtidos apenas dados das zonas não soterradas do substrato. A maior parte destes dados é proveniente das adjacências do campo de dunas. Apesar desta imprecisão, o volume estimado constitui boa aproximação da ordem de grandeza do volume do campo de dunas. O volume de areia foi calculado a partir do programa Surfer 8. 


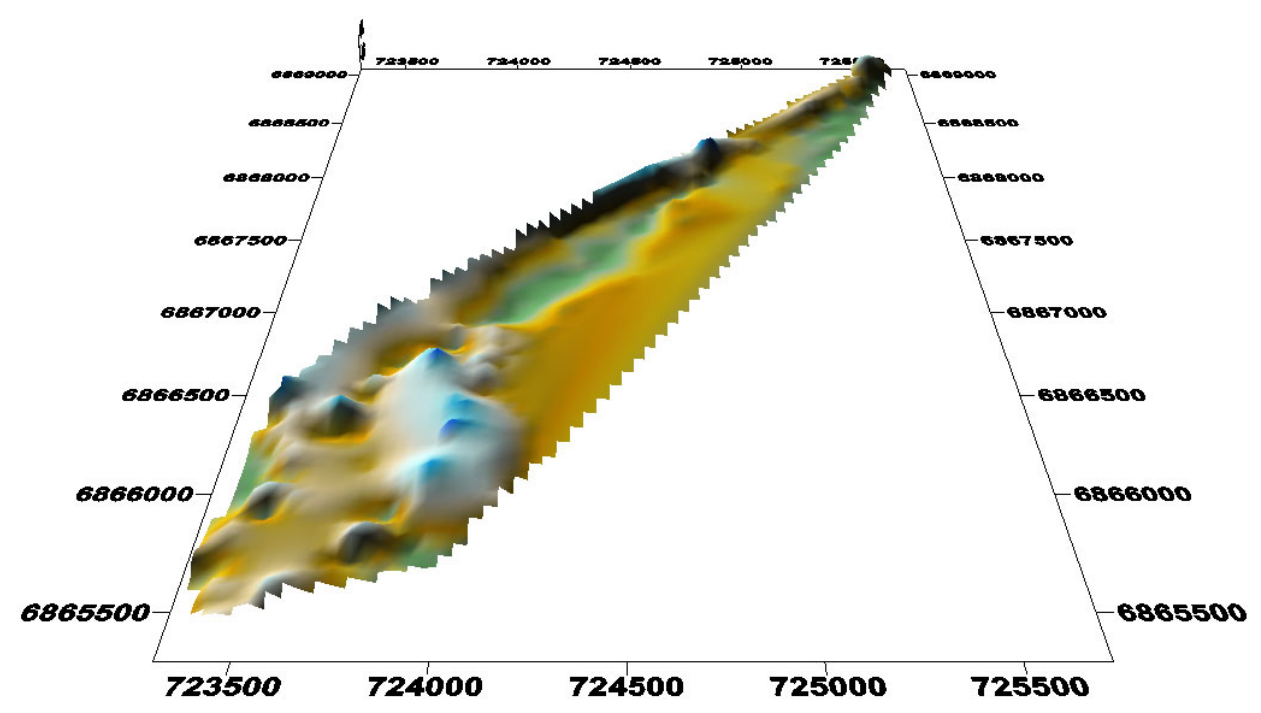

Figura 4.13 - Estimativa do volume do campo de dunas de Itapirubá (Imbituba, SC). Volume estimado $=3,29 \times 10^{7} \mathrm{~m}^{3}$.

Também foram estimados valores de volume de dunas frontais. Estas estimativas foram baseada na aproximação de dunas frontais como formas geométricas prismáticas (Figura 4.14). Esta aproximação fornece valores máximos de volume de cordões de dunas frontais, os quais podem ser calculados a partir da altura e ângulo de inclinação das faces das dunas (Equação 4.27).

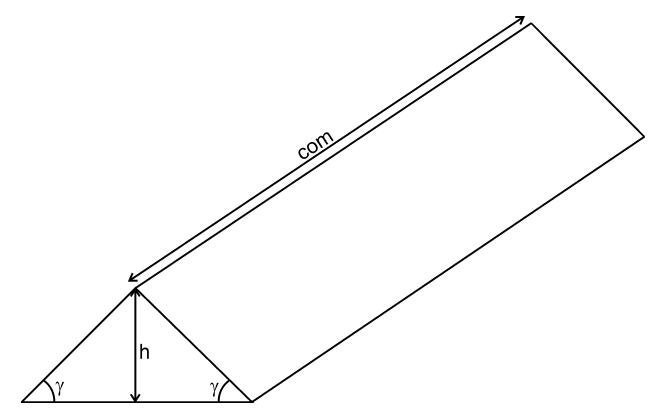

Figura 4.14 - Estimativa do volume de dunas frontais. As dunas frontais foram consideradas volumes prismáticos. Esta aproximação fornece volumes máximos de sedimentos.

$$
V_{d}=\frac{2 h^{2} \cdot \operatorname{com}}{2 \operatorname{tg} \gamma}
$$


Calcularam-se valores de volumes para diversas alturas e ângulo de inclinação das faces das dunas (Tabela 4.1). Tais valores, apesar da imprecisão, também informam a ordem de grandeza do volume de dunas frontais.

\begin{tabular}{|r|r|r|r|}
\hline $\begin{array}{l}\text { h } \\
(\mathbf{m})\end{array}$ & $\begin{array}{l}\boldsymbol{\gamma} \\
\text { (graus) }\end{array}$ & $\begin{array}{l}\text { com } \\
(\mathbf{m})\end{array}$ & Volume $\left.\mathbf{( m}^{\mathbf{3}}\right)$ \\
\hline 1 & 5 & 3800 & $4,34 \times 10^{4}$ \\
\hline 1 & 10 & 3800 & $2,15 \times 10^{4}$ \\
\hline 1 & 30 & 3800 & $6,58 \times 10^{3}$ \\
\hline 2 & 5 & 3800 & $1,74 \times 10^{5}$ \\
\hline 2 & 10 & 3800 & $8,62 \times 10^{4}$ \\
\hline 2 & 30 & 3800 & $2,63 \times 10^{4}$ \\
\hline 4 & 5 & 3800 & $6,95 \times 10^{5}$ \\
\hline 4 & 10 & 3800 & $3,45 \times 10^{5}$ \\
\hline 4 & 30 & 3800 & $1,05 \times 10^{5}$ \\
\hline
\end{tabular}

Tabela 4.1 - Volumes estimados para dunas frontais de alturas e inclinação das faces distintas. $\mathrm{h}=$ altura; $\gamma=$ ângulo de inclinação das faces; com=comprimento.

A ordem de grandeza do volume do campo de dunas de Itapirubá é de $10^{7} \mathrm{~m}^{3}$ enquanto que a ordem de grandeza de cordão de dunas frontais de comprimento igual ao da linha de costa varia de $10^{3} \mathrm{~m}^{3}$ (dunas baixas e de faces íngremes) a $10^{5} \mathrm{~m}^{3}$ (dunas altas). Logo, o volume do campo de dunas é pelo menos duas ordens de grandeza superior ao volume de cordão de dunas frontais. Estes valores foram utilizados como referência para análise de Vc (volume de sedimentos eólicos acumulados).

4.7.3 Experimentos com variação do aporte sedimentar costeiro para período de 1000 anos (1 ka)

Estes experimentos visaram à avaliação da influência do aporte sedimentar costeiro (qfe e qfs) sobre as quantidades de interesse (Vc, Vf, Vfa, qce e dx). Foram realizados experimentos com diferentes valores médios dos fluxos de entrada e saída de sedimentos da área fonte (qfe e qfs). Estes fluxos foram simulados a partir do modelo de probabilidade lognormal sob condições de amplitude de maré constante e sob regime climático de sazonalidade acentuada. Este regime caracteriza-se pelo elevado contraste de velocidade do vento e probabilidade de ocorrência de chuva e tempestade entre os períodos seco e úmido. Foram realizados experimentos desprovidos 
de variabilidade climática interanual, ou seja, com período úmido e seco de duração constante, e experimentos com variação da duração do período seco. No primeiro caso, os períodos seco e úmido possuem duração semelhante (estação seca=180 dias e estação úmida=185 dias) e no segundo o período seco varia de 0 a 120 dias. Deste modo, foi possível a avaliação das quantidades de interesse sob clima estacionário e sob clima com variabilidade climática interanual. Os valores utilizados para simulação dos fluxos de sedimentos nas condições de tempo bom seco e tempo bom úmido foram ajustados para que as condições de operação do sistema nos períodos seco e úmido fossem contrastantes. As variáveis que foram mantidas constantes e seus respectivos valores encontram-se no Quadro 4.3.

No que diz respeito à amplitude de maré, realizaram-se simulações sob regime de micromaré $(\mathrm{amp}=0,6 \mathrm{~m})$ e de macromaré $(\mathrm{amp}=4 \mathrm{~m})$. Os valores de amplitude de maré, para o regime de micromaré, comprimento da costa $(\operatorname{com}=3800 \mathrm{~m})$ e velocidade média do vento utilizados nesta simulação correspondem aproximadamente aos que ocorrem na praia de Itapirubá (Imbituba, SC). Assim, foi possível utilizar o volume e idade aproximada do campo de dunas adjacente a esta praia, assim como a largura da planície costeira, como parâmetros de referência para os dados simulados. Os experimentos foram realizados sob as seguintes condições dos fluxos de entrada e saída de sedimentos da área fonte:

$\mathrm{qfe}=\mathrm{qfs}$, com valores crescentes de qfe e qfs.

qfe $>$ qfs, com amplificação da diferença entre qfe e qfs.

qfe < qfs, com amplificação da diferença entre qfe e qfs.

\begin{tabular}{|l|l|l|l|}
\hline $\begin{array}{l}\text { Probabilidade de } \\
\text { tempestade }\end{array}$ & $\begin{array}{l}\text { Probabilidade } \\
\text { de chuva }\end{array}$ & $\begin{array}{l}\text { Velocidade } \\
\mathbf{d o} \quad \text { vento } \\
\mathbf{( m} / \mathbf{s})\end{array}$ & $\begin{array}{l}\text { Saída de sedimentos do campo de } \\
\text { dunas }\left(\mathbf{m}^{\mathbf{3}} / \mathbf{m} \text { hora }\right)\end{array}$ \\
\hline tempseca $1=0.02$ & ctemp $1=0.6$ & vmtemp $=15$ & qcsmtemp $=0.1$ \\
\hline tempseca $2=0.05$ & ctemp2 $=0.8$ & dvtemp $=1$ & dqcstemp $=1$ \\
\hline Tempumida $1=0.07$ & cseca $1=0.05$ & vmseca $=10$ & qcsmseca $=0.003$ \\
\hline Tempumida2 $=0.1$ & cseca $2=0.1$ & dvseca $=0.3$ & dqcsseca $=0.3$ \\
\hline & cumida $1=0.4$ & vmumida $=8$ & qcsmumida $=0.006$ \\
\hline & cumida2 $=0.7$ & dvumida $=0.3$ & dqcsumida $=0.3$ \\
\hline
\end{tabular}

Quadro 4.3 - Variáveis mantidas constantes nas simulações para avaliação da influência dos fluxos de entrada e saída de sedimentos costeiros no sistema eólico. Notar o contraste das probabilidades de tempestade e chuva, velocidade média do vento e fluxo de entrada e saída de 
sedimentos da área fonte entre as estações seca e úmida. A designação de cada variável pode ser vista no Quadro 4.2.

Sob as condições descritas no Quadro 4.3, foram realizados três conjuntos de experimentos. No primeiro conjunto, cada simulação foi realizada com os mesmos valores médios e de dispersão para a geração de qfe e qfs nas condições de tempestade, tempo bom seco e tempo bom úmido. Assim, realizaram-se simulações com as mesmas condições de entrada e saída de sedimentos da área fonte, porém com valores médios sucessivamente crescentes destes fluxos. O segundo conjunto envolveu simulações com qfe $>$ qfs, sendo que a diferença entre os valores médios destes fluxos foi progressivamente aumentada. No terceiro conjunto, realizaramse experimentos com qfe < qfs e aumento progressivo da diferença entre qfe e qfs. Além disto, cada conjunto contempla simulações com ampliutude de maré elevada e variação da duração da estação seca. A seguir, são apresentados os resultados destes três conjuntos de experimentos, respectivamente, $\mathrm{qfe}=\mathrm{qfs}$, qfe $>$ qfs e qfe $<$ qfs. A confiabilidade dos resultados relativos a variáveis aleatórias foi avaliada pela média e desvio padrão dos respectivos intervalos de confiança. As condições para simulação da ocorrência de chuva e tempestade, assim como a velocidade média e dispersão da velocidade do vento foram mantidas constantes nas simulações desprovidas de variabilidade climática interanual dos três conjuntos de experimentos. Por serem variáveis independentes, seus intervalos de confiança são equivalentes em todos os experimentos com variação do aporte sedimentar costeiro (Tabela 4.2). Nos demais experimentos, os intervalos de confiança destas variáveis são apresentados nas tabelas correspondentes.

\begin{tabular}{|l|l|l|}
\hline Variável & Intervalo de confiança médio & $\begin{array}{l}\text { Desvio padrão do intervalo } \\
\text { de confiança }\end{array}$ \\
\hline Temp (\%) & 0,400 & 0,053 \\
\hline Dias secos $(\%)$ & 0,734 & 0,100 \\
\hline $\mathrm{v}(\mathrm{m} / \mathrm{s})$ & 0,096 & 0,017 \\
\hline
\end{tabular}

Tabela 4.2 - Intervalos de confiança da freqüência de ocorrência de tempestades, porcentagem de dias secos e velocidade do média anual do vento. 


\subsubsection{Costa com balanço sedimentar costeiro nulo $(q f e=q f s)$}

Costa com balanço sedimentar costeiro nulo é caracterizada pela igualdade entre os fluxos médios de entrada e saída de sedimentos costeiros. Equivaleria portanto à aporte costeiro equilibrado dominado por trânsito de sedimentos (bypass).

Para baixos valores médios de qfe e qfs (figuras 4.15 e 4.16), o volume de sedimentos costeiros acumulados (Vfa) sofre redução seguida de estabilização, com flutuações em torno de valor médio. Isto proporciona transgressão, seguida de estabilização da linha de costa. A transgressão atinge cerca de $19 \mathrm{~m}$ em 300 anos e passa a oscilar em torno da posição $-18 \mathrm{~m}$ (sucessão entre transgressões e regressões com cerca de $2 \mathrm{~m}$ de amplitude) a partir deste período. No entanto, a amplitude destas oscilações é semelhante aos respectivos intervalos de confiança médios de modo que após a fase transgressiva, a linha de costa pode ser considerada estável. O volume de sedimentos na área fonte (Vf) inicia-se com o valor mínimo e seu valor médio anual cresce e se estabiliza em torno de $30000 \mathrm{~m}^{3}$, em aproximadamente 200 anos. Este crescimento incial de Vf induz incremento do fluxo médio anual de sedimentos eólicos (qce) nos 200 anos iniciais. $\mathrm{O}$ volume de sedimentos eólicos $(\mathrm{Vc})$ cresce em período correspondente à fase transgressiva. O crescimento de Vc cessa por volta de 300 anos e passa a variar ao redor de $16000 \mathrm{~m}^{3}$. Porém, assim como ocorre com a linha de costa, esta variação é pouco significativa em relação aos intervalos de confiaça médios (tabelas 4.3 e 4.4). O crescimento de $\mathrm{Vc}$ e a queda de Vfa persistem por cerca de 100 anos após a estabilização de Vf. O valor de Vc é muito baixo se comparado ao campo de dunas de Itapirubá. O volume de sedimentos eólicos acumulado no período de 1000 anos é comparável apenas ao volume de dunas frontais baixas. 

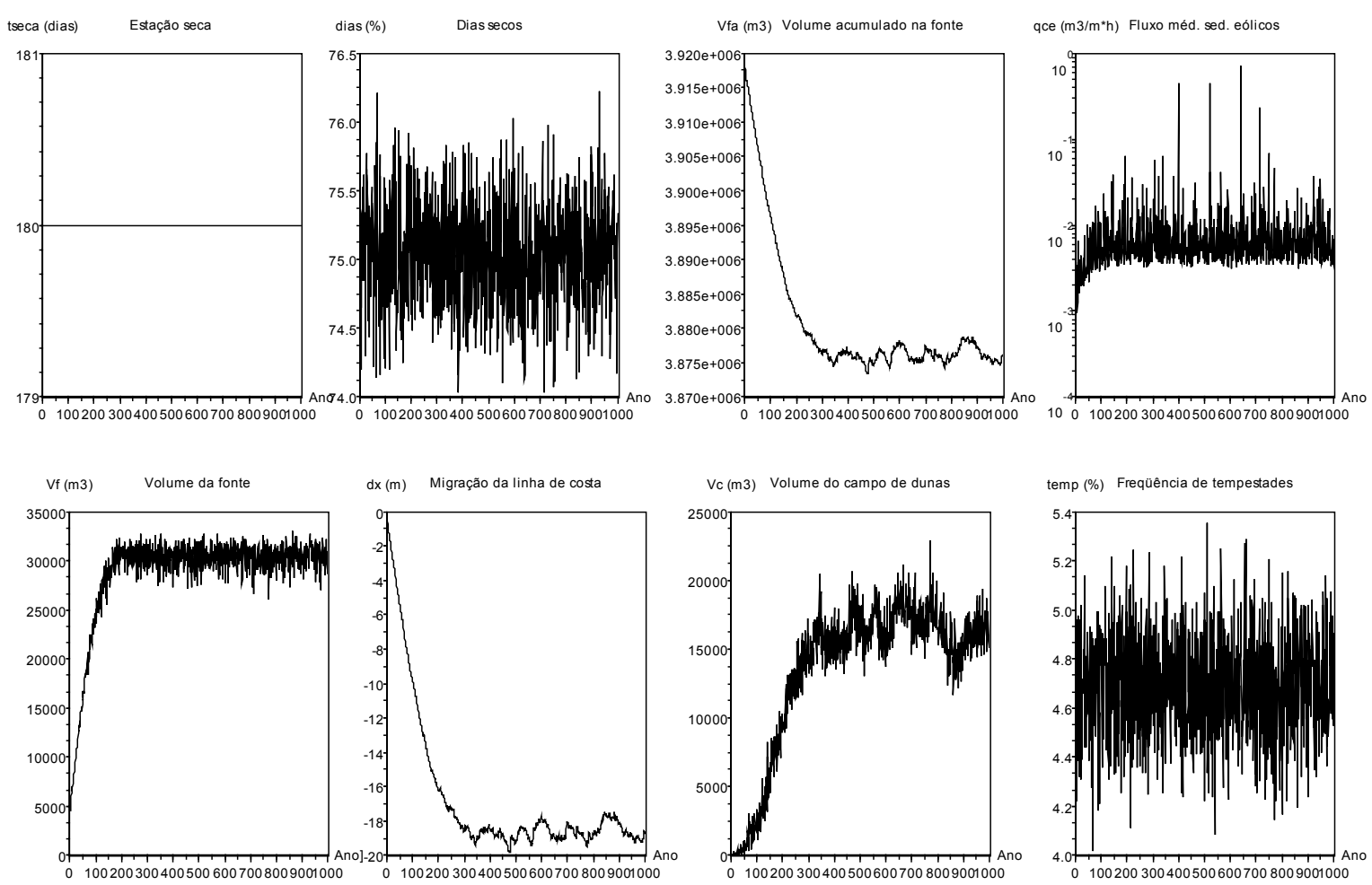

Figura 4.15 - Resultado da simulação de 1000 anos do modelo de sistema eólico costeiro sob condições de sazonalidade acentuada e $\mathbf{q} \mathbf{f e}=\mathbf{q f s}$. Foram utilizados os seguintes valores para simulação de qfe e qfs: qfemtemp=qfsmtemp=0,1, dqfetemp=dqfstemp=1, qfemseca $=$ qfsmsseca $=\mathbf{0 , 0 0 3}, \quad$ dqfeseca $=$ dqfsseca $=\mathbf{0 , 3}, \quad$ qfemumida $=$ qfsmumida $=\mathbf{0 , 0 0 6}$, dqfeumida $=$ dqfsumida $=\mathbf{0 , 3}$.

\begin{tabular}{|l|l|l|}
\hline Variável & Intervalo de confiança médio & $\begin{array}{l}\text { Desvio padrão do intervalo } \\
\text { de confiança }\end{array}$ \\
\hline $\mathrm{qce}\left(\mathrm{m}^{3} / \mathrm{m}^{*} \mathrm{~h}\right)$ & 0,009 & 0,060 \\
\hline $\mathrm{Vc}\left(\mathrm{m}^{3}\right)$ & 2979,850 & 1018,612 \\
\hline $\mathrm{Vf}\left(\mathrm{m}^{3}\right)$ & 1988,237 & 561,098 \\
\hline $\mathrm{Vfa}\left(\mathrm{m}^{3}\right)$ & 3439,224 & 1325,140 \\
\hline $\mathrm{dx}(\mathrm{m})$ & 1,508 & 0,581 \\
\hline
\end{tabular}

Tabela 4.3 - Média e desvio padrão dos intervalos de confiança das variáveis de interesse (simulação de 1000 anos), cujos resultados encontram-se na Figura 4.15. 

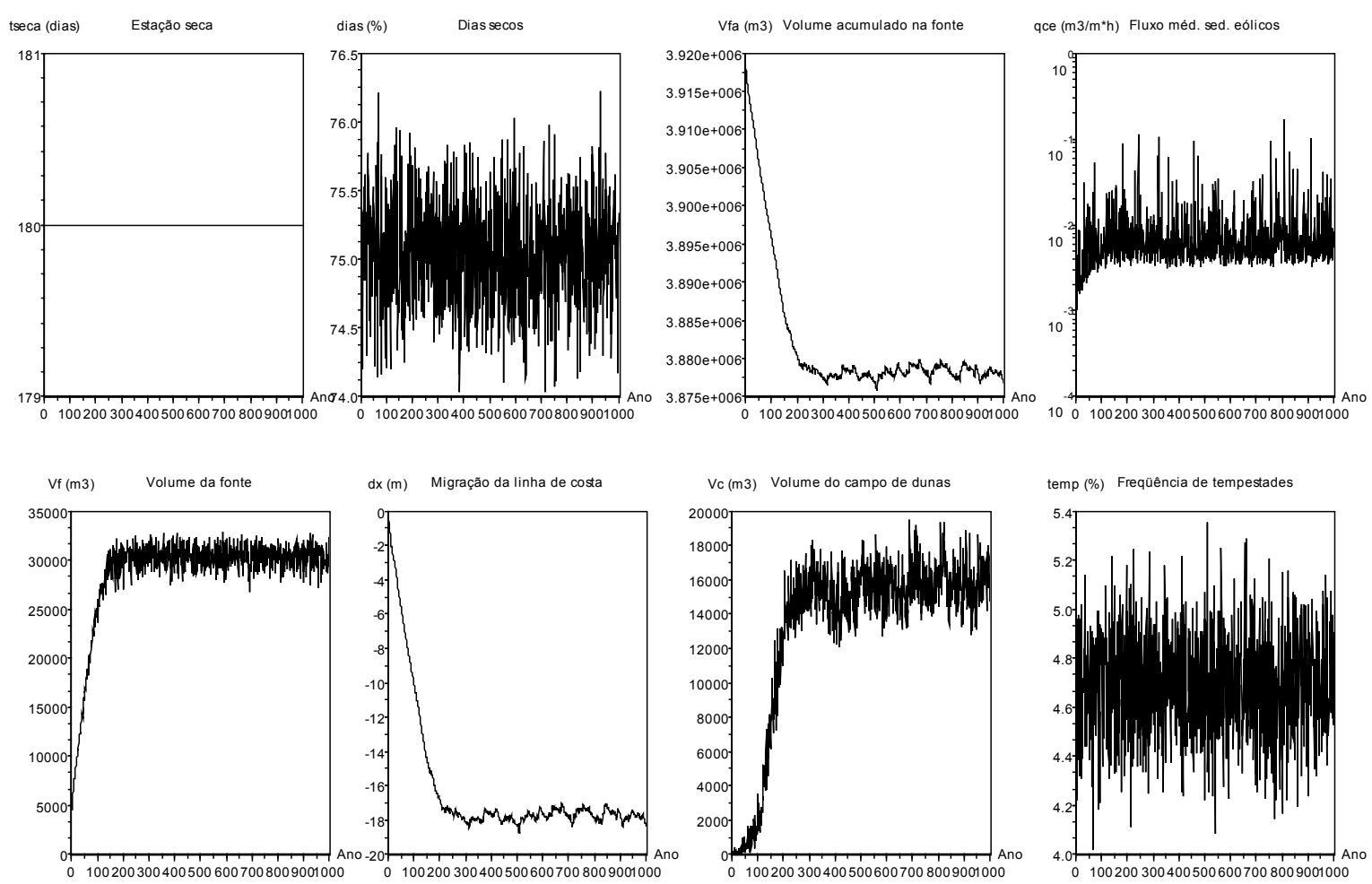

Figura 4.16 - Resultado da simulação de 1000 anos do modelo de sistema eólico costeiro sob condições de sazonalidade acentuada e $\mathbf{q} \mathbf{f e}=\mathbf{q} \mathbf{f s}$. Foram utilizados os seguintes valores para simulação de qfe e qfs: qfemtemp=qfsmtemp=0,1, dqfetemp=dqfstemp=1, qfemseca $=$ qfsmsseca $=\mathbf{0 , 0 3}, \quad$ dqfeseca $=$ dqfsseca $=\mathbf{0 , 3}, \quad$ qfemumida $=$ qfsmumida $=\mathbf{0 , 0 6}$, dqfeumida $=$ dqfsumida $=\mathbf{0 , 3}$.

\begin{tabular}{|l|l|l|}
\hline Variável & Intervalo de confiança médio & $\begin{array}{l}\text { Desvio padrão do intervalo } \\
\text { de confiança }\end{array}$ \\
\hline $\mathrm{qce}\left(\mathrm{m}^{3} / \mathrm{m}^{*} \mathrm{~h}\right)$ & 0,008 & 0,020 \\
\hline $\mathrm{Vc}\left(\mathrm{m}^{3}\right)$ & 2865,434 & 941,622 \\
\hline $\mathrm{Vf}\left(\mathrm{m}^{3}\right)$ & 1996,689 & 559,355 \\
\hline $\mathrm{Vfa}\left(\mathrm{m}^{3}\right)$ & 3078,393 & 1239,608 \\
\hline $\mathrm{dx}(\mathrm{m})$ & 1,350 & 0,543 \\
\hline
\end{tabular}

Tabela 4.4 - Média e desvio padrão dos intervalos de confiança das variáveis de interesse (simulação de 1000 anos), cujos resultados encontram-se na Figura 4.16.

O aumento da variabilidade e dos valores médios dos fluxos de entrada e saída de sedimentos costeiros provoca alterações significativas na dinâmica de crescimento do volume de sedimentos eólicos e de migração da linha de costa (Figura 4.17). Estes incrementos induzem redução do tempo e distância da transgressão da linha de costa e substituição da estabilização por 
regressão. A regressão ocorre de modo irregular, sendo caracterizada por deslocamentos abruptos da linha de costa. No entanto, assim como a taxa de transgressão, a taxa de regressão é baixa se analisada de modo absoluto. A exemplo do experimento anterior, o volume máximo de sedimentos eólicos acumulados é significativo apenas para a formação de dunas frontais. Destaca-se que o crescimento de Vc ocorre tanto sob linha de costa transgressiva quanto regressiva.

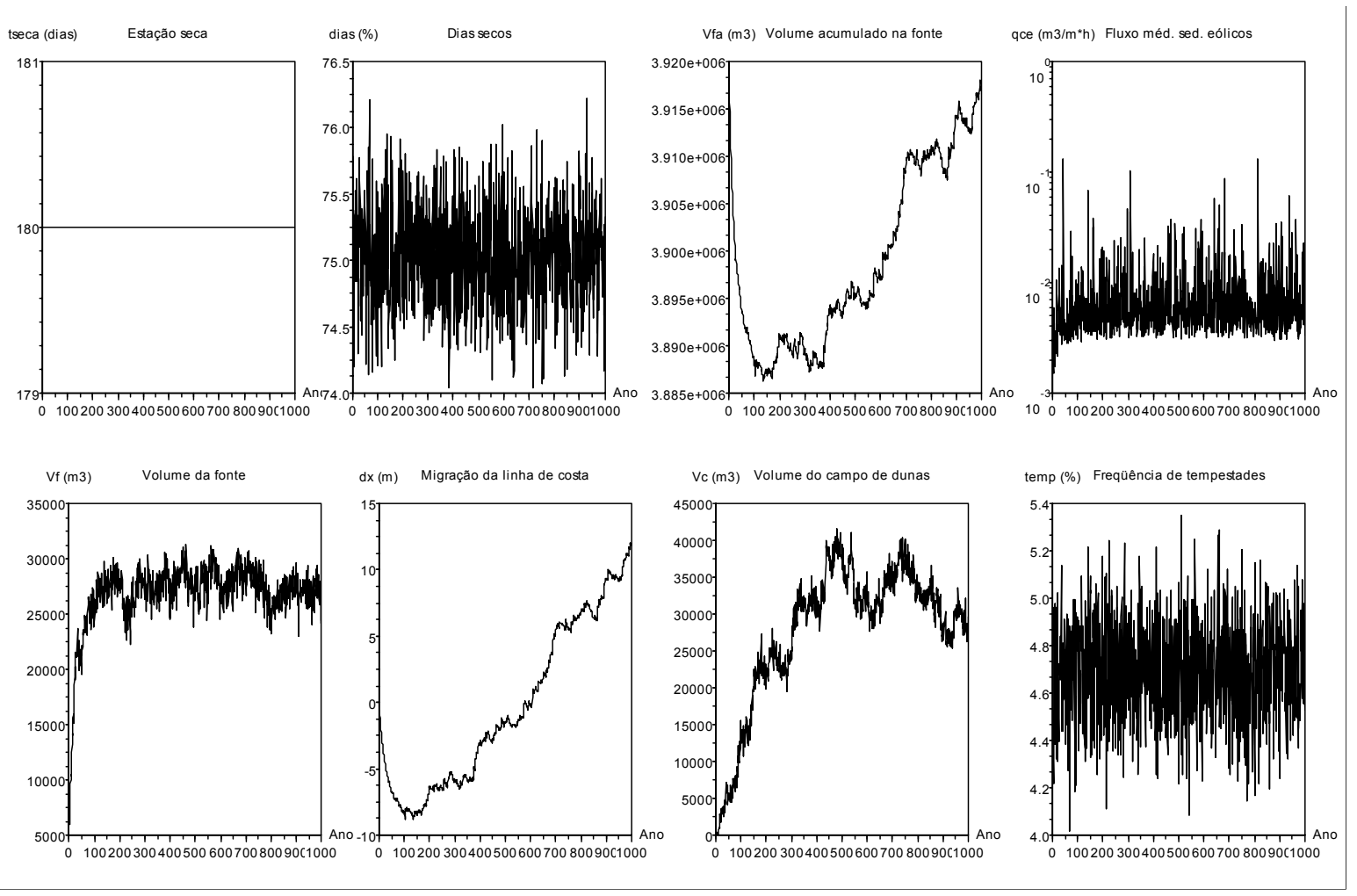

Figura 4.17 - Resultados da simulação de 1000 anos do modelo de sistema eólico costeiro sob condições de sazonalidade acentuada e $\mathbf{q} \mathbf{f e}=\mathbf{q f s}$. Foram utilizados os seguintes valores para simulação de qfe e qfs: qfemtemp=qfsmtemp=1, dqfetemp=dqfstemp $=\mathbf{1}$, qfemseca $=$ qfsmseca $=\mathbf{0 , 3}, \quad$ dqfeseca $=$ dqfsseca $=\mathbf{0 , 3}, \quad$ qfemumida $=$ qfsmumida $=\mathbf{0 , 6}$, dqfeumida $=$ dqfsumida $=\mathbf{0 , 3}$. 


\begin{tabular}{|l|l|l|}
\hline Variável & Intervalo de confiança médio & $\begin{array}{l}\text { Desvio padrão do intervalo } \\
\text { de confiança }\end{array}$ \\
\hline $\mathrm{qce}\left(\mathrm{m}^{3} / \mathrm{m}^{*} \mathrm{~h}\right)$ & 0,007 & 0,017 \\
\hline $\mathrm{Vc}\left(\mathrm{m}^{3}\right)$ & 10832,612 & 3492,711 \\
\hline $\mathrm{Vf}\left(\mathrm{m}^{3}\right)$ & 2949,852 & 457,474 \\
\hline $\mathrm{Vfa}\left(\mathrm{m}^{3}\right)$ & 23950,536 & 10282,085 \\
\hline $\mathrm{dx}(\mathrm{m})$ & 8,827 & 4,080 \\
\hline
\end{tabular}

Tabela 4.5 - Média e desvio padrão dos intervalos de confiança das variáveis de interesse (simulação de 1000 anos), cujos resultados encontram-se na Figura 4.17.

O aumento da amplitude de maré (de 0,6 para 4,0 m) provoca elevação dos volumes de sedimentos acumulados e da distância de migração da linha de costa muito superior à provocada pelo incremento dos valores médios e da variabilidade dos fluxos de entrada e saída de sedimentos costeiros. A elevação da amplitude de maré equivale ao aumento do tamanho do reservatório da fonte eólica (Vf). Nestas condições, observa-se transgressão contínua da linha de costa e crescimento do volume de sedimentos eólicos, que atinge valores significativos para a formação de campo de dunas (Figura 4.18 e Tabela 4.6). A taxa de crescimento de Vc aumenta com o tempo enquanto que a taxa de transgressão é aproximadamente constante. Vc parece apresentar crescimento exponencial e a transgressão da linha de costa parece ocorrer de modo linear. Este experimento demonstra que o modelo é bastante sensível à elevação do tamanho da área fonte eólica. $\mathrm{O}$ aumento deste reservatório propicia o crescimento de $\mathrm{Vc}$ em detrimento de Vfa, pois Vf passa a operar distante do valor máximo (Vfmax), o que favorece a erosão costeira e transgressão da linha de costa. Assim, esta situação é favorável ao abastecimento da área fonte e do campo de dunas pela erosão da costa. A dinâmica deposicional deste experimento equivaleria à formação de campo de dunas em costa transgressiva. 

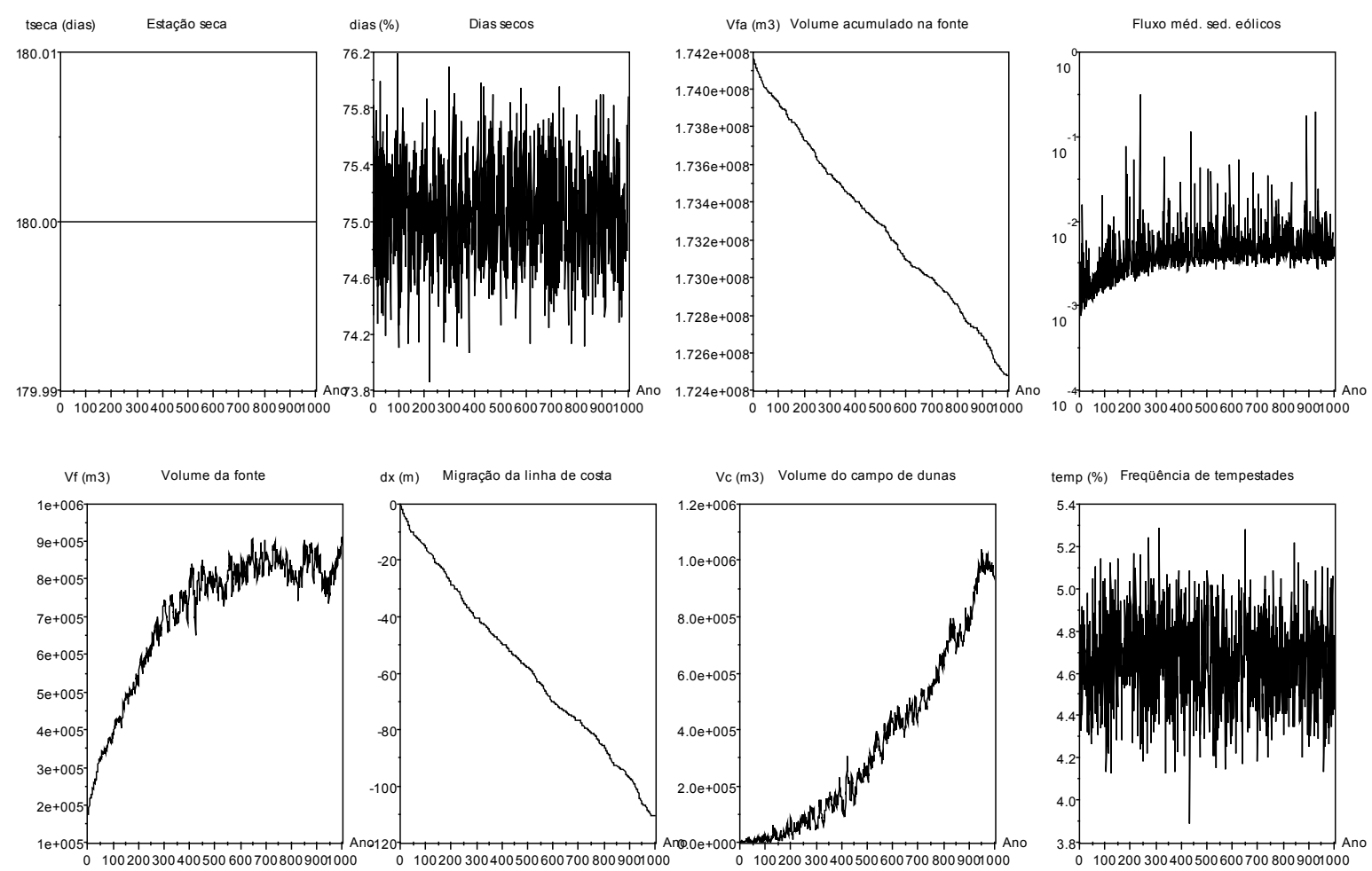

Figura 4.18 - Resultado da simulação de 1000 anos do modelo de sistema eólico costeiro sob condições de sazonalidade acentuada, $\mathbf{q f e}=\mathbf{q f s}$ e amplitude de maré igual a $\mathbf{4} \mathbf{~ m}$. Foram utilizados os seguintes valores para simulação de qfe e qfs: qfemtemp=qfsmtemp=0,1, dqfetemp $=$ dqfstemp $=\mathbf{1}, \quad$ qfemseca $=$ qfsmsseca $=\mathbf{0 , 0 0 3}, \quad$ dqfeseca $=$ dqfsseca $=\mathbf{0 , 3}$, qfemumida $=$ qfsmumida $=\mathbf{0 , 0 0 6}$, dqfeumida $=\mathrm{dqfsumida}=\mathbf{0 , 3}$.

\begin{tabular}{|l|l|l|}
\hline Variável & Intervalo de confiança médio & $\begin{array}{l}\text { Desvio padrão do intervalo } \\
\text { de confiança }\end{array}$ \\
\hline qce $\left(\mathrm{m}^{3} / \mathrm{m}^{*} \mathrm{~h}\right)$ & 0,006 & 0,027 \\
\hline $\mathrm{Vc}\left(\mathrm{m}^{3}\right)$ & 87553,280 & 47561,380 \\
\hline $\mathrm{Vf}\left(\mathrm{m}^{3}\right)$ & 57473,869 & 14607,337 \\
\hline $\mathrm{Vfa}\left(\mathrm{m}^{3}\right)$ & 84053,814 & 27416,028 \\
\hline $\mathrm{dx}(\mathrm{m})$ & 5,529 & 1,804 \\
\hline
\end{tabular}

Tabela 4.6 - Média e desvio padrão dos intervalos de confiança das variáveis de interesse (simulação de 1000 anos), cujos resultados encontram-se na Figura 4.18.

A introdução de variabilidade climática interanual (sob regime de micromaré, amplitude $=0,6 \mathrm{~m}$ ), caracterizada por variação periódica da duração da estação seca, provoca mudanças pouco expressivas no volume de sedimentos eólicos acumulados e na distância de migração da linha de costa. Deve ser salientado que os períodos seco e úmido foram definidos de 
modo contrastante, sendo que o período úmido é caracterizado por ventos de menor velocidade, maior freqüência de chuvas e tempestades e valores médios mais elevados dos fluxos de entrada e saída de sedimentos. Ou seja, o sistema opera de modo mais agitado durante o período úmido. $\mathrm{O}$ aumento da duração deste período provoca incremento da transgressão e pico de crescimento do volume de sedimentos eólicos (Figura 4.19 e Tabela 4.7). Não se observa alteração de Vc e dx (migração da linha de costa) correlacionável aos picos de duração máxima da estação seca. A maior sensibilidade do sistema ao aumento da duração da estação úmida pode estar relacionado à maior freqüência de ocorrência de tempestades. O fluxo médio de sedimentos eólicos (qce) e o volume médio de sedimentos na área fonte (Vf) não apresentam correlação com a freqüência de ocorrência de tempestades. Logo, o efeito das tempestades sobre o volume de sedimentos eólicos deve estar associado à elevação da erosão costeira (redução de Vfa). Portanto, as tempestades favorecem o aumento de Vc pelo fornecimento de sedimentos derivados do reservatório de sedimentos costeiros acumulados (Vfa).
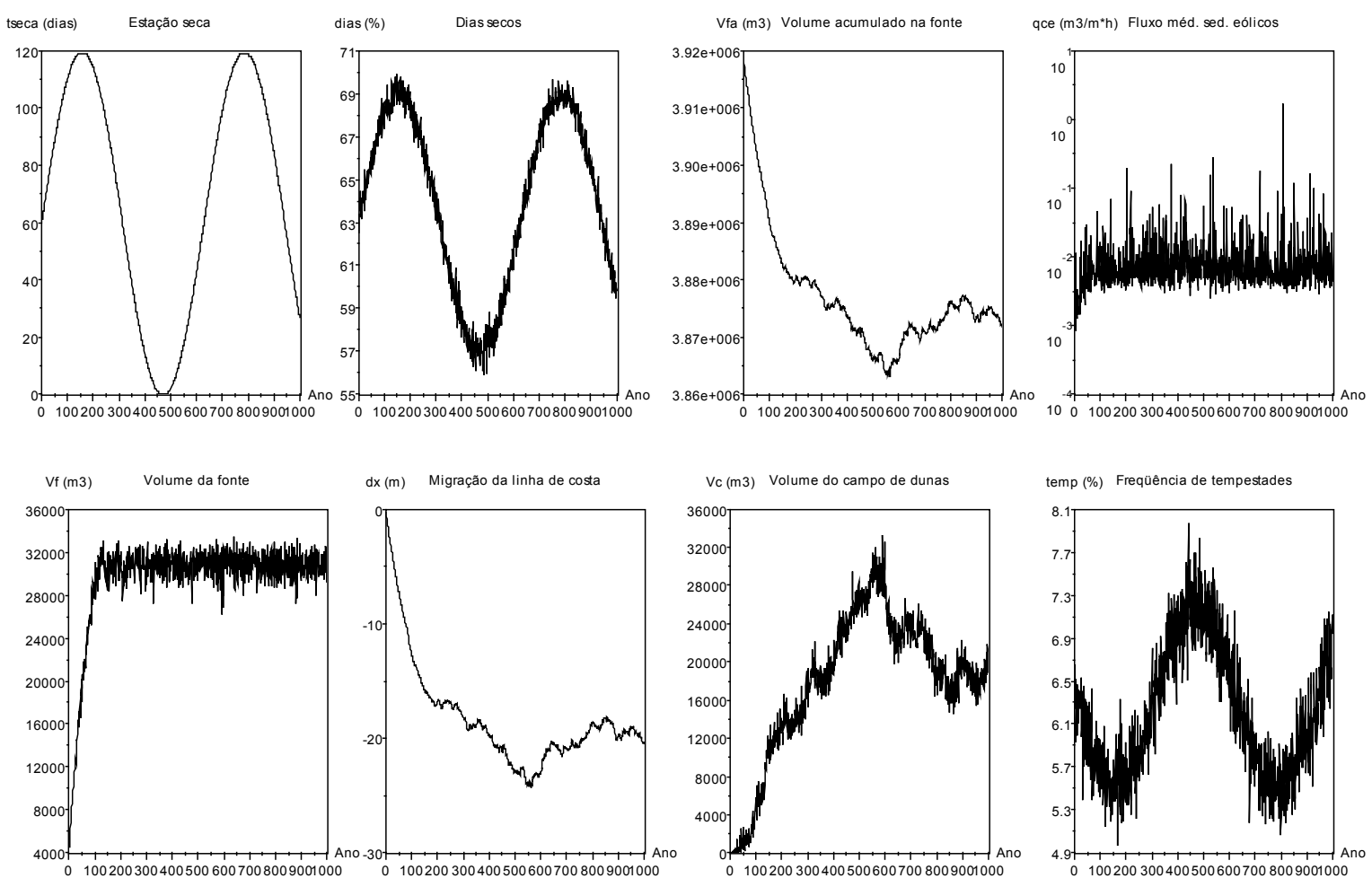

Figura 4.19 - Resultado da simulação de 1000 anos do modelo de sistema eólico costeiro sob condições de sazonalidade acentuada, $\mathbf{q f e}=\mathbf{q} \mathbf{f s}$ e variação periódica da duração da estação seca. Foram utilizados os seguintes valores para simulação de qfe e qfs: qfemtemp=qfsmtemp=0,1, 
dqfetemp $=$ dqfstemp $=\mathbf{1}$,

qfemseca $=$ qfsmsseca $=\mathbf{0 , 0 0 3}$,

dqfeseca $=$ dqfsseca $=\mathbf{0 , 3}$,

qfemumida $=$ qfsmumida $=\mathbf{0 , 0 0 6}$, dqfeumida $=$ dqfsumida $=\mathbf{0 , 3}$.

\begin{tabular}{|l|l|l|}
\hline Variável & Intervalo de confiança médio & $\begin{array}{l}\text { Desvio padrão do intervalo } \\
\text { de confiança }\end{array}$ \\
\hline temp $(\%)$ & 0,460 & 0,063 \\
\hline Dias secos $(\%)$ & 0,845 & 0,117 \\
\hline qce $\left(\mathrm{m}^{3} / \mathrm{m}^{*} \mathrm{~h}\right)$ & 0,014 & 0,109 \\
\hline $\mathrm{Vc}\left(\mathrm{m}^{3}\right)$ & 3954,430 & 1604,161 \\
\hline $\mathrm{Vf}\left(\mathrm{m}^{3}\right)$ & 2036,975 & 567,972 \\
\hline $\mathrm{Vfa}\left(\mathrm{m}^{3}\right)$ & 4113,963 & 1648,691 \\
\hline $\mathrm{dx}(\mathrm{m})$ & 1,804 & 0,722 \\
\hline
\end{tabular}

Tabela 4.7 - Média e desvio padrão dos intervalos de confiança das variáveis de interesse (simulação de 1000 anos), cujos resultados encontram-se na Figura 4.19.

As condições para desenvolvimento de campos de dunas não pode ser analisada apenas em termos dos valores absolutos de sedimentos eólicos acumulados, pois também deve ser levada em consideração a distribuição em área destes sedimentos. Campos de dunas diferenciam-se de dunas frontais pela maior concentração de sedimentos por unidade de área. Desta forma, linha de costa transgressiva ou estável seria favorável à formação de campos de dunas enquanto que linha de costa com regressão simultânea à sedimentação eólica favorece a diluição dos sedimentos eólicos de modo que pode ser mais favorável à formação de dunas frontais. Assim, a formação de campos de dunas pode ocorrer ou mesmo ser favorecida por condições de balanço sedimentar costeiro nulo $(\mathrm{qfe}=\mathrm{qfs})$. $\mathrm{O}$ crescimento contínuo do volume de sedimentos eólicos $(\mathrm{Vc})$ ocorre às custas do reservatório de sedimentos costeiros acumulados (Vfa). Isto implica erosão costeira e transgressão da linha de costa. Ou seja, nestas condições, a geração de campos de dunas ocorreria apenas sob transgressão prolongada da linha de costa. Nas condições de balanço sedimentar nulo, a transgressão contínua da linha de costa ocorre mediante elevação do volume máximo da área fonte (Vfmax), que é determinado pela amplitude de maré. O aumento de Vfmax favorece drasticamente a redução de Vfa. Desta forma, o tamanho dos reservatórios para estocagem de sedimentos, que pode ser controlado pela amplitude de maré por exemplo, é fator importante no controle da variabilidade espacial do aporte sedimentar eólico. O volume de sedimentos costeiros acumulados (Vfa) atua como reservatório de sedimentos interno ao sistema, pois a entrada e saída de sedimentos deste reservatório depende apenas da dinâmica do sistema enquanto que a entrada de sedimentos a partir de fonte externa é independente do sistema. Assim, o volume de 
sedimentos costeiros acumulados exerceria função fundamental para o desenvolvimento de campos de dunas em setores da costa com baixo aporte sedimentar externo. Este volume pode corresponder por exemplo a sedimentos de dunas frontais antigas ou cordões litorâneos.

A variabilidade climática interanual (com estação seca variando entre 0 e 120 dias) não afeta de modo significativo a dinâmica da acumulação de sedimentos eólicos e da migração da linha de costa. Portanto, sob condições de balanço costeiro nulo, o sistema eólico costeiro parece ser pouco sensível a mudanças climáticas.

\subsubsection{Costa com balanço sedimentar costeiro positivo (qfe $>q f s$ )}

Esta condição é caracterizada por entrada externa de sedimentos na área fonte por correntes costeiras superior à saída. Assim, há saldo positivo na troca de sedimentos entre sistema e meio externo.

Quando a diferença entre os fluxos médios de entrada (qfe) e saída (qfs) de sedimentos é pequena, a dinâmica do sistema é bastante semelhante à apresentada pelos experimentos realizados sob balanço sedimentar costeiro nulo. Ou seja, há transgressão seguida de regressão da

linha de costa e crescimento inicial pouco significativo sucedido por estabilização do volume de sedimentos eólicos (Figura 4.20 e Tabela 4.8). A ordem de grandeza do volume de sedimentos eólicos acumulados é compatível apenas com volumes de dunas frontais. 

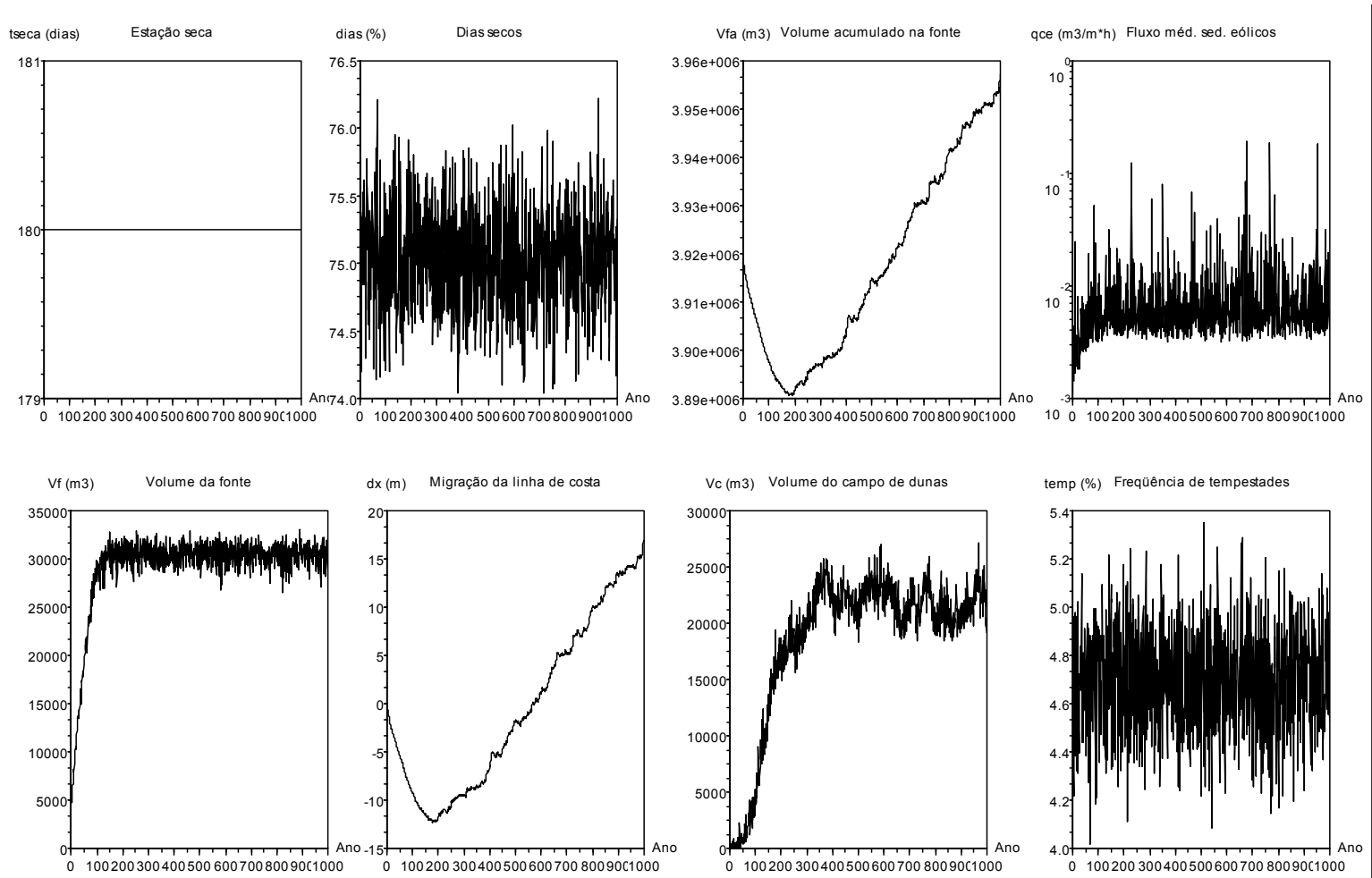

Figura 4.20 - Resultado da simulação de 1000 anos do modelo de sistema eólico costeiro sob condições de sazonalidade acentuada e qfe $>\mathbf{q f s}$. Foram utilizados os seguintes valores para simulação de qfe e qfs: qfemtemp=0,11, qfsmtemp=0,10; dqfetemp=dqfstemp=1, qfemseca $=\mathbf{0 , 0 0 3 1}, \quad$ qfsmsseca $=\mathbf{0 , 0 0 3 0}, \quad$ dqfeseca $=$ dqfsseca $=\mathbf{0 , 3}, \quad$ qfemumida $=\mathbf{0 , 0 0 6 1}$, qfsmumida $=\mathbf{0 , 0 0 6 0}$, dqfeumida $=$ dqfsumida $=\mathbf{0 , 3}$.

\begin{tabular}{|l|l|l|}
\hline Variável & Intervalo de confiança médio & $\begin{array}{l}\text { Desvio padrão do intervalo } \\
\text { de confiança }\end{array}$ \\
\hline $\mathrm{qce}\left(\mathrm{m}^{3} / \mathrm{m}^{*} \mathrm{~h}\right)$ & 0,007 & 0,024 \\
\hline $\mathrm{Vc}\left(\mathrm{m}^{3}\right)$ & 4012,403 & 1310,325 \\
\hline $\mathrm{Vf}\left(\mathrm{m}^{3}\right)$ & 2000,879 & 546,104 \\
\hline $\mathrm{Vfa}\left(\mathrm{m}^{3}\right)$ & 3992,653 & 1509,305 \\
\hline $\mathrm{dx}(\mathrm{m})$ & 1,751 & 0,662 \\
\hline
\end{tabular}

Tabela 4.8 - Média e desvio padrão dos intervalos de confiança das variáveis de interesse (simulação de 1000 anos), cujos resultados encontram-se na Figura 4.20.

$\mathrm{O}$ aumento da diferença entre qfe e qfs provoca redução e desaparecimento da fase de transgressão da linha de costa e crescimento contínuo do volume de sedimentos eólicos acumulados (figuras 4.21 a 4.24 e tabelas 4.9 a 4.12). O aumento da dispersão dos fluxos de entrada e saída de sedimentos (qfe e qfs) provoca redução da taxa de crescimento do volume de 
sedimentos eólicos e elevação da taxa de regressão da linha de costa (figuras 4.21 e 4.22 e tabelas 4.9 e 4.10). Em ambos os casos a diferença entre os fluxos qfe e qfs médios é pequena (da ordem de 0,05 para os fluxos de tempestade e de 0,0005 para os fluxos de tempo bom). A taxa de crescimento de $\mathrm{Vc}$ apresenta variações ao longo do tempo em ambos os casos.
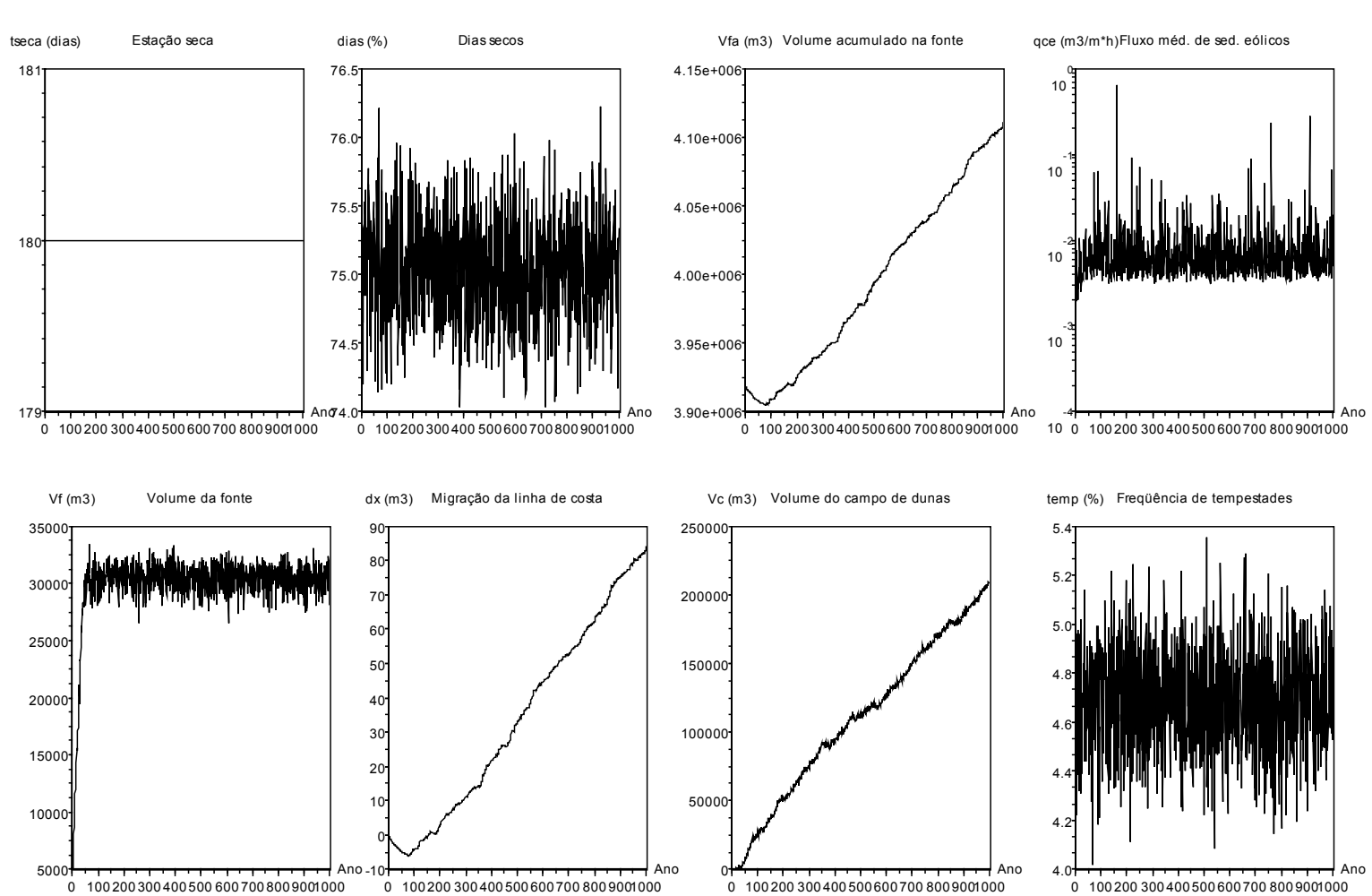

Figura 4.21 - Resultado da simulação de 1000 anos do modelo de sistema eólico costeiro sob condições de sazonalidade acentuada e qfe $>\mathbf{q f s}$. Foram utilizados os seguintes valores para simulação de qfe e qfs: qfemtemp=0,15, qfsmtemp=0,10; dqfetemp=dqfstemp=1, qfemseca $=\mathbf{0 , 0 0 3 5}, \quad$ qfsmsseca $=\mathbf{0 , 0 0 3 0}, \quad$ dqfeseca $=$ dqfsseca $=\mathbf{0 , 3}, \quad$ qfemumida $=\mathbf{0 , 0 0 6 5}$, qfsmumida $=\mathbf{0 , 0 0 6 0}$, dqfeumida $=$ dqfsumida $=\mathbf{0 , 3}$. 


\begin{tabular}{|l|l|l|}
\hline Variável & Intervalo de confiança médio & $\begin{array}{l}\text { Desvio padrão do intervalo } \\
\text { de confiança }\end{array}$ \\
\hline $\mathrm{qce}\left(\mathrm{m}^{3} / \mathrm{m}^{*} \mathrm{~h}\right)$ & 0,009 & 0,048 \\
\hline $\mathrm{Vc}\left(\mathrm{m}^{3}\right)$ & 16422,101 & 9111,048 \\
\hline $\mathrm{Vf}\left(\mathrm{m}^{3}\right)$ & 2037,776 & 573,278 \\
\hline $\mathrm{Vfa}\left(\mathrm{m}^{3}\right)$ & 16191,450 & 9118,652 \\
\hline $\mathrm{dx}(\mathrm{m})$ & 7,101 & 3,999 \\
\hline
\end{tabular}

Tabela 4.9 - Média e desvio padrão dos intervalos de confiança das variáveis de interesse (simulação de 1000 anos), cujos resultados encontram-se na Figura 4.21.
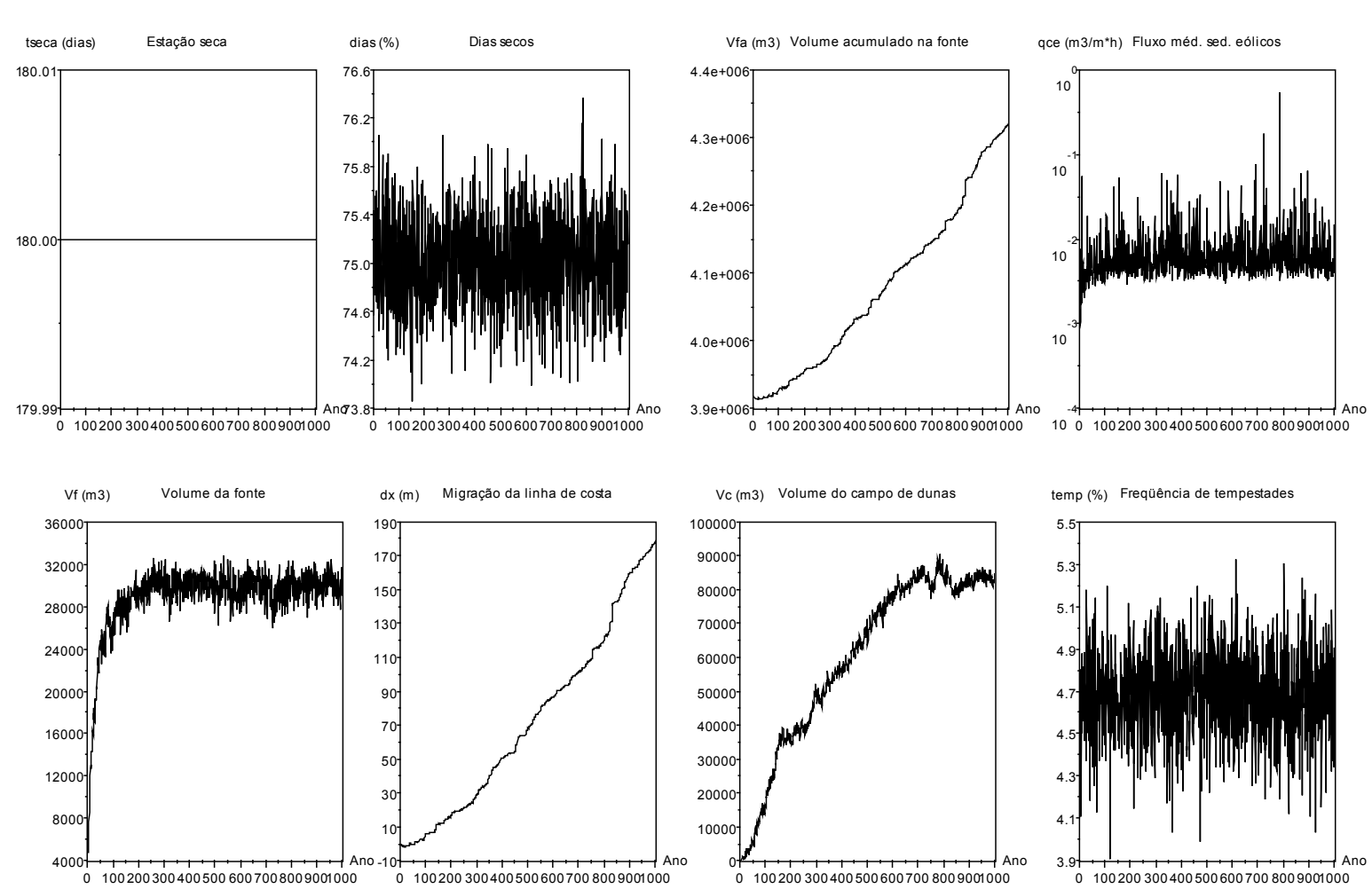

Figura 4.22 - Resultado da simulação de 1000 anos do modelo de sistema eólico costeiro sob condições de sazonalidade acentuada e $\mathbf{q} \mathbf{f e}>\mathbf{q} \mathbf{f s}$. Foram utilizados os seguintes valores para simulação de qfe e qfs: qfemtemp=0,15, qfsmtemp=0,10; dqfetemp=dqfstemp=3, qfemseca $=\mathbf{0 , 0 0 3 5}, \quad$ qfsmsseca $=\mathbf{0 , 0 0 3 0}, \quad$ dqfeseca $=$ dqfsseca $=\mathbf{3}, \quad$ qfemumida $=\mathbf{0 , 0 0 6 5}$, qfsmumida $=\mathbf{0 , 0 0 6 0}$, dqfeumida $=$ dqfsumida $=\mathbf{3}$. 


\begin{tabular}{|l|l|l|}
\hline Variável & Intervalo de confiança médio & $\begin{array}{l}\text { Desvio padrão do intervalo } \\
\text { de confiança }\end{array}$ \\
\hline $\mathrm{qce}\left(\mathrm{m}^{3} / \mathrm{m}^{*} \mathrm{~h}\right)$ & 0,008 & 0,036 \\
\hline $\mathrm{Vc}\left(\mathrm{m}^{3}\right)$ & 15939,088 & 5842,722 \\
\hline $\mathrm{Vf}\left(\mathrm{m}^{3}\right)$ & 2394,900 & 567,073 \\
\hline $\mathrm{Vfa}\left(\mathrm{m}^{3}\right)$ & 44530.092 & 24160,338 \\
\hline $\mathrm{dx}(\mathrm{m})$ & 19,253 & 10,582 \\
\hline
\end{tabular}

Tabela 4.10 - Média e desvio padrão dos intervalos de confiança das variáveis de interesse (simulação de 1000 anos), cujos resultados encontram-se na Figura 4.22.

Quando a diferença entre os fluxos de entrada e saída torna-se elevada (acima de uma ordem de magnitude), o aumento de Vc também é contínuo e segue tendência linear, ou seja, com taxa de crescimento constante na escala de centenas de anos (figuras 4.23 e 4.24 e tabelas 4.11 e 4.12). A elevação desta diferença provoca incremento dos valores absolutos de Vc e, caso extrapolada, a tendência de crescimento linear atinge valores equivalentes ao campo de dunas de Itapirubá em aproximadamente 5000 anos para qfe uma ordem de magnitude maior que qfs. No caso de apenas o fluxo de entrada das condições de tempestade ser superior ao fluxo de saída, o volume de sedimentos do campo de dunas de Itapirubá seria atingido em cerca de 32000 anos. Contudo, como já discutido, volumes elevados de sedimentos eólicos não implicam necessariamente a formação de campos de dunas, pois estes podem ser diluídos pela regressão da linha de costa. No caso de crescimento linear de Vc, a variação da taxa de regressão é extremamente importante para a formação de campos de dunas. A geração de campos de dunas pode ocorrer durante períodos de baixa taxa de regressão ou linha de costa estável. 

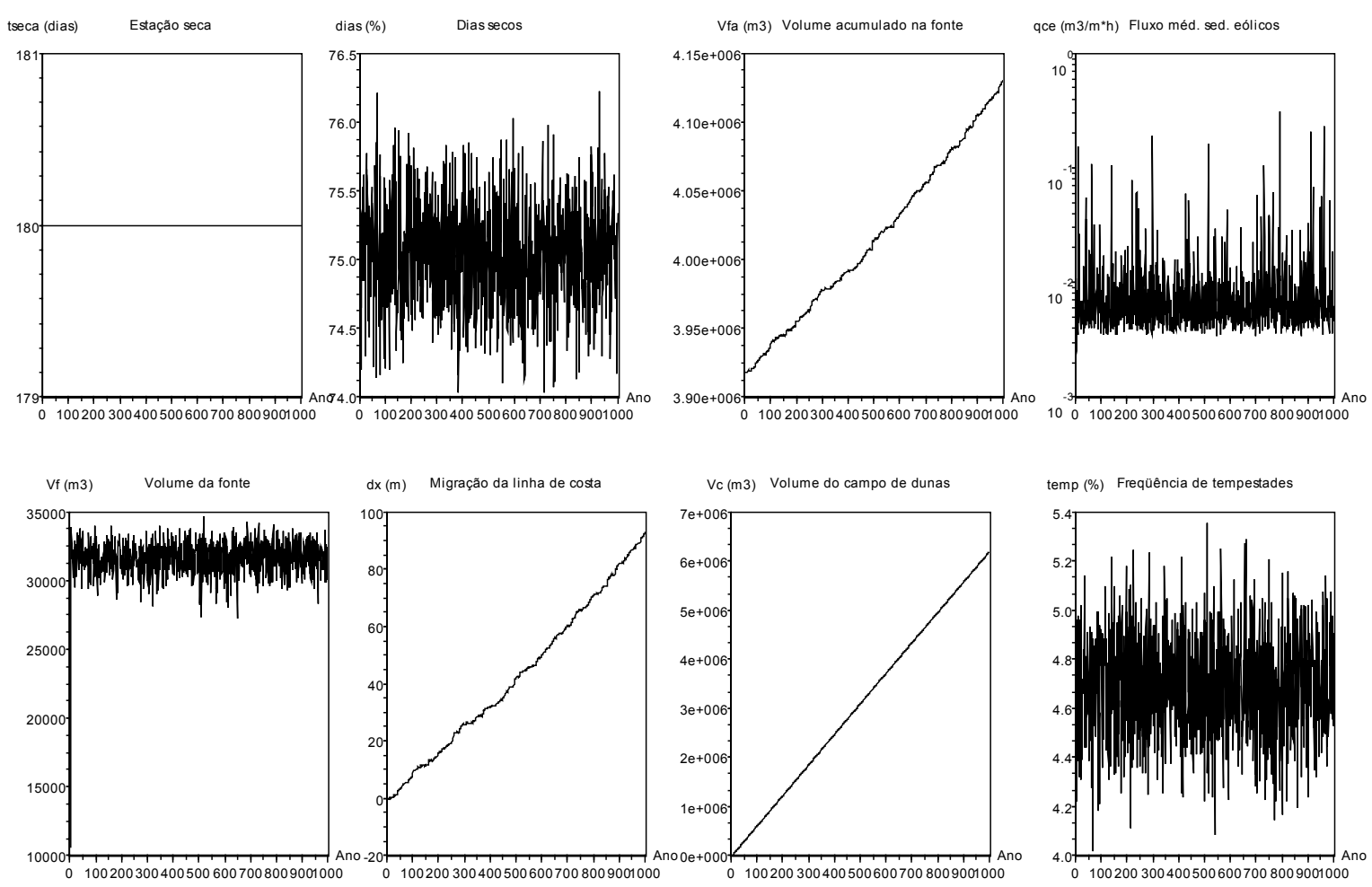

Figura 4.23 - Resultado da simulação de 1000 anos do modelo de sistema eólico costeiro sob condições de sazonalidade acentuada e qfe $>\mathbf{q f s}$. Foram utilizados os seguintes valores para simulação de qfe e qfs: qfemtemp=0,1, qfsmtemp $=\mathbf{0 , 0 1}$; dqfetemp $=$ dqfstemp $=\mathbf{1}$, qfemseca $=\mathbf{0 , 0 3}$, qfsmsseca $=\mathbf{0 , 0 0 3}, \quad$ dqfeseca $=$ dqfsseca $=\mathbf{0 , 3}, \quad$ qfemumida $=\mathbf{0 , 0 6}, \quad$ qfsmumida $=\mathbf{0 , 0 0 6}$, dqfeumida $=$ dqfsumida $=\mathbf{0 , 3}$.

\begin{tabular}{|l|l|l|}
\hline Variável & Intervalo de confiança médio & $\begin{array}{l}\text { Desvio padrão do intervalo } \\
\text { de confiança }\end{array}$ \\
\hline $\mathrm{qce}\left(\mathrm{m}^{3} / \mathrm{m}^{*} \mathrm{~h}\right)$ & 0,009 & 0,035 \\
\hline $\mathrm{Vc}\left(\mathrm{m}^{3}\right)$ & 18707,047 & 5808,433 \\
\hline $\mathrm{Vf}\left(\mathrm{m}^{3}\right)$ & 2109,473 & 558,844 \\
\hline $\mathrm{Vfa}\left(\mathrm{m}^{3}\right)$ & 18128,108 & 5758,495 \\
\hline $\mathrm{dx}(\mathrm{m})$ & 7,951 & 2,526 \\
\hline
\end{tabular}

Tabela 4.11 - Média e desvio padrão dos intervalos de confiança das variáveis de interesse (simulação de 1000 anos), cujos resultados encontram-se na Figura 4.23. 


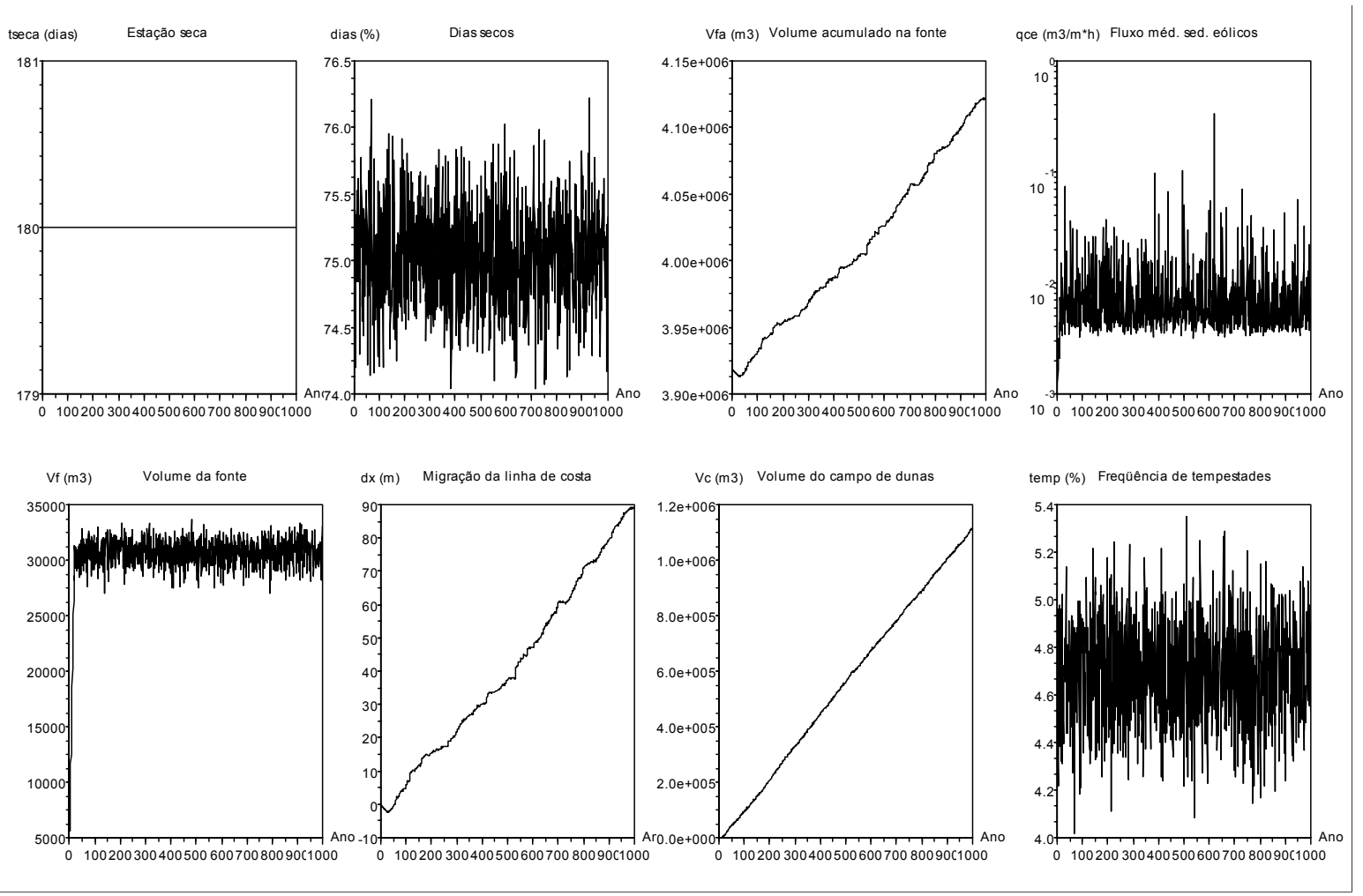

Figura 4.24 - Resultado da simulação de 1000 anos do modelo de sistema eólico costeiro sob condições de sazonalidade acentuada e qfe $>\mathbf{q f s}$. Foram utilizados os seguintes valores para simulação de qfe e qfs: qfemtemp=0,2, qfsmtemp=0,1; dqfetemp=dqfstemp=1, qfemseca=0,006, qfsmsseca $=\mathbf{0 , 0 0 3}, \quad$ dqfeseca $=$ dqfsseca $=\mathbf{0 , 3}, \quad$ qfemumida $=\mathbf{0 , 0 1 2}, \quad$ qfsmumida $=\mathbf{0 , 0 0 6}$, dqfeumida $=$ dqfsumida $=\mathbf{0 , 3}$.

\begin{tabular}{|l|l|l|}
\hline Variável & Intervalo de confiança médio & $\begin{array}{l}\text { Desvio padrão do intervalo } \\
\text { de confiança }\end{array}$ \\
\hline $\mathrm{qce}\left(\mathrm{m}^{3} / \mathrm{m}^{*} \mathrm{~h}\right)$ & 0,008 & 0,025 \\
\hline $\mathrm{Vc}\left(\mathrm{m}^{3}\right)$ & 18154,440 & 7035,891 \\
\hline $\mathrm{Vf}\left(\mathrm{m}^{3}\right)$ & 2057,332 & 554,274 \\
\hline $\mathrm{Vfa}\left(\mathrm{m}^{3}\right)$ & 17681,714 & 7113,640 \\
\hline $\mathrm{dx}(\mathrm{m})$ & 7,755 & 3,120 \\
\hline
\end{tabular}

Tabela 4.12 - Média e desvio padrão dos intervalos de confiança das variáveis de interesse (simulação de 1000 anos), cujos resultados encontram-se na Figura 4.24.

A elevação da amplitude de maré torna a linha de costa transgressiva e também propicia o crescimento contínuo do volume de sedimentos eólicos (Figura 4.25 e Tabela 4.13). A taxa de crescimento de Vc é menor nos 200 anos iniciais e posteriormente passa a ser aproximadamente constante, com pequenas oscilações de escala decenal. Nesta circunstância, o excedente de 
sedimentos derivados de aporte externo é insuficiente para preencher completamente o volume da área fonte de modo que esta opera sob baixos estoques e, portanto, sob condições retrogradacionais (transgressivas). Além disto, o elevação do volume da área fonte dificulta a regressão da linha de costa, pois provoca grande aumento da área da zona intermaré. Assim, o volume excedente de sedimentos deverá ser distribuído por área maior, o que reduz a distância de regressão em função do volume excedente. Em regime de macromaré, a taxa de crescimento de Vc é cerca de $4 \times 10^{6} \mathrm{~m}^{3} / 1000$ anos. Com esta taxa, o volume do campo de dunas de Itapirubá seria atingido em aproximadamente 8000 anos. Deve ser ressaltado que a associação com costa transgressiva favorece a concentração dos sedimentos eólicos e portanto o desenvolvimento de campos de dunas.
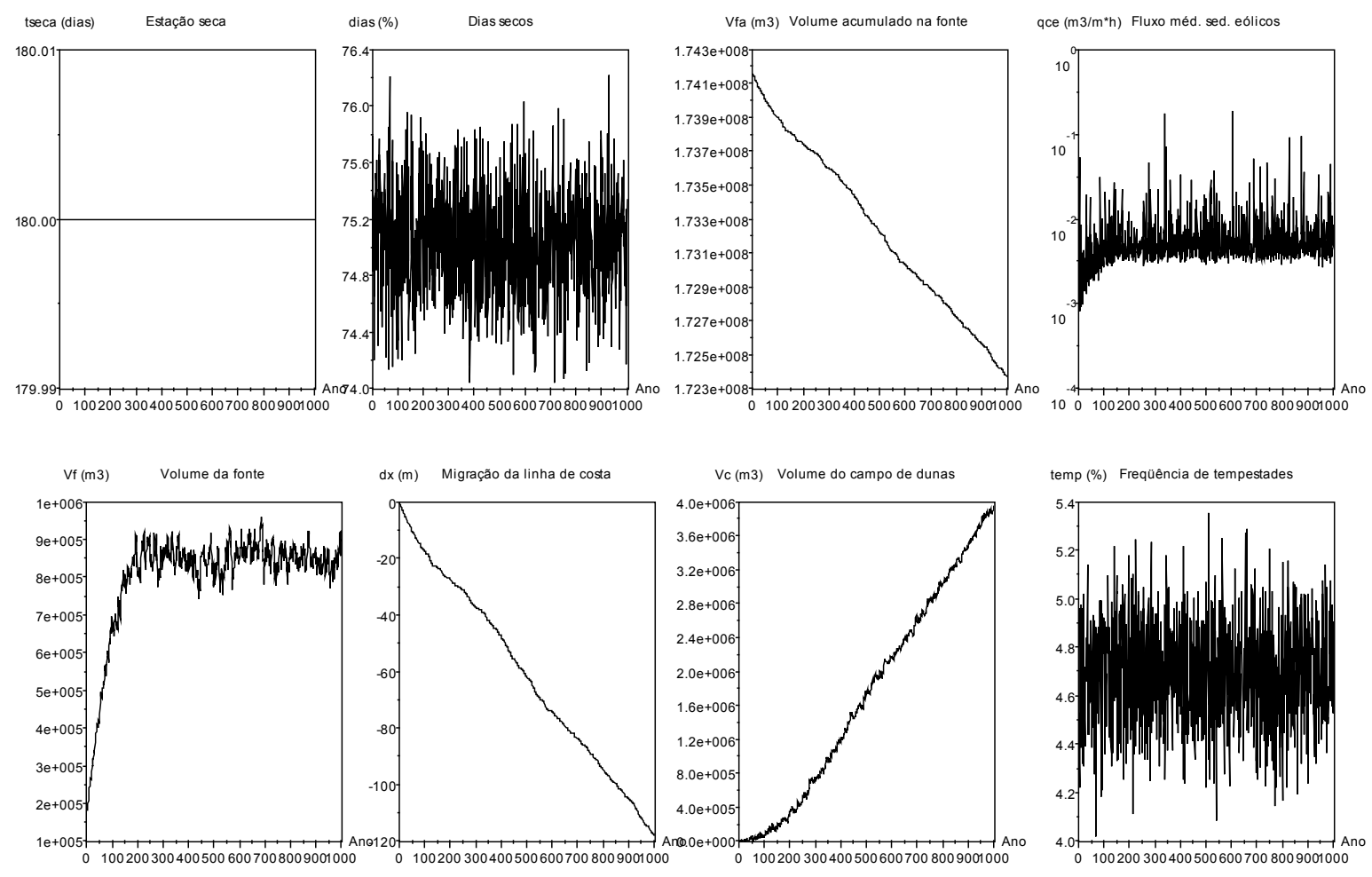

Figura 4.25 - Resultado da simulação de 1000 anos do modelo de sistema eólico costeiro sob condições de sazonalidade acentuada e qfe $>\mathbf{q f s}$. Foram utilizados os seguintes valores para simulação de qfe e qfs: qfemtemp=0,15, qfsmtemp=0,10; dqfetemp=dqfstemp=1, qfemseca $=\mathbf{0 , 0 0 3 5}, \quad$ qfsmsseca $=\mathbf{0 , 0 0 3 0}, \quad$ dqfeseca $=$ dqfsseca $=\mathbf{0 , 3}, \quad$ qfemumida $=\mathbf{0 , 0 0 6 5}$, qfsmumida $=\mathbf{0 , 0 0 6 0}$, dqfeumida $=$ dqfsumida $=\mathbf{0 , 3}$. 


\begin{tabular}{|l|l|l|}
\hline Variável & Intervalo de confiança médio & $\begin{array}{l}\text { Desvio padrão do intervalo } \\
\text { de confiança }\end{array}$ \\
\hline $\mathrm{qce}\left(\mathrm{m}^{3} / \mathrm{m}^{*} \mathrm{~h}\right)$ & 0,006 & 0,020 \\
\hline $\mathrm{Vc}\left(\mathrm{m}^{3}\right)$ & 136670,820 & 49654,531 \\
\hline $\mathrm{Vf}\left(\mathrm{m}^{3}\right)$ & 62493,120 & 15067,241 \\
\hline $\mathrm{Vfa}\left(\mathrm{m}^{3}\right)$ & 115066,440 & 38825,081 \\
\hline $\mathrm{dx}(\mathrm{m})$ & 7,569 & 2,554 \\
\hline
\end{tabular}

Tabela 4.13 - Média e desvio padrão dos intervalos de confiança das variáveis de interesse (simulação de 1000 anos), cujos resultados encontram-se na Figura 4.25.

A variação da duração da estação seca não afeta significativamente a curva de crescimento do volume de sedimentos eólicos. No entanto, redução da duração da estação seca e incremento da freqüência de tempestades induzem período de estabilização da linha de costa, cuja tendência geral é regressiva (Figura 4.26 e Tabela 4.14). Portanto, de maneira indireta e de certo modo paradoxal, a redução da freqüência de dias secos pode ser favorável à formação de campos de dunas, pois sua influência sobre a estabilização da linha de costa pode ser mais importante do que sobre o fluxo de sedimentos eólicos. Isto pode explicar por exemplo a ocorrência de campos de dunas de tamanho elevado em áreas úmidas. O bloqueio do transporte eólico pela ocorrência de chuva pode não ser tão significativo para a manutenção de aporte eólico regular, uma vez que os sedimentos da zona intermaré são diariamente recobertos pela maré alta. 

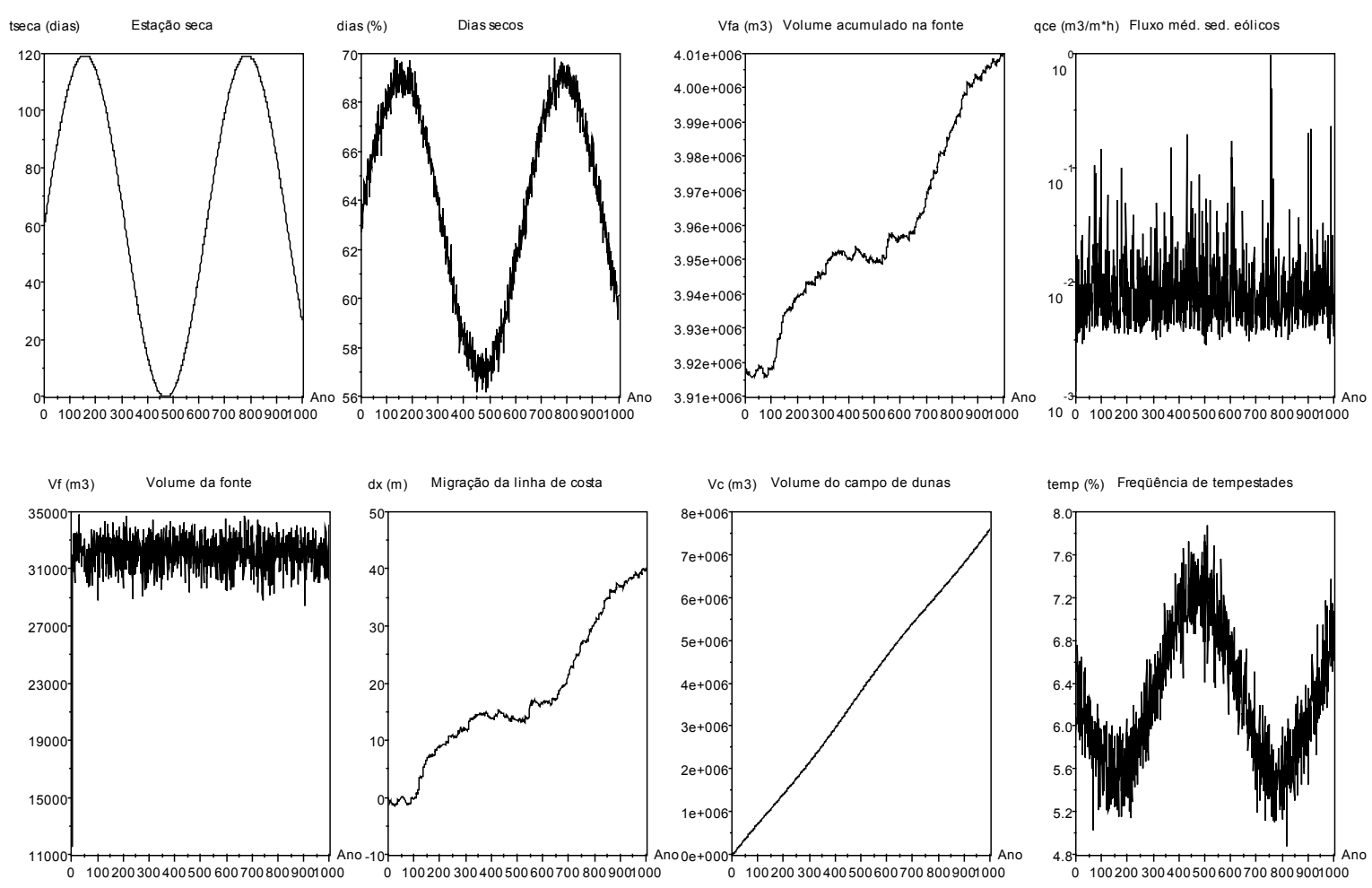

Figura 4.26 - Resultado da simulação de 1000 anos do modelo de sistema eólico costeiro sob condições de sazonalidade acentuada e qfe $>\mathbf{q f s}$. Foram utilizados os seguintes valores para simulação de qfe e qfs: qfemtemp=0,1, qfsmtemp $=\mathbf{0 , 0 1}$; dqfetemp $=$ dqfstemp $=\mathbf{1}$, qfemseca $=\mathbf{0 , 0 3}$, qfsmsseca $=\mathbf{0 , 0 0 3}, \quad$ dqfeseca $=$ dqfsseca $=\mathbf{0 , 3}, \quad$ qfemumida $=\mathbf{0 , 0 6}, \quad$ qfsmumida $=\mathbf{0 , 0 0 6}$, dqfeumida $=$ dqfsumida $=\mathbf{0 , 3}$.

\begin{tabular}{|l|l|l|}
\hline Variável & Intervalo de confiança médio & $\begin{array}{l}\text { Desvio padrão do intervalo } \\
\text { de confiança }\end{array}$ \\
\hline temp $(\%)$ & 0,460 & 0,064 \\
\hline Dias secos (\%) & 0,856 & 0,123 \\
\hline $\mathrm{qce}\left(\mathrm{m}^{3} / \mathrm{m}^{*} \mathrm{~h}\right)$ & 0,015 & 0,074 \\
\hline $\mathrm{Vc}\left(\mathrm{m}^{3}\right)$ & 17966,520 & 5629,499 \\
\hline $\mathrm{Vf}\left(\mathrm{m}^{3}\right)$ & 2135,111 & 576,168 \\
\hline $\mathrm{Vfa}\left(\mathrm{m}^{3}\right)$ & 18131,493 & 5972,482 \\
\hline $\mathrm{dx}(\mathrm{m})$ & 7,952 & 2,619 \\
\hline
\end{tabular}

Tabela 4.14 - Média e desvio padrão dos intervalos de confiança das variáveis de interesse (simulação de 1000 anos), cujos resultados encontram-se na Figura 4.26. 


\subsubsection{Costa com balanço sedimentar costeiro negativo (qfe $<q f s)$}

Este caso configura costa com déficit de sedimentos costeiros, ou seja, a entrada (qfe) de sedimentos a partir do meio externo é inferior à saída (qfs).

Quando a diferença entre qfe e qfs é baixa (diferença de 0,01 para fluxos de tempestade e 0,0001 para fluxos de tempo bom), a evolução do volume de sedimentos eólicos é semelhante à que ocorre em costa de micromaré com balanço sedimentar nulo ou quando qfe é ligeiramente superior a qfs. Em todos estes casos, Vc apresenta fase de crescimento inicial sucedida por estabilização. Já a linha de costa demonstra comportamento distinto, caracterizado por transgressão contínua com taxa decrescente (Figura 4.27 e Tabela 4.15). O volume de sedimentos eólicos acumulados durante período de 1000 anos é comparável apenas ao volume de dunas frontais baixas.

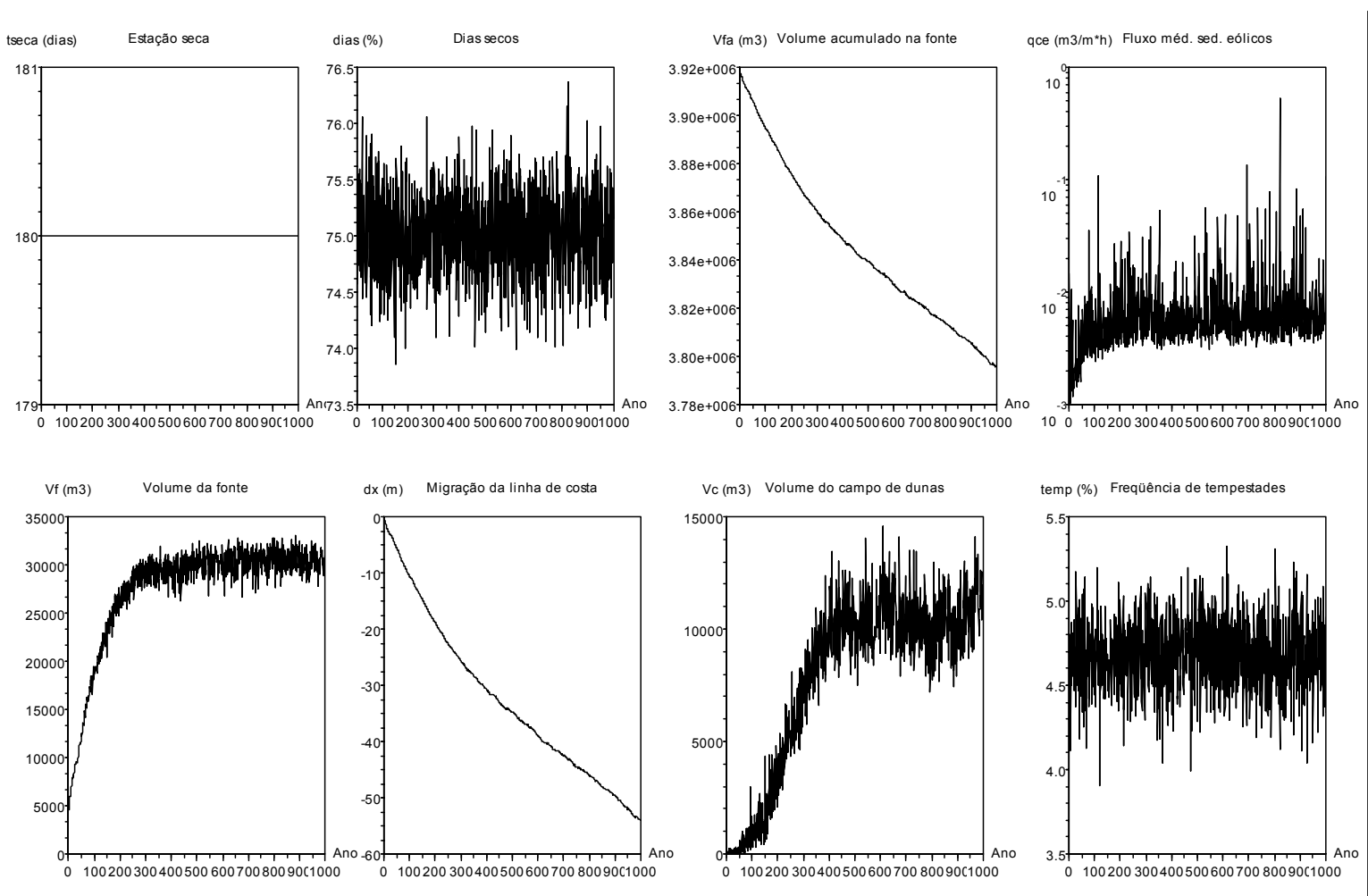

Figura 4.27 - Resultado da simulação de 1000 anos do modelo de sistema eólico costeiro sob condições de sazonalidade acentuada e $\mathbf{q} \mathbf{f e}<\mathbf{q f s}$. Foram utilizados os seguintes valores para simulação de qfe e qfs: qfemtemp=0,10, qfsmtemp=0,11; dqfetemp=dqfstemp=1, 
qfemseca $=\mathbf{0 , 0 0 3 0}, \quad$ qfsmsseca $=\mathbf{0 , 0 0 3 1}, \quad$ dqfeseca $=$ dqfsseca $=\mathbf{0 , 3}, \quad$ qfemumida $=\mathbf{0 , 0 0 6 0}$, qfsmumida $=\mathbf{0 , 0 0 6 1}$, dqfeumida $=$ dqfsumida $=\mathbf{0 , 3}$.

\begin{tabular}{|l|l|l|}
\hline Variável & Intervalo de confiança médio & $\begin{array}{l}\text { Desvio padrão do intervalo } \\
\text { de confiança }\end{array}$ \\
\hline qce $\left(\mathrm{m}^{3} / \mathrm{m}^{*} \mathrm{~h}\right)$ & 0,008 & 0,036 \\
\hline $\mathrm{Vc}\left(\mathrm{m}^{3}\right)$ & 2130,986 & 857,208 \\
\hline $\mathrm{Vf}\left(\mathrm{m}^{3}\right)$ & 2025,054 & 532,527 \\
\hline $\mathrm{Vfa}\left(\mathrm{m}^{3}\right)$ & 2576,837 & 922,808 \\
\hline $\mathrm{dx}(\mathrm{m})$ & 1,131 & 0,405 \\
\hline
\end{tabular}

Tabela 4.15 - Média e desvio padrão dos intervalos de confiança das variáveis de interesse (simulação de 1000 anos), cujos resultados encontram-se na Figura 4.27.

Ligeiro aumento da diferença entre qfe e qfs (diferença de 0,02 para fluxos de tempestade e 0,0002 para fluxos de tempo bom) reduz o volume de sedimentos eólicos acumulados no período de 1000 anos e parece prolongar, porém com taxa de crescimento menor, a fase inicial de incremento de Vc. A curva de crescimento de Vc possui como singularidade o aumento da amplitude de variação de Vc ao longo do tempo (Figura 4.28 e Tabela 4.16). Isto confere um padrão divergente para esta curva. Isto parece resultar da variação do volume médio de sedimentos da área fonte (Vf), que também apresenta tendência de aumento da amplitude de variação com o tempo. Este aumento da variabilidade de Vc e Vf com o tempo não se correlaciona a nenhuma variável aleatória independente de modo que parece ser produto da dinâmica do sistema. O crescimento de Vf implica aumento do volume de sedimentos disponíveis ao transporte eólico. Deste modo, caso haja ventos com competência suficiente para transportar todo sedimento disponível, a redução de Vf e, conseqüentemente, o incremento de Vc, serão maiores. Ou seja, o volume de sedimentos na fonte deixa de ser fator limitante da troca de sedimentos entre Vc e Vf. A linha de costa é transgressiva, com taxa de transgressão constante na escala de centenas de anos. 

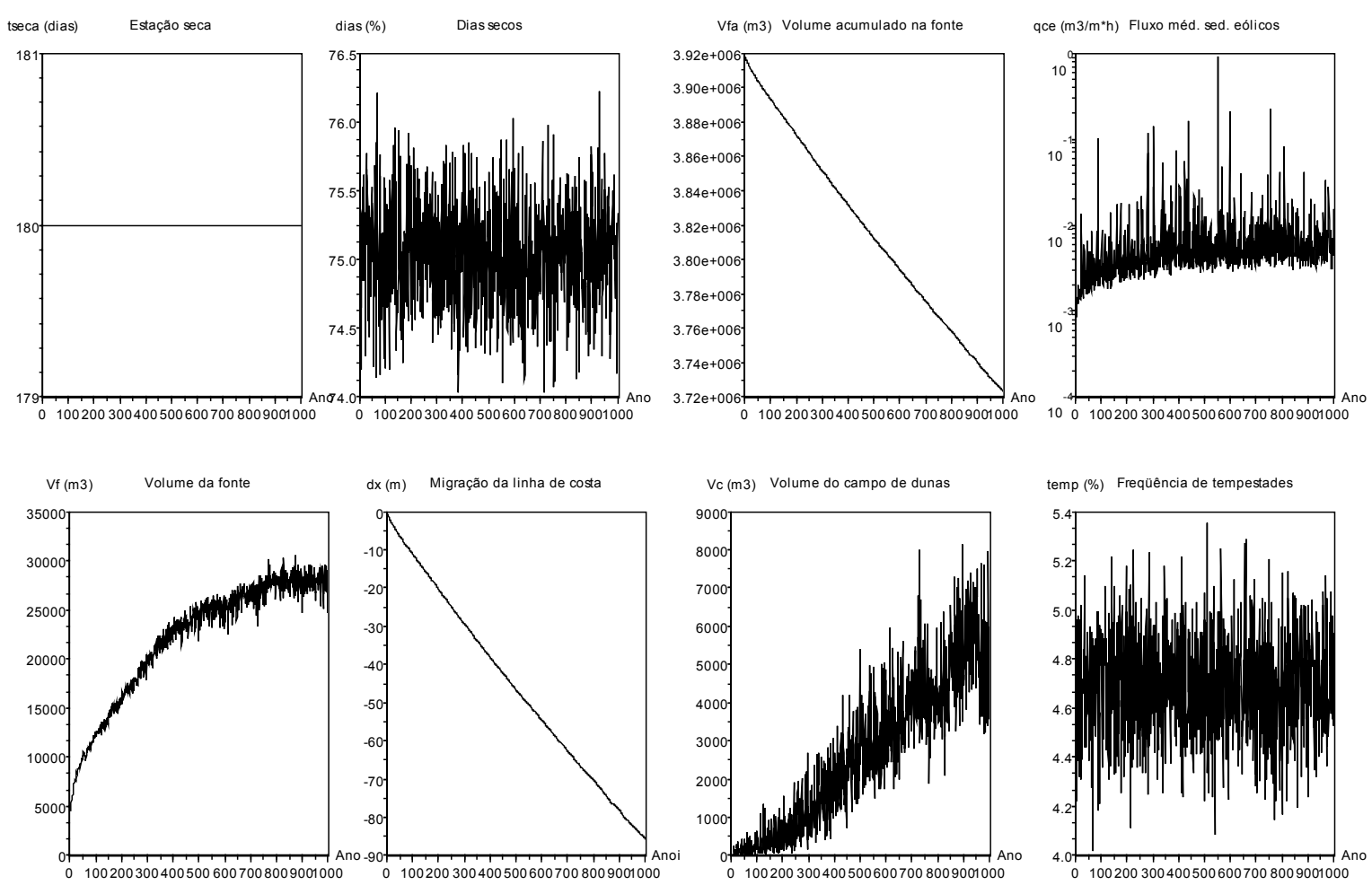

Figura 4.28 - Resultado da simulação de 1000 anos do modelo de sistema eólico costeiro sob condições de sazonalidade acentuada e $\mathbf{q f e}<\mathbf{q f s}$. Foram utilizados os seguintes valores para simulação de qfe e qfs: qfemtemp=0,10, qfsmtemp=0,12; dqfetemp=dqfstemp=1, qfemseca $=\mathbf{0 , 0 0 3 0}, \quad$ qfsmsseca $=\mathbf{0 , 0 0 3 2}, \quad$ dqfeseca $=$ dqfsseca $=\mathbf{0 , 3}, \quad$ qfemumida $=\mathbf{0 , 0 0 6 0}$, qfsmumida $=\mathbf{0 , 0 0 6 2}$, dqfeumida $=$ dqfsumida $=\mathbf{0 , 3}$.

\begin{tabular}{|l|l|l|}
\hline Variável & Intervalo de confiança médio & $\begin{array}{l}\text { Desvio padrão do intervalo } \\
\text { de confiança }\end{array}$ \\
\hline $\mathrm{qce}\left(\mathrm{m}^{3} / \mathrm{m}^{*} \mathrm{~h}\right)$ & 0,009 & 0,061 \\
\hline $\mathrm{Vc}\left(\mathrm{m}^{3}\right)$ & 1483,254 & 861,926 \\
\hline $\mathrm{Vf}\left(\mathrm{m}^{3}\right)$ & 1993,567 & 519,102 \\
\hline $\mathrm{Vfa}\left(\mathrm{m}^{3}\right)$ & 2439,380 & 840,170 \\
\hline $\mathrm{dx}(\mathrm{m})$ & 1,064 & 0,367 \\
\hline
\end{tabular}

Tabela 4.16 - Média e desvio padrão dos intervalos de confiança das variáveis de interesse (simulação de 1000 anos), cujos resultados encontram-se na Figura 4.28.

A fase de crescimento inicial de $V c$ desaparece quando a diferença entre qfe e qfs atinge 0,05 , para fluxos de tempestade, e 0,0005 para fluxos de tempo bom. A elevação da diferença entre qfe e qfs inibe o crescimento de $\mathrm{Vc}$, que passa a variar próximo a valores muito reduzidos (abaixo de $400 \mathrm{~m}^{3}$ ). Nestas condições, a linha de costa transgride com taxa constante (Figura 4.29 
e Tabela 4.17). O volume de sedimentos eólicos é baixo até mesmo para a formação de dunas frontais pequenas.
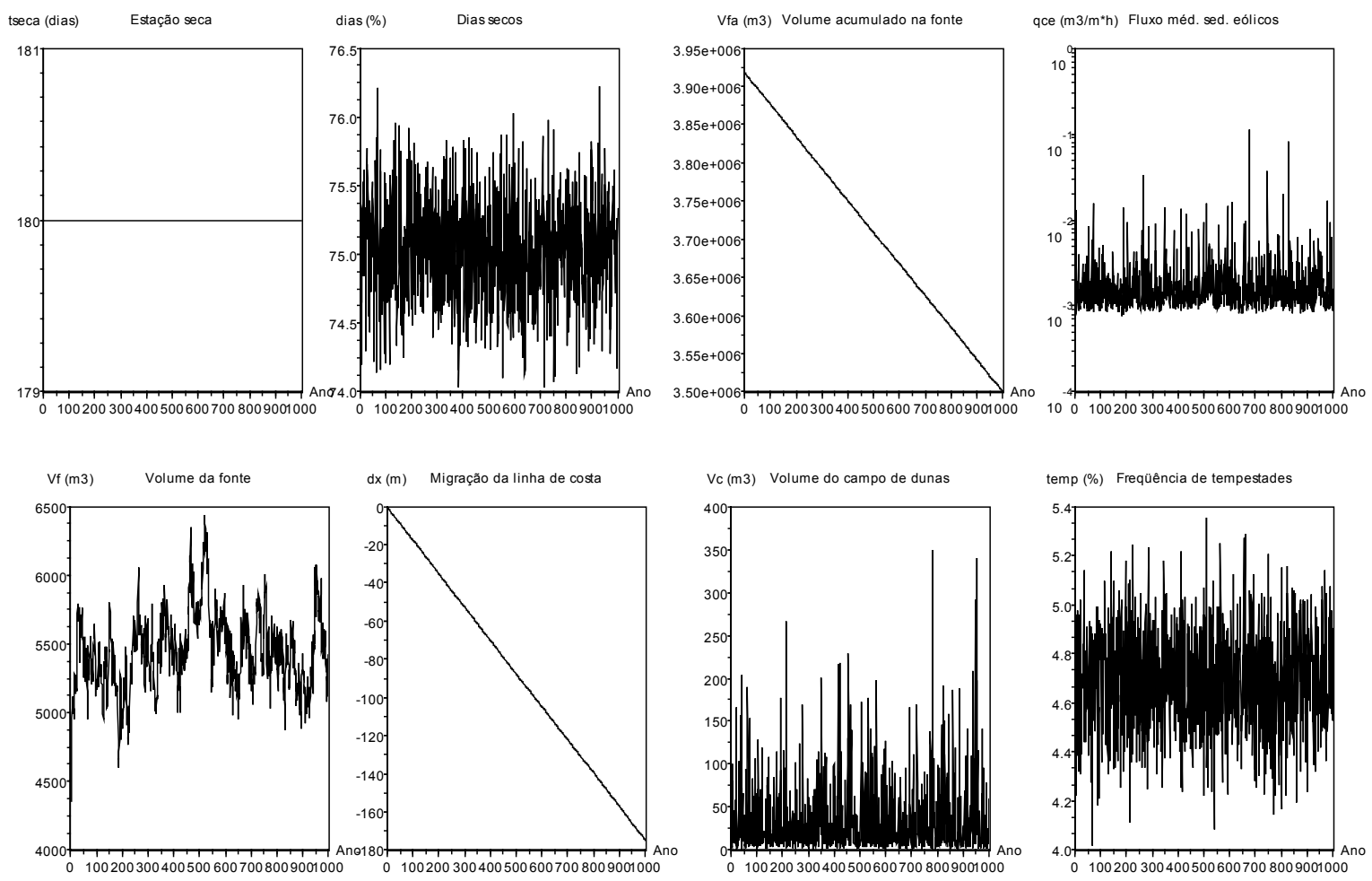

Figura 4.29 - Resultado da simulação de 1000 anos do modelo de sistema eólico costeiro sob condições de sazonalidade acentuada e $\mathbf{q f e}<\mathbf{q f s}$. Foram utilizados os seguintes valores para simulação de qfe e qfs: qfemtemp=0,10, qfsmtemp=0,15; dqfetemp=dqfstemp=1, qfemseca $=\mathbf{0 , 0 0 3 0}, \quad$ qfsmsseca $=\mathbf{0 , 0 0 3 5}, \quad$ dqfeseca $=$ dqfsseca $=\mathbf{0 , 3}, \quad$ qfemumida $=\mathbf{0 , 0 0 6 0}$, qfsmumida $=\mathbf{0 , 0 0 6 5}$, dqfeumida $=$ dqfsumida $=\mathbf{0 , 3}$.

\begin{tabular}{|l|l|l|}
\hline Variável & Intervalo de confiança médio & $\begin{array}{l}\text { Desvio padrão do intervalo } \\
\text { de confiança }\end{array}$ \\
\hline qce $\left(\mathrm{m}^{3} / \mathrm{m}^{*} \mathrm{~h}\right)$ & 0,002 & 0,001 \\
\hline $\mathrm{Vc}\left(\mathrm{m}^{3}\right)$ & 48,450 & 69,170 \\
\hline $\mathrm{Vf}\left(\mathrm{m}^{3}\right)$ & 504,047 & 98,540 \\
\hline $\mathrm{Vfa}\left(\mathrm{m}^{3}\right)$ & 2974,316 & 977,968 \\
\hline $\mathrm{dx}(\mathrm{m})$ & 1,087 & 0,357 \\
\hline
\end{tabular}

Tabela 4.17 - Média e desvio padrão dos intervalos de confiança das variáveis de interesse (simulação de 1000 anos), cujos resultados encontram-se na Figura 4.29.

Na condição de balanço sedimentar negativo elevado, apesar da transgressão prolongada e redução do volume de sedimentos costeiros acumulados (Vfa), a elevação da amplitude de maré 
não é capaz de induzir aumento contínuo do volume de sedimentos eólicos (Figura 4.30 e Tabela 4.18). Desta forma, a transferência dos sedimentos derivados de Vfa para o meio externo parece ser mais efetiva do que para a zona de sedimentação eólica. Isto demonstra que a resposta do sistema a determinado estímulo é condicionada pelo estado de operação. Ou seja, o sistema responde de modo divergente.

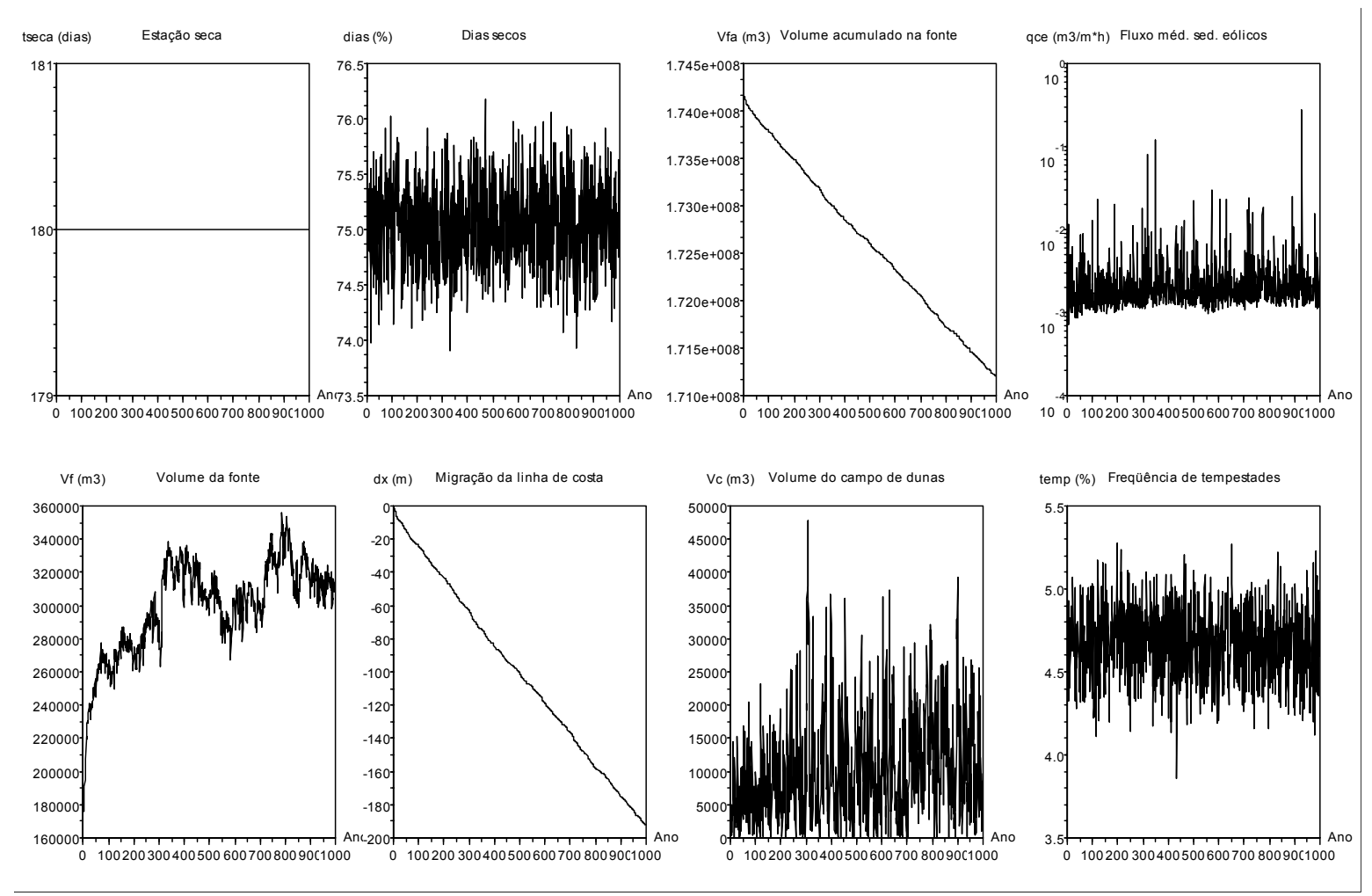

Figura 4.30 - Resultado da simulação de 1000 anos do modelo de sistema eólico costeiro sob condições de sazonalidade acentuada e $\mathbf{q f e}<\mathbf{q f s}$. Foram utilizados os seguintes valores para simulação de qfe e qfs: qfemtemp=0,10, qfsmtemp=0,15; dqfetemp=dqfstemp=1, qfemseca $=\mathbf{0 , 0 0 3 0}, \quad$ qfsmsseca $=\mathbf{0 , 0 0 3 5}, \quad$ dqfeseca $=$ dqfsseca $=\mathbf{0 , 3}, \quad$ qfemumida $=\mathbf{0 , 0 0 6 0}$, qfsmumida $=\mathbf{0 , 0 0 6 5}$, dqfeumida $=$ dqfsumida $=\mathbf{0 , 3}$.

\begin{tabular}{|l|l|l|}
\hline Variável & Intervalo de confiança médio & $\begin{array}{l}\text { Desvio padrão do intervalo } \\
\text { de confiança }\end{array}$ \\
\hline qce $\left(\mathrm{m}^{3} / \mathrm{m}^{*} \mathrm{~h}\right)$ & 0,003 & 0,020 \\
\hline $\mathrm{Vc}\left(\mathrm{m}^{3}\right)$ & 13162,112 & 9267,477 \\
\hline $\mathrm{Vf}\left(\mathrm{m}^{3}\right)$ & 42349,553 & 7243,853 \\
\hline $\mathrm{Vfa}\left(\mathrm{m}^{3}\right)$ & 54614,431 & 11634,192 \\
\hline $\mathrm{dx}(\mathrm{m})$ & 3,752 & 0,814 \\
\hline
\end{tabular}

Tabela 4.18 - Média e desvio padrão dos intervalos de confiança das variáveis de interesse (simulação de 1000 anos), cujos resultados encontram-se na Figura 4.30. 
A inserção de variabilidade climática interanual, por meio de variação da duração da estação seca, não altera de modo significativo as tendências de variação de Vc e de transgressão da linha de costa (Figura 4.31 e Tabela 4.19). Sob condições de balanço sedimentar negativo, o sistema torna-se menos sensível à variabilidade climática interanual. Isto pode ser explicado pelo fato de a área fonte operar com volume reduzido. Ao operar próximo ao valor mínimo (Vfmin), a área fonte passa a ser fator limitante do aporte eólico. Mesmo que isto implique erosão do volume de sedimentos costeiros acumulados (Vfa), estes são rapidamente transferidos para o meio externo e não contribuem para a manutenção de aporte eólico regular. A variação da freqüência de tempestades e da duração da estação seca apresentam maior dificuldade em alterar a dinâmica do sistema, pois os volumes de sedimentos em Vc e Vf disponíveis ao transporte não são capazes de suprir a capacidade de transporte das correntes costeiras e eólicas. Deste modo, o baixo volume de sedimentos provoca redução dos fluxos de transporte efetivos. Ou seja, o que é efetivamente transportado é menor que o que poderia ser. O efeito disto é a redução da variabilidade dos volumes transportados.
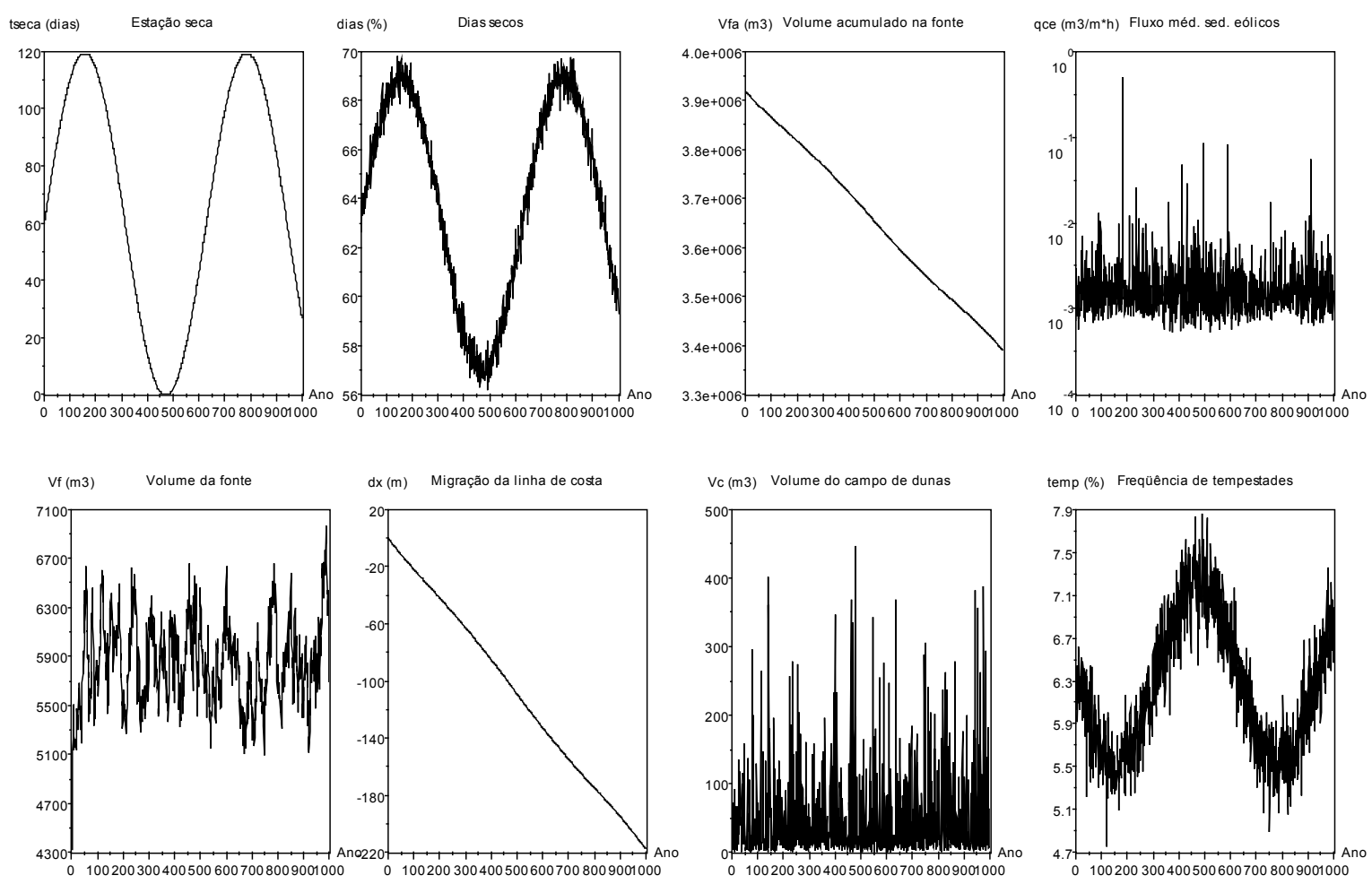

Figura 4.31 - Resultado da simulação de 1000 anos do modelo de sistema eólico costeiro sob condições de sazonalidade acentuada e qfe<qfs. Foram utilizados os seguintes valores para 
simulação de qfe e qfs: qfemtemp=0,10, qfsmtemp=0,15; dqfetemp=dqfstemp=1, qfemseca $=\mathbf{0 , 0 0 3 0}, \quad$ qfsmsseca $=\mathbf{0 , 0 0 3 5}, \quad$ dqfeseca $=$ dqfsseca $=\mathbf{0 , 3}, \quad$ qfemumida $=\mathbf{0 , 0 0 6 0}$, qfsmumida $=\mathbf{0 , 0 0 6 5}$, dqfeumida $=$ dqfsumida $=\mathbf{0 , 3}$.

\begin{tabular}{|l|l|l|}
\hline Variável & Intervalo de confiança médio & $\begin{array}{l}\text { Desvio padrão do intervalo } \\
\text { de confiança }\end{array}$ \\
\hline temp $(\%)$ & 0.4614805 & 0.0664268 \\
\hline Dias secos (\%) & 0.8479942 & 0.1162291 \\
\hline qce $\left(\mathrm{m}^{3} / \mathrm{m}^{*} \mathrm{~h}\right)$ & 0.0033905 & 0.0323166 \\
\hline $\mathrm{Vc}\left(\mathrm{m}^{3}\right)$ & 70.350965 & 102.92426 \\
\hline $\mathrm{Vf}\left(\mathrm{m}^{3}\right)$ & 648.28512 & 125.34249 \\
\hline $\mathrm{Vfa}\left(\mathrm{m}^{3}\right)$ & 4042.8099 & 1711.1164 \\
\hline $\mathrm{dx}(\mathrm{m})$ & 1.3977773 & 0.5974063 \\
\hline
\end{tabular}

Tabela 4.19 - Média e desvio padrão dos intervalos de confiança das variáveis de interesse (simulação de 1000 anos), cujos resultados encontram-se na Figura 4.31.

Os experimentos realizados sob balanço sedimentar costeiro negativo não apresentaram crescimento contínuo do volume de sedimentos eólicos. Apesar de a tendência de transgressão da linha de costa ser favorável à formação de campos de dunas, os volumes acumulados são pouco significativos. Importante constatação deste grupo de experimentos é que sob condição de déficit sedimentar, o sistema torna-se pouco sensível à variação climática ou do tamanho do área fonte (amplitude de maré). Ou seja, a inércia do sistema parece ser maior sob balanço negativo do que sob balanço nulo ou positivo. A sensibilidade do sistema determina sua capacidade em registrar a variabilidade dos fatores que o influenciam. Isto determina a validade do uso de relações processo-produto. Em sistemas pouco sensíveis, a variabilidade dos processos será maior que a variabilidade dos produtos, os quais não serão bons indicadores de condições passadas.

4.7.4 Conclusões derivadas dos experimentos de simulação sob condições climáticas estacionárias

1. Costas com balanço sedimentar nulo podem ser mais propícias ao desenvolvimento de campos de dunas, pois a transgressão ou estabilidade da linha de costa favorecem a concentração do aporte eólico. 
2. Costas com balanço sedimentar positivo, com diferença elevada entre fluxos de entrada e saída, podem não ser favoráveis ao desenvolvimento de campos de dunas, pois altas taxas de regressão da linha de costa propiciam a diluição dos sedimentos eólicos.

3. Sob balanço sedimentar nulo, a elevação da amplitude de maré provoca grande incremento do volume de sedimentos eólicos acumulados com costa transgressiva. Portanto, favorece o desenvolvimento de campos de dunas.

4. Em costa transgressiva, o campo de dunas é alimentado por sedimentos derivados da zona costeira adjacente (Vfa) enquanto que sob costa regressiva ou estável, os sedimentos derivam de zona externa. Isto implica proveniência sedimentar distinta para sedimentos eólicos acumulados sob diferentes tendências de variação da linha de costa.

5. O volume de sedimentos eólicos pode apresentar diversas tendências de crescimento (linear, exponencial, exponencial seguido de estabilização). A variação da taxa de crescimento pode ser determinante para processos internos ao campo de dunas, tais como deflação, migração e geração de tipos diferentes de dunas. Taxas de crescimento elevadas favoreceriam a formação de dunas livres e acumulação de sedimentos enquanto que taxas reduzidas seriam favoráveis à deflação e estabilização de dunas. Deste modo, a variação da taxa de crescimento pode ser interpretada em termos da heterogeneidade do depósito formado. Taxas constantes favoreceriam a formação de depósitos homogêneos (como por exemplo a Formação Botucatu).

6. A migração da linha de costa pode ser tão importante quanto o aporte eólico para a formação de campos de dunas. Taxas de regressão elevadas seriam pouco favoráveis ao desenvolvimento de campos de dunas devido a efeito de diluição. Linha de costa estável ou transgressiva seria mais favorável. Sob balanço sedimentar positivo, o aumento da freqüência de tempestades (que pode estar associada à elevação da quantidade de chuvas) pode provocar estabilização da linha de costa, cuja tendência principal é regressiva, e induzir a formação de dunas. Isto ilustra um efeito imprevisível do clima sob o sistema eólico, ou seja, aumento de chuvas proporcionando condições mais susceptíveis à formação de campos de dunas. 
7. A sensibilidade do sistema à perturbações é maior sob balanço sedimentar costeiro positivo. Sob balanço sedimentar negativo, o sistema adquire inércia elevada, ou seja, grande restrição em mudar de estado.

\subsection{Experimentos com variabilidade climática interanual para período de dezenas de milhares de anos}

\subsubsection{Objetivo dos experimentos}

Estes experimentos tiveram como objetivo o estudo da influência da variabilidade climática interanual sobre o crescimento do volume de sedimentos eólicos e migração da linha de costa. No modelo utilizado, a variabilidade climática interanual é representada pela duração dos períodos seco e úmido. Experimentos realizados sob condições distintas de variação da duração dos períodos seco e úmido permitiram avaliar os fatores que controlam a incorporação do sinal climático na sedimentação eólica e na variação da linha de costa. Para isto, foram realizados diversos experimentos para intervalos de tempo de dezenas de milhares de anos e diversos padrões de variabilidade climática. Quatro experimentos sob condições climáticas interanuais estacionárias serviram de referência para análise das modificações induzidas por diferentes tendências de variação climática. Os demais experimentos envolveram padrões de variação cíclica com periodicidade de $20 \mathrm{ka}$, que corresponde, de modo aproximado, ao ciclo de Milankovitch de precessão dos equinócios. Os resultados foram apresentados em termos de valores seculares (médias e valores do final de cada século) das quantidades de interesse.

\subsubsection{Experimentos de referência: variabilidade climática interanual estacionária}

Foram realizados quatro experimentos sob condições climáticas interanuais estacionárias, sendo que dois experimentos foram realizados sob condição de balanço sedimentar costeiro nulo e dois sob condição de balanço sedimentar positivo. Para cada condição de balanço sedimentar realizou-se um experimento sob regime de micromaré $(\mathrm{amp}=0,6 \mathrm{~m})$ e outro sob regime de macromaré $(a m p=10 m)$. Estes experimentos serviram de referência para análise das modificações 
induzidas pelas diferentes padrões de variabilidade climática interanual nas tendências de crescimento das quantidades de interesse.

Os experimentos realizados sob balanço sedimentar nulo apresentaram tendências de variação do volume do campo de dunas (Vc) e migração da linha de costa (dx) bastante distintas. Sob regime de micromaré, há crescimento linear seguido de estabilização de Vc, cujo valor máximo é de cerca de $3,8 \times 10^{6} \mathrm{~m}^{3}$. Devido à tendência linear, a taxa de acumulação de sedimentos eólicos é constante, sendo aproximadamente $4,75 \times 10^{4} \mathrm{~m}^{3} / 1000$ anos. A linha de costa é transgressiva, com taxa de transgressão constante $(21,25 \mathrm{~m} / 1000$ anos $)$, seguida de estabilização (Figura 4.32 e Tabela 4.20). A distância máxima de migração da linha de costa é próxima a $1700 \mathrm{~m}$. Sob regime de macromaré, Vc varia entre 0 e $10^{4} \mathrm{~m}^{3}$ nos primeiros 60000 anos, quando aumenta para cerca de $3 \times 10^{4} \mathrm{~m}^{3}$ e passa a variar entre $9,5 \times 10^{4} \mathrm{~m}^{3}$ e $3 \times 10^{4} \mathrm{~m}^{3}$. No entanto, estes valores são três ordens de magnitude inferiores ao volume do campo de dunas de Itabirubá. A linha de costa também é transgressiva, porém, nota-se redução da taxa de transgressão com o tempo. A transgressão máxima é inferior a 40 m (Figura 4.33 e Tabela 4.21).

Sob regime de micromaré, o volume médio da fonte (Vf) estabiliza rapidamente. Isto faz com que o fluxo de sedimentos eólicos (qce) apresente variação de pequena amplitude na escala secular. Assim, também há pequena variação dos incrementos de volume do campo de dunas, o que torna seu crescimento linear. Na escala subsecular, Vf atinge seu volume mínimo de modo freqüente, o que propicia a ocorrência de transgressão e alimentação da área fonte por sedimentos derivados de Vfa (volume de sedimentos costeiros acumulados). A estabilização de Vc coincide com o esgotamento de Vfa. Assim, estas condições fazem com que o sistema opere de modo eficiente na transferência de sedimentos de Vfa para Vc. Ou seja, devido ao saldo sedimentar costeiro ser nulo, o crescimento de Vc ocorre às custas de Vfa. Sob regime de macromaré, o volume médio de sedimentos na área fonte sofre crescimento ao longo do tempo. Isto ocorre devido ao tamanho muito elevado do reservatório de sedimentos da área fonte (Vfmax). $\mathrm{O}$ distanciamento progressivo de Vf do seu valor mínimo provoca diminuição gradativa da ocorrência de transgressão. Por ser dependente da relação entre o volume de sedimentos na área fonte e seu volume máximo (Vf/Vfmax), o fluxo de sedimentos eólicos (qce) é inicialmente muito baixo, pois a área fonte é iniciada com seu valor mínimo. Apesar de haver crescimento de qce ao longo do tempo, o intervalo de tempo simulado não é suficiente para preencher completamente a área fonte e fazer com que qce alcance seu valor máximo possível. Por este 
motivo não há crescimento significativo de Vc. No entanto, há salto de Vc por volta de 60000 anos. Este incremento parece estar associado a aumento abrupto de $\mathrm{Vf}$, que ocorre por volta de 50000 anos. Neste caso, haveria defasagem da resposta de Vc a incrementos de Vf.
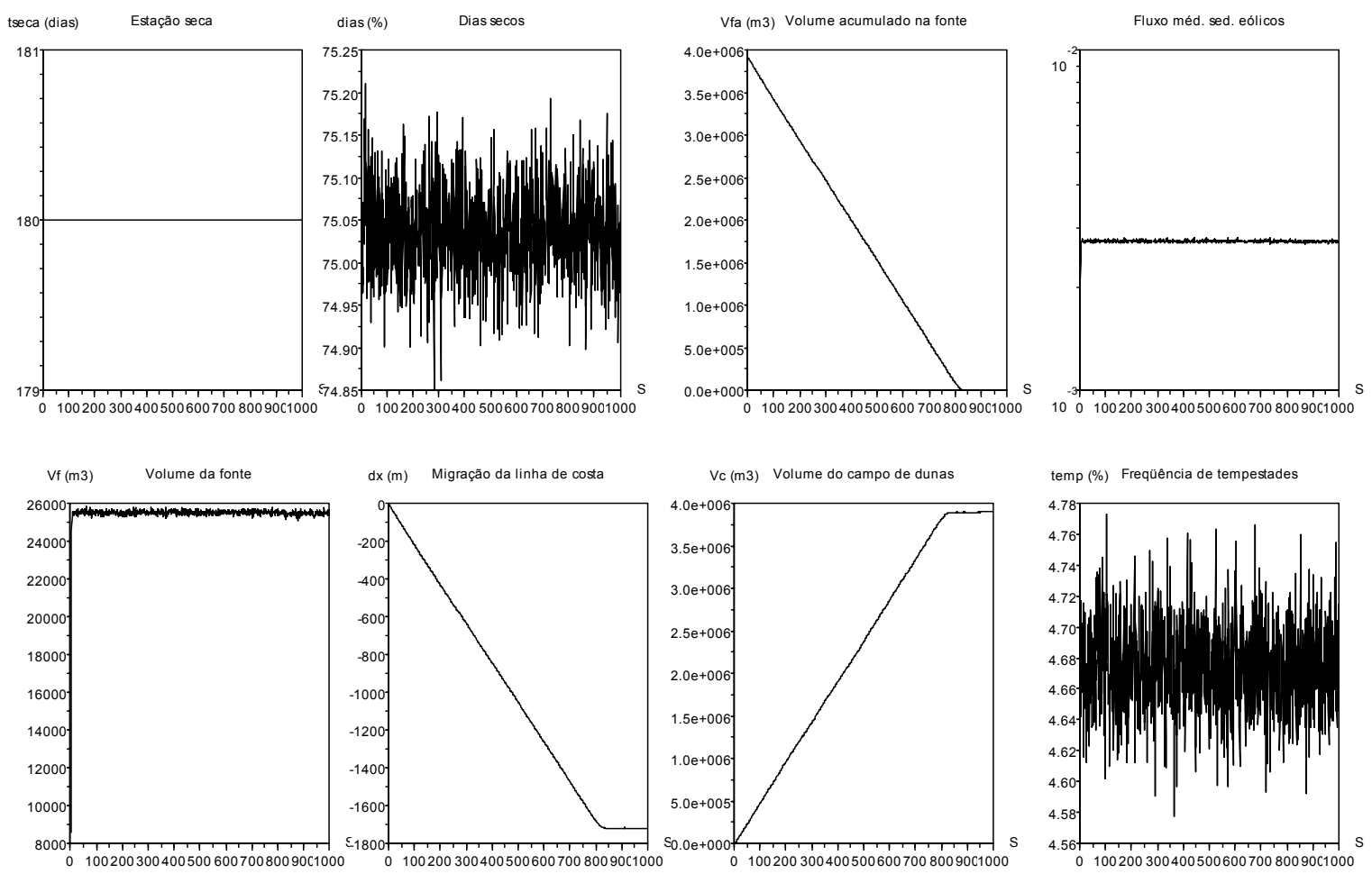

Figura 4.32 - Resultado da simulação de 100000 anos (1000 séculos) do modelo de sistema eólico costeiro sob condições de sazonalidade acentuada, variabilidade climática interanual estacionária, $\mathbf{q} \mathbf{f e}=\mathbf{q f s}$ e regime de micromaré $(\mathrm{amp}=0,6 \mathrm{~m})$. Foram utilizados os seguintes valores para simulação de qfe e qfs: qfemtemp=qfsmtemp $=\mathbf{0 , 1 0}$; dqfetemp $=\mathrm{dqfstemp}=\mathbf{1}$, qfemseca $=\mathbf{0 , 0 0 3}=$ qfsmsseca $=\mathbf{0 , 0 0 3}, \quad$ dqfeseca $=$ dqfsseca $=\mathbf{0 , 3}, \quad$ qfemumida $=$ qfsmumida $=\mathbf{0 , 0 0 6}$, dqfeumida $=$ dqfsumida $=\mathbf{0 , 3}$. Estes resultados correspondem à média de 15 experimentos. $\mathrm{S}=$ séculos. 


\begin{tabular}{|l|l|l|}
\hline Variável & Intervalo de confiança médio & $\begin{array}{l}\text { Desvio padrão do intervalo } \\
\text { de confiança }\end{array}$ \\
\hline temp $(\%)$ & 0,056 & 0,010 \\
\hline Dias secos $(\%)$ & 0,103 & 0,020 \\
\hline qce $\left(\mathrm{m}^{3} / \mathrm{m}^{*} \mathrm{~h}\right)$ & 0,000 & 0,000 \\
\hline $\mathrm{Vc}\left(\mathrm{m}^{3}\right)$ & 42363,916 & 14648,016 \\
\hline $\mathrm{Vf}\left(\mathrm{m}^{3}\right)$ & 200,149 & 86,961 \\
\hline $\mathrm{Vfa}\left(\mathrm{m}^{3}\right)$ & 24736,760 & 14039,254 \\
\hline $\mathrm{dx}(\mathrm{m})$ & 10,867 & 6,131 \\
\hline
\end{tabular}

Tabela 4.20 - Média e desvio padrão dos intervalos de confiança das variáveis de interesse (simulação de 100000 anos, N=15), cujos resultados encontram-se na Figura 4.32.

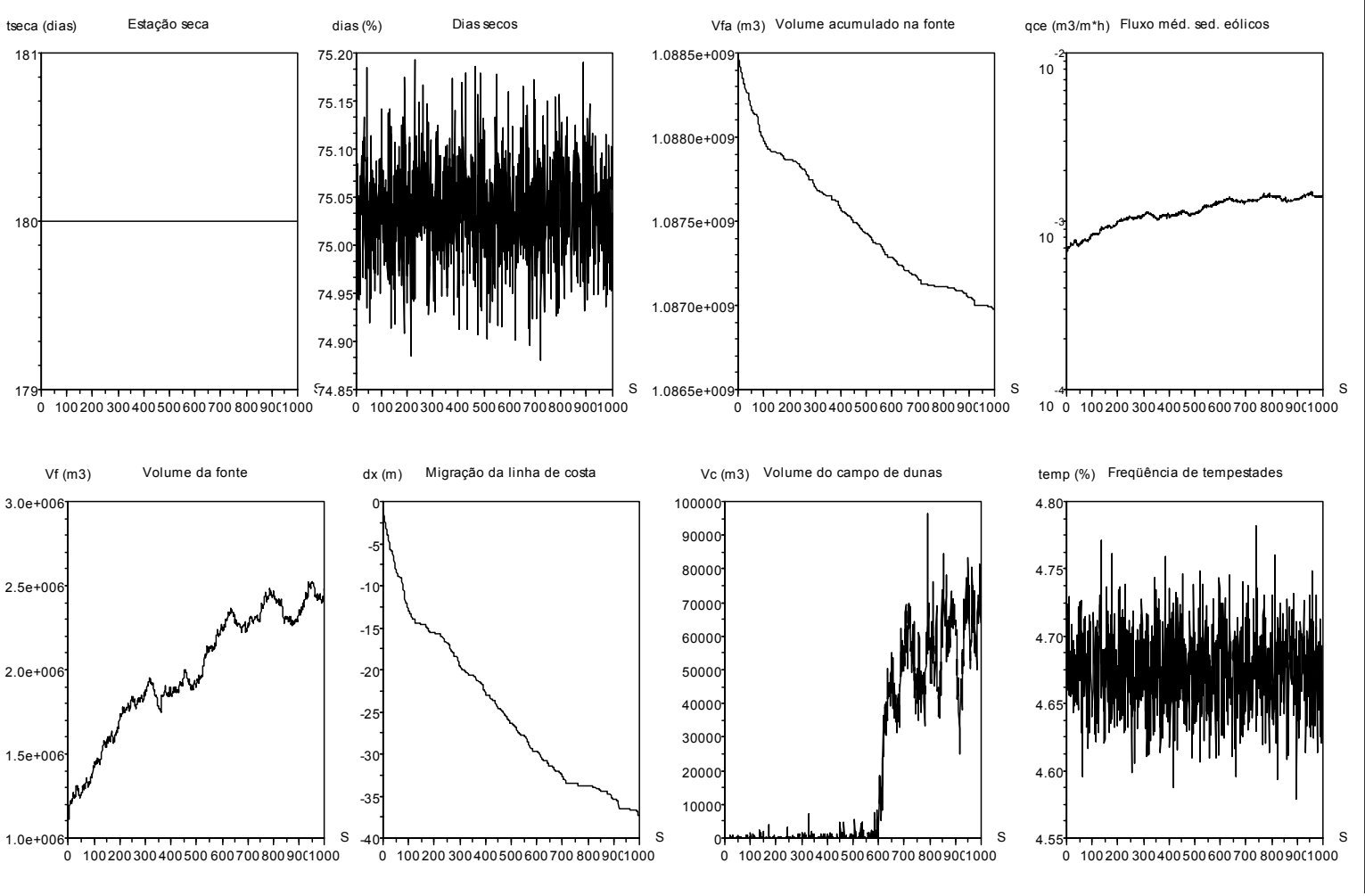

Figura 4.33 - Resultado da simulação de 100000 anos (1000 séculos) do modelo de sistema eólico costeiro sob condições de sazonalidade acentuada, variabilidade climática interanual estacionária, $\mathbf{q} \mathbf{f}=\mathbf{e}=\mathbf{q} \mathbf{f s}$ e regime de macromaré $(\mathrm{amp}=10 \mathrm{~m})$. Foram utilizados os seguintes valores para simulação de qfe e qfs: qfemtemp=qfsmtemp=0,10; dqfetemp=dqfstemp=1, qfemseca $=\mathbf{0 , 0 0 3}=$ qfsmsseca $=\mathbf{0 , 0 0 3}, \quad$ dqfeseca $=$ dqfsseca $=\mathbf{0 , 3}, \quad$ qfemumida $=$ qfsmumida $=\mathbf{0 , 0 0 6}$, dqfeumida $=$ dqfsumida $=\mathbf{0 , 3}$. Estes resultados correspondem à média de 15 experimentos. $\mathrm{S}=$ séculos. 


\begin{tabular}{|l|l|l|}
\hline Variável & Intervalo de confiança médio & $\begin{array}{l}\text { Desvio padrão do intervalo } \\
\text { de confiança }\end{array}$ \\
\hline temp $(\%)$ & 0,056 & 0,011 \\
\hline Dias secos $(\%)$ & 0,103 & 0,020 \\
\hline qce $\left(\mathrm{m}^{3} / \mathrm{m}^{*} \mathrm{~h}\right)$ & 0,0002277 & 0,0000891 \\
\hline $\mathrm{Vc}\left(\mathrm{m}^{3}\right)$ & 41125,244 & 52818,814 \\
\hline $\mathrm{Vf}\left(\mathrm{m}^{3}\right)$ & 392887,29 & 154020,41 \\
\hline $\mathrm{Vfa}\left(\mathrm{m}^{3}\right)$ & 334689,8 & 144294,68 \\
\hline $\mathrm{dx}(\mathrm{m})$ & 8,078 & 3,489 \\
\hline
\end{tabular}

Tabela 4.21 - Média e desvio padrão dos intervalos de confiança das variáveis de interesse (simulação de 100000 anos, N=15), cujos resultados encontram-se na Figura 4.33.

Sob balanço sedimentar positivo e regime de micromaré (Figura 4.34 e Tabela 4.22), o volume de sedimentos do campo de dunas $(\mathrm{Vc})$ desenvolve crescimento linear e a linha de costa apresenta tendência regressiva, também linear em escala milenar, porém, com trechos de incremento abrupto (padrão em escada). O valor de Vc após 100000 anos foi cerca de 3,7 x $10^{7}$ $\mathrm{m}^{3}$ e a regressão da linha de costa foi aproximadamente $9500 \mathrm{~m}$. As taxas de acumulação de sedimentos eólicos e de regressão foram respectivamente $3,7 \times 10^{5} \mathrm{~m}^{3} / 1000$ anos e $95 \mathrm{~m} / 1000$ anos. A taxa de geração de área plana de planície costeira pela regressão da linha de costa pode ser obtida pelo produto da taxa de regressão pelo comprimento da linha de costa (com=3800 m). Esta taxa corresponderia a $3,61 \times 10^{5} \mathrm{~m}^{2} / 1000$ anos. A razão entre a taxa de acumulação e esta taxa indica a concentração do aporte eólico na zona adjacente à área fonte. Deste modo, tem-se $1,02 \mathrm{~m}^{3} / \mathrm{m}^{2}$ de sedimentos para um período de 1000 anos. Este valor é baixo se comparado ao volume de areia, à área superficial plana e à idade máxima do campo de dunas de Itapirubá. 

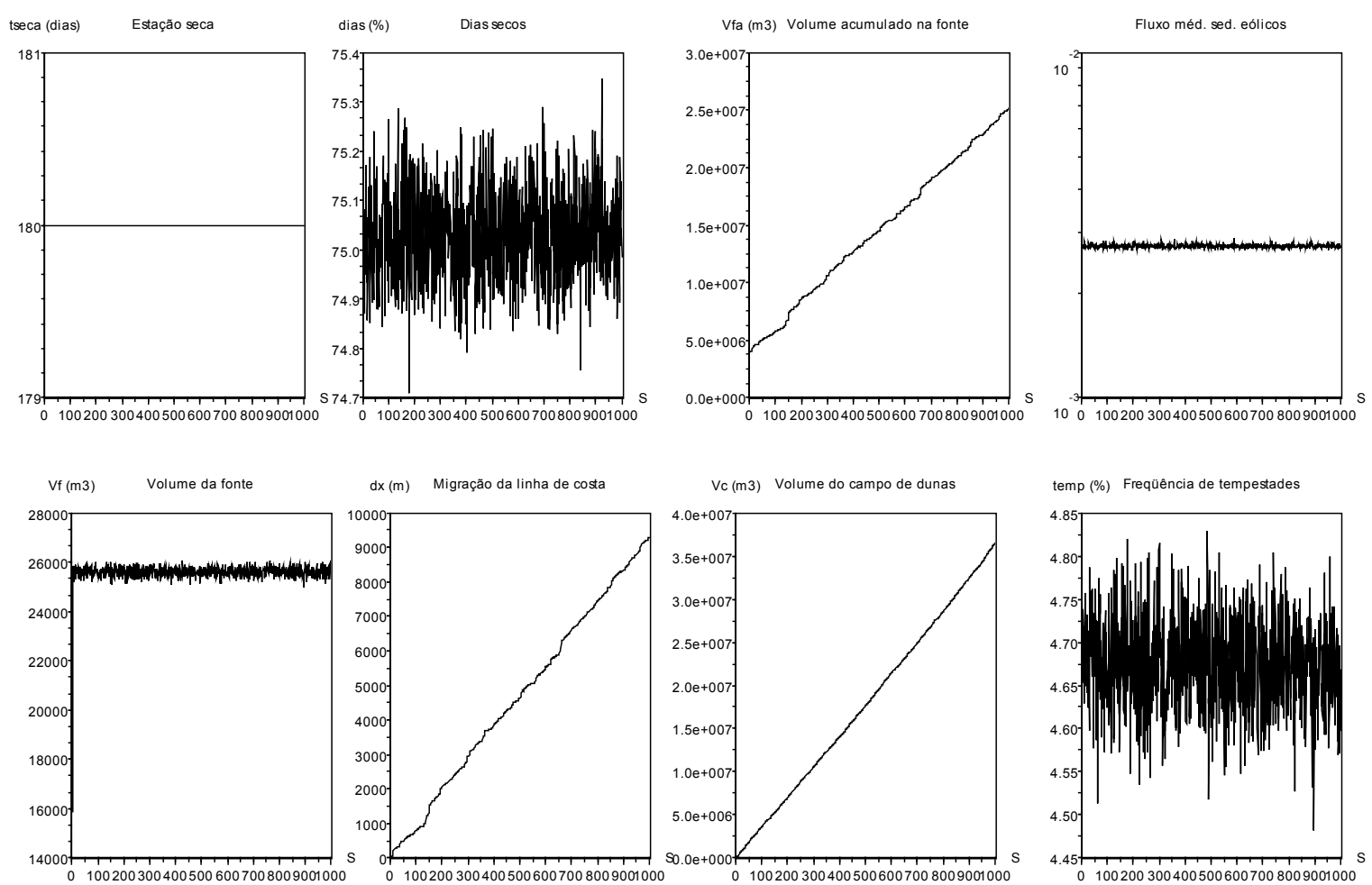

Figura 4.34 - Resultado da simulação de 100000 anos (1000 séculos) do modelo de sistema eólico costeiro sob condições de sazonalidade acentuada, variabilidade climática interanual estacionária, qfe>qfs e regime de micromaré $(\mathrm{amp}=0,6 \mathrm{~m})$. Foram utilizados os seguintes valores para simulação de qfe e qfs: qfemtemp $=\mathbf{0 , 1 5}$, qfsmtemp $=\mathbf{0 , 1 0}$; dqfetemp $=\mathrm{dqfstemp}=\mathbf{3}$, qfemseca $=\mathbf{0 , 0 0 3 5}, \quad$ qfsmsseca $=\mathbf{0 , 0 0 3 0}, \quad$ dqfeseca $=$ dqfsseca $=\mathbf{3}, \quad$ qfemumida $=\mathbf{0 , 0 0 6 5}$, qfsmumida $=\mathbf{0 , 0 0 6 0}$, dqfeumida $=$ dqfsumida $=\mathbf{3}$. Estes resultados correspondem à média de 5 experimentos. $\mathrm{S}=$ séculos.

\begin{tabular}{|l|l|l|}
\hline Variável & Intervalo de confiança médio & $\begin{array}{l}\text { Desvio padrão do intervalo } \\
\text { de confiança }\end{array}$ \\
\hline temp $(\%)$ & 0,093 & 0,033 \\
\hline Dias secos $(\%)$ & 0,171 & 0,061 \\
\hline qce $\left(\mathrm{m}^{3} / \mathrm{m}^{*} \mathrm{~h}\right)$ & 0,00005 & 0,00003 \\
\hline $\mathrm{Vc}\left(\mathrm{m}^{3}\right)$ & 555846,68 & 179024,310 \\
\hline $\mathrm{Vf}\left(\mathrm{m}^{3}\right)$ & 345,453 & 189,145 \\
\hline $\mathrm{Vfa}\left(\mathrm{m}^{3}\right)$ & 2659613,2 & 1119136,2 \\
\hline $\mathrm{dx}(\mathrm{m})$ & 1165,839 & 490,838 \\
\hline
\end{tabular}

Tabela 4.22 - Média e desvio padrão dos intervalos de confiança das variáveis de interesse (simulação de 100000 anos, $\mathrm{N}=5$ ), cujos resultados encontram-se na Figura 4.34. 
Sob balanço sedimentar positivo e macromaré, o volume de sedimentos eólicos cresce de modo linear e a linha de costa fica estável (Figura 4.35 e Tabela 4.22). O valor de Vc após 100000 anos é cerca de $7 \times 10^{8} \mathrm{~m}^{3}$ e a taxa de acumulação de sedimentos eólicos é aproximadamente $7 \times 10^{6} \mathrm{~m}^{3} / 1000$ anos. A estabilidade da linha de costa ocorre pois a diferença entre Vfmin e Vfmax é muito grande de modo que dificilmente Vf supera Vfmax ou fica inferior a Vfmin. O crescimento de Vc ocorre apenas porque o fluxo de entrada de sedimentos na área fonte supera o fluxo de saída. Nestas condições, o sistema é pouco sensível a variações do volume da fonte. Portanto, deve ficar mais sensível a variáveis climáticas, tais como velocidade do vento e ocorrência de chuvas. A estabilidade da costa, devido à elevada amplitude de maré, faz com que o sistema opere em condições mais propícias ao desenvolvimento de campos de dunas do que sob regime de micromaré.
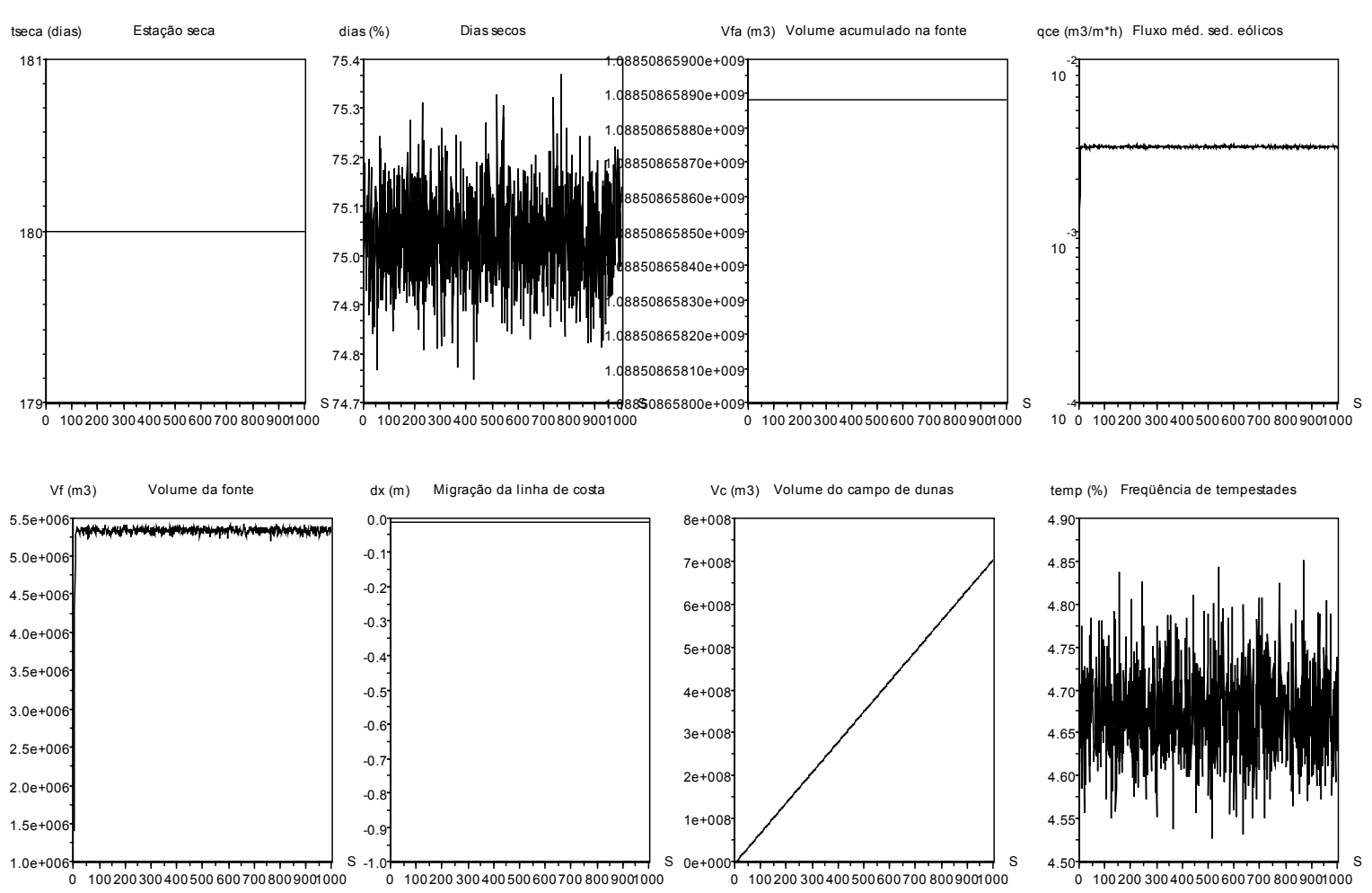

Figura 4.35 - Resultado da simulação de 100000 anos (1000 séculos) do modelo de sistema eólico costeiro sob condições de sazonalidade acentuada, variabilidade climática interanual estacionária, qfe>qfs e regime de macromaré $(\mathrm{amp}=10 \mathrm{~m})$. Foram utilizados os seguintes valores para simulação de qfe e qfs: qfemtemp=0,15, qfsmtemp=0,10; dqfetemp=dqfstemp=3, qfemseca $=\mathbf{0 , 0 0 3 5}, \quad$ qfsmsseca $=\mathbf{0 , 0 0 3 0}, \quad$ dqfeseca $=$ dqfsseca $=\mathbf{3}, \quad$ qfemumida $=\mathbf{0 , 0 0 6 5}$, 
qfsmumida $=\mathbf{0 , 0 0 6 0}$, dqfeumida $=\mathrm{dqfsumida}=\mathbf{3}$. Estes resultados correspondem à média de 5 experimentos. $\mathrm{S}=$ séculos.

\begin{tabular}{|l|l|l|}
\hline Variável & Intervalo de confiança médio & $\begin{array}{l}\text { Desvio padrão do intervalo } \\
\text { de confiança }\end{array}$ \\
\hline temp $(\%)$ & 0,093 & 0,034 \\
\hline Dias secos $(\%)$ & 0,174 & 0,060 \\
\hline qce $\left(\mathrm{m}^{3} / \mathrm{m}^{*} \mathrm{~h}\right)$ & 0,0000559 & 0,0000244 \\
\hline $\mathrm{Vc}\left(\mathrm{m}^{3}\right)$ & 1092378,6 & 261679,74 \\
\hline $\mathrm{Vf}\left(\mathrm{m}^{3}\right)$ & 55249,874 & 24184,084 \\
\hline $\mathrm{Vfa}\left(\mathrm{m}^{3}\right)$ & 523,141 & $8,303 \mathrm{D}-12$ \\
\hline $\mathrm{dx}(\mathrm{m})$ & 0,012 & $2,725 \mathrm{D}-16$ \\
\hline
\end{tabular}

Tabela 4.23 - Média e desvio padrão dos intervalos de confiança das variáveis de interesse (simulação de 100000 anos, $\mathrm{N}=5$ ), cujos resultados encontram-se na Figura 4.35.

4.8.3 Experimentos com variabilidade climática interanual modelada pelos ciclos de Milankovitch de precessão dos equinócios

\subsubsection{Efeito climático do ciclo de precessão dos equinócios}

A variação da quantidade de radiação solar (taxa de insolação) absorvida pela Terra em determinado local pode provocar alterações climáticas de ordem diversa. Em escala milenar, a taxa de insolação varia segundo três movimentos cíclicos da órbita da Terra denominados ciclos de Milankovitch. Estes ciclos são designados de precessão dos equinócios (período de 19000 a 23000 anos), de obliqüidade da eclíptica (período de 40000 a 41000 anos) e de excentricidade da eclíptica (período de 100000 anos). Os equinócios são posições orbitais em que dia e noite apresentam a mesma duração. Cada ano contempla dois equinócios (de outono e inverno) que determinam o início do outono e o final do inverno. A posição dos equinócios na órbita elíptica da Terra em torno do Sol define a duração relativa das estações frias (outono e inverno) e quentes (primavera e verão). A posição dos equinócios varia ao longo dos anos devido a movimento circular do eixo de rotação da Terra. O ciclo de obliqüidade da eclíptica resulta da variação da inclinação do eixo de rotação da Terra em relação ao eixo do norte geográfico, que varia entre 21,5 e $24,5^{\circ}$. A inclinação do eixo de rotação determina o ângulo de incidência da radiação solar e portanto a proporção de radiação solar refletida. O ciclo de excentricidade da eclíptica deriva da variação da posição dos focos da elipse da órbita da Terra ao redor do Sol. Este ciclo provoca 
mudança na forma da órbita e variação da duração relativa das estações do ano. O aumento da duração do inverno nas regiões polares devido ao ciclo de excentricidade da eclíptica é proposto como causa das glaciações quaternárias.

Depósitos sedimentares também podem apresentar padrão cíclico de repetição de litologias ou fácies. A ciclicidade de certos depósitos tem sido correlacionada a ciclos de Milankovitch (Olsen, 1990; Crowley et al., 1993; Dersch \& Stein, 1993; Rea, 1994; Hachiro, 1996; Rachold \& Brumsack, 2001). Neste caso, a associação entre a ciclicidade de depósitos sedimentares e ciclos de insolação ocorreria mediante influência do clima sobre a sedimentação. No entanto, as alterações climáticas induzidas por ciclos de Milankovitch não são facilmente previsíveis, pois dependem da compreensão do modo como variações de taxa de insolação afetam a dinâmica atmosférica. Na Região Sul do Brasil, Cruz et al. (2005) observaram correlação entre razões de isótopos de oxigênio $\left(\delta^{18} \mathrm{O}\right)$ em carbonato de estalactites e taxa de insolação da latitude $30^{\circ} \mathrm{S}$. A razão $\delta^{18} \mathrm{O}$ nas águas pluviais da Região Sul resulta da contribuição isotópica de massas de ar úmido derivadas da região amazônica, cuja incursão rumo sul é maior durante o final do verão e início do outono, e de águas derivadas do oceano Atlântico adjacente, cuja chegada até a região estudada ocorre principalmente durante o inverno e início da primavera através do avanço de frentes frias vindas de sul. As águas de fonte atlântica vindas de sul são mais enriquecidas em $\mathrm{O}^{18}$, de modo que resultam em valores maiores de $\delta^{18} \mathrm{O}$. Assim, o valor da razão $\delta^{18} \mathrm{O}$ seria indicador da freqüência de atuação de frentes frias. Na costa sul do Brasil, frentes frias são caracterizadas por ventos e chuvas mais intensos. Em escala de tempo milenar, Cruz Jr. et al. (2005) observaram correlação positiva entre a taxa de insolação e a razão $\delta^{180}$ de estalactites. Logo, no caso da costa sul do Brasil, períodos de maior insolação corresponderiam à maior freqüência de frentes frias e, por conseguinte, chuvas e ventos de inverno e início da primavera mais intensos. Isto ocorreria devido ao deslocamento para norte da Zona de Convergência do Atlântico Sul (ZCAS). Este caso configura exemplo, onde se pode estabelecer relação entre as variações ciclícas de insolação e variáveis climáticas do sistema eólico. A associação entre dinâmica climática de determinada região e ciclos de insolação permite o modelamento da variabilidade climática em escala milenar, pois a variação das taxas de insolação em função do tempo podem ser calculadas para períodos pretéritos.

No caso da Região Sul do Brasil, a insolação correlaciona-se a atuação das frentes frias. O deslocamento da ZCAS para norte favorece o avanço de frentes frias e, portanto, chuvas e ventos 
mais intensos não apenas durante o inverno e início da primavera, mas também durante o restante do ano. A ZCAS, como zona de nebulosidade, é mais ativa no verão, embora as frentes frias sejam mais fortes e penetrativas rumo norte no inverno. Desta forma, pode-se dizer que o aumento da insolação favorece chuvas e ventos mais intensos. Assim, pode-se dividir o ano em períodos seco e úmido, os quais estariam condicionados à variação da insolação. No período seco predomina a dinâmica de incursões de massas de ar monssônicas provenientes de norte (chuvas e ventos menos intensos) e no período úmido, massas de ar frio derivadas do oceâno Atlântico (chuvas e ventos mais intensos). A duração relativa entre estes dois períodos é ditada pela insolação. Assim, maior a insolação, maior a duração do período úmido. Deste modo, pode-se estudar o efeito da variabilidade climática milenar (ou alternativamente dos ciclos de precessão) sobre a sedimentação eólica costeira da Região Sul do Brasil.

A variação da duração da estação mais seca foi descrita por função seno com periodicidade de 20000 anos, que corresponde ao ciclo de precessão dos equinócios, e amplitude variável. Os picos da duração da estação seca corresponderia a valores mínimos de insolação e vice-versa. As condições climáticas das estações seca e úmida foram definidas de modo diverso, que variou entre extremos uniforme e altamente contrastante no que diz respeito à probabilidades de chuva, tempestade e velocidade do vento. Deste modo, foi possível avaliar a sensibilidade da sedimentação eólica em relação à variabilidade interanual das diferentes variáveis climáticas.

\subsubsection{Resultados dos experimentos}

A seguir são apresentados os resultados de experimentos onde a estação mais seca varia segundo o ciclo de precessão dos equinócios. Todos os experimentos foram realizados sob fluxo de entrada de sedimentos costeiros superior à saída. $\mathrm{O}$ primeiro conjunto de experimentos foi realizado sob as condições climáticas descritas no Quadro 4.4 e amplitude de variação da estação mais seca igual a 180 dias. Estas condições são equivalentes às utilizadas nos experimentos anteriores. Este conjunto reúne dois experimentos, os quais são diferenciados pela amplitude de maré. Assim, apresenta-se um experimento em costa de micromaré (amplitude $=0,6 \mathrm{~m}$ ) e outro em costa de macromaré (amplitude $=10 \mathrm{~m}$ ). 


\begin{tabular}{|l|l|l|l|}
\hline $\begin{array}{l}\text { Probabilidade de } \\
\text { tempestade }\end{array}$ & $\begin{array}{l}\text { Probabilidade } \\
\text { de chuva }\end{array}$ & $\begin{array}{l}\text { Velocidade } \\
\mathbf{d o} \quad \text { vento } \\
\mathbf{( m} / \mathbf{s})\end{array}$ & $\begin{array}{l}\text { Saída de sedimentos do } \\
\text { campo de dunas }\left(\mathbf{m}^{\mathbf{3}} / \mathbf{m} \text { hora }\right)\end{array}$ \\
\hline tempseca $1=0.02$ & ctemp1 $=0.6$ & vmtemp $=15$ & qcsmtemp $=0.1$ \\
\hline tempseca $2=0.05$ & ctemp2 $=0.8$ & dvtemp $=1$ & dqcstemp $=1$ \\
\hline tempumida1 $=0.07$ & cseca $1=0.05$ & vmseca $=10$ & qcsmseca $=0.003$ \\
\hline tempumida2 $=0.1$ & cseca $=0.1$ & dvseca $=0.3$ & dqcsseca $=0.3$ \\
\hline & cumida $1=0.4$ & vmumida $=8$ & qcsmumida $=0.006$ \\
\hline & cumida $2=0.7$ & dvumida $=0.3$ & dqcsumida $=0.3$ \\
\hline
\end{tabular}

Quadro 4.4 - Probabilidades de chuva, velocidade média e dispersão do vento e valores médios e dispersões dos fluxos de saída de sedimentos do campo de dunas para as estações seca, úmida e condição de tempestade.

Sob regime de micromaré, o volume da fonte (Vf) e o fluxo de sedimentos eólicos (qce) variam de modo correspondente à variação da estação seca, ou seja, apresentam variação cíclica. Apesar disto, a tendência de crescimento de Vc é quasi-linear, de modo que não é significativamente afetada pela variação da estação estação seca (Figura 4.36 e Tabela 4.24). A linha de costa demonstra tendência regressiva, com incremento da taxa de regressão durante períodos de redução da porcentagem de dias secos e incremento da freqüência de tempestades. Desta forma, apesar da ciclicidade da estação seca não afetar significativamente o crescimento de Vc, afeta a migração da linha de costa, que por sua vez influencia o desenvolvimento de campos de dunas. Linha de costa regressiva desfavorece a formação de campos de dunas pelo efeito diluidor do aporte eólico. Este efeito torna-se mais intenso durante fase de incremento da taxa de regressão, que pode estar mais diretamente ligado à variações climáticas do que o aporte sedimentar eólico. 

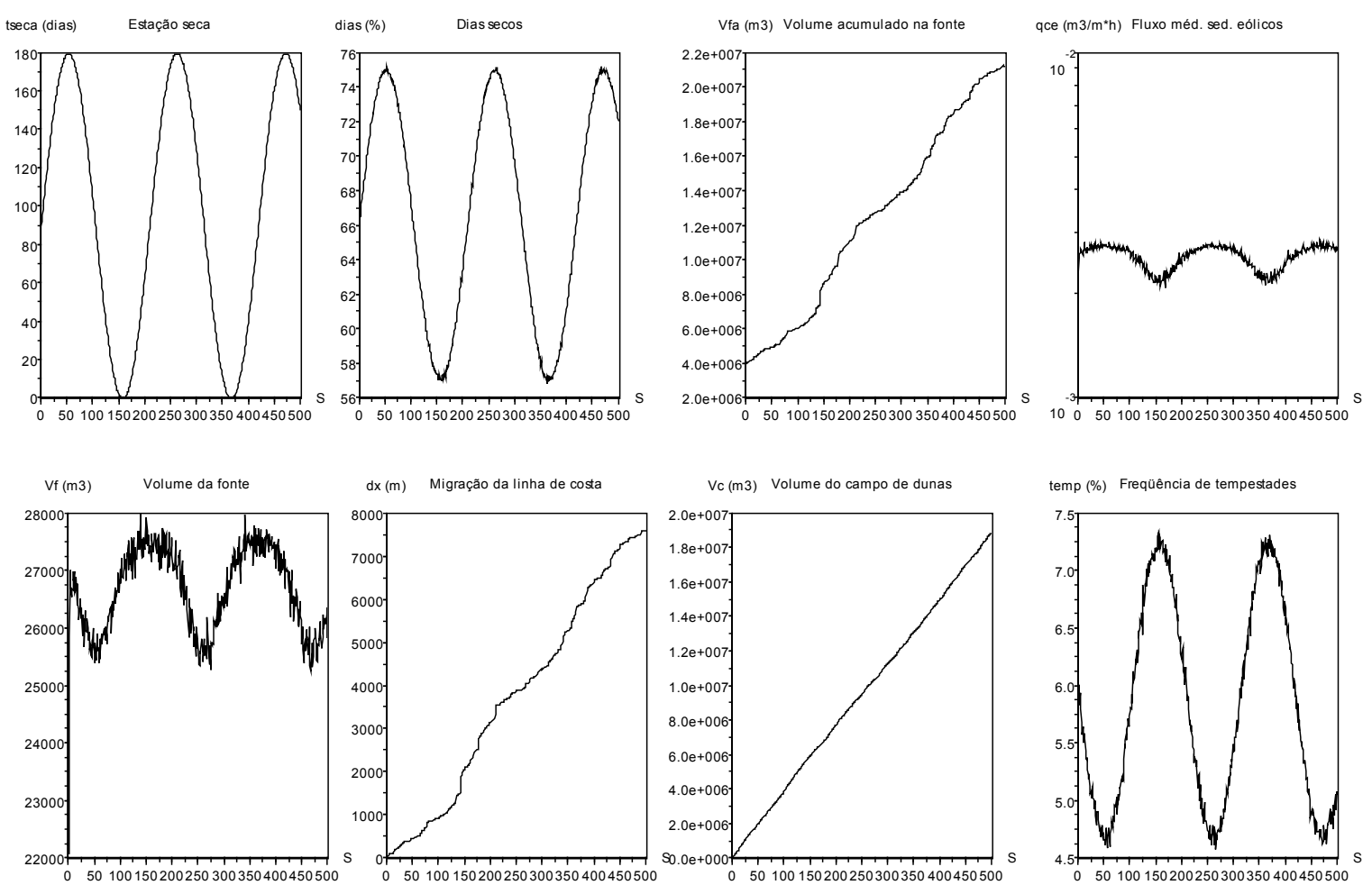

Figura 4.36 - Resultado da simulação de 50000 anos (500 séculos) do modelo de sistema eólico costeiro sob regime de micromaré $(\mathrm{amp}=0,6 \mathrm{~m})$ e qfe $>\mathbf{q f s}$. Foram utilizados os seguintes valores para simulação de qfe e qfs: qfemtemp=0,15, qfsmtemp $=\mathbf{0 , 1 0}$; dqfetemp=dqfstemp $=\mathbf{3}$, qfemseca $=\mathbf{0 , 0 0 3 5}, \quad$ qfsmsseca $=\mathbf{0 , 0 0 3 0}, \quad$ dqfeseca $=$ dqfsseca $=\mathbf{3}, \quad$ qfemumida $=\mathbf{0 , 0 0 6 5}$, qfsmumida $=\mathbf{0 , 0 0 6 0}$, dqfeumida $=$ dqfsumida $=\mathbf{3}$. Estes resultados correspondem à média de 5 experimentos. $\mathrm{S}=$ séculos.

\begin{tabular}{|l|l|l|}
\hline Variável & Intervalo de confiança médio & $\begin{array}{l}\text { Desvio padrão do intervalo } \\
\text { de confiança }\end{array}$ \\
\hline temp $(\%)$ & 0,102 & 0,039 \\
\hline Dias secos $(\%)$ & 0,190 & 0,071 \\
\hline qce $\left(\mathrm{m}^{3} / \mathrm{m}^{*} \mathrm{~h}\right)$ & 0,000 & 0,000 \\
\hline $\mathrm{Vc}\left(\mathrm{m}^{3}\right)$ & 371917,540 & 155331,710 \\
\hline $\mathrm{Vf}\left(\mathrm{m}^{3}\right)$ & 378,242 & 251,416 \\
\hline $\mathrm{Vfa}\left(\mathrm{m}^{3}\right)$ & 2270984,200 & 1361082,200 \\
\hline $\mathrm{dx}(\mathrm{m})$ & 995,712 & 596,804 \\
\hline
\end{tabular}

Tabela 4.24 - Média e desvio padrão dos intervalos de confiança das variáveis de interesse (simulação de 50000 anos, N=5), cujos resultados encontram-se na Figura 4.36.

A elevação da amplitude de maré (macromaré) intensifica a redução da taxa de regressão durante períodos mais secos (maior porcentagem de dias secos) (Figura 4.37 e Tabela 4.25). A 
migração da linha de costa é caracterizada por fases de estabilização, que duram milhares a dezenas de milhares de anos, alternadas com fases de alta taxa de regressão (padrão em escada). As fases de estabilização são coincidentes com períodos de maior freqüência de dias secos. Assim como no experimento anterior, o crescimento do volume de sedimentos eólicos (Vc) não é sigficativamente alterado pela variação da duração da estação seca. Além disto, o fluxo de sedimentos eólicos (qce) e o volume de sedimentos na fonte (Vf) variam de forma cíclica, equivalente à variação da duração da estação seca, porcentagem de dias de chuva e frequiência de tempestades. Sob amplitude de maré elevada, pode haver longo período de linha de costa estável, o que favorece a concentração do aporte eólico e a formação e manutenção de campos de dunas. No entanto, regressão abrupta, posterior a fase de linha de costa estável, pode provocar diluição excessiva do aporte eólico e isolamento de campos de dunas previamente formados. Desta forma, o padrão em escada de migração da linha de costa pode proporcionar a formação de sucessivas gerações de campos de dunas ou cordões de dunas frontais, as quais seriam separadas entre si pelas fases de regressão acelerada. A alternância entre fases de regressão acelerada e estabilização da linha de costa abrange várias escalas de tempo de modo que não apresenta correspondência direta com a ciclicidade da variação da estação seca. As migrações aceleradas de menor amplitude e curto período de tempo podem não ser suficientes para provocar o isolamento de campos de dunas preexistente e a formação de novo campo de dunas em período seguinte, mas pode imprimir caráter pulsátil para o aporte eólico e avanço dos campos de dunas. Assim, esta tendência de migração da linha de costa pode explicar, por exemplo, o fato do campo de dunas de Lençóis Maranhenses apresentar formas de avanço de hierarquia variável, bem como as gerações eólicas do litoral centro-sul catarinense. 

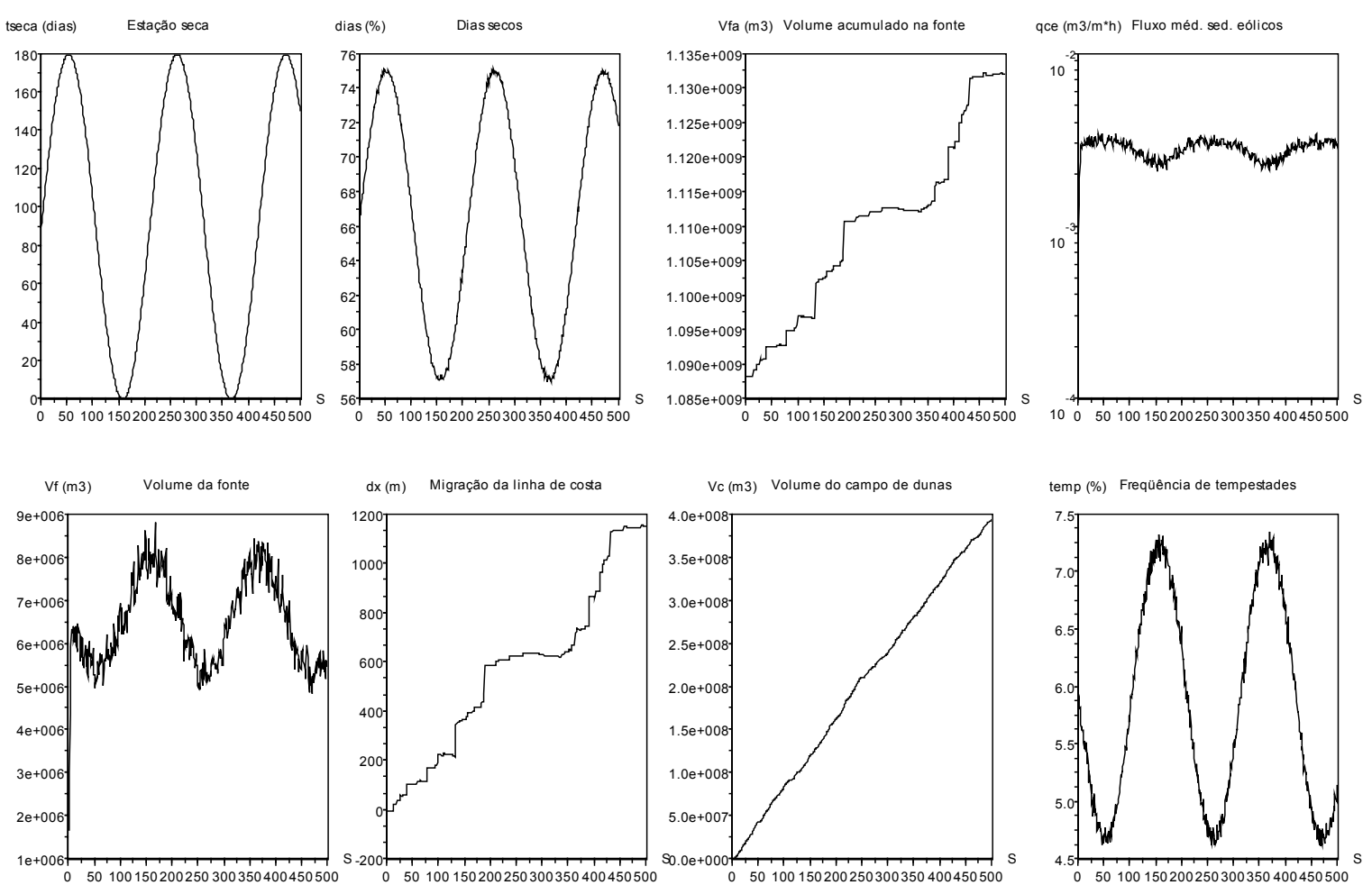

Figura 4.37 - Resultado da simulação de 50000 anos (500 séculos) do modelo de sistema eólico costeiro sob regime de macromaré $(\mathrm{amp}=10 \mathrm{~m})$ e $\mathbf{q f e}>\mathbf{q f s}$. Foram utilizados os seguintes valores para simulação de qfe e qfs: qfemtemp=0,15, qfsmtemp $=\mathbf{0 , 1 0}$; dqfetemp=dqfstemp $=\mathbf{3}$, qfemseca $=\mathbf{0 , 0 0 3 5}, \quad$ qfsmsseca $=\mathbf{0 , 0 0 3 0}, \quad$ dqfeseca $=$ dqfsseca $=\mathbf{3}, \quad$ qfemumida $=\mathbf{0 , 0 0 6 5}$, qfsmumida $=\mathbf{0 , 0 0 6 0}$, dqfeumida $=$ dqfsumida $=\mathbf{3}$. Estes resultados correspondem à média de 5 experimentos. $\mathrm{S}=$ séculos.

\begin{tabular}{|l|l|l|}
\hline Variável & Intervalo de confiança médio & $\begin{array}{l}\text { Desvio padrão do intervalo } \\
\text { de confiança }\end{array}$ \\
\hline temp $(\%)$ & 0,105 & 0,037 \\
\hline Dias secos $(\%)$ & 0,195 & 0,068 \\
\hline qce $\left(\mathrm{m}^{3} / \mathrm{m}^{*} \mathrm{~h}\right)$ & 0,000 & 0,000 \\
\hline $\mathrm{Vc}\left(\mathrm{m}^{3}\right)$ & 10434755,000 & 5620874,900 \\
\hline $\mathrm{Vf}\left(\mathrm{m}^{3}\right)$ & 498457,260 & 263369,380 \\
\hline $\mathrm{Vfa}\left(\mathrm{m}^{3}\right)$ & 14004852,000 & 6751766,200 \\
\hline $\mathrm{dx}(\mathrm{m})$ & 368,961 & 177,876 \\
\hline
\end{tabular}

Tabela 4.25 - Média e desvio padrão dos intervalos de confiança das variáveis de interesse (simulação de 50000 anos, N=5), cujos resultados encontram-se na Figura 4.37.

A elevação da probabilidade de chuva na estação úmida e a redução na estação seca aumentaram a sazonalidade e, em escala interanual, a amplitude de variação da porcentagem de 
dias secos. Em termos médios, houve redução da porcentagem de dias secos. Estas alterações no regime de precipitação visaram a intensificação do efeito da pluviosidade sobre a sedimentação eólica. Sob estas condições e sob regime de micromaré, o volume de sedimentos eólicos demonstra redução da taxa de crescimento durante períodos de máxima precipitação (menor porcentagem de dias secos). Apesar de ser nítida, a redução da taxa de crescimento de Vc durante épocas de maior freqüência de chuvas é tênue (Figura 4.38 e Tabela 4.26). Logo, a tendência de crescimento de Vc em escala milenar é pouco sensível à sazonalidade da precipitação. O volume de sedimentos eólicos atingido ao final do período simulado é cerca de $1,4 \times 10^{7} \mathrm{~m}^{3}$, o que equivale a cerca de $73 \%$ do volume atingido sob as condições do primeiro experimento (Figura 4.36 e Tabela 4.23), caracterizado por maior probabilidade de chuva e porcentagem de dias secos entre 57 e 75\% (nesse experimento a porcentagem de dias secos variou entre 27 e $62 \%$ ). $\mathrm{O}$ volume de sedimentos costeiros acumulados (Vfa) apresenta crescimento, com incrementos abruptos por volta de 3000 anos (30 séculos) e por volta de 30000 anos (300 séculos). Esta tendência implica regressão da linha de costa (mais de 9000 m em 50000 anos), com dois períodos de regressão súbita correspondentes aos períodos de incremento abrupto de Vfa (Figura 4.38). Salienta-se o fato de que estes dois períodos de regressão súbita não se relacionam a variações de escala milenar da precipitação, freqüência de tempestades, volume da fonte ou fluxo de sedimentos eólicos. Isto sugere que tal comportamento é inerente à dinâmica do sistema. Mesmo que a variação do fluxo de sedimentos eólicos e do volume de sedimentos da área fonte seja ditada pela variação da freqüência de chuvas, esta última não é refletida pelas tendências de variação do volume de sedimentos eólicos e da linha de costa. Conclui-se que, sob regime de micromaré, as tendências de variação do volume de sedimentos eólicos e a migração da linha de costa são pouco sensíveis ao aumento da sazonalidade da precipitação (freqüência de chuvas). 

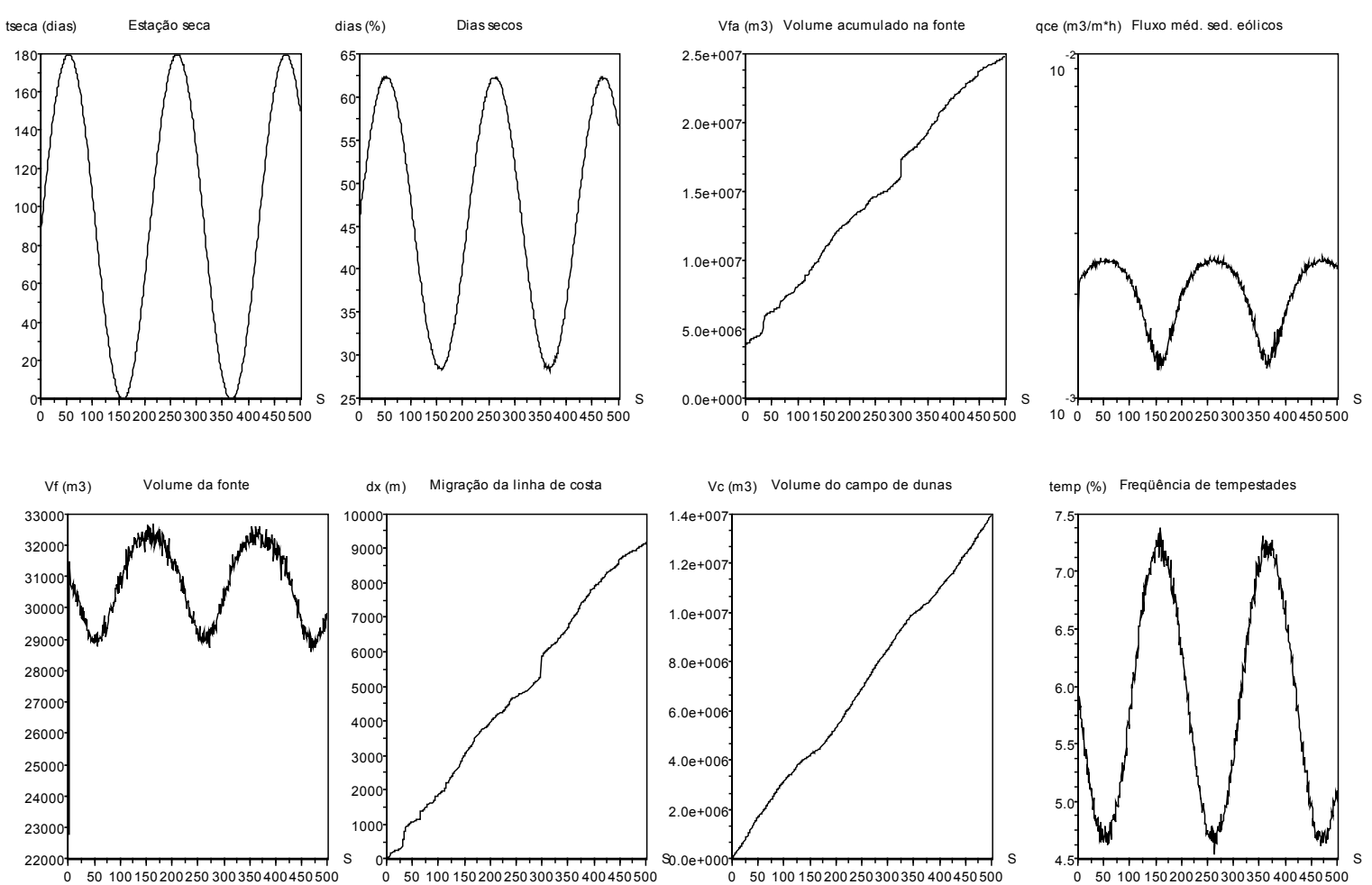

Figura 4.38 - Resultado da simulação de 50000 anos (500 séculos) do modelo de sistema eólico costeiro sob regime de micromaré $(\mathrm{amp}=0,6 \mathrm{~m})$, qfe $>\mathbf{q f s}$ e aumento da diferença entre as freqüências de chuva das estações seca e úmida. Foram utilizados os seguintes valores para simulação de qfe e qfs: qfemtemp=0,15, qfsmtemp=0,10; dqfetemp=dqfstemp=3, qfemseca $=\mathbf{0 , 0 0 3 5}, \quad$ qfsmsseca $=\mathbf{0 , 0 0 3 0}, \quad$ dqfeseca $=$ dqfsseca $=\mathbf{3}, \quad$ qfemumida $=\mathbf{0 , 0 0 6 5}$, qfsmumida $=\mathbf{0 , 0 0 6 0}$, dqfeumida $=\mathrm{dqfsumida}=\mathbf{3}$. Estes resultados correspondem à média de 5 experimentos. Probabilidades de chuva: $\operatorname{ctemp1}=0.8$ e $\operatorname{ctemp2}=0.9 ;$ cseca1 $=0.01$ e $\mathbf{c s e c a 2}=0.02$; cumida1 $=0.7$ e cumida2 $=0.9 . \mathrm{S}=$ séculos.

\begin{tabular}{|l|l|l|}
\hline Variável & Intervalo de confiança médio & $\begin{array}{l}\text { Desvio padrão do intervalo } \\
\text { de confiança }\end{array}$ \\
\hline temp $(\%)$ & 0,101 & 0,040 \\
\hline Dias secos $(\%)$ & 0,168 & 0,066 \\
\hline qce $\left(\mathrm{m}^{3} / \mathrm{m}^{*} \mathrm{~h}\right)$ & 0,0000615 & 0,0000387 \\
\hline $\mathrm{Vc}\left(\mathrm{m}^{3}\right)$ & 320323,64 & 132422,45 \\
\hline $\mathrm{Vf}\left(\mathrm{m}^{3}\right)$ & 329,603 & 248,653 \\
\hline $\mathrm{Vfa}\left(\mathrm{m}^{3}\right)$ & 1683366,3 & 829483,61 \\
\hline $\mathrm{dx}(\mathrm{m})$ & 738,228 & 364,329 \\
\hline
\end{tabular}

Tabela 4.26 - Média e desvio padrão dos intervalos de confiança das variáveis de interesse (simulação de 50000 anos, $\mathrm{N}=5$ ), cujos resultados encontram-se na Figura 4.38. 
O incremento da sazonalidade (mediante elevação da amplitude de variação da porcentagem de dias secos), sob regime de macromaré, não provoca alterações significativas na tendência de crescimento de Vc. Não foram observadas variações da taxa de crescimento de Vc correlacionáveis à variação da porcentagem de dias secos. Assim como no caso anterior (regime de micromaré), o incremento da sazonalidade da precipitação e redução da porcentagem média de dias secos provoca redução do volume de sedimentos eólicos acumulados ao longo de 50000 anos (Figura 4.39). O valor de Vc após 50000 anos foi aproximadamente $3,6 \times 10^{8} \mathrm{~m}^{3}$, que representa cerca de $92 \%$ do volume acumulado no experimento com amplitude de variação da porcentagem de dias secos reduzida (Figura 4.37). O volume de sedimentos costeiros acumulados é crescente, com períodos mais longos de estabilidade alternados com períodos curtos de incremento abrupto. A linha de costa é regressiva, com tendência equivalente, ou seja, períodos longos de estabilidade sucedidos por períodos curtos de regressão. O aumento da freqüência de chuvas na estação úmida e redução na estação seca induzem aumento da fase de estabilidade da linha de costa. A variação de volume da área fonte (Vf) varia de modo cíclico, sendo que seus picos correspondem a valores mínimos da porcentagem de dias secos. Pode-se associar a estabilização da linha de costa à redução de Vf. Deste modo, se for considerado que linha de costa estável favorece a acumulação de sedimentos eólicos, a redução da porcentagem de dias secos auxiliaria o desenvolvimento de campos de dunas. Esta constatação é contra-intuitiva e pode ser explicada pela influência do tamanho da fonte sobre a migração da linha de costa. A elevada diferença entre os volumes máximo (Vfmax) e mínimo (Vfmin) de sedimentos na fonte, os quais determinam respectivamente a ocorrência de regressão e trangressão da linha de costa, auxiliam na estabilidade da linha de costa. Isto ocorre, pois o intervalo de variação de Vf torna-se pequeno em relação à diferença entre os volumes máximo (Vfmax) e mínimo (Vfmin). A superação de Vfmax, com regressão da linha de costa, ocorre apenas durante fases de pico de Vf. Os valores mínimos de Vf são muito superiores à Vfmin, de modo que não há transgressão da linha de costa. Isto faz com que a linha de costa fique estável na maior parte do tempo. O fluxo médio de sedimentos eólicos também apresenta variação cíclica senoidal, sendo que o intervalo de tempo em que o fluxo opera com valores elevados é superior ao intervalo em que opera com valores baixos. Assim, a longa estabilidade da linha de costa e períodos mais longos de fluxo elevado de sedimentos eólicos tornam possível a coincidência no tempo entre estes dois fatores favoráveis à formação de campos de dunas. Deste modo, há dois efeitos contrários do aumento da 
sazonalidade da freqüência de chuvas sobre a sedimentação eólica: estabilização da linha de costa e redução do volume de sedimentos eólicos acumulados. A elevação da duração da fase com linha de costa estável aparenta ser mais significativa que a redução de Vc. O aumento da sazonalidade da precipitação torna a linha de costa mais estável e, portanto, torna o sistema mais susceptível ao desenvolvimento ou crescimento de campos de dunas, mesmo que tenha havido redução do volume de sedimentos eólicos acumulados ao longo período de tempo simulado. Assim, o efeito favorável ao desenvolvimento de campos de dunas seria mais importante que o desfavorável.
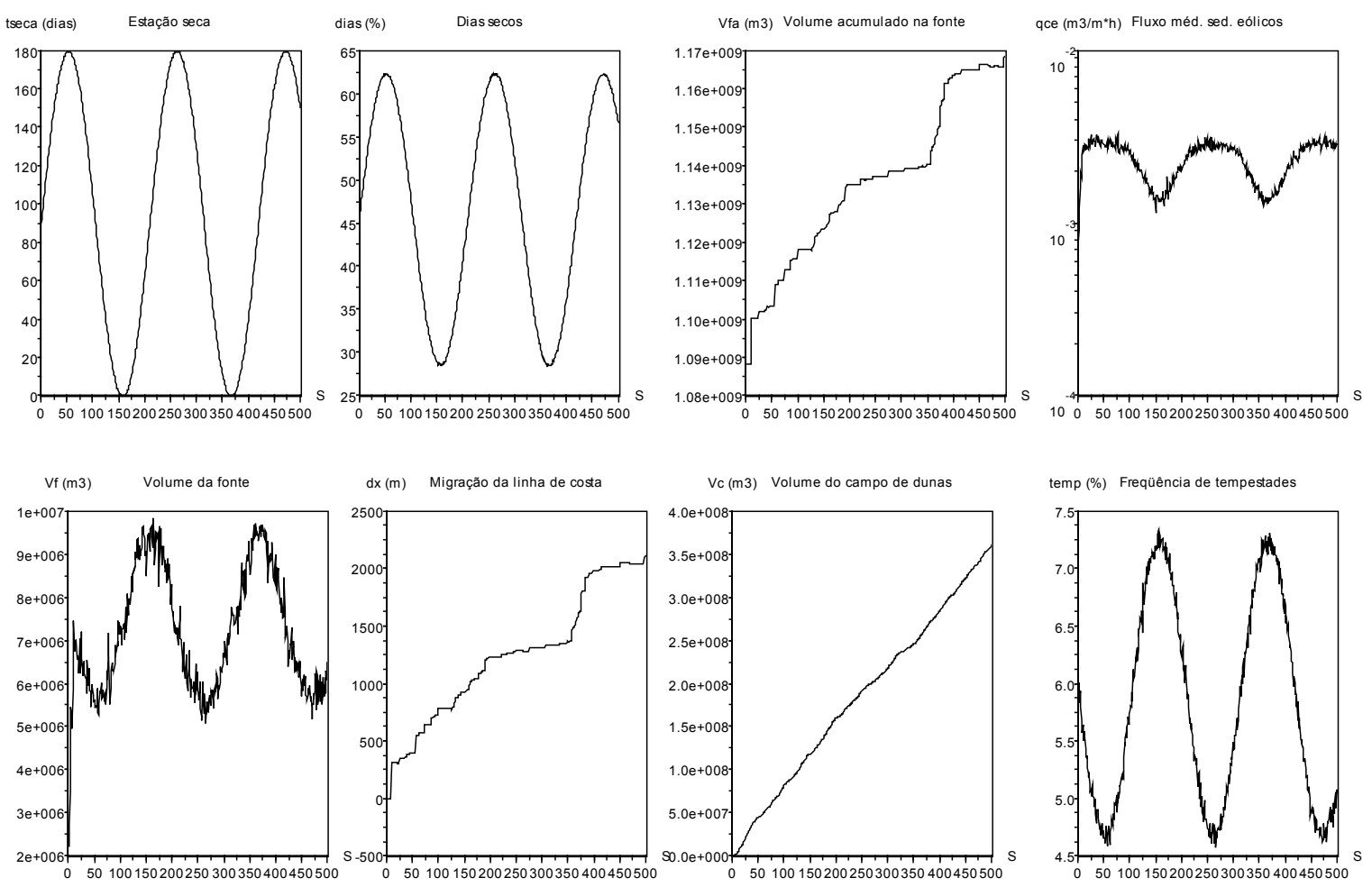

Figura 4.39 - Resultado da simulação de 50000 anos (500 séculos) do modelo de sistema eólico costeiro sob regime de macromaré $(\mathrm{amp}=10 \mathrm{~m})$, qfe $>\mathbf{q f s}$ e aumento da diferença entre as freqüências de chuva das estações seca e úmida. Foram utilizados os seguintes valores para simulação de qfe e qfs: qfemtemp=0,15, qfsmtemp=0,10; dqfetemp=dqfstemp=3, qfemseca $=\mathbf{0 , 0 0 3 5}, \quad$ qfsmsseca $=\mathbf{0 , 0 0 3 0}, \quad$ dqfeseca $=$ dqfsseca $=\mathbf{3}, \quad$ qfemumida $=\mathbf{0 , 0 0 6 5}$, qfsmumida $=\mathbf{0 , 0 0 6 0}$, dqfeumida $=$ dqfsumida $=\mathbf{3}$. Estes resultados correspondem à média de 5 experimentos. Probabilidades de chuva: ctemp1 $=0.8$ e ctemp2 $=0.9 ;$ cseca1 $=0.01$ e cseca2 $=0.02$; cumida1 $=0.7$ e cumida2 $=0.9$. $S=$ séculos. 


\begin{tabular}{|l|l|l|}
\hline Variável & Intervalo de confiança médio & $\begin{array}{l}\text { Desvio padrão do intervalo } \\
\text { de confiança }\end{array}$ \\
\hline temp $(\%)$ & 0,102 & 0,039 \\
\hline Dias secos $(\%)$ & 0,173 & 0,065 \\
\hline qce $\left(\mathrm{m}^{3} / \mathrm{m}^{*} \mathrm{~h}\right)$ & 0,0001981 & 0,0001216 \\
\hline $\mathrm{Vc}\left(\mathrm{m}^{3}\right)$ & 15179314 & 6473161,7 \\
\hline $\mathrm{Vf}\left(\mathrm{m}^{3}\right)$ & 527912,29 & 305147,49 \\
\hline $\mathrm{Vfa}\left(\mathrm{m}^{3}\right)$ & 33812112 & 6190663,8 \\
\hline $\mathrm{dx}(\mathrm{m})$ & 890,750 & 163,109 \\
\hline
\end{tabular}

Tabela 4.27 - Média e desvio padrão dos intervalos de confiança das variáveis de interesse (simulação de 50000 anos, $\mathrm{N}=5$ ), cujos resultados encontram-se na Figura 4.39.

A sazonalidade do regime de ventos foi amplificada através da elevação da velocidade média e dispersão da velocidade do vento durante a estação seca e tempestade e redução destes dois fatores durante a estação úmida (Figura 4.40 e Tabela 4.28). Estas modificações induziram mudanças significativas na migração da linha de costa $(\mathrm{dx})$ e variação do volume de sedimentos eólicos (Vc). A linha de costa apresenta período inicial de transgressão seguido por período caracterizado por fases de regressão sucedida por transgressão alternadas com fases de estabilidade. O volume de sedimentos eólicos apresenta crescimento com taxa variável, sendo que os períodos de maior taxa de crescimento correspondem a períodos de elevação da porcentagem de dias secos e do fluxo médio de sedimentos eólicos. No entanto, assim como nas demais simulações realizadas sob regime de micromaré, a variação da taxa de crescimento de Vc é tênue. A maior modificação ocorre com o padrão de migração da linha de costa, onde os picos de regressão correspondem a fases de baixa porcentagem de dias secos. As fases regressivas/transgressivas e as fases de estabilidade da linha de costa possuem duração semelhante de aproximadamente 10000 anos. O fluxo médio de sedimentos eólicos (qce) demonstra padrão semelhante, porém inverso, o qual é caracterizado por fases de redução sucedidas por elevação alternadas com fases de estabilidade. A duração destas fases também é próxima de 10000 anos. Além disto, há coincidência temporal entre o início e fím dos ciclos de regressão/transgressão e o início e fim dos ciclos redução/elevação do fluxo médio de sedimentos eólicos. Os mínimos de qce apresentam correspondência temporal com mínimos de porcentagem de dias secos enquanto que os máximos dos ciclos de regressão/transgressão encontram-se temporalmente defasados em relação aos mínimos de porcentagem de dias secos. Isto demonstras, que, sob maior sazonalidade do regime de ventos, a ciclicidade climática pode 
induzir ciclos de variação da linha de costa ou do fluxo de sedimentos eólicos. No entanto, não há correspondência da duração destes ciclos, que pode mascarar a associação entre variações climáticas e a dinâmica do sistema eólico costeiro. A menor duração dos ciclos de variação do aporte e migração da linha de costa esta ligada ao volume da área fonte. O período inicial de transgressão da linha de costa provoca o esgotamento de Vfa. Isto propicia estabilidade da linha de costa até que a elevação de Vf se torne significativa para induzir regressões regulares. No entanto, há defasagem entre o início da fase de elvação de Vf e o início da fase de regressões regulares. Isto acontece porque regressões regulares só ocorrem quando Vf opera próximo ao seu valor máximo. Dado que Vf opera próximo ao mínimo durante a fase de estabilidade, sua recuperação para operar em condição próxima ao máximo leva certo tempo para ser atingida. A ocorrência de transgressões e regressões depende da superação de valores limiares extremos. Logo, quando Vf opera distante de seus valores extremos (Vfmax e Vfmin), suas variações não são percebidas pela linha de costa. Por este motivo, a freqüência dos ciclos de regressão/transgressão é maior que a freqüência de variação da estação seca.

A elevação da velocidade média do vento faz com que a saída de sedimentos eólicos da área fonte se torne significativa em relação aos fluxos de entrada e saída por correntes costeiras (qfe e qfs). Devido ao condicionamento da velocidade média do vento às estações seca e úmida e a tempestades, a interferência da variação da duração da estação seca sobre o volume de sedimentos na área fonte torna-se mais intensa. Apesar da grande intensificação da velocidade média do vento, não é possível associar de forma direta ciclos climáticos à variação da linha de costa ou à taxa de crescimento do volume de sedimentos eólicos. Parte das trocas de sedimentos induzidas por variações climáticas são absorvidas pela área fonte sem acarretar variação da linha de costa ou variação significativa do fluxo de sedimentos eólicos. Quanto maior a volume da área fonte, maior sua capacidade em absorver as variações de trocas de sedimentos e portanto, menor a sensibilidade a variáveis primárias do sistema. Este fato torna complicada a associação entre a dinâmica do sistema e variações climáticas. 

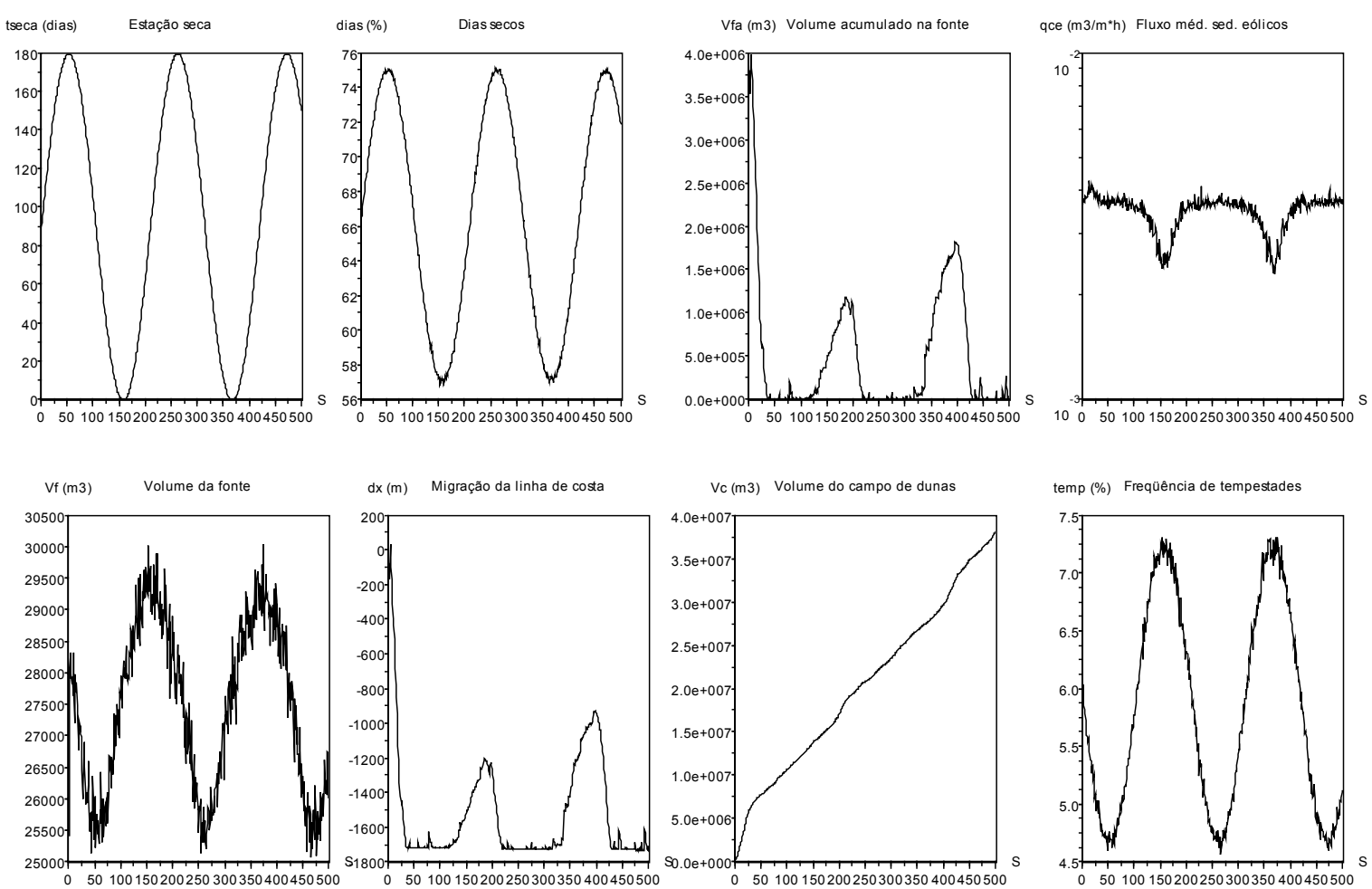

Figura 4.40 - Resultado da simulação de 50000 anos (500 séculos) do modelo de sistema eólico costeiro sob regime de micromaré $(\mathrm{amp}=0,6 \mathrm{~m}$ ), amplificação da diferença da velocidade do vento entre os períodos seco e úmido e qfe $>\mathbf{q f s}$. Foram utilizados os seguintes valores para simulação de qfe e qfs: qfemtemp=0,15, qfsmtemp=0,10; dqfetemp=dqfstemp=3, qfemseca $=\mathbf{0 , 0 0 3 5}, \quad$ qfsmsseca $=\mathbf{0 , 0 0 3 0}, \quad$ dqfeseca $=$ dqfsseca $=\mathbf{3}, \quad$ qfemumida $=\mathbf{0 , 0 0 6 5}$, qfsmumida $=\mathbf{0 , 0 0 6 0}$, dqfeumida $=$ dqfsumida $=\mathbf{3}$. Estes resultados correspondem à média de 5 experimentos. $\mathrm{S}=$ séculos. Velocidades médias e dispersão da velocidade do vento: vmtemp=20 e dvtemp $=0.5$; vmseca $=15$ e dvseca $=0.3$; vmumida $=5$ e dvumida $=0.3$.

\begin{tabular}{|l|l|l|}
\hline Variável & Intervalo de confiança médio & $\begin{array}{l}\text { Desvio padrão do intervalo } \\
\text { de confiança }\end{array}$ \\
\hline temp $(\%)$ & 0,102 & 0,039 \\
\hline Dias secos $(\%)$ & 0,190 & 0,072 \\
\hline $\mathrm{qce}\left(\mathrm{m}^{3} / \mathrm{m}^{*} \mathrm{~h}\right)$ & 0,0001855 & 0,0001088 \\
\hline $\mathrm{Vc}\left(\mathrm{m}^{3}\right)$ & 2243284,3 & 705983,62 \\
\hline $\mathrm{Vf}\left(\mathrm{m}^{3}\right)$ & 593,136 & 211,329 \\
\hline $\mathrm{Vfa}\left(\mathrm{m}^{3}\right)$ & 261386,04 & 323657,6 \\
\hline $\mathrm{dx}(\mathrm{m})$ & 115,023 & 141,591 \\
\hline
\end{tabular}

Tabela 4.28 - Média e desvio padrão dos intervalos de confiança das variáveis de interesse (simulação de 50000 anos, N=5), cujos resultados encontram-se na Figura 4.40. 
O aumento da amplitude de maré muda drasticamente o padrão de variação da linha de costa (Figura 4.41 e Tabela 4.29). Mesmo sob ventos com velocidade mais elevada, a linha de costa apresenta tendência geral regressiva. As regressões são abruptas e separadas por períodos mais longos de pequenas transgressões. O volume de sedimentos eólicos é crescente, com pequenas variações da taxa de crescimento de escala sub-milenar. Em escala milenar, o crescimento é praticamente linear. O fluxo médio de sedimentos eólicos (qce) varia de modo semelhante ao do experimento anterior, ou seja, apresenta variação cíclica caracterizada por fases de fluxo elevado intercaladas com fases de redução e incremento do fluxo de menor duração. $\mathrm{O}$ volume da fonte (Vf) também varia de modo cíclico. Porém, nota-se que o intervalo de tempo em que a área fonte opera com valores mais altos é menor que o intervalo em que opera com valores mais baixos. Isto confere padrão em picos para a variação de Vf. Este padrão é contrário ao observado no experimento realizado sob regime de micromaré, onde o intervalo de tempo em que $\mathrm{a}$ área fonte opera com valores mais altos é maior.

Sob amplitude de maré elevada, a associação entre variação da estação seca e a variação da linha de costa ou do volume de sedimentos éolicos não é nítida como no experimento anterior. Isto reforça a importância do tamanho da área fonte na resposta do sistema eólico costeiro a variações climáticas. Sob regime de micromaré, por exemplo, a elevação da velocidade do vento atua de modo contrário à regressão da linha de costa e portanto, favorece o desenvolvimento de campos de dunas. Já sob regime de macromaré, o efeito da elevação da velocidade do vento sobre migração da linha de costa é pouco significativa. 

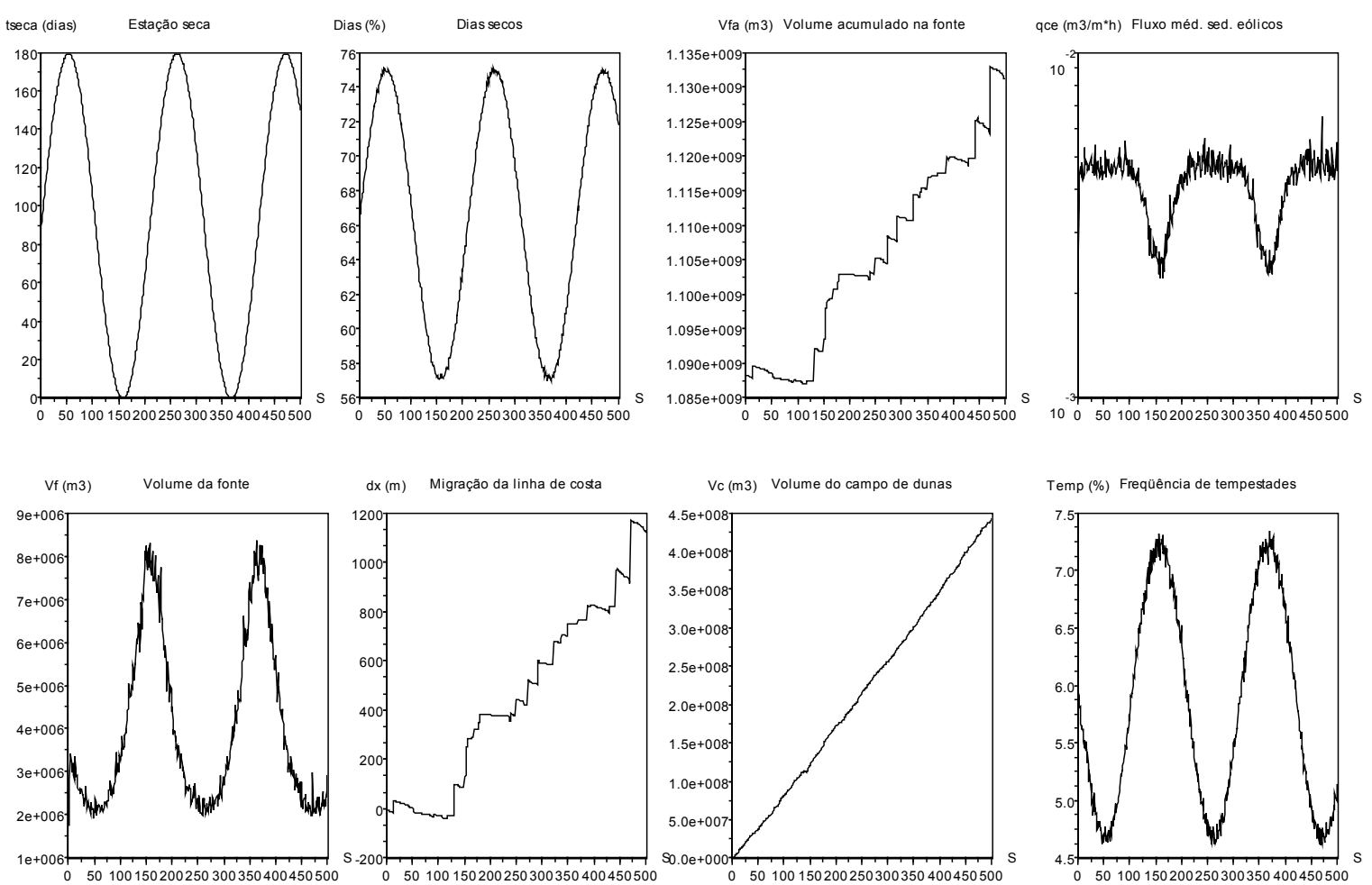

Figura 4.41 - Resultado da simulação de 50000 anos (500 séculos) do modelo de sistema eólico costeiro sob regime de macromaré ( $\mathrm{amp}=10 \mathrm{~m}$ ), amplificação da diferença da velocidade do vento entre os períodos seco e úmido e qfe $>\mathbf{q f s}$. Foram utilizados os seguintes valores para simulação de qfe e qfs: qfemtemp=0,15, qfsmtemp=0,10; dqfetemp=dqfstemp=3, qfemseca $=\mathbf{0 , 0 0 3 5}, \quad$ qfsmsseca $=\mathbf{0 , 0 0 3 0}, \quad$ dqfeseca $=$ dqfsseca $=\mathbf{3}, \quad$ qfemumida $=\mathbf{0 , 0 0 6 5}$, qfsmumida $=\mathbf{0 , 0 0 6 0}$, dqfeumida $=$ dqfsumida $=\mathbf{3}$. Estes resultados correspondem à média de 5 experimentos. $\mathrm{S}=$ séculos. Velocidades médias e dispersão da velocidade do vento: vmtemp=20 e dvtemp $=0.5$; vmseca $=15$ e dvseca $=0.3 ;$ vmumida $=5$ e dvumida $=0.3$.

\begin{tabular}{|l|l|l|}
\hline Variável & Intervalo de confiança médio & $\begin{array}{l}\text { Desvio padrão do intervalo } \\
\text { de confiança }\end{array}$ \\
\hline temp $(\%)$ & 0,105 & 0,038 \\
\hline Dias secos $(\%)$ & 0,195 & 0,068 \\
\hline $\mathrm{qce}\left(\mathrm{m}^{3} / \mathrm{m}^{*} \mathrm{~h}\right)$ & 0,0003981 & 0,0002877 \\
\hline $\mathrm{Vc}\left(\mathrm{m}^{3}\right)$ & 15148147 & 4351957,3 \\
\hline $\mathrm{Vf}\left(\mathrm{m}^{3}\right)$ & 339075,58 & 236271,71 \\
\hline $\mathrm{Vfa}\left(\mathrm{m}^{3}\right)$ & 11804590 & 7521018,6 \\
\hline $\mathrm{dx}(\mathrm{m})$ & 311,091 & 197,692 \\
\hline
\end{tabular}

Tabela 4.29 - Média e desvio padrão dos intervalos de confiança das variáveis de interesse (simulação de 50000 anos, N=5), cujos resultados encontram-se na Figura 4.41. 
A elevação da freqüência de ocorrência de tempestades, sob regime de micromaré, induz aumento significativo do fluxo médio de sedimentos eólicos (qce) e do volume de sedimentos eólicos (Vc). Porém, também há grande incremento da regressão da linha de costa, que atinge distância de migração superior a 20000 m em 50000 anos. A taxa de regressão da linha de costa é variável, sendo que taxas maiores ocorrem durante períodos de maior freqüência de ocorrência de tempestades. Em relação ao padrão de crescimento de Vc, nota-se pequena redução da taxa de crescimento durante fase de menor freqüência de ocorrência de tempestades. Os resultados deste experimento podem ser observados na Figura 4.42 e os intervalos de confiança da algumas quantidades de interesse, na Tabela 4.30.
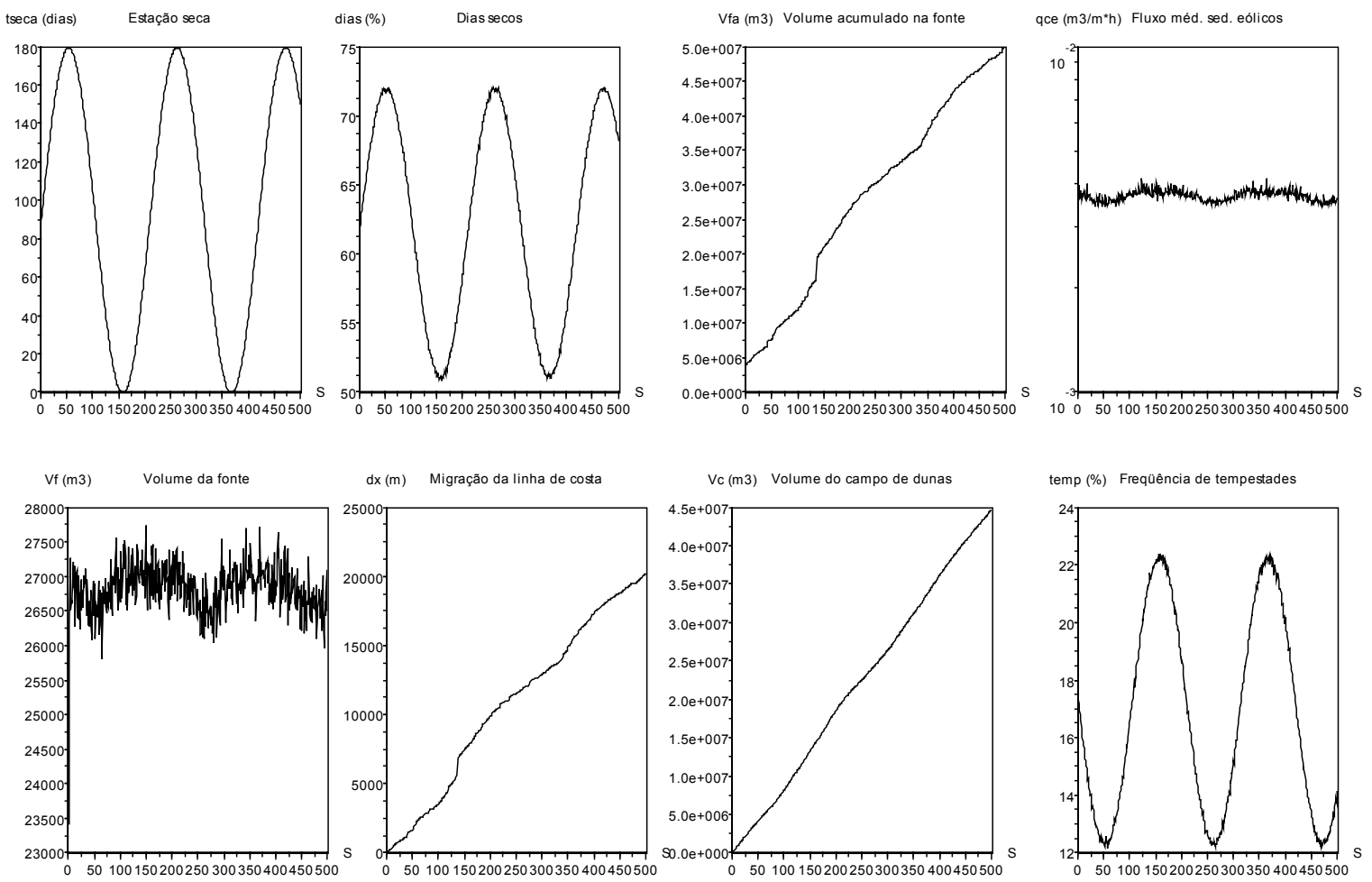

Figura 4.42 - Resultado da simulação de 50000 anos (500 séculos) do modelo de sistema eólico costeiro sob regime de micromaré $(\mathrm{amp}=0,6 \mathrm{~m})$, amplificação da diferença da probabilidade de ocorrência de tempestade entre os períodos seco e úmido e qfe>qfs. Foram utilizados os seguintes valores para simulação de qfe e qfs: qfemtemp=0,15, qfsmtemp=0,10; dqfetemp $=$ dqfstemp $=\mathbf{3}, \quad$ qfemseca $=\mathbf{0 , 0 0 3 5}, \quad$ qfsmsseca $=\mathbf{0 , 0 0 3 0}, \quad$ dqfeseca $=$ dqfsseca $=\mathbf{3}$, qfemumida $=\mathbf{0 , 0 0 6 5}, \quad$ qfsmumida $=\mathbf{0 , 0 0 6 0}, \quad$ dqfeumida $=$ dqfsumida $=\mathbf{3}$. Estes resultados correspondem à média de 5 experimentos. $S=$ séculos. Probabilidades de ocorrência de tempestade: tempseca $1=0.02$ e tempseca $2=0.05$; tempumida $1=0.2$ e tempumida $2=0.3$. 


\begin{tabular}{|l|l|l|}
\hline Variável & Intervalo de confiança médio & $\begin{array}{l}\text { Desvio padrão do intervalo } \\
\text { de confiança }\end{array}$ \\
\hline temp $(\%)$ & 0,174 & 0,063 \\
\hline Dias secos $(\%)$ & 0,193 & 0,075 \\
\hline qce $\left(\mathrm{m}^{3} / \mathrm{m}^{*} \mathrm{~h}\right)$ & 0,0001298 & 0,0000654 \\
\hline $\mathrm{Vc}\left(\mathrm{m}^{3}\right)$ & 683617,34 & 325206,68 \\
\hline $\mathrm{Vf}\left(\mathrm{m}^{3}\right)$ & 498,644 & 201,822 \\
\hline $\mathrm{Vfa}\left(\mathrm{m}^{3}\right)$ & 2843575,1 & 865679,08 \\
\hline $\mathrm{dx}(\mathrm{m})$ & 1246,901 & 379,775 \\
\hline
\end{tabular}

Tabela 4.30 - Média e desvio padrão dos intervalos de confiança das variáveis de interesse (simulação de 50000 anos, $\mathrm{N}=5$ ), cujos resultados encontram-se na Figura 4.42.

Sob regime de macromaré, a elevação da freqüência de ocorrência de tempestades provoca modificações similares às observadas no experimento realizado sob regime de micromaré. Não há modificação significativa do padrão de crescimento de Vc e da migração da linha de costa. A linha de costa é regressiva, com regressões de curto período separadas por fases de estabilidade e o volume de sedimentos eólicos apresenta crescimento quase linear, com pequenas variações da taxa de crescimento. A principal modificação diz respeito aos valores absolutos destas duas variáveis. Tanto a distância de regressão quanto o volume de sedimentos eólicos sofrem grandes incrementos (Figura 4.43 e Tabela 4.31).

Nos experimentos realizados, a elevação da freqüência de ocorrência de tempestades não induziu mudança nos padrões de variação da linha de costa e de crescimento do volume de sedimentos eólicos. A elevação da freqüência de tempestades provoca apenas o incremento da distância de migração e do volume de sedimentos eólicos. Isto ocorre, pois as tempestades, tal como foram definidas, propiciam tanto a elevação da velocidade do vento quanto dos fluxos de sedimentos costeiros. A elevação da velocidade do vento aumenta o fluxo de sedimentos eólicos. No entanto, a freqüência de chuvas é maior durante tempestades. Logo, as tempestades elevam dois fatores que atuam de modo oposto no transporte de sedimentos eólicos: freqüência de chuvas e velocidade do vento. Porém, a relação destes dois fatores com o fluxo de sedimentos eólicos não é equivalente. O fluxo de sedimentos eólicos é uma função de potência da velocidade do vento, de modo que pequenos incrementos da velocidade do vento podem dar origem a grandes incrementos do fluxo. Já a chuva exerce o papel de bloqueio do fluxo de sedimentos eólicos. Desta forma, mesmo que a freqüência de chuvas seja alta, o efeito do incremento do fluxo por ventos de velocidade elevada pode superar a redução pelo bloqueio exercido pela chuva. O 
caráter irregular das tempestades as torna pouco propícias para a geração de campos de dunas, mesmo que elas induzam elevação do fluxo de sedimentos eólicos. Os sedimentos eólicos transportados durante tempestades podem ser importantes para a manutenção de campos de dunas, pois podem constituir estoque interno de sedimentos para serem retrabalhados em épocas de baixo aporte eólico primário (área fonte - campo de dunas). A acumulação de sedimentos eólicos a barlavento dos campos de dunas podem servir de fonte secundária para a manutenção de dunas livres.
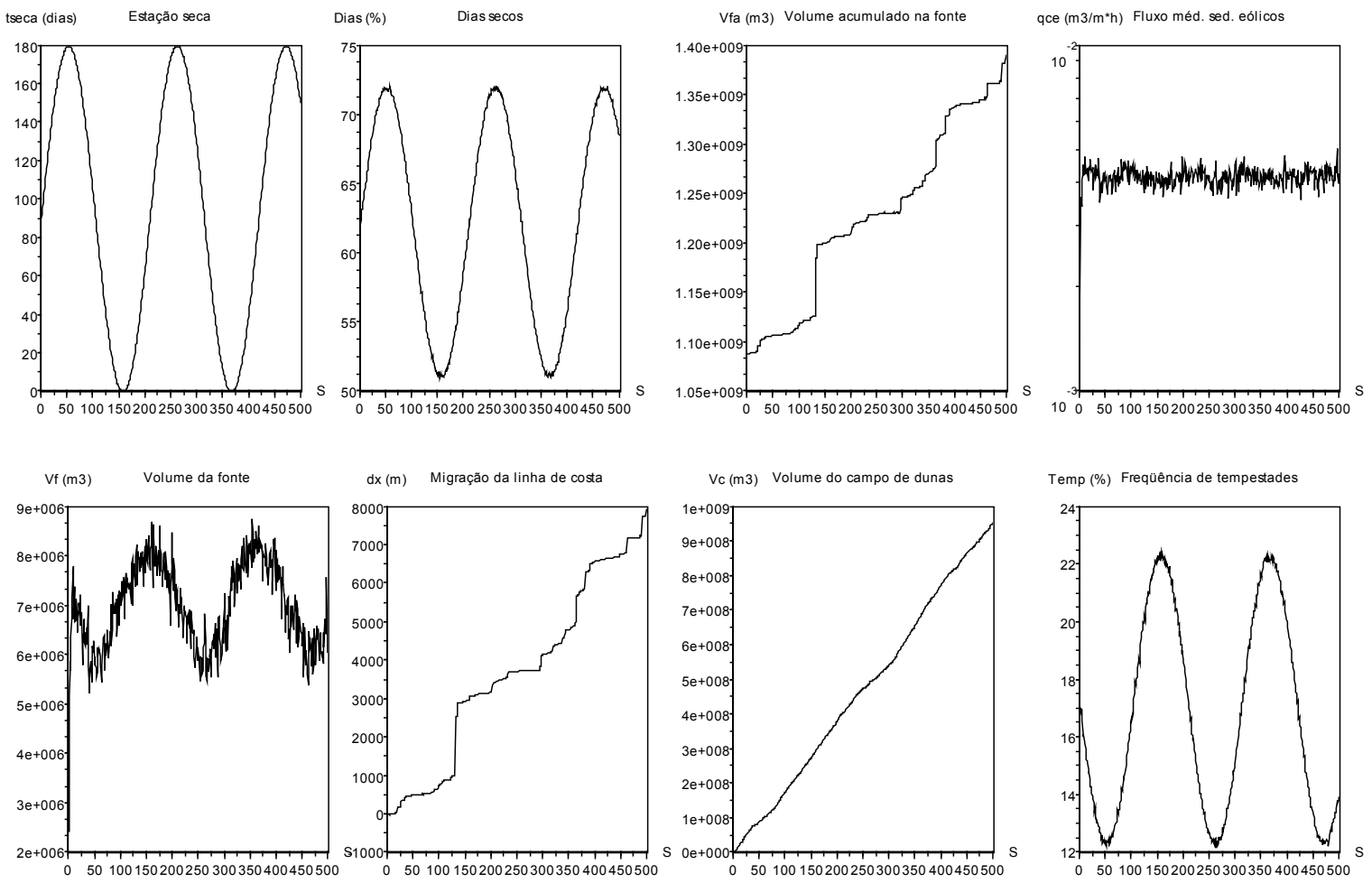

Figura 4.43 - Resultado da simulação de 50000 anos (500 séculos) do modelo de sistema eólico costeiro sob regime de macromaré $(a m p=10 \mathrm{~m})$, amplificação da diferença da probabilidade de ocorrência de tempestade entre os períodos seco e úmido e qfe $>$ qfs. Foram utilizados os seguintes valores para simulação de qfe e qfs: qfemtemp=0,15, qfsmtemp=0,10; dqfetemp $=$ dqfstemp $=\mathbf{3}, \quad$ qfemseca $=\mathbf{0 , 0 0 3 5}, \quad$ qfsmsseca $=\mathbf{0 , 0 0 3 0}, \quad$ dqfeseca $=$ dqfsseca $=\mathbf{3}$, qfemumida $=\mathbf{0 , 0 0 6 5}, \quad$ qfsmumida $=\mathbf{0 , 0 0 6 0}, \quad$ dqfeumida $=$ dqfsumida $=\mathbf{3}$. Estes resultados correspondem à média de 5 experimentos. $S=$ séculos. Probabilidades de ocorrência de tempestade: tempseca $1=0.02$ e tempseca $2=0.05$; tempumida $1=0.2$ e tempumida $2=0.3$. 


\begin{tabular}{|l|l|l|}
\hline Variável & Intervalo de confiança médio & $\begin{array}{l}\text { Desvio padrão do intervalo } \\
\text { de confiança }\end{array}$ \\
\hline temp $(\%)$ & 0,169 & 0,064 \\
\hline Dias secos $(\%)$ & 0,192 & 0,073 \\
\hline qce $\left(\mathrm{m}^{3} / \mathrm{m}^{*} \mathrm{~h}\right)$ & 0,0003808 & 0,0001612 \\
\hline $\mathrm{Vc}\left(\mathrm{m}^{3}\right)$ & 18295121 & 6727747,8 \\
\hline $\mathrm{Vf}\left(\mathrm{m}^{3}\right)$ & 599572,72 & 254071,85 \\
\hline $\mathrm{Vfa}\left(\mathrm{m}^{3}\right)$ & 84682308 & 39476016 \\
\hline $\mathrm{dx}(\mathrm{m})$ & 2229,487 & 1038,700 \\
\hline
\end{tabular}

Tabela 4.31 - Média e desvio padrão dos intervalos de confiança das variáveis de interesse (simulação de 50000 anos, $\mathrm{N}=5$ ), cujos resultados encontram-se na Figura 4.43.

\subsection{Considerações sobre o desenvolvimento de campos de dunas costeiros}

O desenvolvimento de campos de dunas pressupõe aporte eólico regular e taxas de acumulação de sedimentos elevadas. Isto deve ocorrer para inibir a atividade de fatores estabilizadores, tais como vegetação, pedogênese e cimentação precoce, que podem impedir a formação de dunas livres. Taxas de acumulação reduzidas podem dar origem a dunas frontais. A taxa de acumulação de sedimentos eólicos não depende apenas do fluxo de sedimentos transportados por ventos de onshore, uma vez que deve ser considerada também a área de acumulação destes sedimentos. Deste modo, a taxa de acumulação não depende apenas do volume de sedimentos eólicos tranportados, mas também da área para deposição destes sedimentos (espaço). Logo, a taxa de acumulação pode ser expressa pela razão volume de sedimentos/área de deposição. No sistema eólico costeiro, a área de deposição corresponde à zona adjacente à linha de costa, acima do nível da maré alta. Portanto, a área de deposição é função de variações da linha de costa. Assim, a taxa de acumulação de sedimentos em sistema eólico costeiro varia tanto em termos do volume de sedimentos transportados quanto em termos da migração da linha de costa. O volume de sedimentos eólicos depende do fluxo de sedimentos eólicos, que por sua vez está diretamente relacionado a fatores climáticos, tais como velocidade do vento e ocorrência de chuvas, e a fatores ligados à dinâmica sedimentar costeira, como por exemplo granulação dos sedimentos e balanço sedimentar costeiro. A migração da linha de costa depende do balanço sedimentar costeiro e amplitude de maré, porém, pode receber influência indireta do clima. Desta forma, o desenvolvimento de campos de dunas costeiros ou dunas 
frontais é regido pela interação entre o fluxo de sedimentos eólicos e a migração da linha de costa.

A regressão da linha de costa provoca aumento da área de deposição e permite o crescimento do campo de dunas também no sentido offshore (costa afora). Apesar de ser necessária a existência de área de deposição, a regressão acelerada da linha de costa desfavorece o desenvolvimento de campos de dunas, pois ocasiona diluição do aporte eólico costeiro e redução da taxa de acumulação. A transgressão da linha de costa reduz a área de deposição de sedimentos, o que seria benéfico para o desenvolvimento de campos de dunas. No entanto, também provoca erosão dos sedimentos eólicos previamente depositados, o que prejudicaria o crescimento do campo de dunas. Apesar da erosão costeira retirar sedimentos do campo de dunas, esta também pode retirar sedimentos do substrato do campo de dunas, os quais podem abastecer a área fonte e contribuir para a manutenção do suprimento de sedimentos na área fonte. Este efeito seria benéfico à manutenção de aporte eólico regular e portanto, à manutenção de campos de dunas. A estabilidade da linha de costa torna o desenvolvimento de campos de dunas totalmente dependente do fluxo de sedimentos eólicos. Assim, constitui situação favorável, caso haja condições para manutenção de fluxo eólico regular. A linha de costa pode alternar períodos de regressão, estabilidade e transgressão e o fluxo de sedimentos eólicos pode variar em diversas escalas de tempo (desde diária a milenar). Assim, o potencial de formação de campos de dunas será determinado pelo comportamento destes dois fatores ao longo do tempo.

O limite externo da área de deposição é a linha de costa enquanto que o limite interno pode ser de natureza variável, como por exemplo, corpos lagunares, elevações do relevo e florestas. O limite interno corresponde a qualquer obstáculo ao avanço das dunas. A taxa de acumulação de sedimentos eólicos pode ser representada em termos do volume de sedimentos eólicos transportados da área fonte para a área de deposição e em termos da variação da área de deposição devido à migração da linha de costa (Figura 4.44). 


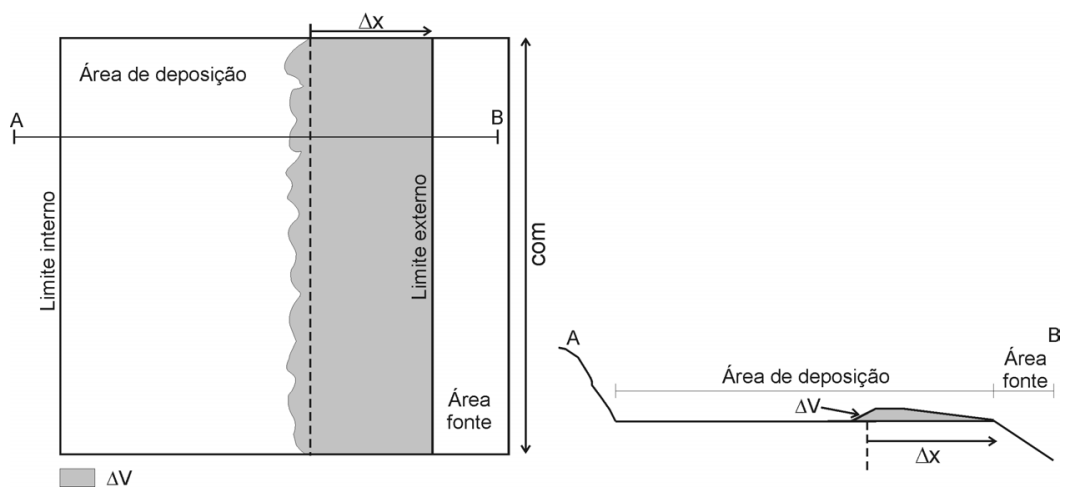

Figura 4.44 - Volume de sedimentos transportados da área fonte para a área de deposição $(\Delta \mathrm{V}) \mathrm{e}$ variação da área de deposição $(\Delta \mathrm{A})$ pela regressão da linha de costa $(\Delta \mathrm{x})$ durante certo intervalo de tempo $(\Delta \mathrm{t})$. A variação da área de deposição corresponde a $\Delta \mathrm{A}=\Delta \mathrm{x} *$ com, sendo que "com" é comprimento da costa.

A diluição da taxa de acumulação de sedimentos eólicos pode ser calculada pela razão entre a o volume de sedimentos transportados $(\Delta \mathrm{V})$ e o incremento de área devido à regressão $(\Delta \mathrm{A})$. Quanto maior a diluição, menor o potencial de formação ou manutenção de campo de dunas livres.

Portanto, a dinâmica de desenvolvimento de campos de dunas costeiros resultaria da interação entre dois fatores principais: crescimento do volume de sedimentos eólicos, que é condicionado pelo fluxo de sedimentos a partir da área fonte, e migração da linha de costa. Estes dois fatores também controlam as características dos elementos que formam o campo de dunas (dunas, depressões interdunas, planícies interdunas e áreas de deflação) e portanto, estarão relacionados à faciologia dos depósitos eólicos gerados pela atividade de campos de dunas costeiros.

Os experimentos de simulação demonstraram a existência de diversos padrões de variação da linha de costa e do volume de sedimentos eólicos. Os padrões de migração da linha de costa são mais diversificados do que os padrões de variação do volume de sedimentos eólicos. $\mathrm{Na}$ maioria dos experimentos, as tendências de crescimento de Vc foram lineares. Alterações a este padrão dizem respeito apenas a variações tênues da taxa de crescimento. Já a linha de costa é mais sensível à dinâmica do sistema e exibiu padrões de variação crescentes, decrescentes, em escada e com variações cíclicas. A análise conjunta das curvas de variação destes dois fatores permite estimar o efeito da diluição do aporte sedimentar eólico e a proposição de modelos conceituais de evolução de campos de dunas e dunas frontais. A seguir são apresentados alguns 
padrões de variação da linha de costa e do volume de sedimentos eólicos, em escala milenar, e seus respectivos modelos conceituais de evolução de campos de dunas ou dunas frontais (Caso 1 a Caso 6).

O primeiro caso (Caso 1) é caracterizado por estabilidade da linha de costa e crescimento linear do volume de sedimentos eólicos (Figura 4.45). Neste caso, campos de dunas serão formados apenas se a taxa de crescimento de $\mathrm{Vc}$ for suficiente para superar a eficácia dos agentes estabilizadores. O desenvolvimento de campos de dunas será linear e o seu volume será proporcional à sua idade. Sob estas circunstâncias, a idade do campo de dunas poderia ser calculada a partir de estimativas da taxa de crescimento (volumétrico) em escala milenar.

Taxa de crescimento constante de Vc implica redução da taxa de acumulação de sedimentos e da taxa de avanço do campos de dunas ao longo do tempo, pois a aumento do tamanho requer cada vez mais sedimentos para manter o crescimento do campo de dunas. Assim, quanto maior o tamanho, mais sedimentos são necessários para a manutenção do campo de dunas. Desta forma, taxa de crescimento constante implicaria estabilização do campo de dunas em certo momento. Para cada taxa de crescimento, haveria certo tamanho limite de campo de dunas e a estabilização deste seria parte natural de sua dinâmica. O período de existência do campo de dunas também seria limitado. A morfologia e tamanho das dunas também sofreriam modificações com o tempo. A fase inicial de desenvolvimento do campos de dunas seria caracterizada pela nucleação e crescimento das dunas, com redução gradativa da distância entre dunas. O aumento de tamanho do campo de dunas dificultaria a manutenção e crescimento de dunas livres, de modo que deveria haver redução do tamanho das dunas livres, aumento das interdunas e formação de dunas vegetadas e áreas de deflação. Após alcançado seu tamanho limite, haveria a estabilização gradativa do campo de dunas. 

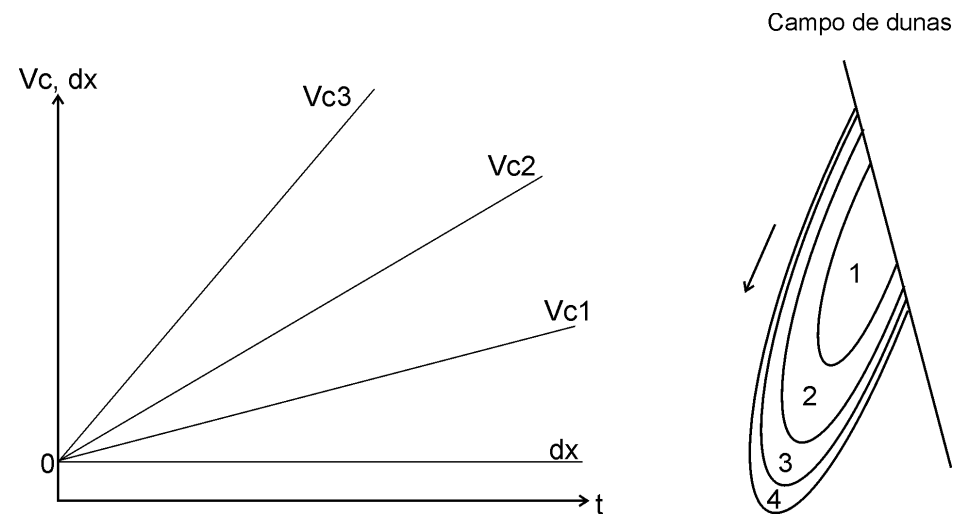

Figura 4.45 - Linha de costa estável (dx) e volume de sedimentos eólicos com crescimento linear (Vc) ao longo do tempo. Vc1, Vc2 e Vc3 representam taxas de crescimento distintas. A origem do gráfico $(\mathrm{dx}=0)$ indica a posição inicial da linha e costa. Os algarismos 1, 2, 3 e 4 representam o tamanho do campo de dunas (para determinada taxa de crescimento de $\mathrm{Vc}$ ) em períodos de tempo sucessivos. Há diminuição da taxa de crescimento em área e de avanço com o tempo. Vc e $\mathrm{dx}$ são representados pelo eixo y (vertical). O eixo x (horizontal) representa o tempo (t).

O segundo caso (Caso 2) é representado por linha de costa estável e crescimento do volume de sedimentos eólicos com taxa crescente (exponencial). Taxa de incremento de Vc crescente pode viabilizar a manutenção de dunas livres, mesmo que haja aumento do tamanho do campo de dunas. Assim, não haveria redução relativa do aporte com o tempo. Taxa de aumento da área do campo de dunas inferior à taxa de aumento de volume faria com que o crescimento do campo de dunas não comprometesse a manutenção de dunas livres. Estas condições seriam menos favoráveis ao desenvolvimento de fácies deflacionares ou dunas vegetadas. Logo, os depósitos eólicos formados teriam prevalência de fácies de dunas livres. A taxa de crescimento em área e a velocidade de avanço não reduziriam com o tempo (Figura 4.46).
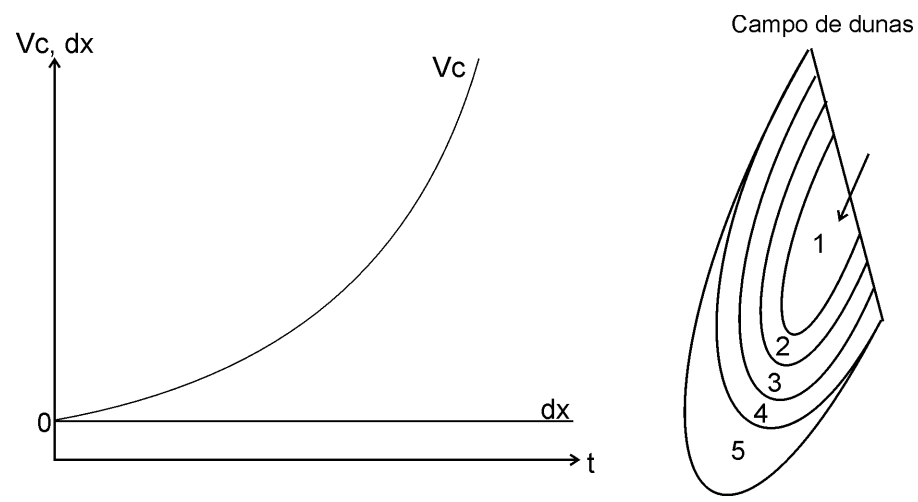

Figura 4.46 - Linha de costa estável (dx) e volume de sedimentos eólicos (Vc) com crescimento exponencial (taxa de crescimento crescente). O aumento da taxa de crescimento de Vc pode manter a velocidade de avanço e a expansão em área do campo de dunas. 
O terceiro caso (Caso 3) é definido por crescimento linear do volume de sedimentos eólicos e linha de costa caracterizada por regressões de curta duração separadas por intervalos mais longos de estabilidade (Figura 4.47). Durante as fases de linha de costa estável, o desenvolvimento do campo de dunas seria análogo ao que ocorre no caso 1 (linha de costa estável e crescimento linear de $\mathrm{Vc}$ ), ou seja, o crescimento de $\mathrm{Vc}$, acompanhado do aumento da área do campo de dunas, dificultaria a manutenção de dunas livres previamente formadas e poderia favorecer a formação de dunas vegetadas e deflação. A regressão abrupta da linha de costa provocaria isolamento do campo de dunas em relação à área fonte. Caso este campo de dunas estivesse em estágio de estabilização devido ao seu tamanho elevado, a regressão da linha de costa intensificaria os processos de estabilização. Caso tivesse tamanho que permitisse a manutenção de dunas livres, a regressão da linha de costa poderia dar início à estabilização e deflação destas dunas. Após a fase de regressão, com a estabilização da linha de costa, haveria retomada do aporte eólico e novo campo de dunas poderia ser formado a barlavento do anterior. Este novo campo de dunas (ou nova fase) poderia migrar sobre o anterior, que se encontria em processo de estabilização. A regressão da linha de costa pode proporcionar o crescimento do campo de dunas no sentido offshore.

A recorrência das fases de regressão e estabilização da linha de costa provocaria a sucessão entre condições favoráveis à formação de dunas livres e condições favoráveis à formação de dunas vegetadas e deflação. Os períodos de maior desenvolvimento de zonas deflacionares e de dunas vegetadas representariam fases de regressão da linha de costa e distanciamento do campo de dunas da sua área fonte. A intercalação entre fases de regressão e de estabilidade da linha de costa pode dar origem a gerações de campos de dunas. Gerações mais novas avançariam sobre as mais antigas em processo de estabilização. A regressão da linha de costa pode ocorrer com nível relativo do mar (NRM) estável ou em queda (regressão forçada). A queda do NRM favorece a erosão do campo de dunas por canais fluviais. Neste caso, a regressão com queda do NRM criaria condições favoráveis à formação de dunas vegetadas, deflação e erosão fluvial do campo de dunas. Já a regressão com NRM estável criaria apenas condições favoráveis à formação de dunas vegetadas e deflação. 

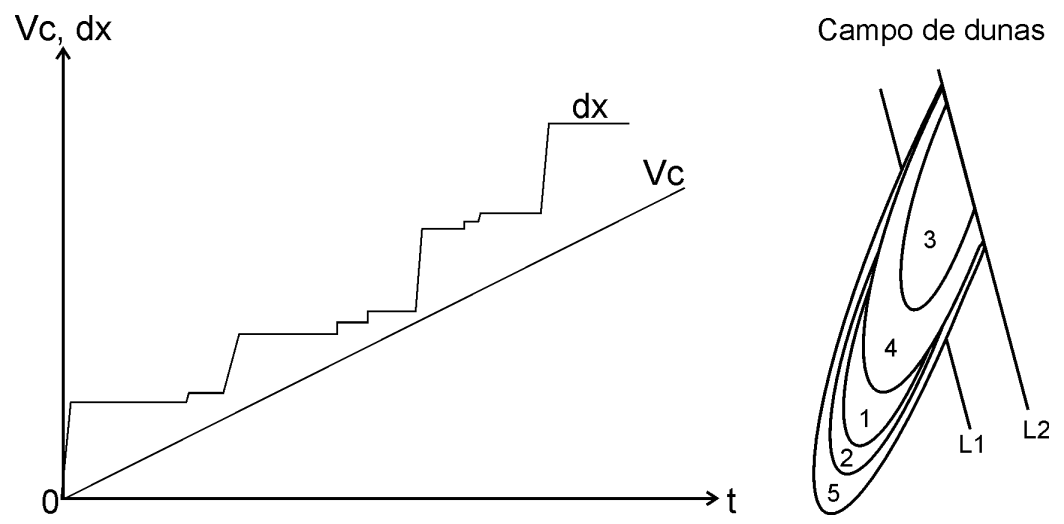

Figura 4.47 - Linha de costa (dx) com regressão em "escada" e crescimento linear do volume de sedimentos eólicos $(\mathrm{Vc})$. As fases de regressão são separadas por períodos de estabilidade. $\mathrm{O}$ crescimento em área e avanço do campo de dunas seguiria padrão em pulsos, caracterizado por crescimento e avanço acelerado durante períodos de linha de costa estável e crescimento e avanço reduzido ou nulo em períodos de linha de costa regressiva.

O próximo caso (Caso 4) é caracterizado por linha de costa (dx) transgressiva e crescimento linear do volume de sedimentos eólicos $(\mathrm{Vc})$. A transgressão da linha de costa é indicada pela tendência decrescente de $\mathrm{dx}$ (Figura 4.48). A transgressão reduz a área de deposição de sedimentos é́licos e provoca erosão do campo de dunas. Desta forma, o campo de dunas avançaria sobre a zona costeira e seria erodido a retaguarda, o que contribuiria para a contenção do crescimento em área do campo de dunas. A contenção do crescimento em área do campo de dunas pode favorecer a manutenção de dunas livres por mais tempo. A formação de dunas vegetadas e zonas de deflação ocorreria somente se o crescimento em área superasse a redução da área pela erosão costeira. Logo, o tempo de duração das condições propícias à manutenção de dunas livres dependeria do balanço entre a erosão costeira e o avanço do campo de dunas. Caso houvesse certo equilíbrio entre estes dois fatores, o campo de dunas migraria com tamanho pouco variável. Se a taxa de transgressão fosse superior à taxa de avanço, haveria redução da área do campo de dunas. Caso contrário, haveria crescimento da área. Os dois primeiros casos são favoráveis à manutenção de dunas livres enquanto que o segundo pode favorecer o desenvolvimento de dunas vegetadas e zonas de deflação.

A transgressão pode ocorrer com nível relativo do mar (NRM) estável ou ascendente. Estes dois modos de transgressão apresentariam efeito diverso sobre a preservação e faciologia dos depósitos eólicos. Sob NRM estavél, só haveria transgressão mediante erosão completa da retaguarda do campo de dunas e de parte do seu substrato. Isto não seria favorável à preservação 
dos depósitos da retaguarda do campo de dunas. Sob NRM em elevação, a erosão do campo de dunas pode ser parcial, de modo que parte dos sedimentos eólicos da retaguarda do campo de dunas seriam submersos e preservados. Além disto, não existiria erosão do substrato do campo de dunas (Figura 4.49).

A elevação do NRM também poderia auxiliar na preservação dos depósitos eólicos mais internos, através da elevação do nível freático. Esta elevação poderia ainda gerar corpos lagunares a sotavento do campo de dunas, os quais restringiriam seu avanço. Nestas condições, haveria confinamento do campo de dunas entre o mar e a laguna, o que seria favorável para a manutenção de dunas livres e acumulação vertical de sedimentos eólicos. Assim, NRM em ascensão seria mais propício à acumulação de fácies de dunas livres enquanto que sob NRM estável poderia haver desenvolvimento de fácies de dunas vegetadas e deflação, se a taxa de transgressão não for capaz de conter a expansão da área do campo de dunas. Logo, a sucessão de fácies formada sob linha de costa transgressiva e NRM estável poderia ser semelhante à formada sob linha de costa estável (Caso 1) e diferiria da sucessão formada sob linha de costa transgressiva e NRM ascendente. Os depósitos da retaguarda do campo de dunas, formados sob linha de costa transgressiva e NRM ascendente, apresentariam grande proporção de fácies de dunas livres e poderiam ser recobertos por depósitos marinhos costeiros. Os depósitos eólicos seriam separados dos marinhos por superfície de erosão marinha. Já os depósitos eólicos situados a onshore poderiam ser recobertos por depósitos lagunares.

A proveniência dos sedimentos eólicos de campos de dunas formados sob linha de costa transgressiva e NRM ascendente ou estável também seria distinta. Em ambos os casos haverá fornecimento de sedimentos do campo de dunas a partir de fonte local. Sob NRM estável, a erosão costeira abastece a área fonte com sedimentos derivados do campo de dunas e do seu substrato enquanto que sob NRM ascendente, apenas sedimentos do campo de dunas contribuem para o abastecimento da área fonte. Deste modo, sob linha de costa transgressiva, o sistema eólico desenvolve policiclismo sedimentar, pois o campo de duna ativo torna-se fonte local de sedimentos para a zona intermaré, que serão retornados ao campo de dunas. Este tipo de policiclismo também pode ser desenvolvido em campos de dunas de costa regressiva, caso existam elementos que proporcionem o transporte de sedimentos do campo de dunas para a área fonte. Tais elementos podem ser representados por canais de maré ou rios. Apesar deste tipo de policiclismo ocorrer também em costa regressiva, ele deve ser mais efetivo em costa 
transgressiva. O policiclismo contribui para o aumento da maturidade dos sedimentos eólicos. Isto pode permitir a diferenciação de sedimentos eólicos acumulados em campos de dunas de costa transgressiva ou regressiva dos campos de dunas de linha de costa estável.
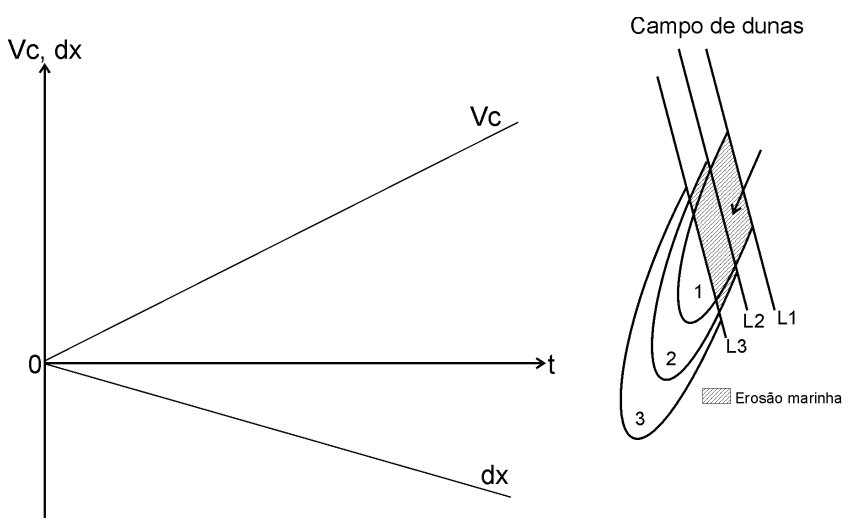

Figura 4.48 - Linha de costa (dx) transgressiva e crescimento linear do volume de sedimentos eólicos. A trangressão também é linear e é indicada pela tendência decrescente de dx. A transgressão erode a retaguarda do campo de dunas e atua contra seu crescimento em área.
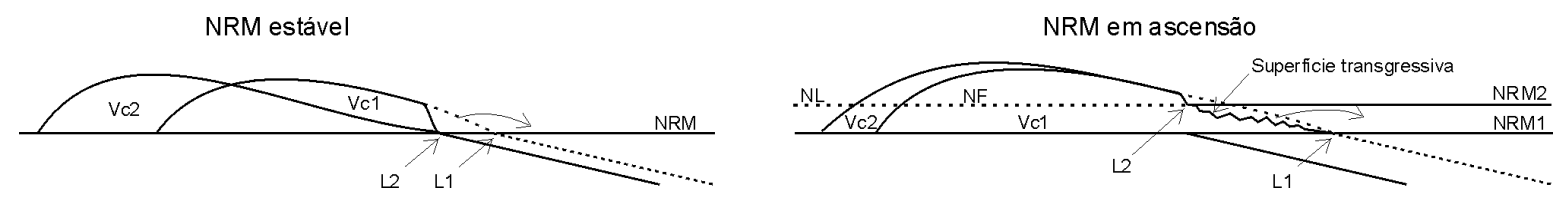

Figura 4.49 - Transgressão da linha de costa sob NRM estável ou em ascensão. Sob NRM estável há erosão completa dos depósitos da retaguarda do campo de dunas enquanto que sob NRM ascendente há erosão apenas parcial e submersão de parte dos depósitos eólicos situados a retaguarda.

No próximo caso (Caso 5), a linha de costa é transgressiva e posteriormente estável enquanto que o volume de sedimentos eólicos apresenta crescimento linear (Figura 4.50). Este caso é semelhante à sucessão entre os casos 4 (linha de costa transgressiva) e 1 (linha de costa estável. Nesta circunstâncias, haveria fase inicial de crescimento acompanhado de erosão da retaguarda do campo de dunas sucedida por fase de crescimento mais lento. A primeira fase seria mais propícia à manutenção de dunas livres enquanto que a permanência na segunda, favorável à formação de dunas vegetadas e deflação. Este exemplo ilustra o modo como a dinâmica de migração da linha de costa pode alterar a dinâmica do sistema eólico e a morfologia das dunas. Assim, mudanças na tendência de variação da linha de costa poderiam gerar dinâmica complexa no sistema eólico. 

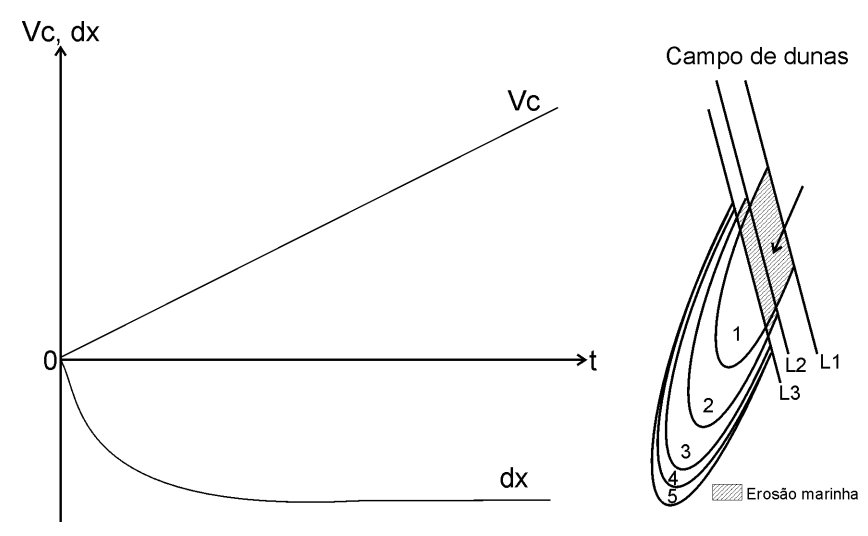

Figura 4.50 - Transgressão da linha de costa seguida por estabilização e crescimento linear do volume de sedimentos eólicos. A transgressão da linha de costa seguida por estabilização provoca variações da taxa de crescimento do campo de dunas. Assim, haveria fase inicial de avanço com crescimento em área pouco acelerado, devido à erosão costeira, seguida por fase de crescimento acelerado (linha de costa estável) sucedida por redução da taxa de crescimento provocada pela elevação da área.

A regularidade do aporte eólico e crescimento do volume de sedimentos eólicos com taxa constante pode transmitir a idéia de que os sistemas eólicos costeiros apresentam dinâmica simples. No entanto, a alteração do padrão de variação da linha de costa pode induzir mudanças na dinâmica do sistema eólico. Por ser sensível tanto a variações no balanço sedimentar costeiro quanto a variações do NRM, a linha de costa pode apresentar grandes mudanças no padrão de migração e gerar sistema eólico com dinâmica complexa. Na Figura 4.51 estão representados campo de dunas com crescimento volumétrico linear e linha de costa com padrão de migração variável (Caso 6). Este padrão de migração ocorreu em experimento de simulação, sendo caracterizado por fase inicial de transgressão, seguida por ciclos regressivos-transgressivos de amplitude variável separados por fases de estabilização. Apesar de complexa, não há motivos para rejeitar a existência desta tendência de variação da linha de costa. A fase inicial transgressiva, seguida de estabilização, daria origem a campo de dunas com padrão de crescimento similar ao descrito no Caso 5. Assim, haveria fase inicial de migração do campo de dunas, com crescimento em área reduzido pela erosão a retaguarda. Nesta fase, a retroalimentação da área fonte por sedimentos derivados do campo de dunas e do seu substrato constituiria traço característico da dinâmica do sistema eólico. As fases de linha de costa estável proporcionariam maior taxa de crescimento em área do campo de dunas. Este crescimento poderia provocar mudanças na morfologia dunar. Crescimento em área acelerado, com taxa 
constante de incremento de volume, seria favorável ao desenvolvimento de dunas vegetadas e deflação. Os ciclos regressivos-transgressivos intensificariam as condições de estabilização e deflação das dunas e posteriormente favoreceriam a formação de dunas livres pela redução da área do campo de dunas e abastecimento da área fonte por sedimentos derivados da erosão costeira. Além disto, as transgressões dariam origem a superfícies de erosão marinha e poderiam provocar também o isolamento de parcela do campo de dunas pela instalação de corpos de água lagunares. A sucessão temporal entre estas fases pode dar origem a depósito de faciologia bastante variável e de estratigrafia marcada por superfícies de deflação, erosão marinha e erosão fluvial por queda do NRM.

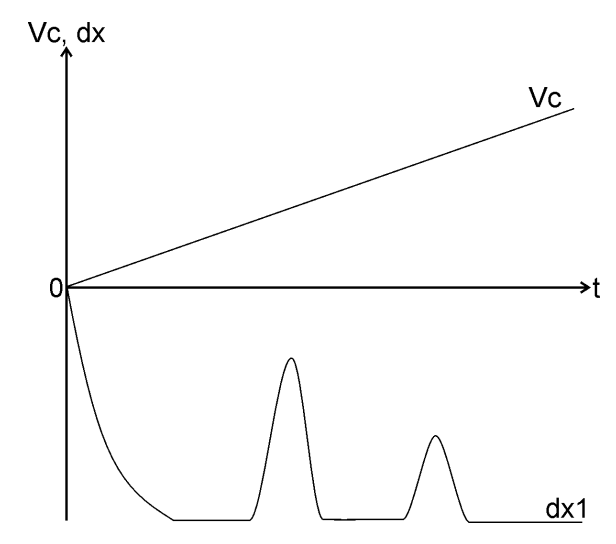

Figura 4.51 - Crescimento de Vc, com taxa constante, sob linha de costa com tendência de migração variável. A migração da linha de costa $(\mathrm{dx})$ compreende fase inicial de transgressão seguida por ciclos regressivos-transgressivos de amplitude variável, separados por fase de estabilização.

\subsection{Modelos de fácies baseados na dinâmica de crescimento do campo de dunas}

Os sistemas eólicos compreendem vários elementos morfológicos, os quais incluem dunas livres ou vegetadas de morfologia diversa, depressões interdunas secas ou inundadas, zonas de deflação e lençóis de areia. Estes elementos podem variar de tamanho e sua distribuição no sistema eólico não é uniforme. Sucessão de dunas livres e depressões interdunas desenvolvem-se em zonas de aporte eólico mais elevado (influxo muito maior que efluxo), sendo que o aumento do aporte provoca incremento do tamanho das dunas e redução das depressões interdunas. Dunas vegetadas e lençóis de areia são formados sob aporte mais reduzido, sendo que as primeiras são 
feições típicas de sistemas eólicos de regiões com clima mais úmido. Zonas de deflação são formadas em regiões ou períodos onde o efluxo é maior que influxo. Isto pode ocorrer tanto devido ao aumento da energia eólica, pela influência da topografia por exemplo, ou através da redução do aporte de sedimentos. Em sistema eólico costeiro, a região adjacente à zona intermaré desempenha papel duplo, pois recebe sedimentos eólicos da zona intermaré e fornece sedimentos para a região situada a sotavento. $\mathrm{O}$ transporte de sedimentos eólicos da zona intermaré para a área adjacente é bloqueado tanto pela elevação da maré quanto pela ocorrência de chuva. Já o transporte de sedimentos a partir da região adjacente à zona intermaré é bloqueado apenas pela ocorrência de chuva. Além disto, esta região está sujeita à ação de tempestades e canais de maré, que podem devolver sedimentos para a zona intermaré. Esta dinâmica de transporte faz com que a retaguarda do campo de dunas apresente razão influxo/efluxo menor que a apresentada pela porção do sistema eólico situada a sotavento. Logo, a retaguarda do sistema eólico constitui zona mais propícia ao desenvolvimento de elementos morfológicos de aporte mais reduzido, tais como dunas livres de tamanho menor, lençóis de areia, dunas vegetadas ou zonas de deflação. Toda região do sistema eólico consititui fonte imediata para a região vizinha situada a sotavento. Deste modo, cada setor do campo de dunas é alimentado pelo setor a barlavento e alimenta o setor a sotavento. Nas porções do sistema eólico livre da ação da maré, esta dinâmica de transporte é bloqueada apenas pela ocorrência de chuva, que afeta o sistema com um todo da mesma forma (desde que o sistema não seja grande o suficiente para haver zonas com maior freqüência de chuvas). No entanto, os fluxos de sedimentos entre setores é afetado pelo tamanho das dunas. Dunas maiores requerem maior volume de sedimentos para serem mantidas, de modo que disponibilizam volume menor de sedimentos para serem transportados para o setor seguinte. Logo, o crescimento das dunas de determinado setor implica redução do aporte nos setores seguintes. Isto pode provocar o desenvolvimento de elementos de aporte mais reduzido nas regiões a sotavento. Devido ao fato do crescimento das dunas reduzir o aporte nos setores seguintes, as regiões situadas a sotavento do sistema eólico teriam maior probabilidade de apresentar aporte eólico menor que o das regiões centrais. Desta forma, devido a fatores distintos porém, interligados, as regiões na retaguarda e na frente do sistema eólico seriam mais propícias ao desenvolvimento de elementos de baixo aporte sedimentar do que as regiões centrais. Condições mais favoráveis à formação de campos de dunas livres ocorreriam na porção central 
do sistema eólico. Assim, o sistema eólico poderia ser dividido em três partes, no que diz respeito à distribuição dos seus elementos morfológicos: retaguarda, centro e frente (Figura 4.52).

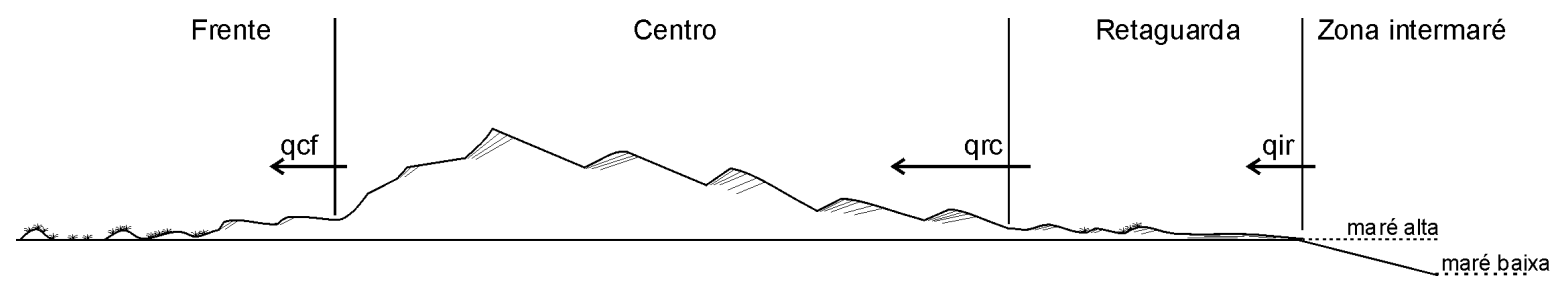

Figura 4.52 - Divisão morfodinâmica do sistema eólico costeiro. qir=fluxo de sedimentos da zona intermaré para a retaguarda; qrc=fluxo de sedimentos da retaguarda para o centro; $q \mathrm{cf}=\mathrm{fluxo}$ de sedimentos do centro para a frente. A regularidade de qir é menor que a dos demais fluxos, pois o primeiro apresenta dois agentes bloqueadores (maré e chuva). A redução de qcf ocorre com o crescimento das dunas na porção central do sistema.

As fácies dos depósitos eólicos apresentam correspondência com os elementos morfológicos que compõem o sistema eólico, cuja distribuição no tempo e espaço será ditada pela interação entre as porções de retaguarda, central e de frente do sistema eólico. A interação entre estas porções, assim como o crescimento e redução de tamanho, depende do dinâmica de crescimento do sistema eólico. Esta associação entre elementos morfológicos eólicos e o transporte sedimentar dentro do sistema eólico permite a elaboração de modelos de fácies conceituais em termos da dinâmica de crescimento do sistema eólico. Assim, fica estabelecida uma associação entre sucessão de fácies sedimentares e fatores controladores da dinâmica de crescimento do sistema eólico, tais como amplitude de maré, regime de chuvas e de vento.

A associação formada pelas fácies de retaguarda, centro e frente do sistema eólico dependerá do modo de crescimento do sistema. Sob linha de costa estável, o crescimento do sistema eólico pode ocorrer apenas no sentido onshore (sotavento). Este modo de crescimento gera sobreposição de fácies de frente por fácies de centro e destas por fácies de retaguarda (Figura 4.53). 


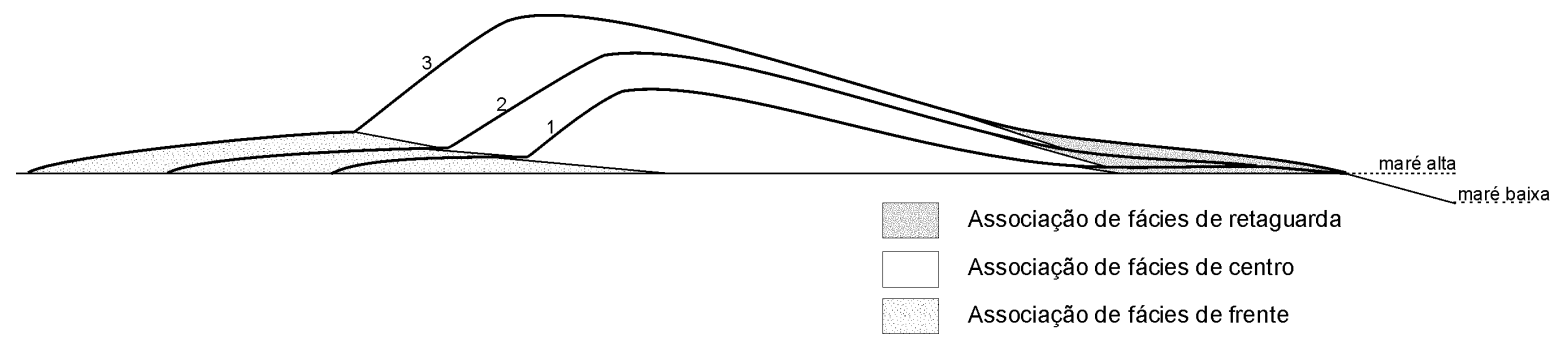

Figura 4.53 - Crescimento do sistema eólico sob linha de costa estável. O crescimento no sentido onshore produzirá sucessão ascendente formada por fácies de frente, centro e retaguarda. Os números 1,2 e 3 representam linhas de tempo em instantes sucessivos.

Caso ocorra mudança na dinâmica do sistema que provoque aumento do aporte eólico primário, pode haver expansão da porção central (associação de dunas livres) e desaparecimento dos elementos morfológicos de baixo aporte das regiões periféricas. O contrário também pode ocorrer, pois na medida em que há crescimento das dunas livres na porção central, mais sedimentos serão necessários para a manutenção destas dunas. Isto pode provocar déficit de sedimentos nas regiões periféricas e expansão dos elementos de baixo aporte da frente e da retaguarda do sistema eólico (Figura 4.54). Assim, para determinado aporte primário, haveria limite para a expansão da porção central, pois o crescimento das dunas livres requereria cada vez mais sedimentos para mantê-las.

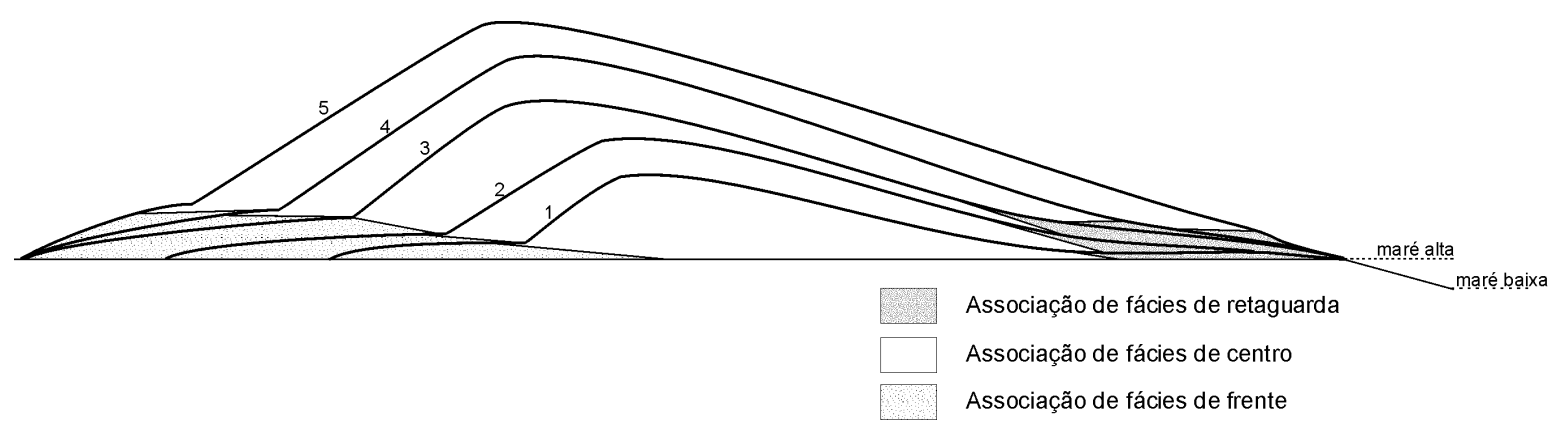

Figura 4.54 - Crescimento do sistema eólico com expansão da porção central sobre as porções periféricas. Neste caso, associação de fácies de centro recobriria associações de fácies periféricas (de retaguarda e de frente). Isto ocorreria mediante elevação do aporte primário ao longo do tempo. Os números 1, 2, 3, 4 e 5 representam linhas de tempo sucessivas. A partir da linha de tempo 3, há expansão da associação de fácies de centro sobre as associações de fácies periféricas (retaguarda e frente). 
Em situação de linha de costa regressiva, há aumento do espaço para crescimento do campo de dunas no sentido offshore. Além disto, o distanciamento da linha de costa, caso repentino, provoca distanciamento do campo de dunas da área fonte primária, que dificulta a manutenção das dunas livres e favorece a expansão de associações de fácies periféricas. A estabilização da linha de costa após regressão repentina pode dar origem a novo campo de dunas livres, que se desenvolve a barlavento do anterior. Assim, regressões e estabilizações sucessivas podem originar gerações de campos de dunas (Figura 4.55), as quais podem se amalgamar ao longo do tempo. Gerações distintas de campos de dunas também poderiam ser formadas através da redução do aporte durante certo intervalo de tempo. Esta redução pode ser desencadeada por diversos fatores, tais como mudança no regime de chuvas ou ventos e mudança no balanço sedimentar costeiro. Os campos de dunas mais antigos seriam alimentados às custas dos mais novos e crescimento destes últimos seria favorável à estabilização dos primeiros, pois com o crescimento dos mais novos haveria menos sedimentos para serem transportados aos mais velhos. A junção de gerações distintas de campos de dunas pode equivaler ao efeito de crescimento abrupto do campo de dunas mais jovem (a barlavento). Isto poderia acelerar a estabilização de ambos os campos de dunas.

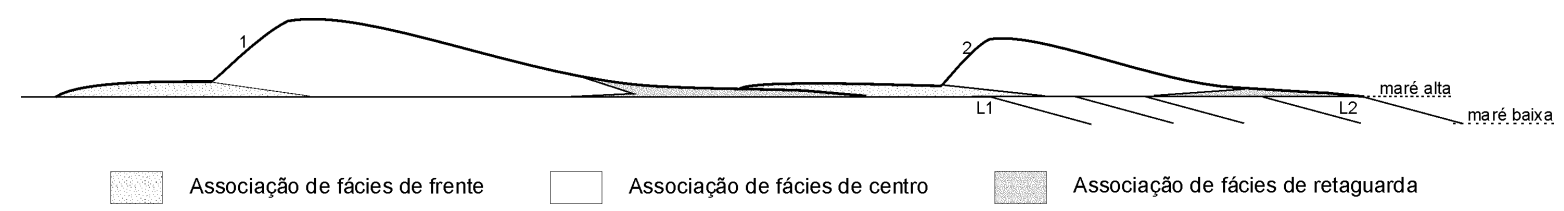

Figura 4.55 - Gerações de campos de dunas formadas pela regressão seguida de estabilização da linha de costa. A regressão acelerada da linha de costa (de L1 para L2) provoca isolamento do campo de dunas da sua área fonte primária. Novo campo de dunas irá se formar após a estabilização da linha de costa. Os números 1 e 2 representam as linhas de tempo nos instantes anterior e posterior à fase de regressão acelerada. As fácies de frente do campo de dunas mais jovem recobrirão as fácies de retaguarda do campo de dunas mais antigo.

A sucessão de fácies eólicas formada no contexto de linha de costa com regressão alternada com estabilização envolverá fácies de centro do sistema eólico intercaladas com fácies de periferia (Figura 4.56). As fácies de retaguarda do campo de dunas mais velho serão recobertas pelas fácies de frente do campo de dunas mais jovem, as quais serão recobertas pelas fácies de centro. $\mathrm{O}$ crescimento da geração mais nova de campo de dunas dependerá não só do aporte eólico primário, mas também da duração do período de linha de costa estável. Este 
crescimento poderá ser suficiente para provocar a amalgamação entre as dunas livres das duas gerações de campos de dunas. Neste caso, parte do depósito sedimentar poderia ser formado apenas pela sucessão de fácies de centro.

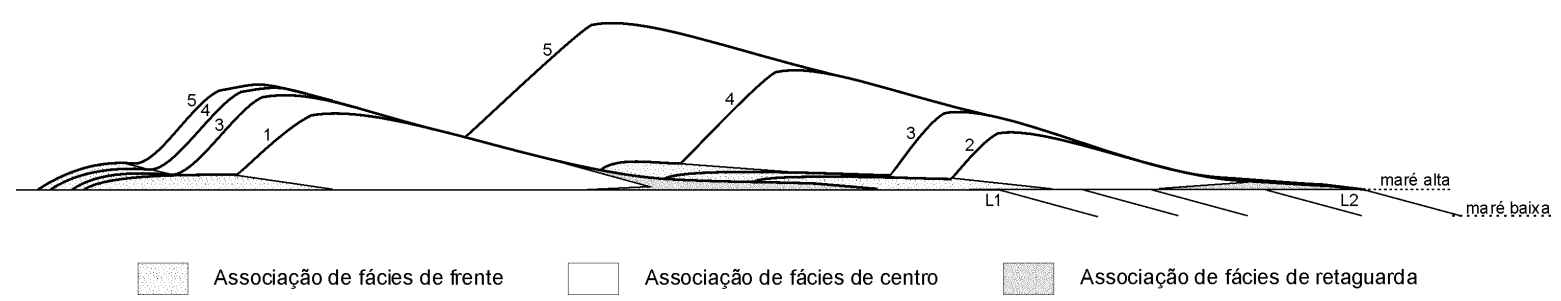

Figura 4.56 - A estabilidade prolongada da linha de costa (L2) pode propiciar o crescimento do campo de dunas situado a barlavento. A amalgamação dos campos de dunas pode provocar sobreposição das fácies de centro do campo de dunas mais velho pelas fácies de centro do mais novo. Os números 1, 2, 3, e 5 indicam linhas de tempo em momentos sucessivos. A regressão ocorreu durante fase após a linha de tempo 1. Em 3, 4 e 5 há crescimento das duas gerações de campos de dunas. A geração de campo de dunas situada a barlavento passa a ser fonte da situada a sotavento. $\mathrm{O}$ aporte sedimentar para o campo de dunas a sotavento diminui com o crescimento do campo de dunas situado a barlavento.

A transgressão da linha de costa pode reduzir a área de retaguarda do campo de dunas e aproximar a zona intermaré da região central. Assim, a transgressão pode fazer com que haja transferência direta de sedimentos da zona intermaré para o campo de dunas livres. No entanto, deve ser destacado que o desaparecimento das fácies de baixo aporte também pode ocorrer sob aporte eólico primário muito elevado. Transgressão sob NRM ascendente pode formar corpo lagunar a sotavento e provocar imersão da frente do sistema eólico. A imersão da região frontal e da retaguarda pode gerar depósitos sedimentares formados, respectivamente, por fácies eólicas sobrepostas por fácies lagunares e fácies eólicas sobrepostas por fácies marinhas costeiras (Figura 4.57). O confinamento do campo de dunas pela laguna e pelo mar pode ser favorável à manutenção das dunas livres, pois não haveria espaço para crescimento do campo de dunas. Isto favoreceria o empilhamento vertical de fácies de dunas livres. Contudo, também deve ser considerado o efeito da erosão costeira sobre o sistema eólico. Apesar de contribuir para a diminuição de tamanho do campo de dunas e favorecer a manutenção de dunas livres, a erosão pode gerar escarpas, que dificultam a transferência de sedimentos da zona intermaré para o campo de dunas. O efeito das escarpas sobre a sedimentação seria mais importante com transgressão sob NRM estável. 


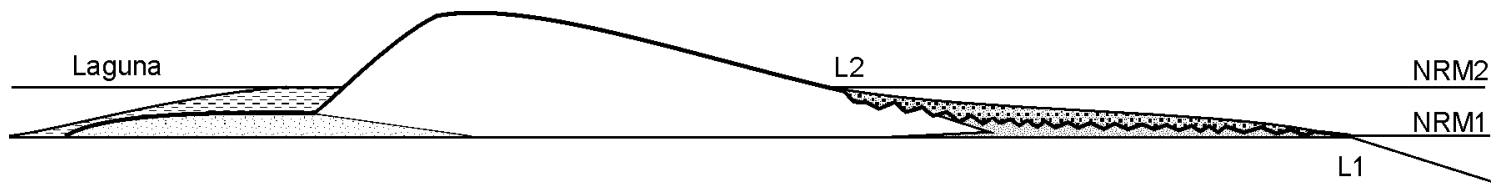

Associação de fácies de frente

20.7

Associação de fácies marinha costeira

Associação de fácies de centro

Associação de fácies lagunar

Associação de fácies de retaguarda

Figura 4.57 - Imersão da frente e retaguarda do campo de dunas por transgressão da linha de costa sob NRM ascendente. A formação de corpo lagunar restringe o crescimento do campo de dunas. O confinamento do campo de dunas e a imersão de suas periferias favorece a concentração do aporte eólico e o desaparecimento das fácies de baixo aporte. NRM1/L1 e NRM2/L2 indicam respectivamente a posição do nível relativo do mar e da linha de costa em períodos sucessivos.

A distribuição espacial das fácies de um depósito eólico costeiro dependerá da interação entre as partes que formam o sistema eólico (retaguarda, centro e frente). O aporte eólico e a tendência de migração da linha de costa determinam o aparecimento/desaparecimento e crescimento/diminuição destas partes. Isto caracteriza a dinâmica interna do sistema eólico. Esta dinâmica controla a sobreposição dos depósitos correspondentes aos elementos morfológicos desenvolvidos em cada parte do sistema e determina a sucessão de fácies formada pela evolução do sistema eólico costeiro. A relação entre as partes do sistema, a migração da linha de costa e o aporte eólico e a relação destes dois últimos com variáveis climáticas e oceanográficas permite atribuir significado genético às sucessões de fácies eólicas. Para a elaboração de modelos de fácies nestes termos, é necessário caracterizar as fácies desenvolvidas em cada parte do sistema eólico costeiro. Para cada parte haveria uma associação de fácies e a análise da sucessão destas associações permitiria a elaboração de modelo da dinâmica pretérita do sistema.

Os elementos morfológicos da região de retaguarda compreendem lençóis de areia, dunas vegetadas diversas, cavas de deflação e dunas livres de tamanho pequeno. Lençóis de areia geram depósitos arenosos tabulares com estratificação plano-paralela e laminações cruzadas. As fácies correspondentes a dunas vegetadas são arenosas e podem conter estratificações cruzadas ou serem maciças. As estratificações podem ser obliteradas pela pedogênese, que deve ser traço característico destas fácies. A deflação gera pavimentos residuais, que podem ocorrer como níveis de cascalho intercalados nas demais fácies. Dunas livres de pequeno tamanho dariam 
origem a depósitos arenosos com estratificação cruzada (tabular, acanalada etc). Além disto, a retaguarda do sistema eólico pode abranger fácies ligadas a agentes subaquosos. Esta região sofre a ação de marés e ondas de tempestade. Assim, pode haver também fácies de canais de maré e de leques de sobrelavagem. A deflação pode ainda produzir cavas, cuja inundação geraria lagoas efêmeras e propiciaria a deposição de fácies pelíticas com feições de exposição subaérea.

A região central é dominada pelos elementos morfológicos dunas livres e depressões interdunas. A migração das dunas produz sucessão de fácies formada pela intercalação de corpos arenosos com estratificação cruzada de geometria variável (fácies de dunas) e estratificação plano-paralela (fácies de interdunas). A espessura das séries de estratificação cruzada e a proporção das fácies de interdunas seriam indicativos do aporte eólico. A elevação do aporte reduz a distância interdunas e provoca aumento da altura das dunas. A ocorrência de chuvas ou a proximidade à linha de costa pode produzir lagoas efêmeras nas depressões interdunas. Assim, pode haver fácies de interdunas com lâminas pelíticas. Esta região pode desenvolver deflação local. Apesar de poder haver fácies associadas a deflação, há amplo domínio das fácies de dunas e interdunas.

Assim como a região de retaguarda, a região frontal também compreende fácies de baixo aporte. Os elementos mais característicos desta região são zonas de deflação e dunas vegetadas. Assim, seus depósitos compreenderiam fácies arenosas com estratificações cruzadas ou maciças e feições pedogenéticas, além de intercalações de níveis cascalhosos gerados por deflação. A porção frontal periférica do campo de dunas apresenta maior probabilidade de interação com sistemas deposicionais aluviais ou fluviais. Neste caso, poderia haver, por exemplo, fácies de fluxo de lama ou detritos e fácies de inundação fluvial intercaladas a fácies eólicas.

$\mathrm{Na}$ região central do sistema eólico costeiro (campo de dunas) é que são depositadas as maiores espessuras de sedimentos. Assim, a proporção volumétrica da associação de fácies da região central será mais elevada que a proporção das associações de fácies das regiões periféricas. A sobreposição das associações de fácies periféricas pela associação de fácies central ocorre com a expansão relativa do campo de dunas. Isto pode ocorrer durante a fase inicial de desenvolvimento do campo de dunas, até o momento em que o aporte primário não for mais suficiente para sustentar a expansão. A expansão do campo de dunas também pode ocorrer através do aumento absoluto do aporte eólico (fluxo de sedimentos a partir da zona intermaré) ou através do aumento relativo, como por exemplo o provocado pela estabilização da linha de costa 
após fase regressiva. Já a sobreposição da associação de fácies central pela associação de fácies de retaguarda e de frente relaciona-se à diminuição (relativa o absoluta) do aporte eólico. A redução do aporte eólico na região central pode ocorrer, por exemplo, com a regressão acelerada da linha de costa ou com o crescimento em área do campo de dunas. Pode haver ainda a sobreposição da associação de fácies central pela associação de retaguarda e a sobreposição da associação de frente pela associação central. Este padrão de sucessão de fácies se desenvolve quando há migração do campo de dunas sem crescimento. A migração sem crescimento pode ocorrer quando o aporte é insuficiente para sustentar a expansão e há transgressão da linha de costa, sem formação de laguna. $O$ crescimento do campo de dunas, sob ausência de incremento do aporte eólico primário, tornaria inevitável o desenvolvimento de fácies de baixo aporte por todo sistema eólico e o desaparecimento das dunas livres. Isto ocorreria, pois o aumento da área superficial do campo de dunas, que ocorre com a expansão do sistema eólico e crescimento das dunas, provocaria diluição do aporte eólico. Assim, a estabilização das dunas livres faria parte da evolução natural do sistema e não estaria necessariamente relacionada, por exemplo, a mudança de ordem climática.

O ciclo de expansão e retração do sistema eólico costeiro produziria sucessão formada por associação de fácies de centro entre associação de fácies de periferia. A fase de expansão do campo de dunas corresponderia à porção da seção com espessamento ascendente das fácies de dunas (séries de estratificações cruzadas), que poderia vir acompanhada de redução da espessura e proporção das fácies de interdunas, e adelgaçamento ascendente das fácies de periferia. Após atingido o tamanho máximo sustentável pelo aporte vigente, haveria formação de padrão inverso, ou seja, adelgaçamento ascendente das fácies de dunas e espessamento das fácies de periferia (Figura 4.58). As fácies de periferia apresentam acunhamento em direção ao centro do campo de dunas, de modo que podem não ocorrer ou serem bastante delgadas nas porção mais central do campo de dunas. 

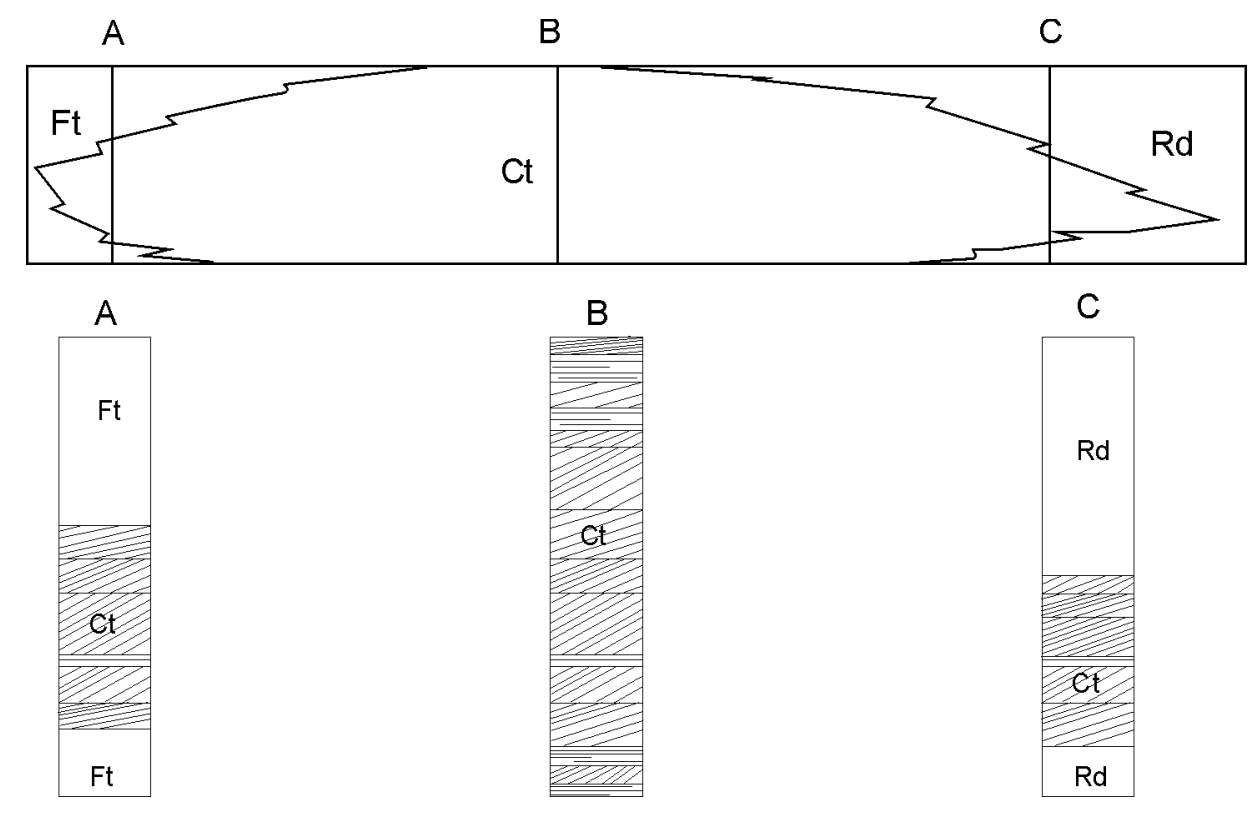

Figura 4.58 - Modelo de sucessão de fácies para um ciclo de expansão e retração do sistema eólico costeiro. A fase de expansão é representada pelo avanço da associação de fácies de centro $(\mathrm{Ct})$ sobre as associações de fácies de frente $(\mathrm{Rt})$ e retaguarda $(\mathrm{Rd})$. Na associação de fácies de centro, este avanço produz espessamento ascendente das fácies de dunas e adelgaçamento das fácies de interdunas. A fase de retração é caracterizada por padrão inverso de sobreposição de associação de fácies e variação da espessura das fácies. As associações de fácies de centro e retaguarda contém fácies eólicas de suprimento sedimentar mais reduzido, as quais podem se interdigitar a fácies de sistemas deposicionais vizinhos (lagunar, estuarino, costa dominada por ondas etc).

Durante uma expansão e retração do sistema eólico costeiro pode haver a formação de mais de uma geração de campo de dunas. Assim como no sistema com um único campo de dunas, na zona situada a barlavento da geração mais nova haveria a formação de sucessão de fácies caracterizada pelo espessamento ascendente (expansão) seguido por adelgaçamento ascendente (retração) das fácies de dunas, as quais ocorreriam entre fácies de retaguarda. Na zona frontal do campo de dunas mais velho haveria a formação de padrão semelhante, porém com fácies de frente substituindo fácies de retaguarda. Porém, as fácies periféricas de frente superiores seriam mais desenvolvidas e, em parte, contemporâneas à fase de crescimento do campo de dunas mais jovem. As sucessões de fácies formadas na zona de interação entre as gerações de campos de dunas dependeriam da existência ou não do cavalgamento do campo de dunas mais velho pelo mais novo. O cavalgamento produziria a seguinte sucessão vertical de fácies (base para o topo): fácies de retaguarda-fácies de centro-fácies de retaguarda (geração velha)-fácies de frente-fácies 
de centro-fácies de frente (geração jovem). Mais próximo à borda da geração mais velha, a sotavento, poderia haver ausência das fácies de centro desta geração e sobreposição das fácies de retaguarda por fácies de frente da geração mais jovem. A ausência das fácies de dunas na zona de interação entre as gerações de campos de dunas também pode estar associada a cavalgamento incipiente ou inexistente. Neste caso, poderia haver sucessão formada somente por fácies de retaguarda da geração mais velha sob fácies de frente da geração mais nova. As sucessões verticais de fácies para um ciclo de expansão e retração com duas gerações de campos de dunas pode ser observada na Figura 4.59.
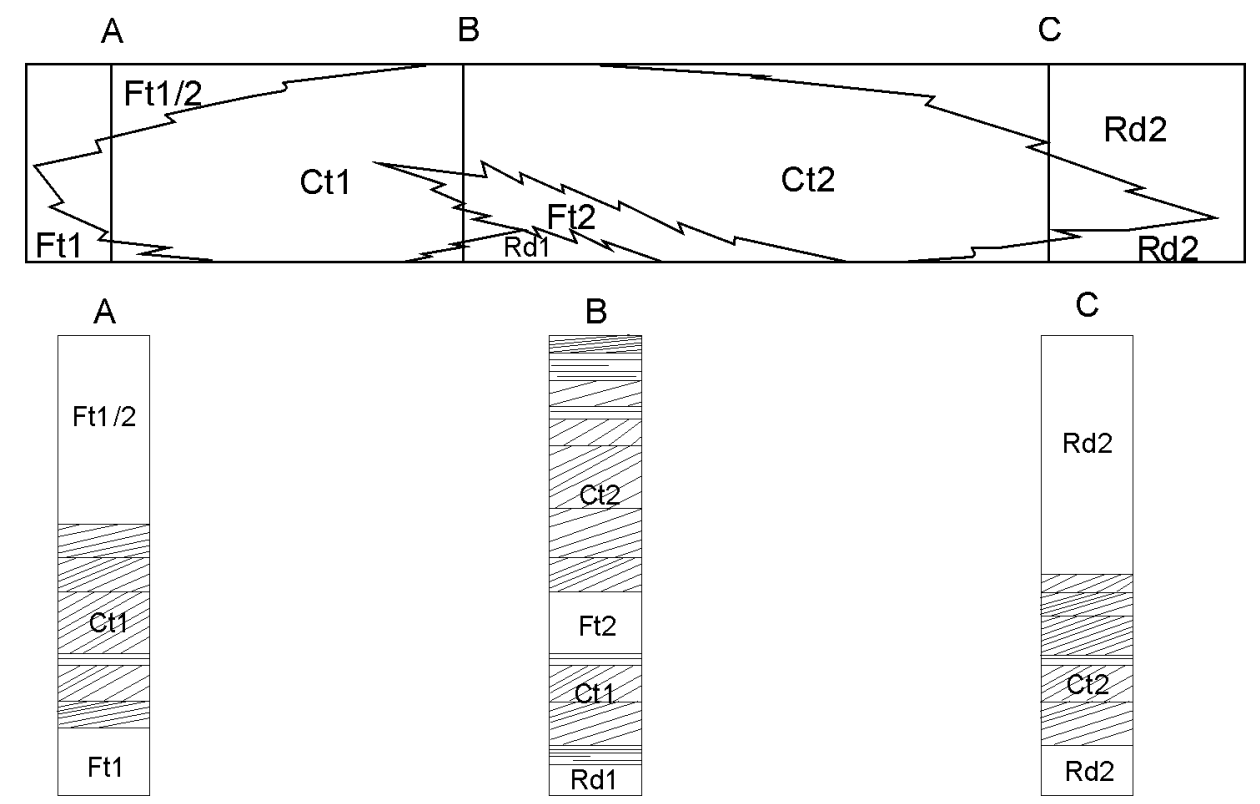

Figura 4.59 - Modelo de sucessão de fácies para ciclo de expansão e retração do sistema eólico com duas gerações de campos de dunas. Os números 1 e 2 referem-se respectivamente às gerações mais antiga e mais nova. Na região central haverá sobreposição da associação de fácies de retaguarda da geração mais velha (Rd1) por associação de fácies de frente (Ft2) da geração mais nova.

\subsection{Dinâmica de sistemas eólicos costeiros e estratigrafia de seqüências}

As variáveis que compõem o modelo de dinâmica do sistema eólico costeiro proposto neste estudo apresentam variabilidade espacial local ou regional, de modo que podem ser consideradas de natureza autocíclica. No entanto, algumas destas variáveis, como por exemplo, o aporte sedimentar costeiro e a migração da linha de costa, são influenciadas pelo nível relativo do 
mar (NRM), que se associa a variável de natureza alocíclica (global), ou seja, o nível eustático. Esta associação entre variáveis autocíclicas do sistema eólico costeiro e o NRM permite a elaboração de modelo de estratigrafia de depósitos eólicos costeiros no âmbito da estratigrafia de seqüências. Tal associação se daria principalmente mediante a relação mantida entre a o NRM e a linha de costa e desta última com a dinâmica do sistema eólico costeiro. Além disto, o NRM também pode alterar de modo direto os depósitos eólicos costeiros. A queda do NRM, além de proporcionar regressão da linha de costa, favorece a erosão da zona emersa pela queda do nível de base. Fato importante que deve ser levado em consideração é a diferença entre a freqüência de variação das variáveis autocílclicas do sistema eólico e a do NRM. As variações de maior amplitude do NRM, capazes de afetar significativamente os depósitos emersos, são de freqüência mais reduzida que a freqüência das variáveis autociclícas do sistema eólico. A ordem de grandeza das variações do NRM, consideradas de alta freqüência, é cerca de dezenas a centenas de milhares de anos. Já as variáveis autocíclicas do sistema ligadas ao clima podem apresentar grandes variações de escala submilenar ou de poucos milhares de anos.

A elaboração de um modelo de estratigrafia de seqüências para depósitos eólicos costeiros requer o conhecimento do efeito das variações de NRM sobre a sedimentação eólica. O problema reside no fato de que este efeito não é unívoco, pois a migração da linha de costa, apesar de influenciada pelo NRM, pode variar de modo independente. Transgressão, estabilidade e regressão da linha de costa podem ocorrer sob NRM estável, em elevação ou em queda, pois tais variações podem estar ligadas apenas ao aporte sedimentar costeiro. O efeito do NRM sobre a linha de costa torna-se mais intenso quando a sua taxa de variação é mais elevada. Assim, NRM com taxa de elevação ou queda alta induziria, respectivamente, transgressão e regressão da linha de costa com maior facilidade. O efeito mais característico das variações de NRM sobre a sedimentação eólica costeira seria sua abrangência espacial.

A transgressão da linha de costa sob NRM estável provocaria erosão completa dos depósitos da retaguarda do campo de dunas enquanto que sob NRM em ascensão, parte dos sedimentos eólicos seria submersa. Com NRM estável, a superfície de erosão marinha (superfície transgressiva) seria formada sobre o substrato do sistema eólico e separaria os depósitos do substrato de depósitos marinhos costeiros formados em parte pelo retrabalhamento de sedimentos eólicos. Já sob NRM em ascensão, parte dos sedimentos eólicos submersos apresentaria maior chance de preservação, de modo que a superfície transgressiva separaria depósitos eólicos 
subjacentes de depósitos marinhos costeiros. A transgressão reduz o tamanho do campo de dunas por erosão ou afogamento (que também pode atingir a frente do campo através da formação de corpo lagunar) e favorece a manutenção das dunas livres. Se o campo de dunas se encontrar em fase onde seu tamanho elevado dificulta a manutenção das dunas livres, transgressão pode promover a intensificação da atividade das dunas livres. Neste caso, haveria depósitos de dunas livres mais retritos, porém mais desenvolvidos associados à transgressão. Os sedimentos eólicos acumulados durante fase transgressiva com NRM ascendente configuraria a parcela do sistema eólico correspondente ao trato de sistemas transgressivos. Na zona mais próxima à linha de costa, estes sedimentos seriam separados dos sedimentos sobrejacentes por superfície de erosão marinha (superfície transgressiva) enquanto que na zona mais interna, seriam separados por superfície de inundação lagunar.

A regressão da linha de costa favoreceria a estabilização do campo de dunas, pois aumenta a área de deposição de sedimentos na retaguarda do campo de dunas e a distância entre a área fonte primária e o campo de dunas. A regressão com NRM em queda acelerada (regressão forçada) pode intensificar a dissecação fluvial dos sedimentos eólicos acumulados, o que auxiliaria ainda mais a estabilização do campo de dunas. Este seria o efeito mais característico da regressão da linha de costa sob NRM em queda. Nestas condições, os depósitos eólicos, caso preservados, seriam recobertos por superfície de erosão fluvial associada à queda do nível de base. Esta superfície corresponderia a um limite de seqüências (Figura 4.60). Caso a regressão da linha de costa sob NRM estável provoque estabilização da linha de costa também haveria a formação de superfície de descontinuidade física. No entanto, esta superfície diferiria do limite de seqüências, pois seria caracterizada mais pela ampla ocorrência de paleossolos e pavimentos residuais de deflação do que por dissecação fluvial. Além disto, caso haja segmentos de costa com diversos campos de dunas, as superfícies de estabilização por regressão sob NRM estável seriam diacrônicas enquanto que o limite de seqüências seria sincrônico. 
NRM em queda

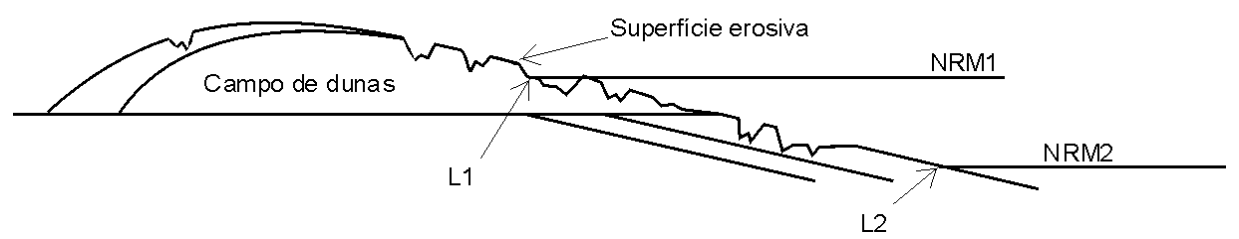

Figura 4.60 - Estabilização e erosão do campo de dunas provocada pela queda do NRM. Há formação de superfície de erosão fluvial.

Os tratos de sistemas de mar alto e mar baixo são formados durante fases de NRM estável ou com baixa taxa de subida ou descida. Nestas condições, a migração da linha de costa fica mais dependente de fatores autocíclicos e os efeitos diretos do NRM sobre a sedimentação eólica são minimizados. Deste modo, as características dos depósitos eólicos correspondentes aos tratos de mar alto e mar baixo podem ser variáveis e semelhantes. O NRM poderia afetar a sedimentação eólica costeira de modo indireto através da sua influência sobre o estoque de sedimentos na zona costeira. Sob NRM elevado haveria maior probabilidade de retenção de sedimentos na zona costeira, pois haveria maior espaço de acomodação na plataforma. O substrato marinho na plataforma é menos inclinado que no talude. Substrato marinho mais inclinado favorece o transporte de sedimentos para costa afora por tempestades enquanto que em substrato menos inclinado, as tempestades podem transportar sedimentos rumo à costa (Roy et al., 1994). Assim, a inundação da plataforma (NRM elevado) favorece o acúmulo de sedimentos na zona costeira, o que auxilia o desenvolvimento do sistema eólico costeiro. Já NRM baixo dificultaria a manutenção de sistemas eólicos previamente formados. Logo, a formação e manutenção de sistemas eólicos costeiros seria mais compatível com trato de sistemas de mar alto do que de mar baixo. No entanto, não deve ser esquecida a influência dos fatores autocíclicos que podem soprepujar o efeito do NRM e tornar esta relação pouco factível.

A suposição de relações entre o NRM e a migração de linha de costa permite a elaboração de um modelo de associação entre as características faciológicas e estratigráficas dos depósitos eólicos costeiros e os elementos da estratigrafia de seqüências. Para isto, deve ser admitido que: 1. o NRM varia de modo senoidal, 2. durante os tratos de sistemas de mar baixo e mar alto a linha de costa seria predominantemente regressiva, com dissecação fluvial pouco significativa, 3 . durante o trato de sistemas transgressivo a linha de costa seria trangressiva, com NRM 
ascendente e 4. a regressão associada ao limite de seqüências viria acompanhada de dissecação fluvial intensa.

A elevação acelerada do NRM (trato de sistemas transgressivo) pode criar condição favorável ao desenvolvimento de sistemas eólicos costeiros, pelo aprisionamento de sedimentos na zona costeira e pelo elevado aporte sedimentar costeiro derivado da erosão marinha. A formação do sistema eólico concomitante à transgressão da linha de costa provocaria inundação e erosão da periferia do campo de dunas. A geração de corpo lagunar, que restringiria o crescimento do campo de dunas no sentido onshore, associada à erosão marinha, seriam favoráveis ao crescimento e manutenção de dunas livres. Logo, os depósitos eólicos pertencentes ao trato de sistemas transgressivo seriam caracterizados pela ampla distribuição de fácies de dunas livres (séries de estratificação cruzada de espessura crescente?), presença de superfície de erosão marinha na porção periférica a barlavento do campo de dunas e de superfície de inundação lagunar na periferia a sotavento, caso houvesse desenvolvimento de laguna. Deve ser destacado que elevação do NRM eleva o potencial de preservação dos sedimentos eólicos submersos.

A desaceleração da subida do NRM (entrada no trato de sistemas de mar alto) propiciaria a regressão da linha de costa, através da progradação dos sistemas marinhos costeiros. Assim, os depósitos eólicos submersos seriam recobertos por sedimentos marinhos costeiros (periferia a barlavento) ou lagunares (periferia a sotavento). Desse modo, a superfície de erosão marinha (superfície transgressiva) separaria depósito eólicos da retaguarda de depósitos marinhos costeiros (fácies de costa dominada por ondas) e a superfície de inundação lagunar separaria depósitos eólicos frontais de depósitos lagunares. A regressão da linha de costa marinha e lagunar provocam desconfinamento do campo de dunas desenvolvido durante a fase transgressiva. Este desconfinamento pode produzir crescimento em área do campo de dunas, que após atingido certo tamanho apresentaria dificuldade em manter as dunas livres em atividade. Isto provocaria surgimento e expansão de fácies de dunas vegetadas, fácies de lençóis de areia e fácies deflacionares, as quais recobririam fácies de dunas livres. A expansão das fácies de baixo aporte ocorreria da borda para o centro do campo de dunas. Os depósitos eólicos pertencentes ao trato de sistemas de mar alto seriam caracterizados por fácies de dunas livres sobrepostas por fácies de baixo aporte (fácies de dunas vegetadas, lençol de areia e deflação). Nas porções marginais do depósito (a barlavento e sotavento), as fácies de dunas livres recobririam fácies marinhas ou lagunares. Assim, nestas porções haveria interdigitação entre fácies eólicas e fácies marinhas ou 
lagunares. Porém, deve ser destacado que nesta fase a dinâmica de migração da linha de costa é mais dependente de fatores locais ligados ao aporte sedimentar. Assim, a sucessão de fácies eólicas do trato de sistemas de mar alto pode ser altamente variável, pois estará ligada à dinâmica de migração da linha de costa. A ocorrência de transgressão (com NRM estável ou pouco variável), por exemplo, poderia erodir os depósitos periféricos da retaguarda do campo de dunas, e criar condições para o crescimento e manutenção das fácies de dunas livres. Assim, seria gerada sucessão de fácies eólicas distinta, com fácies de dunas livres bem desenvolvidas nas porções superiores do depósito. O que deve ser destacado é que no trato de sistemas de mar alto, o sistema eólico é controlado mais por variáveis autocíclicas, independentes das variações de NRM, de modo que não haveria depósito eólico típico do trato de sistemas de mar alto.

A aceleração da queda do NRM (geração do limite de sequências) induz regressão forçada da linha de costa. Se esta regressão for mais duradoura e rápida que a regressão por progradação dos sistemas deposicionais costeiros, poderia provocar estabilização definitiva do campo de dunas. A queda acentuada do NRM induz dissecação fluvial dos sedimentos emersos. Assim, poderia haver erosão fluvial concomitante à estabilização do campo de dunas. A feição mais característica desta fase seria o recobrimento do depósito eólico por superfície erosiva com vales incisos associada a fácies eólicas de baixo aporte.

A desaceleração da queda do NRM, que marca a entrada no trato de sistemas de mar baixo, reduz a intensidade da dissecação fluvial. Nesta fase, a migração da linha de costa torna-se novamente mais dependente de fatores autocíclicos do que do NRM. No entanto, esta fase difere da fase de NRM alto, pois a região marginal da bacia pode apresentar substrato mais íngreme devido ao deslocamento da linha de costa para o centro da bacia (caso, por exemplo, de bacias de margem passiva). Isto favorece a transferência de sedimentos para a costa afora e seria ruim para a retomada da sedimentação eólica. Assim, pode não haver depósitos eólicos neste trato de sistemas. A retomada da sedimentação na porção emersa poderia ocorrer somente através do preenchimento dos vales incisos. Porém, caso a declividade do substrato da zona costeira não interfira sigfinicativamente na disponibilidade de sedimentos costeiros para o transporte eólico, poderia haver a formação de novo campo de dunas, principalmente após o fim da regressão da linha de costa. A sucessão de fácies eólicas formada pode ser variável, pois seria influenciada pela migração da linha de costa, que ficaria mais dependente de fatores autocíclicos. As fácies eólicas do trato de sistemas de mar baixo apresentariam grande chance de interdigitação com 
fácies fluviais geradas pelo preenchimento de vales incisos, os quais seriam amplamente distribuídos pela zona costeira. Esta pode ser a característica mais particular dos depósistos eólicos (ou fluvio-eólicos) desta fase. A inundação dos vales incisos pela elevação do NRM pode originar baías estuarinas, as quais podem segmentar campos de dunas previamente formados. $\mathrm{O}$ modelo de associação entre a faciologia-estratigrafia dos depósitos eólicos e os elementos da estratigrafia de seqüências pode ser observado no Quadro 4.5.

\begin{tabular}{|l|l|l|l|}
\hline NRM & Linha de costa & $\begin{array}{l}\text { Elementos da } \\
\text { estratigrafia de } \\
\text { seqüências }\end{array}$ & Sistema eólico \\
\hline $\begin{array}{l}\text { Baixo, porém em } \\
\text { elevação após ter } \\
\text { atingido o mínimo. }\end{array}$ & $\begin{array}{l}\text { Estável, transgressiva } \\
\text { ou regressiva (por } \\
\text { progradação. Linha } \\
\text { de costa torna-se mais } \\
\text { dependente do aporte. }\end{array}$ & $\begin{array}{l}\text { Trato de sistemas } \\
\text { de mar baixo }\end{array}$ & $\begin{array}{l}\text { Geração e crescimento de campo de dunas. } \\
\text { Nesta fase, a dinâmica do sistema fica mais } \\
\text { sensível a fatores locais. }\end{array}$ \\
\hline Alta taxa de elevação & Transgressiva & $\begin{array}{l}\text { Trato de sistemas } \\
\text { transgressivo }\end{array}$ & $\begin{array}{l}\text { Restrição ao crescimento por desenvolvimento } \\
\text { de lagunas ou erosão costeira favorece o } \\
\text { desenvolvimento de fácies de elevado } \\
\text { suprimento sedimentar. Fase propícia ao } \\
\text { crescimento e manutenção de dunas livres. } \\
\text { Superfície de erosão marinha na retaguarda e de } \\
\text { inundação lagunar na zona frontal ou lateral. }\end{array}$ \\
\hline $\begin{array}{l}\text { Baixa taxa de elevação, } \\
\text { NRM máximo e queda } \\
\text { com taxa reduzida. }\end{array}$ & $\begin{array}{l}\text { Transgressiva, estável } \\
\text { ou regressiva. Sob } \\
\text { aporte elevado, } \\
\text { predomina regressão. } \\
\text { Linha de costa torna- } \\
\text { se mais dependente } \\
\text { do aporte. }\end{array}$ & $\begin{array}{l}\text { Trato de sistemas } \\
\text { de mar alto }\end{array}$ & $\begin{array}{l}\text { Linha de costa estável ou transgressiva favorece } \\
\text { a manutenção ou expansão das dunas livres. } \\
\text { Regressão pode iniciar estabilização do campo } \\
\text { de dunas. Sistema torna-se mais dependente de } \\
\text { fatores locais. }\end{array}$ \\
\hline Alta taxa de queda & $\begin{array}{l}\text { Regressiva (por } \\
\text { queda de NRM). }\end{array}$ & $\begin{array}{l}\text { Limite de } \\
\text { seqüências }\end{array}$ & $\begin{array}{l}\text { Regressão da linha de costa favorece } \\
\text { estabilização do campo de dunas. Queda do } \\
\text { nível de base provoca erosão dos } \\
\text { sedimentos eólicos. }\end{array}$ \\
\hline
\end{tabular}

Quadro 4.5 - Relações entre NRM, migração da linha de costa, elementos da estratigrafia de seqüências e dinâmica do sistema eólico costeiro.

\subsection{Considerações sobre a sedimentação eólica na costa brasileira}

Considerando as variações de NRM ocorridas nas últimas dezenas de milhares de anos, pode-se dizer que a plataforma continental brasileira encontra-se em fase de mar alto (Figura 4.51). Desta forma, os campos de dunas ativos da costa brasileira pertenceriam a trato de sistemas de mar alto. Pelo menos nos últimos 5000 anos, a variação do NRM pode ser considerada pouco significativa (queda de cerca de 2 a 3 m) em relação à elevação, superior a 100 m, ocorrida após o encerramento do último período glacial (há aproximadamente 18000 anos). 


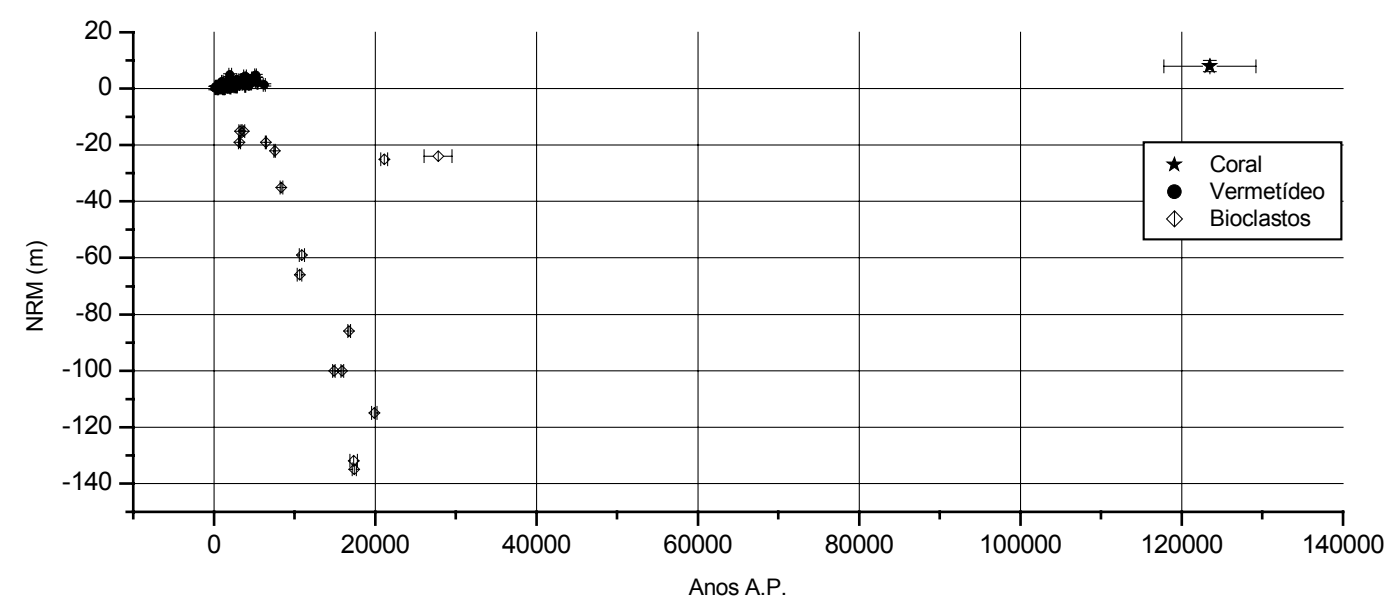

Figura 4.61 - Variação do nível relativo do mar na costa brasileira durante os últimos 120 ka (dados compilados de Martin et al. (1988), Corrêa (1996), Angulo \& Lessa (1997) e Angulo et al. (1999)).

Nas condições de NRM pouco variável (quase estável), a dinâmica de sistemas eólicos costeiros torna-se mais influenciada por fatores autocíclicos, ligados ao clima, maré ou aporte de sedimentos na costa do que por variações do NRM. Estes fatores apresentam variabilidade espacial e temporal maior que as variações do NRM, de modo que se pode esperar grande diversidade do tamanho e morfologia dos campos de dunas. Em fase de NRM elevado, há maior probabilidade de formação de campos de dunas, pois criam-se condições favoráveis ao aprisionamento de sedimentos na zona costeira, área fonte do sistema eólico. Logo, haveria ampla formação de campos de dunas pela costa. No entanto, a estabilidade relativa do NRM deixa a migração da linha de costa mais sensível a variáveis locais. Apesar do NRM elevado auxiliar a sedimentação eólica costeira, a dinâmica local de migração da linha de costa pode impedir a formação de campos de dunas em determinados setores ou épocas. Assim, a distribuição espacial dos campos de dunas também seria condicionada por fatores locais.

A maior sensibilidade do sistema eólico a fatores locais durante fases de NRM "estável" elevado explicaria a grande variabilidade de forma e tamanho dos campos de dunas da costa brasileira, tal como atestada pela elevada assimetria e desvio padrão de diversos caracteres morfométricos medidos nos campos de dunas (Capítulo 3). As regiões com maior freqüência de ocorrência de campos de dunas (setores 1 e 3) podem equivaler a áreas de linha de costa mais estável. A costa do Rio Grande do Sul e de Santa Catarina (a sul de Florianópolis) destaca-se 
tanto pela grande quantidade de campos de dunas quanto de lagunas, o que sugere associação entre a ocorrência destes dois elementos fisiográficos. As lagunas auxiliariam no desenvolvimento de campos de dunas livres, pois constituiriam barreira ao crescimento em área dos campos de dunas, que poderia ser danoso para a manutenção de dunas livres, e atuariam como reservatório de parte dos sedimentos fluviais derivados do continente. $\mathrm{O}$ aprisionamento de sedimentos fluviais nas lagunas reduziria a velocidade de regressão da linha de costa, o que favoreceria o desenvolvimento dos campos de dunas. A associação entre lagunas e campos de dunas também é observada no trecho do setor 2 (região de Cabo Frio, RJ) com maior freqüência de ocorrência de campos de dunas. A grande quantidade de campos de dunas no setor 1 também pode estar associada à baixa taxa de regressão da linha de costa neste setor. No entanto, este setor não dispõe de corpos lagunares amplamente distribuídos. A regressão pouco significativa da linha de costa neste setor pode estar ligada ao fato da maioria dos rios apresentarem bacia de drenagem em região mais seca (até semi-árida). Assim, o aporte de sedimentos fluviais para a costa seria reduzido. Este setor receberia grande aporte de sedimentos derivados da erosão costeira (Formação Barreiras). O fornecimento de sedimentos para a costa implicaria erosão costeira, o que tornaria a linha de costa mais estável e portanto, mais propícia ao desenvolvimento de campos de dunas. O setor 2 apresenta campos de dunas associados a desembocaduras de rios. Estes campos de dunas recobrem planície de cordões litorâneos e se desenvolveriam em contexto de linha de costa regressiva, portanto, pouco favorável à sedimentação eólica. Porém, poucos rios apresentam campos de dunas em sua foz e estes campos de dunas apresentam grande quantidade de dunas vegetadas e feições de deflação. Devido ao fato da linha de costa ser predominantemente regressiva nestes locais, o surgimento de campos de dunas pode estar associado à épocas de estabilização da linha de costa. Regressões alternadas com estabilizações podem dar origem a campos de dunas com grande quantidade de fácies de baixo aporte (dunas vegetadas ou zonas de deflação). A alternância entre períodos regressivos e estáveis pode estar ligada à dinâmica da bacia de drenagem dos rios. Períodos mais secos ou barragens a montante podem diminuir o aporte sedimentar na desembocadura do rio, que estabilizaria ou reduziria a taxa de regressão da linha de costa e seria benéfico à formação de campos de dunas.

A influência da migração da linha de costa sobre a sedimentação eólica pode ser observada na Ilha Comprida (SP). A Ilha Comprida corresponde a uma barreira arenosa formada por sucessão de cordões litorâneos. A alternância entre fases mais favoráveis e menos favoráveis 
à sedimentação eólica é notada através da sucessão entre zonas de cordões litorâneos formados por cristas praiais (beach ridges) e zonas de cordões de dunas frontais, cavas de deflação (blowouts) ou pequeno campo de dunas. A porção mais interna da ilha é formada por planície de cristas praiais, que representam fase de progradação acelerada da barreira. A planície de cristas praiais é interrompida por faixa estreita de cordões de dunas frontais elevadas (geração eólica mais velha), as quais demarcariam fase de estabilização da linha de costa. A sucessão entre zonas de cristas praiais e de dunas (gerações mais novas) repete-se novamente em seguida, porém com menor espaçamento. A geração mais velha de dunas frontais forma cordões de até $8 \mathrm{~m}$ de altura, com cavas de deflação. As gerações mais novas formam uma sucessão mais monótona de paleodunas frontais ou blowouts, com até $4 \mathrm{~m}$ de altura. Há ainda as dunas eólicas adjacentes à linha de costa atual, que incluem dunas frontais ativas, campo de blowouts e um campo de dunas incipiente, que encontra-se em formação na zona mais estreita da ilha situada no setor centronorte. A distribuição espacial das dunas e cordões de cristas praiais da Ilha Comprida pode ser observada na Figura 4.62.

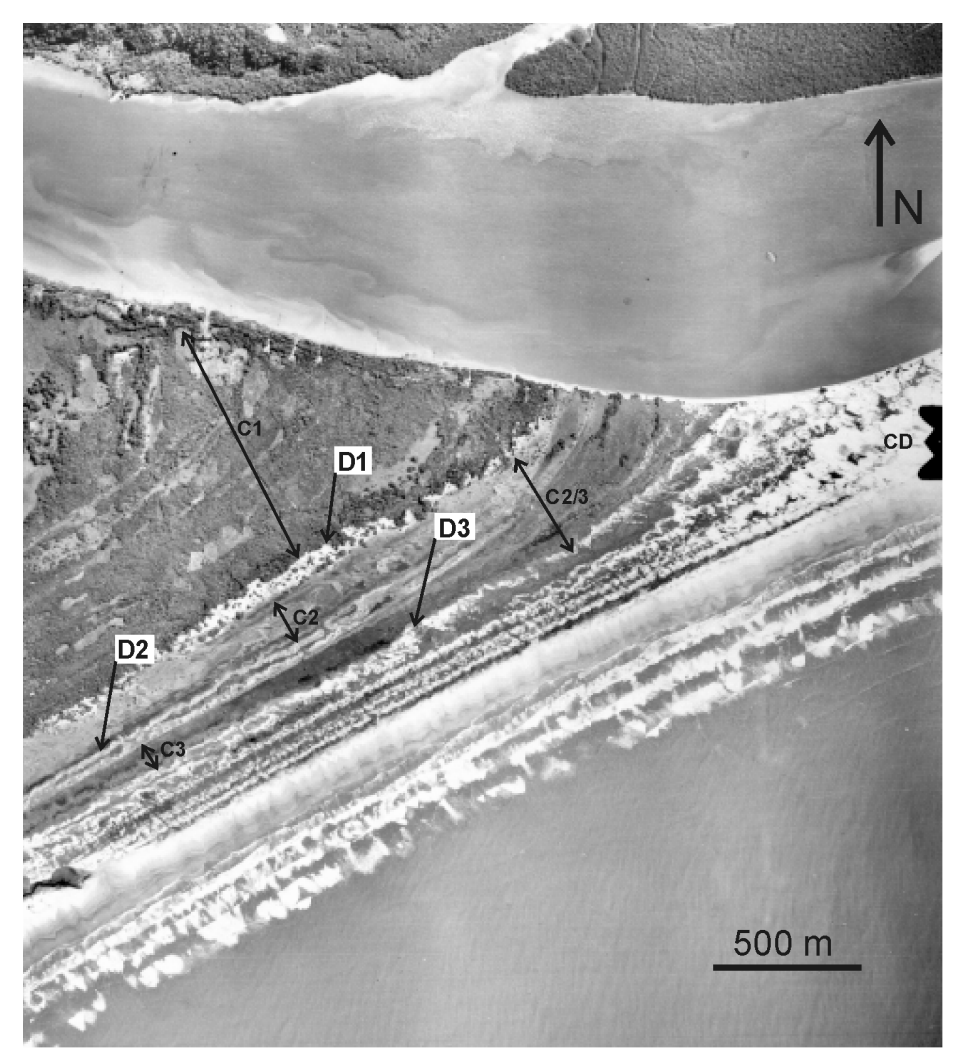

Figura 4.62 - Gerações de dunas dunas frontais, blowouts (D1, D2 e D3) e campo de dunas (CD) separadas por zona de cordões litorâneos $(\mathrm{C} 1, \mathrm{C} 2$ e C3). A geração mais nova (D3) é mais ampla 
e caracterizada por diversos cordões de dunas frontais ou de blowouts. A geração D2 desaparece rumo nordeste, onde há amalgamação entre as zonas de cristas praiais C2 e C3 (C2/C3). Notar ainda que a nordeste, onde a ilha é mais estreita, há a formação de pequeno campo de dunas. Foto aérea da Ilha Comprida (SP).

A dinâmica de migração da linha de costa também controla a distribuição espacial das dunas. O desaparecimento da geração de dunas D2 rumo nordeste coincide com zona onde há crescimento longitudinal e maior espaçamento entre os cordões de cristas praiais. Isto sugere taxas de progradação maiores neste setor. A redução do espaço de acumulação pelo estreitamento da ilha chega a favorecer aí a formação de um pequeno campo de dunas, com cerca de $1 \mathrm{~km}^{2}$, o qual está relacionado à sedimentação eólica atual (geração D3). Segundo Nascimento (2006), a porção da ilha onde encontra-se este campo de dunas foi formada nas últimas dezenas de anos. Portanto, a distribuição espacial das dunas correspondentes à geração mais jovem resultaria da variação de controles autocíclicos de alta freqüência de ocorrência.

A variação do tamanho e tipo das dunas ativas (dunas frontais, campos de blowouts e campo de dunas) ao longo da ilha (no sentido longitudinal) evidencia a influência da dinâmica da linha de costa e do espaço de acumulação sobre a distribuição espacial da sedimentação eólica. As zonas com melhores condições para a construção de dunas corresponderiam à aquelas com linha de costa mais estável e menor espaço de acumulação de sedimentos. Já a distribuição das dunas no sentido transversal ao rumo de progradação da barreira (gerações D1, D2 e D3) evidencia controles temporais da sedimentação eólica.

A Ilha Comprida encontra-se na zona costeira da desembocadura do rio Ribeira do Iguape. Trata-se de zona de elevado aporte sedimentar, o que torna a linha de costa menos suscetível a transgressões e estabilizações. A vocação progradante da área é incentivada ainda pela intensa reciclagem de sedimentos da planície costeira em virtude da dinâmica de meandramento da desembocadura de Icapara, situada imediatamente a sul da desembocadura do rio Ribeira do Iguape. Esta tendência regressiva da linha de costa dificultaria a formação de campos de dunas e a ocorrência de inundações pela elevação do NRM. Além disto, o aporte elevado pode tornar a linha de costa mais dependente de fatores autocíclicos, como por exemplo a vazão do rio Ribeira do Iguape, do que de fatores alocíclicos (regionais) como o NRM. Assim, a distribuição tempo-espacial das dunas da Ilha Comprida constituiria exemplo de controle autocíclico sobre a sedimentação eólica costeira. 
A história de migração da linha de costa também pode explicar a variabilidade da sedimentação eólica em escala de tempo de milhares de anos. Os depósitos eólicos do litoral centro-sul catarinense foram divididos por Giannini (1993) em quatro unidades morfoestratigráficas eólicas, com significado cronológico, as quais foram denominadas gerações eólicas 1, 2, 3 e 4. As gerações eólicas 2, 3 e 4, mais recentes, seriam contínuas no tempo e posteriores ao final do último período glacial. Estas gerações eólicas são separadas da geração eólica 1, mais velha, por discordância erosiva, que demarca hiato deposicional da ordem de dezenas de milhares de anos. A deposição da geração eólica 1 teria ocorrido durante a fase de NRM alto do interglacial Riss-Würm. Datações pelos métodos da termoluminescência (TL) e luminescência opticamente estimulada (OSL) atestaram a continuidade da sedimentação das gerações eólicas 2, 3 e 4 e o hiato deposicional entre as gerações eólicas 1 e 2 (Tabela 4.32).

\begin{tabular}{|l|l|l|l|l|l|l|l|l|}
\hline $\begin{array}{l}\text { Geração } \\
\text { eólica }\end{array}$ & Média & $\begin{array}{l}\text { Desvio } \\
\text { padrão }\end{array}$ & $\begin{array}{l}\text { Primeiro } \\
\text { quartil }\end{array}$ & Mediana & $\begin{array}{l}\text { Terceiro } \\
\text { quartil }\end{array}$ & Mínimo & Máximo & $\mathbf{N}$ \\
\hline 1 & 87,9 & 47,1 & 48,5 & 93,4 & 116,9 & 23,0 & 174,8 & 13 \\
\hline 2 & 7,9 & 2,0 & 5,8 & 8,2 & 9,6 & 4,9 & 10,9 & 12 \\
\hline 3 & 3,5 & 2,0 & 1,9 & 2,6 & 5,8 & 1,4 & 6,3 & 6 \\
\hline
\end{tabular}

Tabela 4.32 - Estatísticas descritivas das idades TL/OSL das gerações eólicas (1, 2 e 3) do litoral centro-sul catarinense (Sawakuchi, 2003). A idade mínima da geração eólica 1 foi obtida em fácies de deflação (areia com cascalho). Idades em $10^{3}$ anos.

A geração eólica 2 é formada por campos de dunas estabilizados encobertos por vegetação. A geração eólica 3 compreende fácies de dunas vegetadas ativas ou inativas e a geração eólica 4 envolve campos de dunas livres. A geração eólica 4 avança sobre depósitos das gerações 2 e 3 . Os campos de dunas estabilizados correspondentes à geração eólica 2 abrangem área maior que os pertencentes à geração eólica 4. Já a geração eólica 3 é de ocorrência mais restrita. A continuidade temporal da sedimentação das três gerações eólicas (ausência de hiato deposicional) indica que o desenvolvimento de gerações mais recentes é parcialmente concomitante à estabilização de gerações mais antigas. Isto sugere a existência de períodos favoráveis à estabilização alternados com períodos favoráveis ao crescimento e avanço de campos de dunas. A duração destes períodos é insuficiente para gerar hiato deposicional entre os depósitos das gerações eólicas 2, 3 e 4. A formação de gerações de sedimentação eólica resultaria da alternância entre estes períodos. 
Segundo o teoria apresentada anteriormente, períodos favoráveis à estabilização ou crescimento e avanço de campos de dunas podem estar associados à dinâmica de migração da linha de costa. Alta taxa de regressão seria favorável à estabilização enquanto que linha de costa estável ou transgressiva seria favorável ao crescimento e avanço dos campos de dunas. $\mathrm{Na}$ planície adjacente à praia do Ji (Laguna, SC), a geração eólica 4 é separada da geração eólica 2 por zona de cordões litorâneos, a qual é recoberta por depósitos irregulares de dunas vegetadas da geração eólica 3. Isto evidencia que houve fase de progradação acelerada da planície costeira anterior ao desenvolvimento da geração eólica 4 (Figura 4.63). A geração eólica 3 teria se desenvolvido durante esta fase de regressão acelerada da linha de costa. O truncamento da geração eólica 2 pelo sistema lagunar indica que esta geração eólica é anterior à máxima inundação associada à elevação do NRM ocorrida após o último período glacial. Logo, os sedimentos da geração eólica 2 teriam sido depositados, pelo menos em parte, durante fase de linha de costa transgressiva. 


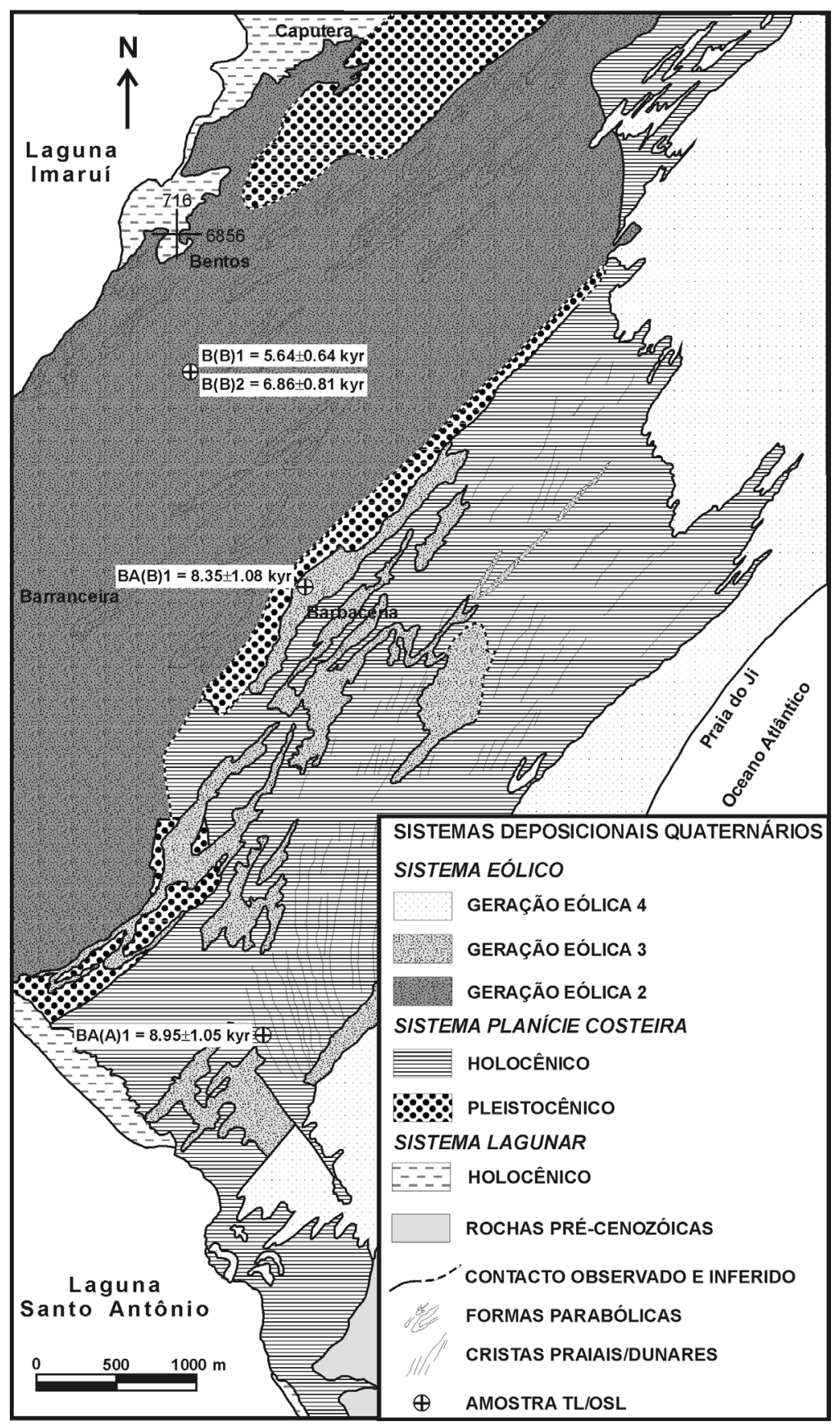

Figura 4.63 - A geração eólica 2 é separada da geração eólica 4 por zona de cordões litorâneos (Sistema planície costeira holocênico). A geração eólica 3 é formada por fácies eólicas de baixo suprimento sedimentar, que se desenvolvem sobre o sistema planície costeira holocênico. A geração eólica 2 teria se desenvolvido em contexto de linha de costa transgressiva/estável. A geração 3 representaria fase de linha de costa com regressão acelerada e a geração 4 representaria fase mais recente de linha de costa mais estável. Por este motivo, as gerações 2 e 4 seriam mais desenvolvidas que a geração 3. Idades TL/OSL confirma a contemporaneidade entre a geração eólica 3 e os cordões litorâneos do sistema planície costeira (amostras BA(A)1 e BA(B)1). As idades TL/OSL também indicam que a atividade da geração eólica 2 persistiu por alguns milhares 
de anos após o início da regressão da linha de costa e formação da planície costeira (amostras $\mathrm{B}(\mathrm{B}) 1$ e $\mathrm{B}(\mathrm{B}) 2)$ ).

As gerações eólicas 2 e 4 representariam dois episódios de maior atividade do sistema eólico, os quais estariam ligados à dinâmica de migração da linha de costa. A geração eólica 2 abrange área muito maior do que a abrangida pela geração eólica 4. Isto sugere que o período de atividade da geração 2 é superior ao da geração 4 e/ou que a geração 2 (costa transgressiva/estável) desenvolveu-se sob condições mais favoráveis ao crescimento dos campos de dunas que a geração 4 (costa regressiva/estável). Na localidade de Barbacena (Figura 4.53), a idade obtida para o cordão litorâneo mais interno, adjacente à geração eólica 2, foi de $8950 \pm$ 1050 anos AP (antes do presente). Esta idade indica aproximadamente o começo da fase regressiva nesta localidade, que pode corresponder ao princípio do período de estabilização da geração eólica 2 e formação da geração 3. A implantação desta fase de linha de costa regressiva pode estar associada à desaceleração da subida do NRM, posterior ao último período glacial. Porém, não há dados que permitam avaliar de modo preciso as variações de NRM anteriores a 5100 anos no litoral centro-sul catarinense. A curva de variação do NRM elaborada a partir de carapaças de vermetídeos sugere que não houve grandes variações da taxa de queda do NRM nos últimos 5100 anos (Angulo et al., 1999). Assim, a fase mais recente de linha de costa regressiva/estável, sugerida como agente indutor do desenvolvimento da geração eólica 4, pode não estar relacionada às variações do NRM.

Amplas áreas com dunas eólicas estabilizadas adjacentes a campos de dunas livres ativos, tal como a configuração apresentada pelas gerações eólicas 2 e 4, também são observadas em outros trechos do litoral brasileiro. No litoral do Rio Grande do Sul observam-se depósitos de dunas vegetadas, cujo modo de ocorrência é semelhante ao da geração eólica 2 do litoral centrosul catarinense, ou seja, as dunas situam-se em região mais interna, encontram-se estabilizadas ou em processo de estabilização e são truncadas ou isoladas da linha de costa pelo sistema lagunar (Figura 4.64). 


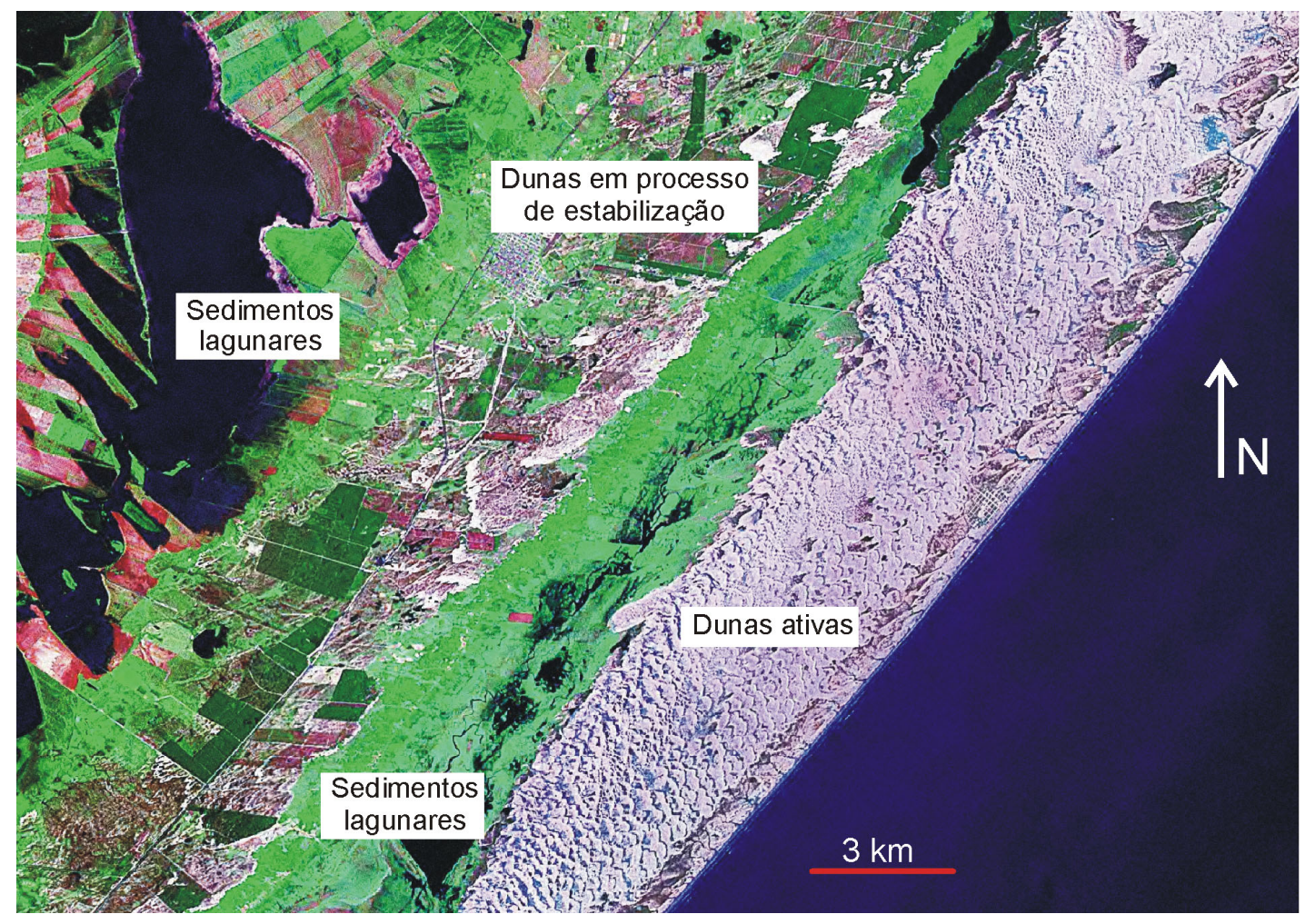

Figura 4.64 - Dunas estabilizadas ou em processo de estabilização truncadas pelo sistema lagunar e separadas dos campos de dunas livres (dunas ativas) em atividade. Os campos de dunas livres avançam sobre planície de cordões litorâneos, o que evidencia fase regressiva (progradacional) após a instalação do sistema lagunar que isolou as dunas em processo de estabilização. Região costeira de Mostardas (RS).

Na costa nordeste (Maranhão) destaca-se a ampla zona de dunas parabólicas estabilizadas situada a sotavento dos Lençóis Maranhenses. Esta zona abrange área muito maior do que a ocupada pelo campo de dunas livres dos Lençóis Maranhenses, o qual avança sobre ela. Estas dunas vegetadas encontram-se truncadas por baías estuarinas (Figura 4.65), configurando situação semelhante à apresentada pelo sistema lagunar e eólico na costa dos estados de Santa Catarina e Rio Grande do Sul. 


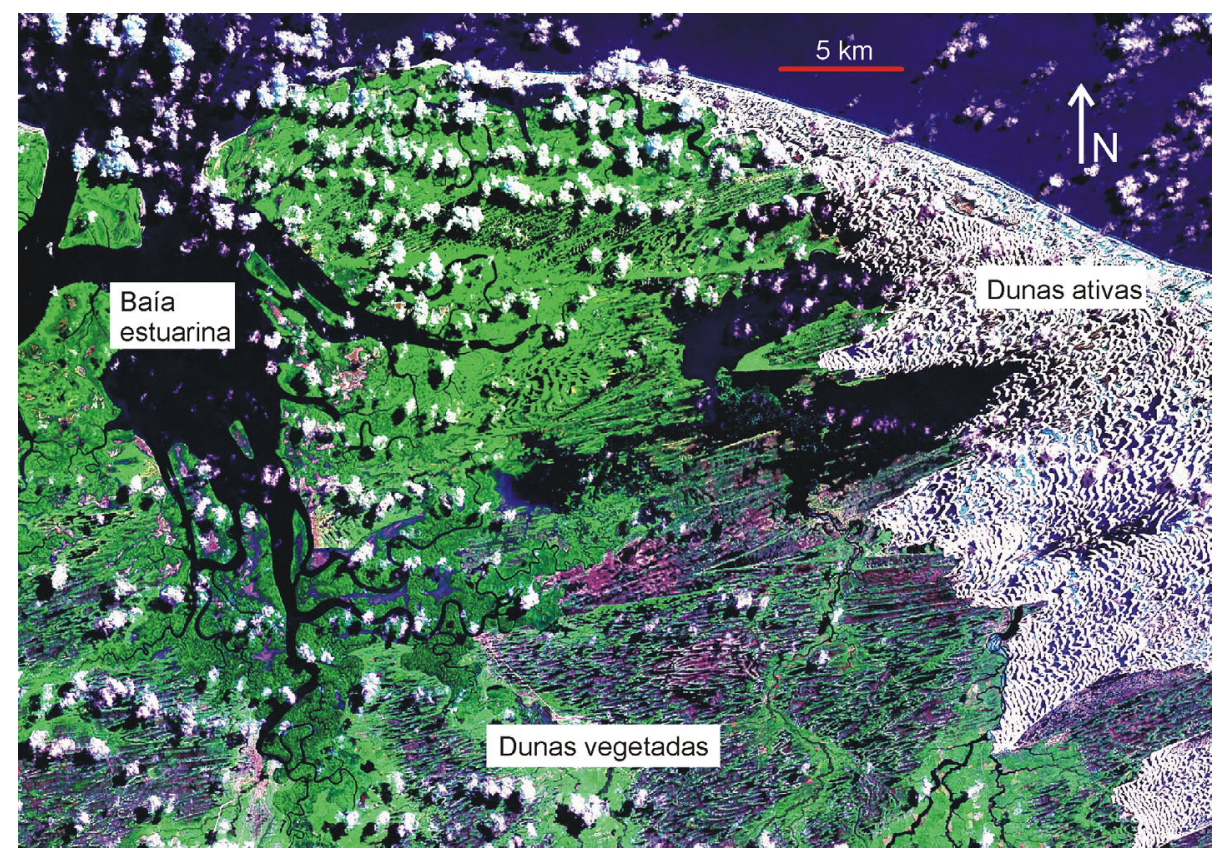

Figura 4.65 - Área de dunas vegetadas (estabilizadas ou em processo de estabilização) a sotavento do campo de dunas dos Lençóis Maranhenses (dunas ativas). Notar o truncamento das dunas vegetadas pelo sistema de baía estuarina. As dunas ativas avançam sobre a área de dunas vegetadas.

Portanto, há diversas semelhanças entre os sedimentos eólicos com morfologia dunar preservada presentes nas costas de Santa Catarina, Rio Grande do Sul e Maranhão. Nestas três regiões, pode-se observar depósitos de dunas estabilizadas que abrangem grande área, os quais são truncados por sistemas de baía estuarina ou lagunar e sobre os quais avançam campos de dunas livres. Os campos de dunas livres ativos e as dunas vegetadas estabilizadas ou em processo de estabilização, situadas a sotavento dos primeiros, evidenciam duas fases de maior atividade do sistema eólico. Estas fases aparentam estar separadas por período de máxima inundação responsável pela formação de baías estuarinas e lagunas seguido por fase de regressão e construção de planície costeira. As diferenças fisiográficas e a distância entre os litorais de Santa Catarina, Rio Grande do Sul e Maranhão apontam para mecanismo de atuação regional, como sendo o fator responsável por estas fases de maior atividade do sistema eólico. Propõe-se que estas duas fases de maior atividade do sistema eólico estejam associadas à dinâmica de migração da linha de costa, que por sua vez mudaria de transgressiva/estável para regressiva e, posteriormente, para regressiva/estável. O final da fase transgressiva/estável e início da fase 
regressiva pode estar associado à desaceleração da subida do NRM, ocorrida após o último período glacial (Wurm).

Apesar de não haver dados cronológicos que permitam correlacionar com segurança os episódios de sedimentação eólica do litoral centro-sul catarinense com episódios observados em outros setores da costa brasileira, o fato de haver dois episódios de sedimentação eólica em zonas bastante distantes e o modo como os sedimentos relativos a estes episódios se relacionam entre si e com outros sistemas deposicionais, permitem supor mecanismo de atuação regional para a gênese destas duas fases de maior atividade do sistema eólico. Este mecanismo corresponderia à influência das variações de NRM sobre a dinâmica de migração da linha de costa.

A associação entre NRM, linha de costa e as duas fases de maior atividade do sistema eólico (correlacionáveis às gerações eólicas 2 e 4 do litoral centro-sul catarinense) permite classificar os depósitos sedimentares correspondentes a estas duas fases em termos de tratos de sistemas deposicionais. A fase mais antiga, correspondente à geração eólica 2 do litoral centrosul catarinense, faria parte do trato de sistemas transgressivo e o início de sua estabilização (intensificação da progradação da planície costeira) representaria a entrada no trato de sistemas de mar alto. A fase inicial deste trato de sistemas é marcada pela menor atividade do sistema eólico (geração eólica 3). Posteriormente, a redução da taxa de regressão ou a estabilização da linha de costa intensificaria a atividade do sistema eólico, que originaria novo episódio de crescimento de campos de dunas (geração eólica 4). Isto conduz à suposição de que haveria uma tendência regional recente, secular a milenar, de estabilização da linha de costa. Essa suposta estabilização poderia resultar do alcance de um equilíbrio entre taxa de variação de NRM (pouco variável desde pelo menos 5000 AP) e aporte sedimentar. Porém, esse equilíbrio teria que ser atingido de modo aproximadamente contemporâneo ao longo de diferentes trechos da costa brasileira. Estas suposições colocam-se como problemas que fogem do escopo deste estudo. No entanto, ilustram o caráter dedutivo decorrente do estudo de sistemas deposicionais mediante abordagem analítica. 


\section{SISTEMAS EÓLICOS INTERIORES}

\subsection{Influência do tamanho e dinâmica da área fonte sobre a evolução de campos de dunas}

Todo sistema eólico envolve a troca de sedimentos entre dois reservatórios: área fonte e área de deposição. Alguns aspectos do modelo conceitual e da dinâmica do sistema eólico costeiro podem ser generalizados para sistemas eólicos alimentados por área fonte continental (planícies aluviais, por exemplo). $\mathrm{O}$ aspecto fundamental que diferencia os sistemas eólicos costeiros de demais sistemas eólicos é a natureza da sua área fonte, que é representada pela zona intermaré. A zona intermaré apresenta como particularidade seu tamanho reduzido, que é definido pela amplitude de maré e declividade da zona intermaré. Estes dois fatores são pouco variáveis no tempo, de modo que o volume máximo de sedimentos estocados na zona intermaré é relativamente constante. O tamanho da zona intermaré controla não só o volume máximo de sedimentos na área fonte, mas também a área exposta à ação do vento. Logo, para um mesmo regime de ventos e sedimentos com mesma granulação, o aumento do fluxo de sedimentos para o campo de dunas torna-se dependente do tamanho da zona intermaré. Assim, o crescimento do campo de dunas costeiro é restringido pelo tamanho da sua área fonte, pois quanto maior o campo de dunas, maior a quantidade e/ou tamanho da dunas e maior o suprimento de sedimentos necessários para manutenção das dunas ativas. A área fonte de campos de dunas costeiros também apresenta outras particularidades que atuam contra o suprimento de sedimentos para o campo de dunas. A imersão diária da zona intermaré possibilita o transporte eólico apenas durante parte do dia (período de emersão com sedimentos incoesos). Além disto, os sedimentos da zona intermaré podem ser transportados para a zona de submaré ou para segmentos praias adjacentes (pela corrente de deriva litorânea). Portanto, o transporte eólico compete com outros agentes de transporte pelo sedimentos da zona intermaré. O crescimento sustentável do campo de dunas só será prolongado caso exista elevação do suprimento sedimentar ao longo do tempo. Por este motivo, o crescimento da área fonte torna-se essencial para a sustentação do crescimento do campo de dunas. Sistemas eólicos alimentados por área fonte de tamanho fixo ou que pode perder sedimentos para áreas vizinhas que não pertencem ao sistema eólico, tal como o sistema eólico costeiro, apresentariam período de crescimento mais curto, pois haveria dificuldade em aumentar o fluxo de sedimentos para o campo de dunas ao longo do tempo. 
Para um mesmo regime de ventos, o fluxo de sedimentos eólicos, que determina a sustentabilidade do crescimento dos campos de dunas, depende do tamanho da área fonte $(A)$, que controla a área exposta à ação do vento e o volume de sedimentos disponíveis, e do intervalo de tempo em que os sedimentos estão incoesos e disponíveis ao transporte pelo vento $(t s)$. O volume de sedimentos disponíveis ao transporte eólico $(V f)$ dependerá do balanço entre os fluxos de entrada ( $q f e)$ e saída $(q f s)$ de sedimentos da área fonte devido à atuação de outros agentes de transporte. Assim, o fluxo máximo de sedimentos eólicos ( $q \mathrm{cmax}$ ) pode ser considerado função destas variáveis (Equação 5.1):

$$
q c \max (A, t s, V f), \text { sendo que } V f(q f e, q f s)
$$

O crescimento de $q c \max$ ao longo do tempo dependerá da variação das variáveis $A, t s, q f e$ e $q f s$ ao longo do tempo. No sistema eólico costeiro, o tamanho da área fonte $(A)$ é pouco variável e não apresenta crescimento regular, o intervalo de tempo em que os sedimentos ficam incoesos (ts) é diminuído pela elevação da maré e pela ocorrência de chuva e o volume de sedimentos armazenados na área fonte dependerá do balanço entre $q f e$ e $q f s$, porém nunca ultrapassará certo valor máximo definido pela amplitude de maré e declividade da zona intermaré. Já em sistemas eólicos que têm como fonte sistemas aluviais por exemplo, a área fonte $(A)$ pode crescer ao longo do tempo. O intervalo de tempo em que os sedimentos ficam incoesos $(t s)$ será diminuido apenas pela ocorrência de chuva e inundações fluviais (que estão associadas à ocorrência de chuvas). O volume de sedimentos na área fonte $(V f)$ pode ser mais elevado, pois os agentes não eólicos que retiram sedimentos da área fonte aluvial ( $q f s$ ) não atuam diariamente tal como a atuação das ondas na zona intermaré. Assim, há grande diferença entre a dinâmica da área fonte de sistemas eólicos costeiros e de sistemas eólicos com fonte em sistemas aluviais. Os campos de dunas com fonte aluvial apresentariam maior suprimento sedimentar (potencial) que os campos de dunas com fonte costeira e, portanto, seu período de crescimento sustentável pode ser maior. Desta forma, os campos de dunas com fonte aluvial podem atingir tamanho muito maior que os campos de dunas costeiros. Poderia se pensar que a maior granulação dos sedimentos de leques aluviais, em relação aos sedimentos praiais, constituiria fator restritivo ao transporte eólico. Porém, a restrição ocorreria somente se não houvesse quantidade significativa de areia. A presença de areia em superfície cascalhosa pode facilitar o transporte desta areia pelo vento. O recobrimento da 
superfície por grãos maiores proporciona maior turbulência na superfície deposicional, o que facilita o transporte dos sedimentos mais finos situados entre os mais grossos (Bagnold, 1941).

A comparação entre a área fonte de sistema eólico costeiro e sistema eólico de fonte aluvial, segundo os fatores descritos anteriormente, pode ser observada na Quadro 5.1.

\begin{tabular}{|l|l|l|}
\hline Variável/característica & Sistema eólico costeiro & $\begin{array}{l}\text { Sistema eólico de fonte } \\
\text { aluvial }\end{array}$ \\
\hline Tipo de área fonte & Zona intermaré & Leque aluvial, rio temporário \\
\hline $\begin{array}{l}\text { Tamanho máximo da área } \\
\text { fonte em função do tempo } \\
(\text { Amax }(t))\end{array}$ & Amax $(t)$ constante & Amax $(t)$ crescente \\
\hline $\begin{array}{l}\text { Agente bloqueador do } \\
\text { transporte eólico }\end{array}$ & Maré e chuvas & Chuvas \\
\hline $\begin{array}{l}\text { Intervalo de tempo com } \\
\text { sedimentos incoesos }(t s)\end{array}$ & ts baixo & ts alto \\
\hline $\begin{array}{l}\text { Volume máximo de } \\
\text { sedimentos disponíveis ao } \\
\text { transporte eólico em função } \\
\text { do tempo }(V f m a x(t))\end{array}$ & Vfmax $(t)$ constante & Vfmax $(t)$ crescente \\
\hline $\begin{array}{l}\text { Volume de sedimentos } \\
\text { eólicos em determinado } \\
\text { instante }(V f)\end{array}$ & $\begin{array}{l}\text { Pf dependerá de }(q f e-q f s) . \\
\text { Pode ser infeior a } V f m a x, \\
\text { pois } q f s \text { pode ser importante }\end{array}$ & $\begin{array}{l}\text { Vf pode ficar próximo a } \\
\text { significativo. }\end{array}$ \\
\hline Abastecimento da fonte & Mais contínua & Mais episódica \\
\hline
\end{tabular}

Quadro 5.1 - Comparação entre a área fonte de sistemas eólicos costeiro e com fonte aluvial de clima seco.

A impossibilidade de crescimento da área fonte (zona intermaré) pode explicar o tamanho reduzido dos campos de dunas costeiros atuais em relação aos campos de dunas de áreas interiores, cuja fonte é representada por leques aluviais, rios entrelaçados ou planícies de deflação. O maior campo de dunas (paleodunas) interiores conhecido do Brasil é o do médio São Francisco, com $7000 \mathrm{~km}^{2}$, depositados em intervalo de tempo de pelo menos 20ka (Barreto, 1996). Isto é cerca de sete vezes maior do que o maior campo de dunas costeiro do Brasil. Desta forma, pressupõe-se relação entre o tamanho dos campos de dunas e sua área fonte. Campos de dunas de tamanho muito elevado estariam associados a sistemas de leques aluviais ou de rios temporários, de modo que haveria ligação entre a evolução destes dois sistemas e de suas sucessões de fácies. 


\subsection{Considerações sobre as sucessões de fácies eólicas de depósitos antigos}

\subsubsection{Análise de fácies em depósitos eólicos}

As sucessões de fácies de sistemas eólicos reúnem baixo número de fácies em relação às formadas por outros tipos de sistemas deposicionais. O fato de os depósitos eólicos serem considerados relativamente homogêneos faz com que suas sucessões de fácies sejam tratadas de modo uniforme e menos detalhado que outros tipos de sucessões de fácies. A suposta homogeneidade dos depósitos eólicos também conduz à idéia de que as sucessões de fácies eólicas pouco informam sobre as condições ambientais passadas do local onde se desenvolveram. A homogeneidade relativa das sucessões de fácies eólicas se refere à litotologia e estratificações. Os tipos de fácies contemplados pelos campos de dunas pouco informam sobre a dinâmica do sistema eólico, pois este sistema diferencia-se dos demais por não possuir divisões maiores com características faciológicas peculiares. Por exemplo, o sistema de planície de maré é divido nas zonas de supramaré, intermaré e submaré, sendo que cada zona abrange um conjunto particular de fácies. O modo como as associações de fácies características de cada zona se empilham permite por exemplo interpretar se a sucessão sedimentar é retrogradacional ou progradacional e assim inferir o modo de variação da linha de costa ou NRM e, por conseguinte, fatores a eles ligados. A análise da sucessão de fácies de um sistema de planície de maré permite não só indentificar o tipo de sistema deposicional, mas também inferir o comportamento de fatores que influenciam sua dinâmica, ou seja, há relação mais bem estabelecida entre processos e produtos. A análise de fácies tradicional, ou seja, aquela que visa apenas descrever de modo qualitativo as fácies sedimentares, não permite que se aplique o raciocínio exemplificado pelo sistema de maré a uma sucessão de fácies eólicas.

Kocurek \& Havholm (1993) reconheceram dois tipos distintos de sistemas eólicos, os quais se diferenciam pelo suprimento sedimentar. Estes sistemas foram nomeados sistema eólico seco (maior suprimento) e sistema eólico úmido (menor suprimento). Esta classificação merece destaque, pois relaciona não só os tipos de fácies, mas também a proporção entre fácies, ao suprimento sedimentar, que por sua vez está ligado a fatores que interferem na dinâmica do sistema eólico, como por exemplo clima e NRM. Os fatores que controlam a dinâmica do sistema eólico afetam principalmente o suprimento de sedimentos ao campo de dunas. A variação do 
suprimento sedimentar modificará o tipo de fácies do sistema eólico apenas se for muito intensa. Variações menores modificam apenas a altura e espaçamento entre dunas e taxa de avanço do campo de dunas. Estas seriam características mais sensíveis do sistema eólico. Assim, a análise da proporção das fácies de interdunas e da espessura das fácies de dunas poderiam trazer mais informações sobre a dinâmica pretérita do sistema eólico que a simples descrição das fácies. Uma análise de fácies que possibilite avaliação mais refinada do significado das sucessões de fácies eólicas requer melhor conhecimento do funcionamento do sistema eólico, especialmente no modo como as partes que constituem o sistema respondem a alterações ambientais diversas. Isto possibilitaria uma análise de fácies mais analítica e menos "descritivista". Alguns conceitos acerca da dinâmica dos campos de dunas, advindos dos experimentos de simulação, podem ser utilizados neste sentido, ou seja, para análise do significado das sucessões de fácies eólicas, tais como as apresentadas pelas unidades litoestratigráficas Pirambóia, Botucatu, Serra Geral e Caiuá.

\subsubsection{As sucessões de fácies eólicas das formações Pirambóia, Botucatu, Serra Geral e do Grupo}

\section{Caiuá}

As formações Pirambóia, Botucatu e Serra Geral e o Grupo Caiuá destacam-se por possuírem fácies sedimentares predominantemente eólicas e por ocorrerem sobrepostas entre si, formando sucessão sedimentar de centenas de metros de espessura e que recobre área de centenas de milhares a milhões de quilômetros quadrados. A Formação Pirambóia é a unidade mais antiga desta sucessão e seus sedimentos teriam sido depositados no final do Permiano e/ou início do Triássico. A unidade mais jovem é representada pelo Grupo Caiuá, que recobre basaltos da Formação Serra Geral, os quais possuem idade eocretácica. Portanto, estas unidades litoestratigráficas representam período de tempo cujo registro sedimentar é dominado pela sedimentação eólica. A elevada continuidade lateral de associações de fácies eólicas de aporte sedimentar elevado indica ainda que estas unidades representam campos de dunas de tamanho muito grande, o que pressupõe existência de área fonte capaz de manter o suprimento adequado ao crescimento sustentável dos campos de dunas por longo período de tempo. Diversas questões acerca desta sucessão eólica são polêmicas ou encontram-se em aberto, como por exemplo, as relações de contato entre as unidades litoestratigráficas, suas idades e as áreas fontes para os campos de dunas. 
A Formação Pirambóia compreende associação de fácies eólicas e aluviais. As fácies eólicas são representadas por depósitos de lençóis de areia, interdunas e dunas enquanto que as fácies aluviais são representadas por depósitos de rios entrelaçados e rios efêmeros (Figura 5.1). As fácies de lençol de areia ocorrem na porção inferior da unidade, que também apresenta maior proporção de fácies de interdunas. As fácies de dunas (séries de estratificações cruzadas acanaladas) aumentam de espessura e tornam-se mais freqüentes rumo ao topo da unidade, onde ocorrem intercaladas a fácies de rios entrelaçados. O topo da Formação Pirambóia é caracterizado pela ampla distribuição de depósitos de rios entrelaçados. Assim, a sucessão vertical de fácies observada na Formação Pirambóia representa incremento ascendente das fácies eólicas de suprimento mais elevado, as quais são recobertas por depósitos aluviais. Esta sucessão indicaria atividade de sistema eólico com campos de dunas em crescimento sustentável sobreposto por sistema aluvial. A sucessão de fácies indica avanço do sistema aluvial sobre o sistema eólico em franco desenvolvimento, pois fácies aluviais ocorrem intercaladas a associação de fácies com alta proporção de fácies de dunas eólicas. A Formação Pirambóia recobre depósitos de mar restrito do Grupo Passa Dois, os quais são predominantemente lamosos e não abrangem sistemas deposicionais de elevado aporte arenosos, capazes de alimentar de forma sustentável os campos de dunas do sistema eólico Pirambóia. Portanto, coloca-se como melhor candidato a fonte alimentadora dos campos de dunas, o sistema aluvial que progradou sobre o sistema eólico e cujos depósitos ocorrem com maior freqüência no topo da Formação Pirambóia. De acordo com alguns autores (Fúlfaro \& Bósio, 1968; Matos, 1995; Donatti et al., 2001), o Sistema Deposicional Eólico Pirambóia seria contemporâneo aos sistemas deposicionais de mar raso ou lacustres do Grupo Passa Dois (formações Teresina, Corumbataí e Rio do Rasto). Apesar de ocorrer adjacente à costa, grande parte do Sistema Eólico Pirambóia não seria genuinamente costeiro, pois sua área fonte seria aluvial. 

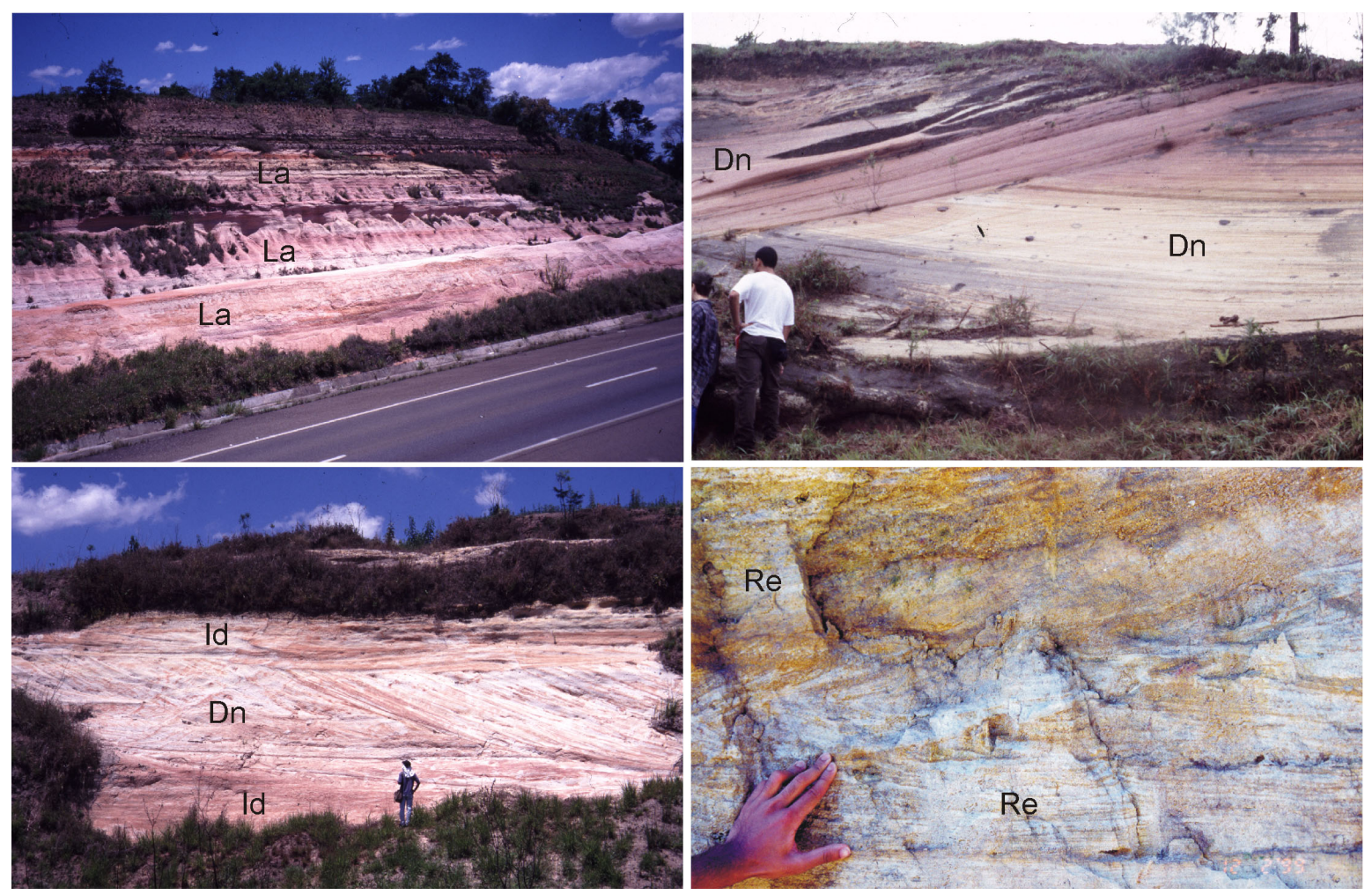

Figura 5.1 - Principais fácies que compõem a Formação Pirambóia: fácies de lençol de areia (La), fácies de dunas (Dn), fácies de interdunas (Id) e fácies de barras de rios entrelaçados (Re).

As paleocorrentes medidas em arenitos conglomeráticos com estratificações cruzadas indicam que o sistema aluvial teria avançado rumo oeste sobre o sistema eólico. Paleoventos inferidos a partir de fácies de dunas eólicas indicam que a Formação Pirambóia contempla dois grandes campos de dunas, com rumos de avanço aproximadamente opostos. O crescimento do sistema eólico seria condicionado pelo crescimento do sistema aluvial, que por sua vez avançaria sobre o sistema eólico. O crescimento e avanço do sistema aluvial para oeste pode estar ligado à redução da taxa de subsidência e soerguimento do embasamento da bacia a leste. Os sistemas de leques aluviais do topo da Formação Pirambóia marcariam o final de uma fase de subsidência e máximo assoreamento da bacia.

A Formação Botucatu é formada por sucessão de séries métricas a decamétricas de arenitos com estratificações cruzadas acanaladas. Observam-se raramente estratificações planoparalelas. Os depósitos desta unidade representam sucessão de fácies de campo de dunas de elevado suprimento sedimentar. O elevado suprimento sedimentar indicado pela sua sucessão de fácies (baixa proporção de fácies de interdunas e fácies de dunas de espessura muito elevada) é a 
característica que mais distingue a Formação Botucatu da Formação Pirambóia. Nos termos de Kocurek \& Havholm (1993), a Formação Pirambóia seria representativa de sistema eólico úmido e a Formação Botucatu, de sistema eólico seco (Giannini et al., 2004, 2006). Um grande problema da Formação Botucatu é que ela representa uma sucessão de fácies eólicas incompleta, pois contém apenas fácies de centro de campo de dunas, faltanto fácies de periferia de campo de dunas e também fácies representativas da sua área fonte. A sucessão de fácies eólicas da Formação Botucatu é recoberta por vulcânicas da Formação Serra Geral, que também apresenta intercalações de fácies eólicas, idênticas às que ocorrem na Formação Botucatu. Portanto, as formações Botucatu e Serra Geral abrangem uma mesma associação de fácies eólicas, que interdigita-se com rochas vulcânicas. Deste modo, representa uma associação de centro de campos de dunas recoberta por derrames de lava (principalmente de composição básica). As fácies eólicas (de elevado suprimento sedimentar!) destas duas unidades e de unidades correlatas na Argentina, Uruguai e Paraguai abrangem área de aproximadamente $1.300 .000 \mathrm{~km}^{2}$ (Assine et al., 2004). Por representarem associação de fácies de maior suprimento sedimentar que a apresentada pela Formação Pirambóia, o Sistema Eólico Botucatu-Serra Geral requer área fonte capaz de propiciar a manutenção de dunas livres em campo de dunas em franco crescimento. $\mathrm{O}$ crescimento do campo de dunas sob estas condições só ocorre mediante elevação do suprimento de sedimentos ao longo do tempo. Isto sugere a existência de área fonte também crescente. $\mathrm{O}$ contraste de maturidade mineralógica entre os arenitos da formações Botucatu (mais maturos) e Pirambóia (menos maturos), além da mudança faciológica abrupta (de associação de fácies de suprimento mais reduzido para associação de maior suprimento), eliminam a hipótese de continuidade da sedimentação entre estas duas unidades. A interdigitação entre fácies eólicas da Formação Pirambóia e suas fácies aluviais de topo, impede a consideração destas últimas como fonte para o Sistema Eólico Botucatu - Serra Geral. A contemporaneidade entre o Sistema Eólico Pirambóia e os sistemas deposicionais do Grupo Passa Dois indicaria idade permo-triássica para o Sistema Eólico Pirambóia e a interdigitação entre rochas vulcânicas e arenitos eólicos da Formação Serra Geral indicaria idade eocretácica para o Sistema Eólico Botucatu - Serra Geral. Assim, haveria hiato deposicional de pelo menos dezenas de milhares de anos entre os períodos de atividade dos sistemas deposicionais Pirambóia e Botucatu - Serra Geral. Este hiato poderia ser superior a 100 milhões de anos caso seja considerada idade permiana para as rochas da 
Formação Pirambóia. Portanto, persiste o problema das áreas fontes do Sistema Eólico Botucatu Serra Geral.

O caráter interior (desértico) do Sistema Eólico Botucatu - Serra Geral associado ao elevadíssimo tamanho dos seus campos de dunas sugere área fonte aluvial para este sistema. Portanto, a sucessão sedimentar completa representativa deste sistema deposicional, incluindo sua área fonte, deveria abranger fácies eólicas e aluviais. Acima das rochas vulcânicas da Formação Serra Geral encontram-se as unidades eólicas e aluviais do Grupo Caiuá (Fernandes, 1998). As fácies eólicas do Grupo Cauiá são representadas por arenitos finos a muito finos com séries métricas a decamétricas de estratificação cruzada acanalada e arenitos com estratificação plano-paralela. Estas fácies representam associação de fácies de dunas e interdunas e de lençol de areia. Portanto, corresponde a uma associação de menor suprimento sedimentar do que a representada pelas formações Botucatu e Serra Geral. As fácies eólicas do Grupo Caiuá interdigitam-se e passam lateralmente para fácies de sistemas aluviais. Trata-se portanto de uma associação eólica de baixo suprimento (em relação à apresentada pelo Sistema Botucatu-Serra Geral), a qual foi recoberta pela progradação de associação de fácies aluvial. Esta associação eólica-aluvial pode corresponder às partes ausentes do Sistema Eólico Botucatu-Serra Geral, ou seja, as fácies de periferia de campo de dunas e as fácies da área fonte aluvial. Neste caso, as fácies eólicas e aluviais das unidades Botucatu, Serra Geral e Cauiá fariam parte de um mesmo sistema deposicional, o Sistema Deposicional Eólico-Aluvial Botucatu - Serra Geral -Caiuá (Figura 5.2). Este sistema apresenta como singularidade o fato de ter sido recoberto por derrames de lava, os quais inibiram a atividade do sistema eólico, principalmente na sua porção central. Porém, com o término da atividade magmática teria havido retomada da sedimentação eólica e recobrimento dos derrames por campos de dunas e destes por sistemas aluviais da borda da bacia (representados pelos depósitos do Grupo Caiuá). Neste caso, não haveria hiato deposicional entre as unidades Botucatu, Serra Geral e Caiuá. Pelo menos nas áreas de borda de bacia. 
A

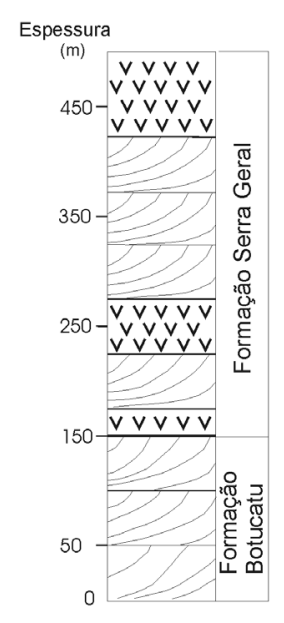

B

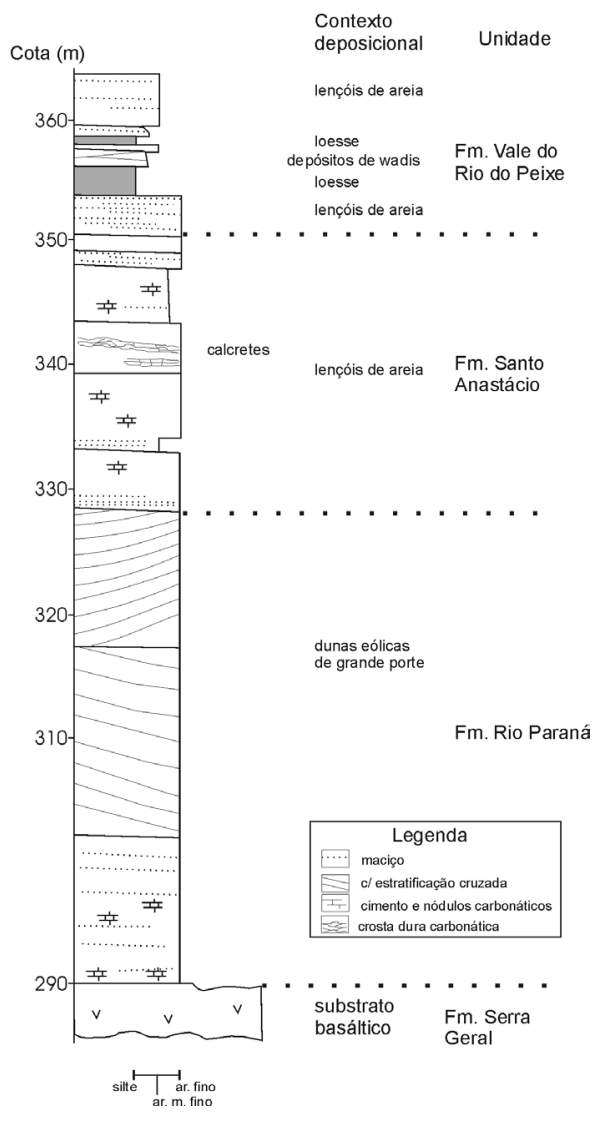

Figura 5.2 - A seção A representa as formações Botucatu e Serra Geral aflorantes na serra de Botucatu (Botucatu, SP). A seção B foi elaborada por Fernandes (1998) e representa unidades do Grupo Caiuá (formações Rio Paraná e Santo Anastácio) e do Grupo Bauru (Formação Vale do Rio do Peixe), que afloram em Pereira Barreto (SP). A associação de fácies basal do Grupo Caiuá é indicativa de campos de dunas de suprimento elevado. Esta associação equivale às associações de fácies eólicas das formações Botucatu e Serra Geral. As formações Santo Anastácio e Vale do Rio do Peixe contêm associações de fácies eólicas de suprimento reduzido (periferia de campos de dunas).

A semelhança dos paleoventos (indicados por rumos de mergulho de estratificações cruzadas) e da maturidade mineralógica (determinada por minerais pesados) dos arenitos da Formação Botucatu e do Grupo Caiuá não permitem a rejeição da hipótese de continuidade da sedimentação entre estas unidades. Logo, estas unidades fariam parte de um mesmo ciclo de subsidência, iniciado antes da atividade magmática registrada na Formação Serra Geral. A associação genética entre as fácies das unidades Botucatu, Serra Geral e Caiuá resolve o problema das áreas fontes e das fácies de periferia de campo de dunas do Sistema Eólico Botucatu - Serra Geral. Sob este ponto de vista, as pegadas fósseis de vertebrados, que ocorrem 
na Formação Botucatu estariam associadas aos vertebrados fósseis do Grupo Bauru. De certa forma, isto resolve o problema da falta de ambientes propícios à vida na época da sedimentação Botucatu, ou seja, tais vertebrados viveriam nas zonas mais úmidas situadas na periferia dos campos de dunas. Sob esta óptica, também haveria mudanças de cunho estratigráfico. Caso se considerem os depósitos do ciclo de subsidência posterior à Formação Pirambóia como sendo pertencentes a outra bacia sedimentar (Bacia Bauru), as formações Botucatu e Serra Geral seriam unidades da Bacia Bauru. Portanto, a sedimentação da Bacia do Paraná teria sido encerrada com a Formação Pirambóia. O vínculo entre a Formação Botucatu e a Bacia Bauru implica que a fase de subsidência responsável pela geração desta bacia teria se iniciado na época da sedimentação Botucatu, ou seja, anterior ao magmatismo Serra Geral. A subsidência pré-magmatismo pode estar vinculada à falhas normais geradas por esforços distensivos (subsidência mecânica) e/ou a desequilíbrio isostático proporcionado por afinamento crustal (McKenzie, 1978). A Formação Botucatu seria o registro do início do ciclo de subsidência e seu depocentro pode estar indicar a zona de máximo afinamento crustal. Após o magmatismo, a subsidência seria incrementada pelo peso e resfriamento das rochas ígneas recém cristalizadas (subsidência flexural e termal). Convém salientar que estas considerações derivam de hipótese proposta para explicar a gênese dos campos de dunas representados pelas formações Botucatu e Serra Geral. Portanto, também são de cárater hipotético. Este exemplo ilustra o modo de análise do registro sedimentar baseada em conceitos derivados de modelo de dinâmica de sistemas deposicionais. Esta abordagem permite analisar problemas de ordem diversa (estratigráficos, paleogeográficos, etc), que ultrapassam, porém se relacionam, à evolução dos sistemas deposicionais. 


\section{CONSIDERAÇÕES SOBRE OS DEPÓSITOS EÓLICOS COMO RESERVATÓRIOS DE HIDROCARBONETOS}

\subsection{Reservatórios eólicos}

Segundo North \& Prosser (1993), os reservatórios formados por depósitos eólicos eram considerados simples e homogêneos. No entanto, a história produtiva de muitos campos petrolíferos localizados neste tipo de reservatório têm demonstrado que a simplicidade é aparente. Lâminas de fluxo de grãos podem apresentar porosidade e permeabilidade uma ordem de magnitude maior que a de estratos adjacentes. Processos de cimentação precoce na base de campos de dunas podem produzir barreiras para a permeabilidade vertical. A interdigitação entre fácies de dunas e interdunas e entre fácies eólicas e fácies de sistemas deposicionais adjacentes (fluviais ou costeiros) podem provocar o isolamento de parcelas do reservatório. Estes fatores fazem com que a permeabilidade de reservatórios eólicos seja extremamente anisotrópica (North \& Prosser, 1993). A diversidade faciológica de sistemas deposicionais eólicos úmidos (Kocurek \& Havholm, 1993; Caetano-Chang, 1993; Sawakuchi, 2000; Donatti, 2002) e os tipos de laminação eólica resultam em reservatórios com distribuição de porosidade e permeabilidade altamente variável (Lindquist, 1988). Fácies de dunas e interdunas apresentam valores de porosidade bem distintos e permeabilidade que pode diferir em até quatro ordens de magnitude (Tabela 6.1).

\begin{tabular}{|c|c|c|c|}
\hline Fácies & $\begin{array}{c}\text { Porosidade } \\
\mathbf{( \% )}\end{array}$ & $\begin{array}{c}\text { Permeabilidade } \\
\text { horizontal } \\
\text { (miliDarcy) }\end{array}$ & $\begin{array}{c}\text { Permeabilidade } \\
\text { vertical (miliDarcy) }\end{array}$ \\
\hline Duna (fluxo de grãos) & $16.3 \%$ & 137 a 154 & 200 \\
\hline Interduna & $2.3 \%$ & 0.01 a 0.02 & 0.01 \\
\hline
\end{tabular}

Tabela 6.1 - Valores de porosidade (média) e permeabilidade (horizontal e vertical) em fácies de dunas e interdunas do arenito Nugget (campo petrolífero Anschutz Ranch East, Utah-Wyoming, EUA). Fonte: Lindquist (1988). 
O tipo de laminação tem grande influência nos valores de porosidade e permeabilidade de fácies eólicas. Fácies de dunas formada por laminações de fluxo de grãos bem preservadas apresentam porosidade e permeabilidade significativamente mais elevada do que fácies de dunas composta por lâminas de fluxo de grãos mal preservadas ou queda de grãos (Lindquist, 1988). A anisotropia da permeabilidade em fácies de dunas está associada ao padrão de distribuição dos azimutes de mergulho das estratificações cruzadas. A máxima permeabilidade ocorre na direção perpendicular ao rumo de mergulho das estratificações (Lindquist, 1988). Logo, a modelagem de reservatórios eólicos resume-se na previsão da distribuição espacial das heterogeneidades na escala de laminação e fácies, incluindo o padrão de distribuição dos rumos de mergulho das estratificações.

Fácies eólicas podem ocorrer de forma subordinada em sistemas deposicionais aluviais. Desta forma, pode haver reservatórios mistos, formados pela associação de fácies eólicas e fluviais (Ellis, 1993). Em geral, fácies de dunas eólicas constituem reservatórios melhores que os formados por fácies fluviais. Assim, é de suma importância para a exploração de hidrocarbonetos conhecer as parcelas do reservatório mais ricas em fácies eólicas. Isto se traduz no conhecimento da distribuição e preservação das fácies eólicas e fluviais ao longo do desenvolvimento do sistema deposicional em questão.

Strong (1993) descreveu arenitos eólicos triássicos (Lancashire, Reino Unido) com porosidade extremamente alta $(25-30 \%)$. Neste caso, trata-se de porosidade secundária formada pela dissolução de cimentos eodiagenéticos (calcita, dolomita não ferrosa e possivelmente gipsita, anidrita e halita), os quais teriam preservado a porosidade primária durante o soterramento e litificação dos sedimentos eólicos. Depósitos eólicos acumulados sob clima árido, associado a sabkhas, são altamente suscetíveis à cimentação precoce evaporítica. Este caso ilustra a importância da diagênese na geração de porosidade em arenitos eólicos formados por sedimentos de sistema eólico seco. Caso análogo foi observado por França et al. (2003) no arenito Botucatu (Bacia do Paraná).

Deformação tectônica rúptil pode produzir zonas de cimentação intensa (bandas de deformação). Fruturas podem inicialmente servir de conduto para a migração de fluidos diagenéticos cimentantes. A cimentação ocorre tanto ao longo das fraturas como nos estratos adjacentes, onde se processa de forma heterogênea devido às diferenças de porosidade e permeabilidade das laminações eólicas. A elevada permeabilidade das lâminas de fluxo de grãos 
amplifica a zona de cimentação. Desta forma, a cimentação pode resultar da interação entre fatores tectônicos e sedimentares. As bandas de deformação atuam como barreiras hidráulicas e provocam a compartimentação do reservatório eólico (Edwards et al., 1993).

Apesar de apresentarem certa homogeneidade litológica, os depósitos eólicos não podem ser considerados homogêneos do ponto de vista da caracterização de reservatórios de hidrocarbonetos. A precisão desta caracterização depende da capacidade dos modelos de sistemas deposicionais eólicos em descrever e prever a distribuição das fácies eólicas. Tais modelos também devem fornecer subsídios para o entendimento das modificações das fácies devido à atuação de processos pós-deposicionais.

\subsection{Modelos de reservatórios eólicos baseados em modelos de fácies sedimentares}

As heterogeneidades ligadas a processos deposicionais (heterogeneidades primárias) controlam em grande parte as propriedades petrofísicas (porosidade e permeabilidade) dos reservatórios eólicos. As heterogeneidades primárias são representadas pelo arranjo espacial das fácies sedimentares e de suas estratificações. Fácies de dunas e interdunas podem apresentar grande variação de permeabilidade, que pode diferir em mais de uma ordem de magnitude entre estas fácies. A maior parcela volumétrica destes reservatórios corresponde à associação de fácies de campos de dunas, que é caracterizada pela alternância entre fácies de dunas e interdunas. As fácies de interdunas apresentam maior teor em sedimentos pelíticos e podem apresentar também arcabouço com empacotamento mais fechado que as fácies de dunas. A presença de sedimentos pelíticos e o empacotamento mais fechado diminuem o tamanho dos poros, o que aumenta a pressão capilar (pressão de injecção) e diminui a permeabilidade das fácies de interdunas. A menor permeabilidade das fácies de interdunas interfere na migração secundária e pode propiciar o aprisionamento de hidrocarbonetos. O comportamento diferencial das fácies de interdunas no que diz respeito à migração e aprisionamento de hidrocarbonetos pode ser observado nos arenitos asfálticos da Formação Pirambóia, onde se notam fácies de interdunas desprovidas de hidrocarbonetos adjacentes a fácies de dunas altamente impregnadas por hidrocarbonetos (Figura $6.1)$. 


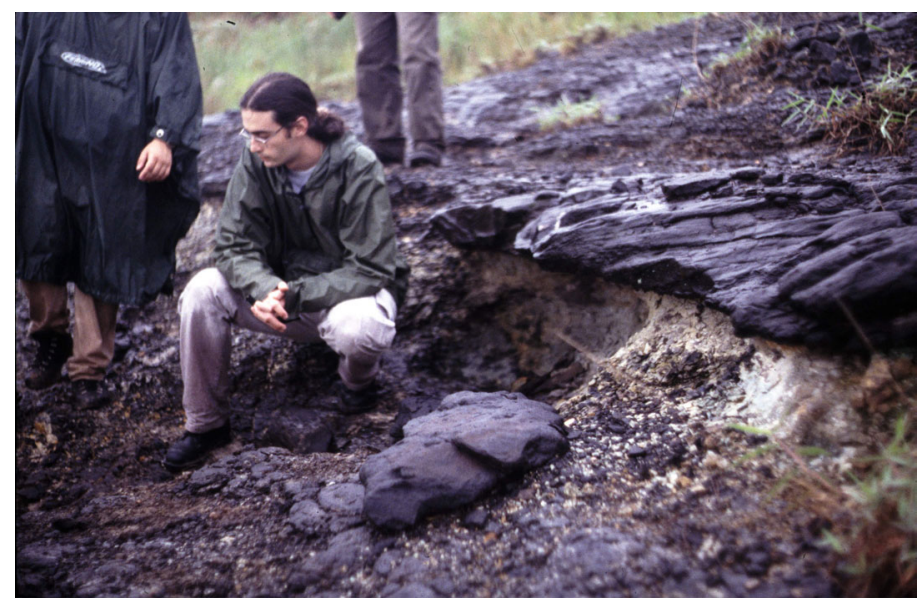

Figura 6.1 - Preenchimento diferencial de hidrocarbonetos em fácies de dunas e interdunas da Formação Pirambóia. As fácies de dunas são preenchidas preferecialmente por hidrocarbonetos (arenito fino de cor preta) enquanto que fácies de interdunas (arenito fino pelítico esbranquiçado) podem servir de barreira interna à migração dos hidrocarbonetos. Foto: Paulo César Fonseca Giannini.

A migração secundária de hidrocarbonetos é controlada pelo balanço entre a pressão capilar (Pc), que está diretamente ligada ao diâmetro das gargantas dos poros, e a força de flutuação $(\mathrm{Pe})$ devido à diferença de densidade entre os hidrocarbonetos e a água subterrânea, a qual depende da altura da coluna de hidrocarbonetos. Para haver migração secundária, a força de flutuação deve superar a pressão capilar das gargantas dos poros (Figura 6.2).

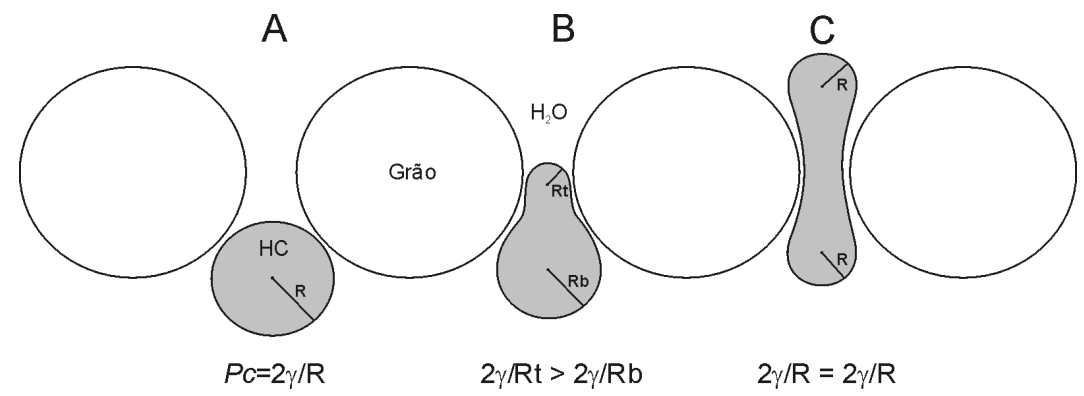

Figura 6.2 - Transporte de glóbulo de óleo através da garganta de um poro (Berg, 1975). Em A, a pressão capilar $(P c)$ na superfície do glóbulo é uniforme, de modo que não há gradiente de pressão capilar. Ao adentrar na garganta do poro, a pressão capilar no topo do glóbulo torna-se superior à da base (B). Isto cria um gradiente de pressão capilar com força dirigida para baixo, contrária à força de flutuação $(P e)$. Ao atravessar a garganta do poro, a pressão capilar no topo do glóbulo é igualada pela pressão da base (C). Nesta condição, o gradiente de pressão capilar é nulo e o glóbulo é transportado para cima pela força de flutuação. A migração secundária ocorre quando a força de flutuação $(P e)$ supera o gradiente de pressão capilar dirigido para baixo $(P c)$. A 
retenção de hidrocarbonetos ocorre quando a força de flutuação não for suficiente para que o glóbulo de óleo adentre a garganta do poro. Rt representa o raio da garganta do poro, $R p$ o raio do poro conectado à garganta e $\gamma$ representa a tensão interfacial óleo-água.

A força de flutuação $(P e)$ é proporcional ao produto da altura da coluna de hidrocarbonetos pela diferença de densidade entre a água e o hidrocarboneto em questão (Equação 6.1).

$P e=h g\left(\rho_{H C}-\rho_{H 2 O}\right)$

onde, $h$ é a altura da coluna de hidrocarbonetos, g é a aceleração da gravidade e $\rho_{\mathrm{HC}}$ e $\rho_{\mathrm{H} 2 \mathrm{O}}$ corresponde respectivamente à densidade dos hidrocarbonetos e da água.

A pressão capilar relaciona-se com os raios do poro $(R p)$ e da garganta do poro $(R t)$ e com a tensão interfacial hidrocarbonetos-água $(\gamma)$. A pressão capilar é descrita por (Equação 6,2):

$$
P c=2 \gamma\left(\frac{1}{R t}-\frac{1}{R p}\right)
$$

As fácies de interdunas podem ser consideradas elementos de maior pressão capilar e sua geometria tabular e disposição horizontal as torna potenciais barreiras à migração vertical de hidrocarbonetos. A relação entre o teor em pelíticos das fácies de interdunas e a espessura das fácies de dunas será de extrema importância para a migração secundária de hidrocarbonetos. A espessura das fácies de dunas pode definir a altura da coluna de hidrocarbonetos e controlar a migração secundária e aprisionamento de hidrocarbonetos nos reservatórios eólicos (Figura 6.3). 


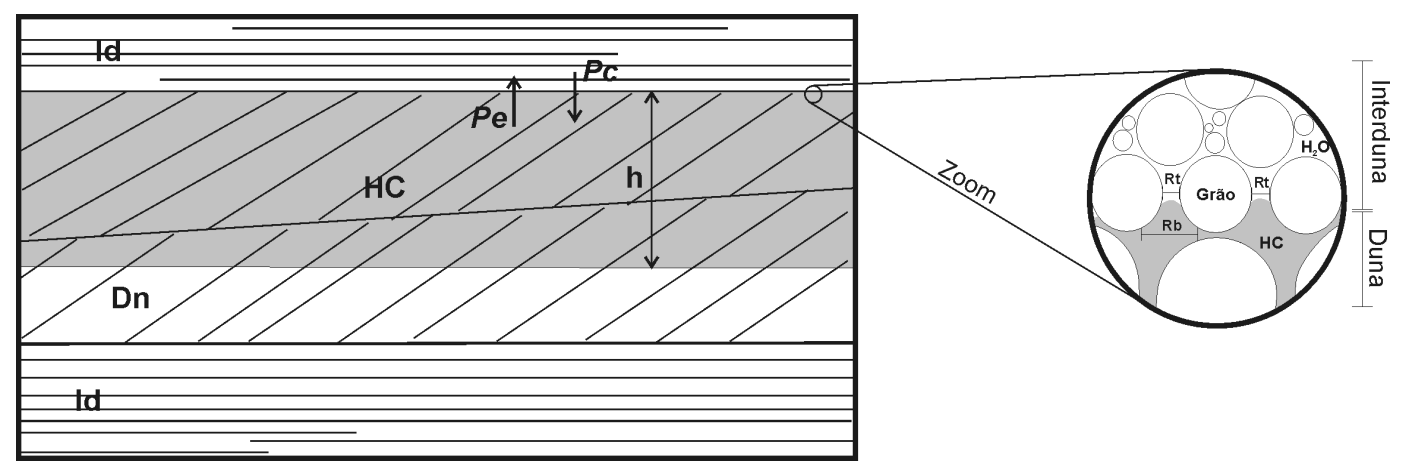

Figura 6.3 - Fácies de dunas (Dn) entre fácies de interdunas (Id). A pressão capilar $(P c)$ das fácies de interdunas relaciona-se ao conteúdo de sedimentos pelíticos e a altura máxima da coluna de hidrocarbonetos (HC) das fácies de dunas relaciona-se à espessura das séries de estratificações cruzadas e ao número de séries sobrepostas. A migração vertical ocorrerá somente se $P c$ superar $\mathrm{Pe}$.

As fácies do sistema eólico podem ser caracterizadas quanto à pressão capilar. Esta caracterização leva em conta apenas fatores ligados a processos deposicionais e pode variar drasticamente devido a processos diagenéticos, tais como cimentação e dissolução pósdeposicional. Além das fácies de dunas e interdunas, acrescenta-se a fácies de lençol de areia, que pode apresentar características petrofísicas semelhantes às das fácies de interdunas, porém distinguem-se pela sua maior continuidade lateral. A caracterização qualitativa das fácies de dunas, interdunas e lençol de areia pode ser vista no Quadro 6.1. Esta caracterização pode ser quantificada mediante medidas de diâmetro dos poros, espessura e comprimento das fácies.

\begin{tabular}{|l|l|l|l|}
\hline Fácies & Pressão capilar & Espessura & $\begin{array}{l}\text { Continuidade } \\
\text { lateral }\end{array}$ \\
\hline Dunas & Baixa & Decimétrica a decamétrica & Baixa a alta \\
\hline Interdunas & Alta & Decimétrica a métrica & Baixa a média \\
\hline Lençol de areia & Alta & Decimétrica a métrica & Alta \\
\hline
\end{tabular}

Quadro 6.1 - Caracterização qualitativa de propriedades sedimentológicas, morfométricas e petrofísicas das fácies de dunas, interdunas e lençol de areia. As propriedades das fácies listadas na tabela são classificadas de modo relativo entre si.

As características texturais e o contexto deposicional das fácies eólicas podem controlar a história diagética destas fácies. Fácies de interdunas e lençol de areia se desenvolvem em zona mais próxima ao nível freático, o que pode favorecer sua cimentação precoce. Além disto, a cimentação também será favorecida pela menor permeabilidade original destas fácies (devido ao 
maior conteúdo de sedimentos pelíticos e arcabouço com empacotamento mais fechado). Esta predisposição à cimentação apenas aumentaria o contraste de pressão capilar entre fácies de dunas e fácies de interdunas e lençol de areia. Estas três fácies perfazem a maior parcela volumétrica dos depósitos eólicos de modo que pode-se elaborar modelo de reservatório baseado na distribuição espacial destas fácies. Este modelo, apesar de simples, permite definir o estilo da migração secundária e condições para aprisionamento de hidrocarbonetos em depósitos eólicos. O controle da gênese e distribuição das fácies eólicas, por parte do suprimento de sedimentos ao campo de dunas, permite associar estes modelos de reservatório à dinâmica do sistema deposicional eólico. Assim, teria-se modelo de reservatório com significado genético, o que poderia embasar modelos com maior capacidade de predição.

A seguir, é apresentado modelo conceitual de reservatório eólico baseado na distribuição de associações de fácies de suprimento baixo (lençol de areia e interdunas) e elevado (dunas). A distribuição destas associações de fácies definirá o estilo da migração secundária e possibilidades de aprisionamento de hidrocarbonetos. Este modelo representa sistema eólico com suprimento crescente de sedimentos e expansão da associação de fácies de centro de campo de dunas (suprimento elevado). Portanto, configura aumento ascendente das fácies de maior suprimento. Assim, haveria fácies de lençol de areia sobrepostas por fácies de interdunas e dunas, sendo que a proporção dunas/interdunas e a espessura das fácies de dunas aumentam com a evolução do sistema. Deste modo, há redução dos elementos de maior pressão capilar rumo ao topo do reservatório. Esta sucessão de fácies representaria a transição de sistema eólico úmido para sistema eólico seco. As fácies de interdunas e lençol de areia podem constituir barreira à migração vertical. Assim, a migração de hidrocarbonetos na porção inferior do reservatório seria mais horizontal do que na porção superior (mais vertical), dominada pelas fácies de dunas. Fácies de dunas que gradam lateralmente ou que são recobertas em contato convexo por fácies de interdunas podem propiciar o aprisionamento de hidrocarbonetos (Figura 6.4). O aprisionamento dependerá da relação entre a pressão capilar das fácies de interdunas e a espessura das fácies de dunas subjacentes, que controlará a altura da coluna de hidrocarbonetos. Fácies de lençol de areia podem dificultar a entrada direta de hidrocarbonetos a partir das unidades subjacentes. A altura máxima da coluna de hidrocarbonetos em migração dependerá do grau de conectividade e espessura das séries de estratificações cruzadas, que formam as fácies de dunas. 


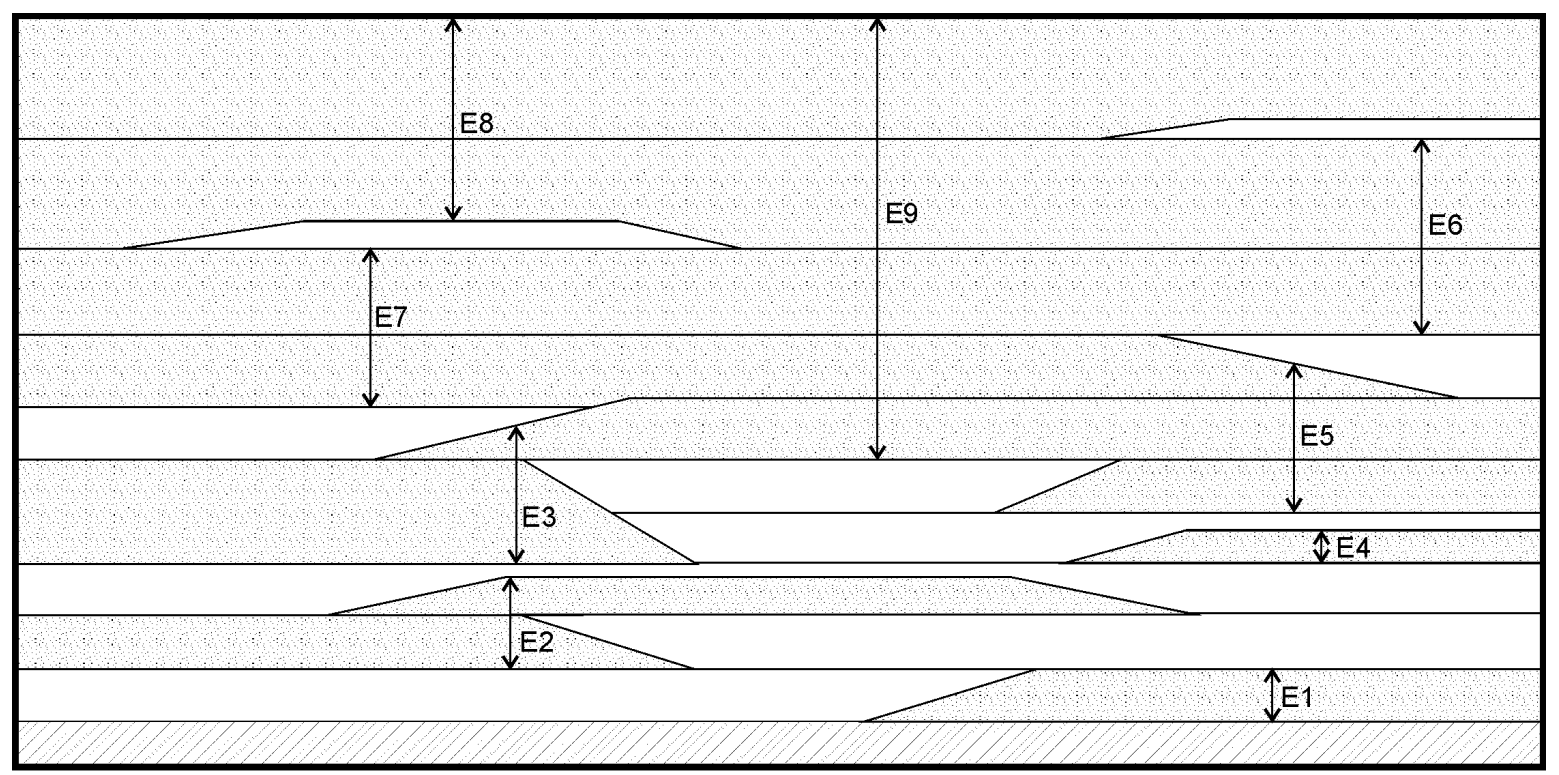

Fácies de lençol de areia

Fácies de interduna

Fácies de duna

Figura 6.4 - Modelo de reservatório para sistema eólico desenvolvido sob suprimento sedimentar crescente. A maior freqüência de fácies de interdunas dificulta a migração vertical na porção inferior do depósito eólico. A migração através das fácies de interdunas dependerá da altura da coluna de óleo nas fácies subjacentes. A espessura e conectividade vertical das fácies de dunas (E) determina a altura máxima da coluna de hidrocarbonetos subjacente a fácies de interdunas. $\mathrm{O}$ aprisionamento de hidrocarbonetos pode ocorrer com o recobrimento de fácies de dunas por fácies de interdunas.

A retenção de hidrocarbonetos por fácies de interdunas ou lençol de areia depende das características da sucessão de fácies subjacente. Neste caso, armadilhas situadas na porção inferior do reservatório teriam maior potencial de aprisionamento, pois estariam sobre zona de menor espessura de fácies de dunas. No entanto, menor espessura de fácies de dunas implica armadilhas de menor volume. A redução do suprimento sedimentar após fase de crescimento e expansão do campo de dunas pode dar origem à sucessão espessa de fácies de dunas recobertas por fácies de interdunas e/ou lençol de areia. Isto pode propiciar a formação de armadilhas de maior volume. A redução de suprimento pode ser relativa, devido ao crescimento do campo de dunas, ou absoluta, provocada por fatores ligados à dinâmica da área fonte. Em sistemas eólicos costeiros, a redução do suprimento de sedimentos ao campo de dunas pode ocorrer pela regressão acelerada da linha de costa e isolamento do campo de dunas da sua área fonte praial. Armadilhas para aprisionamento de hidrocarbonetos também podem ser geradas pelo encobrimento de dunas por material de elevada pressão capilar e com preservação da morfologia. A preservação da 
morfologia dunar requer que o processo responsável por tal encobrimento apresente baixa capacidade de erosão. Como exemplos podem ser citados o encobrimento por derrames de lava básica ou por lamas lagunares. Fácies de dunas com morfologia preservada recobertas por basaltos podem ser observadas na Formação Botucatu (Bacia do Parará).

A divisão do reservatório eólico em termos das fácies de dunas, interdunas e lençol de areia permite ainda a elaboração de modelo para descrever a dinâmica da migração secundária. A sucessão entre elementos tabulares de disposição horizontal e pressão capilar distinta (fácies de dunas e interdunas) pode fazer com que a migração secundária ocorra por pulsos. Isto ocorreria, pois fácies de interdunas requereriam maior coluna de hidrocarbonetos para serem ultrapassadas. Assim, o fornecimento de hidrocarbonetos para armadilhas situadas acima de sucessões de fácies de dunas e interdunas seria descontínuo. Já sucessões de suprimento muito elevado formadas quase exclusivamente por fácies de dunas podem apresentar dinâmica de migração distinta, caracterizada pela maior continuidade do fluxo de hidrocarbonetos (Figura 6.5).

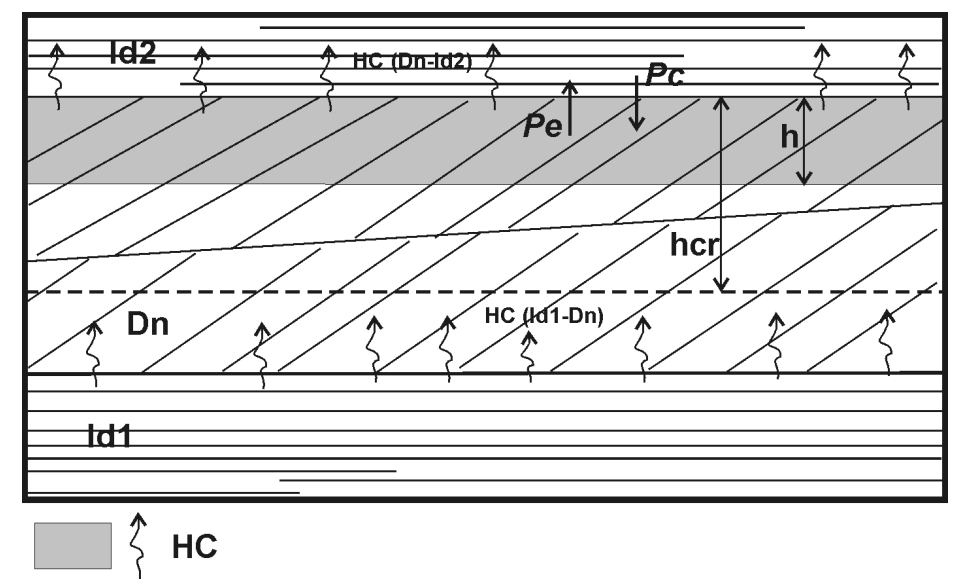

Figura 6.5 - Dinâmica de migração secundária controlada pela sucessão de fácies de dunas e interdunas. A fácies de dunas (Dn) recebe hidrocarbonetos a partir da fácies de interdunas subjacente (fluxo $\mathrm{HC}(\mathrm{Id} 1-\mathrm{Dn})$ ). A presença de fácies de interdunas sobre a fácies de dunas provoca contenção da migração secundária até que a altura da coluna de hidrocarbonetos $(\mathrm{h})$ alcance certo valor (hcr) suficiente para que $P e$ (força de flutuação) supere $P c$ (pressão capilar da fácies de interduna). O fluxo para a fácies sobrejacente (HC(Dn-Id2)) ocorrerá quando h superar hcr. Isto tornará a migração secundária descontínua e dependente da superação de um valor crítico (hcr) de altura da coluna de hidrocarbonetos. 


\section{REFERÊNCIAS BIBLIOGRÁFICAS}

AGER, D.V. 1993. The Nature of Stratigraphical Record. J. Wiley, New York, 151 p.

ANDERSON, R.S. \& BUNAS, K.L. 1993. Grain size segregation and stratigraphy in aeolian ripples modelled with a celluar automaton. Nature, 365:740-743.

ANDERTON, R. 1985. Clastic facies models and facies analysis. In: BRENCHLEY, P.J. \& WILLIAMS, B.P.J. eds. Sedimentology: Recent Developments and Applied Aspects. Oxford, The Geol. Soc., Blackwell Scientific Publ.: 31-47.

ANGULO, R.J. \& LESSA, G.C. 1997. The Brazilian sea-level curves: a critical review with emphasis on the curves from the Paranaguá and Cananéia regions. Marine Geology, 140: 141-166.

ANGULO, R.J.; GIANNINI, P.C.F.; SUGUIO, K.; PESSENDA, L.C.R. 1999. Relative sea-level changes in the last 5500 years in southern Brazil (Laguna-Imbituba region, Santa Catarina State) based on vermitid ${ }^{14} \mathrm{C}$ Ages. Marine Geology, 159: 323-339.

ASSINE, M. L., PIRANHA, J. M., CARNEIRO, C. D. R. 2004. Os paleodesertos Pirambóia e Botucatu. In: MANTESSO NETO, V., BARTORELLI, A., CARNEIRO, C. D. R., BRITO NEVES, B.B. (eds.). Geologia do Continente Sul-Americano: Evolução da Obra de Fernando Flávio Marques de Almeida. São Paulo, Beca, p.7792.

BAGNOLD, R.A. 1941. The Physics of Blown Sand and Desert Dunes. Methuen, London, $265 \mathrm{p}$.

BAK, P. 1997. How nature works - The science of self-organized criticality. Oxford University Press, Oxford, $212 \mathrm{p}$.

BAK, P.; TANG, C. \& WIESENFELD, K. 1987. Self-organized criticality, an explanation of 1/f noise. Physical Review Letters, 59:381.

BARBOSA, L.M. 1997. Campos de dunas costeiras associados à desembocadura do Rio São Francisco (SE/AL). Salvador, Instituto de Geociências da Universidade Federal da Bahia, Tese de Doutoramento, $202 \mathrm{p}$.

BARRETO, A. M. F. 1996. Interpretação paleoambiental do sistema de dunas fixadas do médio Rio São Franscisco, Bahia. São Paulo, Instituto de Geociências, Universidade de São Paulo, Tese de Doutoramento, 174 p.

BERG, R.R.1975. Capillary Preassures in Stratigraphic Traps. AAPG Bulletin, 59 (6): 939956.

BIGARELLA, J.J. 1970/1971. Wind pattern deduced from dune morphology and internal structures. Bol. Paran. de Geociênc., 28/29: 74-114.

BIGARELLA, J.J. 1972. Eolian environments: their characteristics, recognition, and importance. In : RIGBY,J.K. \& HAMBLIN,W.K. eds. Recognition of Ancient Sedimentary Environments. Soc. Econ. Paleontologists Mineralogists. Spec.Publ., 16:12-62. 
BIGARELLA, J.J. 1975. Lagoa dune field (State of Santa Catarina, Brazil), a model of eolian and pluvial activity. In: International Symposium on the Quaternary, Curitiba. Special Contributions... Boletim Paranaense de Geoiencias, 33: 133-167.

BROOKFIELD, M.E. 1992. Eolian Systems. In: WALKER, R. G. \& JAMES, N.P. eds. 1992. Facies Models - Response to Sea Level Change. Geologiacal Association of Canada, Stittsville, p.143-156.

CAETANO-CHANG, M.R. 1993. Estado d'arte dos conhecimentos sedimentológicos/estratigráficos das Formações Pirambóia e Botucatu no Estado de São Paulo. In: SIMP. CRONOEST. DA BACIA DO PARANÁ, 1, Rio Claro, SP. Bol. Res. Expandidos...Rio Claro, UNESP-SBG, 84-85.

CARTER, R.W.G.; NORDSTROM, K.F. \& PSUTY, N.P. 1990. The study of coastal dunes. In: NORDSTROM, K.F.; PSUTY, N.P \& CARTER, R.W.G. (eds.). 1990. Coastal Dunes - Form and Process. John Wiley \& Sons, Chichester, p.1-11.

CHURCHMAN, C.W. 1963. An analysis of the concept of simulation. Symposium on simulation Models. In: HOGGATT, A.C. \& BALDERSTON, F.E. Cincinatti, South Western Publishing Co..

CLAUDINO SALES, V. \& PEULVAST, J.P. 2001. Geomorfologia dos campos de dunas do Estado do Ceará. Anais do VIII Simpósio da ABEQUA, 273-276, Porto Alegre.

CLIFTON, H.E. 1988. Sedimentologic relevance of convulsive geologic events. Geological Society of America Special Paper, 229:1-5.

CORREA, I.C.S. 1996. Les variations du niveau de la mer durant les derniers 17.500 ans PB: l'exemple de la plate-forme continentale du Rio Grande do Sul-Brésil. Marine Geology, 130: 163-178.

CROWLEY, T.J.; YIP, K.J. \& BAUM, S.K. 1993. Milankovitch cycles and carboniferous climate. Geophysical Research Letters, 20(12): 1175-1178.

CRUZ Jr., F.W.; BURNS, S.J.; KARMANN, I.; SHARP, W.D.; VUILLE, M.; CARDOSO, A.O.; FERRARI, J.A.; DIAS, P.L.S. \& VIANA Jr., O. 2005. Insolation-driven changes in atmospheric circulation over the past 116,000 years in subtropical Brazil. Nature, 434: 63-66.

DERSCH, M \& STEIN, R. 1993. Late Cenozoic records of eolian quartz flux in the sea of Japan (ODP Leg 128, sites 798 and 799) and paleoclimate in Asia. Palaeogeography, Palaeoclimatology, Palaeoecology, 108(3-4): 523-535.

DIRETORIA DE HIDROGRAFIA E NAVEGAÇÃO (DHN) - MARINHA DO BRASIL. 1974. Altas de Cartas Piloto - Oceano Atlântico de Trinidad ao Rio da Prata.

DONATTI, L.M. 2002. Faciologia, Proveniência e Paleogeografia das Formações Pirambóia e Botucatu no Estado do Paraná. Instituto de Geociências, Universidade de São Paulo, Dissertação de Mestrado, 135 p.

DONATTI L.M., SAWAKUCHI A.O., GIANNINI P.C.F., FERNANDES L.A. 2001. The Pirambóia-Botucatu sucession (Late Permian-Early Cretaceous, Paraná Basin, São Paulo and Paraná States): two contrasting eolian systems. An. Acad. Bras. Ciênc., 73(3): 465. 
EDWARDS, H.E.; BECKER, A.D. \& HOWELL, J.A. 1993. Compartmentalization of an aeolian sandstone by structural heterogeneities: Permo-Triassic Hopeman Sandstone, Moray Firth, Scotland. In: NORTH, C.P. \& PROSSER, D.J. (eds.). 1993. Characterization of fluvial and aeolian reservoirs. Geological Society, London, p. 265-277.

ELLIS, D. 1993. The Rough Gas Field: distribuition of Permian aeolian and non-aeolian reservoir facies and their impact on field development. In: NORTH, C.P. \& PROSSER, D.J. (eds.). 1993. Characterization of fluvial and aeolian reservoirs. Geological Society, London, p. 265-277.

FERNANDES, L.A. 1998 Estratigrafia e Evolução Geológica da Parte Oriental da Bacia Bauru (Ks, Brasil). Instituto de Geociências, Universidade de São Paulo, Tese de Doutoramento, $216 \mathrm{p}$.

FISHER, W.L. \& McGOWEN, J.H. 1969. Depositional systems in Wilcox Group (Eocene) of Texas and their relation to occurrence of oil and gas. The American of Petroleum Geology Bulletin, 53(1): 30-54.

FRANÇA, A.B.; ARAÚJO, L.M.; MAYNARD, J.B. \& POTTER, P.E. 2003. Secondary porosity formed by deep meteoric leaching: Botucatu eolianite, southern South America. AAPG Bulletin, 87(7): 1073-1082.

FRETTE, V.; CHRISTENSEN, K.; MALTHE-SORENSSEN, A.; JOSSANG, T. \& MEAKIN, P. 1996. Avalanche dynamics in a pile of rice. Nature, 379: 49-52.

FÚLFARO V.J. \& BÓSIO N.J. 1968. Novas observações sobre a faciologia do Arenito Botucatu no Estado de São Paulo. In: SBG, CONG. BRAS. GEOL., 22, Bol. Resumos, p. 57-59.

GARDNER, D.E. 1955. Beach-sand heavy-mineral deposits of Eastern Austrália. BMR Bull. No. 28, 103 p.

GIANNINI, P.C.F. 1993. Sistemas Deposicionais no Quaternário Costeiro entre Jaguaruna e Imbituba, SC. São Paulo, Instituto de Geociências, Universidade de São Paulo, Tese de Doutoramento (Inéd.) 2v, 2 mapas, 439p.

GIANNINI, P.C.F. \& SANTOS, E.R. 1994. Padrões de variação espacial e temporal na morfologia de dunas de orla costeira no centro-sul catarinense. Bol. Paran. Geociênc., 42: 73-96.

GIANNINI, P.C.F.; GUEDES, C.C.F.; ANGULO, R.J.; ASSINE, M.L.; SOUZA M.C.; MORI, E.K. 2003. Geometria de cordões litorâneos e espaço de acomodação sedimentar na ilha Comprida, litoral sul paulista: modelo baseado em aerofotointerpretação. In: CONGR. ASSOC. BRASIL. DE ESTUDOS DO QUATERNÁRIO, 9, Recife, PE. Recife, ABEQUA, Anais... (cd).

GIANNINI, P.C.F.; SAWAKUCHI, A.O.; FERNANDES, L.A. \& DONATTI, L.M. 2004. Paleoventos e paleocorrentes subaquosas do Sistema Deposicional Pirambóia nos estados de São Paulo e Paraná, Bacia do Paraná: estudo baseado em análise estatística de dados azimutais. São Paulo, Revista Brasileira de Geociências, 34(2): 282-292. 
GIANNINI, P.C.F.; ASSINE, M.L.; BARBOSA, L.M.; BARRETO, A.M.F.; CARVALHO, A.M.; CLAUDINO-SALES, V.; MAIA, L.P.; MARTINHO, C.T.; PEULVAST, J.P.; SAWAKUCHI, A.O. \& TOMAZELLI, L.J. 2005. Dunas Eólicas Costeiras e Interiores. In: SOUZA, C.R.G.; SUGUIO, K,; DE OLIVEIRA, P.E. \& OLIVEIRA, A.M.S. (Eds.). Quaternário do Brasil. ABEQUA, São Paulo, p. 235-257.

GIANNINI, P.C.F., ASSINE, M.L. \& SAWAKUCHI, A.O.S. Sistemas Deposicionais Eólicos. In: Pedreira, A. Ambientes de Sedimentação no Brasil. Petrobras. (no prelo).

GIANNINI, P.C.F.; GUEDES, C.C.F.; NASCIMENTO JR, D.R.; TANAKA, A.P.B.; ANGULO, R.J.; ASSINE, M.L.; SOUZA, M.C. 2006. Sedimentology and morphologic evolution of the Ilha Comprida Barrier System, southern São Paulo coast. In: DILLENBURG, S.R. \& HESP, P. (eds.). Geology of the Brazilian coastal barriers: Lecture Notes in Earth Sciences. Springer-Verlag (em exame).

GIANNINI, P.C.F.; SAWAKUCHI, A.O.; MARTINHO, C.T. \& TATUMI, S.H. Eolian depositional episodes controlled by Late Quaternary relative sea level changes on the Imbituba-Laguna coast (southern Brazil). Marine Geology (submetido).

GLENNIE, K.W. 1970. Desert Sedimentary Environments. Elsevier, Amsterdam, 222 p.

GOMEZ, B.; PAGE, M.; BAK, P. \& TRUSTUM, N. 2002. Self-organized criticality in layered, lacustrine sediments formed by landsliding. Geology, 30(6):519-522.

GOULD, S.J. \& ELDREDGE, N. 1993. Punctuated equilibrium comes of age. Nature, 366: 223-227.

GUEDES, C.C.F. 2003. Os Cordões Litorâneos e as Dunas Eólicas da Ilha Comprida, Estado de São Paulo. São Paulo, Instituto de Geociências, Universidade de São Paulo. Monografia de Trabalho de Formatura, 54 p.

HACHIRO, J. 1996. O Subgrupo Irati (Neopermiano) da Bacia do Paraná. São Paulo, Instituto de Geociências, Universidade de São Paulo. Tese de Doutoramento (Inéd.), $196 \mathrm{p}$.

HOWARD, A.D., MORTON, J.B., GAD-EL-HAK, M., PIERCE, D.B. 1978. Sand transport model of barchan dune equilibrium. Sedimentology, 25:307-338.

HSÜ, K.J. 1983. Actualistic catastrophism - address of the retiring President of the International Association of Sedimentologists. Sedimentology, 30:3-9.

HSÜ, K.J. 1989. Catastrophic extinctions and the inevitability of the improbable. Journal of the Geological Society of London, 146:749-754.

INSTITUTO BRASILEIRO DE GEOGRAFIA E ESTATÍSTICA. 1992. Atlas Nacional do Brasil. IBGE, Rio de Janeiro.

IVANOV, S. 1996. Variability of sedimentary sequences: numerical modeling of the deposition-erosion process. Geol. Rundsch, 85:12-18.

KALOS, M.H. \& WHITLOCK, P.A. 1986. Monte Carlo Methods, volume I: basics. John Wiley \& Sons, New York, 186 p.

KOCUREK, G. \& HAVHOLM, K. G. 1993. Eolian sequence stratigraphy - A Conceptual Framework. In: WEIMER, P. \& POSAMENTIER, H. (Eds.). 1993. Siliciclastic 
Sequence Stratigraphy: Recent Developments and Applications. AAPG Memoir, 58: 393-409.

KORVIN, G. 1992. Fractal models in the earth sciences. Elsevier, Amsterdam, 396 p.

KOWSMANN, R.O. \& COSTA, M.P. de A. 1979. Sedimentação quaternária da margem continental brasileira e das áreas oceânicas adjacentes. Relatório final. Projeto REMAC (Reconhecimento Global da Margem Continental Brasileira). PETROBRÁS-DNPM-CPRM-DHN-CNPq. 55p. v.8.

LINDQUIST, S.J. 1988. Practical characterization of eolian reservoirs for development: Nugget Sandstone, Utah-Wyoming thrust belt. Sedimentary Geology, 56: 315-339.

MAGAlHÃES, M.N. \& LIMA, A.C.P. DE. 2001. Noções de Probabilidade e Estatística. $3^{\mathrm{a}}$ edição, São Paulo, Instituto de Matemática e Estatística da Universidade de São Paulo, 392 p.

MAKSE, H.A.; HAVLIN, S.; KING, P.R.; \& STANLEY, E. 1997. Spontaneous stratification in granular mixtures. Nature, 386:379-382.

MALIN, M.C.; CARR, M.H.; DANIELSON, G.E.; DAVIES, M.E.;HARTIMANN, W.K.; INGERSOLL, A.P.; JAMES, P.B.; MASURSKY, H.; McEWEN, A.S.; SODERBLOM, L.A.; THOMAS, P.; VEVERKA, J.; CAPLINGER, M.A.; RAVINE, M.A.; SOULANILLE, T.A. \& WARREN, J.L. 1998. Early views of the martian surface from the Mars Orbiter Camera of Mars Global Surveyor. Science, 279:16811685.

MANLY, B. F. J. 1994. Multivariate Statistical Methods: a primer. Chapman, London, 215 p.

MARDIA, K.V. 1972. Statistics of Directional Data. Academic Press, London, 357 p.

MARTIN, L.; SUGUIO, K. \& FLEXOR, J.N. 1988. Hauts niveaux marins pleistocenes du litoral bresilien. Palaeogeog., Palaeoclimat., Paleoecol., 68(3):231-239.

MARTINHO, C.T. 2001. Morfodinâmica de Draas Costeiros e Gerações de Depósitos Eólicos no Quaternário da Região de Imbituba-Laguna, SC. São Paulo, Instituto de Geociências, Universidade de São Paulo, Monografia de Trabalho de Formatura, 62 p.

MARTINHO, C.T. 2004. Morfodinâmica e Sedimentologia de Campos de Dunas Transgressivos da Região de Jaguaruna-Imbituba, Santa Catarina. Dissertação de Mestrado, Instituto de Geociências, Universidade de São Paulo, São Paulo, 108 p.

MARTINHO, C.T., GIANNINI, P.C.F., SAWAKUCHI, A.O.; HESP, P.A. 2006. Morphological and depositional facies of transgressive dunefields in the ImbitubaJaguaruna region, Santa Catarina State, Southern Brazil. Journal of Coastal Research, no prelo.

MATOS S.L.F. 1995. O contato entre o Grupo Passa Dois e a Formação Pirambóia na borda leste da Bacia do Paraná no Estado de São Paulo. Dissertação de Mestrado, Instituto de Geociências, Universidade de São Paulo, 110 p.

McKENZIE, D. P. 1978. Some remarks on the development of sedimentary basins. Earth Planet. Sci. Letters, 40: 25-32. 
METROPOLIS, N. \& ULAM, W. 1949. The Monte Carlo method. J. Amer. Stat. Assoc., 44(247): 335-341.

MILANI, E.J. \& RAMOS, V.A. 1998. Orogenias paelozóicas no domínio sul-ocidental do Gondwana e os ciclos de subsidência da Bacia do Paraná. Revista Brasileira de Geociências 28(4):473-484.

NAMIKAS, S.L. 2003. Field measurement and numerical modelling of aeolian mass flux distributions on a sandy beach. Sedimentology, 50:303-326.

NAYLOR, T.H.; BALINTFY, J.L.; BURDICK, D.S. \& CHU, K. 1971. Técnicas de Simulação em Computadores. Tradução de Edmundo Emanuel Teixeira. Editora Vozes, São Paulo, 402 p.

NASCIMENTO Jr., D.R. 2006. Morfologia e Sedimentologia ao Longo do Sistema PraiaDuna Frontal de Ilha Comprida, SP. São Paulo, Instituto de Geociências, Universidade de São Paulo, Dissertação de Mestrado, 96 p.

NORTH, C.P. \& PROSSER, D.J. 1993. Characterization of fluvial and aeolian reservoirs: problems and approaches. In: NORTH, C.P. \& PROSSER, D.J. (eds.). 1993. Characterization of fluvial and aeolian reservoirs. Geological Society, London, 450 p.

OLSEN, H. 1990. Astronomical forcing of meandering river behaviour: Milankovitch cycles in Devonian of east Greenland. Palaeogeography, Palaeoclimatology, Palaeoecology, 79(1-2): 99-115.

POPPER, K.R. 1934. A Lógica da Pesquisa Científica. $8^{\mathrm{a}}$ edição. Cultrix, São Paulo, 567 p..

POSAMENTIER, H.W. \& VAIL, P.R. 1988. Eustatic controls on clastic deposition IIsequence and systems tract models. In: WILGUS et al., eds. Sea-level Changes: An Integrated Approach. Society of Economic Paleontologists and Mineralogists Special Publication, 42: 125-154.

RACHOLD, V. \& BRUMSACK, H.J. 2001. Inorganic geochemistry of albian sediments from the lower Saxony basin NW Germany: palaeoenvironmental constraints and orbital cycles. Palaeogeography, Palaeoclimatology, Palaeoecology, 174(1): 121143.

REA, D.K. 1994. The paleoclimatic record provided by eolian deposition in the deep sea: the geologic history of wind. Reviews of Geophysics, 32(2): 159-196.

ROSEMBLUETH \& WEIMER. 1945. The role of models in science. Philosophy of Science XII(4):316-321.

ROSS, S.M. A Course in Simulation. Mcmillian Publishing Company, New York, 202 p.

ROTHMAN, D.H.; GROTZINGER, J.P. \& FLEMINGS, P. 1994. Scaling in turbidite deposition. Journal of Sedimentary Research, A64(1): 59-67.

ROY, P.S.; COWELL, P.J.; FERLAND, M.A. \& THOM, B.G., 1994. Wave-dominated coasts. In: CARTER, R.W.G. \& WOODROFFE, C.D. (Ed.), Coastal Evolution - Late Quaternary Shoreline Morphodinamics. Cambridge University Press, Cambridge, pp. 121-186. 
RUBIN, D.M. \& McCULLOCH, D.S. 1980. Single and superimposed bedforms: a synthesis of San Francisco bay and flume observations. Sedimentary Geology, 26:207-231.

SADLER, P.M. 1981. Sediment accumulation rates and the completeness of stratigraphic sections. Journal of Geology, 89: 569-584.

SADLER, P.M. \& STRAUSS, D.J. 1990. Estimation of completeness of stratigraphical sections using empirical data and theoretical models. Journal of the Geological Society, 147:471-485.

SANT'ANNA NETO, J.L. \& NERY, J.T. 2005. Variabilidade e mudanças climáticas no Brasil e seus impactos regionais. In: SOUZA, C.R.G.; SUGUIO, K.; OLIVEIRA, A.M. S. \& OLIVEIRA, P.E. (eds.). 2005. Quaternário do Brasil. Holos Editora, Ribeirão Preto, p. 28-51.

SAWAKUCHI, A.O. 2000. Dinâmica e contexto paleogeográfico do sistema deposicional eólico Pirambóia no Estado de São Paulo. São Paulo, Instituto de Geociências, Universidade de São Paulo. Monografia de Trabalho de Formatura, 38 p.

SAWAKUCHI, A.O. 2003. Sistemas deposicionais eólicos quaternários na costa centrosul catarinense: relações com o nivel do mar. Dissertação de Mestrado, Instituto de Geociências, Universidade de São Paulo, 86 p.

SCHUMM, S.A. 1991. To Interpret the Earth - Ten Ways to be Wrong. Cambridge University Press, Cambridge, $133 \mathrm{p}$.

SOBOL, I.M. 1976. Lecciones populares de matemática - Método de Monte Carlo. Mir, Moscou, 79 p.

STRONG, G.E. 1993. Diagenesis of Triassic Sherwood Sandstone Group rocks, Preston, Lancashire, UK: a possible evaporitic cement precursor to secondary porosity? In: NORTH, C.P. \& PROSSER, D.J. (eds.). 1993. Characterization of fluvial and aeolian reservoirs. Geological Society, London, p. 265-277.

SUGUIO, K.; MARTIN, L.; BITTENCOURT, A.C.S.P.; DOMINGUEZ， J.M.L.; FLEXOR, J.M. \& AZEVEDO, A.E.G. 1985. Flutuações do nível relativo do mar durante o Quaternário Superior a longo do litoral brasileiro e suas implicações na sedimentação costeira. Rev. Bras. Geocien. 15(4): 273-286.

SUNDBORG, A. 1956. The river Klaralven, a study of fluvial processes. Geog. Ann., 38:127-316.

THOMAS, P.C.; MALIN, M.C.; CARR, M.H.; DANIELSON, G.E.; DAVIESK, M.E.; HARTMANN, W.K.; INGERSOLL, A.P.; JAMES, P.B.; McEWEN, A.S.; SODERBLOM, L.A. \& VEVERKA, J. 1999. Bright dunes on Mars. Nature, 397:592594.

TOMAZELLI, L.J. 1994. Morfologia, Organização e Evolução do Campo Eólico Costeiro do Litoral Norte do Rio Grande do Sul, Brasil. Pesquisas, 21(1): 64-71.

TYLER, N. \& FINLEY, R.J. 1991. Architetural controls on the recovery of hydrocarbons from sandstone reservoirs. In: MIALL, A.D. \& TYLER, N. 1991. The threedimensional facies architeture of terrigenous clastic sediments and its implications for 
hydrocarbon discovery and recovery. Concepts in sedimentology and paleontology, $\mathrm{v}$ 3, SEPM, Tulsa, p.1-5.

VAIL, P.R.; MITCHUM, R.M.Jr.; THOMPSON, S. 1977. Seismic stratigraphy and global changes of sea level. American Association of Petroleum Geologists, Memoir, 26.

WALKER, R. G. \& JAMES, N.P. eds. 1992. Facies Models - Response to Sea Level Change. Geologiacal Association of Canada, Stittsville, 454 p..

WASSON, R.J. \& HYDE, R. 1983. Factors determining desert dune type. Nature, 304:337339.

WHITE, B.R. 1979. Soil transport by winds on Mars. J. Geophys. Res., 84:4643-51.

WOLMAN, M.G. \& MILLER, J.P. 1960. Magnitude and frequency of forces in geomorphic processes. Jour. Geology, 68:54-74. 
ANEXO 1 - Tabelas de correspondência e teste qui-quadrado para avaliação da associação entre número de meses secos, velocidade e freqüência dos ventos, amplitude de maré e setores geográficos

\begin{tabular}{|l|l|l|l|l|l|}
\hline \multicolumn{7}{|c|}{ Número de meses secos vs. setores geográficos } \\
\hline \multirow{2}{|c|}{0} & Setor 1 & Setor 2 & Setor 3 & Total \\
\hline \multirow{2}{*}{4 a 3 meses secos 6} & Freq. observada & 0 & 37 & 53 & 90 \\
\cline { 2 - 7 } & Freq. esperada & 52,15 & 15,56 & 22,29 & 90,00 \\
\hline \multirow{2}{*}{7 a 8 meses secos secos } & Freq. observada & 74 & 0 & 0 & 74 \\
\cline { 2 - 7 } & Freq. esperada & 42,88 & 12,79 & 18,33 & 74,00 \\
\hline \multirow{7}{*}{ Total } & Freq. observada & 50 & 0 & 0 & 50 \\
\cline { 2 - 7 } & Freq. esperada & 28,97 & 8,64 & 12,38 & 50 \\
\hline \multicolumn{7}{|c|}{ Teste qui-quadrado } & 53 & 214 \\
\hline Qui-quad.=214,00 & Freq. observada & 124 & 37 & 53,00 & 214,00 \\
\cline { 2 - 6 } & Freq. esperada & 124,00 & 37,00 & $\mathrm{p}=0,000$ \\
\hline
\end{tabular}

Tabela A1 - Tabela de correspondência e teste qui-quadrado para avaliar a dependência entre o número de meses secos e os setores geográficos 1,2 e 3 . O valor de $p$ inferior a 0,05 indica a existência de associação entre o número de meses secos e os setores geográficos. Neste caso, aceita-se a hipótese de que as freqüências observadas e esperadas são distintas.

\begin{tabular}{|c|c|c|c|c|c|}
\hline \multicolumn{6}{|c|}{ Número de meses secos vs. amplitude de maré } \\
\hline & & Macromaré & Mesomaré & Micromaré & Total \\
\hline \multirow[t]{2}{*}{0 a 3 meses secos } & Freq. observada & 0 & 9 & 81 & 90 \\
\hline & Freq. esperada & 7,99 & 47,94 & 34,07 & 90,00 \\
\hline \multirow[t]{2}{*}{4 a 6 meses secos } & Freq. observada & 19 & 55 & 0 & 74 \\
\hline & Freq. esperada & 6,57 & 39,42 & 28,01 & 74,00 \\
\hline \multirow[t]{2}{*}{7 a 8 meses secos } & Freq. observada & 0 & 50 & 0 & 50 \\
\hline & Freq. esperada & 4,44 & 26,64 & 18,93 & 50,00 \\
\hline \multirow[t]{2}{*}{ Total } & Freq. observada & 19 & 114 & 81 & 214 \\
\hline & Freq. esperada & 19,00 & 114,00 & 81,00 & 214,00 \\
\hline \multicolumn{6}{|c|}{ Teste qui-quadrado } \\
\hline \multicolumn{2}{|l|}{ Qui-quad. $=205,83$} & \multicolumn{2}{|c|}{ Graus de liberdade $=4$} & \multicolumn{2}{|l|}{$\mathrm{p}=0,000$} \\
\hline
\end{tabular}

Tabela A2 - Tabela de correspondência e teste qui-quadrado para avaliar a dependência entre o número de meses secos e a amplitude de maré. $\mathrm{O}$ valor de $\mathrm{p}$ inferior a 0,05 indica a existência de associação entre o número de meses secos e amplitude de maré. Neste caso, aceita-se a hipótese de que as freqüências de contagem observadas e esperadas são distintas. Notar que há um valor de freqüência esperada inferior a 5,0. Porém, este valor é próximo a 5,0. Valor de p inferior a 5,0 deve ser interpretado com certa cautela. 


\begin{tabular}{|l|l|l|l|l|l|}
\hline \multicolumn{6}{|c|}{ Número de meses secos vs. freqüência de atuação dos ventos geradores (janeiro) } \\
\hline \multirow{2}{*}{ 0 a 3 meses secos } & 26 a 32\% & 43 a 54\% & $\mathbf{6 4 \%}$ & Total \\
\cline { 2 - 7 } & Freq. observada & 37 & 11 & 0 & 48 \\
\hline & Freq. esperada & 15,31 & 16,14 & 16,55 & 48,00 \\
\hline \multirow{2}{*}{ a 8 meses secos } & Freq. observada & 0 & 28 & 40 & 68 \\
\cline { 2 - 6 } & Freq. esperada & 21,69 & 22,86 & 23,45 & 68,00 \\
\hline \multirow{2}{*}{ Total } & Freq. observada & 37 & 39 & 40 & 116 \\
\cline { 2 - 6 } & Freq. esperada & 37,0 & 39,0 & 40,0 & 116,0 \\
\hline \multicolumn{7}{|c|}{ Teste qui-quadrado } \\
\hline Qui-quad. $=83,442$ & Graus de liberdade $=2$ & $\mathrm{p}=0,000$ \\
\hline
\end{tabular}

Tabela A3 - Tabela de correspondência e teste qui-quadrado para avaliar a dependência entre o número de meses secos e a freqüência de atuação dos ventos geradores de dunas durante o mês de janeiro. $\mathrm{O}$ valor de $\mathrm{p}$ inferior a 0,05 indica a existência de associação entre a o número de meses secos e a freqüência de atuação dos ventos. Neste caso, aceita-se a hipótese de que as freqüências observadas e esperadas são distintas.

\begin{tabular}{|l|l|l|l|l|l|}
\hline \multicolumn{6}{|c|}{ Número de meses secos vs. freqüência de atuação dos ventos geradores } \\
(julho)
\end{tabular}

Tabela A4 - Tabela de correspondência e teste qui-quadrado para avaliar a dependência entre o número de meses secos e a freqüência de atuação dos ventos geradores de dunas durante o mês de julho. $\mathrm{O}$ valor de $\mathrm{p}$ inferior a 0,05 indica a existência de associação entre a o número de meses secos e a freqüência de atuação dos ventos. Neste caso, aceita-se a hipótese de que as freqüências observadas e esperadas são distintas. 


\begin{tabular}{|l|l|l|l|l|}
\hline \multicolumn{5}{|c|}{ Número de meses secos vs. velocidade dos ventos geradores (janeiro) } \\
\hline \multirow{2}{*}{0} & $\mathbf{3 , 6}$ a 5,1 m/s & $\mathbf{5 , 7}$ a 8,2 m/s & Total \\
\hline \multirow{2}{*}{4 a 3 meses secos 8 meses secos } & Freq. observada & 28 & 20 & 48 \\
\cline { 2 - 5 } & Freq. esperada & 23,17 & 24,83 & 48,00 \\
\hline & Freq. observada & 28 & 40 & 68 \\
\cline { 2 - 5 } Total & Freq. esperada & 32,83 & 35,17 & 68,00 \\
\hline & Freq. observada & 56 & 60 & 116 \\
\cline { 2 - 5 } & Freq. esperada & 56,00 & 60,00 & 116,0 \\
\hline \multicolumn{7}{|c|}{ Teste qui-quadrado } & p $=0,069$ \\
\hline Qui-quad.=3,317 & Graus de liberdade $=1$ & \\
\hline
\end{tabular}

Tabela A5 - Tabela de correspondência e teste qui-quadrado para avaliar a dependência entre o número de meses secos e a velocidade média dos ventos geradores de dunas durante o mês de janeiro. $\mathrm{O}$ valor de $\mathrm{p}$ superior a 0,05 indica ausência de associação entre a o número de meses secos e a freqüência de atuação dos ventos. Neste caso, rejeita-se a hipótese de que as freqüências observadas e esperadas são distintas.

\begin{tabular}{|l|l|l|l|l|}
\hline \multicolumn{5}{|c|}{ Número de meses secos vs. velocidade dos ventos geradores (julho) } \\
\hline \multicolumn{2}{|c|}{} & $\mathbf{3 , 6}$ a 5,1 m/s & $\mathbf{5 , 7}$ a 8,2 m/s & Total \\
\hline \multirow{2}{*}{ 0 a 3 meses secos } & Freq. observada & 24 & 24 & 48 \\
\cline { 2 - 5 } & Freq. esperada & 9,93 & 38,07 & 48,00 \\
\hline \multirow{2}{*}{4 a 8 meses secos } & Freq. observada & 0 & 68 & 68 \\
\cline { 2 - 5 } & Freq. esperada & 14,07 & 53,93 & 68,00 \\
\hline \multirow{2}{*}{ Total } & Freq. observada & 24 & 92 & 116 \\
\cline { 2 - 5 } & Freq. esperada & 56,00 & 60,00 & 116,0 \\
\hline \multicolumn{7}{|c|}{ Teste qui-quadrado } \\
\hline Qui-quad.=42,870 & Graus de liberdade=1 & $\mathrm{p}=0,000$ \\
\hline
\end{tabular}

Tabela A6 - Tabela de correspondência e teste qui-quadrado para avaliar a dependência entre o número de meses secos e a velocidade média dos ventos geradores de dunas durante o mês de julho. $\mathrm{O}$ valor de $\mathrm{p}$ inferior a 0,05 indica a existência de associação entre a o número de meses secos e a freqüência de atuação dos ventos. Neste caso, aceita-se a hipótese de que as freqüências observadas e esperadas são distintas. 


\begin{tabular}{|c|c|c|c|c|c|}
\hline \multicolumn{6}{|c|}{ Amplitude de maré vs. freqüência de atuação dos ventos geradores (janeiro) } \\
\hline & & 26 a $32 \%$ & 43 a $54 \%$ & $64 \%$ & Total \\
\hline \multirow[t]{2}{*}{ Macromaré } & Freq. observada & 0 & 0 & 19 & 19 \\
\hline & Freq. esperada & 6,06 & 6,39 & 6,55 & 19,00 \\
\hline \multirow[t]{2}{*}{ Mesomaré } & Freq. observada & 0 & 28 & 21 & 49 \\
\hline & Freq. esperada & 15,63 & 16,47 & 16,90 & 49,00 \\
\hline \multirow[t]{2}{*}{ Micromaré } & Freq. observada & 37 & 11 & 0 & 48 \\
\hline & Freq. esperada & 15,31 & 16,14 & 16,55 & 48,00 \\
\hline \multirow[t]{2}{*}{ Total } & Freq. observada & 37 & 39 & 40 & 116 \\
\hline & Freq. esperada & 37,00 & 39,00 & 40,00 & 116,00 \\
\hline \multicolumn{6}{|c|}{ Teste qui-quadrado } \\
\hline \multicolumn{2}{|c|}{ Qui-quad. $=109,704$} & Graus de 1 & $\mathrm{e}=4$ & $\mathrm{p}=0,00$ & \\
\hline
\end{tabular}

Tabela A7 - Tabela de correspondência e teste qui-quadrado para avaliar a dependência entre a amplitude de maré e a freqüência de atuação dos ventos geradores de dunas durante o mês de janeiro. $\mathrm{O}$ valor de $\mathrm{p}$ inferior a 0,05 indica a existência de associação entre a o número de meses secos e a freqüência de atuação dos ventos. Neste caso, aceita-se a hipótese de que as freqüências observadas e esperadas são distintas.

\begin{tabular}{|c|c|c|c|c|c|}
\hline \multicolumn{6}{|c|}{ Amplitude de maré vs. freqüência de atuação dos ventos geradores (julho) } \\
\hline & & 21 a $29 \%$ & 39 a $44 \%$ & $58 \%$ & Total \\
\hline \multirow[t]{2}{*}{ Macromaré } & Freq. observada & 0 & 19 & 0 & 19 \\
\hline & Freq. esperada & 6,06 & 8,35 & 4,59 & 19,00 \\
\hline \multirow[t]{2}{*}{ Mesomaré } & Freq. observada & 0 & 21 & 28 & 49 \\
\hline & Freq. esperada & 15,63 & 21,54 & 11,83 & 49,00 \\
\hline \multirow[t]{2}{*}{ Micromaré } & Freq. observada & 37 & 11 & 0 & 48 \\
\hline & Freq. esperada & 15,31 & 21,10 & 11,59 & 48,00 \\
\hline \multirow[t]{2}{*}{ Total } & Freq. observada & 37 & 51 & 28 & 116 \\
\hline & Freq. esperada & 37,00 & 51,00 & 28,00 & 116,00 \\
\hline \multicolumn{6}{|c|}{ Teste qui-quadrado } \\
\hline \multicolumn{2}{|c|}{ Qui-quad. $=109,122$} & Graus de 1 & $\mathrm{de}=4$ & $\mathrm{p}=0,00$ & \\
\hline
\end{tabular}

Tabela A8 - Tabela de correspondência e teste qui-quadrado para avaliar a dependência entre a amplitude de maré e a freqüência de atuação dos ventos geradores de dunas durante o mês de julho. $\mathrm{O}$ valor de $\mathrm{p}$ inferior a 0,05 indica a existência de associação entre a o número de meses secos e a freqüência de atuação dos ventos. Neste caso, aceita-se a hipótese de que as freqüências observadas e esperadas são distintas. Notar que há um valor de freqüência esperada inferior a 5,0. Porém, este valor é próximo a 5,0. Valor de p inferior a 5,0 deve ser interpretado com certa cautela. 


\begin{tabular}{|l|l|l|l|l|}
\hline \multicolumn{5}{|c|}{ Amplitude de maré vs. velocidade dos ventos geradores (janeiro) } \\
\hline \multirow{2}{*}{ Macromaré } & Freq. observada & 0 & $\mathbf{5 , 7} \mathbf{~ m} / \mathbf{8 , 2}$ m/s & Total \\
\cline { 2 - 6 } & Freq. esperada & 9,17 & 19 & 19 \\
\hline \multirow{2}{*}{ Mesomaré } & Freq. observada & 28 & 9,83 & 19,00 \\
\cline { 2 - 5 } & Freq. esperada & 23,66 & 21 & 49 \\
\hline \multirow{2}{*}{ Micromaré } & Freq. observada & 28 & 25,34 & 49,00 \\
\cline { 2 - 5 } & Freq. esperada & 23,17 & 20 & 48 \\
\hline \multirow{5}{*}{ Total } & Freq. observada & 56 & 24,83 & 48,00 \\
\cline { 2 - 5 } & Freq. esperada & 56,00 & 60 & 116 \\
\hline \multicolumn{5}{|c|}{ Teste qui-quadrado } \\
\hline Qui-quad.=21,21 & Graus de liberdade $=2$ & 116,00 \\
\hline
\end{tabular}

Tabela A9 - Tabela de correspondência e teste qui-quadrado para avaliar a dependência entre a amplitude de maré e a velocidade média dos ventos geradores de dunas durante o mês de janeiro. $\mathrm{O}$ valor de $\mathrm{p}$ inferior a 0,05 indica a existência de associação entre a o número de meses secos e a freqüência de atuação dos ventos. Neste caso, aceita-se a hipótese de que as freqüências observadas e esperadas são distintas.

\begin{tabular}{|c|c|c|c|c|}
\hline \multicolumn{5}{|c|}{ Amplitude de maré vs. velocidade dos ventos geradores (julho) } \\
\hline & & 3,6 a $5,1 \mathrm{~m} / \mathrm{s}$ & 5,7 a $8,2 \mathrm{~m} / \mathrm{s}$ & Total \\
\hline \multirow[t]{2}{*}{ Macromaré } & Freq. observada & 0 & 19 & 19 \\
\hline & Freq. esperada & 3,93 & 15,07 & 19,00 \\
\hline \multirow[t]{2}{*}{ Mesomaré } & Freq. observada & 0 & 49 & 49 \\
\hline & Freq. esperada & 10,14 & 38,86 & 49,00 \\
\hline \multirow[t]{2}{*}{ Micromaré } & Freq. observada & 24 & 24 & 48 \\
\hline & Freq. esperada & 9,93 & 38,07 & 48,00 \\
\hline \multirow[t]{2}{*}{ Total } & Freq. observada & 24 & 92 & 116 \\
\hline & Freq. esperada & 24,00 & 92,00 & 116,00 \\
\hline \multicolumn{5}{|c|}{ Teste qui-quadrado } \\
\hline \multicolumn{2}{|c|}{ Qui-quad. $=42,870$} & \multicolumn{2}{|c|}{ Graus de liberdade $=2$} & $\mathrm{p}=0,000$ \\
\hline
\end{tabular}

Tabela A10 - Tabela de correspondência e teste qui-quadrado para avaliar a dependência entre a amplitude de maré e a velocidade média dos ventos geradores de dunas durante o mês de julho. $\mathrm{O}$ valor de $\mathrm{p}$ inferior a 0,05 indica a existência de associação entre a o número de meses secos e a freqüência de atuação dos ventos. Neste caso, aceita-se a hipótese de que as freqüências observadas e esperadas são distintas. Notar que há um valor de freqüência esperada inferior a 5,0. Porém, este valor é próximo a 5,0. Valor de p inferior a 5,0 deve ser interpretado com certa cautela. 


\begin{tabular}{|l|l|l|l|l|l|}
\hline \multicolumn{7}{|c|}{ Amplitude de maré vs. setores geográficos } \\
\hline \multirow{3}{*}{ Macromaré } & Freq. observada & 19 & 0 & 0 & 19 \\
\cline { 2 - 7 } & Freq. esperada & 11,01 & 3,29 & 4,71 & 19,00 \\
\hline \multirow{2}{*}{ Mesomaré } & Freq. observada & 105 & 9 & 0 & 114 \\
\cline { 2 - 6 } & Freq. esperada & 66,06 & 19,71 & 28,23 & 114,00 \\
\hline \multirow{5}{*}{ Total } & Treq. observada & 0 & 28 & 53 & 81 \\
\cline { 2 - 6 } & Freq. esperada & 46,93 & 14,00 & 20,06 & 81,00 \\
\hline & Freq. observada & 124 & 37 & 53 & 214 \\
\cline { 2 - 6 } & Freq. esperada & 124,00 & 37,00 & 53,00 & 214,00 \\
\hline Qui-quad.=185, qui-quadrado \\
\hline \multicolumn{7}{|c|}{ Graus de liberdade $=4$} & $\mathrm{p}=0,000$ \\
\hline
\end{tabular}

Tabela A11 - Tabela de correspondência e teste qui-quadrado para avaliar a dependência entre a amplitude de maré e os setores geográficos 1,2 e 3 . O valor de $p$ inferior a 0,05 indica a existência de associação entre a amplitude de maré e os setores geográficos. Neste caso, aceita-se a hipótese de que as freqüências observadas e esperadas são distintas. Notar que há dois valores de freqüência esperada inferiores a 5,0.

\begin{tabular}{|c|c|c|c|c|c|}
\hline \multicolumn{6}{|c|}{ Setores geográficos vs. freqüência de atuação dos ventos geradores (janeiro) } \\
\hline & & 26 a $32 \%$ & 43 a $54 \%$ & $64 \%$ & Total \\
\hline \multirow[t]{2}{*}{ Setor 1} & Freq. observada & 0 & 28 & 40 & 68 \\
\hline & Freq. esperada & 21,69 & 22,86 & 23,45 & 68,00 \\
\hline \multirow[t]{2}{*}{ Setor 2} & Freq. observada & 9 & 0 & 0 & 9 \\
\hline & Freq. esperada & 2,87 & 3,03 & 3,10 & 9,00 \\
\hline \multirow[t]{2}{*}{ Setor 3} & Freq. observada & 28 & 11 & 0 & 39 \\
\hline & Freq. esperada & 12,44 & 13,11 & 13,45 & 39,00 \\
\hline \multirow[t]{2}{*}{ Total } & Freq. observada & 37 & 39 & 40 & 116 \\
\hline & Freq. esperada & 37,00 & 39,00 & 40,00 & 116,00 \\
\hline \multicolumn{6}{|c|}{ Teste qui-quadrado } \\
\hline \multicolumn{2}{|c|}{ Qui-quad. $=86,997$} & Graus de 1 & $\mathrm{de}=4$ & $\mathrm{p}=0,00$ & \\
\hline
\end{tabular}

Tabela A12 - Tabela de correspondência e teste qui-quadrado para avaliar a dependência entre os setores geográficos 1,2 e 3 e a freqüência de atuação dos ventos geradores de dunas durante o mês de janeiro. $\mathrm{O}$ valor de $\mathrm{p}$ inferior a 0,05 indica a existência de associação entre a o número de meses secos e a freqüência de atuação dos ventos. Neste caso, aceita-se a hipótese de que as freqüências observadas e esperadas são distintas. Notar que há três valores de freqüência esperada inferior a 5,0. Valor de $\mathrm{p}$ inferior a 5,0 deve ser interpretado com certa cautela. 


\begin{tabular}{|c|c|c|c|c|c|}
\hline \multicolumn{6}{|c|}{ Setores geográficos vs. freqüência de atuação dos ventos geradores (julho) } \\
\hline & & 21 a $29 \%$ & 39 a $44 \%$ & $58 \%$ & Total \\
\hline \multirow[t]{2}{*}{ Setor 1} & Freq. observada & 0 & 40 & 28 & 68 \\
\hline & Freq. esperada & 21,69 & 29,90 & 16,41 & 68,00 \\
\hline \multirow[t]{2}{*}{ Setor 2} & Freq. observada & 9 & 0 & 0 & 9 \\
\hline & Freq. esperada & 2,87 & 3,96 & 2,17 & 9,00 \\
\hline \multirow[t]{2}{*}{ Setor 3} & Freq. observada & 28 & 11 & 0 & 39 \\
\hline & Freq. esperada & 12,44 & 17,15 & 9,41 & 39,00 \\
\hline \multirow[t]{2}{*}{ Total } & Freq. observada & 37 & 51 & 28 & 116 \\
\hline & Freq. esperada & 37,00 & 51,00 & 28,00 & 116,00 \\
\hline \multicolumn{6}{|c|}{ Teste qui-quadrado } \\
\hline \multicolumn{2}{|c|}{ Qui-quad. $=83,580$} & Graus de 1 & $\mathrm{de}=4$ & $\mathrm{p}=0,00$ & \\
\hline
\end{tabular}

Tabela A13 - Tabela de correspondência e teste qui-quadrado para avaliar a dependência entre os setores geográficos 1, 2 e 3 e a freqüência de atuação dos ventos geradores de dunas durante o mês de julho. $\mathrm{O}$ valor de $\mathrm{p}$ inferior a 0,05 indica a existência de associação entre a o número de meses secos e a freqüência de atuação dos ventos. Neste caso, aceita-se a hipótese de que as freqüências observadas e esperadas são distintas. Notar que há três valores de freqüência esperada inferior a 5,0. Valor de p inferior a 5,0 deve ser interpretado com certa cautela.

\begin{tabular}{|c|c|c|c|c|}
\hline \multicolumn{5}{|c|}{ Setores geográficos vs. velocidade dos ventos geradores (janeiro) } \\
\hline & & 3,6 a $5,1 \mathrm{~m} / \mathrm{s}$ & \begin{tabular}{|lll}
5,7 & a & 8,2 \\
$\mathrm{~m} / \mathrm{s}$ & & \\
\end{tabular} & Total \\
\hline \multirow{2}{*}{ Setor 1} & Freq. observada & 28 & 40 & 68 \\
\hline & Freq. esperada & 32,83 & 35,17 & 68,00 \\
\hline \multirow[t]{2}{*}{ Setor 2} & Freq. observada & 0 & 9 & 9 \\
\hline & Freq. esperada & 4,34 & 4,66 & 9,00 \\
\hline \multirow[t]{2}{*}{ Setor 3} & Freq. observada & 28 & 11 & 39 \\
\hline & Freq. esperada & 18,83 & 20,17 & 39,00 \\
\hline \multirow[t]{2}{*}{ Total } & Freq. observada & 56 & 60 & 116 \\
\hline & Freq. esperada & 56,00 & 60,00 & 116,00 \\
\hline \multicolumn{5}{|c|}{ Teste qui-quadrado } \\
\hline \multicolumn{2}{|c|}{ Qui-quad. $=18,412$} & \multicolumn{2}{|c|}{ Graus de liberdade $=2$} & $\mathrm{p}=0,000$ \\
\hline
\end{tabular}

Tabela A14 - Tabela de correspondência e teste qui-quadrado para avaliar a dependência entre os setores geográficos 1,2 e 3 e a velocidade média dos ventos geradores de dunas durante o mês de janeiro. $\mathrm{O}$ valor de $\mathrm{p}$ inferior a 0,05 indica a existência de associação entre a o número de meses secos e a freqüência de atuação dos ventos. Neste caso, aceita-se a hipótese de que as freqüências observadas e esperadas são distintas. Notar que há dois valores de freqüência esperada inferior a 5,0 . Valor de p inferior a 5,0 deve ser interpretado com certa cautela. 


\begin{tabular}{|c|c|c|c|c|}
\hline \multicolumn{5}{|c|}{ Setores geográficos vs. velocidade dos ventos geradores (julho) } \\
\hline & & 3,6 a $5,1 \mathrm{~m} / \mathrm{s}$ & $\begin{array}{lll}5,7 & \text { a } & 8,2 \\
\text { m/s } & & \\
\end{array}$ & Total \\
\hline \multirow{2}{*}{ Setor 1} & Freq. observada & 0 & 68 & 68 \\
\hline & Freq. esperada & 14,07 & 53,93 & 68,00 \\
\hline \multirow[t]{2}{*}{ Setor 2} & Freq. observada & 0 & 9 & 9 \\
\hline & Freq. esperada & 1,86 & 7,14 & 9,00 \\
\hline \multirow[t]{2}{*}{ Setor 3} & Freq. observada & 24 & 15 & 39 \\
\hline & Freq. esperada & 8,07 & 30,93 & 39,00 \\
\hline \multirow[t]{2}{*}{ Total } & Freq. observada & 24 & 92 & 116 \\
\hline & Freq. esperada & 24,00 & 92,00 & 116,00 \\
\hline \multicolumn{5}{|c|}{ Teste qui-quadrado } \\
\hline \multicolumn{2}{|c|}{ Qui-quad. $=59,746$} & Graus de liber & $\mathrm{de}=2$ & $\mathrm{p}=0,000$ \\
\hline
\end{tabular}

Tabela A15 - Tabela de correspondência e teste qui-quadrado para avaliar a dependência entre os setores geográficos 1,2 e 3 e a velocidade média dos ventos geradores de dunas durante o mês de julho. $\mathrm{O}$ valor de $\mathrm{p}$ inferior a 0,05 indica a existência de associação entre a o número de meses secos e a freqüência de atuação dos ventos. Neste caso, aceita-se a hipótese de que as freqüências observadas e esperadas são distintas. Notar que há um valor de freqüência esperada inferior a 5,0. Valor de $\mathrm{p}$ inferior a 5,0 deve ser interpretado com certa cautela. 


\title{
ANEXO 2 - ALGORITMO DO PROGRAMA PARA SIMULAÇÃO DO SISTEMA EÓLICO COSTEIRO (SISTEOLCO)
}

\section{A2.1 Algoritmo para representação dos resultados através de valores anuais}

\author{
||||||||||||||||||||||||||||||||||||||||||||||||||||||||||||||||||||||||||||||||||||||||||||||||||||||||||||||||||||||||||||||| \\ /l PROGRAMA SISTEMA EÓLICO COSTEIRO - SISTEOLCO \\ ||||||||||||||||||||||||||||||||||||||||||||||||||||||||||||||||||||||||||||||||||||||||||||||||||||||||||||||||||||||||||||||||||
}

\author{
$/ / * * * * * * * * * * * * * * * * * * * * * \operatorname{VARIÁ} V E I S * * * * * * * * * * * * * * * * * * * * * * * * * * * * * * * * * * * * * * * * * * * * * * * * * * * * * * * * *$ \\ // n: contador do número de simulações \\ // nmax: número máximo de simulações \\ // ano: tempo em anos \\ // anomax: número máximo de anos \\ // t: tempo (dias) \\ // tmax: duração do ciclo de sazonalidade (dias)-duração do ano \\ // tseca: duração da estação seca (dias) \\ // A: amplitude de variação da duração da estação seca (dias) \\ // K: frequência de variação da duração da estação seca. Se K aumenta, a freqüência aumenta. \\ // B: valor mínimo da duração da estação seca (dias) \\ // dt: duração de cada iteração (horas do dia que pode haver transporte eólico) \\ $/ / \mathrm{u}$ : variável aleatória padrão $\mathrm{u} \sim \mathrm{U}(0,1)$ \\ // temp: tempestade (temp $=0$ - com tempestade e temp $=1$ sem tempestade - v.a.) \\ // tempseca1: probabilidade de ocorrer tempestade em t dado que não ocorreu em t-1 (estação seca) \\ // tempseca2: probabilidade de ocorrer tempestade em t dado que ocorreu em t-1 (estação seca) \\ // tempumida1: probabilidade de ocorrer tempestade em $\mathrm{t}$ dado que não ocorreu em t-1 (estação úmida) \\ // tempumida2: probabilidade de ocorrer tempestade em t dado que ocorreu em t-1 (estação úmida) \\ $/ / \mathrm{c}$ : chuva ( $\mathrm{c}=0$ - com chuva e $\mathrm{c}=1$ sem chuva - v.a.) \\ // ctemp1: probabilidade de ocorrer chuva em $t$ dado que não ocorreu chuva em t-1 (condição de tempestade) \\ // ctemp2: probabilidade de ocorrer chuva em $t$ dado que ocorreu chuva em t-1 (condição de tempestade) \\ // cumida1: probabilidade de ocorrer chuva em $t$ dado que não ocorreu chuva em t-1 (estação úmida de tempo \\ bom) \\ // cumida2: probabilidade de ocorrer chuva em $t$ dado que ocorreu chuva em t-1 (estação úmida de tempo \\ bom) \\ // cseca1: probabilidade de ocorrer chuva em t dado que não ocorreu chuva em t-1 (estação seca de tempo \\ bom) \\ // cseca2: probabilidade de ocorrer chuva em $\mathrm{t}$ dado que ocorreu chuva em t-1 (estação seca de tempo bom) \\ // angmin: ângulo de inclinação mínima da zona intermaré (graus) \\ // angmax: ângulo de inclinação máxima da zona intermaré (graus) \\ // com: comprimento da costa $(\mathrm{m})$ \\ // larmin: largura mínima da zona intermaré $(\mathrm{m})$ \\ // larmax: largura máxima da zona intermaré $(\mathrm{m})$ \\ // amp: amplitude de maré (m) \\ // Vfmax: volume máximo de sedimentos na área fonte (m3) \\ // Vfmin: volume mínimo de sedimentos na zona intermaré (m3) \\ // Vf: volume de sedimentos na área fonte no instante $\mathrm{t}(\mathrm{m} 3)$ \\ // Vfa: volume de sedimentos acumulados na área fonte no instante $\mathrm{t}(\mathrm{m} 3)$ \\ // Vc: volume de sedimentos no campo de dunas no instante $\mathrm{t}(\mathrm{m} 3)$ \\ // DV: volume retirado de Vc e Vfa por redução de Vf $(\mathrm{m} 3)$ \\ $/ / \mathrm{dx}$ : variação da posição da linha de costa em relação à posição inicial $\mathrm{dx}=0(\mathrm{~m} 3)$
}


// h: altura do prisma do campo de dunas retirado quando $\mathrm{Vf}<\mathrm{Vfmin}(\mathrm{m})$

// v: velocidade do vento a $10 \mathrm{~m}$ de altura (v.a. - distribuição lognormal-m/s)

// vmtemp: velocidade média do vento $(\mathrm{m} / \mathrm{s})$ na condição de tempestade

// dvtemp: dispersão da velocidade média do vento $(\mathrm{m} / \mathrm{s})$ na condição de tempestade

// vmseca: velocidade média do vento $(\mathrm{m} / \mathrm{s})$ na estação seca de tempo bom

// dvseca: dispersão da velocidade do vento $(\mathrm{m} / \mathrm{s})$ na estação seca de tempo bom

// vmumida: velocidade média do vento $(\mathrm{m} / \mathrm{s})$ na estação úmida de tempo bom

// dvumida: dispersão da velocidade do vento $(\mathrm{m} / \mathrm{s})$ na estação úmida de tempo bom

// vs: velocidade cisalhante $(\mathrm{m} / \mathrm{s})$

// vst: velocidade cisalhante crítica de transporte para grãos com diâmetro $\mathrm{d}(\mathrm{m} / \mathrm{s})$

// d: diâmetro dos grãos (m)

$/ /$ ar: densidade do ar $(\mathrm{kg} / \mathrm{m} 3)$

// qz: densidade dos grãos $(\mathrm{kg} / \mathrm{m} 3)$

// areia: densidade da areia $(\mathrm{kg} / \mathrm{m} 3)$

// g: aceleração da gravidade $(\mathrm{m} / \mathrm{s} 2)$

// ds: diâmetro dos grãos que recobrem a superfície (m)

// qfe: fluxo de entrada de sedimentos na área fonte (v.a. - m3/m*hora)-distribuição lognormal

// qfemtemp: fluxo médio de entrada de sedimentos na área fonte na condição de tempestade ( $3 / \mathrm{m} *$ hora)

// dqfetemp: dispersão do fluxo de entrada de sedimentos na área fonte na condição de tempestade (m3/m*hora)

// qfemseca: fluxo médio de entrada de sedimentos na área fonte na estação seca de tempo bom (m3/m*hora)

// dqfeseca: dispersão do fluxo de entrada de sedimentos na área fonte na estação seca de tempo bom (m3/m*hora)

// qfemumida: fluxo médio de entrada de sedimentos na área fonte na estação úmida de tempo bom (m3/m*hora)

// dqfeumida: dispersão do fluxo de entrada de sedimentos na área fonte na estação úmida de tempo bom (m3/m*hora)

// qfs: fluxo de saída de sedimentos da área fonte (v.a. - m3/m*hora)-distribuição lognormal

// qfsmtemp: fluxo médio de saída de sedimentos na área fonte na condição de tempestade (m3/m*hora)

// dqfstemp: dispersão do fluxo de saída de sedimentos na área fonte na condição de tempestade $(\mathrm{m} 3 / \mathrm{m} *$ hora $)$

// qfsmseca: fluxo médio de saída de sedimentos na área fonte na estação seca de tempo bom (m3/m*hora)

// dqfsseca: dispersão do fluxo de saída de sedimentos na área fonte na estação seca de tempo bom (m3/m*hora)

// qfsmumida: fluxo médio de saída de sedimentos na área fonte na estação úmida de tempo bom (m3/m*hora)

// dqfsumida: dispersão do fluxo de saída de sedimentos na área fonte na estação úmida de tempo bom (m3/m*hora)

// qce: fluxo de sedimentos da área fonte para o campo de dunas ( $\mathrm{m} 3 / \mathrm{m} *$ hora)

// qcs: fluxo de saída de sedimentos do campo de dunas para a área fonte $(\mathrm{m} 3 / \mathrm{m} *$ hora $)$-distribuição lognormal // qcsmtemp: fluxo médio de saída de sedimentos do campo de dunas ( $3 / \mathrm{m} *$ hora) na condição de tempestade

// dqcstemp: dispersão do fluxo de saída de sedimentos do campo de dunas (m3/m*hora) na condição de tempestade

// qcsmseca: fluxo médio de saída de sedimentos do campo de dunas (m3/m*hora) na estação seca de tempo bom

// dqcsseca: dispersão do fluxo de saída de sedimentos do campo de dunas (m3/m*hora) na estação seca de tempo bom

// qcsmumida: fluxo médio de saída de sedimentos do campo de dunas (m3/m*hora) na estação úmida de tempo bom

// dqcsumida: dispersão do fluxo de saída de sedimentos do campo de dunas (m3/m*hora) na estação úmida de tempo bom 
// vet_tseca: vetor para armazenamento da duração da estação seca

// mat_cmed(n,ano): matriz para armazenamento da porcentagem de dias sem chuva

// mat_vmed(n,ano): matriz para armazenamento da velocidade média do vento

// mat_qcemed(n,ano): matriz para armazenamento da média do fluxo de entrada de sedimentos no campo de dunas

// mat_qcsmed(n,ano): matriz para armazenamento da média do fluxo de saída do campo de dunas

$/ /$ mat Vc(n,ano): matriz para armazenamento do volume do campo de dunas ao final do ano

// mat_Vf(n,ano): matriz para armazenamento do volume da fonte ao final do ano

// mat_Vfa(n,ano): matriz para armazenamento do volume acumulado na fonte ao final do ano

// med_cmed: VETORES QUE ARMAZENAM OS VALORES MÉDIOS ANUAIS DAS n SIMULAÇÕES

$/ /$ med_vmed:

$/ /$ med qcemed:

$/ /$ med_qcsmed:

$/ /$ med Vc:

$/ /$ med_Vf:

$/ /$ med Vfa:

// med_balanco: BALANÇO ENTRE OS FLUXOS DE ENTRADA E SAÍDA DO CAMPO DE DUNAS

// std tseca: VETORES QUE ARMAZENAM VALORES DE DESVIO PADRÃO DAS n SIMULAÇÕES

// std cmed:

// std_vmed:

// std_qcemed:

// std_qcsmed:

$/ /$ std_Vc:

// std Vf:

// std_Vfa:

// icf_cmed: VETORES QUE ARMAZENAM OS INTERVALOS DE CONFIANÇA (95\%) DAS MÉDIAS

// icf_vmed:

// icf_qcemed:

// icf_qcsmed:

$/ /$ icf_Vc:

$/ /$ icf Vf:

// icf_Vfa:

$/ / * * * * * * * * * * * * * * * \mathrm{VALORES} \mathrm{INICIAIS******************************************************}$

$\mathrm{n}=1 \quad$ /Número de simulações e tempo

$\operatorname{nmax}=30$

ano $=1$

anomax $=1000$

$\mathrm{t}=1$

$\operatorname{tmax}=365$

$\mathrm{A}=0$

$\mathrm{K}=0.01$

$\mathrm{B}=180$

$\mathrm{dt}=12$

temp $=1$

tempseca $1=0.02 / /$ Probab. de ocorrência de tempestade $(2>1)$

tempseca $2=0.05$

tempumida $1=0.07$

tempumida $2=0.1$ 


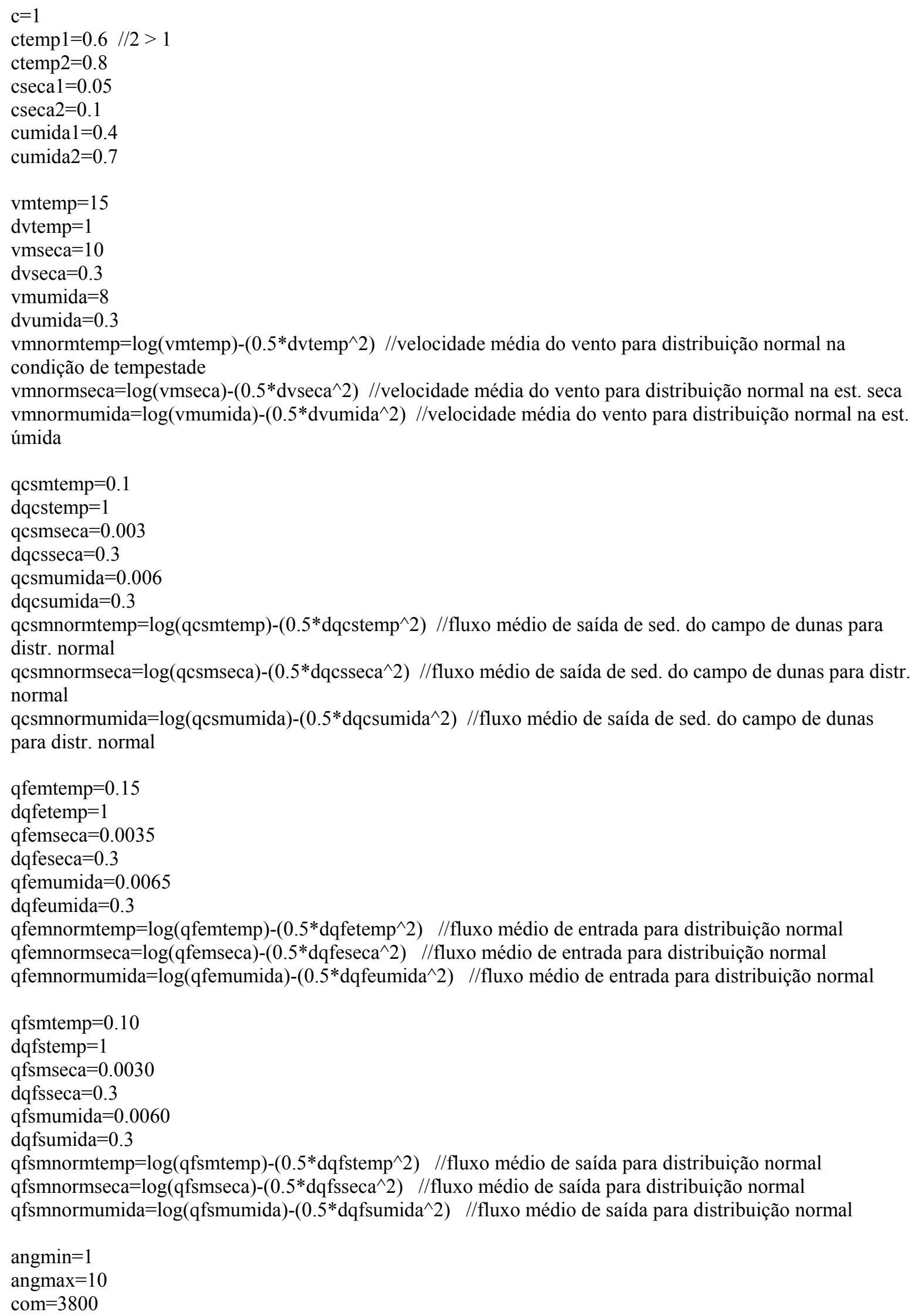




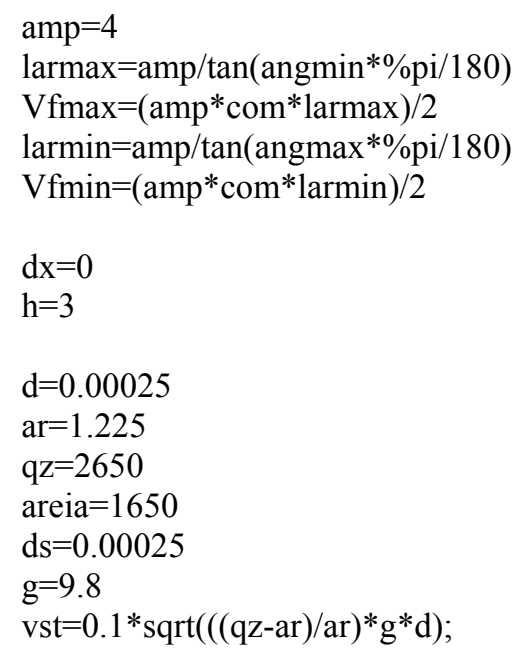

function temp $=\operatorname{CLIMA}(\mathrm{a}, \mathrm{b}) ; \quad / / \mathrm{a}=\mathrm{prob}$. de temp $=0$ em $\mathrm{t}$ dado que temp $=1 \mathrm{em}(\mathrm{t}-1)$

$\mathrm{u}=\mathrm{rand}()$; select temp

case 1

$$
\begin{aligned}
& \text { if } \mathrm{u}<=\text { a then } \\
& \text { temp }=0 \\
& \text { else } \\
& \text { end }
\end{aligned}
$$

case 0

$$
\begin{aligned}
& \text { if } \mathrm{u}<=\mathrm{b} \text { then } \\
& \text { temp }=0 \\
& \text { else } \\
& \text { end }
\end{aligned}
$$


end

endfunction

||||||||||||||||||||||||||||||||||||||||||||||||||||||||||/FIM DA FUNÇÃO CLIMA/|||||||||||||||||||||||||||||||||||||||||||||||||||||||||||||

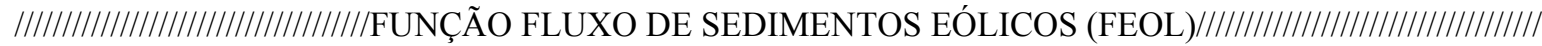

function qce $=\mathrm{FEOL}(\mathrm{c}, \mathrm{v}, \mathrm{ds}, \mathrm{qz}, \mathrm{ar}, \mathrm{d}, \mathrm{g}$, areia)

if $\mathrm{c}==1$ then

$\mathrm{vs}=\mathrm{v} /(5.75 *(1-\log 10(\mathrm{ds} / 30)))$;

vst $=0.1 *$ sqrt $\left.((\text { qz-ar }) / \text { ar })^{*} \mathrm{~g} * \mathrm{~d}\right)$;

if $\mathrm{vs}>=\mathrm{vst}$ then

else $\mathrm{qce}=\left(\left(2.61 * \mathrm{vs}^{\wedge} 3 *(1-\mathrm{vst} / \mathrm{vs}) *\left(1+\mathrm{vst}^{\wedge} 2 / \mathrm{vs} \wedge 2\right) * \operatorname{ar} / \mathrm{g}\right) /\right.$ areia $) * 3600 ;$

end

$\mathrm{qce}=0$;

else

qce $=0$;

end

endfunction

||||||||||||||||||||||||||||||||||||||||||||||||||/FIM DA FUNÇÃO FEOL/||||||||||||||||||||||||||||||||||||||||||||||||||||||||||||||||

||||||||||||||||||||||//FUNÇÃO VARIAÇÃO DE VOLUME DA FONTE POR DERIVA (VFDER)//|||||||||||||||||

function $\mathrm{Vf}=\mathrm{VFDER}(\mathrm{qfe}, \mathrm{qfs}$, larmax, dt)

$\mathrm{DVf}=(\mathrm{qfe}-\mathrm{qfs}) *(24-\mathrm{dt}) *($ larmax $)$; //Variação de volume na fonte

$\mathrm{Vf}=\mathrm{Vf}+\mathrm{DVf}$

if $\mathrm{Vf}<0$ then //Regulariza $\mathrm{Vf}$ entre os valores limites

$\mathrm{Vf}=0$;

end

endfunction

|||||||||||||||||||||||||||||||||||||||||||||||||||/FIM DA FUNÇÃO VFDER/|||||||||||||||||||||||||||||||||||||||||||||||||||||||||||||||||

stacksize $(10000000)$

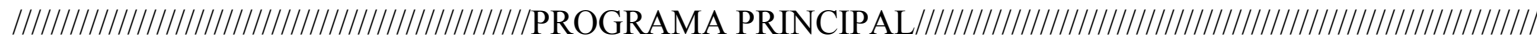

for $\mathrm{n}=1: \mathrm{nmax}$;

$\mathrm{Vf}=\mathrm{Vfmin} ; \quad$ //Condições iniciais

$\mathrm{Vfa}=100 * \mathrm{Vfmax}$

$\mathrm{Vc}=0$;

$\mathrm{sdx}=0$;

$\mathrm{qce}=0$;

$\mathrm{qcs}=0$;

$\mathrm{qfe}=0$;

$\mathrm{qfs}=0$;

$\mathrm{c}=1$;

temp $=1$;

for ano=1:anomax;

tseca $=\operatorname{int}\left(\mathrm{A}^{*} \sin \left(\mathrm{K}^{*} \mathrm{ano}\right)+\mathrm{A}\right)+\mathrm{B}$; 


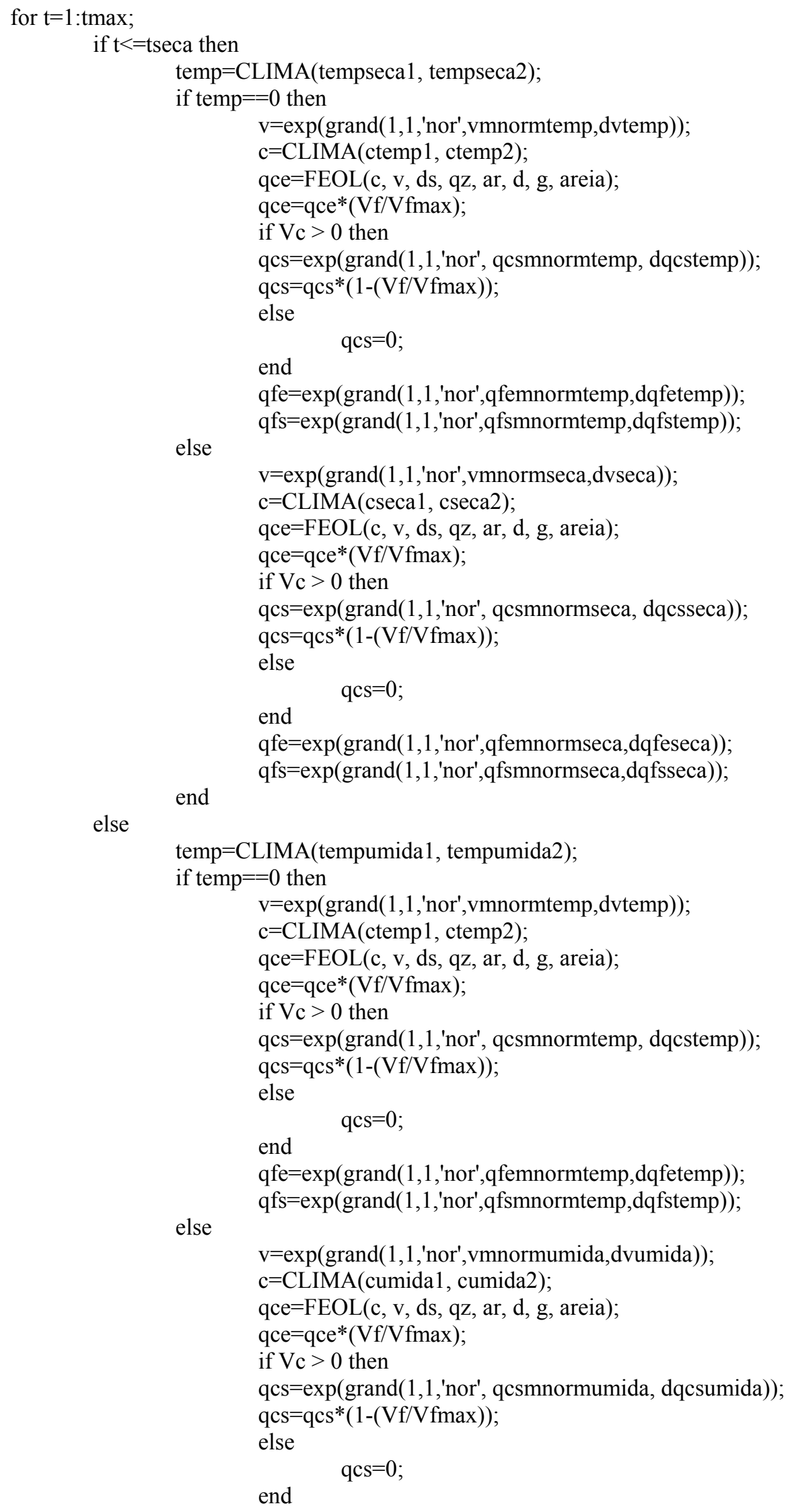




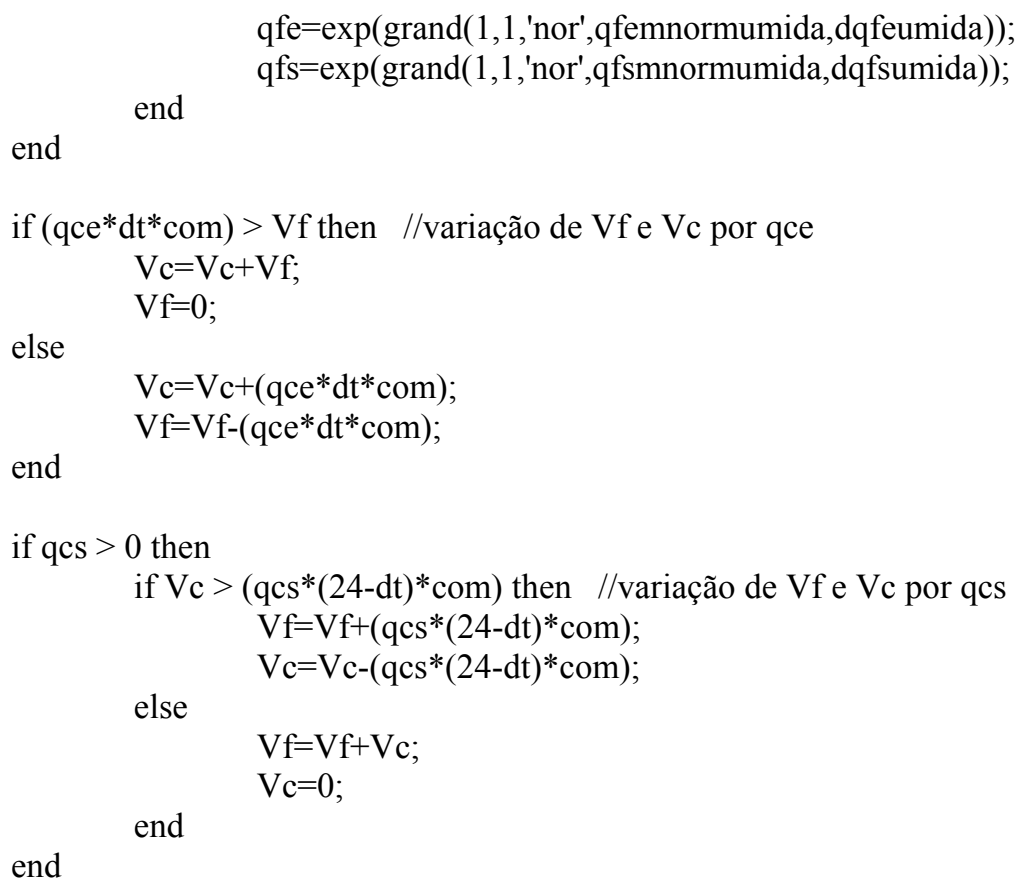

$\mathrm{Vf}=\operatorname{VFDER}(\mathrm{qfe}, \mathrm{qfs}$, larmax, dt); //variação do volume da fonte por qfe e qfs

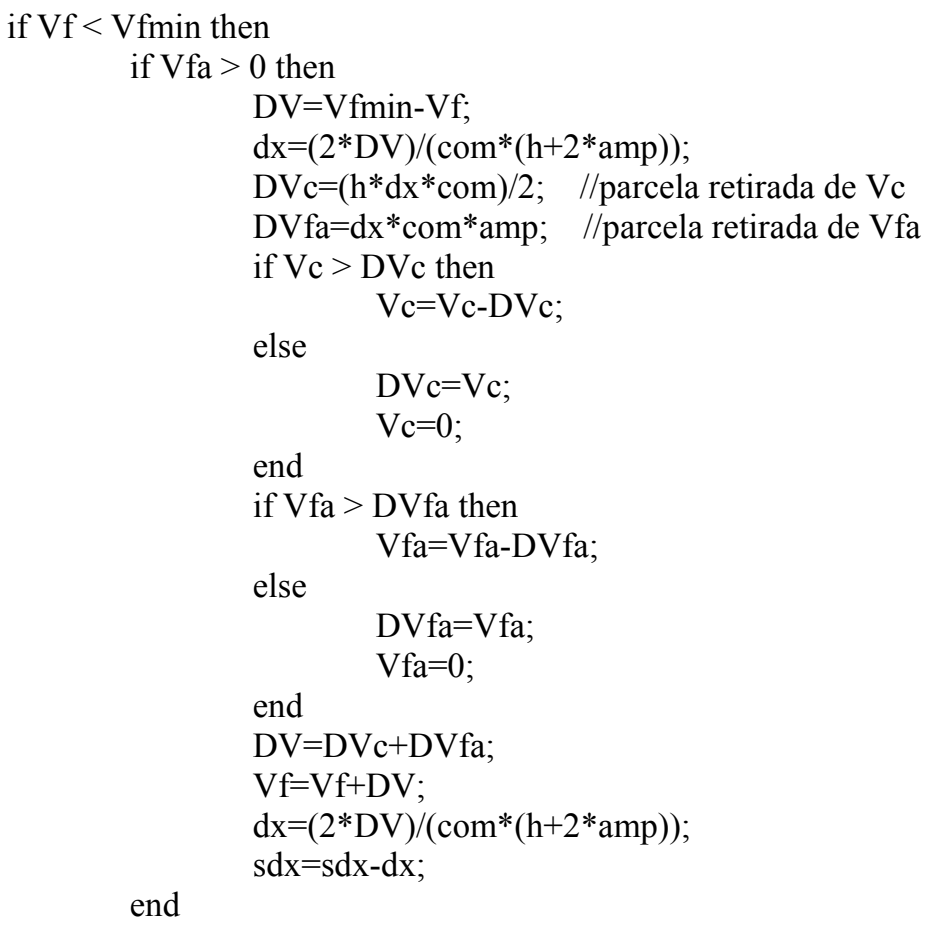

end

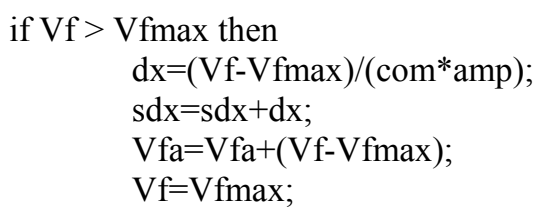




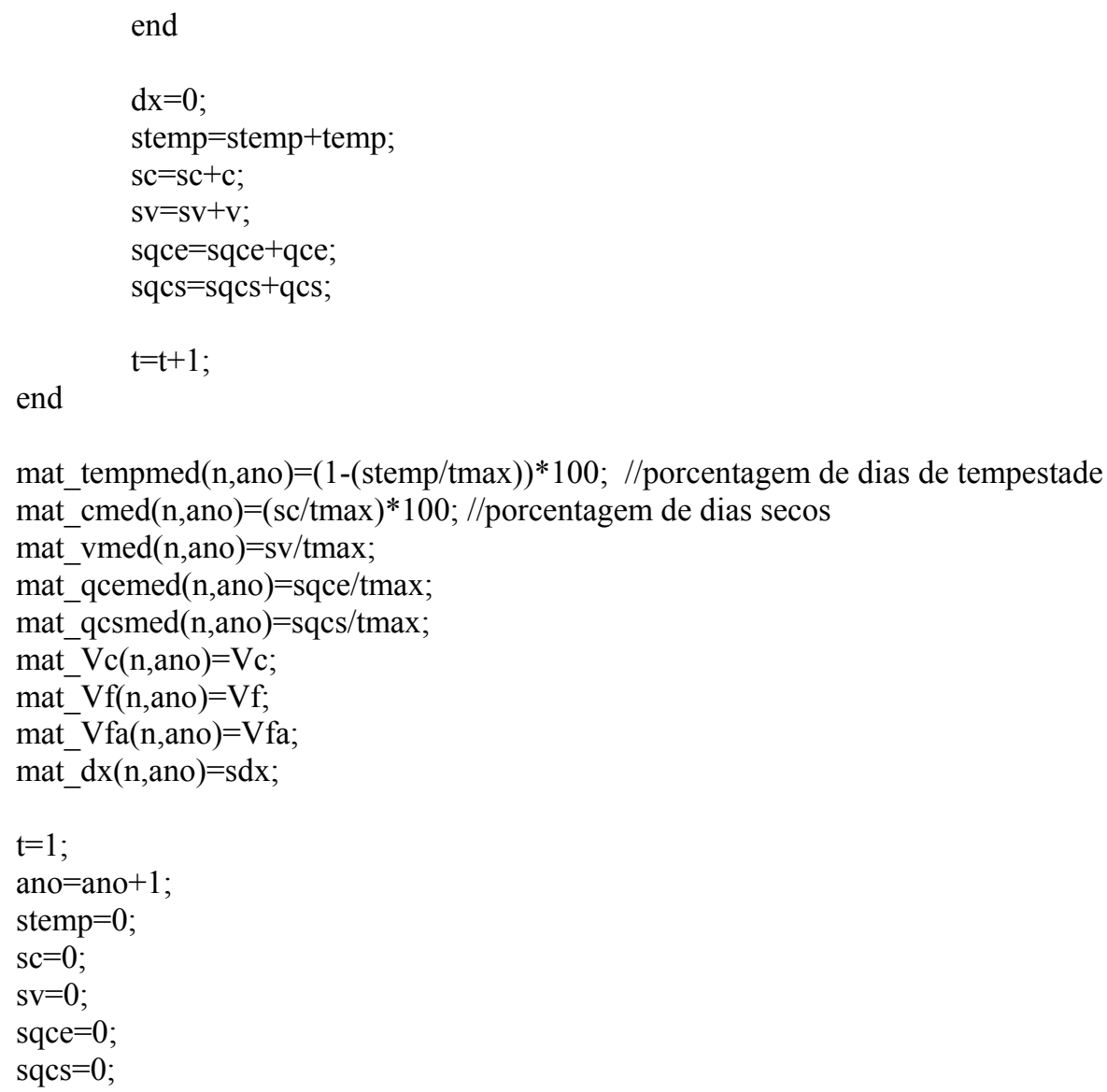


std_dx=st_deviation(mat_dx,'r');

icf_tempmed $=(1.96 *$ std_tempmed $) / \mathrm{sqrt}(\mathrm{nmax})$; icf_cmed $=(1.96 *$ std_cmed $) /$ sqrt(nmax $)$

//intervalo de confiança de $95 \%$ da nmax simulações icf_vmed $=(1.96 *$ std_vmed $) /$ sqrt(nmax $)$;

icf_qcemed $=\left(1.96^{*}\right.$ std_qcemed $) / \operatorname{sqrt}(\mathrm{nmax})$;

icf_qcsmed $=(1.96 *$ std_qcsmed $) /$ sqrt $($ nmax $)$;

icf $\mathrm{Vc}=(1.96 * \mathrm{std} \mathrm{Vc}) / \mathrm{sqrt}(\mathrm{nmax})$;

icf $\mathrm{Vf}=(1.96 *$ std_Vf $) / \mathrm{sqrt}(\mathrm{nmax})$;

icf_Vfa $=(1.96 *$ std_ Vfa $) /$ sqrt(nmax $)$;

icf_dx $=(1.96 *$ std_dx $) / \operatorname{sqrt}(\mathrm{nmax})$;

icfmed_temp $=$ mean(icf_tempmed)

icfstd_temp=st_deviation(icf_tempmed)

icfmed_c=mean (icf_cmed)

icfstd_c=st_deviation(icf_cmed)

icfmed_v=mean(icf_vmed)

icfstd_vest_deviation(icf_vmed)

icfmed_qce=mean(icf_qcemed)

icfstd_qce=st_deviation(icf_qcemed)

icfmed_qcs=-mean(icf_qcsmed)

icfstd_qcs=st_deviation(icf_qcsmed)

icfmed_Vc=mean(icf_Vc)

icfstd_V $\mathrm{V}=$ st_deviation(icf_Vc)

icfmed_Vf=-mean(icf_Vf)

icfstd_V $\mathrm{V}=$ =st_deviation(icf_Vf)

icfmed $\mathrm{Vfa}=$ mean (icf Vfa)

icfstd_Vfa=st_deviation(icf_Vfa)

icfmed_dx=mean(icf_dx)

icfstd_ $\mathrm{d} x=$ st_deviation(icf_dx)

vet ano $=1: 1$ :anomax;

vet_tseca=int $\left(\mathrm{A}^{*} \sin \left(\mathrm{K}^{*}(\right.\right.$ vet_ano $\left.\left.)\right)+\mathrm{A}\right)+\mathrm{B} ; \quad / /$ vetor para armazenar a duração da estação seca

$\operatorname{clf}()$

xsetech([0,0,0.25,0.5]);xtitle("Estação seca (dias)");plot2d(vet_ano,vet_tseca) //impressão de gráficos

$/ /$ xsetech([0.01,0,0.25,0.5]);xtitle("qcsmed");histplot(10,med_qcsmed*10^3)

$/ / x \operatorname{xsetech}([0.01,0,0.25,0.5]) ; x t i t l e(" q c e m e d ") ; \operatorname{histplot}(10$, med_qcemed)

xsetech([0.23,0,0.25,0.5]);xtitle("Dias secos (\%)");plot2d(vet_ano,med_cmed)

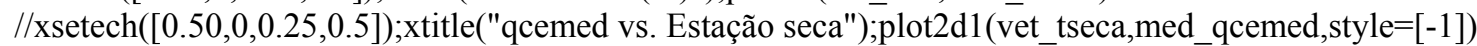

xsetech([0.51,0,0.25,0.5]);xtitle("Volume acumulado na fonte (m3)");plot2d1(vet_ano,med_Vfa)

xsetech([0.75,0,0.25,0.5]);xtitle("Fluxo médio de sedimentos eólicos

$(\mathrm{m} 3 / \mathrm{m} * \mathrm{~h}) ") ;$ plot2d(vet_ano,med_qcemed,logflag="nl")

xsetech([0.02,0.5,0.25,0.5]);xtitle("Volume da fonte (m3)");plot2d(vet_ano,med_Vf)

//xsetech([0.25,0.5,0.25,0.5]);xtitle("Fluxo médio de saída do Campo de

dunas");plot2d(vet_ano,med_qcsmed)

xsetech([0.25,0.5,0.25,0.5]);xtitle("Migração da linha de costa $(\mathrm{m})$ ");plot2d(vet_ano,med_dx)

$/ / x \operatorname{xsetech}([0.25,0.5,0.25,0.5]) ; x t i t l e(" B a l a n c ̧ o$ do fluxo no campo de dunas

$(\mathrm{m} 3 / \mathrm{m} * \mathrm{~h}) ") ;$ plot2d(vet_ano,med_balanco)

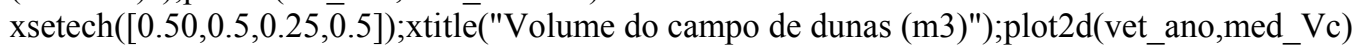

xsetech([0.75,0.5,0.25,0.5]);xtitle("Freqüência de tempestades (\%)");plot2d(vet_ano,med_tempmed)

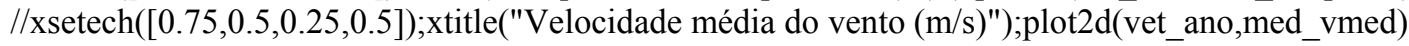




\section{A2.2 Algoritmo para representação dos resultados através de valores seculares}

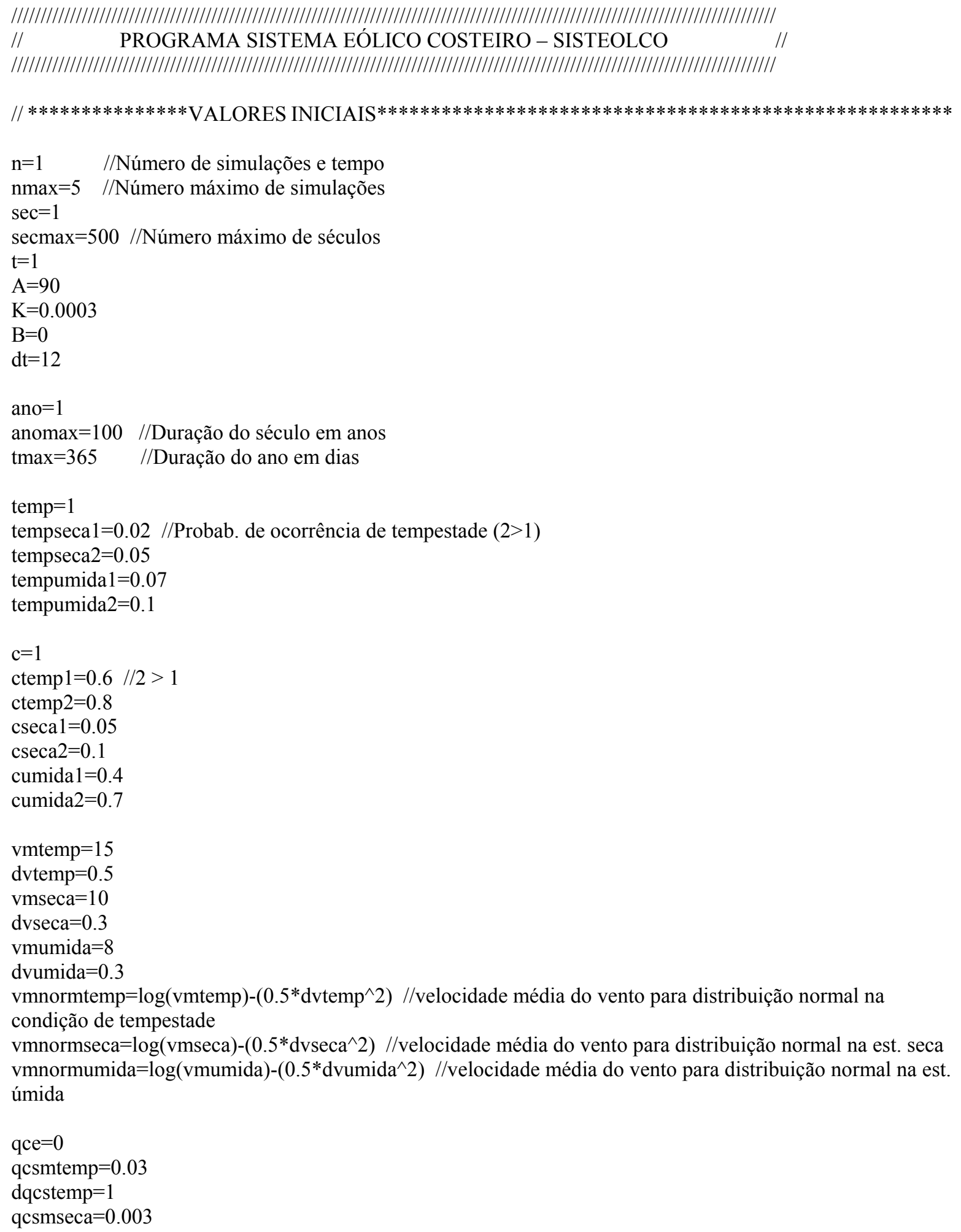


dqcsseca $=0.3$

qcsmumida $=0.005$

dqcsumida $=0.3$

qcsmnormtemp $=\log (q \operatorname{csmtemp})-\left(0.5^{*}\right.$ dqcstemp^$\left.{ }^{\wedge}\right)$ //fluxo médio de saída de sed. do campo de dunas para distr. normal

qcsmnormseca $=\log (q \operatorname{csmseca})-\left(0.5^{*}\right.$ dqcsseca^ 2$)$ //fluxo médio de saída de sed. do campo de dunas para distr. normal

qcsmnormumida= $\log ($ qcsmumida $)-\left(0.5 *\right.$ dqcsumida $\left.^{\wedge} 2\right)$ //fluxo médio de saída de sed. do campo de dunas para distr. normal

qfemtemp $=0.15$

dqfetemp $=3$

qfemseca $=0.0035$

dqfeseca $=3$

qfemumida $=0.0065$

dqfeumida $=3$

qfemnormtemp $=\log (q f e m t e m p)-\left(0.5^{*}\right.$ dqfetemp^ 2$)$ //fluxo médio de entrada para distribuição normal qfemnormseca $=\log ($ qfemseca $)-\left(0.5 *\right.$ dqfeseca $\left.^{\wedge} 2\right) \quad / /$ fluxo médio de entrada para distribuição normal qfemnormumida $=\log ($ qfemumida $)-\left(0.5^{*}\right.$ dqfeumida^ 2$)$ //fluxo médio de entrada para distribuição normal

qfsmtemp $=0.1$

dqfstemp $=3$

qfsmseca $=0.003$

dqfsseca $=3$

qfsmumida $=0.006$

dqfsumida $=3$

qfsmnormtemp $=\log ($ qfsmtemp $)-\left(0.5^{*}\right.$ dqfstemp $\left.{ }^{\wedge} 2\right)$ //fluxo médio de saída para distribuição normal qfsmnormseca $=\log (\mathrm{qfsmseca})-\left(0.5^{*} \mathrm{dqfsseca}^{\wedge} 2\right)$ //fluxo médio de saída para distribuição normal qfsmnormumida $=\log ($ qfsmumida $)-\left(0.5 *\right.$ dqfsumida $\left.^{\wedge} 2\right)$ //fluxo médio de saída para distribuição normal

angmin $=1$

angmax $=10$

$\operatorname{com}=3800$

$\mathrm{amp}=0.6$

larmax $=\operatorname{amp} / \tan (\operatorname{angmin} * 0 \mathrm{pi} / 180)$

Vfmax $=(\operatorname{amp} *$ com*larmax $) / 2$

larmin $=$ amp $/ \tan (\operatorname{angmax} * \% \mathrm{pi} / 180)$

Vfmin $=(a m p * c o m * l a r m i n) / 2$

$\mathrm{dx}=0$

$\mathrm{h}=3$

$\mathrm{d}=0.00025$

ar $=1.225$

$\mathrm{qz}=2650$

areia $=1650$

$\mathrm{ds}=0.00025$

$\mathrm{g}=9.8$

vst $=0.1 *$ sqrt(((qz-ar)/ar)*g*d);

// *************VALORES INICIAIS DAS SOMAS ANUAIS*

stemp $=0 ; / /$ soma dos dias com tempestade

$\mathrm{sc}=0 ; \quad / /$ soma dos dias sem chuva

$\mathrm{sv}=0 ; \quad / /$ soma das velocidades do vento

sqce $=0 ; / /$ soma dos valores do fluxo de entrada de sedimentos no campo de dunas 
$\mathrm{sdx}=0 ; \quad$ //soma dos deslocamentos da linha de costa

// ***********VETORES PARA ARMAZENAMENTO DE VALORES ANUAIS $* * * * * * * * * * * * * * * * * * * * *$

vet_tempmed=zeros(anomax);

vet_cmed=zeros(anomax);

vet_vmed=zeros(anomax);

vet_qcemed=zeros(anomax);

vet_Vf=zeros(anomax);

// ************MATRIZES PARA ARMAZENAMENTO DE VALORES SECULARES $* * * * * * * * * * * * * * *$

mat_tempmed=zeros(nmax,secmax $)$;

mat_cmed $=$ zeros $($ nmax,secmax $)$;

mat_vmed=zeros(nmax,secmax);

mat_qcemed=zeros(nmax,secmax);

mat_Vc=zeros(nmax,secmax);

mat_Vf=zeros(nmax,secmax);

mat_Vfa=zeros(nmax,secmax);

mat_dx=zeros(nmax,secmax);

// **************************DEFINIÇÃO DE FUNÇÕES INTERNAS $* * * * * * * * * * * * * * * * * * * * * * * * * * * *$

//////////////////////////////////////////////FUNÇÃO CLIMA (CLIMA)////////////////////////////////////////////////////

function temp $=\operatorname{CLIMA}(\mathrm{a}, \mathrm{b}) ; \quad / / \mathrm{a}=$ prob. de temp $=0$ em $\mathrm{t}$ dado que temp $=1 \mathrm{em}(\mathrm{t}-1)$

$\mathrm{u}=\operatorname{rand}()$;

select temp

case 1

$/ / \mathrm{b}=$ prob. de temp $=0$ em $\mathrm{t}$ dado que temp $=0$ em $(\mathrm{t}-1)(\mathrm{b}>=\mathrm{a})$

$/ /$ temp $=0$ indica ocorrência do evento climático (chuva ou tempestade)

$$
\begin{aligned}
& \text { if } \mathrm{u}<=\text { a then } \\
& \text { temp }=0 \\
& \text { else } \\
& \text { end }
\end{aligned}
$$

case 0

$$
\begin{aligned}
& \text { if } \mathrm{u}<=\mathrm{b} \text { then } \\
& \text { temp }=0 ; \\
& \text { else } \\
& \text { temp }=1 \text {; }
\end{aligned}
$$

end

end

endfunction

function qce $=$ FEOL (c, v, ds, qz, ar, d, g, areia)

if $\mathrm{c}==1$ then

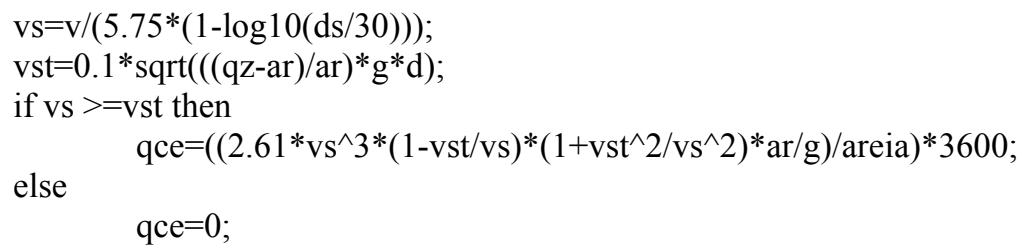


else

end

$\mathrm{qce}=0$;

endfunction

|||||||||||||||||||||||||||||||||||||||||||||||||||||||||||||||||/|FIM DA FUNÇÃO FEOL/||||||||||||||||||||||||||||||||||||||||||||||||||||||||||||

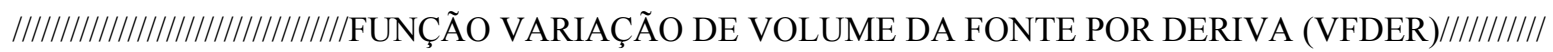

function $\mathrm{Vf}=\mathrm{VFDER}(\mathrm{qfe}, \mathrm{qfs}$, larmax, $\mathrm{dt}$ )

$\mathrm{DVf}=(\mathrm{qfe}-\mathrm{qfs}) *(24-\mathrm{dt}) *($ larmax $) ; / /$ Variação de volume na fonte

$\mathrm{Vf}=\mathrm{Vf}+\mathrm{DVf}$

if $\mathrm{Vf}<0$ then //Regulariza $\mathrm{Vf}$ entre os valores limites

$\mathrm{Vf}=0$;

end

endfunction

||||||||||||||||||||||||||||||||||||||||||||||||||||||||||||/FIM DA FUNÇÃO VFDER/||||||||||||||||||||||||||||||||||||||||||||||||||||||||||

stacksize(10000000)

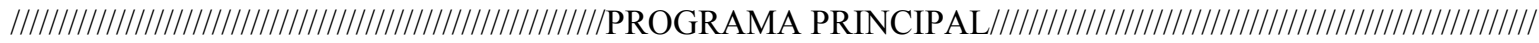

for $\mathrm{n}=1: \mathrm{nmax}$;

$\mathrm{Vf}=\mathrm{Vfmin} ; \quad / /$ Valores iniciais

$\mathrm{Vfa}=100 * \mathrm{Vfmax}$

$\mathrm{Vc}=0$;

$\mathrm{sdx}=0$;

$\mathrm{qce}=0$;

$\mathrm{qcs}=0$

$\mathrm{qfe}=0$;

$\mathrm{qfs}=0$;

$\mathrm{c}=1$;

temp $=1$;

for $\sec =1$ :secmax;

for ano=1:anomax;

anotseca $=((\sec -1) * 100)+$ ano; $\quad / /$ contagem contínua dos anos para cálculo de tseca

tseca $=\operatorname{int}\left(\mathrm{A}^{*} \sin \left(\mathrm{K}^{*}\right.\right.$ anotseca $\left.)+\mathrm{A}\right)+\mathrm{B}$;

for $\mathrm{t}=1$ :tmax;

if $\mathrm{t}<=$ tseca then

temp=CLIMA(tempseca1, tempseca2);

if temp $=0$ then

$\mathrm{v}=\exp (\operatorname{grand}(1,1$, 'nor', vmnormtemp,dvtemp $))$;

$\mathrm{c}=\mathrm{CLIMA}(\mathrm{ctemp} 1, \mathrm{ctemp} 2)$;

qce $=$ FEOL (c, v, ds, qz, ar, d, g, areia);

$\mathrm{qce}=\mathrm{qce} *(\mathrm{Vf} / \mathrm{Vfmax})$;

if $\mathrm{Vc}>0$ then

$q \operatorname{cs}=\exp (\operatorname{grand}(1,1$, 'nor', qcsmnormtemp, dqcstemp)); $\mathrm{qcs}=\mathrm{qcs} *(1-(\mathrm{Vf} / \mathrm{Vfmax}))$;

else

end

$\mathrm{qcs}=0$;

qfe $=\exp ($ grand $(1,1$, 'nor',qfemnormtemp,dqfetemp $))$;

else qfs=exp(grand $(1,1$, 'nor',qfsmnormtemp,dqfstemp $))$; 


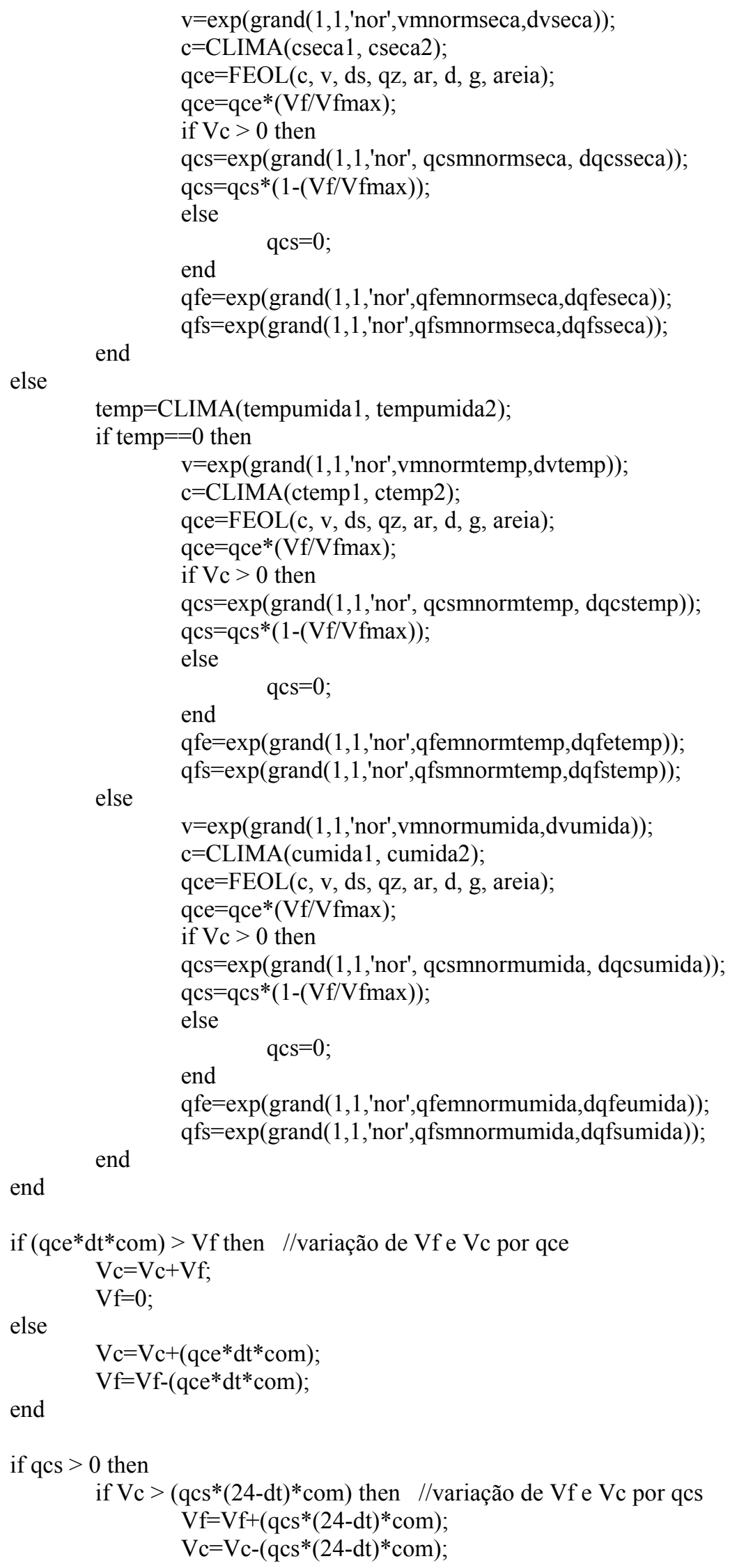




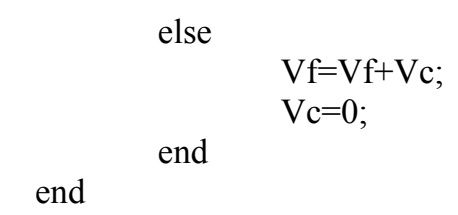

$\mathrm{Vf}=\operatorname{VFDER}(\mathrm{qfe}, \mathrm{qfs}$, larmax, dt); //variação do volume da fonte por qfe e qfs

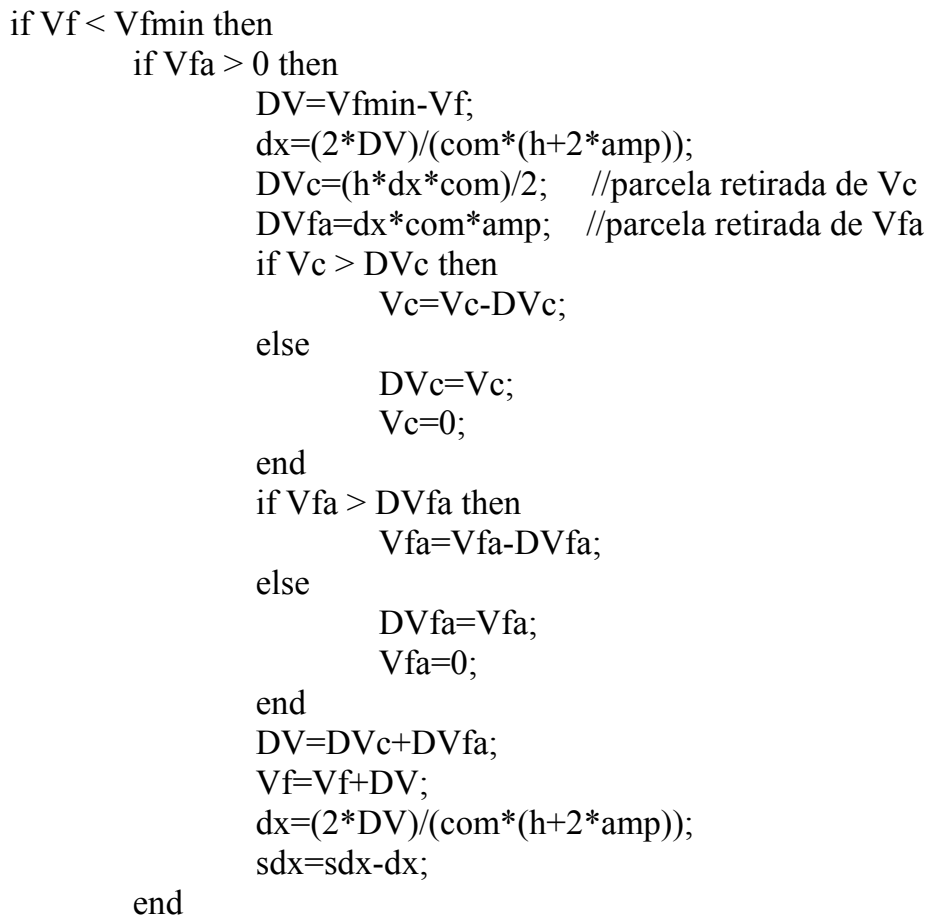

end

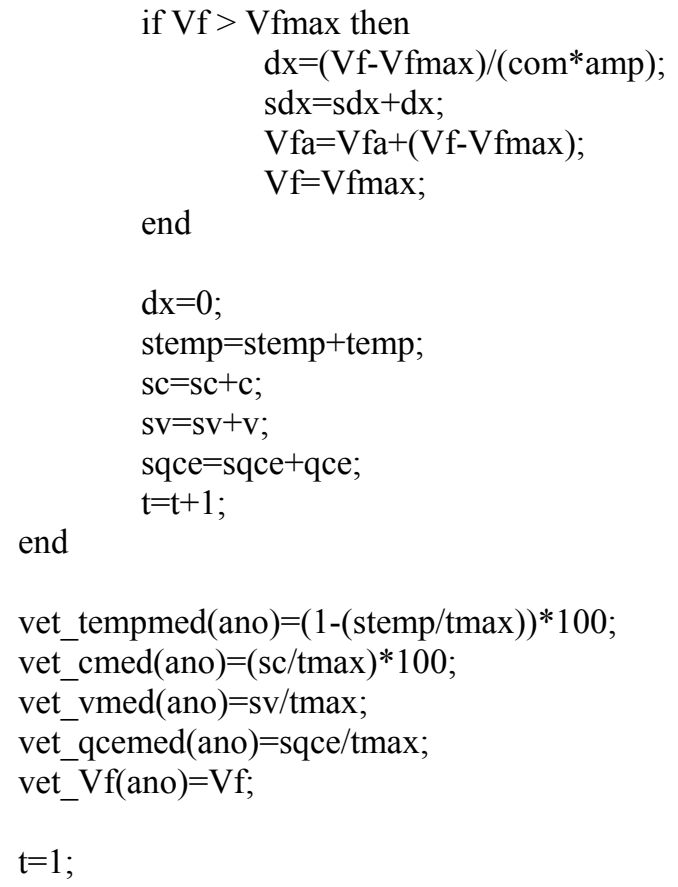




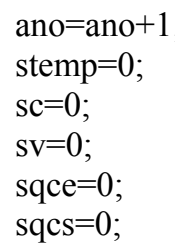

std tempmed=st deviation(mat tempmed,' $r$ '); std_cmed=st_deviation(mat_cmed,'r');

//desvio padrão dos valores seculares das nmax simulações std_vmed=st_deviation(mat_vmed,'r'); std_qcemed $=$ st_deviation(mat_qcemed,' $r$ '); std_Vc=st_deviation(mat_Vc, $\left.{ }^{\prime} \mathrm{r}^{\prime}\right)$; std_Vf=st_deviation(mat_Vf,' $\left.\mathrm{r}^{\prime}\right)$; std_Vfa $=$ st_deviation(mat_Vfa, 'r'); std_dx=st_eviation(mat_d $\left.\bar{d} x, r^{-}\right)$;

icf tempmed $=\left(1.96^{*}\right.$ std tempmed $) / \operatorname{sqrt}($ nmax $)$; icf_cmed $=\left(1.96^{*}\right.$ std_cmed $) / \operatorname{sqrt}(\operatorname{nmax})$; //intervalo de confiança de $95 \%$ das nmax simulações icf_vmed $=(1.96 *$ std_vmed $) /$ sqrt $($ nmax $)$; icf_qcemed $=\left(1.96^{*}\right.$ std_qcemed $) / \operatorname{sqrt}($ nmax $)$; icf $\mathrm{Vc}=\left(1.96^{*}\right.$ std $\left.\mathrm{Vc}\right) / \mathrm{sqrt}(\operatorname{nmax})$; icf_Vf $=\left(1.96^{*}\right.$ std_Vf $) /$ sqrt(nmax); icf_Vfa $=(1.96 *$ std_ Vfa $) / \operatorname{sqrt}($ nmax $)$; icf_dx $=\left(1.96^{*}\right.$ std_ $\left.\bar{d} x\right) / \operatorname{sqrt}(\operatorname{nmax})$; 
icfmed temp $=$ mean(icf tempmed)

icfstd_temp=st_deviation(icf_tempmed)

icfmed_c=mean(icf_cmed)

icfstd_c =st_deviation(icf_cmed)

icfmed_v=mean(icf_vmed)

icfstd_vest_deviation(icf_vmed)

icfmed_qce=mean(icf_qcemed)

icfstd_qce $=$ st_deviation(icf_qcemed)

icfmed_Vc=mean(icf_Vc)

icfstd_V $\mathrm{V}=$ st_deviation(icf_Vc)

icfmed_Vf=mean(icf_Vf)

icfstd_Vf=st_deviation(icf_Vf)

icfmed_Vfa $=$ mean(icf_Vfa)

icfstd_Vfa=st_deviation(icf_Vfa)

icfmed_dx=mean(icf_dx)

icfstd_- $\mathrm{d} x=s t$ deviation(icf_dx)

vet_sec $=1: 1:$ secmax;

i=secmax*100; $\quad$ //para elaborar gráfico da variação da estação seca

vet_ano $=1: 100: \mathrm{i}$

vet_tseca=int $\left(\mathrm{A}^{*} \sin \left(\mathrm{K}^{*}(\right.\right.$ vet_ano $\left.\left.)\right)+\mathrm{A}\right)+\mathrm{B}$; //vetor para armazenar a duração da estação seca

$\operatorname{clf}()$

xsetech([0,0,0.25,0.5]);xtitle("Estação seca (dias)");plot2d(vet_sec,vet_tseca) //impressão de gráficos

$/ / x \operatorname{xsetech}([0.01,0,0.25,0.5]) ; x \operatorname{title}(" q c e m e d ") ; \operatorname{histplot}(10$, med_qcemed)

xsetech([0.23,0,0.25,0.5]);xtitle("Dias secos (\%)");plot2d(vet_sec,med_cmed)

$/ / x \operatorname{xsetech}([0.50,0,0.25,0.5]) ; x t i t l e(" q c e m e d ~ v s$. Estação seca");plot2d1(vet_tseca,med_qcemed,style=[-1])

xsetech([0.51,0,0.25,0.5]);xtitle("Volume acumulado na fonte (m3)");plot2d1(vet_sec,med_Vfa)

xsetech([0.75,0,0.25,0.5]);xtitle("Fluxo médio de sedimentos eólicos

$(\mathrm{m} 3 / \mathrm{m} * \mathrm{~h}) ") ;$ plot2d(vet_sec,med_qcemed,logflag="nl")

xsetech([0.02,0.5,0.25,0.5]);xtitle("Volume da fonte (m3)");plot2d(vet_sec,med_Vf)

//xsetech([0.25,0.5,0.25,0.5]);xtitle("Fluxo médio de saída do Campo de

dunas");plot2d(vet_sec,med_qcsmed)

xsetech([0.25, $0.5,0.25,0.5]) ; x$ xtitle("Migração da linha de costa (m)");plot2d(vet_sec,med_dx)

xsetech([0.50,0.5,0.25,0.5]);xtitle("Volume do campo de dunas (m3)");plot2d(vet_sec,med_Vc)

xsetech([0.75,0.5,0.25,0.5]);xtitle("Freqüência de tempestades (\%)");plot2d(vet_sec,med_tempmed)

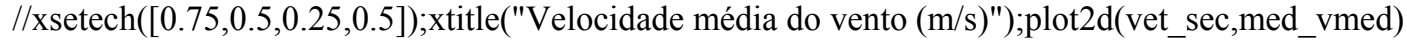

